\title{
Biology and Ecology of Fishes in Southern African Estuaries
}

\section{Alan K. Whitfield}

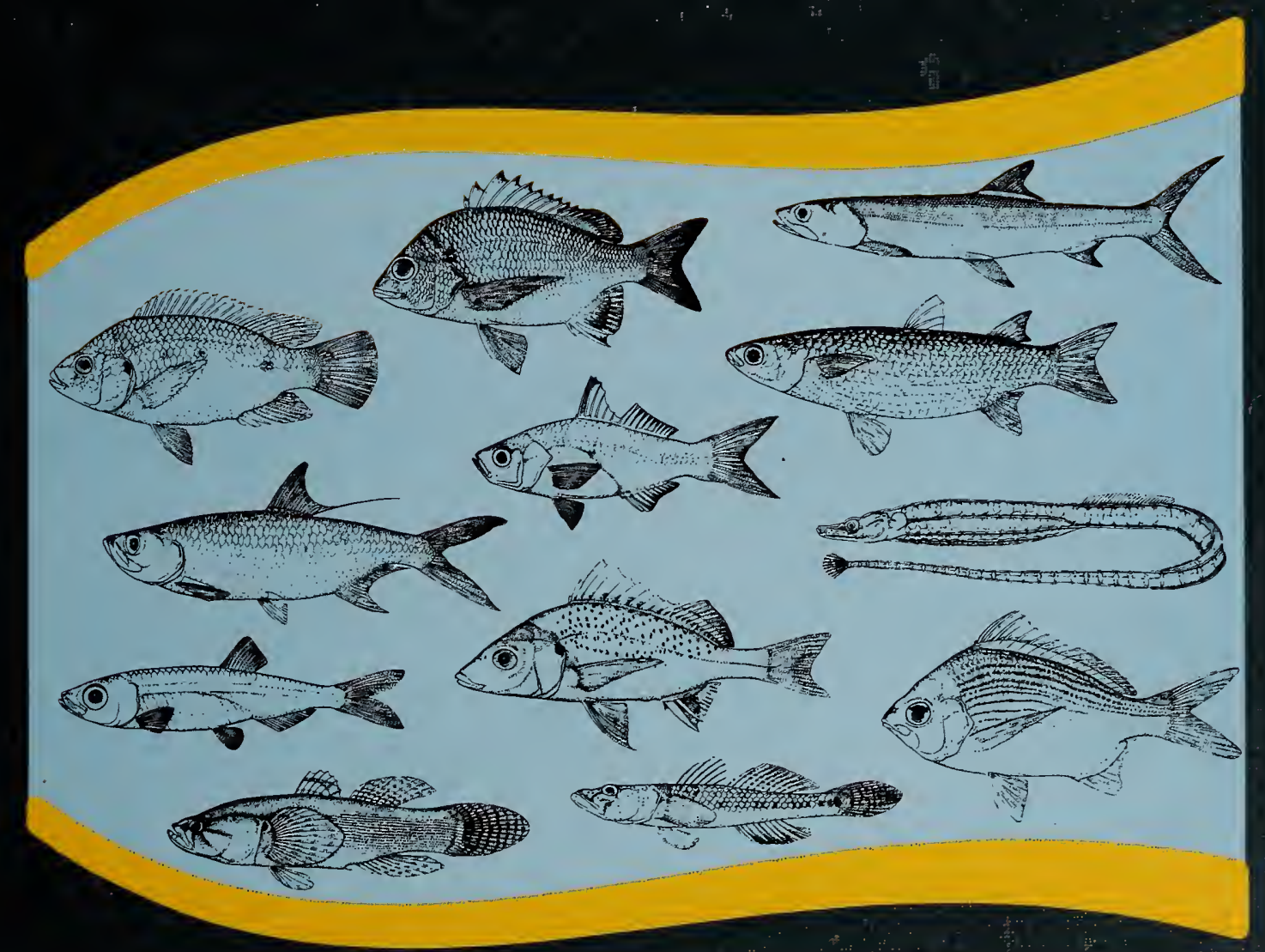

J.L.B. Smith Institute of Ichthyology Ichthyological Monograph Number 2 



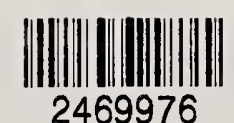

2469976 

Digitized by the Internet Archive in 2017 with funding from JRS Biodiversity Foundation 

This book is dedicated to:

My family, especially my wife Elspeth, daughter Lisa and son Mark

The fishes that were sacrificed during the course of my research

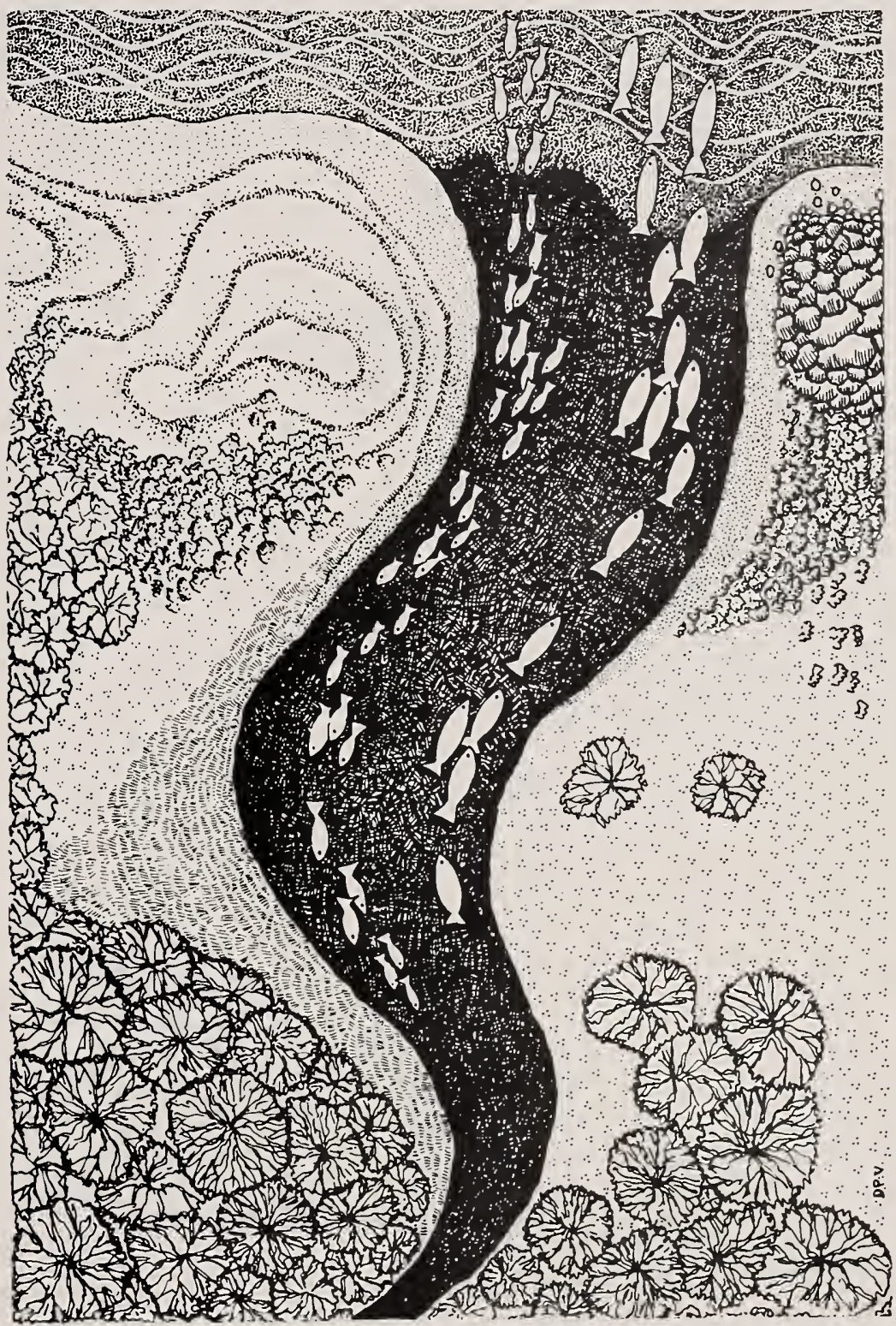





\section{Biology and Ecology of Fishes}

\section{in Southern African Estuaries}

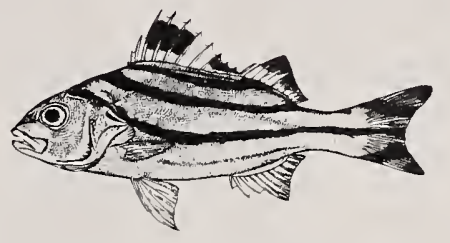

by

ALAN K. WHITFIELD

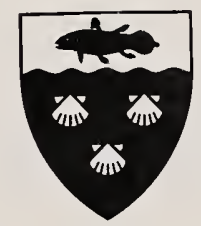

J.L.B. Smith Institute of Ichthyology

Grahamstown, South Africa 
For bibliographic purposes this book should be cited as follows:

Whitfield, A.K. 1998. Biology and Ecology of Fishes in Southern African Estuaries. Ichthyological Monographs of the J.L.B. Smith Institute of Ichthyology, No. 2, 223 pp.

Ichthyological Monograph Series Editor: Dr Phillip C. Heemstra

Copyright (C) 1998 by the J.L.B. Smith Institute of Ichthyology, Grahamstown. All rights reserved. Apart from citations for the purposes of research or review, no part of this book may be reproduced in any form, mechanical or electronic, including photocopying, without prior permission in writing from the publisher.

ISBN 0-86810-333-0 hardcover

ISSN 1029-0605

Published by the J.L.B. Smith Institute of Ichthyology, Private Bag 1015, Grahamstown 6140, South Africa

Printed and bound by NMB Printers, Port Elizabeth

Frontispiece: Mtentu Estuary in 1952

(Photograph by Professor J.L.B. Smith)

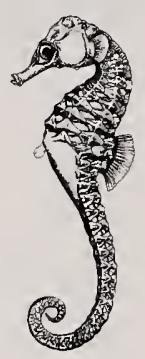

Sponsorship of the printing costs by the Foundation for Research Development, J.L.B. Smith Institute of Ichthyology and Anglo American \& De Beers Chairman's Fund is gratefully acknowledged.

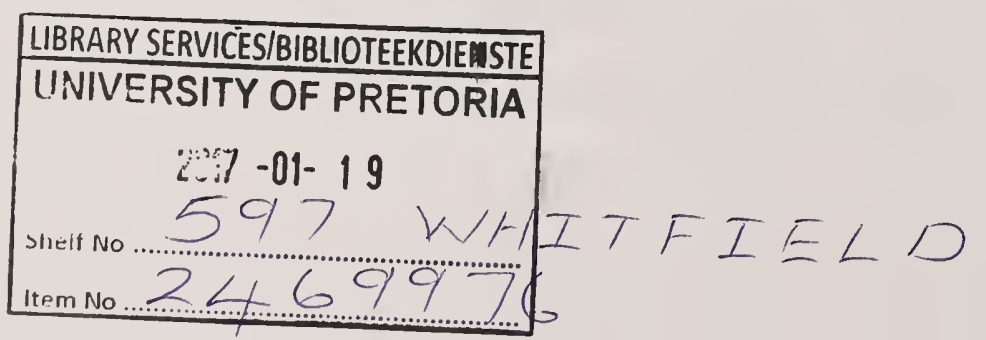




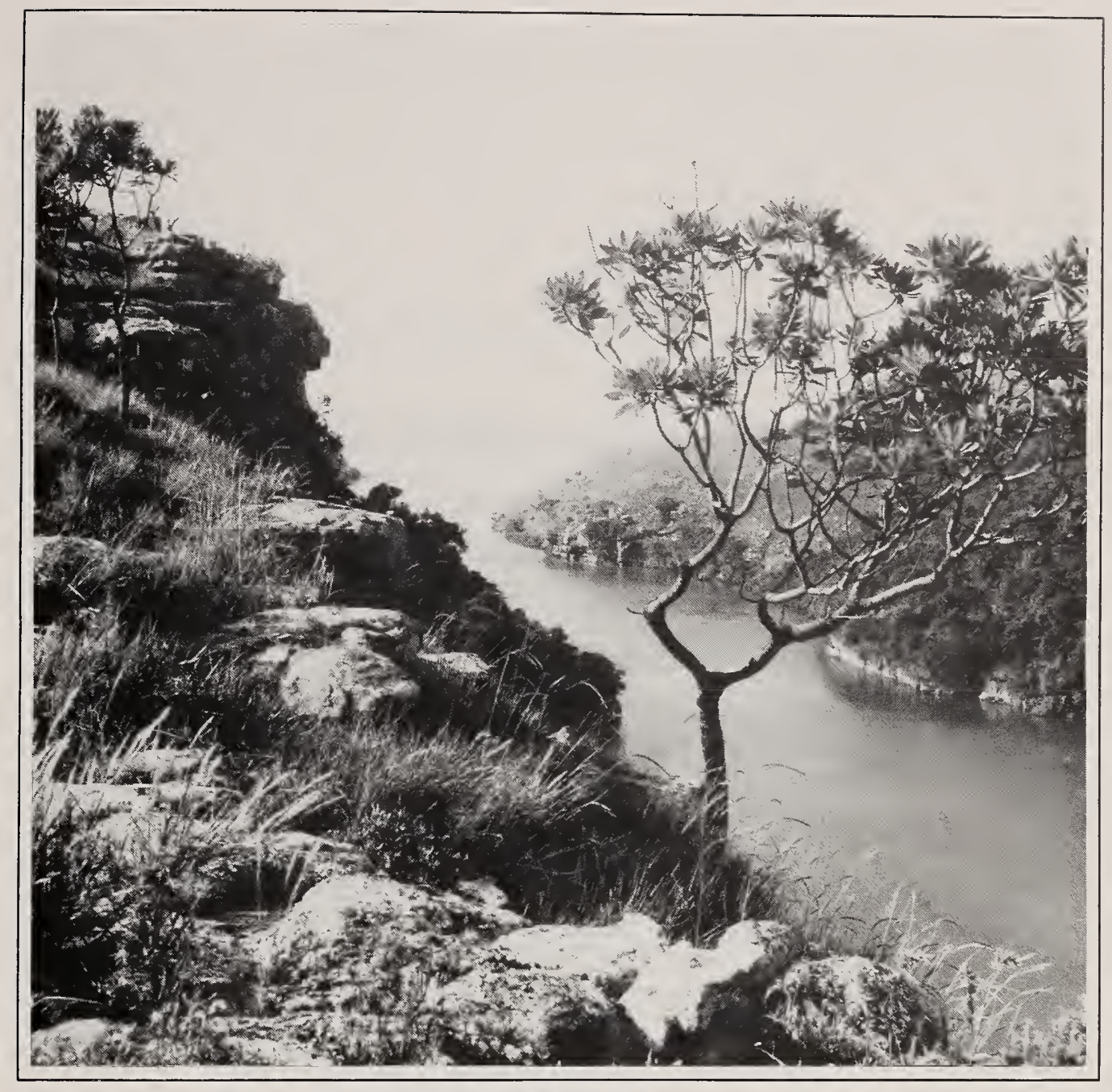

Nature is like a living painting

The patterns are those of an artist

Who is present yet absent

Can we be part of the picture

And still interpret the painting? 



\section{Contents}

Foreword

Preface

Acknowledgements

Chapter 1 Estuarine environment and ichthyological history

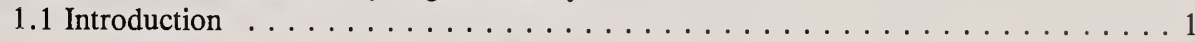

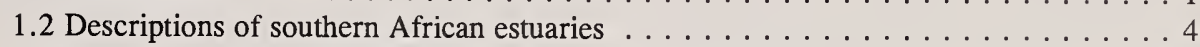

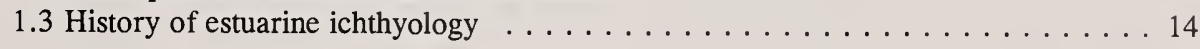

Chapter 2 Fishes of southern African estuaries

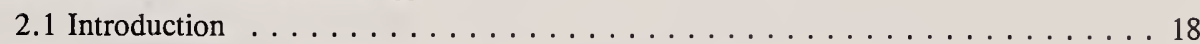

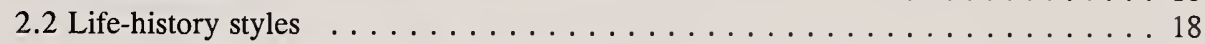

2.3 Factors influencing estuarine utilization . . . . . . . . . . . . . . . . 29

2.4 Species diversity: an evolutionary perspective . . . . . . . . . . . . 44

Chapter 3 Estuary-associated fish species profiles

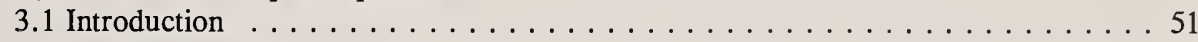

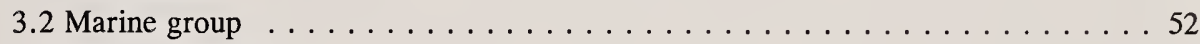

3.3 Estuarine group . . . . . . . . . . . . . . . . . . . . . . . . 109

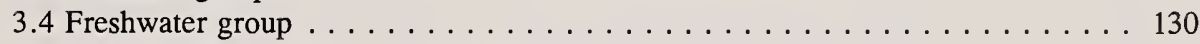

Chapter 4 Estuarine ecosystems and their ichthyofauna

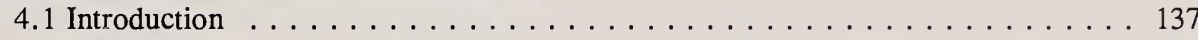

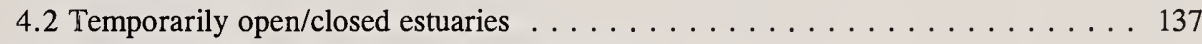

4.3 Permanently open estuaries and river mouths $\ldots \ldots \ldots \ldots \ldots \ldots \ldots 14$

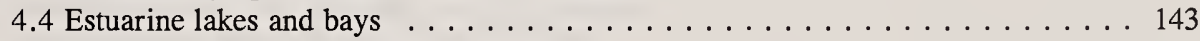

4.5 Estuary type and ichthyofaunal structure $\ldots \ldots \ldots \ldots \ldots \ldots \ldots$

Chapter 5 Environmental and anthropogenic impacts

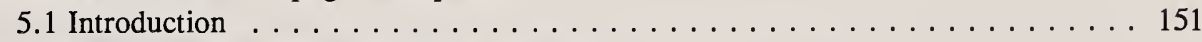

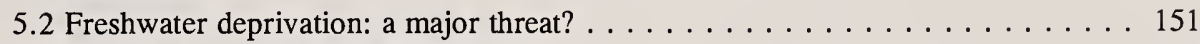

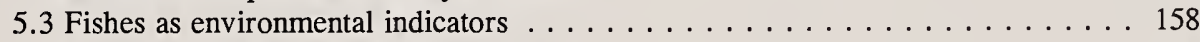

5.4 Mass mortalities of fishes in estuaries . . . . . . . . . . . . . . . . . 164

Chapter 6 Conservation of fishes in southern African estuaries

6.1 Introduction . . . . . . . . . . . . . . . . . . . . . . . 167

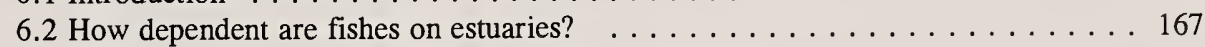

6.3 Present and future conservation trends $\ldots \ldots \ldots \ldots \ldots \ldots \ldots \ldots$

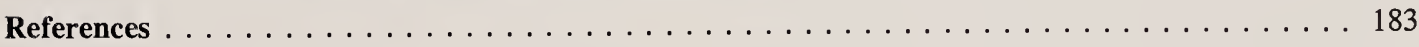

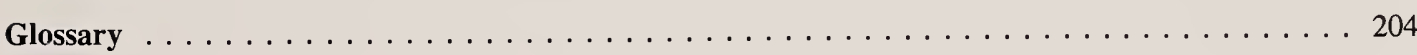

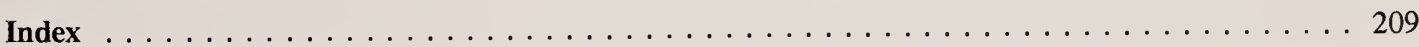

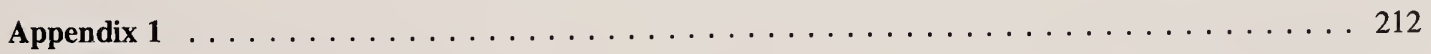

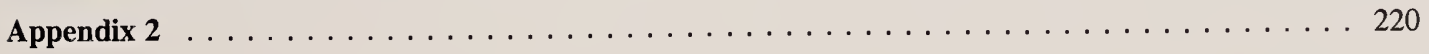




\section{Foreword}

The South African coastline is one of the most striking features of the country's renowned natural heritage, with the numerous and diverse estuaries being major components that contribute greatly to this natural splendour. Estuaries have always been an attraction to humans, not only for their scenic beauty but probably more for the opportunities they present in terms of food supplies, shelter and, especially in modern times, recreation. The fish $\mathrm{s}$ that live in estuaries are undoubtedly one of the reasons that attract man in the first place - they are often easily seen and caught. The fishes themselves are attracted to estuaries for the same reasons that man is attracted - these systems provide them with abundant food and shelter, particularly for the juveniles of many marine and estuarine species. So a book that details our present state of knowledge on the biology and ecology of fishes in southern African estuaries is at once a most welcome addition to the available literature on our natural heritage - especially when it is written by the leading authority on the subject at the present time.

In focusing on estuarine fishes this book fills an important knowledge-niche in ichthyology. It is the first of its kind for Africa and sets a high standard for future estuarine fish books from other parts of the world. There have been books on southern African estuaries, in which there are chapters on estuarine fishes, but this is the first where estuarine-associated fishes are the focus of the entire work. For Alan Whitfieid it is a major milestone in a most industrious career and serves to bring together his own considerable first hand experience and that of all who have contributed to our understanding of estuarine fishes on the subcontinent. The book is a thorough, authoritative and up-to-date scientific review. Its publication now is timeous, for estuaries are undergoing unprecedented development and degradation from human activities, and it will take all the skills and knowledge available to society to conserve these precious environments.

Estuarine ichthyology in the J.L.B. Smith Institute can be traced back to J.L.B. Smith himself but the appointment of Alan Whitfield to the staff in 1987 firmly established the discipline. For the Institute, the book follows an established tradition of producing major works of world-class standard. As a milestone it is especially significant and fulfilling in that it completes the set of major contributions made to all the environmental sectors with which our research is involved. It is a landmark for the Institute in other ways - although it is not the first book that we have published ourselves, it is the first for which, cover to cover (including the cover!), everything, apart from the printing, has been done in-house. The extraordinary thing is that the author himself has practically single-handedly, managed the production from beginning to end, and raised most of the finances for it as well.

It is therefore with a great deal of pride and appreciation that I both welcome and recommend this wonderful book by Dr Alan Whitfield. I predict that it will become the standard work and an essential reference on estuarine fishes, for southern Africa and beyond. 


\section{Preface}

The late Dr Humphry Greenwood has asserted that the world's fish faunas are by no means well-known, either taxonomically or with regard to the biology of their component species. Apart from the very large number of fish species (estimated to be approximately 28500 ) and the difficulties posed by the medium in which they live, there are other reasons for that state of affairs. An obvious and universal reason is the shortage of money available for fundamental studies and consequently a shortage of research workers (Greenwood 1992). This situation is unlikely to improve and many research institutions around the world are operating on shrinking rather than expanding budgets. The onus of responsibility to disseminate information on the world's fish faunas therefore rests squarely on the shoulders of those who are fortunate enough to be employed in the fascinating field of ichthyology. This book is an attempt to synthesize the available information on fishes associated with southern African estuaries and to highlight the importance of conserving these systems for both fishes and people of the region. Comparisons between fish life-history styles, trophic structures etc. in African estuaries and elsewhere in the world will be the subject of a second and more comprehensive volume in the future.

South Africa, despite its relatively small size, is often called 'a world in one country'. This phrase arises mainly from the range of terrestrial, oceanographic and climatic features; the diversity of human cultures, languages, races and religions; the mix of developed and developing economies; the wide range in political opinion and parties; the vast array of mineral resources; and finally, what biologists find most interesting of all, the richness of the indigenous flora and fauna. Although southern African aquatic scientists cannot boast an equivalent of the Cape Floral Kingdom, the stretch of coast between northern Namibia and southern Mozambique has a particularly rich marine biota. There are over 10000 species (12\% endemicity), or almost $15 \%$ of all the coastal marine species known world-wide (Branch et al. 1994). Similarly, Smith \& Heemstra (1986a) reveal that with some 2200 species, the southern African fish fauna includes about $15 \%$ of the total number of marine fish species in the world. The ichthyofaunal richness is due to a number of factors, including the variety of habitats around the subcontinent, ranging from coral reefs, kelp beds, sheltered bays, sandy beaches, exposed rocky shores, coastal lakes to estuaries. In addition, southern Africa is the meeting place of three great oceans and is thus the recipient of species from each of these separate faunas. A total of 270 families of marine fishes are represented in southern African seas out of a world total of 325 .

The estuaries of southern Africa (defined as south of $26^{\circ} \mathrm{S}$ latitude for the purposes of this book) are also highly diverse, both in terms of form and functioning. They range from the clear Kosi Estuary entering the coral rich subtropical Indian Ocean waters on the east coast, to the turbid Orange River flowing into the cool upwelled waters of the Atlantic Ocean on the west coast. The estuaries of the subcontinent are fed by catchments which range in size and also have a wide variety of climatic and geological characteristics. For example, the cool-temperate west coast is characterized by winter rains and summer dry periods, whereas on the subtropical east coast the opposite rainfall pattern prevails. While most southwestern Cape estuaries are fed by rivers with low suspended sediment levels, those of KwaZulu-Natal normally carry high silt loads during the rainy season. Between Mossel Bay and St Francis Bay, rainfall patterns show no distinct seasonal peak and relatively acidic waters with low nutrient levels enter a variety of estuarine types along this section of the coast. The Eastern Cape is a region of transition between the subtropical and warm-temperate biogeographic provinces. It is prone to both droughts and floods, and its estuaries can be influenced by tropical Agulhas Current waters one day and cool upwelled marine waters the next.

The southern African estuarine environment is an unpredictable and often harsh habitat to occupy, yet each year millions of larval and juvenile fishes enter and thrive in these systems. The fish species that utilize estuaries as nursery areas exhibit diversity in size, body form, salinity tolerance, diet, habitat preference and breeding behaviour. There is also a complete gradation in terms of the dependence each species has on the estuarine environment. These and many other issues relating to the biology and ecology of estuary-associated fish species in southern Africa are dealt with in this book. 


\section{Acknowledgements}

The idea of writing this book arose from a discussion I had with Professor Paul Skelton in 1991 while he was busy with his volume $A$ Complete Guide to the Freshwater Fishes of Southern Africa. Paul succeeded in persuading me that a book on the fishes of southern African estuaries was needed and that I should start 'rattling my keyboard'. Paul, thank you for starting me off on what turned out to be a seven year long project of renewed discovery and interpretation of the estuarine ichthyological data base.

The contents of this book are drawn from past and present information about the fishes of southern African estuaries, some of which was published long before I embarked on a career in ichthyology. To the pioneers of estuarine and ichthyological research on the subcontinent, especially the late Professors John Day and J.L.B. Smith, I express my gratitude for lighting the path for the rest of us to follow. I would also like to thank the late Professor Waldo Meester, Head of the Zoology Department at the University of Natal during the 1970s, for sharing his views with six young honours students. In his 1972 inaugural address to the university entitled The Human Breakthrough he stated "I would like to dream of a world in which our knowledge of nature is far more complete than it is now, and in which this knowledge is used for the betterment not only of mankind but of the natural world on which we depend". It is a dream which I fully endorse and convey, in turn, to my students.

The bulk of this book draws on the last two decades of research, during which time numerous people have actively and unselfishly assisted me to explore the fishes of southern African estuaries. To all these friends, colleagues and students I express my sincere appreciation and gratitude. In particular, I should like to thank the following for their support and encouragement; Janine Adams, Brian Allanson, Guy Bate, Lynnath Beckley, Bruce Bennett, Steve Blaber, Anton Bok, Andre Boshoff, Charles Breen, Mike Bruton, Lee Christmas, Paul Cowley, Digby Cyrus, Humphry Greenwood, Colin Hall, Trevor Harrison, Tom Hecht, Jan Heeg, Phil Heemstra, Piet Huizinga, Hennie Kok, Tim Martin, Angus Paterson, Ian Potter, Nevil Quinn, Tony Ribbink, Paul Skelton, Jill Slinger, Leslie Ter Morshuizen, Koos Wagner and Tris Wooldridge.

Dave Voorvelt deserves special mention for his exceptional fish illustrations that have captured the character of the different species by virtue of his accuracy and meticulous attention to detail. I have enjoyed and appreciated greatly the opportunity of working closely with him on this project. Elaine Heemstra has also added her finishing touches to the book with several larval fish illustrations as well as proof reading of the text. Ralton Maree provided considerable assistance with the distribution maps used in Chapter 3 and Robin Stobbs with the printing of photographs used in the text and Appendix 1. Valuable contributions in terms of 'fine tuning' the text were provided by my experienced colleagues Kim Bell, Trevor Harrison, Phil Heemstra, Helen Larson, Angus Paterson and Paul Skelton - to all of you, my grateful thanks.

A comprehensive library and efficient administration service are important for the smooth running of any research project. In this regard I have been extremely fortunate to have had people of the calibre of Margaret Crampton, Ria Greaves and Catherine Price running the J.L.B. Smith Library; with Linda Coetzee, Pat Eva, Wendy Sweetman and Huibre Tomlinson facilitating the administration of my projects over the years. A first class fish collection curated mainly by Andy Bentley, Billy Ranchod and Leslie Ter Morshuizen was particularly useful in updating the distribution patterns of estuary-associated species. The enthusiastic support for this book by my two Directors, Professors Mike Bruton and Paul Skelton, is gratefully acknowledged. I also thank Ray Vogel for his assistance with the production of an advertising pamphlet for the book.

Funding is a critical component of all scientific endeavours. The financial backing of the Institute for Freshwater Studies (Rhodes University) for the period 1979-1987 and the J.L.B. Smith Institute from July 1987 until the present has been vital to the success of the research reported on in this book. The support of my work by both councils, especially the encouragement of the two chairmen, Dr Derek Henderson (1979-1996) and Dr Dave Woods (1996-present), has meant a lot to me. The Foundation for Research Development also deserves a special mention; this organization has been the major funding agency throughout my career. Their support of my estuarine research, and particularly the efforts of André van der Westhuysen, Annette Schnetler, Roger Krohn and Johan Pauw, is gratefully acknowledged. Finally, I would like to thank the Water Research Commission for contributing to the funding of my research in recent years, with Drs Peter Reid and Steve Mitchell playing a key role in facilitating these studies. 


\section{Estuarine environment and ichthyological history}

\subsection{INTRODUCTION}

Southern African estuaries, like the rivers that enter them, are driven by the fundamental variables of water quantity, quality and movement, which in turn influence the type of substratum that prevails in different parts of each system (Reddering \& Rust 1990). Fishes, like most other aquatic organisms, respond to these fundamental driving variables on temporal scales that will vary from one estuary to another. Central to the distribution and abundance of fishes in estuaries are the abiotic and biotic gradients that are established by the cycle of disturbance which affect all estuaries on an almost continuous basis.

The nature of individual estuarine systems is directly related to the catchment and coastal environment characteristics in which they are located. This is particularly evident on the southern part of the African continent where sharply contrasting conditions occur (Heydorn 1989). The coastal distance between the Orange River Estuary in the west and the Kosi Estuary in the east is approximately $3100 \mathrm{~km}$ (Figure 1). To the west of C.ape Point the coastline borders on the South Atlantic. To the east of Cape Point water temperatures increase markedly, with a transition from warm-temperate to subtropical waters occurring on the Transkei coast. These Indian Ocean waters are dominated by the warm Agulhas Current, which moves progressively further away from the coast as it flows southwards along continental shelf margin. In contrast, the Atlantic west coast is driven by sporadic upwelling of cool, nutrient-rich waters typical of the Benguela Current regime.

The above oceanographic conditions also influence the coastal climate of southern Africa, with summer rainfall prevailing along the east coast, summer and winter rainfall along the south coast, winter rainfall along the southwest coast, and semiarid conditions along the northwest coast (Figure 1). In general the east coast waters are characterized by great biotic diversity, whereas the more productive waters of the west and southwest coasts have fewer species in greater profusion (Heydorn \& Flemming 1985).
The geomorphology of coastal regions also has a profound influence on the type of estuarine environment. Because of the steep gradients, geology and heavy summer rainfall, the rivers of KwaZuluNatal flow at a high velocity over a short distance, have greater cutting action and tend to carry a large silt load. Rivers along the Tsitsikamma coast also tend to be short and steep, but they generally drain sandstone/quartzite formations with little unbound soil cover and therefore carry relatively low silt loads. Some west coast catchments are little more than dry river beds for much of the time and are only linked to the sea at times of exceptional rainfall. There are also profound differences between the vegetation surrounding the estuaries along the subtropical, warm-temperate and cool-temperate coasts (Heydorn 1989).

The number of estuaries in southern Africa varies according to which type of systems are included in the definition of an estuary. Based on information provided by Whitfield (1995a), which deals with functional estuarine systems, their distribution along the coast is as follows; subtropical estuaries number 117 , warm-temperate estuaries 123 , and cooltemperate estuaries 10 . Namibia has 20 river courses over a distance of about $1000 \mathrm{~km}$ but these cannot be classified as estuaries because they seldom contain any water. From the above it is apparent that the eastern and southern coasts are better endowed with estuaries than those in the western sector. The total area of South African estuaries has been estimated at between 500 and $600 \mathrm{~km}^{2}$ (Heydorn 1989), with those in subtropical KwaZulu-Natal occupying an area of approximately $400 \mathrm{~km}^{2}$, due primarily to the contribution of the St Lucia and Kosi lake systems.

Salinity is a key factor in the characterization of individual estuaries and the description of zones within a particular system. In this book the Venice system of classification for describing salinity ranges has been followed, i.e. oligohaline $(0.5-4.9 \%$ ), mesohaline $(5.0-17.9 \%$ ) , polyhaline $(18.0-29.9 \%$ ) and euhaline (30.0-39.9\%o). Hypersaline conditions refer to any salinity above $35 \%$. 


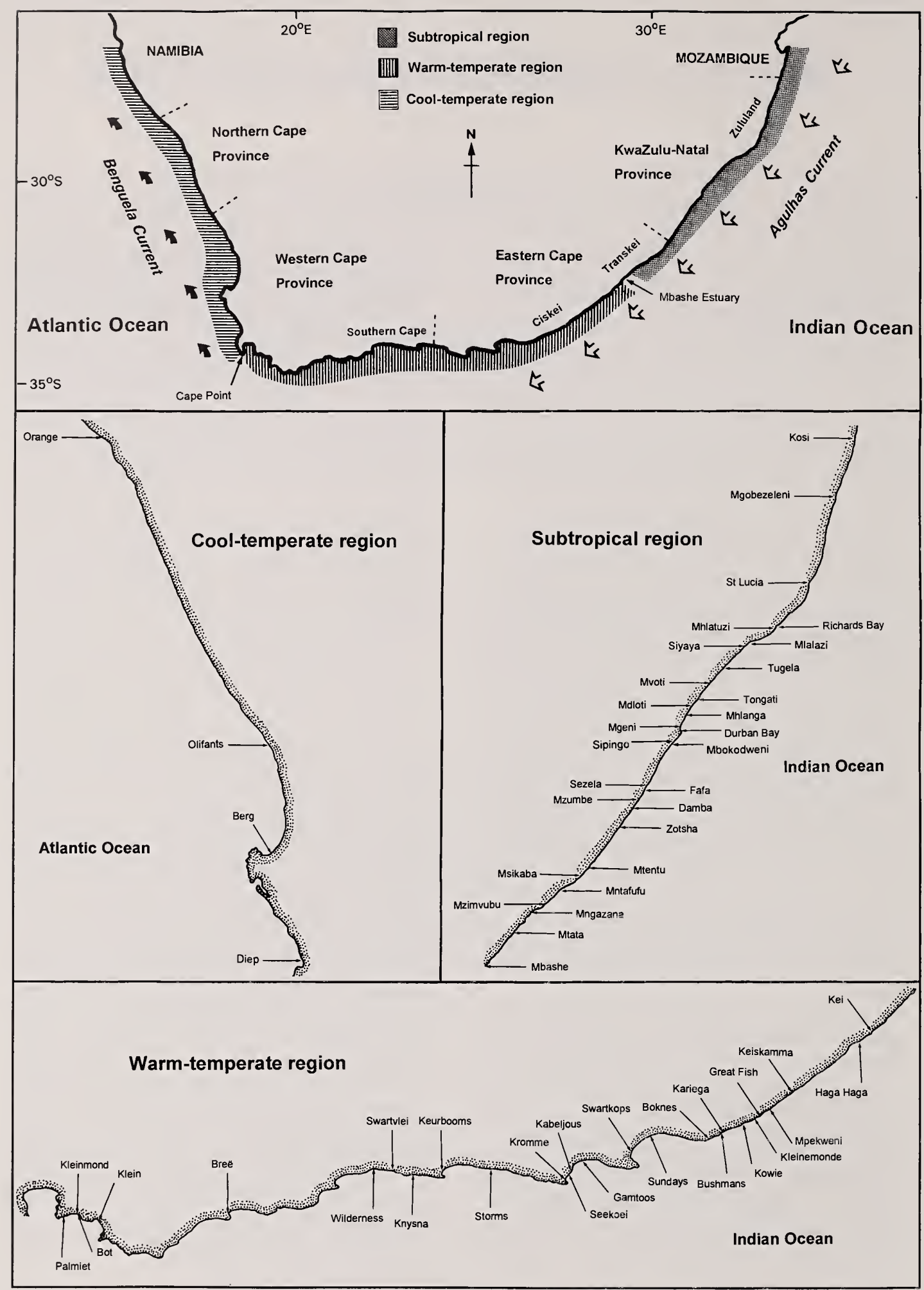

Figure 1. Regional maps of southern Africa showing the localities of selected estuaries mentioned in the text. 
What is an estuary?

During the first international conference on estuaries in 1964 there was wide support for the following definition: "An estuary is a semi-enclosed body of water which has a free connection with the open sea and within which sea water is measurably diluted with fresh water derived from land drainage" (Pritchard 1967). While the above definition is still widely accepted by scientists working in the northern hemisphere, Day (1981a) has pointed out that certain problems arise when attempts are made to apply it to the estuaries of southern Africa. Sand bars are frequently formed at the mouths of most estuaries during the drier periods of the year. These systems then are only opened by high riverine discharge or artificial methods for breaching (Fromme 1985). During the often lengthy periods when they are closed, these so-called 'blind' estuaries do not have the free connection with the open sea considered to be crucial in Pritchard's definition.

In order to accommodate the peculiarities of these systems, Day (1980) redefined an estuary as "a partially enclosed coastal body of water which is either permanently or periodically open to the sea and within which there is a measurable variation of salinity due to the mixture of sea water with fresh water derived from land drainage". More recently, Heydorn (1989) has defined an estuary as "that portion of a river system entering the sea where there is, within the boundaries of the land, a gradual transition in physical, chemical and biological characteristics from fresh water to sea water". Because most southern African estuaries are closed for much of the year and reversed salinity gradients are a regular feature of several permanently open systems, the definition of Day (1980) is regarded as being more appropriate for this region.

\section{Water exchange and estuary mouth dynamics}

Three factors play a major role in the structure of estuary mouths; freshwater discharges from the catchment rivers, tidal flow through the mouth and sediment transport processes in the sea. Sediment suspended in sea water near the mouth may be carried into the system by flood tidal currents. The material then settles in the calmer estuary waters and is only partially removed during the ebb tide. This results in an accretion of sand inside the estuary mouth and may eventually result in the formation of a flood tidal delta. River flow also has a marked influence on the amount of marine sediment deposited in an estuary. Reduced river flow tends to result in greater influx of marine sand into the estuary whereas episodic floods normally carry large quantities of sand back to the sea, thereby maintaining the sediment balance in the lower part of the estuary. Because of the intermittent nature of major floods, large variations in the quantities of marine sand in an estuary occur, the natural pattern often being a slow accumulation of sand over a number of years with a rapid depletion during episodic floods (Rossouw et al. 1991). Due to variation in the quantities of sand near the mouth, and changes in the deposition and erosion rates, there is a tendency for the mouth to migrate. Changes in position of up to a kilometre over several years can occur if nothing restricts this movement, but most permanently open estuary mouths on the southern African coast are stabilised by rocky areas on either the left or right bank.

If tidal exchange and/or river flow is insufficient to maintain mouth depth, a sand bar forms. The bar will increase in size until it eventually cuts off all tidal exchange of water with the sea. Following renewed river flow, the bar is overtopped, the mouth scours open and the process begins again. If the mouth remains open for an extended period, the salinity in the lower and sometimes middle reaches of the estuary can approach that of sea water prior to closure. The water levels after closure are determined mainly by the balance between evaporation and the rate of freshwater inflow. However, seepage of estuarine water into the sea and wave overtopping of the sandbar can also have a major influence on water levels and salinities in certain systems. The duration of the open mouth phase varies considerably from one estuary to another. In some cases it is closed for the larger part of the year and only opens after an extended wet season or after a flood. In other cases the mouth is usually open for most of the year and only closes during droughts.

In large estuaries where the mouth is permanently open, water levels are more predictable, fluctuating with the tides and rising during floods. The salinity of these systems is controlled by the water exchange at the seaward end, evaporation from the estuary, and freshwater inflow. During periods of low run-off, the salinity throughout the estuary can approach that of sea water. In some cases a lack of riverine input can lead to hypersaline conditions ( $>35 \%$ ) developing in the upper reaches due to evaporation and a lack of water exchange with the marine environment. During major floods, salinities decline considerably, but the duration of the oligohaline conditions is limited because tidal exchange rapidly replaces the river water after the flood has dissipated. Silt, sand and debris that are brought down by the rivers during floods are usually carried directly out to sea, but if a reduction in flow velocity occurs within the estuary, part of the sediment load is deposited in the system. 


\subsection{DESCRIPTIONS OF SOUTHERN AFRICAN ESTUARIES}

It is important to note that a description of any estuary is subject to the inevitable changes that occur in all systems through time. These changes are usually driven by sea level fluctuations but will also be influenced by climatic shifts, especially where such shifts have an influence on sediment transport and deposition rates. The present day estuarine lake at Botriviervlei did not exist 18000 years B.P. when the mouth of the Bot River was situated in a palaeovalley approximately $40 \mathrm{~km}$ south-west of the existing estuary (Rogers 1985). The recent history of the Botriviervlei mouth also reflects major changes, from a system that allowed free interchange of marine and fluvial waters, into an estuary which is now seldom open to the sea (van Heerden 1985). Similarly, about 6000 years ago the sea level was some $2.5 \mathrm{~m}$ above present mean sea level and the Swartvlei Estuary was probably served by a $2 \mathrm{~km}$ wide tidal inlet (Whitfield et al. 1983). Today the mouth of the Swartvlei Estuary is less than $100 \mathrm{~m}$ wide at high tide and is generally closed for more than 6 months each year.

During its lifespan a typical southern African estuary goes through various stages of development, from a youthful, newly drowned river valley to a mature system where the valley is filled with sediment (Reddering \& Rust 1990). Channel dimensions of a mature estuary are determined by the flood discharge and slope of the river, the cohesion of the sediment bed and by the tidal influx of marine sediment during periods between fluvial floods. Mature estuaries, a stage reached by many of the permanently open systems along the coast, establish an equilibrium whereby tidally accumulated sediment is eroded from the estuary only during episodic floods (Reddering 1988a). This equilibrium is likely to be altered as a result of changes described below.

According to Reddering \& Rust (1990) modifications to the structure and functioning of southern African estuarine systems can be placed into two major categories; firstly changes that have been driven by global forces such as climatic and sea level fluctuations, and secondly changes that have resulted from direct human interference and are of a local or regional nature. Both the above categories will determine the rate and magnitude of morphological and hydrodynamic changes within these estuaries, and therefore have a major impact on the characterization of individual systems in the future.

River inflow is perhaps one of the most critical factors influencing estuaries on the subcontinent because of its role in sedimentary and hydrodynamic processes within individual systems (van Heerden 1986, Badenhorst et al. 1989, Cooper 1993). The increasing retention of fresh water in dams for domestic, industrial and agricultural use has a distinct effect on estuaries, and includes the removal of an essential element in their natural cycle, namely the normal flood events (Whitfield \& Wooldridge 1994). Dams cause not only a decrease in the overall number of floods but also reduce the volume of water per flood (Reddering and Rust 1990). The extent to which river water is impounded varies, but in some catchment basins the combined capacity of existing dams already exceeds the mean annual runoff of the river system (Bickerton \& Pierce 1988). The potential deleterious effects on estuaries so affected are obvious and take the form of an increase in the size of sand shoals situated in the lower estuarine reaches (Reddering \& Esterhuysen 1984). This modification may have two further effects. Firstly, the development of large flood tidal deltas tend to constrict the channel of the lower estuary, so that tidal exchange between the sea and the estuary becomes gradually less efficient, and consequently the tidal prism cannot maintain an open tidal inlet as before. Secondly, when a flood of sufficient discharge does occur, the sediment in the delta would have a larger than normal volume and therefore take longer to be scoured to a specific base level. In the case of muddy estuaries, the sediment would attain a higher degree of erosion resistance (Reddering 1988a) and be much more difficult to remove. Consequently, a river flood would not be able to scour the estuary channel to its normal dimensions as easily as a flood under natural conditions. As an overall result, smaller estuary channel dimensions are established under prolonged conditions of reduced freshwater discharge.

Apart from the scouring action of fresh water, rivers are also important in the prevention of hypersaline conditions. For example, during the 1989 drought in the Eastern Cape, salinities in the middle and upper reaches of the Great Fish Estuary seldom rose above $10 \%$ because of a high freshwater input, whereas salinities in the upper reaches of the nearby Kariega Estuary attained $42 \%$ (Whitfield \& Bruton 1989). In some small temporarily closed estuaries, the salinity extremes during the 1989 drought were even more marked, ranging from $98 \%$ in the Seekoei system (excessive freshwater abstraction in the catchment) to $29 \%$ in the Boknes Estuary (no major dams in catchment). As has been mentioned, salinities in estuarine lakes often fluctuate widely and in the St Lucia system these can range from less than $5 \%$ during wet cycles to more than $100 \%$ during extreme droughts (Taylor 1982). 
The estuaries of southern Africa can be divided into three major regions: cool-temperate, warmtemperate and subtropical. The cool-temperate region extends from Walvis Bay to Cape Point (Figure 1) with permanently open estuaries along this coast being strongly influenced by $\operatorname{cool}\left(<14^{\circ} \mathrm{C}\right)$ upwelled waters. In addition, strong river flow associated with winter rainfall can depress estuarine water temperatures below $12^{\circ} \mathrm{C}$. The warm-temperate region extends from Cape Point to the Mendu Estuary on the Transkei coast. Although upwelled water $\left(<16^{\circ} \mathrm{C}\right)$ frequently intrudes into the lower reaches of estuaries along this section of the coast during summer (Hanekom et al. 1989), annual estuarine water temperatures are usually within the $12-26^{\circ} \mathrm{C}$ range. The subtropical region extends from the Mbashe Estuary to Maputo Bay (Figure 1). Upwelling seldom occurs along this section of the coast and estuarine water temperatures usually range from $14-28^{\circ} \mathrm{C}$, with coastal shelf conditions above $20^{\circ} \mathrm{C}$ due to the close proximity of the warm Agulhas Current (Beckley \& van Ballegooyen 1992). The tropical region is located north of Maputo Bay and is outside the geographic scope of this book.

Eustatic changes in sea level play a major role in the type of estuaries which develop (Schubel \& Hirschberg 1978). Various preliminary models of global climate change suggest increases of about $2-6^{\circ} \mathrm{C}$ in average surface temperatures over the next 100 years, accompanied by a possible sea level rise of between 0.2 and $1.6 \mathrm{~m}$ (Kennedy 1990). If global warming should cause a rise in sea level of approximately $1 \mathrm{~m}$, the tidal prism in southern African estuaries will be affected, with estuarine conditions extending further inland, especially in the case of permanently open systems. Furthermore, isostatic settling of the crust as a result of the added weight of water over areas with a wide continental shelf (e.g. Agulhas Bank) will locally accentuate apparent sea level rise (Reddering \& Rust 1990). In general, a rise in sea level has the potential to improve the hydrodynamic processes and secondary production of estuaries (Zimmerman et al. 1991). A rise in sea level may, however, also result in a change in estuarine base levels until a new equilibrium is attained, so in many instances estuaries will be affected by an initial increase in net sedimentation (Reddering \& Rust 1990). If the rate of sedimentation within an estuary should keep up with the rate of sea level rise, that estuary will experience very little functional change. At most, the tidal prism may increase for those estuaries where a combination of local conditions causes the tidal range to flood a wider section of the river valley and its estuary (Reddering \& Rust 1990). However, any substantial sea level rise would have major implications for existing estuarine salt marshes and mangroves, since existing intertidal habitats would become subtidal and supratidal areas would develop into the new intertidal zone (Zimmerman et al. 1991).

Ramm (1990a) has shown that a rise in sea level would cause the additional influx of marine water into the Kosi estuarine system, resulting in increased sulphate concentrations in the upper lakes. This could, in turn, lead to an expansion of the toxic sulphide-rich areas (Allanson \& van Wyk 1969) and result in a loss of hospitable habitat in Lake Mpungwini. A simulation model, based on sulphate enrichment experiments conducted in the field, suggested that increased sulphate reduction rates from a rising sea level could result in the mixing of high concentrations of free sulphides into Mpungwini surface waters. In addition, the simulations suggested that upwelling of bottom water is likely during periods of high turbulence in the water column, and that the resulting rapid transport of free sulphides into surface waters could cause mass mortalities of fish and other biota. The prediction of the model was supported during the spring equinox tides of September 1989 when thousands of fish, representing all the major species in the central Kosi system, died due to toxic concentrations of sulphides $\left(>10 \mathrm{mg} \mathrm{l}^{-1}\right)$ being upwelled into surface waters (Ramm 1990a). If such hydrodynamic events were to become a regular feature of the system, a chemical barrier to fish (especially the movements of $0+$ juveniles within the Kosi system) could be created (Ramm 1992).

Coastal waves are known to be an important factor controlling the closure of estuaries. Estuaries on open, wave-exposed coasts tend to close more often than their counterparts on sheltered, embayed coasts (Reddering 1988b). If wave energy increases as a result of global warming then it is likely that the tidal inlets of southern African estuaries will become more constricted. Conversely if climatic change were to reduce wave energy, then the effect of tidal scour in estuaries would increase, particularly if the tidal prisms were substantially expanded by a rise in sea level (Reddering \& Rust 1990). This could lead to estuaries that are presently classified as temporarily open becoming permanently open, and certain river mouths and coastal lakes receiving a stronger marine influence. Hughes \& Brundrit (1992) have suggested that southern African estuaries, which are fairly sheltered from the open sea and have their tidal signal significantly dampened by the frictional characteristics of the mouth, may become more vulnerable to storm water ingress as a result of sea level rise. Higher coastal water levels during storms would be capable of penetrating even the most restrictive inlet, provided the event was of sufficient duration. 
Estuaries are usually classified by their salinity characteristics, hydrography, sedimentation patterns, physiography, geomorphology and ecosystem energetics (Kennish 1986). Although geologists tend to classify estuaries according to their geomorphology or physiography; and oceanographers according to their hydrography and salinity, there is no reason why a combination of the above features should not be used. The classification of estuaries described here draws (Table 1) mainly on the physiographic, hydrographic and salinity characteristics of individual systems, thereby providing a more comprehensive classification system than would be possible if only one or two factors were considered.

Although the definition of an estuary by Day (1980) encompasses all southern African systems, it does not convey the variety of estuarine types occurring on the subcontinent. Indeed, it is this variety that has led to scientists using different terminology when describing identical systems, e.g. Begg (1978) refers to temporarily closed estuaries as 'lagoons', Day (1981a) uses the term 'blind estuaries', and Bennett (1989) differentiates between 'seasonally open' and 'normally closed' estuaries. The lack of standardised and/or appropriate terminology is not confined to southern African system descriptions, e.g. Australian literature frequently refers to temporarily closed estuaries as 'lagoons' (Bird 1984).

Reddering \& Rust (1990) consider few southern African systems to be true estuaries, with only 37 river mouths maintaining permanent tidal inlets. They suggest that estuaries on the subcontinent have the following features: (i) the majority are small, their tidal prisms being $10^{6} \mathrm{~m}^{3}$ or less; (ii) most occupy drowned river valleys; (iii) most tidal inlets are constricted or periodically blocked by sand bars; (iv) flood tidal deltas are well developed whereas ebb tidal deltas are poorly developed.
The maximum tidal range off the southern African coast is approximately $2 \mathrm{~m}$ between successive high and low spring tides, with most estuaries having a range considerably less than $1.5 \mathrm{~m}$. This, together with some of the estuarine features described above (e.g. constricted tidal inlets), has led to estuaries on the subcontinent being described as microtidal systems. Those that are permanently open are subject to a semi-diurnal tidal cycle, i.e. two high and two low waters per day.

Southern African estuaries are unpredictable environments (Table 2) and the fluctuating nature of these systems makes them difficult to place in specific categories. According to Largier \& Slinger (1991) this applies particularly to salinity stratification, that varies with time and location within an estuary. The above authors make a distinction between those systems that are permanently highly stratified and those that display highly stratified phases, factors which have not been fully addressed in past characterizations of southern African estuarine types.

It has been suggested that estuaries are often not distinct from one another but represent a range of types. In addition, an estuary of one type can behave at times like quite a different type, depending on fluctuations in river flow and the changing condition of the mouth. A typical example quoted by Noble \& Hemens (1978) is an estuary which forms a lagoon, cut off from the sea at times of low river flow. The same estuary can behave like a permanently open system when the mouth is open, with tidal exchange and well developed salinity gradients. During episodic flooding it is possible for this system to behave like a river mouth, with the zone of salinity mixing having been pushed out to sea.

Despite the fiuctuating nature of southern African estuaries described above, it is possible to categorize these systems (see below) using the dominant phase prevailing in each estuary.

Table1. Some generalised physical characteristics of southern African estuarine systems (after Whitfield 1992a).

\begin{tabular}{llll} 
System type & Spring tidal prism & Mixing process & Mean salinity \\
\hline Estuarine bay & Large $\left(>10 \times 10^{6} \mathrm{~m}^{3}\right)$ & Tidai & $25-35 \% \circ$ \\
Permanently open estuary & Moderate $\left(1-10 \times 10^{6} \mathrm{~m}^{3}\right)$ & Tidal/riverine & $15-40 \%$ \\
River mouth & Small $\left(<1 \times 10^{5} \mathrm{~m}^{3}\right)$ & Riverine & $1-15 \% o$ \\
Estuarine lake & Negligible $\left(<0.1 \times 10^{6} \mathrm{~m}^{3}\right)$ & Wind & $1->35 \%$ \\
Temporarily closed estuary & Absent & Wind & $1->35 \% \circ$
\end{tabular}


Table 2. Characteristics associated with predictable/unpredictable environments (after Bruton 1989) and with southern African estuarine systems (after Whitfield 1990).

$\begin{array}{llll}\begin{array}{l}\text { Characteristics of } \\ \text { the environment }\end{array} & \begin{array}{l}\text { Predictable } \\ \text { environment }\end{array} & \begin{array}{l}\text { Unpredictable } \\ \text { environment }\end{array} & \begin{array}{l}\text { Southern African } \\ \text { estuaries }\end{array}\end{array}$

$\begin{array}{llll}\text { Inertia } & \text { high } & \text { low } & \text { low } \\ \text { Elasticity } & \text { low } & \text { high } & \text { high } \\ \text { Amplitude } & \text { low } & \text { high } & \text { high } \\ \text { Dynamic property } & \text { fragile } & \text { robust } & \text { robust } \\ \text { Maturity } & \text { high } & \text { low } & \text { low } \\ \text { Stability } & \text { resistant } & \text { resilient } & \text { resilient }\end{array}$

\section{Definitions}

Inertia: the ability of the system to resist perturbations.

Elasticity: the speed with which a system returns to its original state following perturbation.

Amplitude: the magnitude of the perturbations and the degree of displacement from a previous state.

Dynamic property: the variety and nature of forces operating within a system.

Maturity: the degree to which a system approaches a climax state.

Stability: the tendency of a system to remain near an equilibrium point or to return to it after a disturbance.

\section{Permanently open estuaries}

Systems that are permanently open to the sea (Figure 2) show typical estuarine characteristics, e.g. a moderate tidal prism with a horizontal salinity gradient and vertical salinity stratification dependent upon factors such as bathymetry, tidal cycle and river inflow (Mackay \& Schumann 1990). The catchments of these estuaries are usually larger than $500 \mathrm{~km}^{2}$ and often greater than $10000 \mathrm{~km}^{2}$, with the rivers having a perennial flow in their natural condition. Although river flow contributes to the maintenance of an open mouth condition, the tidal prism in these systems is generally large enough to maintain a permanent link with the sea. However, during extreme droughts the mouths of these systems can close.

Generally there is a wetland area within lower half of these estuaries, which may be occupied by salt marshes in the more temperate regions or mangroves in subtropical areas. The eelgrass (Zostera capensis) often colonizes intertidal and subtidal zones of low turbidity systems, especially in the lower and middle reaches (Talbot \& Bate 1987). However, in systems were the flow of fresh water has been curtailed, eelgrass extends its distribution into the upper reaches (Adams \& Talbot 1992).

Tides and tidal currents provide the ultimate driving force for most of the turbulence and mixing in stratified and well mixed estuaries (Kennish 1986).
Although Day (1981a) has subdivided 'normal' (i.e. permanently open) southern African estuaries into saltwedge, highly stratified, partially mixed and vertically homogeneous systems, recent evidence (Mackay \& Schumann 1990, Largier \& Slinger 1991) suggests that the degree of stratification is very variable on both a spatial and temporal scale, and that many estuaries move from one state to another depending upon factors such as river flow, tidal range and mouth condition.

Largier \& Slinger (1991) described estuarine circulation patterns in the highly stratified Palmiet system and emphasized the importance of internal hydraulic control of exchange through the narrow mouth, buoyancy-driven landward intrusion of sea water, upward shear-driven entrainment and ebb tidal outflow. They also drew a distinction between those estuaries that are normally highly stratified, such as the Palmiet, and those that display highly stratified phases. An example of the latter can be found in the Sundays Estuary which is highly stratified during neap tides but become completely mixed during spring tides (MacKay \& Schumann 1990). Although tidal currents dominate mixing processes in these estuaries under low and even moderate river flow conditions, floods can result in a complete reversal of the situation, with riverine energy driving water movements within the system until a tidal regime is re-established. 
Intense stratification is often present in deeper areas of permanently open estuaries where isolated 'pockets' of higher salinity water are trapped. For example, in the fjord-like Msikaba Estuary surface and bottom salinities of $20 \%$ and $35 \%$ respectively were measured during the low flow winter season, while the equivalent readings in spring during higher flows were $2 \%$ and $35 \%$. The marked salinity stratification in summer leads to oxygen depletion of bottom waters, with a concomitant negative influence on the sessile biota below $6 \mathrm{~m}$ depth (Blaber et al. 1974). Similar highly stratified and anoxic conditions have been recorded in deep regions $(>10 \mathrm{~m}$ ) within the upper Keurbooms Estuary.

Average salinities in permanently open estuaries tend to fluctuate between $15 \%$ and $35 \%$ but are usually greater than $25 \%$. Hypersaline conditions $(>40 \%$ ) have been recorded in the upper reaches of certain Eastern Cape systems during extreme droughts, due to very low or zero river inflow and high summer evaporation rates (Whitfield \& Bruton 1989). Oligohaline (0.5-4.9\%o) and highly turbid conditions can extend into the lower reaches of these estuaries for brief periods during major flood events. The sudden decline in salinities and high silt loads may even cause extensive mortalities of the estuarine biota (McLachlan \& Grindley 1974, Whitfield \& Paterson 1995).

Estuarine water temperatures are highly variable. Generally temperatures tend to reflect riverine conditions during floods, with the sea having a stronger influence during normal river flows or droughts. For example Read (1983) found that the Keiskamma Estuary was vertically isothermal during a dry summer (halocline absent), whereas during wet summers a thermocline (halocline present) was recorded in the water column. A comparison of the vertical temperature structure in the Keiskamma Estuary during stratified winter conditions revealed that the water above the halocline was cooler than that below, whereas in summer the opposite pattern occurred. These differences emphasize the influence of both the marine and riverine components on estuarine water temperatures, and verify the fact that rivers in the warm-temperate region are usually cooler than the sea in winter and warmer in summer.

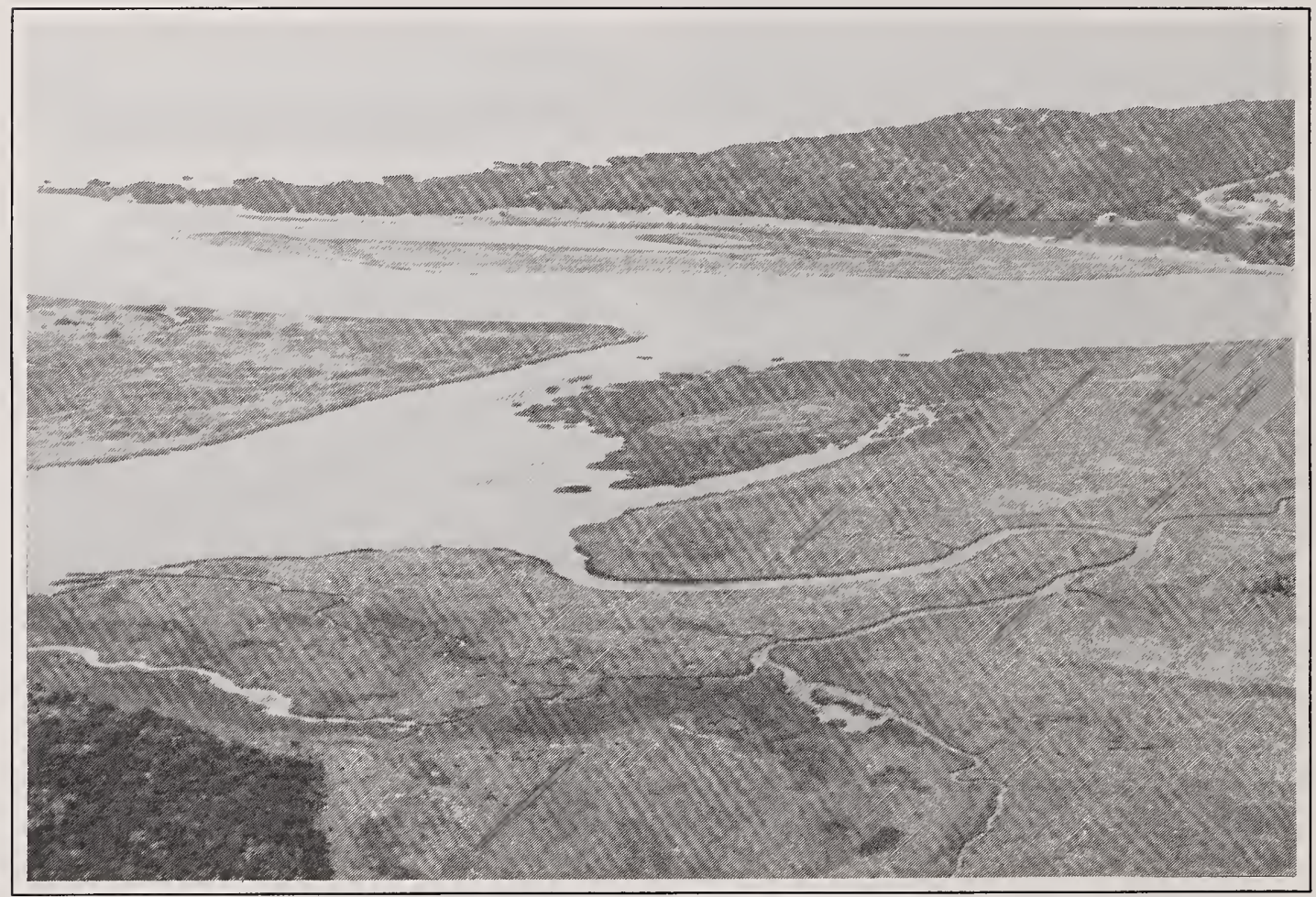

Figure 2. The permanently open Keiskamma Estuary in the Eastern Cape Province. Note the extensive floodplain which has been colonized by salt marsh vegetation. 
These systems are blocked off from the sea for varying lengths of time by a sand bar which forms at the mouth (Figure 3 ). This occurs during low river flows combined with longshore sand movements in the nearshore marine environment (Day 1981b). Most of these estuaries have small river catchments $(<500$ $\mathrm{km}^{2}$ ) and long periods (several months) when the river flow is minimal or stops altogether. The tidal prism is small $\left(<1 \times 10^{6} \mathrm{~m}^{3}\right)$ when the mouth is open and absent when the sand bar is fully formed. The latter condition predominates for most estuaries in this category.

When open these systems usually behave like a typical estuary but during floods they often take on the characteristics of a river mouth. Large amounts of sediment are removed from the smaller estuaries during flooding (Reddering \& Esterhuysen 1987) but subsequent infilling of the scoured lower reaches with marine sediment is usually rapid. Fluvially derived sediments accumulate in the upper reaches, with silt deposits usually overlaying coarser material. The surface silt deposits in the channel are usually transient by nature, being scoured during each flood and then gradually replaced by new deposits as the floodwaters dissipate and the mouth closes.
Some temporarily open/closed estuaries are connected to estuarine lakes (e.g. Swartvlei) and their behaviour is then closely tied to water level fluctuations within these lake systems (Whitfield et al. 1983). A rise in lake level due to freshwater inflow exceeding evaporation leads to a rise in water level in the adjacent temporarily closed estuary. When the level of the estuary exceeds the height of the sandbar at the mouth, the estuary opens.

Although strong horizontal salinity gradients are sometimes present in temporarily open estuaries during the tidal phase, more uniform oligohaline $(0.5-4.9 \%)$ or mesohaline $(5.0-17.9 \%)$ conditions usually prevail in KwaZulu-Natal systems during the prolonged closed phase (Begg 1984a). During episodic floods, river conditions may briefly dominate the estuary, but during extreme droughts salinities in some of the Eastern Cape systems can exceed 50\%o (Whitfield \& Bruton 1989). Seepage of estuarine water through the sand bar into the sea, and barrier overwash by exceptionally high tides, has been recorded in closed estuaries (Begg 1984b, Cooper 1989). Barrier overwash can lower of the height of the sand bar thus reducing the volume of estuarine water needed to breach the mouth.

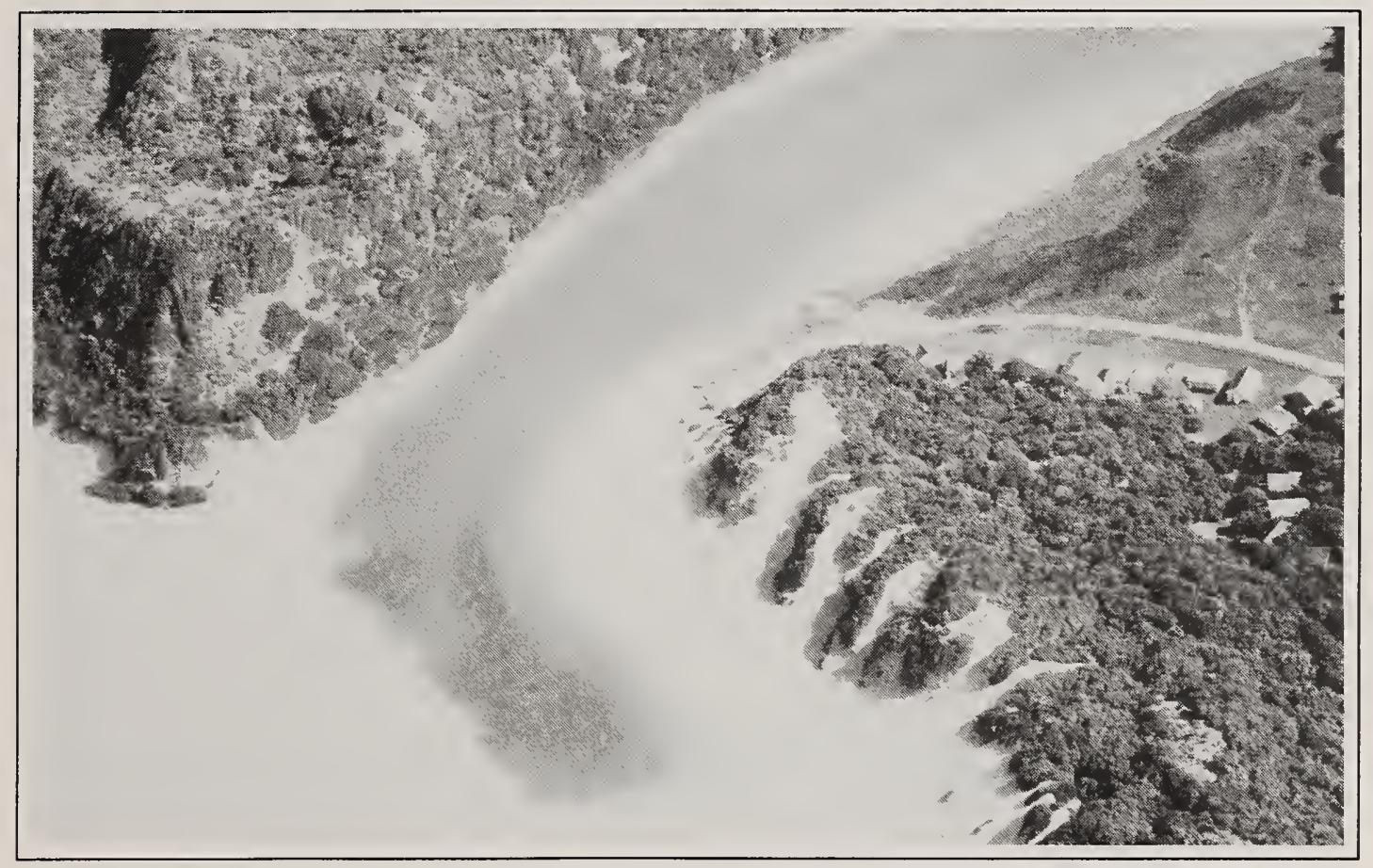

Figure 3. The temporarily closed Kasuka Estuary showing vegetated dunes on either side of the sandy mouth. 
The circulation in these estuaries is driven by both tidal and river flow when the mouth is open and wind when the mouth is closed. Cooper (1989) recorded current velocities of $50-60 \mathrm{~cm} \mathrm{~s}^{-1}$ during a river flood in the Mhlanga Estuary, but tidal conditions soon dominated circulation during the open phase due to the short-lived flood peak. Water temperatures during the open phase are strongly influenced by both riverine and marine conditions, but are normally independent of these influences when the estuary is closed and river flow is either minimal or zero. During the closed phase solar heating and evaporative cooling of the estuarine water body are the prime determinants of the prevailing temperature regime.

The aquatic fauna of temporarily open/closed estuaries is dominated by marine and estuarine forms, although certain freshwater organisms may increase in abundance during the closed phase when oligohaline conditions prevail (Begg 1984a), e.g. the cichlid Oreochromis mossambicus is abundant in temporarily closed estuaries along the KwaZulu-Natal and Eastern Cape coasts (Harrison \& Whitfield 1995), but is usually rare in these systems during the open phase (Whitfield \& Blaber 1979a).

\section{River mouths}

These are systems in which the river usually dominates physical processes within the estuary, with salinities tending towards oligohaline in both the upper and middle reaches. Although the mouths of these estuaries are permanently open (Figure 4), the tidal prism is relatively small, with sea water seldom penetrating any major distance upstream during high or even moderate river flow periods. When river flooding occurs, freshwater conditions can extend well into the marine environment. During such flood events the system ceases to behave like an estuary and becomes an extension of the river.

Southern African river mouths generally have relatively large catchment areas $\left(>10000 \mathrm{~km}^{2}\right)$ and the rivers are often characterized by heavy silt loads, a portion of which is deposited in the estuary (van Heerden 1986). Consequently river mouths are usually shallow ( $<2 \mathrm{~m}$ deep) despite the large volume of water which passes through these systems. Episodic floods can result in scour depths of up to $15 \mathrm{~m}$ being recorded during peak flooding in the Orange River mouth (Swart et al. 1988).

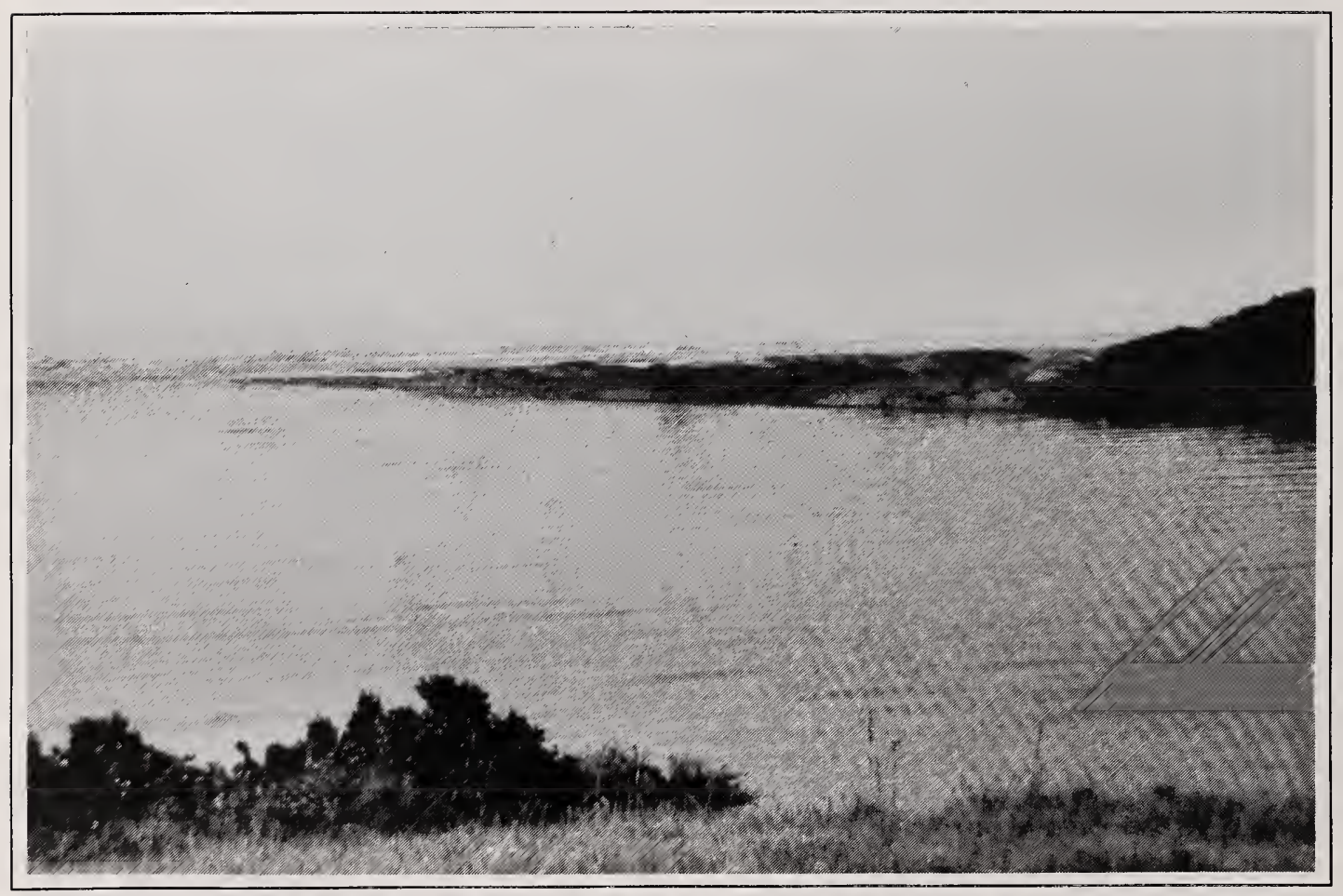

Figure 4. The Tugela River mouth during February 1997. The average water depth is less than $2 \mathrm{~m}$ at spring high tide. 
Mixing of the water column in this type of estuary is usually dominated by turbulence derived mainly from river flow. Under moderate or high river flow conditions, the fresh water will flow over the top of any marine water which may be present in the estuary. Water temperatures are closely linked to those in the river, although the sea will sometimes influence bottom waters in the lower reaches, especially at spring high tide.

River mouths along the Tsitsikamma coast do not reflect all the features described above. Systems in this region drain catchment areas comprising mainly Table Mountain sandstone and the perennial rivers carry negligible sediment loads, even under moderate or high flow conditions. Due to the geology of the area, river mouths along this section of the coastline are generally short and situated in narrow, steep sided valleys with limited sedimentary deposits on the rocky base.

Freshwater biota are widespread in these systems (Day 1981c), with marine and estuarine organisms usually confined to the lower reaches (Brown 1958) and seldom penetrating beyond the middle reaches, especially during moderate or high river flow conditions. Submerged aquatic macrophytes are rarely recorded in river mouths.

\section{Estuarine lakes}

Most estuarine lakes (Figure 5) in southern Africa evolved from drowned river valleys (Hill 1975) that were largely filled in by reworked sediments to varying degrees and are now separated from the sea by vegetated sand dune systems. In some instances the dune barrier has completely isolated the lake, which then loses its estuarine character and is then referred to simply as a coastal lake (e.g. Lake Sibaya, Groenvlei). Relict estuarine biota (e.g. the amphipod Grandidierella lignorum and clupeid Gilchristella aestuaria), that are physiologically tolerant of freshwater conditions and do not require a marine link for breeding purposes, still occur in these isolated systems (Allanson et al. 1966, Ratte 1989).

Estuarine lakes may have a permanent marine connection (e.g. Kosi), or may be seasonally linked to the sea (e.g. Swartvlei), while others are seldom linked to the sea (e.g. Botriviervlei). Salinities in estuarine lakes are spatially and temporally variable (Hutchison \& Midgley 1978) and depend primarily on the balance between freshwater input, evaporation and the periodicity of the marine connection (Bally \& McQuaid 1985).

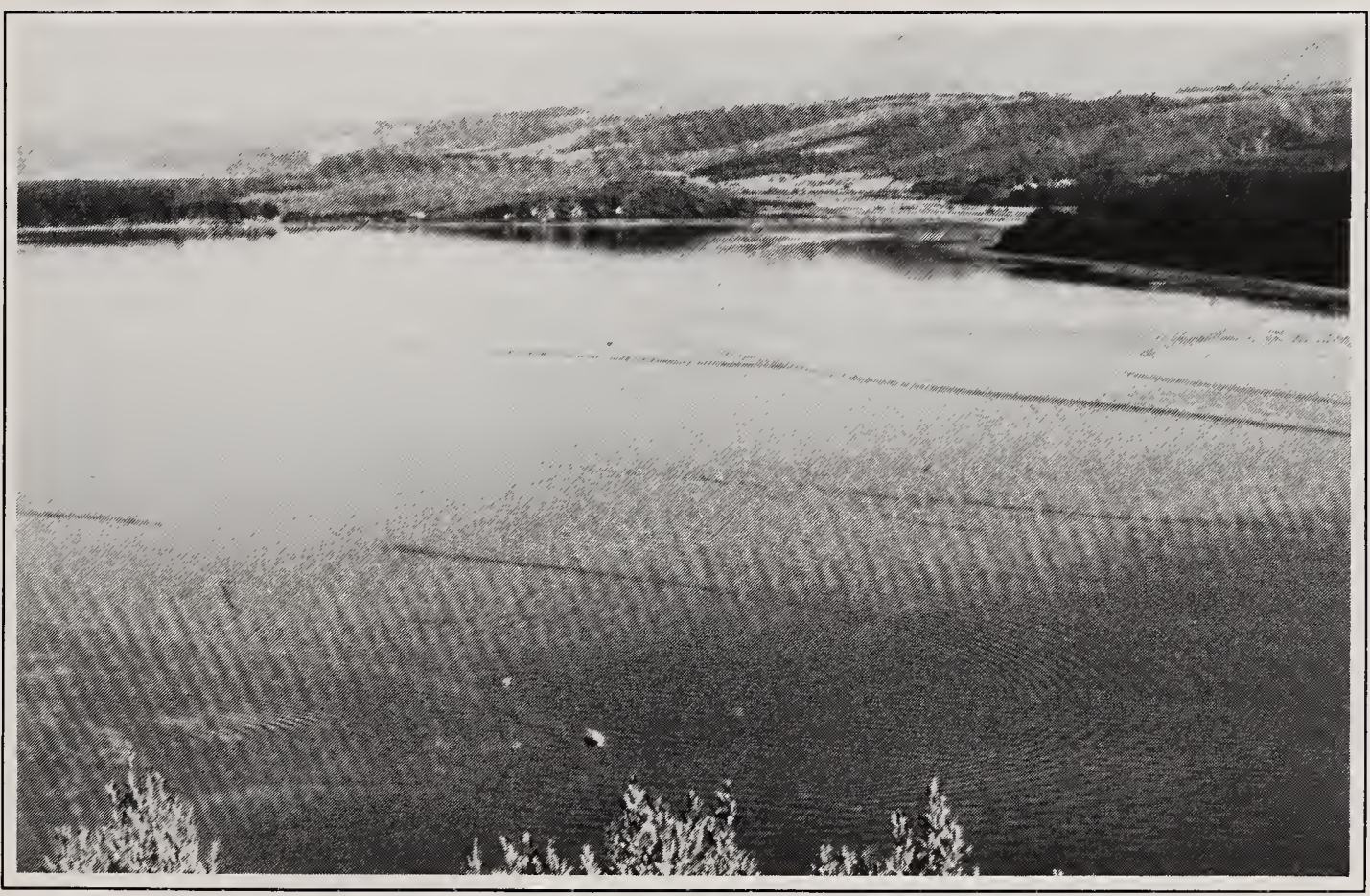

Figure 5. The estuarine lake component of the Swartvlei system with the Outeniqua Mountains in the background. 
Although the mouth of this type of system is often open, tidal prisms within estuarine lakes are usually negligible due to the narrowness of channels linking them to the sea. In some cases segmentation has resulted in a very tenuous connection with the marine environment, especially for the lakes at the end of each chain, e.g. Lake Nhlange in the Kosi system (Begg 1978) and Rondevlei in the Wilderness system (Hall et al. 1987).

Meromixis is common in the deeper $(>5 \mathrm{~m})$ estuarine lakes but seldom occurs in the shallower systems. Wind is the dominant mixing force, even in the deeper lakes where it may take several months to break down the halocline (Allanson \& HowardWilliams 1984). Spatial and temporal salinities within estuarine lakes vary from oligohaline to hypersaline, e.g. Lake St Lucia salinities can range from 1-115\%o (Taylor 1982) whereas salinities in Swartvlei lake vary between $2 \%$ and $20 \%$ (Allanson \& Howard-Williams 1984). Water temperatures in these systems are directly related to solar heating and radiation, and are little influenced by either rivers or the sea.
Marine and estuarine fauna dominate estuarine lakes, although certain freshwater species (e.g. fishes Oreochromis mossambicus and Clarias gariepinus in Lake St Lucia) tend to increase in abundance during prolonged oligohaline conditions (Whitfield 1980a).

\section{Estuarine bays}

Only three estuarine bays occur in southern Africa, with two in the subtropical zone and one in the warmtemperate region. They are either natural (e.g. Knysna) or partly artificial due to dredging activities in the mouth and harbour region (e.g. Durban Bay). In its natural state, Richards Bay was more of a coastal lake than a bay (Millard \& Harrison 1954), but with recent harbour developments it has taken on the characteristics of a marine dominated embayment (Begg 1978).

Estuarine bays have large tidal prisms $\left(>10 \times 10^{6}\right.$ $\mathrm{m}^{3}$ ) that result in the regular replacement of marine water in the lower and middle reaches. Mixing of the

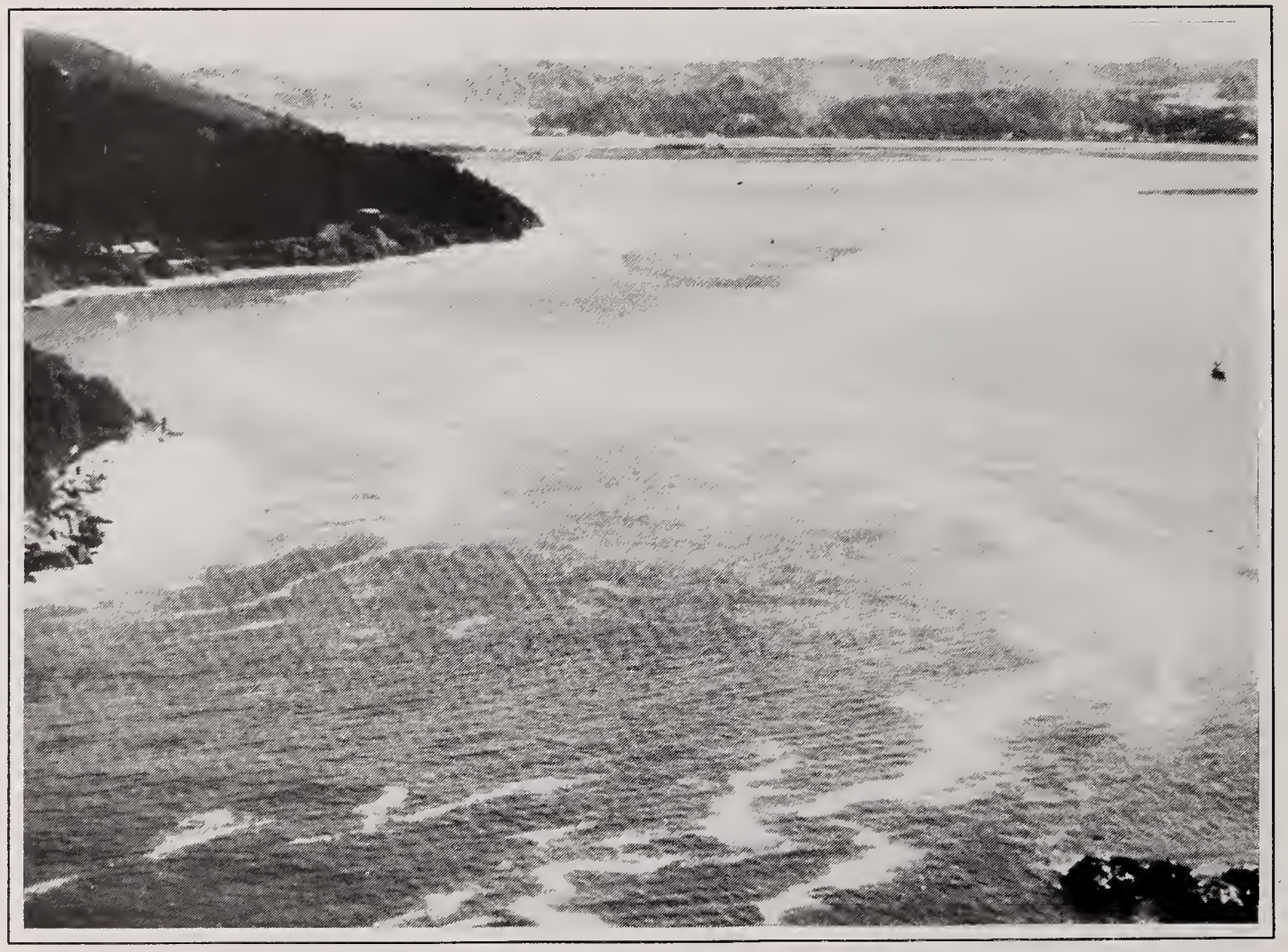

Figure 6. The mouth of the Knysna Estuary is $230 \mathrm{~m}$ wide with an average channel depth of approximately $10 \mathrm{~m}$. 
water column is tidally driven, and strong salinity stratification is a feature only in the upper and sometimes middle reaches of the Knysna system (Grindley 1985). Even under high river flow conditions, seawater salinities persist in the bottom waters of the lower reaches. The mouth is usually more than $5 \mathrm{~m}$ deep at spring high tide and tidal height fluctuations within the estuary are normally similar to those in the marine environment. For example, in the Knysna Estuary (Figure 6) a spring tidal range of $1.8 \mathrm{~m}$ persists into the upper reaches of this system and even increases slightly at the estuary head (Day 1981c).

Salinities in the lower reaches of estuarine bays tend to exceed $30 \%$ due to the large volume of sea water entering these systems. Salinities below $30 \%$ are usually recorded in the upper and middle reaches, with reduced salinity conditions extending into the lower reaches during river flooding. Near marine conditions can extend into the upper reaches of certain estuarine bays during dry periods when river input is low. Hypersaline conditions have not been recorded in these systems due to the efficient exchange of water between the marine and estuarine environments. Water temperatures in both the lower and middle reaches are strongly influenced by marine conditions (Day 1981c). However, surface heating in summer and radiation in winter causes water to be warmer than the sea during summer and slightly cooler in winter (Day \& Morgans 1956).

The fauna is predominantly marine, with estuarine taxa usually well represented in the middle and upper reaches of these systems. Stenohaline marine biota are often present in the mouth region of this type of bay. Freshwater species are generally absent from estuarine bays (Day \& Morgans 1956, Day 1967) but may be washed into these systems during river flooding.

Extensive mangrove or salt marsh areas are normally present in estuarine bays, although in some cases these have been removed to facilitate harbour developments (Figure 7). Dredging of both Durban and Richards bays has reduced the availability of littoral habitats to the biota and increased the magnitude of tidal exchange. This has resulted in these systems becoming more marine dominated, in terms of both physico-chemical and biological characteristics, than under natural conditions. Despite these modifications, certain estuarine species are still abundant in estuarine bays (Cyrus \& Forbes 1996).

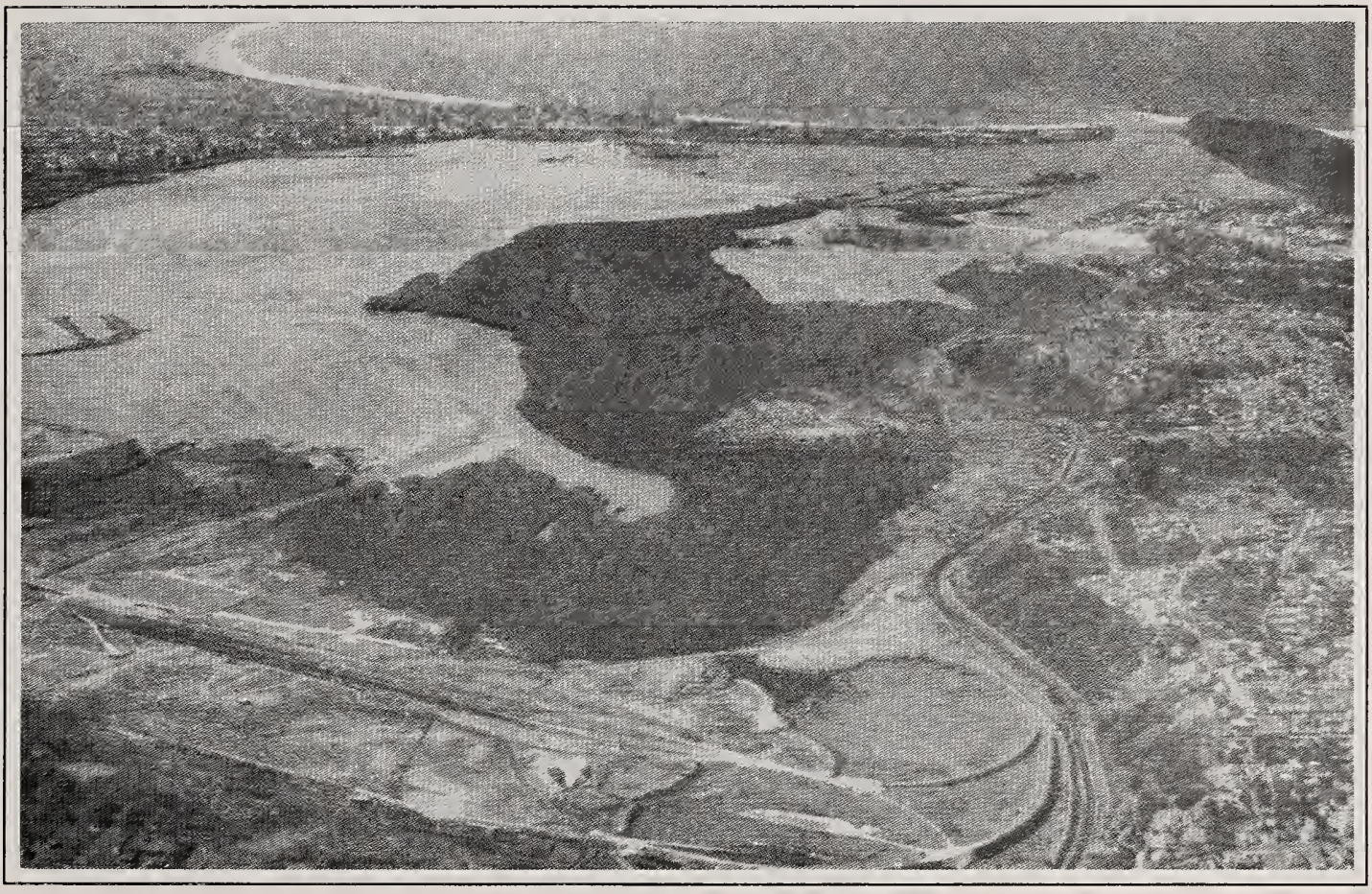

Figure 7. An aerial view of Durban Bay in the 1950s, prior to the removal of most of the remaining mangroves for harbour developments (photograph: The Natal Mercury). 


\subsection{HISTORY OF ESTUARINE ICHTHYOLOGY}

The origin of estuarine ichthyology in southern Africa can be traced back to the turn of the century and the perceived problems being experienced by anglers in the Swartkops Estuary. These anglers claimed that the netting of fishes in this estuary, which was permitted by an Act promulgated in 1883, was causing marked reductions in the fish available to recreational fishermen. In 1912 it was resolved to close the estuary for three years to netting and "to attempt to discover by a series of experimental nettings and other observations what were the real facts of the case" (Gilchrist 1918). Unfortunately, no experimental netting was conducted during 1912 because of financial constraints but a temporary ban on commercial netting was implemented.
Towards the end of 1913 "it was represented to the Government that there had been a great falling off of the fish in the river, and this was alleged to be so marked as to necessitate some restriction even on angling operations" (Gilchrist 1918). At a meeting of anglers and netters at Zwartkops in June 1915, "it was mutually agreed that the estuary should remain closed to netting for a period of twelve months, during which regular experimental netting should take place". Two days later the first comprehensive ichthyological survey of a South African estuary commenced (Figures 8 and 9). Monthly sampling was conducted between July 1915 and July 1916 with the results of the investigation being published by Gilchrist in 1918 .
Figure 8. Fish sampling in the Swartkops Estuary entitled "Results of Netting No.1 at Modder Spruit, comprising 123 Steenbras, 270 Springer, etc." (after Gilchrist 1918).

Figure 9. "Netting No. 20 at Telegraaf Spruit" in the Swartkops Estuary (after Gilchrist 1918).
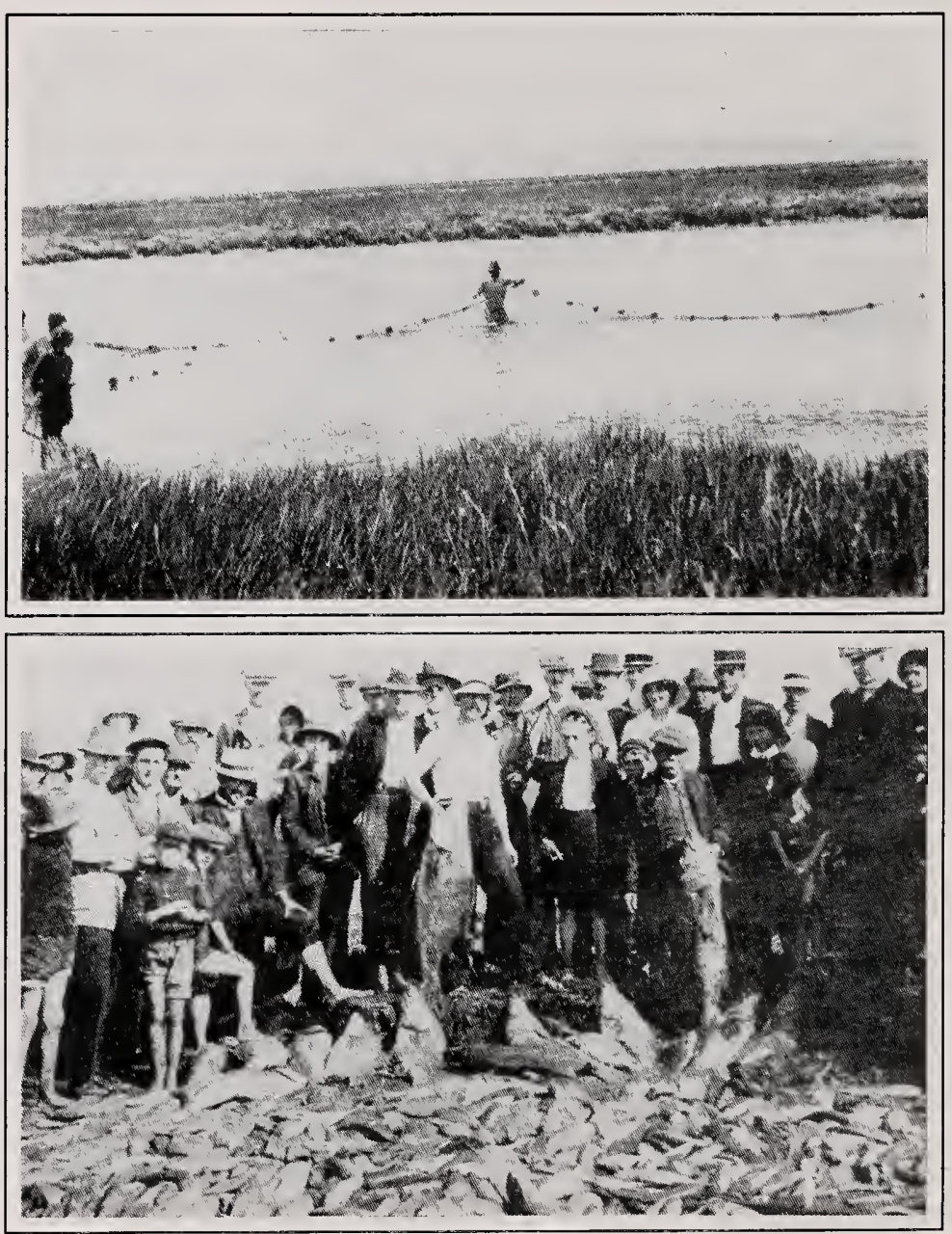
Between 1919 and 1945 very little estuarine fish research appears to have been conducted along the southern African coast. However, well-known ichthyologists such as Dr K.H. Barnard and Professor J.L.B. Smith sampled in a number of estuaries during this period, so that the documentation of marine fish diversity could be as comprehensive as possible. Professor Smith in particular used estuaries (e.g. the Knysna system, where he had a holiday home) to collect fish which he sometimes used for the resolution of marine taxonomic issues.

\section{Period 1946-1955}

This decade marked the beginning of a number of estuarine surveys undertaken by Professor J.H. Day and his research team from the University of Cape Town. Day's (1977) reason was "that research funds were very limited and it was cheaper to make an ecological survey of estuaries than to hire fishingboats". Fishes were one of many components covered during these surveys and in some cases only very limited information was obtained. In the Knysna Estuary, for example, Day et al. (1952) stated "We ourselves have done a certain amount of netting, but our nets were small and the catches accordingly restricted to small species or the fry of larger ones".

In contrast to the lack of even a species checklist for the Knysna Estuary, the later survey of the St Lucia system (Day et al. 1954) contained a list of over 70 fish taxa together with notes on the relative abundance, distribution, breeding and feeding biology of the more common species. Already, these authors had identified the importance of freshwater supplies to the lake ecology and suggested that "Unless the circulation through the lakes is maintained, the salinity may rise to such high values that the fish and bottom fauna may die". Prophetic words indeed. Richards Bay was next on the Zululand list, with Millard \& Harrison (1954) conducting a detailed survey of this system.

Back in the Western Cape, Scott et al. (1952) investigated the fishes of the Klein Estuary, and this was followed by the first cool-temperate estuarine survey (Diep/Milnerton system) on the Atlantic west coast (Millard \& Scott 1954). Once again attention was given to the distribution, diet and recorded salinities of the various fish species. During this period the first autecological study on an estuaryassociated fish species was conducted by Talbot (1955) in the Klein Estuary, with his investigation covering the feeding, growth and breeding biology of the white stumpnose Rhabdosargus globiceps.

\section{Period 1956-1965}

The trend of collecting increasingly useful ichthyological information during the University of Cape Town estuarine studies was carried over into the Durban Bay survey (Day \& Morgans 1956), primarily because the Natal Parks Board financed the study and specifically requested the scientists to pay special attention to the fish fauna. Thousands of fish were caught, identified, measured and weighed. The dominant species were dissected to determine what they had been feeding on, the size at sexual maturity and the spawning season. Altogether, 186 fish taxa were collected and a preliminary analysis of the habitats occupied by the ichthyofaunal components was attempted, viz. pelagic, demersal and mangrove fish groups. Biological notes on all the important species appeared in Day \& Morgans (1956) but the "voluminous statistical data" arising from this study was never published.

The detail gleaned from the above study contrasted to that in the Orange River Estuary (Brown 1958) where only limited information on the fish species was collected. Similarly, the fish survey by Broekhuysen \& Taylor (1959) of the Kosi estuarine system was also incomplete and limited to "a little seining when time permitted". However, by combining their information with that of Campbell \& Allanson (1952), a Kosi Estuary checklist comprising more than 60 fish species was compiled.

\section{Period 1966-1975}

This decade was characterised by increasing involvement in estuarine fish research by universities and research institutions beyond the Western Cape. Dr B.J. Hill from Rhodes University published the first detailed checklist of fish species from the Mlalazi Estuary in Zululand (Hill 1966). The advent of hypersaline conditions in the nearby St Lucia system resulted in Millard \& Broekhuysen (1970) being commissioned to conduct a detailed survey, with emphasis being placed on the recorded salinity ranges of fish species found in the lake.

In the late 1960s a group of scientists from the Oceanographic Research Institute, under the leadership of Dr J.H. Wallace, embarked on a major estuarine fish research programme centred in KwaZulu-Natal (Wallace 1975a, 1975b, Wallace \& van der Elst 1975). These ichthyologists presented a detailed analysis of the species composition, reproduction, recruitment, migrations, length distribution, seasonal abundance and ecology of estuary-associated marine fishes along the east coast of South Africa. 
The pioneering autecological research of Talbot (1955) on the white stumpnose Rhabdosargus globiceps was followed in 1970 by $\mathrm{Dr}$ S.J.M. Blaber's field and laboratory study on another estuary-associated sparid, the Cape stumpnose Rhabdosargus holubi. His investigation focused on the salinity and temperature tolerance, population dynamics, growth, food and feeding ecology of $R$. holubi in the temporarily closed West Kleinemonde Estuary in the Eastern Cape (Blaber 1973a, 1973b, $1974 a, 1974 b, 1974 c)$. For the first time, comprehensive information was available on the juvenile life-history stages of an estuarine-dependent fish species.

\section{Period 1976-1985}

The autecological and synecological approach of the previous decade gained momentum, with major studies being initiated in all the coastal provinces. The family Mugilidae came under the spotlight, with particular emphasis on the feeding ecology of this group of fishes (Masson \& Marais 1975, Marais \& Erasmus 1977, Blaber 1976, 1977, Blaber \& Whitfield 1977a, Bok 1979). This focus was broadened at Lake St Lucia where the Natal University team investigated the food and feeding ecology of detritivorous, planktivorous and piscivorous fish species (Whitfield \& Blaber 1978a, 1978b, Blaber 1979). In addition, the diet of piscivorous birds and crocodiles in a southern African estuarine system was assessed for the first time (Whitfield \& Blaber 1978c, 1979b, 1979c, 1979d).

Studies by Cyrus \& Blaber (1982a, 1982b, 1983a, 1983b, 1984a, 1984b, 1984c) on the Gerreidae, Martin \& Blaber $(1983,1984)$ on the Ambassidae, and Blaber \& Cyrus (1983) on the Carangidae, resulted in detailed biological and ecological information being collected on these estuary-associated families. During this period single species studies were continued, with Rhabdosargus sarba, Gilchristella aestuaria and Sphyraena barracuda all receiving attention (Blaber 1982a, 1984, Blaber et al. 1981, Melville-Smith et al. 1981, Talbot \& Baird 1985a, 1985b). In addition, fish assemblage studies in a variety of South African estuaries (e.g. Whitfield 1980b, 1980c, Marais 1981, 1983a, Begg 1984a, Beckley 1984a, Hanekom \& Baird 1984, Plumstead et al. 1985) gained momentum, with increasing attention being given to aspects such as distribution, seasonality and variation in community structure. A number of more specific biological and ecological issues were also being addressed (e.g. Marais 1982, 1984, Whitfield 1984,
Beckley 1985a, Bennett 1985, Bennett et al. 1985, Whitfield 1985), thus providing the basis for a more comprehensive understanding of the factors influencing estuarine fish diversity and abundance (Blaber 1981a, Whitfield 1983, Marais 1988).

\section{Period 1986-1996}

The earlier work on ichthyoplankton in the Swartkops Estuary by Melville-Smith \& Baird (1980) and Beckley (1985a), gained momentum during this period (e.g. Whitfield 1989a, Harrison \& Whitfield 1990, Martin et al. 1992, Harris \& Cyrus 1995, Harris et al. 1995), with emphasis on the composition, distribution and abundance of these early life stages. In addition, particular attention was given to recruitment processes of fish larvae and juveniles entering estuaries, and the factors influencing their abundance (Whitfield 1989b, 1989c, 1994a, Harrison \& Cooper 1991).

Work conducted by Blaber (1981a) suggested that many southern African estuary-associated fishes are essentially 'turbid-water' species that evolved in turbid areas of the Indo-Pacific. This hypothesis was tested in a series of field and laboratory studies which showed that the distribution of most juvenile marine fish in estuaries is significantly influenced by turbidity (Cyrus \& Blaber 1987a, 1987b, 1987c). More recently, Hecht \& van der Lingen (1992) have investigated the influence of turbidity on the feeding strategies of several fish species in estuaries and concluded that visual predators are more affected by high suspensoid levels than other types of predators.

Fish community studies continued to receive attention, with emphasis being placed on resource utilization (Whitfield 1988a, Bennett \& Branch 1990), anthropogenic impacts (Plumstead 1990, Kyle 1993, Bennett 1994), recruitment and seasonality (Bennett 1989, Whitfield \& Kok 1992, Harrison \& Whitfield 1995). It was also an era where fish communities were used as a major component in the assessment of estuarine 'health' or condition (Ramm 1990b, Cooper et al. 1994). There was a definite decline in single family and single species studies during this period, with Martin $(1988,1989,1990)$ concluding his earlier work on the Ambassidae.

The 1990s have been a 'coming of age' for estuarine ichthyology in southern Africa (Whitfield 1996a). The previous two decades had resulted in the accumulation of a considerable information source which needed to be synthesized. Life-history styles of fishes in estuaries on the subcontinent were reviewed by Potter et al. (1990) and Whitfield $(1990,1994 b)$, with the question of estuarine dependence being investigated by Cyrus (1991) and 
Whitfield (1994c). The 1990s also saw the first attempt at modelling energy flow through the fish assemblage of a southern African estuary (Heymans \& Baird 1995, Baird \& Heymans 1996).

\section{The future}

Although considerable progress has been made over the last 25 years in particular, much work remains to be done. More than $70 \%$ of southern African estuaries have no comprehensive fish species checklist and less than $10 \%$ of the systems can be described as well studied. The relatively undisturbed Ciskei and Transkei estuaries have been particularly neglected in past research efforts, despite the biogeographical transition zone that occurs in the latter region. With the prospect of intensive tourist and recreational developments along these sections of the coast, a limited 'window of opportunity' is available to conduct pre-impact baseline studies.

As far as more detailed studies are concerned, the words of Day (1977) are as valid now as they were then "... we need quantitative studies of the estuarine flora and fauna with the ultimate aim of assessing energy flow through the whole estuarine ecosystem". In addition he stated "We know the dominant plants and animals that live in our estuaries. We must now study them individually and in great detail - their rates of recruitment, their tolerance to environmental conditions, how much food they consume, their biomass and their productivity". Although a number of recent studies have addressed some of the issues raised above, we still have a long way to go before we can adequately predict the consequences of human induced disturbances on the ichthyofauna in particular and estuarine ecosystems in general.

During the next decade, new demands will be placed on estuarine scientists, with funding being closely linked to management issues (Figure 10). However, these demands should also be seen as a challenge, and our research should be geared towards providing the type of information required for the maintenance of vital ecological processes within estuaries. There is also an urgent need for estuarine research in Mozambique, Tanzania and further north. The reason for East African estuarine studies is self evident; most of the southern African fish species are tropical Indo-Pacific in origin but have been little studied in this important biogeographical region. Indeed, there are large areas on both the East and West African coasts where even basic checklists of fish species are lacking. Research opportunities are opening up and it is up to African ichthyologists to take primary responsibility for estuarine research on the continent.

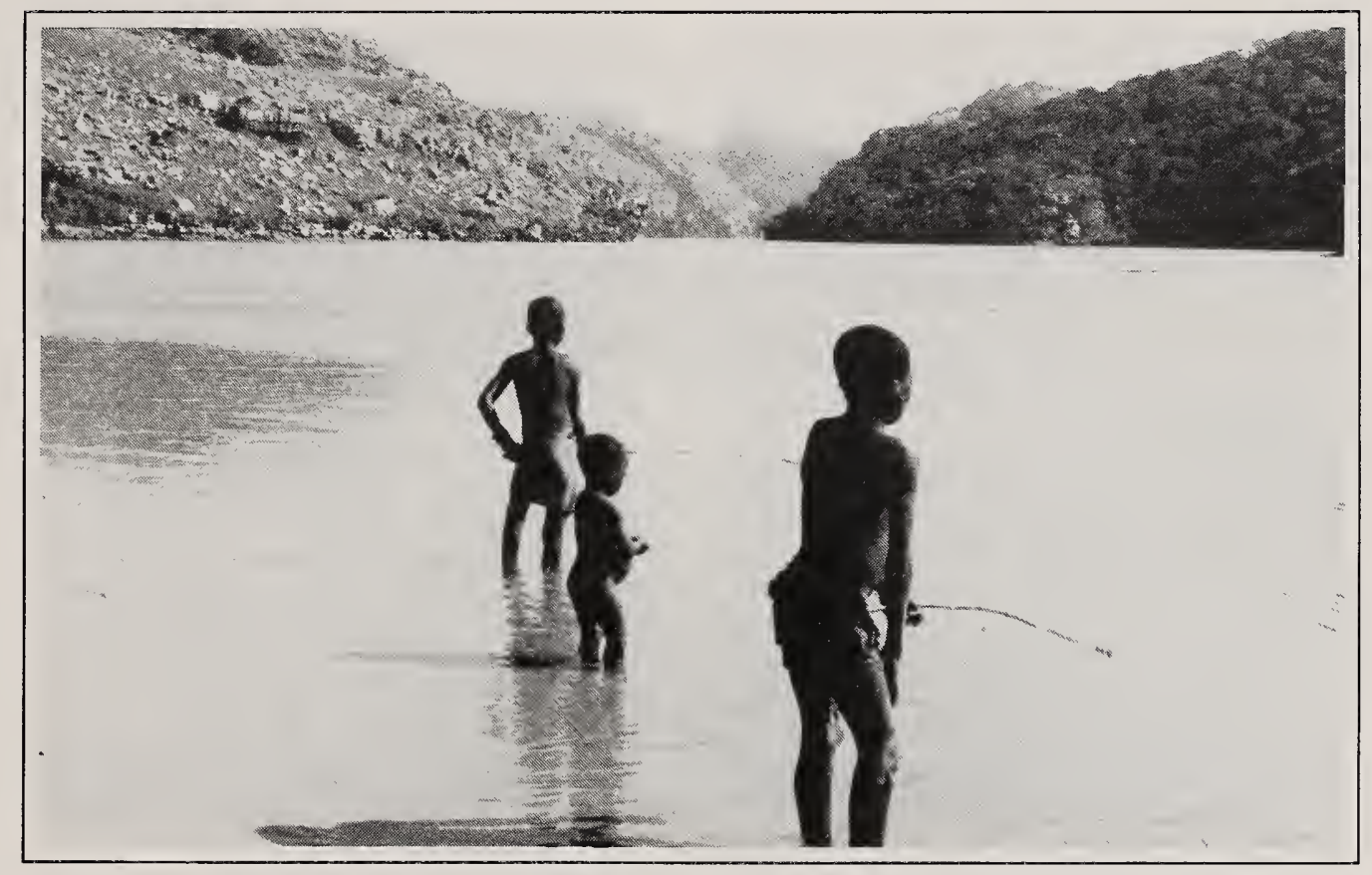

Figure 10. Growing human populations will place increasing pressures on estuaries in the future. 


\section{Fishes of southern African estuaries}

\subsection{INTRODUCTION}

Estuaries are regions where marine and fresh waters meet, where environmental gradients are steep, and where exceptionally high levels of primary and secondary production are often recorded. These factors have a major influence on the numbers, variety and biomass of fishes that can live in these systems. In particular, the often abrupt changes in salinity, water temperature, dissolved oxygen and turbidity place considerable physiological demands on the fishes that utilize estuaries. However, those species which are broadly tolerant of biotic and abiotic variability are at a considerable advantage over those fishes that cannot survive such fluctuations, since the former group are able to occupy a food-rich environment from which many potential competitors are excluded. In this chapter the life-history styles and attributes required by fishes utilizing southern African estuaries will be examined in detail.

\subsection{LIFE-HISTORY PATTERNS}

The fishes inhabiting estuaries may be divided into two major groups according to their ability to breed within the estuarine environment. The first group is dominant and comprises euryhaline marine species that spawn at sea but make extensive use of estuaries during juvenile and/or adult life stages (Dando 1984). The second group spawn within the estuarine environment, although certain species may also breed at sea or in fresh water. For the purposes of this book, the former group has been classified as marine and the latter as estuarine. Stenohaline marine and freshwater fishes, which sometimes occur in the lower and upper reaches of certain southern African estuaries respectively, are not included in the following life-history analysis.

The main feature of the life cycle of most marine species utilizing South African estuaries is a division into a juvenile phase that is predominantly estuarine and an adult period that is predominantly marine (Wallace 1975b). The proportion of juveniles entering estuaries varies according to species. Juveniles enter estuaries between $10 \mathrm{~mm}$ and $60 \mathrm{~mm} \mathrm{SL}$, although many species have completed their active recruitment phase by the time a length of $20 \mathrm{~mm}$ is attained (Wallace \& van der Elst 1975). After a residence period of between one and three years these fish return to the sea where they join adult stocks when mature. Although some species may attain sexual maturity within the estuarine environment, spawning generally occurs in the sea (Wallace 1975b).
There are relatively few fish species that can complete their entire life cycle within southern African estuaries and these are invariably small species (Table 3). Sexual maturity usually occurs at less than $70 \mathrm{~mm}$ $\mathrm{SL}$, in contrast to marine taxa where most mature above $200 \mathrm{~mm}$ SL (Table 4). Wallace (1975b) has suggested that the small size of estuarine species would reduce their physical ability to undertake migrations to and from the sea. Predation by adult piscivorous fish populations in the sea may also deter mass migrations by these small species. Furthermore, the typically shallow microtidal estuaries of southern Africa tend to favour occupation by small species.

The African subcontinent has four obligate catadromous fish species (Anguilla bengalensis labiata, A. bicolor bicolor, A. marmorata and A. mossambica) and no recorded anadromous taxa. Of these four anguillid eel species, only $A$. mossambica is both abundant and widespread in southern African waters. According to Bruton et al. (1987) the probable reasons for the paucity of diadromous fishes on the subcontinent are the unstable nature of the rivers, high soil moisture deficits, and the unreliable availability of resources such as food and space compared with the ocean. Since anguillid eels are not resident estuarine species, and only use these systems as a conduit between the marine and freshwater environments, the life-history styles of this family are not dealt with in this chapter. 
Table 3. Approximate standard length (SL) at sexual maturity of some southern African estuarine fish species which have been recorded breeding in these systems.

\begin{tabular}{llll} 
Fish species & Family & SL (mm) & Reference \\
\hline Ambassis natalensis & Ambassidae & 35 & Wallace (1975b) \\
Ambassis productus & Ambassidae & 50 & van der Elst (1988) \\
Atherina breviceps & Atherinidae & 40 & Ratte (1989) \\
Caffrogobius gilchristi & Gobiidae & 50 & Bennett (1989) \\
Caffrogobius nudiceps & Gobiidae & 45 & Day et al. (1981) \\
Clinus spatulatus & Clinidae & 65 & Bennett (1983) \\
Clinus superciliosus & Clinidae & 50 & Prochazka (1994) \\
Croilia mossambica & Gobiidae & 30 & Blaber \& Whitfield (1977b) \\
Gilchristella aestuaria & Clupeidae & 30 & Blaber (1979) \\
Glossogobius callidus & Gobiidae & 35 & Boulle (1989) \\
Hippocampus capensis & Syngnathidae & 65 & Genade \& Hirst (1986) \\
Hyporhamphus capensis & Hemiramphidae & 80 & Wallace (1975b) \\
Periophthalmus argentilineatus & Gobiidae & 50 & Stebbins \& Kalk (1961) \\
Psammogobius knysnaensis & Gobiidae & 30 & Bennett (1989) \\
Syngnathus acus & Syngnathidae & 120 & Bennett (1989) \\
Syngnathus watermeyeri & Syngnathidae & 100 & Whitfield (1995b)
\end{tabular}

Myxus capensis is one of the few marine fish species that makes extensive use of the riverine environment as a nursery area (Bok 1979). Although spawning occurs at sea, $M$. capensis lives mainly in the freshwater zone of Eastern Cape rivers, with smaller numbers in the brackish water at the head of estuaries. Bok (1979) has suggested that interspecific competition with other mugilids may be an important factor accounting for the virtual absence of $M$. capensis from the saline parts of those systems. According to Bok (1983), the relatively wide range in size and age at sexual maturity is an insurance by this species against consecutive dry years due to isolation in fresh water reaches during droughts. Other life-history tactics of $M$. capensis include reduced gonadal development in fresh water which minimizes the risk of energy wastage if ripe fish are isolated in freshwater reaches. In addition, downriver spawning migrations occur at a large size, thus facilitating the full exploitation of food reserves available in the freshwater areas. The predominantly catadromous life-history style of $M$. capensis in the Eastern Cape Province therefore differs from that of other mugilids utilizing southern African estuaries, with the exception of Mugil cephalus which also makes use of riverine habitats in this region for feeding. However, the catadromous behaviour of both $M$. capensis and M. cephalus is rare in KwaZulu-Natal and Western Cape systems where these species are usually confined to estuaries.
The cichlid Oreochromis mossambicus is the only abundant freshwater species in southern African estuaries. It occurs in large numbers in coastal lakes and temporarily closed estuaries, but is usually absent from the lower reaches of permanently open estuaries (Whitfield \& Blaber 1979a). When temporarily closed estuaries are breached, this species usually retreats into the upper reaches. Widespread breeding has been recorded in several estuaries during the closed phase, with parental care enhancing survival of offspring in these environments: Young are released by mouthbrooding adults when they attain about $10 \mathrm{~mm} \mathrm{SL}$ (Bruton \& Boltt 1975), by which time they can avoid being swept out to sea when the estuary opens. In small subtropical estuaries, which are seldom open to the sea, this species is often a dominant component of the ichthyofaunal community (Begg 1984a).

The paucity of freshwater fish species in southern African estuaries, even during periods of elevated freshwater input, may be partially attributed to the abundant estuarine and marine fish assemblages in these systems (Ter Morshuizen et al. 1996a, 1996b). Exclusion from estuaries is likely to be due to competition with the latter groups, as well as predation by a wide variety of piscivorous taxa found in certain systems. However, in those lagoons or river mouth type estuaries where marine species are rare due to prevailing oligohaline conditions, freshwater fish taxa may assume greater significance (Begg 1984a). 
Table 4. Approximate standard length (SL) at sexual maturity of some marine fish species recorded in southern African estuaries.

Fish species

Family

SL $(\mathrm{cm})$

Reference

Acanthopagrus berda

Argyrosomus japonicus

Caranx ignobilis

Caranx sexfasciatus

Chanos chanos

Diplodus sargus capensis

Galeichthys feliceps

Gerres acinaces

Gerres methueni

Hilsa kelee

Johnius dorsalis

Leiognathus equula

Lichia amia

Lithognathus lithognathus

Liza dumerilii

Liza richardsonii

Liza macrolepis

Liza tricuspidens

Lutjanus argentimaculatus

Lutjanus fulviflamma

Monodactylus argenteus

Monodactylus falciformis

Mugil cephalus

Myxus capensis

Otolithes ruber

Platycephalus indicus

Pomadasys commersonnii

Pomadasys olivaceum

Pomatomus saltatrix

Rhabdosargus globiceps

Rhabdosargus holubi

Rhabdosargus sarba

Sarpa salpa

Sphyraena barracuda

Terapon jarbua

Valamugil buchanani

Valamugil cunnesius

\begin{tabular}{|c|c|}
\hline Sparidae & 17 \\
\hline Sciaenidae & $780^{7} 90$ \\
\hline Carangidae & 58 \\
\hline Carangidae & 42 \\
\hline Chanidae & 87 \\
\hline Sparidae & 20 \\
\hline Ariidae & $260^{r} 249$ \\
\hline Gerreidae & 11 \\
\hline Gerreidae & $110^{x} 14$ 우 \\
\hline Clupeidae & 15 \\
\hline Sciaenidae & $100^{x} 13$ \\
\hline Leiognathidae & 13 \\
\hline Carangidae & 58 \\
\hline Sparidae & 54 \\
\hline Mugilidae & 18 \\
\hline Mugilidae & 18 \\
\hline Mugilidae & 23 \\
\hline Mugilidae & 38 \\
\hline Lutjanidae & 49 \\
\hline Lutjanidae & 13 \\
\hline Monodactylidae & 13 \\
\hline Monodactylidae & 14 \\
\hline Mugilidae & 34 \\
\hline Mugilidae & $190^{x} 23$ ? \\
\hline Sciaenidae & 23 \\
\hline Platycephalidae & 36 \\
\hline Haemulidae & $300^{\prime 36}$ \\
\hline Haemulidae & $12 \sigma^{\prime \prime} 13$ \\
\hline Pomatomidae & $190^{x} 20 \%$ \\
\hline Sparidae & $27 \sigma^{\prime 23}$ \\
\hline Sparidae & 15 \\
\hline Sparidae & 20 \\
\hline Sparidae & $130^{r} 15$ \\
\hline Sphyraenidae & 60 \\
\hline Teraponidae & 13 \\
\hline Mugilidae & 36 \\
\hline Mugilidae & 17 \\
\hline
\end{tabular}

Wallace (1975b)

Griffiths (1996)

van der Elst (1988)

van der Elst (1988)

van der Elst (1988)

Mann \& Buxton (1993)

Tilney \& Hecht (1993)

Cyrus \& Blaber (1984a)

Cyrus \& Blaber (1984a)

Blaber (1979)

Day et al. (1981)

Wallace (1975b)

vani cier Elst (1988)

Bennett (1993)

Wallace (1975b)

de Villiers (1987)

Wallace (1975b)

Wallace (1975b)

van der Elst (1988)

van der Elst (1988)

Day et al. (1981)

Beckley (1984a)

Whitfield \& Blaber (1978d)

Bok (1983)

Wallace (1975b)

Wallace (1975b)

Wallace (1975b)

Joubert (1981)

van der Elst (1976)

Talbot (1955)

Wallace (1975b)

Wallace (1975b)

Joubert (1981)

Blaber (1982a)

Day et al. (1981)

Wallace (1975b)

Wallace (1975b)

\section{Early life history of estuary-associated species}

Southern African estuaries are prone to temperature, salinity, turbidity and water current variations, all of which will affect the breeding of resident fish species. Reproductive specializations to reduce the mortality of eggs, embryos and larvae are therefore very evident in the estuarine group of fishes. Both Clinus superciliosus and $C$. spatulatus are viviparous and their young exceed $15 \mathrm{~mm}$ in length when released into the estuarine environment (Veith 1979, Bennett 1983). The elimination of pelagic eggs and embryo stages, which are susceptible to a wide variety of mortality factors, appears to have enabled the clinids to reduce the number of young produced, e.g. C. superciliosus produces a maximum of 450 embryos (Veith 1979). 
Among estuarine spawning species, relatively few complete their entire life cycle within estuaries, with some of the estuarine spawners appearing to require a marine phase in their life cycle. For example, the goby Psammogobius knysnaensis and blenny Omobranchus woodi have a marine larval phase that is achieved by a synchronised hatching of the embryos at high tide, thus facilitating a mass export to the sea during the ebb tide (Figure 11). In contrast, most estuarine spawning species have reproductive specializations which facilitate the retention of eggs, embryos and larvae within the estuarine environment. For example, both the male Syngnathus acus and Hippocampus capensis have a brood pouch in which the offspring are carried until they have reached an advanced developmental stage, thusavoiding the rigours of the estuary (Melville-Smith \& Baird 1980, Whitfield 1995c). The spawning of Atherina breviceps is also closely associated with submerged macrophyte beds. This species has relatively large eggs with glutinous filaments that are used for attachment to aquatic plants

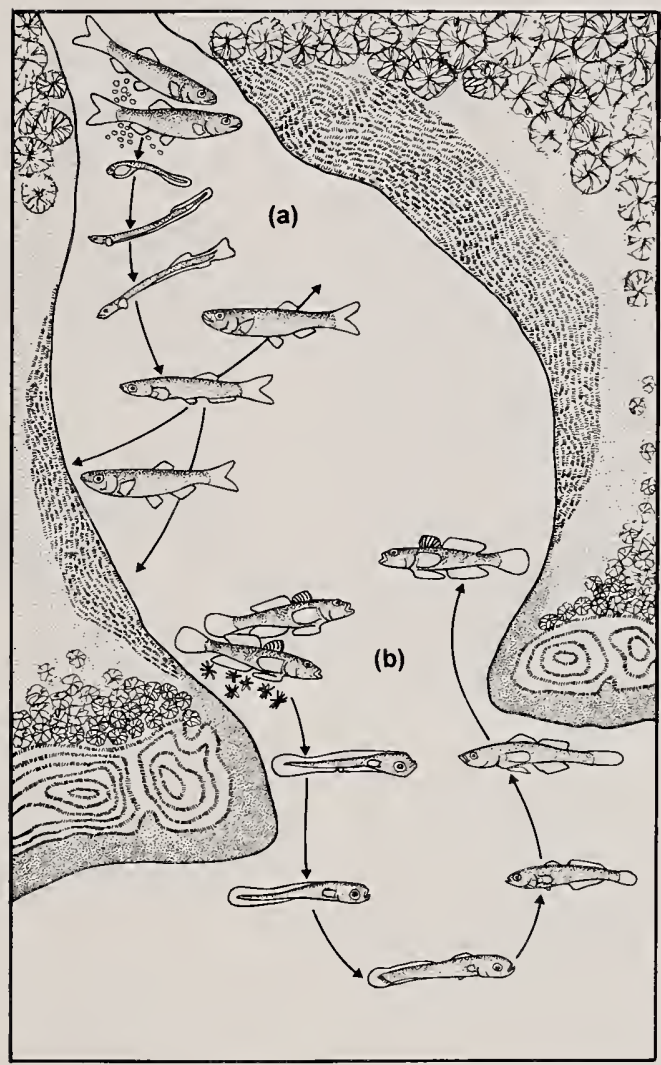

and other objects (Neira et al. 1988), thus aiding their retention within the estuarine environment. Although the eggs of Gilchristella aestuaria are free-floating (Wooldridge \& Bailey 1982), this species spawns in the upper reaches of open estuaries (Talbot 1982), thereby reducing losses of embryos and larvae to the sea.

Evidence suggests that the spawning of most marine species found in estuaries occurs close inshore, often in the vicinity of estuary mouths (Wallace 1975b, Lasiak 1983a, Harris 1996). Inshore currents along the KwaZulu-Natal coast also retain eggs, embryos and larvae in the region (Wallace 1975b), thus reducing the distance between breeding and nursery areas. According to Heydorn et al. 1978), the retention of these early life stages inshore prior to migration into KwaZulu-Natal estuaries is favoured by the slow overall movement of the water mass between the Agulhas Current and the coast, frequent current reversals parallel with the shore, and the occurrence of onshore components.

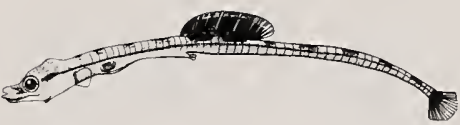

Syngnathus acus (12 mm SL)

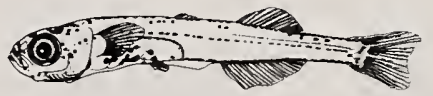

Atherina breviceps (12 mm SL)

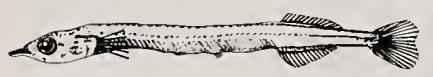

Hyporhamphus capensis (13 mm SL)

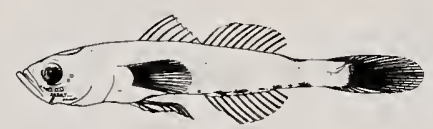

Caffrogobius gilchristi $(10 \mathrm{~mm} \mathrm{SL})$

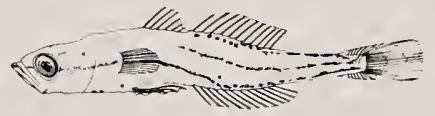

Psammogobius knysnaensis (6 mm SL)

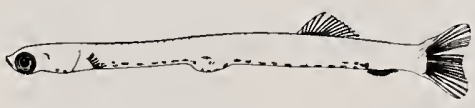

Gilchristella aestuaria (12 mm SL)

Figure 11. Diagrammatic representation of the life cycles of two types of estuarine spawners. The examples shown here are the estuarine roundherring Gilchristella aestuaria (a) and speckled sandgoby Psammogobius knysnaensis (b). Detailed illustrations of the postlarvae of selected estuarine spawners are also shown. 
Within Algoa Bay and other bays along the Eastern Cape coast, cyclonic within-bay circulation occurs (Harris 1978). It has been suggested that in Algoa Bay preflexion larvae become entrained within this cyclonic circulation and, upon attainment of the postflexion stage of development, would not have to swim great distances to recruit into coastal nursery areas (Beckley 1986). Thus, species which spawn close inshore are likely to be retained within the bay until the onset of the estuarine phase in the life cycle (Lasiak 1984a).

Drift card analyses indicate that in the Cape there is a greater frequency of surface onshore flow during the summer than in winter (Shannon \& Chapman 1983). Onshore water currents, particularly during the summer, would assist the movement of estuaryassociated fish larvae towards the coast (Figure 12).
Some marine species occasionally spawn in estuaries. The sparid Acanthopagrus berda has been recorded spawning in the mouth region of the Kosi estuary at night, with the eggs being transported out to sea during the nocturnal ebb tide (Garratt 1993). Solea bleekeri breeds in Lake St Lucia when conditions are suitable (Cyrus 1991a), but this species has not been recorded spawning in other KwaZulu-Natal estuaries. Galeichthys feliceps are mouth brooders (Tilney \& Hecht 1993) and adult males have been recorded carrying eggs and young in Eastern Cape estuaries (Marais \& Venter 1991), thus providing juveniles with direct access to the estuarine environment. In contrast, the eggs of other marine species are mainly pelagic (Brownell 1979) and postlarvae need to locate and enter estuaries without parental assistance.

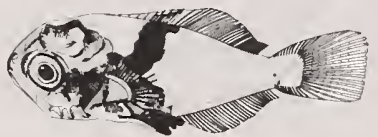

Monodactylus falciformis (6 mm SL)

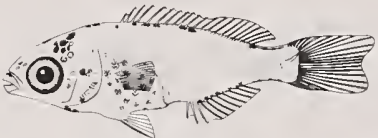

Lithognathus lithognathus (12 mm SL)

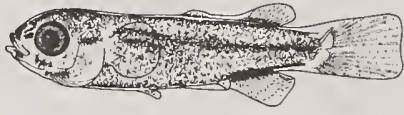

Liza richardsonii $(8 \mathrm{~mm} \mathrm{SL})$

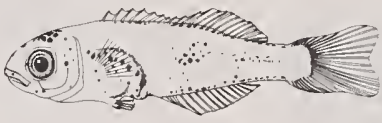

Rhabdosargus globiceps (12 mm SL)

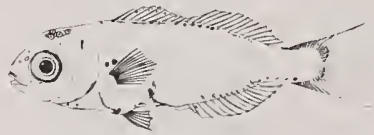

Rhabdosargus holubi (11 mm SL)

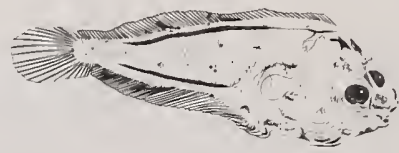

Solea bleekeri (4 mm SL)
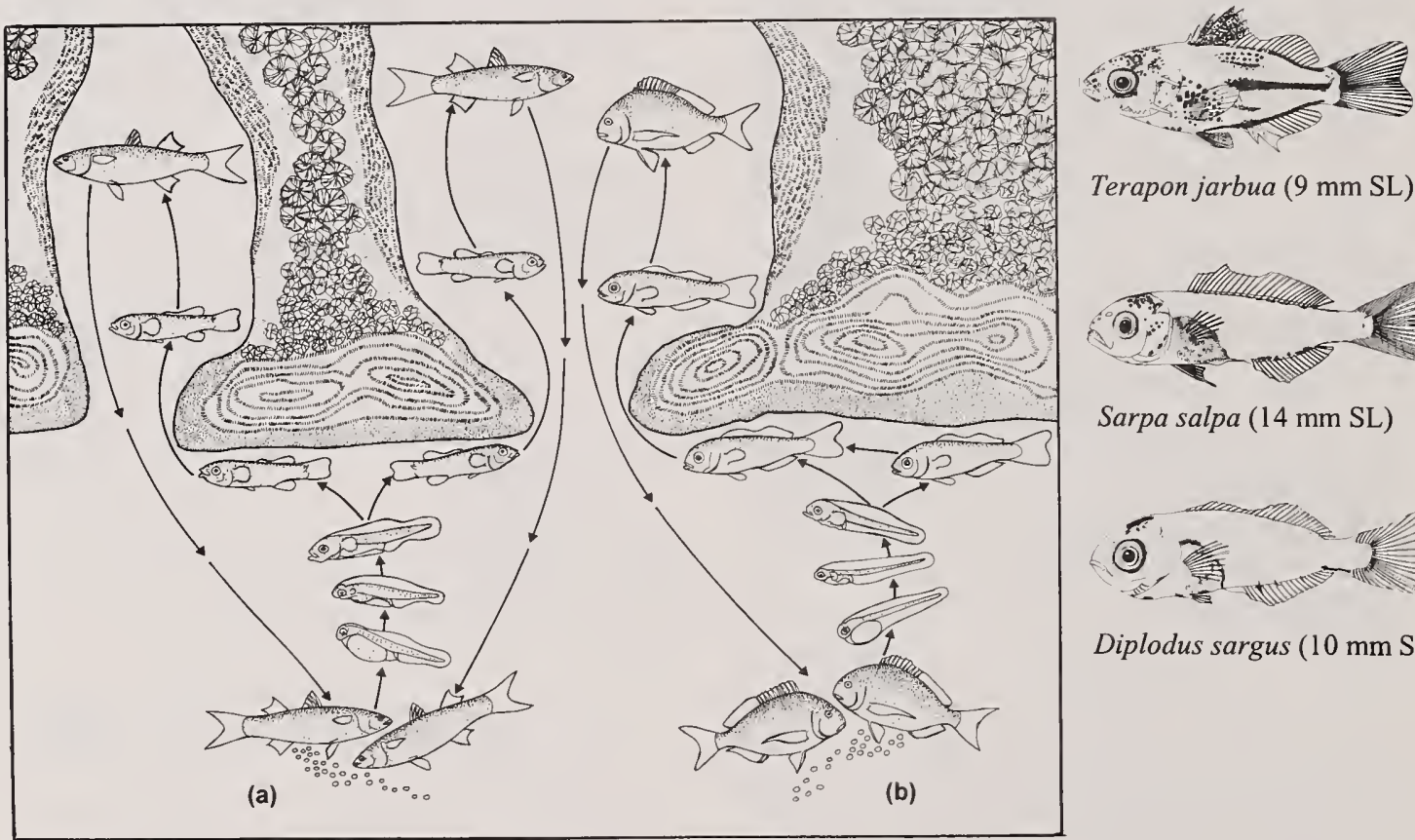

Terapon jarbua $(9 \mathrm{~mm} \mathrm{SL})$

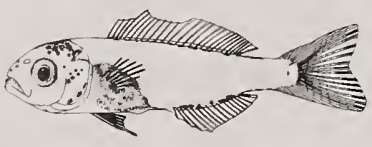

Sarpa salpa (14 mm SL)

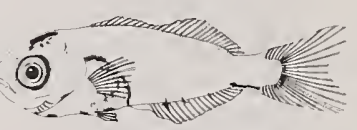

Diplodus sargus (10 mm SL)

Figure 12. Diagrammatic representation of the predominant life cycles of estuary-associated marine spawners. The two examples shown here are the flathead mullet Mugil cephalus (a) and Cape stumpnose Rhabdosargus holubi (b). Detailed illustrations of the postlarvae of selected estuary-associated marine species are also shown. 


\section{Recruitment mechanisms and possible cues}

The egg, embryonic and larval stages of marine species are retained within the nearshore environment by cyclonic circulation patterns and predominantly onshore surface current components (Heydorn et al. 1978). Once the preflexion larval stage of development has been completed, fish movement becomes active and the individuals then enter the surf zone which may be used as an interim nursery area before seeking out an estuary (Table 5, Figure 12). More than $60 \%$ of the ichthyoplankton found in the Swartvlei Bay and St Lucia surf zones belonged to estuary-associated taxa (Whitfield 1989b, Harris \& Cyrus 1996). The increase in fish densities towards both the Swartvlei and St Lucia estuaries suggests that there is an active onshore and longshore movement towards estuary mouths.

How do the postlarvae locate the estuary mouth once they have entered the surf zone? Blaber \& Blaber (1980) have suggested that turbidity gradients in the marine environment (Figure 13) may aid juvenile fishes to locate estuarine nursery areas, and Harris (1996) presents evidence to support this hypothesis in the St Lucia region. Whitfield (1994a) compared the recruitment of larval and juvenile fishes into three Eastern Cape estuaries with differing turbidities and found that both the Sundays (average turbidity 10 NTU) and Great Fish (average turbidity 65 NTU) had similar ichthyonekton abundance. These results suggest that in warm temperate southern African estuaries, turbidity gradients do not play a major role in larval and postlarval abundance within these systems.
Whitfield (1994a) found that the abundance of newly-recruited marine fishes in Eastern Cape estuaries showed a significant positive correlation with longitudinal salinity gradients within these systems. However, detectable salinity gradients within the marine environment are usually absent, and it is most likely that riverine and estuarine olfactory cues associated with ebb tidal waters attract the postlarvae into estuaries. Indirect evidence to support the olfactory hypothesis comes from the observation that marine postlarvae are able to enter temporarily closed estuaries when marine overtopping of the mouth sandbar occurs (Whitfield 1992b) and no salinity gradient between the estuary and sea is detectable. Olfactory cues associated with seepage of estuarine water through sand bars could provide the key to locating the mouth area of temporarily closed estuaries, and thus facilitate the migration of postlarvae over these barriers during overwash events. Additional evidence to support this hypothesis can be found in the concentration of postflexion larvae of estuaryassociated species adjacent to sand bars blocking the Swartvlei and St Lucia mouths, suggesting that olfactory rather than turbidity cues are attracting these fish to the area (Whitfield 1989b, Harris 1996).

The immigration of larvae and postlarvae into large, well-flushed estuaries of the northern hemisphere mainly takes place using passive and/or selective tidal transport both for entry to and retention within these systems (e.g. Weinstein et al. 1980, Fortier \& Leggett 1982, Boehlert \& Mundy 1988). In contrast, in microtidal estuaries in South Africa, New

Table 5. Some possible processes and behaviour influencing marine fish immigration to southern African estuarine nursery areas.

\section{Habitat:}

Nearshore marine

Surf zone

Estuary mouth

Estuary

\begin{tabular}{lllll}
$\begin{array}{l}\text { Physical } \\
\text { process: }\end{array}$ & $\begin{array}{l}\text { Wind/coastal current } \\
\text { driven surface drift }\end{array}$ & $\begin{array}{l}\text { Longshore } \\
\text { transport }\end{array}$ & $\begin{array}{l}\text { Tidal flux } \\
\text { transport }\end{array}$ & Estuarine \\
$\begin{array}{l}\text { Fish } \\
\text { development: }\end{array}$ & $\begin{array}{l}\text { Egg/embryo/larval } \\
\text { stages }\end{array}$ & $\begin{array}{l}\text { Larval/juvenile } \\
\text { stages }\end{array}$ & $\begin{array}{l}\text { Larval/juvenile } \\
\text { stages }\end{array}$ & $\begin{array}{l}\text { Juvenile } \\
\text { stage }\end{array}$ \\
$\begin{array}{l}\text { Fish } \\
\text { movement: }\end{array}$ & Mainly passive & Mainly active & Active and passive & Mainly active \\
$\begin{array}{l}\begin{array}{l}\text { Orientation } \\
\text { to estuarine cues: }\end{array} \\
\text { No }\end{array}$ & Yes & Yes & Yes \\
\hline
\end{tabular}


Zealand and Australia, where for much of the year the two-layered circulation pattern is less pronounced or absent, the larvae and juveniles of some marine speoies enter these systems on the flood tide and are retained by rapidly settling along the banks or on the bottom where water movements are reduced (Beckley 1985a, Roper 1986, Neira \& Potter 1994). Indeed, Harris (1996) found that fish larvae of estuary-associated species used selective tidal stream transport to facilitate retention within large KwaZulu-Natal estuaries, with larval densities being significantly higher on flood tides and in bottom waters. She also recorded postflexion larvae of estuary-associated marine fish species accumulating near the mouth of the St Lucia Estuary at low tide, and subsequently using flood tidal currents to enter the estuarine environment. Motile juveniles can, however, easily enter estuaries on the ebb tide by keeping to the margins where current speeds are attenuated. In the Zotsha Estuary, postlarval fish were recorded moving into the system through the bottom of standing waves, swimming upstream in a series of steps (Harrison \& Cooper 1991).

Yet another recruitment mechanism, which has already been mentioned in this chapter, involves the larvae and juveniles entering temporarily closed or closing estuaries during oceanic overtopping of the sand bar at the mouth. Preliminary indications are that largescale ichthyonekton migration into temporarily closed estuaries may occur in this manner.
Whitfield (1989a) has quantified marine ichthyoplankton recruitment into the Swartvlei Estuary and found up to 315000 fish larvae and postlarvae entering the system over a $24 \mathrm{~h}$ period. This study also documented that there was a net loss of the larvae of certain estuarine spawners which subsequently returned to the estuary as postlarvae. Movements of larvae and postlarvae between the estuary and sea occurred mainly during twilight and nocturnal hours when predation rates would probably be lower than during the day. Nevertheless, the magnitude of the above immigration figures in relation to juvenile and adult densities within the estuary suggests that high mortalities of these early recruits occurs.

Once the $0+$ juveniles have entered an estuary, they usually continue to move up the system, often in concert with flood tidal currents. Hall et al. (1987) found that more than $99 \%$ of the juvenile fishes captured in the Serpentine channel (Wilderness lakes system) were moving upstream on flood tidal currents but very little migration took place at low tide. There was a strong positive correlation between the number of fish moving upstream per hour and mean water depth. Furthermore, the highest numbers of migrating fish were recorded during daylight hours but several species only moved up the channel during the night. Altogether 52000 juvenile marine fishes, comprising at least seven species, were estimated to have migrated up the Serpentine during February 1984.

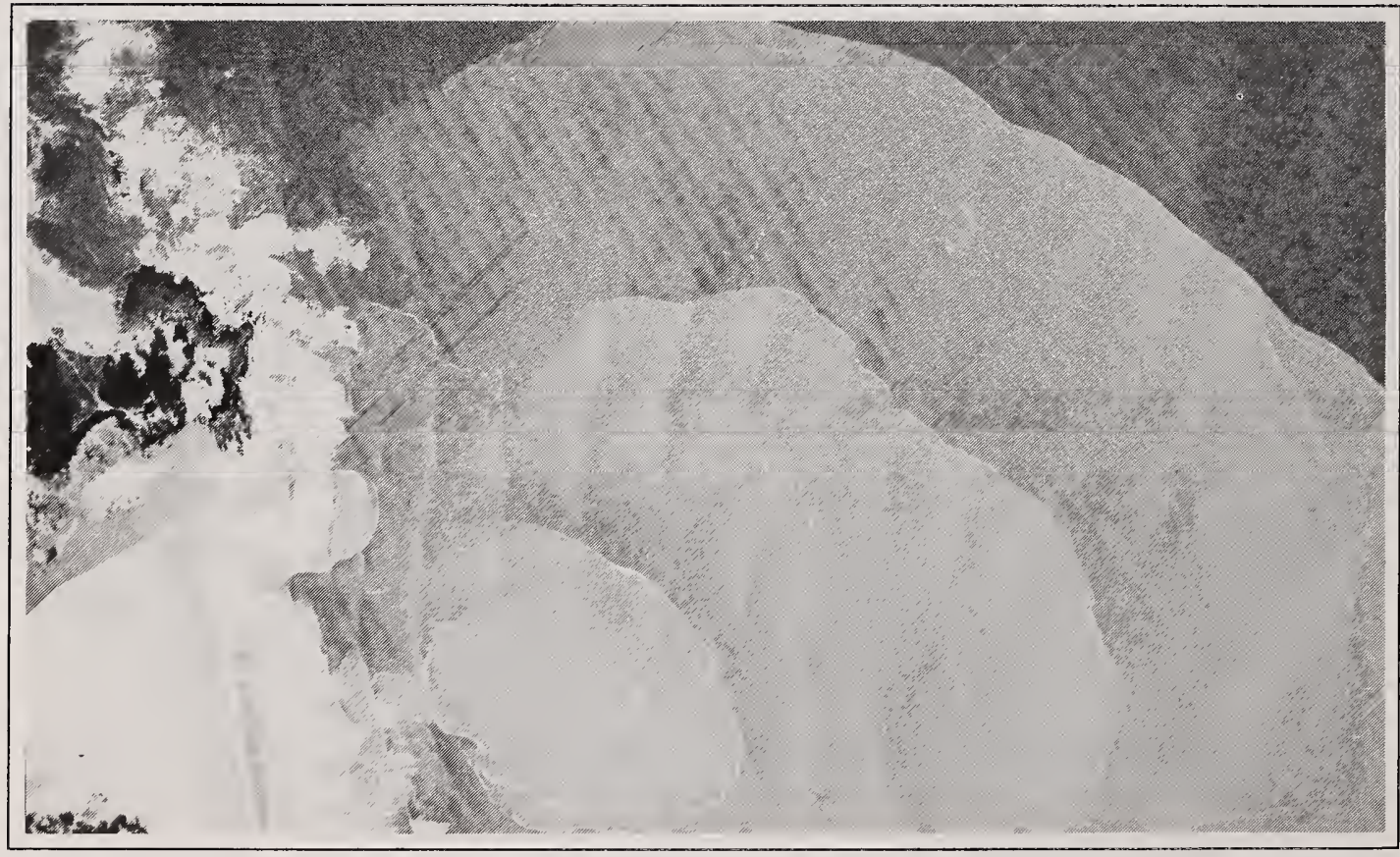

Figure 13. Ebb-tide turbidity plumes entering the Eastern Cape marine environment from the Great Fish Estuary. 
Several cues are available within an estuary to assist fish orientation towards specific nursery areas. Salinity gradients are perhaps the most obvious but have been largely discounted by Blaber (1987) on the basis of experimental and field evidence. Temperature is an unlikely cue, as thermal gradients within estuaries are irregular and highly variable, depending upon tidal regime, river flow, oceanic upwelling etc. However, the juveniles of a number of fish species are attracted to warm littoral areas, so the use of water temperatures, possibly in conjunction with other cues, cannot be discounted. Turbidity gradients are usually strongly developed within estuaries, and Blaber (1987) is of the opinion that both vertical and horizontal gradients may be important to certain species. Studies by Cyrus \& Blaber (1987a, 1987b, 1987c) have shown that the juvenile marine fishes of KwaZulu-Natal estuaries can be divided into five main groups according to their occurrence in various turbidities. The above field and laboratory studies indicate that turbidity plays a major role, either singly or in combination with other variables, in determining the distribution of juvenile marine fishes in estuaries. Future research in this field should focus on olfactory cues as one such variable, since these 'markers' hold great potential in 'fine tuning' ichthyonekton movements within the estuarine environment.

In contrast to the marine migrants, larvae of species such as Gilchristella aestuaria do not have to enter the estuary. Instead, they need to remain within the system during the vulnerable embryonic and larval stages. Melville-Smith et al. (1981) have described how $G$. aestuaria larvae in the Sundays Estuary utilize tidal transport in order to avoid being swept out to sea. Evidence suggests that these larvae remain in the middle and upper reaches of the estuary where zooplanktonic food resources are most abundant, and avoid the more marine areas near the mouth until at least the juvenile stage has been attained. Nevertheless, large numbers of $G$. aestuaria larvae are sometimes flushed from estuaries during river flood events.

\section{Spatial and temporal patterns}

The migration of marine larvae and juveniles into KwaZulu-Natal estuaries occurs mainly during late winter and spring when river flow is often at a minimum (Wallace \& van der Elst 1975). Although all of the permanently open estuaries and bays are available for colonization, many of the smaller systems along the KwaZulu-Natal coast are closed during the winter and only open after spring rains in October (Whitfield 1980c). Recruitment into these temporarily closed estuaries is therefore only possible when increased water flow forces open the mouths of the above systems. The prolonged period of juvenile immigration (Figure 14), which is a function of the extended spawning season of most species, may therefore be regarded as a strategy against unseasonal floods which could open blind estuaries prematurely, and droughts that would delay mouth opening until mid-summer.

In Eastern and Western Cape estuaries, a similar prolonged recruitment pattern is evident, but in this case the peak immigration phase occurs early summer when most temporarily closed estuaries in the region are already open. In addition, the late winter and spring rains send pulses of fresh water into the estuaries, thereby ensuring the replenishment of nutrients needed to stimulate summer primary productivity. Thus, in both KwaZulu-Natal and Cape estuaries, juvenile fishes are able to exploit the abundant summer food resources and warm temperatures to grow rapidly before the onset of winter. Refuges in the form of submerged aquatic vegetation are also most prolific during summer and higher turbidities due to increased river flow would aid predator avoidance by juvenile fish.

Spawning by estuarine fish taxa occurs mainly during spring, with the larvae and juveniles being particularly abundant during summer (Figure 15). Some of these fish species grow very rapidly in the warm highly productive waters and, with the onset of winter, have already attained sexual maturity. For example, Gilchristella aestuaria consume approximately $12 \%$ of body mass per day in summer and mature within seven months of hatching (Talbot \& Baird 1985a). Daily food consumption then declines to less than $2 \%$ of body mass in winter when water temperatures decline and zooplankton resources become more scarce.

A major factor influencing the composition of ichthyoplankton in South African estuaries is sea temperature, which is linked not only to season but also to latitude. Species diversity (number of taxa) generally declines from the subtropical systems in the northeast to the cool-temperate region in the southwest (Whitfield 1994c). The subtraction of tropical fish species is clearly reflected in Figure 16 which shows the decline in family representation between the Kosi and Swartvlei estuaries. Approximately half of the fish families represented in the St Lucia Estuary were present in Eastern and Western Cape systems. The decline becomes even more apparent if the Kosi Estuary diversity is compared with that of the warmtemperate estuaries (Figure 16). In both KwaZuluNatal and Cape systems, ichthyoplankton densities fluctuate widely and are generally much higher in summer than in winter (Melville-Smith \& Baird 1980, Whitfield 1989c, Harrison \& Whitfield 1990, Harris \& Cyrus 1995). In certain Eastern Cape estuaries, larval and postlarval fish densities showed a strong positive correlation with temperature (Whitfield 1994a). 


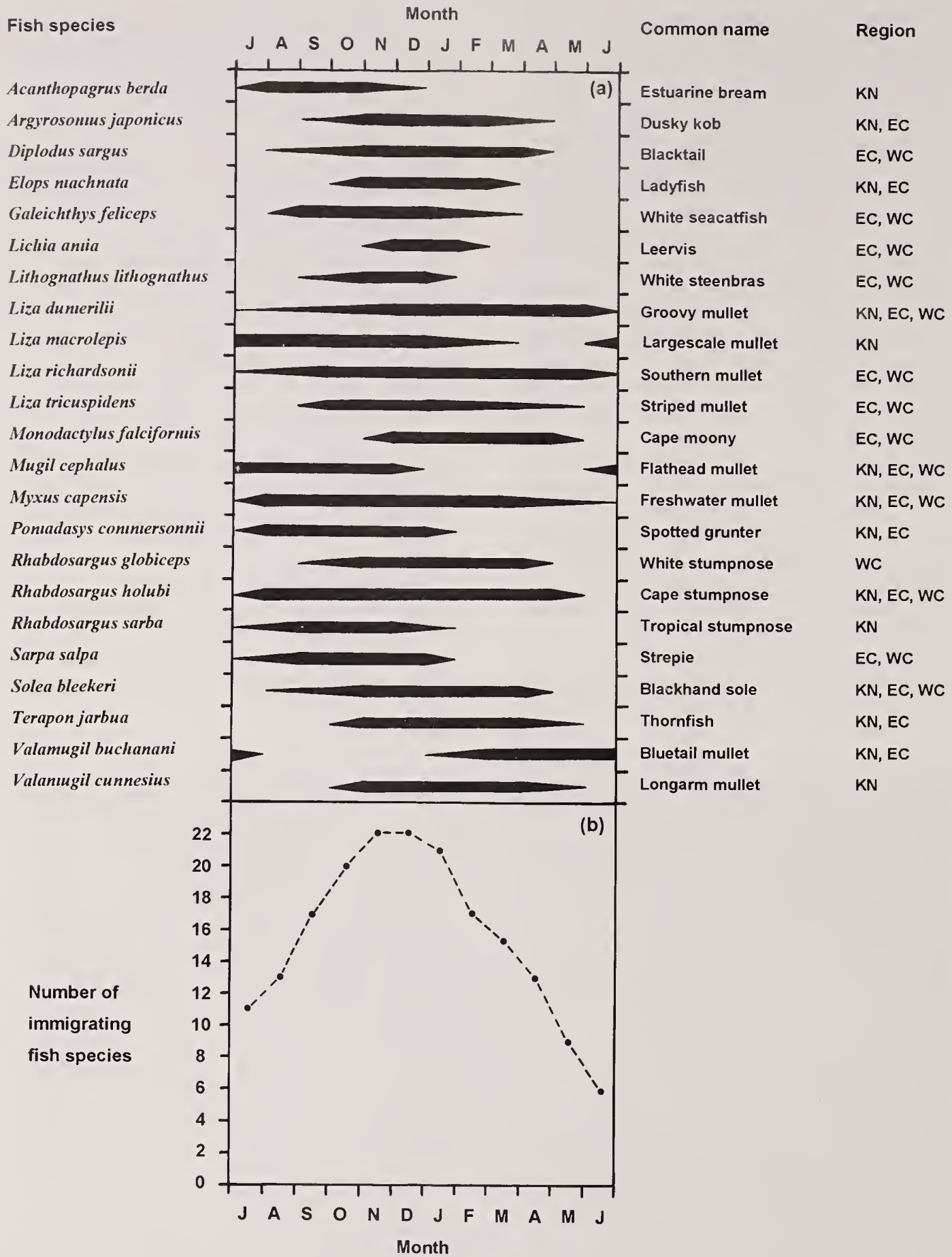

Figure 14. (a) Diagrammatic representation of the immigration periods of estuary-associated fish larvae and juveniles from the marine environment. Regional information used; $\mathrm{KN}=\mathrm{KwaZulu}-\mathrm{Natal}$, EC = Eastern Cape, WC $=$ Western Cape. Data from Wallace \& van der Elst (1975), Bok (1979), Melville-Smith \& Baird (1980), Whitfield (1990), Whitfield \& Kok (1992) and Harris \& Cyrus (1995). (b) Monthly variation in the numbers of species entering southern African estuaries, as derived from bar representations shown in (a). 


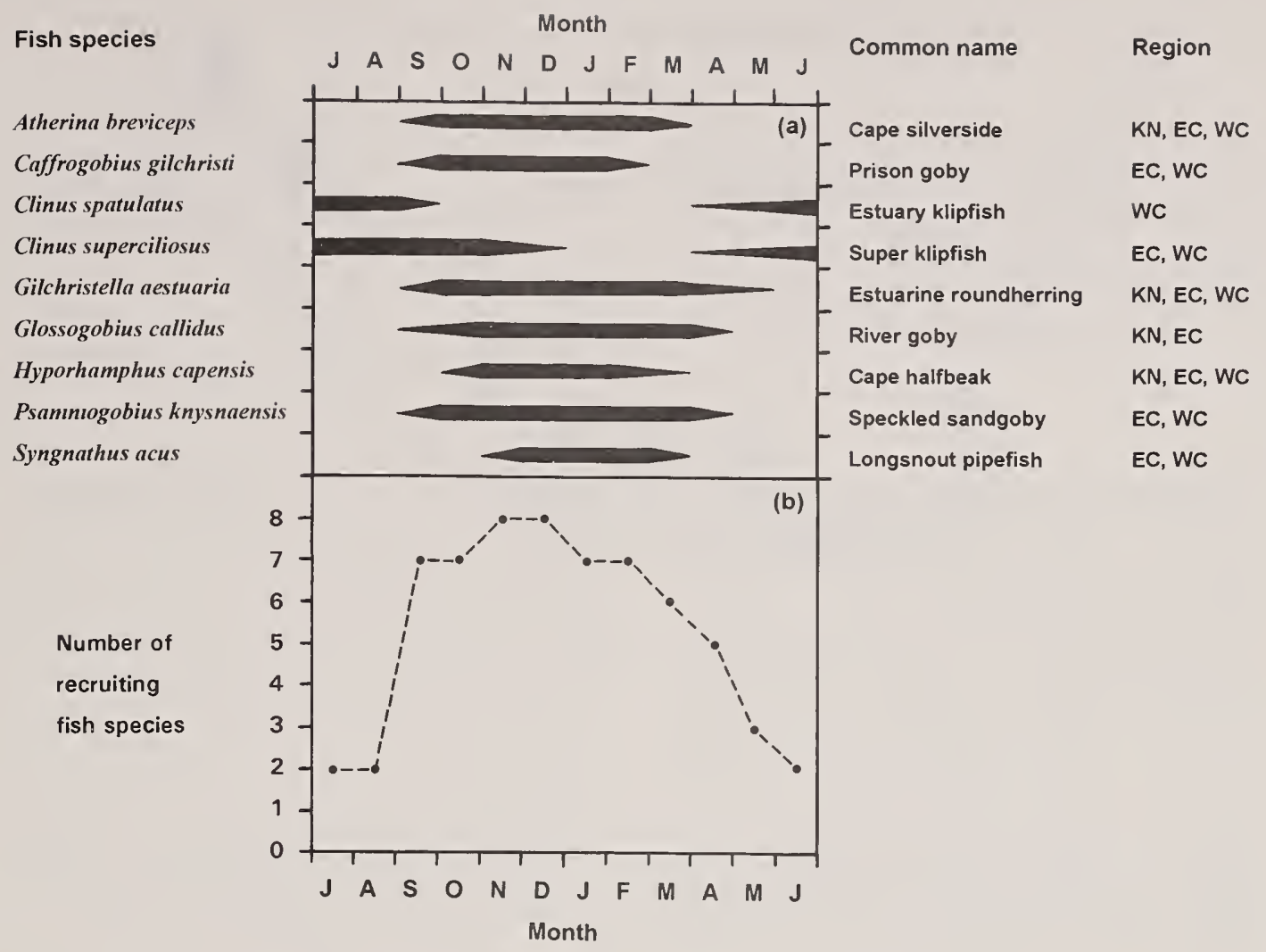

Figure 15. (a) Diagrammatic representation of the periods of abundance of larvae spawned within southern African estuaries. Regional information used; $\mathrm{KN}=$ KwaZulu-Natal, $\mathrm{EC}=$ Eastern Cape, WC $=$ Western Cape. Data from Melville-Smith \& Baird (1980), Whitfield (1990) and Harris \& Cyrus (1995). (b) Monthly variation in the numbers of species represented by larvae in southern African estuaries, as derived from bar representations shown in (a).

\section{Larvae and postlarvae in estuaries}

Juveniles of a number of marine fish species are dependent on estuaries as nursery areas but their flexion and postflexion larvae are usually absent from these systems. The available evidence suggests that abiotic constraints to the survival of larval stages, under fluctuating salinity, temperature and dissolved oxygen regimes, could be problematical. In addition, tidal fluctuations could easily transport embryos and non-motile larvae into unfavourable reaches of an estuary. The unpredictable abiotic characteristics of estuaries outlined above contrast to conditions in the more predictable marine environment.

The biotic environment within estuaries may also present problems for the survival of large numbers of ichthyoplanktonic organisms. Larval fishes feed mainly on microzooplankton, whereas postlarval fishes utilize both micro- and macrozooplankton. According to Vernberg \& Vernberg (1972), zooplankton are the dominant primary consumers in oceanic waters, so fish larvae are more likely to find a suitably sized and reliable planktonic food supply in the sea. Carter (1978) found that zooplankton biomass off the KwaZulu-Natal coast was higher over the continental shelf than in offshore areas. The highest biomass values were recorded within $5 \mathrm{~km}$ of the coast, a region usually occupied by the fish larvae of estuaryassociated marine species (Heydorn et al. 1978).

Zooplankton abundance in southern African estuaries is spatially highly variable, with east coast systems tending to have a higher biomass (up to 1200 $\mathrm{mg} \mathrm{m}^{-3}$ ) than south coast estuaries (up to $120 \mathrm{mg} \mathrm{m}^{-3}$ ) (Grindley 1981). In addition, the unpredictable nature of estuarine zooplankton on a temporal basis, even in those systems with characteristically abundant stocks, mitigates against the use of this environment by the larvae of marine species. 


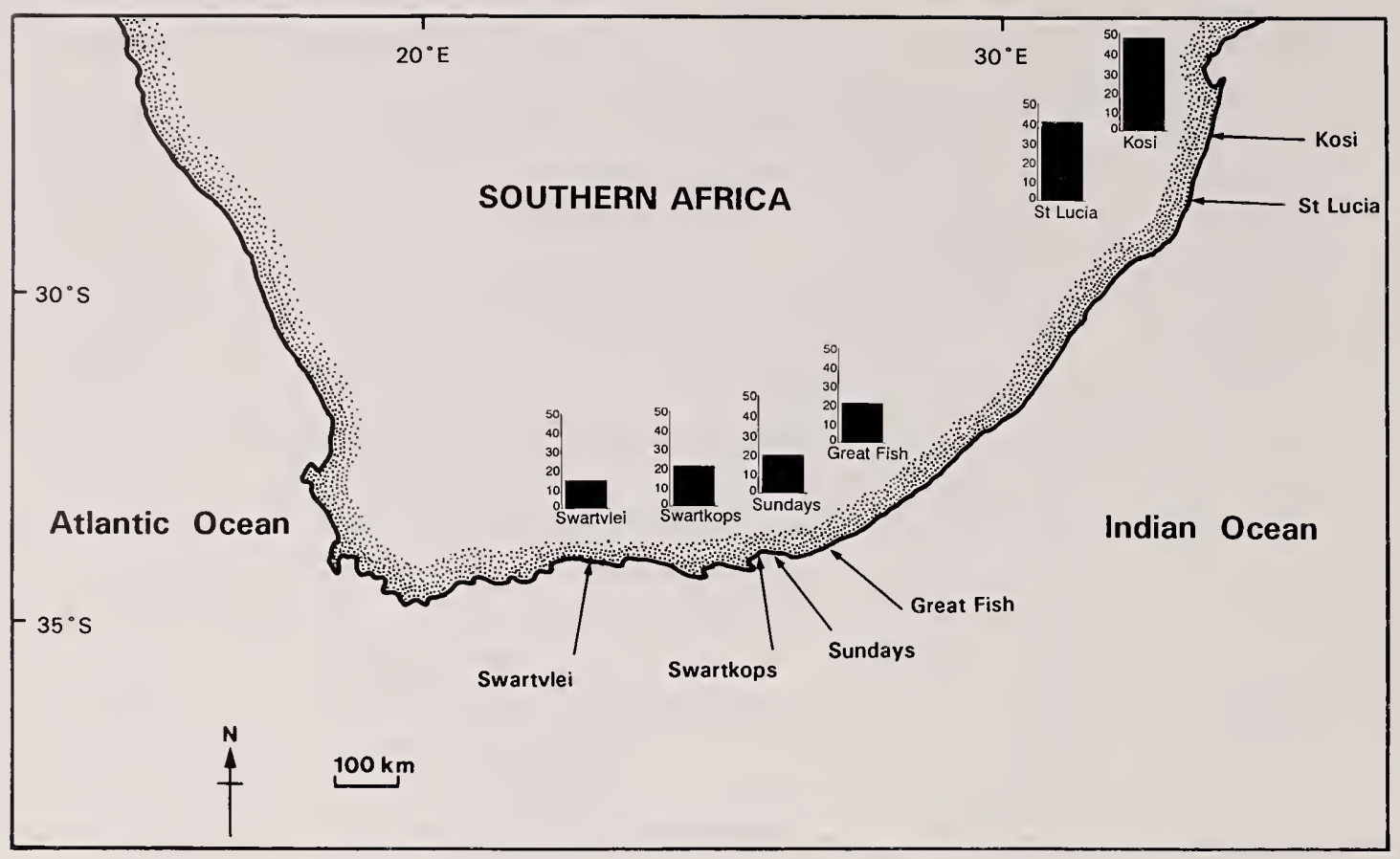

Figure 16. Number of fish families (excluding oceanic taxa) recorded from ichthyoplankton samples in six South African estuaries. Information from Melville-Smith \& Baird (1980), Beckley (1985a), Whitfield (1989a), Whitfield (1989c), Harrison \& Whitfield (1990), Whitfield (1994b), Harris \& Cyrus (1995) and Harris et al. (1995).

Virtually all of the marine fish larvae and postlarvae which enter South African estuaries feed initially on zooplankton (Whitfield 1985), regardless of their ultimate juvenile or adult diet. Calanoid copepods are particularly important for newly-recruited ichthyoplankton. The switch from a predominantly zooplanktonic diet to one dominated by zoobenthos, detritus or aquatic plants is rapid and usually occurs between $10 \mathrm{~mm}$ and $30 \mathrm{~mm}$ SL. Since most estuarineassociated marine species first enter these systems between $10 \mathrm{~mm}$ and $20 \mathrm{~mm} \mathrm{SL}$, the transition in diet occurs within the estuarine environment. Blaber \& Whitfield (1977a) have shown that mugilid postlarvae in estuaries feed initially on zooplankton, then vertically migrating zooplankton and meiobenthos, and finally microbenthos. The role of vertically migrating zooplankton in initiating dietary switches by the postlarvae may be important, and therefore requires further investigation both in the field and the laboratory.

The seasonal abundance of ichthyoplankton in Eastern Cape estuaries is positively correlated with copepod densities (Harrison \& Whitfield 1990), thereby increasing the potential growth and survival of larval fish. The spring and summer peak in zooplanktonic productivity is particularly important to those estuarine fish species whose larvae do not develop within the marine environment. Available evidence (e.g. Whitfield \& Harrison 1996) tend to support the expectation that estuaries with large zooplankton stocks also have high densities of resident planktivores such as Gilchristella aestuaria. In Swartvlei, an estuarine lake that has poor zooplankton resources (Coetzee 1981a), G. aestuaria larvae averaged 26 individuals per $100 \mathrm{~m}^{3}$ during 1986/87 (Whitfield 1989c). In contrast, the Sundays Estuary has a rich zooplanktonic resource (Wooldridge \& Bailey 1982) and $G$. aestuaria larvae averaged 204 individuals per $100 \mathrm{~m}^{3}$ during 1986/87 (Harrison \& Whitfield 1990). In addition, larval $G$. aestuaria from the Swartvlei system are narrower bodied than those from the Sundays Estuary (Haigh \& Whitfield 1993), thus reinforcing the suggestion by Blaber et al. (1981) that zooplanktonic prey abundance may influence the morphometrics of this species. The thinner larvae from Swartvlei would presumably be more susceptible to starvation-associated mortalities than those in the Sundays Estuary. 


\subsection{FACTORS INFLUENCING ESTUARINE UTILIZATION}

Estuaries are characterised by a relatively low ichthyofaunal diversity but high abundance of individual taxa, most of which exhibit wide tolerance limits to the fluctuating conditions found in these systems. Indeed, most southern African estuaries are occupied by fewer than 50 species, with fish population sizes probably totalling several million individuals in some of the larger systems. Even very small estuaries $\left(<1 \mathrm{~km}^{2}\right)$ can have single species populations ranging from 10000-50000 individuals (Blaber 1973a), and fish densities in these systems invariably exceed that of the adjacent marine or freshwater environments (Whitfield 1993). This observation leads directly to the question which has been repeatedly asked by both scientists and anglers; why are estuaries so attractive to fishes? Although selected aspects of this question have been directly and indirectly addressed by ichthyologists over the years, it was only during the 1980s that overviews of the situation were presented (Whitfield 1983, Blaber 1985, Marais 1988). During the past decade much additional information on the biology and ecology of a number of fish species associated with estuaries has been published, and we are now in a position to examine the issue in more detail (Whitfield 1996b).

Although most ichthyofaunal studies in southern African estuaries have tended to cover only one or two factors at a time, all scientists acknowledge that multiple variables influence both the abundance and diversity of fishes in these systems. Some of the following factors have been identified as probable or possible determinants of estuarine utilization by fishes, viz. latitude (Wallace 1975a, Blaber 1981a), estuary size (Whitfield 1980b, Begg 1984a), seasonality (Wallace 1975b, Branch \& Grindley 1979), catchment size (Marais 1988), habitat type (Hanekom \& Baird 1984, Whitfield 1986a), nearshore marine conditions (Whitfield 1989b, Potter et al. 1990), mouth depth and degree of marine influence (Whitfield \& Kok 1992, Harrison \& Whitfield 1995), physical constrictions within estuarine systems (Hall et al. 1987), river water quantity and quality (Marais 1988, Plumstead 1990), estuarine productivity (Howard-Williams \& Allanson 1981, Heymans \& Baird 1995), the occurrence and severity of floods (Marais 1982, Whitfield \& Paterson 1995), olfactory cues (Whitfield 1994a), estuary type (Bennett 1989, Kok \& Whitfield 1986), timing of the open phase (Wallace \& van der Elst 1975, Whitfield \& Kok 1992), the ability of species to adjust to salinity and temperature fluctuations (Blaber 1974a, Martin 1988), dissolved oxygen levels (Russell 1994, Blaber et al. 1984), turbidity (Cyrus \& Blaber 1987a, 1987b, 1987c), available food resources (Whitfield 1980e, Marais 1984, Whitfield 1988a), predation (Blaber 1973a, Whitfield \& Blaber 1978a), competition (Blaber
1976, Whitfield \& Blaber 1978b), reproductive condition and proximity to spawning grounds (Wallace 1975b, Whitfield 1994a), juvenile cohort abundance (Blaber 1974c, Wallace \& van der Elst 1975), and habitat degradation as a result of pollution (Blaber et al. 1984) or dredging (Cyrus \& Blaber 1988). Some of the above factors are expanded upon below.

\section{Salinity}

The most essential adaptation by fish which enter estuarine systems is an ability to adjust to changes in salinity (Panikkar 1960). The change may be gradual, as normally occurs in a temporarily closed estuary, or sudden, as often takes place in tidal estuaries. The magnitude of the change in salinity depends mainly upon the balance between freshwater inflow and the tidal regime, with evaporation playing a major role in lagoonal or lacustrine systems with a high surface area to volume ratio (e.g. Lake St Lucia).

A characteristic of many fish species entering southern African estuaries is an ability to adapt to both low and high salinity regimes, although it is noteworthy that less than 20 species have their upper recorded limits above $69 \%$, whereas more than 60 species can survive in water with a salinity of $1 \%$. Fishes are therefore more tolerant of low rather than high salinity conditions (Ter Morshuizen et al. 1996a). This is important since most estuaries are subject to periods of freshwater flooding, whereas salinities seldom rise above sea water except in Lake St Lucia and a few temperate systems to the south. Furthermore, the closure of estuaries is usually associated with declining salinities, and only fishes tolerating these conditions are able to utilize the rich food resources available within these systems.

A few southern African freshwater teleosts have developed hypotonic regulation but most species are incapable of this adaptation and are therefore excluded from estuaries. Of the eight species shown in Figure 16, only Oreochromis mossambicus may be classified as truly euryhaline. O. mossambicus were abundant in Lake St Lucia during hypersaline conditions and were recorded in areas where the salinity exceeded $90 \%$

According to Panikkar (1960) only a few species of sharks and rays are known to enter estuarine waters because of their method of osmoregulation. Nevertheless three species of elasmobranchs were recorded from the St Lucia system during 1975 and 1976 (Whitfield et al. 1981). The shark Carcharinus leucas, stingray Himantura uarnak and sawfish Pristis zijsron all occurred in water with a salinity of less than $3 \%$ (Figure 17). C. leucas was also regularly netted at 


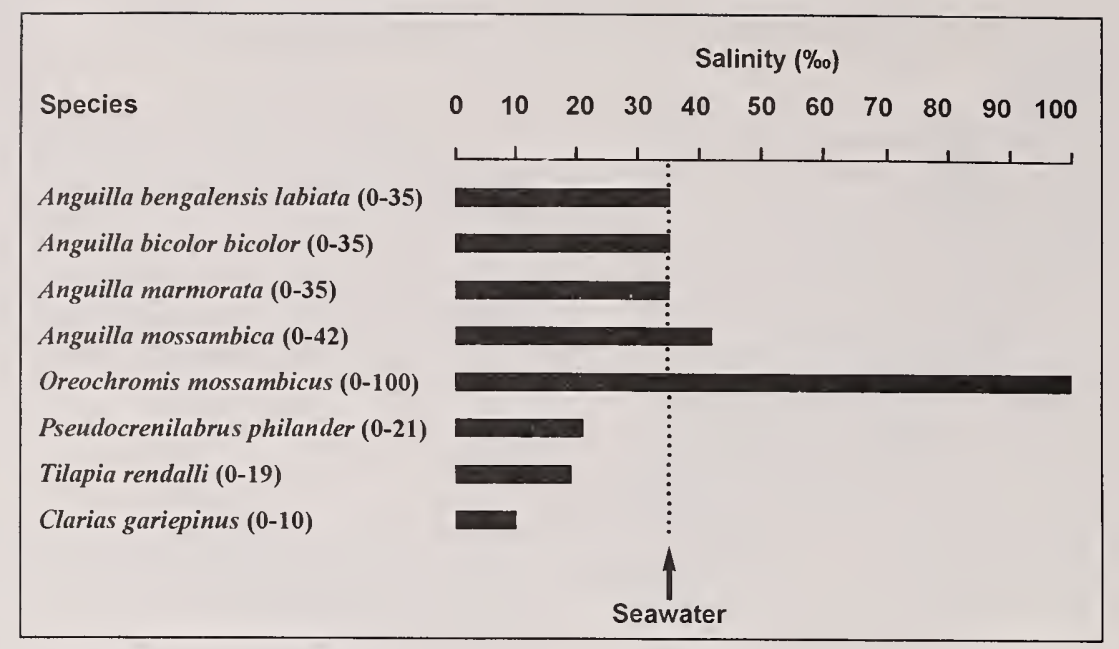

Figure 16. Recorded salinity ranges of selected freshwater teleosts found in southern African estuaries.

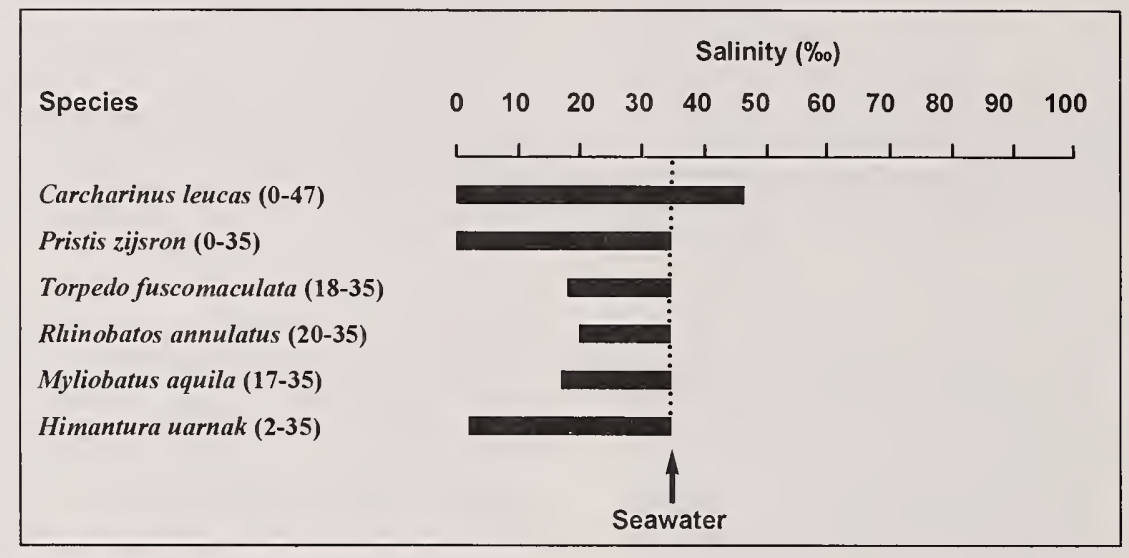

Figure 17. Recorded salinity ranges of selected marine elasmobranchs found in southern African estuaries.

Lake St Lucia in salinities up to $47 \%$ by Bass et al. (1973). Large numbers of the spotted ragged-tooth shark Carcharias taurus move into the freshwater deprived Kariega Estuary during coastal upwelling events. In addition, Paterson (1995) recorded juveniles and adults of the blackspotted electric ray Torpedo fuscomaculata and blue stingray Dasyatis chrysonota in the lower half of this estuary. None of these species have been recorded in the Kariega system under low salinity conditions $(<18 \% 0)$.

Most marine fish species associated with estuaries are strong osmoregulators (Figure 18), capable of surviving under both oligohaline and hypersaline conditions. However, of the approximately 1200 marine species found in northern KwaZulu-Natal coastal waters (Smith 1980), only 201 (16\%) have been recorded entering estuaries (Whitfield 1980d). Fewer than 50 of these species are common in estuaries, with the implication that less than $5 \%$ of marine fishes use estuaries to any great extent.

Do salinity fluctuations within estuaries limit the use by marine fish of estuaries? Observations from the Kariega and other estuaries in the Eastern Cape Province suggest that some stenohaline marine species do penetrate estuaries which have no freshwater input for extended periods, but that these taxa are poorly represented and usually confined to the lower reaches (Ter Morshuizen \& Whitfield 1994). 
Several euryhaline marine fish species sometimes penetrate considerable distances up the rivers of southern Africa. Pooley (1975) recorded Acanthopagrus berda and Mugil cephalus on the Phongolo floodplain approximately $100 \mathrm{~km}$ from the sea, and Bok (1984) found both Myxus capensis and Mugil cephalus $120 \mathrm{~km}$ upstream from the head of the Gamtoos Estuary. Similarly, in the Great Fish system marine species tend to dominate the fish assemblage immediately above the ebb and flow region (Ter Morshuizen et al. 1996a). However, relatively high conductivity of these and other river systems, which sometimes contain large numbers of marine fishes, suggests that dissolved salts of terrestrial origin may be important in reducing osmoregulatory stress for these temporary riverine residents.

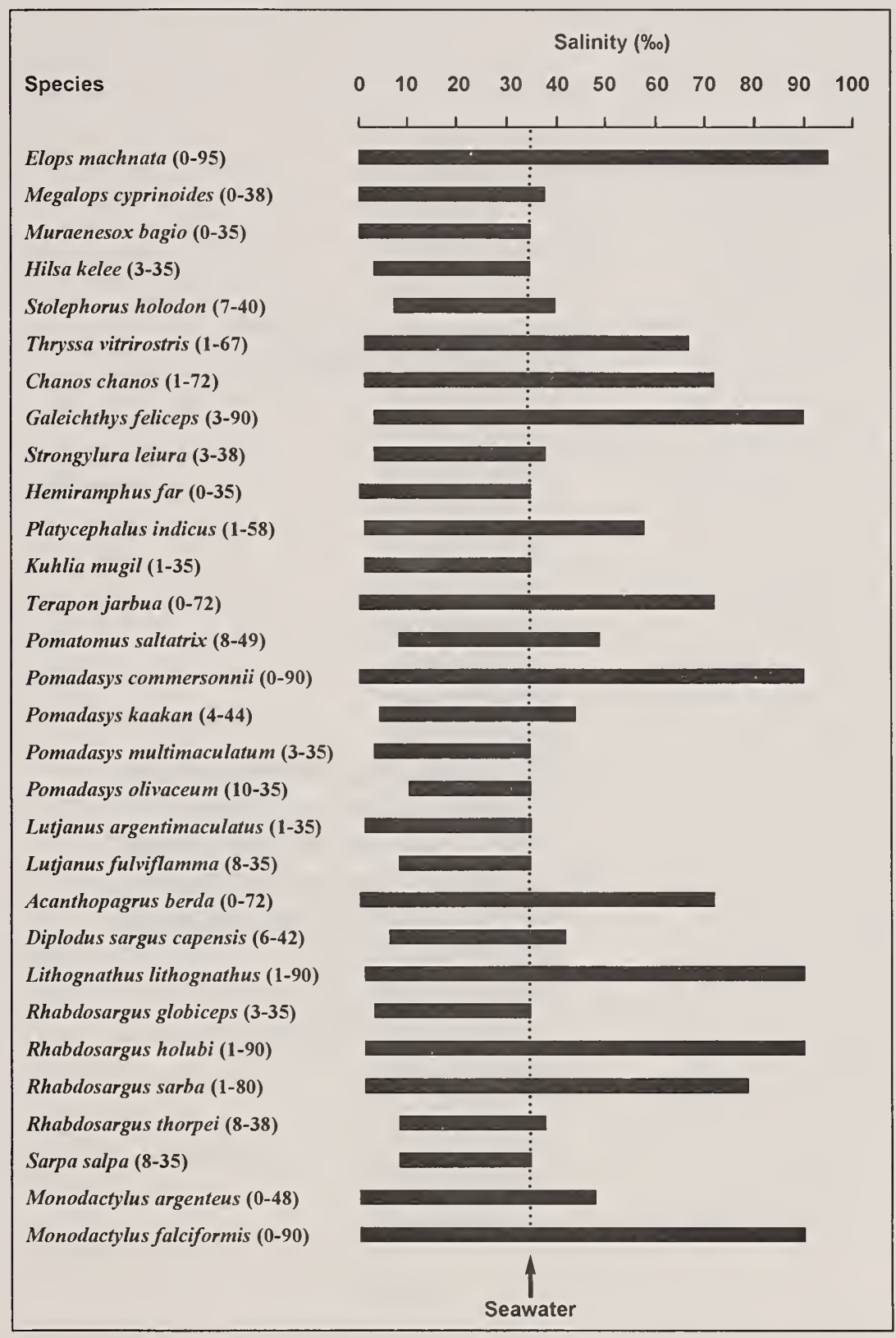

Figure 18. Recorded salinity ranges of selected marine teleosts found in southern African estuaries. 
Both species composition and abundance seem to respond to salinity changes. Van der Elst et al. (1976) have shown that there is an inverse relationship between salinity and numbers of fish species at Lake St Lucia. Abundance is also affected, with gill net catch rates when salinities were less than $20 \%$ being double those when salinities exceeded $50 \%$. Although the lower catches during the hypersaline period could have been due to osmoregulatory stress, forcing certain fish taxa out of the area, the disappearance of certain food resources (Boltt 1975) may also have played a role in reducing fish abundance. Wallace (1975a) found that Pomadasys commersonnii and Rhabdosargus sarba captured in areas where the salinity was in excess of $70 \%$ were no longer feeding on normal molluscan and crustacean prey but were consuming filamentous algae.

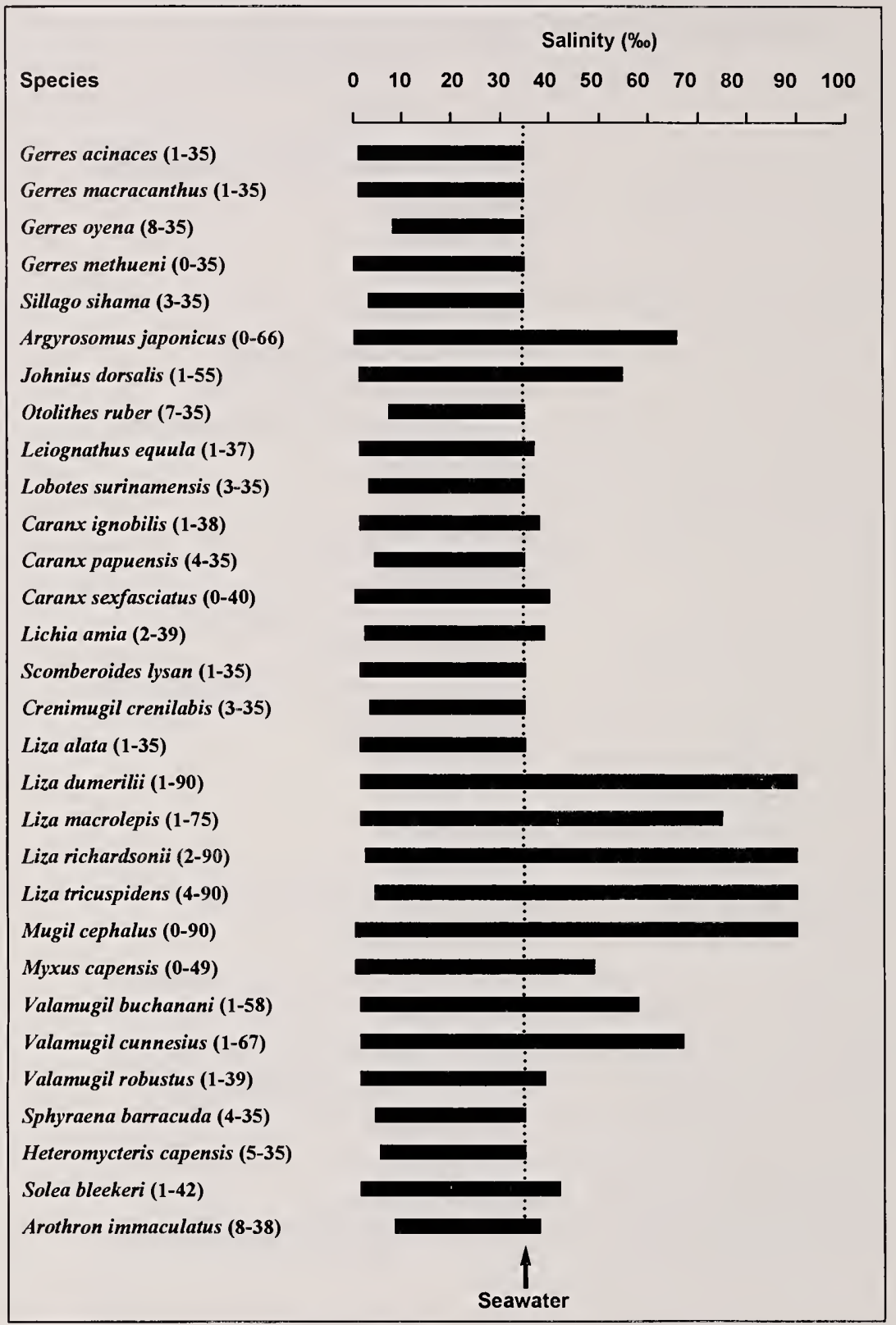

Figure 18 (continued). Recorded salinity ranges of selected marine teleosts found in southern African estuaries. 
Prolonged closure of an estuary, in association with dilution of lagoonal waters from catchment rivers, can cause osmoregulatory stress in many marine fish species. However, estuarine spawners appear to be tolerant of prolonged oligohaline conditions, with all species recorded in salinities below $10 \%$ and most having been found in fresh water (Figure 19). In contrast to marine taxa, the estuarine group does not appear well adapted to hypersaline conditions, with only $G$. aestuaria having been recorded in salinities above $60 \%$. Although the eggs and larvae of estuarine species are found under both oligohaline and hypersaline conditions, it would appear that the eggs of many marine taxa cannot survive decreased salinities (Sylvester et al. 1975) but the fry of these species are attracted to low salinity waters (Mires et al. 1974).

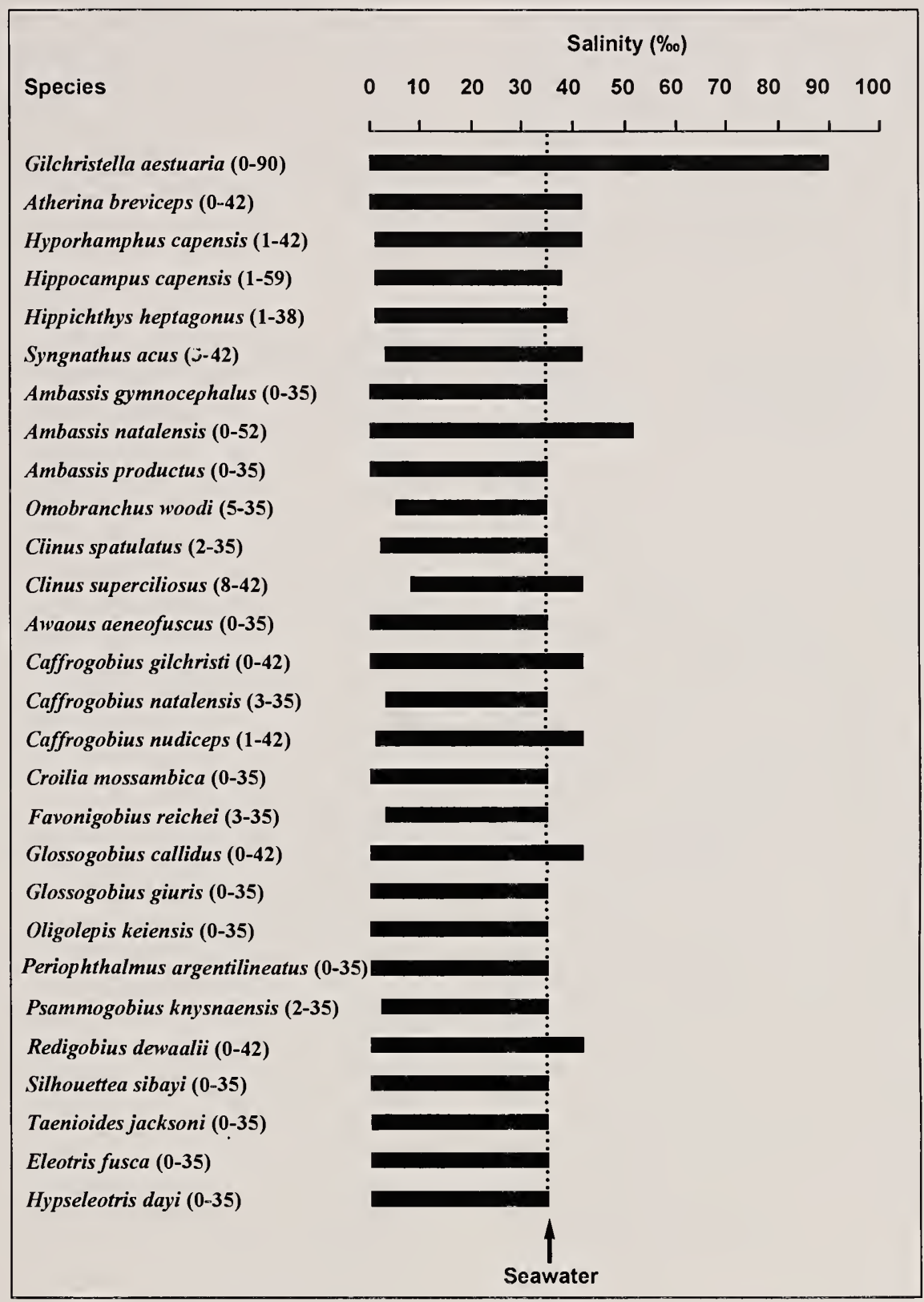

Figure 19. Recorded salinity ranges of selected estuarine teleosts found in southern African estuaries. 


\section{River flow}

River flow into estuaries influences not only the salinity but also the biochemical properties of the water body, including the introduction of catchment olfactory cues Fishes have a highly developed sense of smell and it is possible that olfactory cues guide the larvae of species such as the longfin eel Anguilla mossambicus up estuaries and into the river catchments. Olfactory cues, which can be of freshwater or estuarine origin (Stabell 1992), may also guide those marine postlarvae that utilise estuaries as nursery areas. Permanently open Eastern Cape estuaries with longitudinal salinity gradients greater than $19 \%$ have considerably higher densities of $0+$ juvenile marine fishes than those systems where salinity gradients are small or absent (Whitfield 1994a). A similar finding was arrived at by Martin et al. (1992) who found that the densities of postlarval marine migrants in the St Lucia Estuary increased markedly for virtually all species following an episodic flushing of the system. Although the inference from the above studies is that the salinity gradients are the attractant for these $0+$ juvenile fishes, it is more likely that the increased amount of olfactory cues that are exported to the marine environment on each ebb tide are vital to the recruitment process. Indications are that these juveniles remain within the selected estuary for several years because data presented by Marais (1988) shows that gill net catches in Eastern Cape estuaries are positively correlated with increasing longitudinal salinity gradients.

River pulses also seem important in influencing the abundance of estuarine spawners. Whitfield \& Wooldridge (1994) have described the cascading effect freshwater pulses have on southern African ecosystems, primarily through the stimulation of the planktonic food web. Martin et al. (1992) recorded considerably higher abundances of virtually all estuarine resident species following the flushing of the St Lucia Estuary. They found that an order of magnitude increase in the abundance of Gilchristella aestuaria could be indirectly linked to the phytoplankton bloom and increased zooplankton stocks which followed the flooding. Conversely, the decimation of the rare estuarine pipefish Syngnathus watermeyeri has been attributed to the indirect effect freshwater deprivation has had on the three Eastern Cape estuaries where this endemic species had previously been recorded (Whitfield 1995b).

Despite the positive effects of frequent minor freshwater pulses, river flooding and/or prolonged large freshwater inputs into estuarine systems can result in a depletion of marine and estuarine species (Marais 1983b, Ter Morshuizen et al. 1996b). River floods carrying high suspensoid loads can be lethal to both marine migrants and estuarine residents. Whitfield \& Paterson (1995) recorded extensive mortalities of both groups of fishes in the Sundays Estuary following a flash flood. Although the suspended silt resulted in a clogging of the gills of fishes which died in the mass mortality, it is also plausible that reduced oxygen levels associated with the floodwaters contributed to the asphyxiation of fishes in this estuary.

The morphology of an estuary may also influence the response of certain fish taxa to major flooding events. Marais (1982) found that densities of Mugilidae increased in the broad Swartkops Estuary after river floods but decreased markedly in the channel-like Sundays Estuary. He postulated that the organic rich mud and silt which are deposited in the floodplain-like middle and lower reaches of the Swartkops Estuary act as a food source for the mullet species, whereas the rich epibenthic layer in the Sundays Estuary is washed away by heavy floods.

\section{Turbidity}

Water turbidity influences fishes associated with southern African estuaries, with the juveniles of most estuarine-associated marine species being attracted to turbid waters (Cyrus \& Blaber 1987c). However, excessively high water turbidities have been shown to negatively effect fish egg survival, hatching success, feeding efficiency, growth rate and population size. In the case of those estuarine species which remain within these systems for their entire life cycle, all life-history stages need to be tolerant of turbid waters. Indeed, few southern African estuaries fall into the clear water category ( $<10 \mathrm{NTU}$ ) of Cyrus (1988a), with the majority either semi-turbid (10-50 NTU) or turbid ( $>50$ NTU). Closure of an estuary mouth leads to decreased water turbidity but when it re-opens at times of high river inflow, turbidities increase rapidly, mainly due to suspensoids carried into the estuary by floodwaters. This may account for the occurrence of both clear and turbid water species in these systems (Harrison \& Whitfield 1995).

Blaber (1981a) suggested that many southern African estuary-associated fishes are essentially turbid water species that have evolved in turbid areas. Research conducted on juvenile marine fishes in KwaZulu-Natal estuaries and in the laboratory (Cyrus \& Blaber 1987a, 1987b) has shown that $80 \%$ of the species studied were turbid water taxa, whereas only $20 \%$ could be classed as truly clear water species. It was suggested that the protective isolation created by turbidity, coupled with other factors, are advantageous to the survival and growth of juvenile fish in estuaries. Supporting this hypothesis, Blaber (1981a) showed that where these conditions exist outside estuaries in the Indo-Pacific region, the same juvenile fish are also present. Shallow, turbid areas are usually found only within estuaries along the southern African coast. 
Turbidity gradients usually exist not only within estuaries but also from the mouth region into the sea. Blaber (1987) suggested that postlarval fishes in the marine environment, by following an increasing turbidity gradient, could ultimately reach shallow estuarine areas. If this hypothesis is true, the export of estuarine suspensoids could affect fish recruitment into these systems, thereby influencing community structure.

Why is turbidity so important to juvenile fish? Two possible factors include the cover it affords small fishes from predatory teleosts and birds, as well as increased feeding success in suspensoid rich waters. Turbidity preference of juveniles may differ from that of the adults, e.g. Blaber \& Cyrus (1983) have shown that Caranx sexfasciatus juveniles inhabit estuarine waters which are more turbid than those occupied by the adults. Blaber \& Cyrus (1987a) suggested that this difference in turbidity preference may reduce intraspecific predation.
Although it is important for fishes to evade predators, the ability to detect food in water where visibility is poor is also important. Species such as Galeichthys feliceps have long barbels which perform tactile foraging functions, whereas others (e.g. Argyrosomus japonicus) can use olfactory and lateral line sense organs to detect prey (van der Elst 1988). In Eastern Cape estuaries, visual foraging piscivorous fishes are adversely affected by high turbidity conditions, whereas non-visual foragers are largely unaffected (Whitfield et al. 1994).

Hecht \& van der Lingen (1992) determined that the feeding rate of visual fish predators was reduced at high turbidity levels. They also confirmed that visual pelagic predators are more affected by increased turbidity than non-visual macrobenthic feeders (Figure 20 ). However, both fish groups do have the ability to change their foraging strategies in order to optimize the acquisition of food under different turbidity conditions.

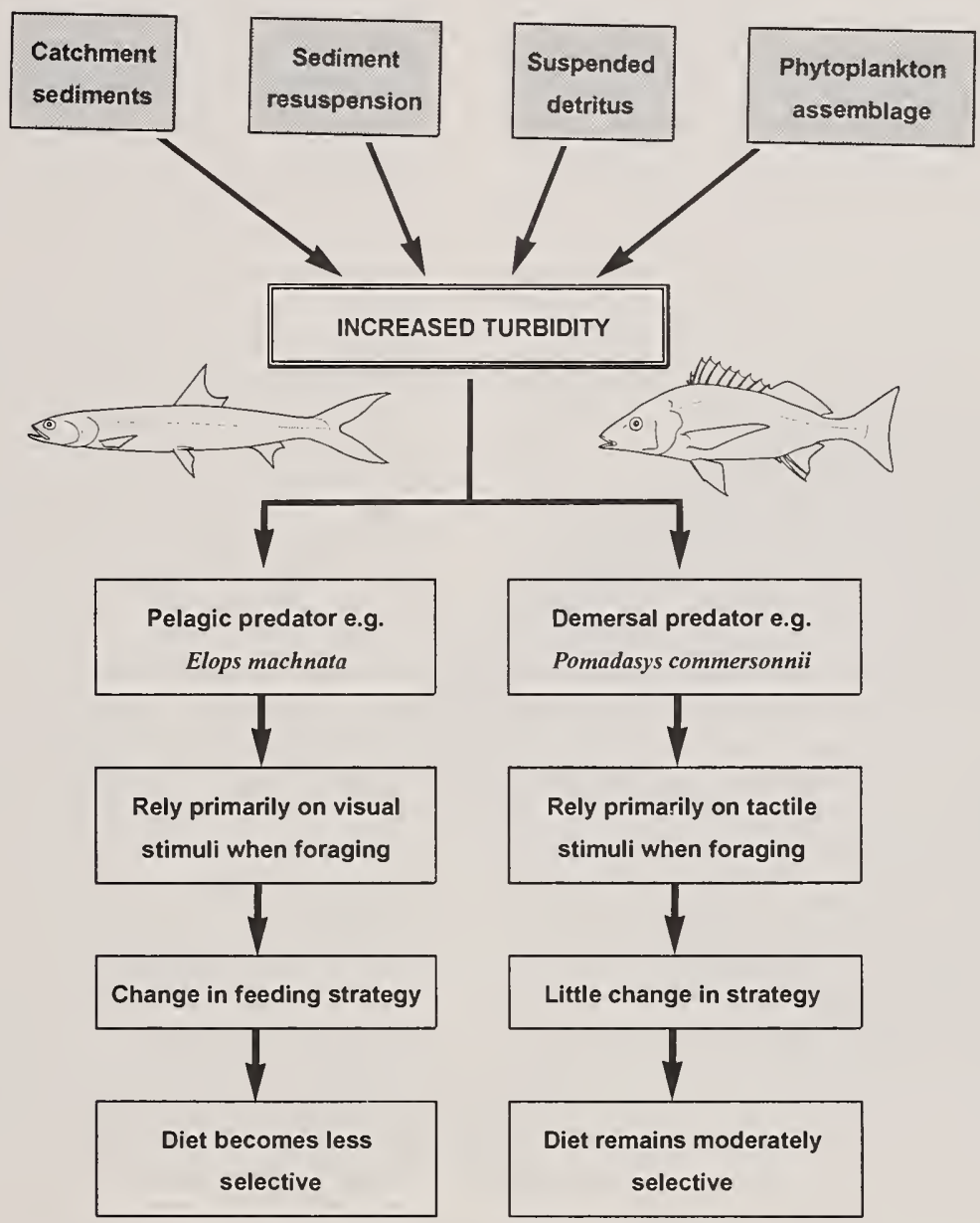

Figure 20. Diagram showing effects of high turbidity on the foraging strategies of certain fish species in estuaries. 
Although the zoogeographical affinities of fishes in southeast African estuaries lie with the turbid waters of the northeast Indian Ocean zone (Blaber 1981a), low turbidity estuaries in southern Africa sometimes have a higher species diversity than more turbid systems. Approximately 100 fish species have been documented from the turbid St Lucia system whereas the clear Kosi system has more than 150 species (Whitfield 1980d). Similarly, a much lower species diversity was recorded in the turbid Great Fish Estuary when compared to the clearer Kowie Estuary (Whitfield et al. 1994). According to Day \& Grindley (1981), estuaries characterized by physically unstable conditions often have a low biological diversity, so the lower diversities in the St Lucia and Great Fish systems may simply be a reflection of the more extreme physical conditions in these water bodies when compared to similar sized estuaries with lower freshwater inputs.

\section{Mouth phase}

The magnitude of river inflow into an estuary is usually related to catchment size, which in turn has a major influence on the condition of an estuary mouth. Although the degree of isolation of an estuary from the sea has long been recognized as a major factor influencing southern African estuarine ichthyofaunal diversity, it was only comparatively recently that studies have quantified this evaluation. Formation of a sand bar across the mouth of an estuary effectively blocks any further recruitment of marine juveniles, or emigration of subadults/adults back to the sea, thereby directly influencing the composition of the fish community. Bennett (1989), working in the temporarily closed Bot Estuary, calculated that marine migrants numerically comprised only $1 \%$ and residents $99 \%$ of the fish fauna, whereas the two groups occurred in approximately equal abundance in the nearby permanently open Palmiet Estuary. In contrast to the prolonged (several years) closed phase of the Bot Estuary, the Swartvlei system usually opens annually, so the marine migrants arewell represented in this estuary (Kok \& Whitfield 1986, Russell 1996). Evidence from Australian studies suggests that the state of an estuary mouth is probably the single most important factor influencing fish species diversity. Lenanton \& Hodgkin (1985) found that the number of fish species in the temporarily open Beaufort Estuary (Western Australia) more than doubled, compared to the closed phase, due to juvenile recruitment of marine species into that system.

Comparisons between the nearby Swartvlei and Knysna estuaries indicated that the CPUE of most marine migrants were higher in the latter system (Whitfield \& Kok 1992). Apart from mouth condition, most of the factors influencing fish abundance in the two estuaries were similar, so it appears that the higher densities of most species in the Knysna system may be attributed to the deep, permanently open mouth and strong marine influence. Similarly, the species richness (R) of fishes associated with Zostera capensis beds in the Knysna Estuary was more than twice that of Swartvlei Estuary eelgrass beds (Whitfield et al. 1989).

In KwaZulu-Natal, Begg (1984a) found that species rich estuaries were normally open and dominated by a wide variety of marine teleosts, especially mugilids and sparids. In contrast, systems which were normally closed had relatively few species and commonly dominated by a few estuarine and freshwater taxa. Harrison \& Whitfield (1995) found that the species diversity in three temporarily open/closed KwaZuluNatal estuaries was related to the duration of the open mouth phase. The Damba Estuary remained closed for much of the study period and had the lowest diversity, whereas the Zotsha Estuary remained open for most of the study period and had the highest diversity. In addition, in both the Zotsha and Mhlanga estuaries there was a significant positive correlation $(r>0.80$, $\mathrm{P}<0.05$ ) between the number of species recorded within each system and the time that the mouth remained open during a particular season.

The fact that estuarine ichthyofaunal diversity is positively linked to the duration of the open mouth phase can result in an overemphasis of the importance of permanently open estuaries as nursery areas for juvenile marine fish. There are distinct benefits to those juvenile fish which enter estuaries that subsequently close, e.g. the nursery area available to foraging fishes in the Mhlanga, Bot and Swartvlei estuaries increases considerably during the lagoonal phase due to elevated water levels inundating intertidal and supratidal habitats (Whitfield 1980e, Bennett et al. 1985, Kok \& Whitfield 1986). These vegetated shallow littoral areas are less accessible to large predatory fishes, thereby enhancing their nursery function. Breaching of closed estuaries results in a decline in the volume and area of the aquatic environment, together with a slump in aquatic plant and invertebrate food resources (Whitfield 1980e, Branch et al. 1985). In contrast, permanently open systems such as the Knysna Estuary offer a more predictable nursery area, which fluctuates in depth and area according to the tidal regime. However, low tide conditions usually result in the intertidal flats being made unavailable for occupation by juvenile fishes, often forcing them into channel areas where they are more vulnerable to predation by large piscivorous fishes.

Immigration of juvenile fishes into estuaries may be either active or passive when the mouth is open (Beckley 1985a, Harrison \& Cooper 1991). However, Begg (1984a) postulated that juvenile marine fish may also gain access into temporarily closed estuaries by being washed into them at high tide when waves 
overtop the bar. This was confirmed by Whitfield (1992b) who recorded postlarval mugilids and Rhabdosargus holubi entering the Haga Haga Estuary when the sand bar at the mouth was being overtopped (Figure 21). Similar juvenile recruitment mechanisms have been observed in the Nhlabane and Siyaya estuaries in KwaZulu-Natal (L. Vivier, pers. comm.) and the East Kleinemonde system in the Eastern Cape (P. Cowley, pers. comm.). Overwash water depths of less than a centimetre are sufficient to facilitate the above immigration process.

Adult fish have also been reported migrating over Eastern Cape estuary sand bars during major marine overwash events. Dundas (1994) describes how large Argyrosomus japonicus and Lithognathus lithognathus were observed entering the Kabeljous Estuary in association with exceptionally high seas. Based on the above evidence, large-scale overtopping events may have a profound effect on the ichthyofaunal structure of temporarily closed estuaries, particularly those systems that remain closed for several years in succession.

Estuary mouth state affects water level and therefore also water connections within segmented coastal lakes and lagoons. In the Wilderness system, movement of fishes between the lakes can only take place along narrow channels linking each compartment (Hall et al. 1987). When the estuary mouth is open, some interconnecting channels are too shallow to permit the migration of even juvenile fishes. Only when the mouth closes and water levels rise do these connections become viable migration routes for fishes. Ultimately, however, the natural progression for segmented estuarine lake systems is towards the isolation of sections which then become brackish or freshwater coastal lakes. This has already happened to Groenvlei, which was previously linked to the Swartvlei Estuary. Although relic estuarine fish species are still found in Groenvlei, all the marine migrants have disappeared from the system (Ratte \& Ritchie 1984). A similar situation exists in Lake Sibaya where only a few estuarine species have survived the loss of a link to the marine environment (Bruton 1979a).

\section{Dissolved oxygen}

Oxygen depletion within the water column has the potential to restrict the distribution and movement of fishes within estuaries. In subtropical estuaries this may be more pronounced because of the generally higher water temperatures. Additional oxygen-demanding substances added to the water in the form of domestic or industrial pollution may further limit the distribution of fishes in an estuary, or result in fish mortalities. Begg (1984a) noted that organic pollution played a role in suppressing species diversity in some degraded

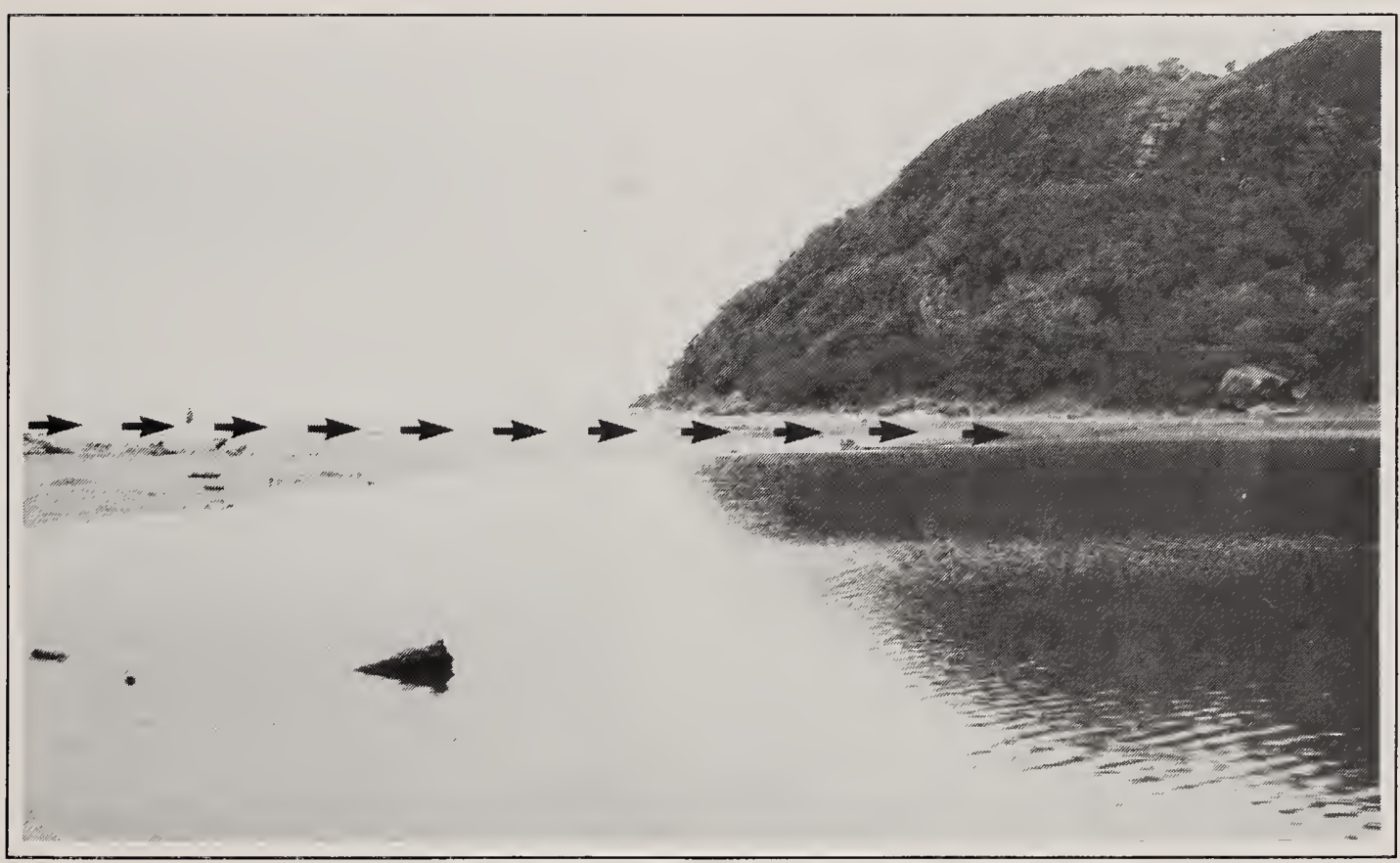

Figure 21. Wave overtopping of the temporarily closed Haga Haga Estuary during a spring high tide. The path taken by postlarval fishes entering the system is indicated by arrows. 
KwaZulu-Natal estuaries such as the Sipingo, Tongati, Sezela and Mbokodweni. Blaber et al. (1984) suggested that low dissolved oxygen values contributed to the impoverished fish fauna in the Tongati Estuary, and Russell (1994) has shown how depleted oxygen levels resulted in fish mortalities within a Western Cape estuarine lake. Under natural conditions it is probable that only a few southern African estuaries would have experienced exceptionally low dissolved oxygen levels $\left(<1 \mathrm{mg} \mathrm{l}^{-1}\right)$. Examples of such systems include the meromictic lakes Mpungwini and Swartvlei where the bottom waters are usually anoxic and rich in hydrogen sulphide (Allanson \& Howard-Williams 1984). Periodic dissolved oxygen depletion can also occur during episodic river floods which, together with excessive silt loads, may cause mass mortalities of fishes in estuaries (Whitfield 1995d).

\section{Habitat variability}

A factor frequently overlooked in the assessment of ichthyofaunal diversity is habitat variation. Estuaries with a wide range of substrata and littoral plant growth normally have a higher species diversity than more uniform systems (Whitfield 1983). Twenty percent of the fish species in the Kosi Estuary were found to be associated with a rocky outcrop near the mouth (Blaber 1978), and their absence from the rest of the system suggests that their presence in the estuary was dependent on the reef. Branch \& Grindley (1979) found that more than $60 \%$ of the fish species in the Mngazana estuary were associated with Zostera beds. Most southern African estuaries lack submerged macrophyte beds, and extensive rocky intrusions are usually confined to the upper reaches.

Day et al. (1981), reviewed the ichthyofaunal diversity of certain very turbid estuaries such as the Mzimkulu, Mzimvubu and Kei, and concluded that the relatively low biodiversity was due to the heavy silt loads carried by these rivers. Suspended silt reduces light penetration and when large quantities are deposited following river flooding it smothers submerged vegetation, thus reducing habitat diversity. The low species diversity of very turbid estuaries may therefore be linked to the indirect effect of silt deposition and substrate disturbance on aquatic macrophytes and their associated invertebrate prey, rather than turbidity. In the Mhlanga and Swartvlei estuarine systems, the ichthyofaunal diversity did not decline when water transparency decreased as a result of river flooding (Whitfield 1983), thus supporting Blaber's (1981a) postulate that marine teleosts occurring in Indo-Pacific estuaries are tolerant of turbid water. However, the long term effects of persistent siltation on both the food resources and species diversity of an estuary have yet to be quantified. In the
Swartvlei system siltation due to river flooding is a relatively infrequent occurrence, whereas in the Mzimvubu Estuary siltation is a feature even under relatively low flow conditions. Marais (1982, 1983b) determined that river floods in the Swartkops, Sundays and Gamtoos estuaries have a considerable impact on the fish populations, depending on the severity of the flood, the configuration of the estuary and the extent to which food sources are affected.

Prolonged droughts can increase habitat diversity in permanently open estuaries where eelgrass (Zostera capensis) beds expand in systems where freshwater inflow is minimal or has ceased altogether (Adams \& Talbot 1992). Fish that are usually closely associated with aquatic macrophyte beds in estuaries include the syngnathids Hippocampus capensis and Syngnathus acus, and sparids Rhabdosargus holubi and Sarpa salpa. Hanekom \& Baird (1984) recorded both $R$. holubi and the monodactylid Monodactylus falciformis in significantly higher numbers in Zostera than in nonZostera regions of the Kromme Estuary. $R$. holubi and M. falciformis declined in abundance in the Swartvlei littoral zone when Potamogeton beds entered a senescent phase (Whitfield 1986a), thus emphasizing the importance of suitable aquatic macrophyte habitats to certain fish species.

\section{Zoogeography and seasonality}

According to Vieira \& Musick (1993) latitude (water temperature characteristics) affects both fish diversity (number of species) and equitability (relative abundance of the different taxa) in tropical and warmtemperate estuaries of the western Atlantic. Their review showed that studies conducted in tropical estuaries reported more species, and more equitability between species, than did those from temperate areas.

Similarly, there is a decline in estuarine fish diversity from KwaZulu-Natal, along the Eastern Cape coast, around the Western Cape and up the Atlantic west coast (Wallace \& van der Elst 1975, Day et al. 1981, Whitfield 1994d). The decline in diversity towards the southwest seems due to the attenuation in the distribution of tropical and subtropical marine species which comprise the bulk of the southern African ichthyofauna. The influence of latitude can be illustrated by comparing the species diversity of the Kosi system ( $>150$ species) to that of the Swartvlei system ( $<50$ species). Both estuarine lake systems are clear and have a wide variety of available habitats. The rocky outcrop inside the mouth of the Kosi estuary has a much higher species diversity than the rocky reef inside the mouth of the Swartvlei Estuary, primarily because the Kosi region supports an abundance of tropical Indo-Pacific reef-dwelling fishes, some of which utilize the Kosi outcrop (Blaber \& Cyrus 1981). 
Species diversity in estuaries along the Atlantic coast are much lower than estuaries on the Indian Ocean coast. There are almost 30 commonly occurring fish species in estuaries near Port St Johns, compared to less than 10 in estuaries on a similar latitude along the Western Cape coast (Day et al. 1981). According to Smith (1980), $80 \%$ of all marine fishes of shallow waters known from southern Africa occur in northern KwaZulu-Natal seas. Consequently it is not surprising that KwaZulu-Natal estuaries have the highest species diversity in South Africa. The cool upwelled waters of the west coast are the obvious reason for the scarcity of tropical and subtropical fishes in this region. Even in summer, water temperatures along the Atlantic coast seldom rise above $15^{\circ} \mathrm{C}$ (Christensen 1980). These low marine water temperatures probably act as a barrier preventing estuary-associated tropical West African fish species from reaching the Northern and Western Cape. Between 80 and 120 fish taxa were associated with each of five West African systems quoted by Albaret \& Diouf (1994) but few of these species enter temperate Namibian or South African waters. A further barrier to the southward movement of some of these fishes, particularly those that spawn in estuaries, is the absence of estuarine systems along the Namibian coast.

Seasonal temperature changes influence the fish community structure of estuaries on the subcontinent, but are not nearly as marked as in boreal systems. In the Mngazana Estuary there was an increase in temperate fish species during winter whereas many species of tropical origin appeared only in the summer (Branch \& Grindley 1979). In cold temperate northern hemisphere estuaries, marine fishes (largely juveniles) migrate into estuaries when the surface ice sheets melt and the water becomes warmer. Biological activity in these highly seasonal environments peaks in the summer but it declines by late fall as many populations emigrate to the ocean as temperatures fall (Kennish 1990). In contrast to the harsh thermal climate described above, water temperatures in southern African estuaries seldom decline below $12^{\circ} \mathrm{C}$ in winter and are generally warmer than the adjacent ocean during summer (Day 1981b). Indeed, during upwelling events on the Eastern and Western Cape coasts (Schumann et al. 1982), offshore marine fishes have been known to take temporary refuge in adjacent estuarine systems where warmer conditions prevail (Hanekom et al. 1989).

\section{Catchment and estuary size}

These two factors are difficult to examine in isolation since both have an influence on other processes and parameters such as hydrodynamics and mouth condition. How does estuary size and catchment characterisitics influence ichthyofaunal abundance?
Clearly large estuaries will invariably have greater fish populations than small estuaries, due primarily to increased food and habitat availability. As far as catchment characterisitics are concerned, Marais (1988) determined that in the Eastern Cape Province there was a highly significant positive correlation $(r=0.46, P<0.001)$ between estuarine fish abundance and catchment size, as well as between fish biomass and catchment area $(r=0.59, P<0.001)$. He suggested that it was not the actual catchment size that influenced fish stocks, but rather the hydrological consequences of increased river inflow with increasing catchment area. The higher run-off from larger catchments almost invariably leads to positive estuarine salinity gradients and increased water turbidity, both of which have been shown to result in increased fish abundance (Whitfield et al. 1994).

A factor not included in the Marais (1988) analysis is the tendency towards higher nutrient and organic matter loading of estuaries with larger catchments, and hence the potential for elevated primary and secondary productivity within these systems. Another potential factor accounting for the positive correlation between fish abundance and catchment size in Eastern Cape estuaries is the magnitude of olfactory cues entering the marine environment. Large perennial rivers are going to transmit greater volumes of land based cues to potential marine fish recruits, when compared to small intermittent river systems. Clearly, further research in this field is required before the exact cause(s) of the positive correlations between fish abundance/biomass and catchment size in Eastern Cape estuaries can be clearly identified.

The number of species found in an estuary appears to be related to estuary size, with larger systems generally having a higher ichthyofaunal diversity (Whitfield 1980d, Blaber 1985). This is probably related to two major factors; marine interaction and habitat diversity. Firstly, small estuaries are often closed to the sea for prolonged periods, with a concomitant reduction in the number of marine species that can recruit into these systems (Begg 1984a). Secondly, the range of habitats is generally lower in smaller systems which tend to have a greater degree of uniformity in both physical and biotic characteristics. For example, the longitudinal salinity gradient between the upper and lower reaches of small temporarily closed estuaries is usually minimal when compared to larger permanently open systems. Fringing Phragmites beds usually extend into the lower reaches of temporarily closed estuaries, whereas the lower reaches of permanently open estuaries are usually occupied by salt marsh plants or mangroves, with reed beds often dominating the upper reaches. Submerged aquatic macrophytes are also more diverse in large permanently open estuaries when compared to small temporarily closed systems (Day 1981d). 
Maximum water depths are also related to estuary size, with large estuaries usually having a wider range in water depths than small estuaries. Juvenile fish in estuaries tend to prefer littoral areas, especially where nursery habitats such as aquatic macrophytes, emergent reed beds or mangroves are present (Wallace \& van der Elst 1975). Shallow waters provide these small fishes with a refuge from larger piscivorous teleosts, which are usually restricted to deeper areas (Whitfield and Blaber 1978a). Harrison \& Whitfield (1995) have shown that in temporarily closed estuaries piscivorous species such as Argyrosomus japonicus, Caranx sexfasciatus, Lichia amia, Lutjanus argentimaculatus and Platycephalus indicus were present in the deeper Mhlanga and Zotsha systems (channels 1.5-3 m depth), while in the relatively shallow Damba Estuary (channel $<1.5 \mathrm{~m}$ depth) these predators were usually absent. A similar trend pertains to other types of estuaries, where large piscivorous species are abundant only in those systems which have channel depths greater than $1.5 \mathrm{~m}$ (Coetzee 1982a, Marais 1984).

\section{Productivity}

Estuaries are highly productive ecosystems ranking with coral reefs and mangrove swamps. According to Correll (1978) the elevated primary productivity of estuaries is maintained because of high nutrient levels in the bottom sediments and water column. Some systems in the Eastern Cape Province have large inputs of nutrient rich river water (Emmerson 1989), often leading to elevated phytoplankton levels (Hilmer \& Bate 1991). The abundant fish stocks associated with estuaries such as the Great Fish are probably linked to the exceptional primary productivity of these systems (Whitfield et al. 1994, Allanson \& Read 1995).

Although the high productivity of estuaries is widely accepted, the considerable autochthonous production would be have little effect on the biota if exported to the sea. The key to the attractiveness of estuarine systems to fishes therefore lies in the fact that they act as detritus traps for both authochthonous and allochthonous production, thus providing abundant food resources for filter and deposit-feeding invertebrate prey, as well as detritivorous fish species. Visual evidence of this process can be seen in estuaries where marine macroalgal debris accumulates in the lower reaches, and littoral plants such as mangroves, salt marsh grasses and reeds accumulate mats of decomposing riverine and estuarine plant material around their stems and roots.

How do the different types of estuaries act as detritus traps? Temporarily closed systems automatically accumulate all detritus that enters them during the closed phase. Estuarine coastal lakes usually have only narrow channels linking them to the sea, which effectively reduces the loss of organic products from these systems. Indeed, it could be argued that because of the narrow exit channels and the limited scouring action within the lakes, only a relatively small proportion of the accumulated detrital material within these systems is exported to the sea. In permanently open estuaries, however, river floods cause large-scale exports of both macrodetritus and finer particulate organic matter into the sea. Nevertheless, during the non-flood phase, which is the dominant condition in permanently open estuaries, seawater wedges and tidal action aid in the retention and accumulation of detrital material (Whitfield 1988b).

\section{Resource utilization}

Does the efficient utilization of estuarine food resources depend on the species diversity of the fish community? There were fewer than 10 fish taxa found to be abundant in the Mhlanga Estuary, yet a study by Whitfield (1980e) indicated that all potential food categories, with the possible exception of phytoplankton (which was not consumed by any of the fish species), were utilized. Furthermore, the composition of the ichthyofaunal community was related to the proportions, based on standing stock energy values, of the different food types. In the Swartvlei Estuary, there were also fewer than 10 abundant fish species captured, with the available food resources being exploited but not always in proportion to their availability (Whitfield 1988a). Using Ivlev's electivity index, which compares the availability of a particular food resource to its utilization by the fish community, it was shown that there was a strong positive selection for epifaunal invertebrates but poor utilization of infauna and aquatic plants.

Plant consumption by herbivorous fishes in the Swartvlei Estuary indicated poor utilization of the available resources, and mainly centred around filamentous algae and diatoms growing on Zostera capensis, rather than eelgrass leaf material (Whitfield 1988a). Both Rhabdosargus holubi and Sarpa salpa digest algae but appear unable to assimilate aquatic macrophyte material (Blaber 1974b, Gerking 1984). The low abundance of predominantly herbivorous fish species in estuaries is not simply a reflection of the absence of a cellulase in the digestive tract of teleosts (Kapoor et al. 1975) but is more likely due to the fluctuating nature (or absence) of submerged plant communities within these systems.

Detritus in estuaries consists of a mixture of plant debris and amorphous organic matter, together with associated heterotrophic and autotrophic microorganisms (Bowen 1976). Detritus is an important food source for many estuarine invertebrates (Whitfield 1989d) which are in turn consumed by carnivorous 
fishes (Bennett \& Branch 1990). Detritivorous fish taxa are well represented in southern African estuaries (Blaber 1977) and, despite the often higher species diversity of carnivorous fishes, the former group are often dominant in terms of biomass (Branch \& Grindley 1979, Harrison \& Whitfield 1995).

In northern hemisphere estuaries the supply of energy to fishes depends primarily on the detrital food web (Odum 1971, Yanez-Aráñcibia 1985) and studies in southern African systems reinforce this concept (Blaber 1985, Whitfield 1988a). Indeed, food webs in estuaries on the subcontinent seem to show a surprisingly small number of energy pathways and therefore a high energy flow per pathway (Whitfield 1980 e, Heymans \& Baird 1995). This is reflected in Swartvlei (Figure 22) where only five trophic compartments could be recognised and no compartment was less than $11 \%$ of the total fish biomass.
DOMINANT FOOD

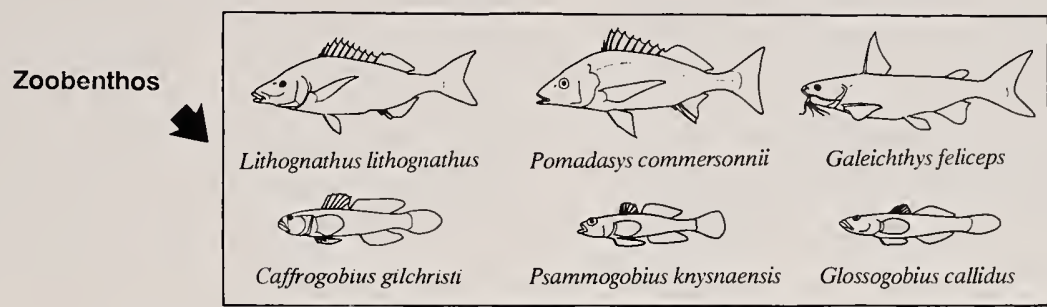

Zooplankton

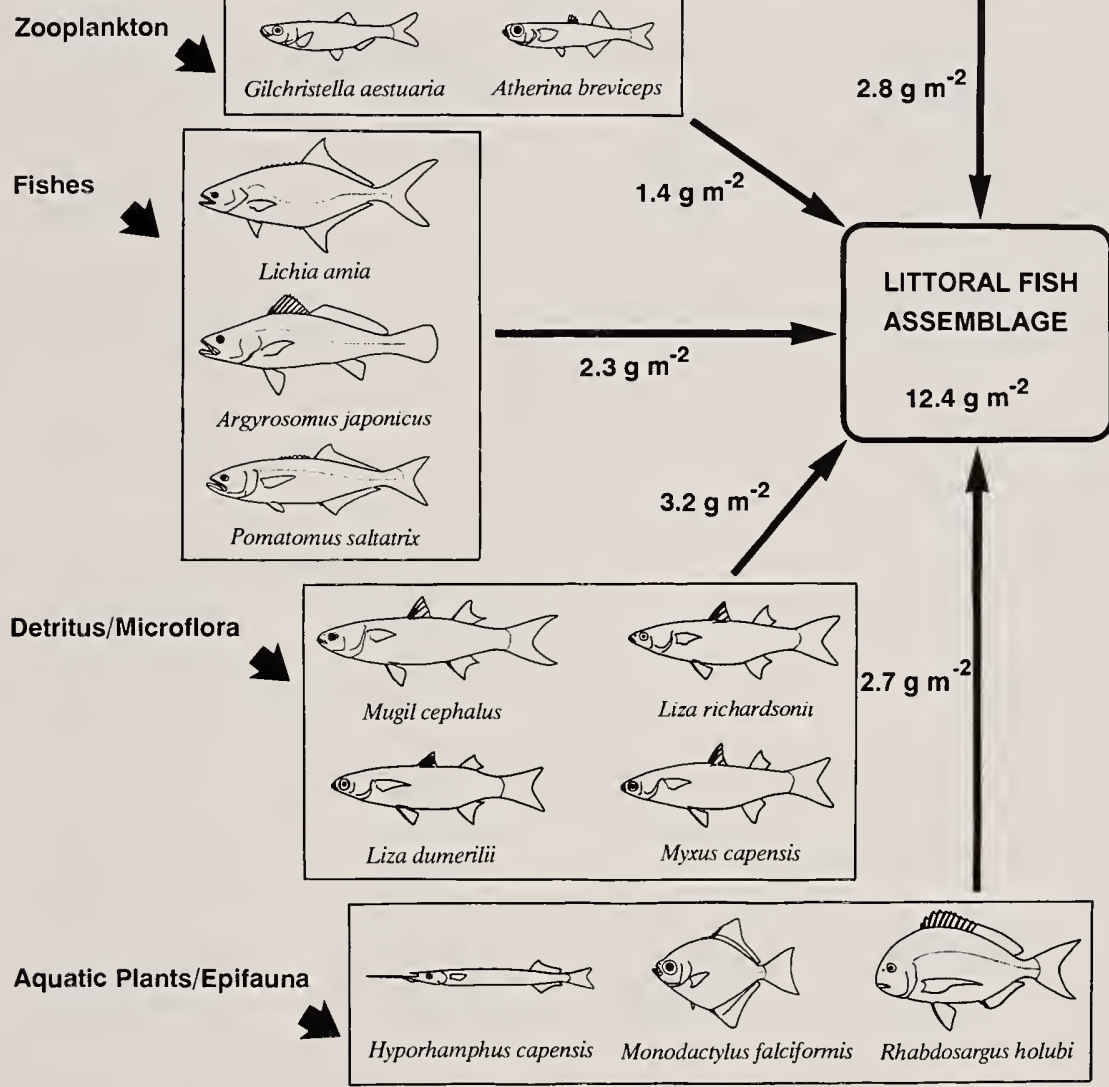

Figure 22. Diagrammatic representation of the 1980 biomass (wet) contributions by various trophic groupings to the Swartvlei littoral fish assemblage (after Whitfield 1993). 
Zooplanktonic invertebrates, which feed extensively on phytoplankton and particulate organic material, are sometimes present in large numbers in estuaries and are an important food source for planktivorous fishes (Blaber 1979). However, phytoplankton biomass varies both spatially and seasonally (Campbell et al. 1991), whereas an abundance of detritus is available to estuarine consumers, including planktivorous and detritivorous fish species, throughout the year (Whitfield 1980a). It would appear, therefore, that detritus confers stability to estuarine ecosystems by extending the availability of seasonally fixed energy.

Microphytobenthos is an important component in the detrital food web. Most invertebrate and fish detritivores ingest diatoms and other benthic algae along with particulate organic material. The high incidence of unicellular algae in the diet of mugilids from the Eastern Cape (Masson \& Marais 1975) and KwaZulu-Natal (Blaber 1976) suggests that benthic microalgae (especially diatoms) are a favoured food item. The senescence of Swartvlei Potamogeton pectinatus beds, and their replacement by benthic microalgae and filamentous algal mats, resulted in an increase in the abundance of mugilids in the littoral zone of this lake (Whitfield 1986a).

Clearly the balance between energy supply sources in an estuarine ecosystem varies on a temporal basis, as well as from one estuary to another. An illustration of the major carbon (detrital) pathways within the Kariega Estuary is shown in Figure 23, with the macrophytes Spartina maritima and Zostera capensis being of prime importance in supplying energy to the ichthyofauna.

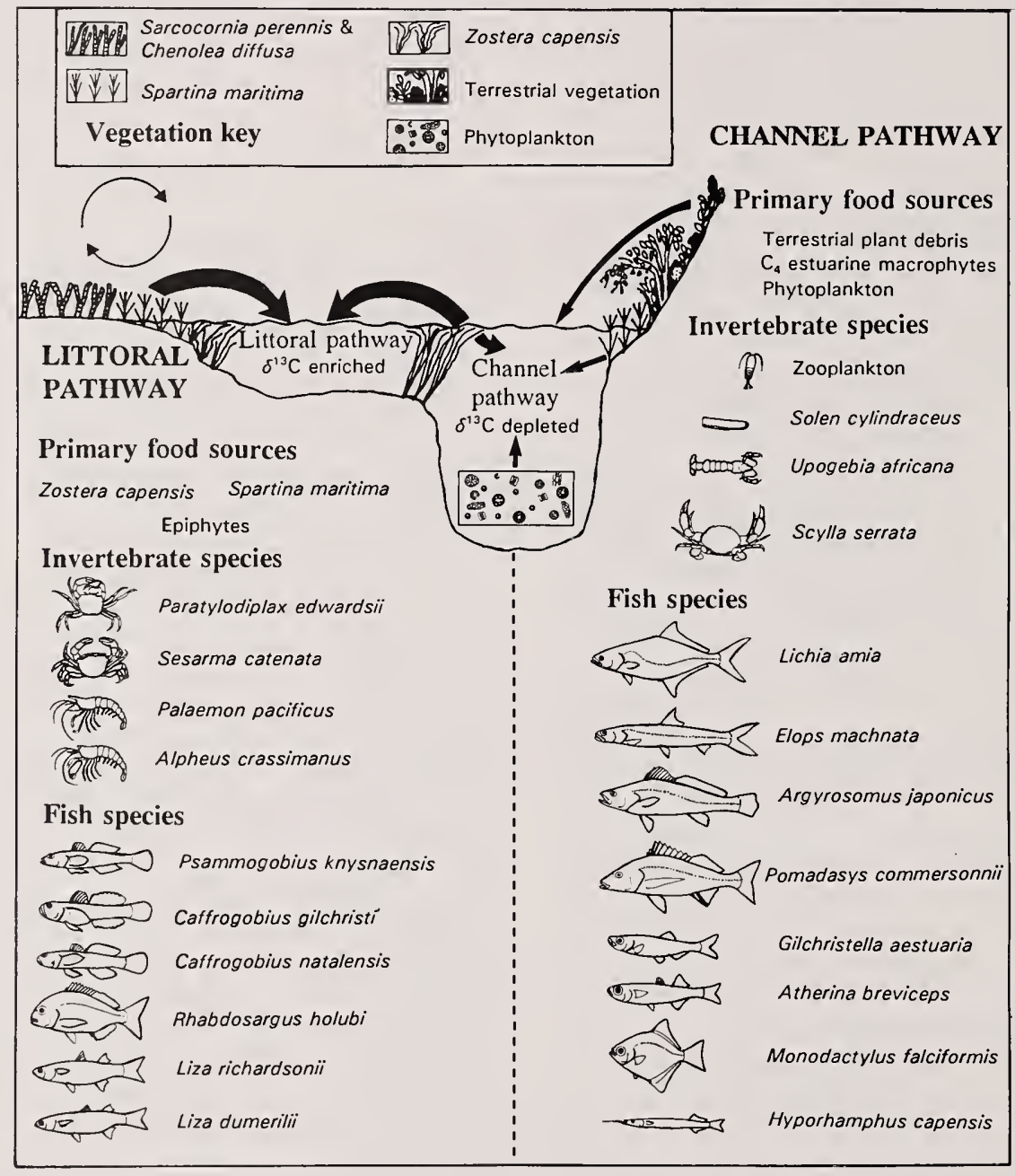

Figure 23. Diagrammatic representation, based upon stable carbon isotope analyses, of major energy pathways within the Kariega Estuary food web (after Paterson \& Whitfield 1997). 
Very little quantitative information is available on competition for food resources by fishes within southern African estuaries. Most carnivorous species feed on a wide range of prey and can adjust their diet according to environmental conditions and food availability (Marais 1984). In the Bot Estuary, resident fish consumed only $30 \%$ of the secondary production by prey species (Bennett \& Branch 1990), suggesting that food was not in short supply. Dietary overlap was common, with the most successful fish species in this estuary being those with the broadest niche.

There appears to be an even greater overlap in the diets of detritivorous fish species in estuaries, with competition being reduced by different feeding mechanisms which result in the available food items being consumed in differing quantities (Whitfield \& Blaber 1978b). However, among mugilids there appears to be little feeding segregation between species (Blaber 1976, 1977), with the large biomass, abundance and diversity of this family indicating a possible superabundance of detritus within estuaries.

\section{Conclusion}

The biotic and abiotic factors which determine the distribution and abundance of fishes in southern African estuaries are shown in Figure 24. These factors are are not independent but interact directly and indirectly with the fishes that inhabit estuaries. For example, river floods directly influence estuarine water temperature, salinity, turbidity, dissolved oxygen concentrations and olfactory cues, and indirectly affect mouth condition, habitat diversity, productivity, fish recruitment, food availability and competition. Previous estuary-associated fish studies, particularly those which have been laboratory based, have tended to examine the effects of one or two factors in isolation, e.g. salinity and temperature. However, with the realisation that multiple factors impinge on the lives of fishes in estuaries, research emphasis is now moving away from attempting to determine the influence of isolated environmental variables and adopting a more holistic approach

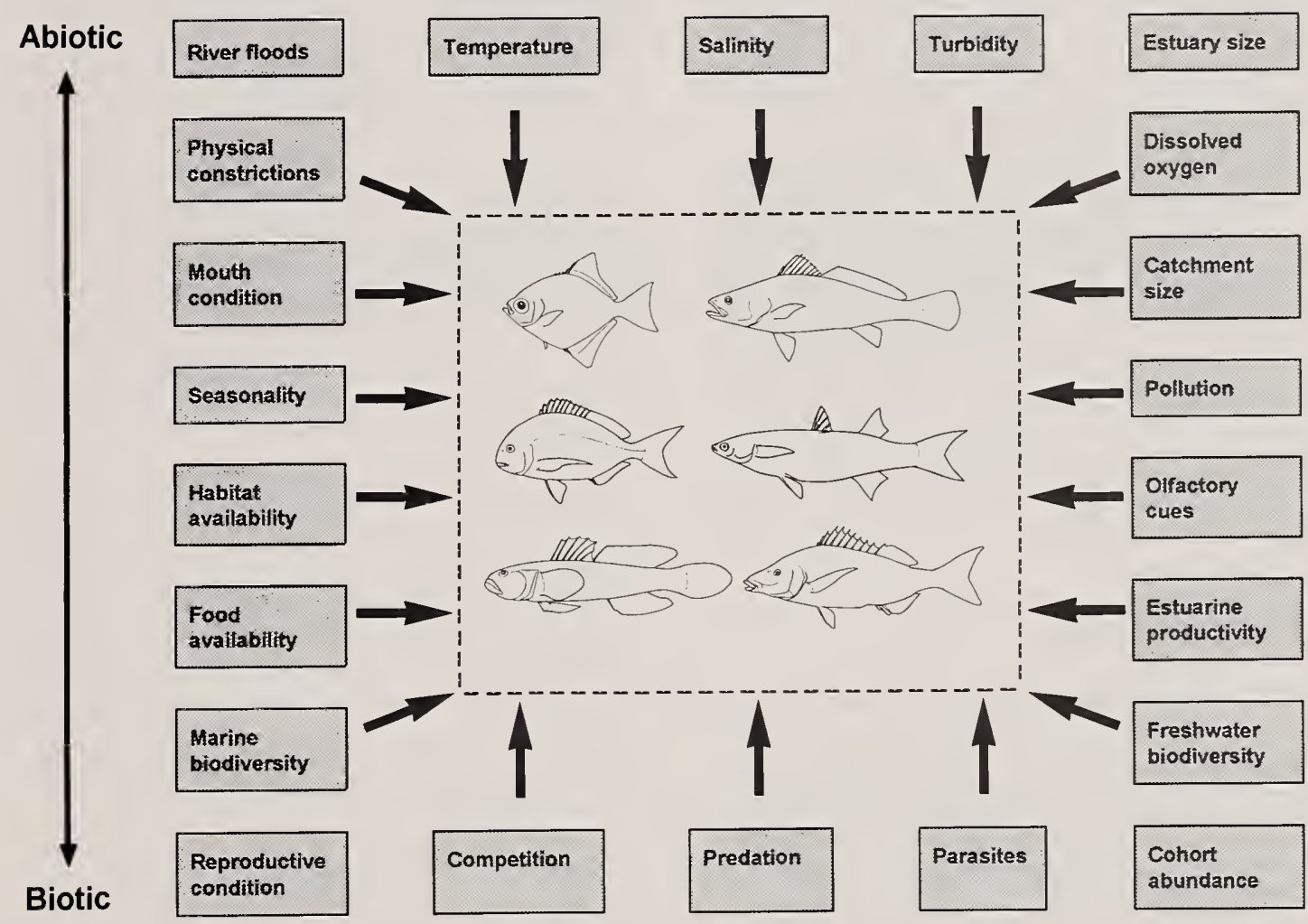

Figure 24. Biotic and abiotic factors influencing fish species in southern African estuaries. The scale on the left-hand side illustrates the trend from predominantly abiotic variables in the top of the diagram to biotic variables at the bottom. 


\subsection{SPECIES DIVERSITY: AN EVOLUTIONARY PERSPECTIVE}

Fish are a major component of the nektonic community in estuaries and represent the most motile element of these systems (Kennish 1990). Their mobility confers them with considerable advantages over sessile organisms, enabling them to avoid unfavourable conditions, exploit a wide variety of habitats and food sources, evade predatory attacks, and move from one estuarine system to another via the marine environment. This latter characteristic allows extensive genetic mixing and, together with factors outlined below, may provide the key to an understanding of fish speciation (or lack of it) in southern African estuaries.

According to Levinton (1980), studies of several invertebrate and vertebrate taxa in estuaries indicate genetic divergence of estuarine populations from conspecific populations in coastal marine waters. In a southern African context, Ratte (1989) found significant positive genetic autocorrelation over distance among populations of Atherina breviceps separated by less than $200 \mathrm{~km}$, and strong negative correlation between populations separated by $300 \mathrm{~km}$ or more. This tendency does not appear to have been translated into widespread estuarine speciation, despite the variety of barriers (e.g. closure of estuary mouths for extended periods) to gene flow between the different ecosystems.

The ichthyofauna of estuaries throughout the world may be characterized by the numerical dominance of only a few species (Kennish 1990). This observation gives rise to questions; (a) why do so few species utilize estuaries compared to adjacent nearshore marine environments and (b) why has fish speciation in estuaries been less extensive when compared to other aquatic habitats? In attempting to answer these questions we need to examine both the organism and its environment in more detail.

\section{The estuarine environment}

As has already been discussed (see Chapter 1 for details), southern African estuaries are highly variable habitats in which conditions such as salinity, temperature, turbidity, water currents and dissolved oxygen concentrations can fluctuate rapidly, both temporally and spatially. In addition, they are variable in terms of size, shape, degree of marine/ riverine influence and catchment characteristics. Based on that information, one could characterize estuaries as regions where environmental stress is pronounced and periods of stability are short-lived.
Climatic variations and sea-level fluctuations control the development and distribution of estuaries around the world. During high stands of sea level, estuaries tend to be abundant and relatively large; during low stands they are likely to be less abundant and small (Schubel \& Hirschberg 1978). During full glacial periods, declines in the productivity of estuaries has occurred due to their decreased area, reduced capacity for nutrient entrapment and decreased ability to dampen environmental perturbations (Stone et al. 1978). In addition, the lifetimes of estuaries are usually limited to a few thousand years and, according to Schubel \& Hirschberg (1978), these systems have been abundant during only $10-20 \%$ of the last million years.

Sea level in southern Africa was approximately $130 \mathrm{~m}$ below existing levels at the end of the last glacial period 17000 years B.P. (Miller 1990) and as recently as 6000 years ago it was about 2-3 m above mean sea level (Marker \& Miller 1993). Consequently present day estuarine systems probably differ considerably from those in the past, although estuaries in one form or another have existed on the sub-continent ever since rivers started flowing into the sea. An example of such a change can be seen in the evolution of Lake St Lucia, the largest estuarine system in southern Africa. This coastal lake did not exist during the interglacial \pm 125000 years B.P. and the western arm of the lake was a marine embayment opening directly to the sea (Orme 1973). The nearby Lake Sibaya has undergone a similar transformation during the last 10000 years, and has altered from an estuarine system into a freshwater coastal lake (Allanson 1981).

Blaber (1991) argued that the boundaries between habitats need to be defined according to whether such divisions are important to the species living in these environments. He asks whether the movements of fishes from a rocky reef habitat in the sea to an adjacent soft bottom sponge/gorgonian habitat, also in the sea, are not as great a change as the movement of fishes from the sea into an estuary? Horizontal linkages between the sea and rivers through estuaries are common, but for some fish species the physiological barriers between fresh and salt water are almost as great as between water and land (Blaber 1991). In addition, the boundaries and behaviour of individual estuaries fluctuate on both a spatial and temporal scale, and we need to recognize that the freshwater/estuarine interface represents a completely different barrier to fishes than the estuarine/marine interface. 


\section{Estuarine fish communities}

If, on a geological time-scale, individual estuaries are ephemeral features of the coast, perhaps individual estuary-associated fish species should be placed in the same category. How many taxa have become extinct and how have southern African estuarine fish communities changed within the last 500 million years?

Fossil fish research in Witpoort Formation black shale deposits in the Grahamstown area has revealed evidence of a fish assemblage that occupied an estuarine lagoon or lake approximately 360 million years ago. Four major groups of Palaeozoic fishes (acanthodians, placoderms, chondrichthyans and osteichthyans) are represented in the Witpoort ichthyofauna, with the former two extinct and the latter two extant (Anderson et al. 1994). Most of the species found so far are represented by both adults and juveniles, with the variety of groups present in the deposits suggesting that a range of salinities occurred within the estuary (Gess 1995). The abundance of juveniles indicates that estuaries in the Devonian Period also acted as important nursery areas for small fish (Gess \& Hiller 1995). As is the case today, large predatory fish were present, but spiny sharks (Acanthodii) and armoured fishes (Placodermi) dominated the ichthyofauna (Anderson 1995, Long et al. 1997). An acanthodian and a crossopterygian, both approximately $1.5 \mathrm{~m}$ in length have been found at the Grahamstown site and both were probably piscivorous. The placoderms are represented by at least three species (e.g. Groenlandaspis riniensis, Africanaspis doryssa and Bothriolepis africana), all of which were probably benthic invertebrate feeders (Gess 1995). Smaller predatory fishes such as coelacanths have also been recorded at the site (Figure 25).

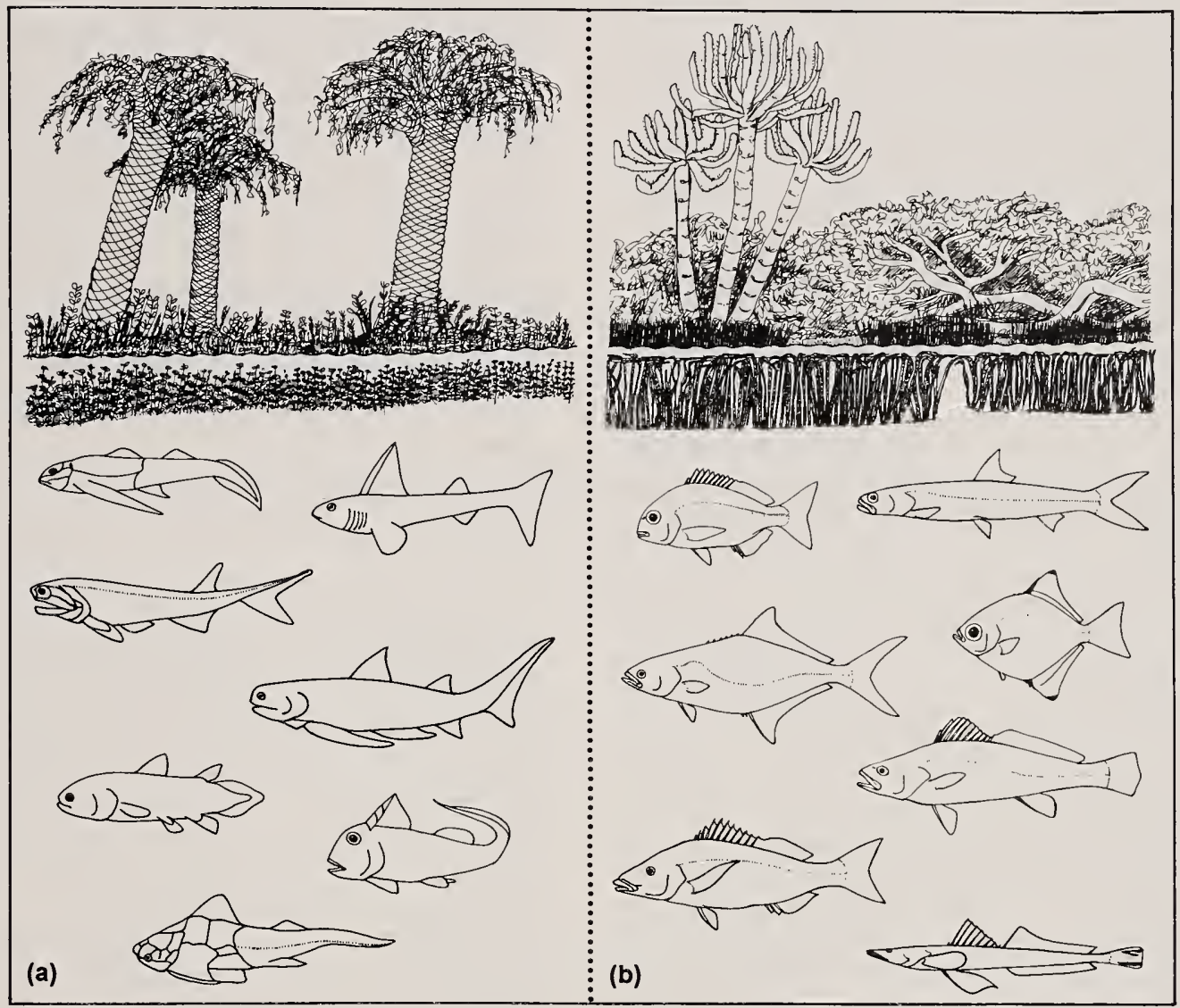

Figure 25. A diagrammatic representation of a section of the Grahamstown Devonian estuarine ichthyofauna (a) and a selection of species from the current Eastern Cape estuarine fish assemblage (b). 
Despite the physical instability of estuaries, the species composition of fish communities within the various biogeographic regions is relatively stable and the fishes have more or less predictable patterns of abundance and distribution. Moyle \& Cech (1982) attribute such stability to four principal conditions, all of which apply to southern African estuaries. These are: (1) the regular distribution of fish populations along environmental gradients of salinity, temperature etc.; (2) seasonal movements of fishes into and out of estuaries; (3) the dominance of estuaries by relatively few species; and (4) the robust nature of food webs within estuaries. A fifth condition can be added to those above, viz. the wide physiological and ecological tolerances of fish species utilizing estuaries.

Although the ichthyofaunal communities in southern African estuaries may be relatively stable, they are characterized by a low species diversity. Wallace et al. (1984a) have shown that, of the approximately 1500 species of fishes found on the continental shelf of the subcontinent, fewer than 150 species make regular use of estuaries in the region. According to Whitfield (1994d) approximately 100 southern African fish species are wholly or partially dependent on the estuarine environment. However, on an individual estuary basis the number of species associated with these systems is much lower. Of the four South African and four Western Australian estuaries reviewed by Potter et al. (1990), all had less than 60 fish species. A similar conclusion was reached by Kennish (1990) who reviewed a large number of northern hemisphere studies and found that less than 100 species are usually recorded in these estuaries. In addition, less than half of the taxa recorded in both northern and southern hemisphere estuaries are usually abundant in these systems (e.g. Potter et al. 1990, Yoklavich et al. 1991).

The pattern of declining estuarine species diversity with increase in latitude along the western Atlantic and south-eastern Indian Ocean coasts has already been mentioned. In the western Atlantic this decline was attributed to the increasing disturbance frequency or magnitude (e.g. temperature variations) with increasing latitude (Vieira \& Musick 1993). These authors also suggested that the greater fish diversity of tropical estuaries arose from the prolonged coexistence of species whose traits would otherwise lead to competitive exclusion. In a southern African context, temperate estuaries are dominated by relatively few species when compared to more tropical systems, but the extent to which competitive interactions or food resource limitations affect species diversity is not yet known.

According to Kennish (1990), the higher species diversity in the mouth region of estuaries is indicative of the osmotic problems many species experience as they progress up an estuary. Osmoregulatory stress may be part of the reason why less than $5 \%$ of marine and freshwater fish species from southern Africa utilize estuaries to any significant extent, but the variable nature of these systems probably plays a greater role (Table 7). In an unpredictable environment (e.g. an estuary) only organisms that can tolerate wide perturbations are present, and the ecosystem tends to be simple but also more robust (Bruton 1989). In contrast, a more predictable environment (e.g. a coral reef) may permit a relatively complex ecosystem, with increased species diversity, to evolve (Margalef 1968).

Table 7. Community traits associated with predictable/unpredictable environments as presented by Bruton (1989), compared to the southern African estuarine fish fauna (after Whitfield 1990).

$\begin{array}{llll}\begin{array}{l}\text { Traits of the } \\ \text { organisms }\end{array} & \begin{array}{l}\text { Predictable } \\ \text { environment }\end{array} & \begin{array}{l}\text { Unpredictable } \\ \text { environment }\end{array} & \begin{array}{l}\text { Southern African } \\ \text { estuaries }\end{array}\end{array}$

$\begin{array}{llll}\text { Species diversity } & \text { high } & \text { low } & \text { low } \\ \text { Breeding guilds } & \text { few } & \text { many } & \text { many } \\ \text { Species interdependence } & \text { high } & \text { low } & \text { low } \\ \text { Mutualisms } & \text { high } & \text { low } & \text { low } \\ \text { Rare species } & \text { common } & \text { uncommon } & \text { uncommon } \\ \text { Migratory species } & \text { uncommon } & \text { common } & \text { common } \\ \text { Sedentary species } & \text { common } & \text { uncommon } & \text { uncommon } \\ \text { Speciation rates } & \text { high } & \text { low } & \text { ?low } \\ \text { Extinction rates } & \text { high } & \text { low } & \text { ?low } \\ \text { Species saturation } & \text { high } & \text { low } & \text { low }\end{array}$




\section{Reproductive modes of estuary-associated fishes}

Early developmental modes of southern African estuarine fishes fall into three main categories, namely viviparity, ovoviparity and oviparity. The viviparous (e.g. Clinus spatulatus) and ovoviparous (e.g. Hippocampus capensis) forms breed within the estuarine environment and have a relatively low fecundity (Whitfield 1990). However, the embryos generally develop to a larger size prior to parturition or hatching and, on average, a high percentage of them survive. Because of their large size, the young of these fishes are less susceptible to predation and typically exert greater control in their movements and ability to capture prey organisms (Kennish 1990).

In contrast, oviparous fishes (e.g. Mugil cephalus) produce many more eggs, which are unprotected and have limited yolk reserves. Survival is closely linked to the duration of the planktonic egg and/or larval interval (May 1974). The dispersal ranges of these species greatly surpass those of the viviparous or ovoviparous forms (Norcross \& Shaw 1984) as do their rates of mortality, especially during the embryo and larval stages (Houde 1987). The number of planktonic eggs, embryos and larvae that perish as a result of currents transporting them to unfavourable environments is high (Kennish 1990). However, the dispersal by ocean currents also decreases the probability that a localized biological perturbation will devastate an entire year class through direct effects on the species or its food (Shaw et al. 1988). In addition, ichthyoplankton may be removed from areas of intense predation and spread over wide areas, thus increasing survival of larvae (Miller et al. 1984). Overall larval survival is also enhanced by the protracted spawning period of most fish species, which ensures that only a proportion of the offspring are exposed to unfavourable marine or estuarine conditions at any one time.

Miller et al. (1985) have suggested that the movement of fish larvae and juveniles from spawning areas to estuarine nursery areas can be considered from the perspective of costs and benefits. Benefits of estuaries include the abundance of food, shelter from large marine piscivores and favourable temperature regimes. Miller et al. (1985) emphasized that the costs of migration are difficult to assess and will have to be determined for each type of migratory behaviour. Despite the difficulty in assigning a value relating to predator avoidance in estuarine systems, the above authors concluded that juvenile fish which tolerate variable estuarine abiotic conditions benefit from this association. Benefits would presumably be greatest in those species that breed in estuaries and have eliminated the marine migratory phase from their life cycle. If an exclusively estuarine life cycle is advantageous from a bio-energetic viewpoint, why have so few southern African fish species followed this evolutionary route? Since fish speciation is favoured by a high degree of environmental stability (Margalef 1969), the answer may be found in the extreme variability of estuarine systems on both a spatial and temporal scale, i.e. the unpredictability of southern African estuaries does not encourage speciation (Whitfield 1994b).

\section{Eurytopes and stenotopes}

Most southern African fish species in estuaries may be described as eurytopes, as first defined by Eldredge (1979). The words eurytope and stenotope, although they can represent ends of a continuum, are also used in this book as adjectives, indicating which half of the continuum the organism occupies. A eurytopic species has a broader habitat tolerance range relative to a stenotopic species (Vrba 1980) and during its life-history a eurytope may live in a wide range of conditions, often moving readily from one habitat to another. Characteristically, eurytopes are mobile and frequently have a wide geographical distribution. In contrast, a stenotope is usually confined to a single habitat during its life-history and often has a restricted geographical distribution (Ribbink 1994).

Some of the features of eurytopes and stenotopes are compared to the characteristics of estuarine residents and marine estuarine-opportunist groups of fishes in southern African estuaries (Table 8). Based on this comparison it is apparent that the estuarine spawners, with the possible exceptions of Atherina breviceps and Gilchristella aestuaria (which exhibit mainly eurytopic features), are primarily stenotopic and the marine spawners are generally eurytopic. Since marine migrants dominate the above estuarine systems, it can be concluded that eurytopy is the predominant life form in these systems, and that estuarine fish communities are both resilient and flexible. If one includes the two estuarine spawners (viz. A. breviceps and G. aestuaria) which are mainly eurytopic, then the overwhelming number and biomass of fishes in estuaries on the subcontinent are eurytopic. It is also tempting to suggest that the loss of the stenotopic Syngnathus watermeyeri from the Kariega Estuary may be directly or indirectly a result of prolonged hypersaline conditions arising from droughts and the artificial impoundment of the Kariega catchment rivers (Whitfield 1995b). In contrast eurytopic fish species in the Kariega Estuary were found to be abundant, which reflects their tolerance of hypersaline conditions prevailing in the system (Ter Morshuizen \& Whitfield 1994). 
Attention has already been drawn to the paucity of freshwater fish species in estuaries. Perhaps it is noteworthy that the only freshwater fish taxon which utilizes these estuarine systems to any major extent is the predominantly eurytopic cichlid Oreochromis mossambicus. The absence of many freshwater fish species from the upper reaches of estuarine systems where salinities are usually less than $15 \%$ is difficult to explain, since these species are hyperosmotic within this salinity range (Whitfield \& Blaber 1976). Perhaps the erratic nature of river inflow into southern African estuaries, which can result in hypersaline conditions developing in the upper reaches of certain systems (Whitfield \& Bruton 1989), effectively prevents freshwater species from establishing themselves in these areas. Also, increased predation within estuaries when compared to the riverine environment may play a role in preventing colonization of these systems by freshwater species. Apart from the anguillid eels, there are no large piscivorous fish predators in Eastern or Western Cape rivers, whereas both small and large piscivorous fish species are present in the estuaries of these regions (Coetzee 1982a, Smale \& Kok 1983).

According to Macfarlane (1923) teleosts originated in freshwater areas, from which colonization of the marine environment occurred. Presumably these fishes would have passed through estuaries on route to the sea and some may have remained in this transitional zone to become the first estuarine residents. An alternative explanation is that estuaryassociated fishes are examples of recent recolonization of estuaries by marine species (Panikkar 1960), with few species having adapted their entire life cycle to the fluctuating conditions of the estuarine environment. This view is supported by the fact that even the most estuarine dependent of the marine species (e.g. Rhabdosargus holubi, Monodactylus falciformis and Lithognathus lithognathus) all spawn at sea, where abiotic conditions are more stable and predictable.

The importance of salinity and temperature stability on embryo development of estuary-associated Mugil cephalus is indicated by the work of Walsh et al. (1991) which showed that the optimum survival of normal larvae was at $36 \%$ and $25^{\circ} \mathrm{C}$. The lower salinity tolerance limit of $M$. cephalus eggs was approximately $15 \%$, a value that is frequently attained during moderate river flow conditions in estuaries on the subcontinent. In addition, Sylvester et al. (1975) found that $M$. cephalus eggs were negatively buoyant in salinities below $30 \%$, accumulating on the bottom and dying if aeration was inadequate. This probably explains why southern African estuaries are unsuitable for egg survival of this and other marine fishes.

In contrast to the physiological sensitivity of $M$. cephalus egg and larval stages, early juveniles of this species in the Eastern Cape are attracted to riverine environments (Bok 1979) where salinities are usually less than $0.5 \%$ and temperatures show wide fluctuations. The catadromous freshwater mullet Myxus capensis is also an obligate marine spawner, with the $0+$ juveniles attracted to riverine areas and the upper reaches of estuaries (Bok 1979). Adults that become trapped in riverine pools or estuaries are unable to spawn within these environments.

Table 8. Some of the principal characteristics of eurytopes and stenotopes (after Ribbink 1994) compared to those predominating in the estuarine and marine groups of fishes (after Whitfield 1990) from southern African estuaries.

$\begin{array}{llll}\text { Stenotopy } & \text { Estuarine spawners } & \text { Eurytopy } & \text { Marine spawners }\end{array}$

$\begin{array}{ll}\begin{array}{l}\text { Narrow habitat } \\ \text { tolerance range }\end{array} & \begin{array}{l}\text { Narrow habitat } \\ \text { tolerance range }\end{array} \\ \text { Narrow distribution } & \text { Narrow distribution } \\ \text { Sedentary } & \text { Sedentary } \\ \text { Small body size } & \text { Small body size } \\ \text { Small populations }^{\text {Precocial }}{ }^{1} & \text { Small populations } \\ & \text { Precocial }^{1}\end{array}$

Broad habitat
tolerance range
Wide distribution
Mobile
Large body size
Large populations
Altricial $^{2}$

Broad habitat tolerance range

Wide distribution

Mobile

Large body size

Large populations

Altricial $^{2}$

\footnotetext{
'A specialist sensu lato; usually common in a predictable and competitive environment (Balon 1981).
}

${ }^{2} \mathrm{~A}$ generalist sensu lato; usually common in an unpredictable and harsh environment (Balon 1981). 


\section{Successionary trends and fish speciation}

Estuaries differ from certain other inland aquatic ecosystems in that they show a weak successionary trend towards a more mature plant and animal community. In Lake Malawi, for example, the fish community is characterised by an increasing proportion of specialised forms with progressively stronger species interdependence. In contrast, the estuarine systems of southern Africa are characterized by wide fluctuations in abiotic conditions, the constant re-organization of biological communities and homeostatic mechanisms, and the frequent resetting of the ecological succession to an earlier state (Whitfield \& Bruton 1989). Thus, the fish fauna of these estuaries is characterized by a relatively low species diversity, consisting mainly of migratory forms with weak interspecific connections (e.g. a lack of mutualistic relationships). Although there are a relatively large number of breeding styles employed by the different groups of fishes in southern African estuaries, species saturation may be considered low when compared to the communities present in certain central African freshwater lakes, or the assemblages associated with coral reefs on the subcontinent.

Vrba (1980) has suggested that the environment is the 'motor' of evolutionary change. Similarly, Ribbink (1994) has proposed that the environment plays a major role in the speciation process of African cichlids and it is possible that it performs a similar function in the fish communities of southern African estuarine systems. Speciation in seasonally stable, uniform environments (e.g. large lakes) was shown by Bruton \& Merron (1990) and Ribbink (1994) to be greater than that of seasonally unstable, heterogeneous environments (e.g. rivers). A number of authors (e.g. Rensch 1959, Eldredge 1979) have suggested that diversification of stenotopes (specialists) is more rapid than that of eurytopes (generalists). Since southern African estuaries are dominated by eurytopes, and these systems are one of the most unstable aquatic environments in the region, it is perhaps not surprising that they exhibit a very low species diversity. In addition, the few stenotopes occurring in estuaries are faced with major short and long-term environmental changes, which effectively reduces the potential for speciation. This is because adaptations developed by existing stenotopes in a particular estuarine system may be eliminated as a result of episodic (e.g. river flood cycle) or longer term fluctuations (e.g. rise in sea level) in the aquatic environment.

A more detailed examination at the species level reveals that there are several stenotopic taxa (e.g. Syngnathus watermeyeri, Clinus spatulatus and Hippocampus capensis) which are restricted to less than five estuarine systems altogether, whereas most of the eurytopic species (e.g. Pomadasys commersonnii,
Liza dumerilii and Lichia amia) on the subcontinent occur in more than 100 estuarine systems. It is perhaps noteworthy that the two most eurytopic species within the estuarine spawners, Atherina breviceps and Gilchristella aestuaria, breed in both freshwater dominated and hypersaline systems (Day et al. 1981), and are abundant in temperate and subtropical estuaries of the region (Potter et al. 1990).

Although a number of stenohaline marine fish species enter the mouth region of estuaries (Wallace $1975 b)$, these taxa make minimal use of this environment and are usually transient components of the estuarine ichthyofauna. Potter et al. (1990) refer to these species as marine stragglers. The poor numerical representation and transient nature of marine stragglers in southern African estuaries can probably be attributed to their more stenotopic environmental requirements when compared to the marine estuarine-opportunists. For example, $20 \%$ of the fishes recorded in the Kosi Estuary were restricted to a rocky outcrop near its mouth (Blaber 1978), with both the species composition and abundance of individual taxa fluctuating according to changing biotic (e.g. fish movements) and abiotic (e.g. salinity regime) factors. The absence of these reef-associated marine species from the rest of the system suggests that their presence in this estuary was dependent on the rocky outcrop.

The disappearance of euryhaline marine species from coastal lakes that have become isolated from the sea results in the opening up of these environments to speciation by freshwater and relic estuarine groups, yet very few fish species are found in these habitats. In the warm-temperate Groenvlei for example, which has been isolated from the nearby Swartvlei estuary for less than 5000 years, the eurytopic $A$. breviceps and $G$. aestuaria were the only two indigenous fish species recorded from this system (Ratte \& Ritchie 1984). According to Ratte (1989) these two species are in the early stages of allopatric speciation. A. breviceps and $G$. aestuaria from Groenvlei are separated from their historic populations in the nearby Swartvlei estuarine system by a genetic distance of 0.1 and 0.05 respectively. Although these genetic differences have not yet reached the subspecies level of divergence, they were sufficiently different for Ratte (1989) to suggest that the populations of both species in Groenvlei should receive a priority conservation status. The lack of indigenous freshwater fishes from Groenvlei may be linked to the absence of any rivers entering this lake, together with the relatively low species diversity of freshwater fishes from the region (Skelton 1986). Prior to the successful introduction of three exotic and one alien freshwater fish species into Groenvlei (Ratte \& Ritchie 1984), there were no piscivorous or detritivorous fishes in the system, and only a narrow component of the available resource spectrum was being utilized by the two indigenous fish species (Coetzee 1982b). 
When compared to Groenvlei, subtropical Lake Sibaya has a more diverse ichthyofauna (18 species), with five taxa having estuarine affinities (Bruton 1980a). According to Bruton (op. cit.) the most successful and abundant fishes in Lake Sibaya are those species with wide habitat and food tolerances, i.e. eurytopes. Although Lake Sibaya has a more stable aquatic environment when compared to estuarine systems, fluctuations in lake level, either as a result of seasonal or long-term changes in rainfall patterns, have a marked effect on the littoral fish community. At low lake levels the littoral terrace is a barren, harsh environment, inhabited mainly by the eurytopic Oreochromis mossambicus, whereas at higher lake levels the more diverse and stable marginal habitats harbour a variety of fishes (Bruton 1980a, Bowen \& Allanson 1982). It is important to note that Lake Sibaya has been classified as oligo-mesotrophic (Allanson 1979) and this may also have had a negative influence on fish species diversity, e.g. a shortage of prey fish would reduce the potential for exclusively piscivorous species to maintain viable populations.

Lake Sibaya, like Groenvlei, is a relatively young system (Hobday 1979) and it is unlikely that major speciation could have occurred within a period of less than 10000 years. However, one species (Silhouettea sibayi) was originally thought to be endemic to the lake. This small cryptic goby is present over barren sandy substrata but little is known about its biology or ecological requirements (Bruton \& Kok 1980). Did $S$. sibayi evolve in Lake Sibaya or does it represent a relic estuarine species which is either rare or has disappeared from other southern African coastal systerns? Recent evidence, especially the presence of $S$. sibayi in certain northern KwaZulu-Natal estuaries, indicates that this species did not evolve in Lake Sibaya.
According to several authors (e.g. Ribbink 1994) a degree of environmental permanency is necessary for stenotopes to evolve and speciate. In systems that undergo major changes seasonally or over longer periods, eurytopes survive and speciation is rare. Estuaries do not exhibit the environmental permanency necessary for eurytopes to develop into stenotopes, and although some stenotopic species are found in estuarine systems, these taxa are forced to become 'survivors' rather than 'increasers' using the terminology of Vrba (1980). Thus the barriers to gene flow along estuarine and latitudinal gradients, together with intense natural selection (Levinton 1980), have not resulted in widespread speciation as has occurred in other more stable (predictable) aquatic ecosystems, e.g. the coral reefs of the Indo-Pacific or the great lakes of central Africa.

The lack of speciation in southern African coastal lakes, which exhibit a greater degree of environmental permanency and predictability than estuaries, can probably be attributed to three principal factors; (a) the recent history of these systems which only became isolated during the Holocene, (b) the eurytopy of the dominant freshwater and relic estuarine fish species, and (c) the lack of opportunities for additional founder species to colonise these systems. In addition, the relatively low species diversity of potential ichthyofaunal colonists from the adjacent estuarine and freshwater systems has given rise to species poor communities. Preliminary information (YanezAráñcibia 1985) indicates that a similar pattern to that described above may apply to coastal lake and lagoonal systems in both the northern and southern hemispheres. However, further research and collation of data from around the world is necessary before any firm conclusions can be reached. 


\section{Chapter 3}

\section{Estuary-associated fish species profiles}

\subsection{INTRODUCTION}

The fishes associated with southern African estuaries may be divided into three broad categories according to origin and spawning habits. Marine species usually breed at sea although some taxa have also been recorded spawning in the mouth region of selected estuaries. The juveniles of most marine species covered in this chapter utilize estuaries as nursery areas. Estuarine species generally spawn within the estuarine ecosystem, but several taxa have also been recorded breeding in the marine or freshwater environment. For some of these fishes the entire life cycle occurs in estuaries, whereas for others part of the cycle is spent in either the sea or adjacent freshwater habitats. Freshwater species usually spawn in rivers, streams, lakes or pans, although some taxa (e.g. Oreochromis mossambicus) have also been recorded breeding in estuaries. The anguillid eels spawn at sea but are grouped with the freshwater species because they spend most of their life in river systems.

A primary aim of this chapter is to provide a source of biological and ecological information on commonly encountered fishes in southern African estuaries. Some of the rare and unusual species occurring in estuaries have also been included to provide a more complete coverage of the range of fishes utilizing ecosystems on the subcontinent. Although the species profiles of some of the more abundant fishes are reasonably comprehensive, very little is known about the biology and ecology of a number of species, especially those that are small and cryptic. Hopefully this treatise will serve to stimulate research on these taxa, including those which are perceived to be rare and endangered. In this context 18 estuary-associated fish species have been included in the IUCN Red List of Threatened Animals (Baillie \& Groombridge 1996). For some of these species (e.g. Clinus spatulatus, Hippocampus capensis, Croilia mossambica and Redigobius dewaalii) a good database exists, but for others (e.g. Redigobius bikolanus, Favonigobius reichei, Taenioides jacksoni and Glossogobius biocellatus) the available information is very limited.

The scientific and common names are based on those used by Smith \& Heemstra (1986a) and Skelton (1993), with adjustments for recent taxonomic changes having been implemented in consultation with $\mathrm{Dr}$ Heemstra and Professor Skelton. Detailed guides to the identification of southern African fish species are given in the above two publications. In this chapter only a limited number of external diagnostic features are described for each species, with the lateral scale count (LS) given in Smith \& Heemstra (1986) being used wherever possible. In addition, selected anatomical features (especially fin element counts) which are characteristic of each species are also given. For all the bony fishes (Osteichthyes) Roman numerals indicate spines and Arabic numerals indicate soft rays.

Fish illustrations were prepared by $\mathrm{Mr} \mathrm{D}$. Voorvelt, mainly from preserved specimens housed in the J.L.B. Smith Institute of Ichthyology but often in conjunction with colour plates, photographs or transparencies when available. Wherever possible, standard length (SL) of bony fish and total length (TL) or disc width (DW) for cartilaginous fish illustrations are used. Fish lengths above $100 \mathrm{~mm}$ are given in centimetres whereas those below $10 \mathrm{~cm}$ are given in millimetres.

Distribution maps are given for each species and have been compiled from the published literature, museum records and unpublished data collected by the author. The distributions shown here apply to the confirmed occurrence of species in estuaries and the marine environment. It should be emphasized that although fishes have the potential to colonize all estuaries within a particular distributional range, their actual occurrence in individual systems is determined by a wide variety of factors, e.g. species that favour clear water are unlikely to occur in highly turbid estuaries and turbid water species are usually absent from clear estuaries. In addition, there is likely to be seasonal variation in the distributional patterns of certain species, with the range of some tropical taxa extending southwards during summer and retreating northwards during winter. Conversely, some of the more temperate species may extend their distribution northwards during winter and are forced southwards with the onset of summer. For the purposes of this book the maximum range for each species is depicted on the distributional map, i.e. summer and winter ranges are included in the overall distribution. 
Family: CARCHARHINIDAE

Species: Carcharhinus leucas (Valenciennes, 1839)

Common name: Bull shark

Smiths' Sea Fishes number: 9.9

Illustrated specimen length: $166 \mathrm{~cm}$ TL

\section{Selected anatomical features}

Tooth count: Upper jaw; 26 lateral, 2 central Lower jaw; 24 lateral, 2 central.

First dorsal fin height up to 3.1 times second dorsal fin height.

Maximum recorded length in southern African waters: $\pm 320 \mathrm{~cm}$ TL.

\section{Distribution}

C. leucas is a predominantly inshore warm-water shark, known from all the major oceans (Bass et al. 1986 ) and extending to $150 \mathrm{~m}$ depth (Compagno et al. 1989). Within local waters this species ranges from Mozambique in the northeast to Cape St Francis in the southeast (Compagno et al. 1989), juveniles entering large estuarine bays, lakes and rivers.

\section{Biology and ecology}

Sexual maturity is attained after about $13-18$ years at a length of 220-250 cm TL (Branstetter \& Stiles 1987). Mating in southern Africa probably occurs in northern subtropical coastal waters (Bass et al. 1973), and the young are born in summer after a gestation period of approximately 10-11 months (van der Elst 1988). Gravid females often congregate in the mouth of the St Lucia and other large estuaries to give birth to about 12 young, each measuring $60-70 \mathrm{~cm}$ TL. Juveniles forage in the estuary, occasionally visit the sea, or ascend into the adjacent lake and rivers (Day et al. 1981).

Juvenile bull sharks in Lake St Lucia have been regularly recorded in salinities ranging from $10-47 \%$ (Bass et al. 1973). The absence of $C$. leucas from the northern sections of the lake when salinities were above $50 \%$ suggests that this species leaves areas of extreme hypersalinity. Juveniles sometimes move into the larger river systems of tropical and subtropical Africa, and specimens have been captured hundreds of kilometres up the Zambezi, Limpopo and Phongolo rivers (Skelton 1993). Adult C. leucas sometimes enter the lower reaches of southern African estuaries but do not appear to penetrate the river systems. Although bull sharks are

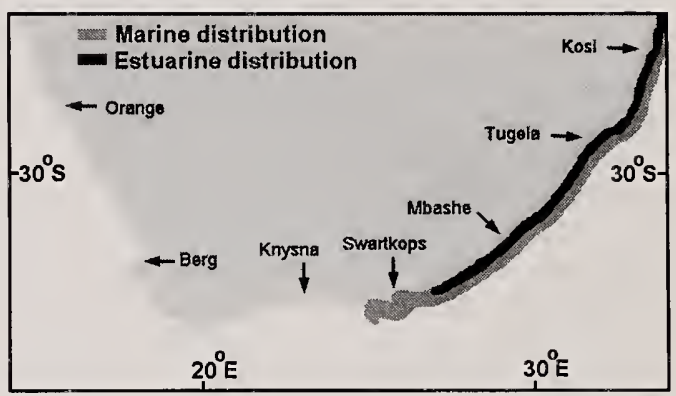

associated with a range of water turbidities, they are attracted to turbid areas (Last \& Stevens 1994), especially flooding river mouths which often provide this species with a source of food in the form of drowned terrestrial mammals.

D'Aubrey (1971) noted that young C. leucas from KwaZulu-Natal feed mainly on teleost fish, with a higher proportion of elasmobranchs in the diet of larger specimens. According to Bass et al. (1973) this reflects not so much a change in food preference as a change in the availability of different types of prey in estuaries and the sea. Bull sharks in Lake St Lucia and other KwaZulu-Natal estuarine systems consume mainly mugilids and haemulids, although a wide variety of other teleost fish species such as Argyrosomus japonicus, Acanthopagrus berda and Rhabdosargus sarba are also captured. Although small sharks, skates and rays dominated the diet of $C$. leucas in the marine environment, dolphins, turtles and crabs are also taken. The presence of terrestrial mammalian remains in the stomach contents of bull sharks from both the estuarine and marine environment suggest that this species is also a scavenger. 
Family: PRISTIDAE

Species: Pristis zijsron Bleeker, 1851

Common name: Longcomb sawfish

Smiths' Sea Fishes number: 22.3

Illustrated specimen length: $109 \mathrm{~cm}$ TL

\section{Selected anatomical features}

Rostral tooth count: $24-28$ pairs of lateral saw teeth.

Space between basal two teeth 3-6 times space between distal two teeth.

Maximum recorded length in southern African waters: $\pm 550 \mathrm{~cm}$ TL .

\section{Distribution}

P. zijsron has a mainly tropical Indo-West Pacific distribution, extending from New South Wales in Australia to KwaZulu-Natal and the Eastern Cape in South Africa (Last \& Stevens 1994). Within southern African waters it is an inshore marine species that enters some of the larger estuaries and rivers (Compagno et al. 1989). A relative, Pristis microdon, is often found in the estuaries and larger rivers of Mozambique (Skelton 1993) and may also enter South African estuaries.

Note: According to Dr L.J.V. Compagno (pers. comm.) all illustrated and photographed Pristis pectinata from the southern African region (e.g. Wallace 1967a, Compagno 1986a, van der Elst 1988) are in fact the closely related $P$. zijsron. Consequently, the presence of $P$. pectinata in subcontinental waters has yet to be confirmed.

\section{Biology and ecology}

Due to the previous misidentification outlined above, the biological and ecological information supplied by Wallace (1967a), Compagno (1986a) and van der Elst (1988) for P. pectinata from southern African waters applies to $P$. zijsron.

Males mature at $430 \mathrm{~cm}$ (Compagno 1986a). All sawfishes are ovoviviparous with adult female $P$. zijsron having been recorded entering the St Lucia Estuary and Richards Bay to pup. Each of the 15-20 young is about $60 \mathrm{~cm}$ long at birth and has its saw enveloped in a membrane to avoid injuring the mother (van der Elst 1988). The young often remain in estuaries and bays which are used as nursery areas, with juveniles ( $<1$ year old) sometimes captured by anglers in the southern portion of Lake St Lucia.

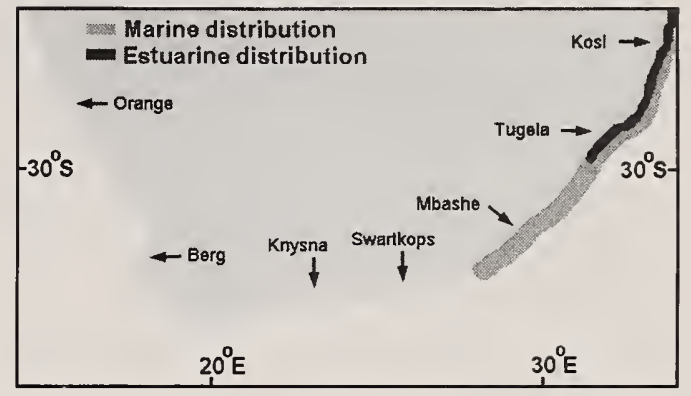

The longcomb sawfish occurs in salinities ranging from freshwater to $35 \%$ but appears to avoid hypersaline conditions. It is most abundant in warm seas where temperatures are above $20^{\circ} \mathrm{C}$. This mainly littoral species has been recorded in turbid and clear water areas, over both muddy and sandy substrata

The diet of $P$. zijsron in southern Africa consists of slow swimming and shoaling fish, especially mugilids, that are killed or stunned by thrashing the saw from side to side. This is evident from fish scales that are often found impaled on the rostral teeth and from foraging behaviour observed whilst in captivity. The longcomb sawfish can feed in highly turbid water, and has also been recorded preying on prawns, crabs and bivalves (van der Elst 1988). 
Family: TORPEDINIDAE

Species: Torpedo fuscomaculata Peters, 1855

Common name: Blackspotted electric ray

Smiths' Sea Fishes number: 23.1

Illustrated specimen length: $27 \mathrm{~cm} \mathrm{TL}$

\section{Selected anatomical features}

Small caudal fin and small papillae around the spiracles.

Dull grey above with variable markings, underside white.

Maximum recorded length in southern African waters: $\pm 64 \mathrm{~cm}$ TL.

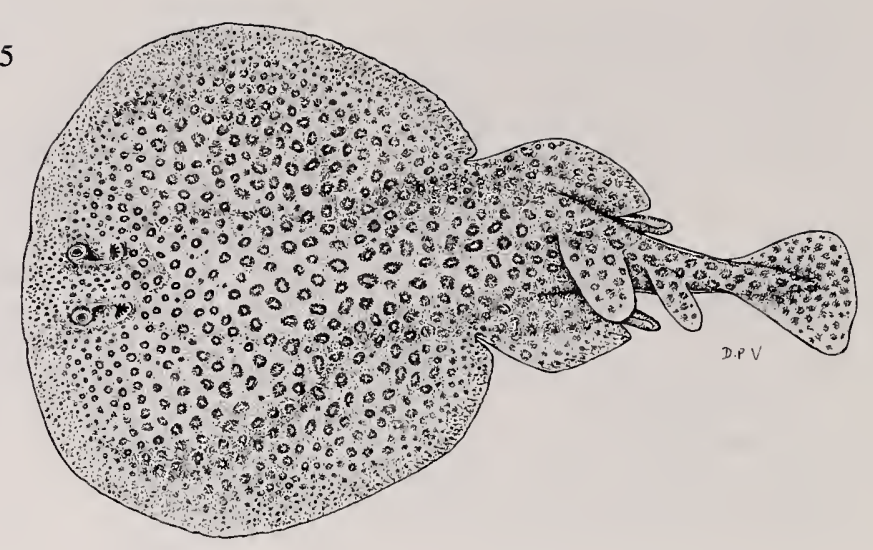

\section{Distribution}

T. fuscomaculata is described by Compagno et al. (1989) as ranging from Cape Agulhas to southern Mozambique. Although this species has also been reported as occurring in the Seychelles, Mauritius, Madagascar and Zanzibar (Wallace 1967b), the identity of these specimens is uncertain (Compagno et al. 1989). The closely related marbled electric ray Torpedo sinuspersici also occurs in estuaries and is sometimes confused with $T$. fuscomaculata.

\section{Biology and ecology}

The blackspotted electric ray is sometimes a common inhabitant of the shallow lower and middle reaches of estuaries, but also occurs down to the upper slope of the continental shelf at approximately $440 \mathrm{~m}$ depth. $T$. fuscomaculata is ovoviviparous and the young are born in summer (Compagno et al. 1989), sometimes in estuaries (Smith 1965). The ray is propelled by the caudal fin and not the enlarged fleshy pectoral fins. This species is generally sluggish and often get stranded in the intertidal areas of estuaries. According to Smith (1965) they can survive for hours when left stranded on moist sand by the receding tide.

$T$. fuscomaculata, like all other electric rays, has two large kidney shaped electric organs in the disc on either side of the head. These organs are capable of generating strong electric shocks which are administered at will (Compagno 1986b) but decline in effectiveness if repeated at very short intervals (Smith 1965). This species has been observed to stun both demersal and pelagic fishes with shocks and then consume the stunned prey. Electric shocks are probably also used as a deterrent to predators. The absence of $T$. fuscomaculata from estuaries where average salinities

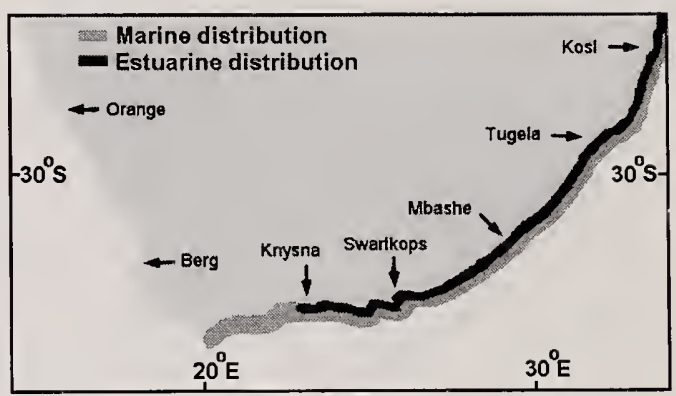

are less than $15 \%$ suggests that it may be sensitive to mesohaline and oligohaline conditions.

The blackspotted electric ray is a solitary species which frequently buries itself beneath the substratum during the day but is active at night. The jaws have small cuspidate teeth and the mouth is highly distensible. A $31 \mathrm{~cm}$ TL specimen captured in the Kariega Estuary (Paterson 1995) was found to have swallowed a $13 \mathrm{~cm}$ SL Cape stumpnose Rhabdosargus holubi. From the size of the mouth, it is apparent that the ray completely immobilises its prey and the highly distensible jaw mechanism enables it to cope with the swallowing of large fish. According to Compagno et al. (1989) they consume merlucciids, cynoglossids, engraulids, sparids, gonorhynchids, carangids and triglids in the marine environment. Laboratory observations by Paterson (1995) indicate that bottom dwelling gobies and clinids are preferred to midwater species and that most feeding takes place at night. $\mathrm{He}$ also noted that the blackhand sole Solea bleekeri was not preyed upon by $T$. fuscomaculata, and in many cases the sole were observed burying themselves in the sand layer covering the ray. 
Family: MYLIOBATIDAE

Species: Myliobatus aquila (Linnaeus, 1758)

Common name: Eagleray

Smiths' Sea Fishes number: 28.2

Specimen width: $36 \mathrm{~cm} \mathrm{DW}$

\section{Selected anatomical features}

Snout broad and short, pectoral tips blunt.

Disc brown to black above, underside white.

Maximum recorded disc width in southern

African waters: $\pm 150 \mathrm{~cm}$.

\section{Distribution}

The eagleray ranges from the Mediterranean and eastern Atlantic around Cape Point to KwaZulu-Natal. It is described by Compagno (1986c) as a mainly coastal species that readily enters shallow bays and estuaries. Within the marine environment it occurs down to at least $95 \mathrm{~m}$ (Compagno et al. 1989).

\section{Biology and ecology}

M. aquila is commonest in warm-temperate Eastern and Western Cape waters where it is often found in groups (Compagno et al. 1989). This species is most abundant during summer and usually swims just below the water surface when not foraging. Individuals are sometimes trapped by the closure of estuary mouths and appear to tolerate the salinity changes within these systems. A powerful swimmer, the eagleray occasionally leaps from the water (van der Elst 1988).

Sexual maturity is attained at a disc width of $50 \mathrm{~cm}$, with females tending to be larger than males. After a one year gestation period, females give birth to 3-7

Family: DASYATIDAE

Species: Himantura uarnak (Forsskål, 1775)

Common name: Honeycomb stingray

Smiths' Sea Fishes number: 30.10

Specimen width: $34 \mathrm{~cm} \mathrm{DW}$

\section{Selected anatomical features}

Disc 1.0-1.1 times disc length; tail

2.6-3.0 times longer than disc.

Conspicuous dark spots or reticulations on a light brown disc, underside white.

Maximum recorded disc width in southern African waters: $\pm 200 \mathrm{~cm}$.
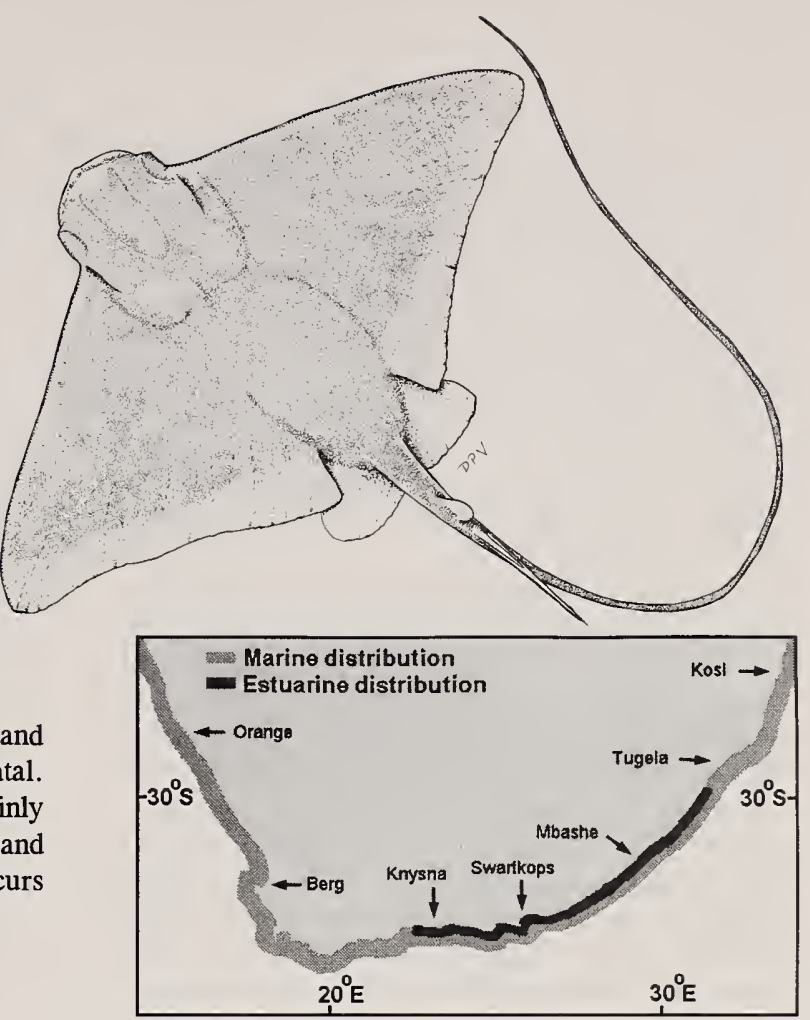

live young in shallow water (van der Elst 1988), sometimes in estuaries (Smith 1965). Newly born eaglerays have a disc width of $20-25 \mathrm{~cm}$.

Foraging appears to occur mainly in bottom waters since their diet consists mostly of bivalves, gastropods, brachyurans, anomurans, echiurids, polychaetes, tunicates and small bony fish such as gobies and eels (Compagno et al. 1989). The upper and lower jaws have seven rows of plate-like teeth for crushing the molluscan and crustacean prey. As a deterrent to predators, $M$. aquila has one or two serrated spines near the base of its tail.

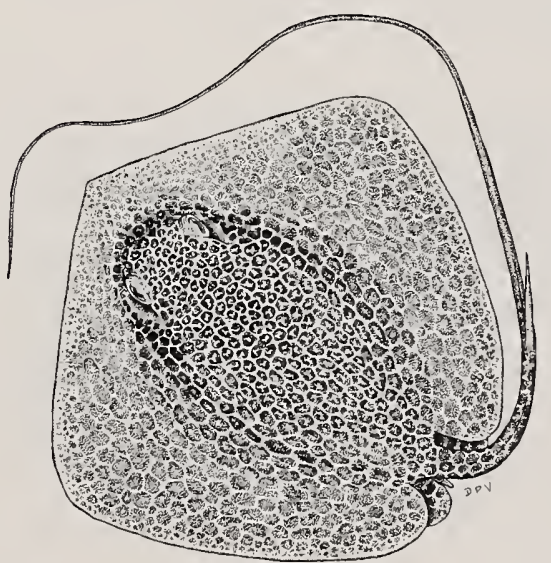




\section{Distribution}

The honeycomb ray is a widespread Indo-West Pacific species (Compagno 1986d). Within southern Africa it extends from the Eastern Cape to Mozambique, being more abundant in the subtropical waters of KwaZuluNatal than the warm-temperate region farther south. This stingray is common off sandy beaches and in shallow estuaries, extending from the intertidal zone to offshore banks down to $50 \mathrm{~m}$ (van der Elst 1988).

\section{Biology and ecology}

H. uarnak occurs in KwaZulu-Natal waters throughout the year, although it is most abundant during the summer months (Wallace 1967c). They attain sexual maturity at a disc width of approximately $100 \mathrm{~cm}$, which corresponds to an age of 4-5 years. During the summer 3-5 young are born after a one year gestation period (van der Elst 1988).

The honeycomb ray has been recorded in salinities ranging from $2-35 \%$ and shows considerable tolerance of reduced salinities and turbid conditions found in estuaries such as Lake St Lucia. Respiration in muddy environments is facilitated by the large spiracles situated

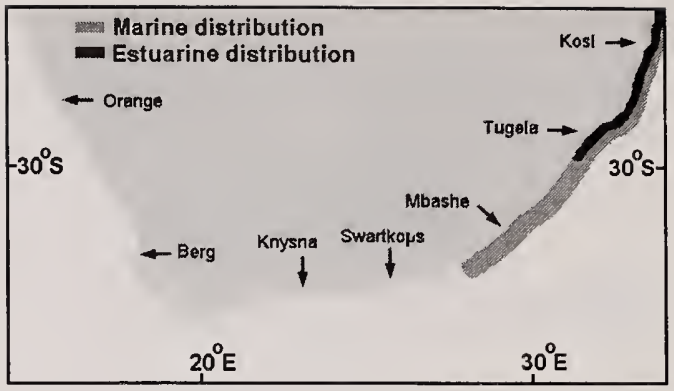

on top of the head behind the eyes and through which clean water is taken in. Foraging may occur singly or in small groups, with a tendency to move into littoral estuarine waters at night. The strong, pavement-like teeth are used to crush molluscs, crabs and prawns that constitute the major portion of the ray's diet. Tube worms are also occasionally eaten (van der Elst 1988).

$H$. uarnak has 1-3 stout spines near the base of the tail. These spines are poisonous and are used as a defence mechanism by this species. Honeycomb stingrays may attain at least 24 years of age, by which stage they weigh almost $120 \mathrm{~kg}$ (van der Elst 1988).

Family: ELOPIDAE

Species: Elops machnata (Forsskål, 1775)

Common name: Ladyfish

Smiths' Sea Fishes number: 36.2

Illustrated specimen length: $33 \mathrm{~cm}$ SL

\section{Selected anatomical features}

Fin elements: Dorsal 22-27;

Anal 15-18; Pectoral 17-18.

Lateral scales: 90-103.

Maximum recorded length in southern

African waters: $\pm 85 \mathrm{~cm} \mathrm{SL}$.

\section{Distribution}

The ladyfish has a range extending from the Breë River Estuary in South Africa northwards to the Red Sea, India, and into the western Pacific (Smith 1986a). Within southern Africa, both juveniles and adults are well represented in the larger subtropical estuaries and some permanently open systems along the Eastern Cape coast. A few individuals enter warm-temperate southern Cape estuaries, mainly during the summer (Smith 1965).

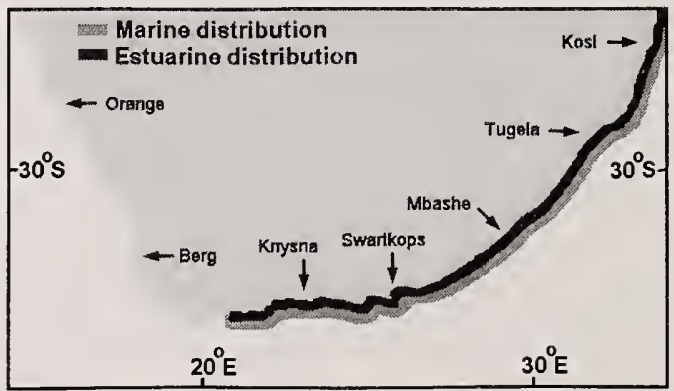


Little is known about gonadal development or spawning phases in the life cycle of this species in southern Africa. Wallace (1975b) found a single reproductively active specimen in KwaZulu-Natal but no ripe individuals were recorded. According to van der Elst (1988) large shoals of breeding adults are found off Mozambique during winter. The transparent leptocephali larvae enter KwaZulu-Natal and Eastern Cape estuaries between $20 \mathrm{~mm}$ and $40 \mathrm{~mm}$ BL during spring and summer (Melville-Smith \& Baird 1980, Harris \& Cyrus 1995), often congregating in the upper reaches. Although juveniles less than $20 \mathrm{~cm}$ SL are often recorded in estuaries they are not abundant.

The recorded salinity range of this fish is $0-95 \%$, with the larva sometimes entering freshwater areas above the ebb and flow of certain estuaries, e.g. in the Great Fish and Nahoon rivers. Adults were recorded in Lake Nhlange at salinities less than $1 \%$ (Blaber \& Cyrus 1981) and no individuals were documented dying during the May 1976 oligohaline fish kill in Lake St Lucia (Blaber \& Whitfield 1976). This species did, however, perish in salinities above $95 \%$ in the temporarily closed Seekoei Estuary (Whitfield 1989e). $E$. machnata has been recorded in a wide range of turbidities, from less than 10 NTU to more than 80 NTU. It is classified by Cyrus \& Blaber (1987a) as a turbid water species because almost $70 \%$ of the specimens captured at St Lucia occurred in 51-80 NTU waters.

Ladyfish forage mainly during the early evening, either individually or in small groups (van der Elst 1988). The diet of specimens greater than $28 \mathrm{~cm} \mathrm{SL}$ in southern African estuaries has been well studied and indications are that this mainly visual predator utilizes both fish and crustaceans as food (Whitfield \& Blaber 1978a, Marais 1984, Hecht \& van der Lingen 1992). Although relatively slow swimming clupeids (e.g. Gilchristella aestuaria) are favoured prey items, faster swimming mugilids are also captured. Penaeid prawns and mysids are the dominant invertebrate taxa consumed. It would appear that increasing turbidity levels cause a modification of its foraging strategies from capturing fast moving prey organisms with a higher escape probability (e.g. fish) to slow moving taxa with a lower escape probability (e.g. mysids) (Hecht \& van der Lingen 1992). The large tubular mouth and well developed gill rakers create an effective sieving apparatus for use in turbid waters.

Family: MEGALOPIDAE

Species: Megalops cyprinoides (Broussonet, 1782)

Common name: Oxeye tarpon

Smiths' Sea Fishes number: 37.1

Illustrated specimen length: $26 \mathrm{~cm} \mathrm{SL}$

\section{Selected anatomical features}

Fin elements: Dorsal 17-20;

Anal 24-31; Pectoral 15-16.

Lateral scales: $36-40$.

Maximum recorded length in southern

African waters: $\pm 70 \mathrm{~cm} \mathrm{SL}$.

\section{Distribution}

M. cyprinoides is a tropical Indo-West Pacific species extending into the subtropical waters of southern Africa. It favours estuaries (Smith 1965) and has been reported from as far inland as the lower Shire River in Malawi, and the Save-Runde junction in Zimbabwe (Skelton 1993). Stray specimens reach as far south as Algoa Bay (Smith 1986b) but do not appear to enter rivers in this region.

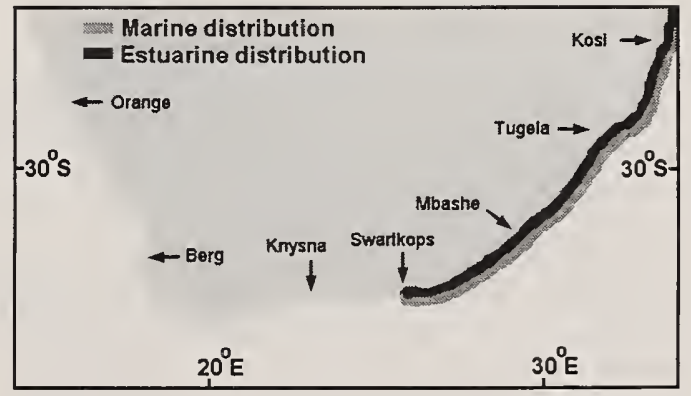




\section{Biology and ecology}

This predominantly solitary species is found in marine, estuarine and freshwater environments (van der Elst 1988). Breeding occurs at sea with the leptocephali larvae entering estuaries at a length of between $17 \mathrm{~mm}$ and $31 \mathrm{~mm}$ BL (Harris \& Cyrus 1995).

Juveniles appear to be attracted to brackish or freshwater lakes and pans which they enter when these systems are linked to the adjacent estuary during high rainfall periods. Skelton et al. (1989) recorded juvenile $M$. cyprinoides (27-39 mm SL) entering the freshwater Mkuze swamps from Lake St Lucia during a summer flood. Crass (1964) collected adults (maximum size 54 $\mathrm{cm}$ FL) in Lake Bhangazi South, a freshwater system that is only connected to Lake St Lucia (via a swamp) during heavy rainfall events. Postlarvae and juveniles could migrate up this swamp from South Lake during such periods, but adults would be trapped in Lake Bhangazi unless major freshwater flooding occurred.

The recorded salinity range of this species is from $0-38 \%$ (Whitfield 1996b). Tarpons are among the few marine fishes known to breathe air, rising regularly to the surface to do so. The swim bladder is modified for this purpose (Skelton 1993). M. cyprinoides is a powerful swimmer, hunting at speed and consuming small pelagic fish, the juveniles of larger species, and shrimps (van der Elst 1988).

\section{Family: MURAENIDAE}

Species: Strophidon sathete (Hamilton, 1822) Common name: Slender giant moray Smiths' Sea Fishes number: 41.28 Illustrated specimen length: $79 \mathrm{~cm} \mathrm{SL}$

\section{Selected anatomical features}

Body depth \pm 40 in total length. Body length 1.5-2.0 in tail length. Two series of unequal sharp teeth in each jaw. Maximum recorded length in southern

African waters: $\pm 300 \mathrm{~cm}$ TL.

\section{Distribution}

This moray is a widespread tropical Indo-Pacific species, extending into the subtropical waters of southern Africa where it is considerably more abundant in the sea than in estuaries. Specimens have been collected as far south as the Mbashe Estuary on the Eastern Cape coast (Castle \& McCosker 1986).

\section{Biology and ecology}

Details of its breeding biology in southern Africa are unknown (van der Elst 1988) but spawning probably occurs in the marine environment. Harris \& Cyrus (1995) recorded $S$. sathete leptocephali larvae (19-100 $\mathrm{mm} \mathrm{BL}$ ) entering the St Lucia Estuary.

Although the slender giant moray is often captured by KwaZulu-Natal anglers in estuaries, very little is known about this species. According to van der Elst (1988) this eel is usually solitary and confined to coastal waters and offshore banks. In contrast to many moray eels that live in coral reefs, this species often

enters estuaries, especially those with muddy bottoms. The recorded salinity range of $S$. sathete is $17-35 \%$ but further sampling in estuaries is likely to extend these limits.

This species is resident in the turbid St Lucia Narrows (Millard \& Broekhuysen 1970). The brownish body colouration of the slender giant moray provides effective camouflage in muddy systems where it feeds on demersal fish, prawns and small crabs (van der Elst 1988). Some of the sharp conical teeth in both jaws are depressible (Smith 1965) and may aid prey retention. 
Family: MURAENESOCIDAE

Species: Muraenesox bagio (Hamilton, 1822)

Common name: Pike conger

Smiths' Sea Fishes number: 45.1

Illustrated specimen length: $48 \mathrm{~cm}$ TL

\section{Selected anatomical features}

Dorsal rays before anus: $47-49$.

Body depth 16-22 in total length.

Lateral line pores before anus: 33-39.

Maximum recorded length in southern

African waters: $\pm 175 \mathrm{~cm} \mathrm{TL}$.

\section{Distribution}

The pike conger is an Indo-Pacific species, extending into Eastern Cape waters, with a coastal distribution extending to $100 \mathrm{~m}$ depth (Castle 1986a). In southern African estuaries it is most common in larger KwaZulu-Natal systems.

\section{Biology and ecology}

This species reaches sexual maturity at approximately $100 \mathrm{~cm}$ TL and spawning occurs at sea during spring and early summer (van der Elst 1988). Leptocephali larvae 73-85 mm BL have been recorded entering the St Lucia Estuary (Harris \& Cyrus 1995), a system that harbours large numbers of adults.

The pike conger is a predominantly solitary species which may shelter in burrows or depressions (van der Elst 1988). It is often found over muddy bottoms and is particularly common in turbid areas of Lake St Lucia and Richards Bay. The recorded salinity range of $M$. bagio is 0-35\%o (Whitfield 1996b) but it has not been recorded entering southern African rivers. This species was absent from the upper sections of Lake St Lucia when salinities increased above $35 \%$, indicating an intolerance to hypersaline conditions.

$M$. bagio is a predator and scavenger of dead or decaying fish. Both jaws are armed with several rows of sharp teeth, some of which are enlarged into canines. When the mouth is closed, these larger teeth slot into cavities in the opposite jaw. Prey taxa include Johnius dorsalis, Pomadasys kaakan and mugilids, as well as prawns (van der Elst 1988). Fish species consumed by adult pike conger ( $90-143 \mathrm{~cm}$ TL) in Lake St Lucia include Solea bleekeri, Johnius dorsalis and Leiognathus equula (Whitfield \& Blaber 1978a).

\section{Family: CLUPEIDAE}

Species: Hilsa kelee (Cuvier, 1829)

Common name: Kelee shad

Smiths' Sea Fishes number: 54.5

Illustrated specimen length: $19 \mathrm{~cm} \mathrm{SL}$

\section{Selected anatomical features}

Fin elements: Dorsal 16-19; Anal 17-23; Pectoral 13-16.

Lateral scales: $39-44$.

Maximum recorded length in southern

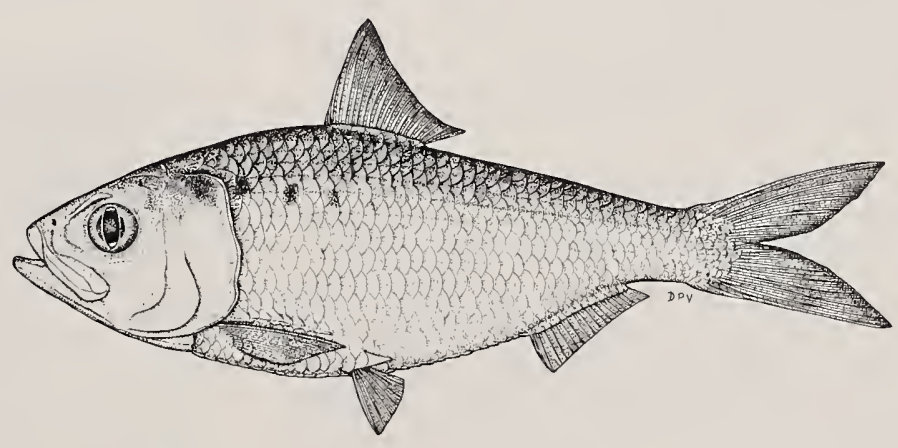
African waters: $\pm 27 \mathrm{~cm}$ SL. 


\section{Distribution}

The kelee shad is a widespread tropical Indo-West Pacific species (Whitehead \& Wongratana 1986a), extending as far south as the Transkei. Within subtropical southern African estuaries this species is sometimes abundant in the larger turbid northern KwaZulu-Natal systems.

\section{Biology and ecology}

$H$. kelee starts maturing after one year at a length of 15 $\mathrm{cm}$ SL (van der Elst 1988). The breeding season covers the period September-February, with spent individuals sometimes entering estuaries. Spawning usually occurs in the marine environment although ripe-running specimens have been recorded in Durban Bay during December (Wallace 1975b). Recruiting juveniles 20-40 mm SL usually occupy the lower reaches of estuaries (van der Elst 1988). Juveniles (30-50 mm SL) were recorded in Lake St Lucia during February 1978 and grew approximately $10 \mathrm{~mm}$ per month to reach a length of $110 \mathrm{~mm}$ SL by August 1978 (Blaber 1979).

The kelee shad is a pelagic shoaling fish that frequents deeper areas of an estuary where salinities range from 3-35\% (Whitfield 1996b). This species avoids hypersaline and freshwater conditions, and was recorded dying when salinities declined below $3 \%$.

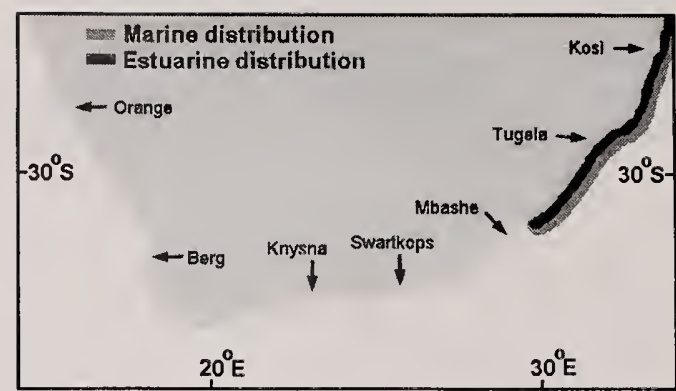

In the St Lucia system, Blaber (1979) found that the diet of $H$. kelee juveniles was dominated by centric diatoms, calanoid copepods and gastropod veligers. A variety of other zooplankters were also eaten, including cyclopoid copepods, amphipods and brachyuran zoae. Adults were also pelagic filter feeders and consumed mainly calanoid copepods and centric diatoms. $H$. kelee has a relatively fine filtering apparatus, with the gill raker and denticle gap altering little after a length of about $70 \mathrm{~mm} \mathrm{SL}$. This species forages throughout the $24 \mathrm{~h}$ cycle with a peak in the early evening (Blaber 1979). Although kelee shad are an important food source for predators such as the king mackerel (Scomberomorus commerson) and various species of tuna in the marine environment (van der Elst 1988), very few are consumed by piscivorous fishes in estuaries (Whitfield \& Blaber 1978a).

Family: ENGRAULIDAE

Species: Stolephorus holodon (Boulenger, 1900)

Common name: Thorny anchovy

Smiths' Sea Fishes number: 55.2

Illustrated specimen length: $53 \mathrm{~mm}$ SL

\section{Selected anatomical features}

Fin elements: Dorsal 15-17;

Anal 20-23; Pectoral 12-14.

Lateral scales: $38-40$.

Maximum recorded length in southern

African waters: $\pm 90 \mathrm{~mm}$ SL.

\section{Distribution}

The thorny anchovy is endemic to eastern and southern Africa, ranging from Kenya to the Eastern Cape Province (Whitehead \& Wongratana 1986b). This fish is an inshore marine species that also occurs in bays and estuaries.
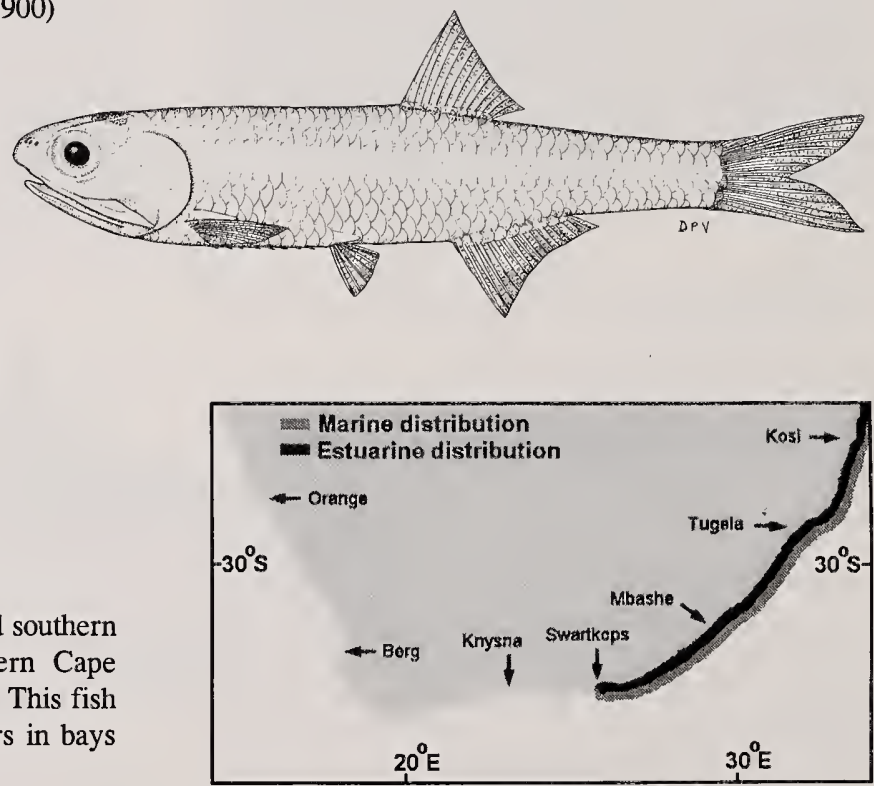


\section{Biology and ecology}

S. holodon reaches sexual maturity at a length of approximately $50 \mathrm{~mm} \mathrm{SL}$, with gonads being inactive in winter and ripe during summer (Blaber 1979). Spawning by this shoaling species usually occurs in the nearshore marine environment, but $S$. holodon eggs have also been recorded in the St Lucia estuarine system (Connell 1996). The eggs are oval in shape and were present in Lake St Lucia in small numbers between September and April 1994.

The thorny anchovy is a moderate osmoregulator and has been recorded in salinities from $7-40 \%$. The apparent absence of this species from Lake St Lucia during oligohaline $(<5 \%$ ) and hypersaline $(>40 \%)$ periods suggests that $S$. holodon is sensitive to extreme salinities.

The diet of the planktivorous $S$. holodon in Lake St Lucia was dominated by the copepod Pseudodiaptomus stuhlmanni, with gastropod post-veligers, mysids and bivalve spat also being consumed (Blaber 1979).

Although it is consumed by Argyrosomus japonicus in Lake St Lucia, the thorny anchovy is unimportant as a dietary item when compared to Thryssa vitrirostris, the other engraulid prey of the dusky kob in this lake system.

Family: ENGRAULIDAE

Species: Thryssa vitrirostris (Gilchrist \& Thompson, 1908 )

Common name: Orangemouth glassnose

Smiths' Sea Fishes number: 55.6

Illustrated specimen length: $14 \mathrm{~cm} \mathrm{SL}$

\section{Selected anatomical features}

Fin elements: Dorsal 13-14; Anal 34-43; Pectoral 12-13.

Lateral scales: $40-44$.

Maximum recorded length in southern

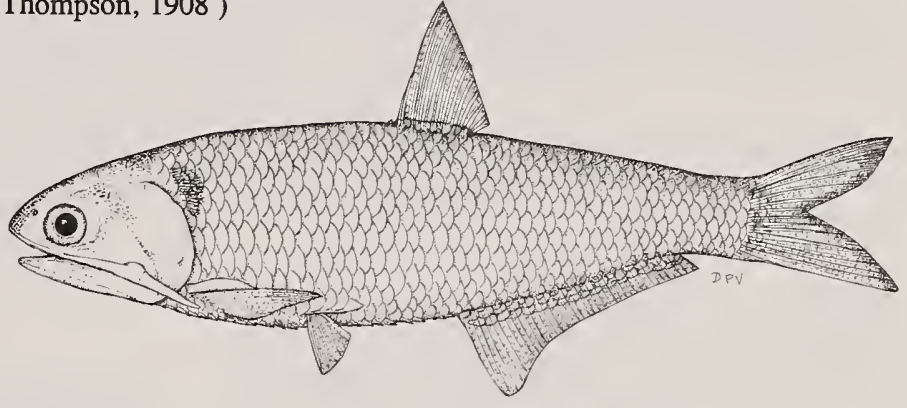
African waters: $\pm 18 \mathrm{~cm} \mathrm{SL}$.

\section{Distribution}

This anchovy is most common in tropical and subtropical bays of the Indian Ocean region, from South Africa to the Persian Gulf and India (Whitehead \& Wongratana 1986b). Within southern African estuaries this species is abundant in the larger turbid northern KwaZulu-Natal systems and rare in warmtemperate estuaries. The closely related longjaw glassnose, Thryssa setirostris, also occurs in the estuaries of KwaZulu-Natal.

\section{Biology and ecology}

Sexual maturity is attained after one year at a length of approximately $80 \mathrm{~mm} \mathrm{SL} \mathrm{(Blaber} \mathrm{1979).} \mathrm{Spawning}$ usually occurs in the nearshore marine environment but has also been recorded in certain estuarine lakes and bays (Wallace 1975b). At Lake St Lucia, large numbers of reproductively active fish (12-18 cm SL) appeared between July and September 1977. Following spawning most of the adults left the lake, although small numbers of reproductively spent individuals did

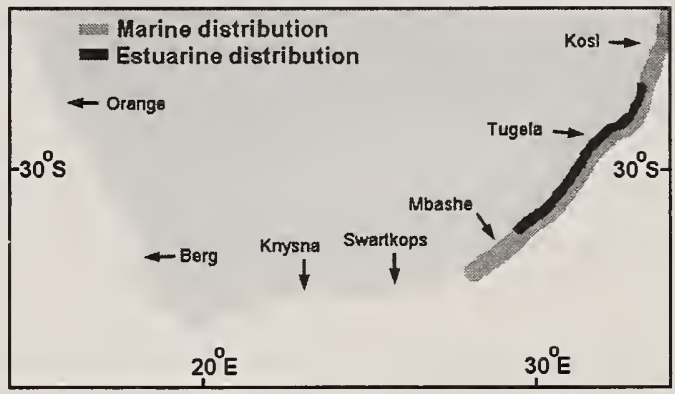

remain within the system (Blaber 1979). Larvae first appeared in the lake during spring and the subadults emigrated during the following winter when the adults arrived in the lake.

T. vitrirostris is a strong osmoregulator and has been recorded in salinities ranging from 1-67\% (Whitfield 1996b). Hypersaline conditions in Lake St Lucia during 1970 may have accounted for an absence of viable larvae during that spawning season (Wallace 
$1975 b) . T$. vitrirostris is a turbid water species with 98\% of the specimens captured in Lake St Lucia being associated with water turbidities greater than $50 \mathrm{NTU}$ (Cyrus \& Blaber 1987a).

The diet of $T$. vitrirostris less than $20 \mathrm{~mm} \mathrm{SL}$ in the St Lucia system was dominated by copepods, and those between $20 \mathrm{~mm}$ and $90 \mathrm{~mm}$ SL consumed copepods, mysids and a variety of other planktonic organisms (Blaber 1979). Large shoals of the orangemouth glassnose feed in synchrony, each individual opening its mouth wide and using its elaborate gill rakers to strain zooplankton from the water (van der Elst 1988).
Adults greater than $100 \mathrm{~mm}$ SL prey mainly on small fish ( $<30 \mathrm{~mm} \mathrm{SL}$ ), especially Gilchristella aestuaria. Foraging in the turbid waters of Lake St Lucia occurs between the bottom and mid-water level and takes place during both the day and night (Blaber 1979). The diet of adults in the marine environment consists mainly of fish and crustaceans (e.g. mysids and cumaceans).

This species is intensively utilized by piscivorous fishes in Lake St Lucia (Whitfield \& Blaber 1978a) and is an important food source for gamefish in the marine environment (van der Elst 1988).

\section{Family: CHANIDAE}

Species: Chanos chanos (Forsskål, 1775)

Common name: Milkfish

Smiths' Sea Fishes number: 58.1

Illustrated specimen length: $18 \mathrm{~cm} \mathrm{SL}$

\section{Selected anatomical features}

Fin elements: Dorsal 13-17; Anal 8-10; Pectoral 15-17.

Lateral scales: 78-90.

Maximum recorded length in southern

African waters: $\pm 120 \mathrm{~cm} \mathrm{SL}$.

\section{Distribution}

The milkfish is widely distributed in those tropical and subtropical waters of the Indo-Pacific region which are enclosed by the $20^{\circ} \mathrm{C}$ isotherm (Bagarinao 1994). This species is sometimes common in the larger subtropical estuarine lakes and bays on the KwaZulu-Natal coast, with a few individuals having been recorded in the warm-temperate region as far south as Swartvlei.

\section{Biology and ecology}

This species is most common in Lake St Lucia during the summer and appears to leave this system between June and September (Whitfield \& Blaber 1978b). Sexual development of the females begins at $50 \mathrm{~cm}$ TL and males at about $90 \mathrm{~cm}$, but both sexes are reproductively active by the age of 4 years (van der Elst 1988). Spawning occurs at sea, usually at night, and is strongly seasonal (Bagarinao 1994). The fertilized eggs are pelagic, spherical and approximately $1 \mathrm{~mm}$ in diameter. Pelagic larvae greater than $9 \mathrm{~mm}$ BL (2 to 3 weeks old) move inshore via a combination of passive advection and active migration (Bagarinao

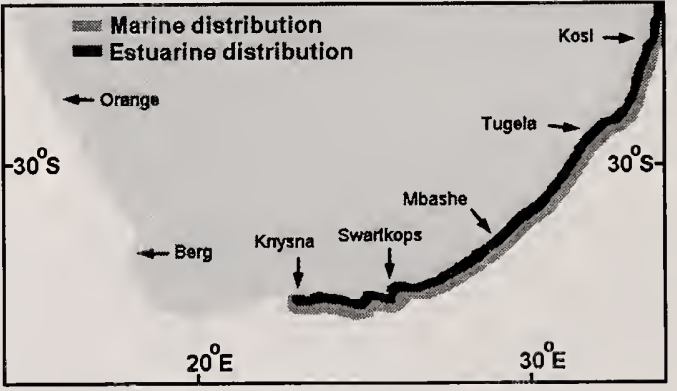

1994). The larvae (10-15 mm BL) enter South African estuaries during summer where a metamophosis into pigmented juveniles occurs (van der Elst 1988, Harris \& Cyrus 1995).

Juvenile and subadult milkfish occur in both clear and turbid estuarine systems along the southern African coast. In Lake St Lucia they have been recorded in salinities ranging from 1-72\%o (Whitfield 1996b) and appear to tolerate temperatures from $13-41^{\circ} \mathrm{C}$ (Bagarinao 1994). Temperatures lower than $23^{\circ} \mathrm{C}$ decrease food intake, growth and development of larvae and juveniles (Villaluz \& Unggui 1983). 
Shoals of $C$. chanos are frequently seen feeding over shallow estuarine banks, with their dorsal fins and tails protruding from the water (Smith 1965). The diet in Lake St Lucia consists mainly of benthic meiofauna such as foraminiferans, gastropods, bivalves, tanaids, ostracods, copepods and zoeae larvae, together with particulate organic matter, detritus and benthic diatoms (Whitfield \& Blaber 1978b). According to van der Elst
(1988) milkfish feed mainly on particulate organic matter and benthic micro-organisms, with occasional small crustaceans, worms and fish also being consumed.

C. chanos was not recorded as a prey item of any of the piscivorous teleosts in Lake St Lucia (Whitfield \& Blaber 1978a), possibly due to their relatively large size in this system together with an exceptionally powerful swimming ability.

Family: ARIIDAE

Species: Galeichthys feliceps Valenciennes, 1840

Common name: White seacatfish

Smiths' Sea Fishes number: 59.3

Illustrated specimen length: $23 \mathrm{~cm} \mathrm{SL}$

\section{Selected anatomical features}

Fin elements: First dorsal I, 7;

Anal 17-21; Pectoral I, 9-11.

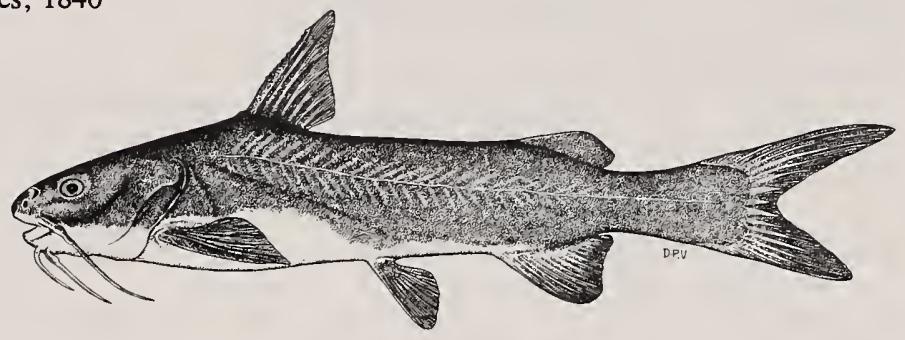

Lateral silvery stripe sometimes present.

Maximum recorded length: $\pm 45 \mathrm{~cm} \mathrm{SL}$.

\section{Distribution}

This southern African endemic frequents both the sea and estuaries, from Namibia to the Eastern Cape. Although $G$. feliceps occurs mainly in water less than $30 \mathrm{~m}$ deep, it has been recorded down to $60 \mathrm{~m}$ (Tilney \& Hecht 1990). This sluggish species prefers protected waters and is frequently found in underwater caves and below rocky ledges in the marine environment (van der Elst 1988). Within estuaries they are most abundant in turbid, muddy areas, with the juveniles often associated with plant beds.

\section{Biology and ecology}

White seacatfish females mature at $24 \mathrm{~cm} \mathrm{SL}$ and males at $26 \mathrm{~cm} \mathrm{SL}$. Little is known of the spawning behaviour of this species, but it is the only fish in southern African estuaries with paternal buccal incubation. The eggs are relatively large $(16 \mathrm{~mm}$ in diameter) and the average brood size is 49 (Tilney \& Hecht 1993). Ventilation of the eggs by the adult is carried out using the branchial pump mechanism, with a considerable current of water passing over the embryos during breathing movements. Hatching occurs between 75 and 80 days of age, with the juveniles being released after 140 days at $54 \mathrm{~mm}$ TL (Tilney \& Hecht 1993). G. feliceps males lose up to $24 \%$ of their total body weight during the incubation period as they do not feed while mouth brooding. Males with eggs

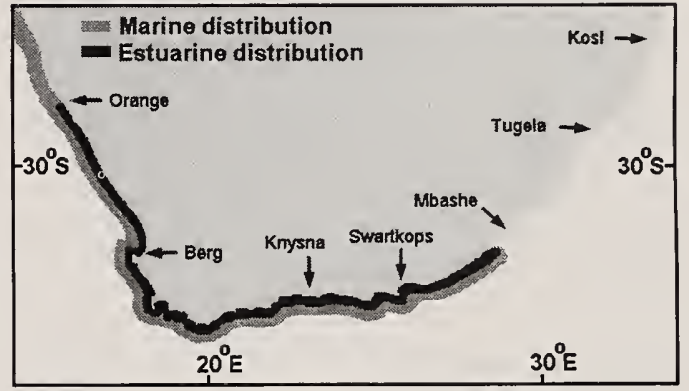

frequent estuaries during spring and summer, with a peak between September and December (Marais \& Venter 1991). The sex ratio of $1: 1$ for adults in the marine environment contrasts to the 7:1 ratio in favour of males in Eastern Cape estuaries and is indicative of the nursery function of these systems for this species.

Although $G$. feliceps is most frequently recorded in the lower and middle reaches of permanently open estuaries, this species is a strong osmoregulator and is relatively common in the mesohaline upper reaches of certain estuarine lake systems (Whitfield 1993). Large numbers were recorded dying in the temporarily closed Bot Estuary at a salinity of approximately $3 \%$ (Bennett 1985 ) and in the Seekoei Estuary when salinities rose above $90 \%$ (Whitfield 1989e). 
Foraging is exclusively benthic and the well developed barbels aid prey detection in muddy waters (van der Elst 1988). The diet of $G$. feliceps in estuaries is dominated by anomurans and brachyurans, with macrurans, mysids, isopods, gastropods, cephalopods, polychaetes and fish also being consumed (Marais 1984, Tilney \& Hecht 1990). In the marine environment this species feeds mainly on brachyurans, echiurids and polychaetes. The high incidence of teleost scales in the diet of juveniles was found to be a consequence of scavenging (Tilney \& Hecht 1990). White seacatfish can consume large amounts of food, with up to $19 \%$ of body mass being recorded in the stomachs of some specimens (Marais 1984).

\section{Family: BELONIDAE}

Species: Strongylura leiura (Bleeker, 1851)

Common name: Yellowfin needlefish

Smiths' Sea Fishes number: 113.3

Illustrated specimen length: $44 \mathrm{~cm} \mathrm{SL}$

\section{Selected anatomical features}

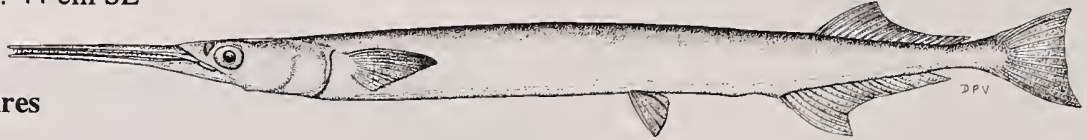

Fin elements: Dorsal 18-21;

Anal 22-26; Pectoral 11-12.

Predorsal scales: 121-152.

Maximum recorded length in southern

African waters: $\pm 73 \mathrm{~cm} \mathrm{SL}$.

\section{Distribution}

The yellowfin needlefish has a mainly tropical and subtropical Indo-West Pacific distribution, ranging from southern China and northern Australia to KwaZulu-Natal (Collette 1986a). The crocodile needlefish Tylosurus crocodilus also occurs in the lower reaches of certain KwaZulu-Natal estuaries together with S. leiura (Blaber \& Cyrus 1981).

\section{Biology and ecology}

This needlefish is an inshore marine and estuarine species which spawns in KwaZulu-Natal waters during spring and summer. Although females in a ripe condition have been captured in Lake St Lucia during October, none of the typically large eggs or larvae have been recorded in KwaZulu-Natal estuarine systems. It has been suggested that since the postlarvae are seldom found in inshore habitats, the early developmental stages probably occur offshore (van der Elst 1988).

S. leiura has been recorded in salinities ranging from 3-38\%o (Whitfield 1996b). The prime limiting factor in the distribution of this tropical species in South African estuaries is probably winter temperatures below about $14^{\circ} \mathrm{C}$, since it is not found south of Durban (Collette 1986a). The yellowfin needlefish is most abundant in the surface waters of estuarine lakes and

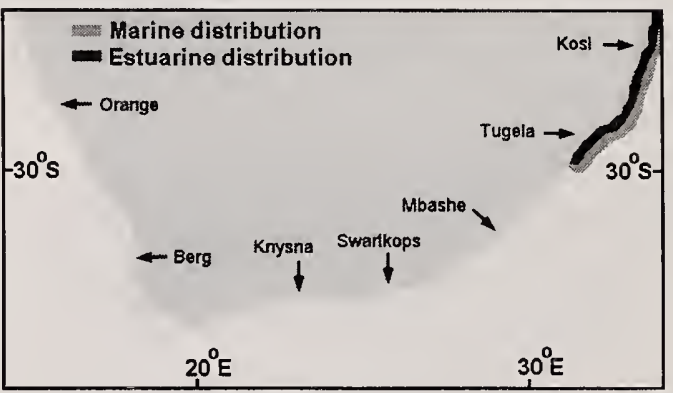

bays where it is often seen chasing small fish in the shallows. It is capable of considerable bursts of speed, and when disturbed can 'skip' across the water surface using powerful thrusts from its tail (van der Elst 1988). More than $80 \%$ of the yellowfin needlefish captured in gill nets at Lake St Lucia occurred in the upper $30 \mathrm{~cm}$ of the water column, and this probably accounts for the high selectivity by fish eagles for this species (Whitfield \& Blaber 1978c).

The diet of $S$. leiura in estuaries is dominated by surface dwelling and midwater fishes such as mugilids, engraulids, hemiramphids, atherinids, ambassids and clupeids, with terrestrial insects floating on the water surface also being consumed (Hill et al. 1975, Whitfield \& Blaber 1978c). Parasitic cestodes were found in the intestines of $63 \%$ of the $S$. leiura examined in Lake St Lucia (Whitfield \& Heeg 1977). 
Family: HEMIRAMPHIDAE

Species: Hemiramphus far (Forsskål, 1775)

Common name: Spotted halfbeak

Smiths' Sea Fishes number: 115.2

Illustrated specimen length: $16 \mathrm{~cm} \mathrm{SL}$

\section{Selected anatomical features}

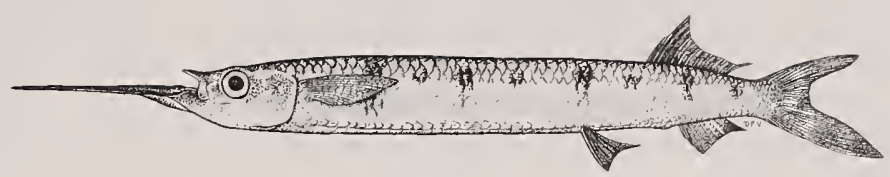

Fin elements: Dorsal 13-15; Anal 11-13; Pectoral 11-12.

Predorsal scales: $36-41$.

Maximum recorded length in southern African waters: $\pm 47 \mathrm{~cm} \mathrm{SL}$.

\section{Distribution}

H. far occurs throughout the tropical and subtropical waters of the Indo-West Pacific. Within southern Africa this species is common from Maputo Bay to Knysna, with a few records west to False Bay (Collette 1986b).

\section{Biology and ecology}

Sexual maturity is attained at a length of $25 \mathrm{~cm} \mathrm{SL}$ and the breeding season lasts from October to March (Smith 1933). Spawning usually occurs in the marine environment but has also been recorded in estuarine bays such as Knysna. Females produce up to 12000 large eggs ( $\pm 3 \mathrm{~mm}$ diameter) per season. The eggs have numerous glutinous filaments by which they attach to floating objects and aquatic plants (van der Elst 1988). The larvae have no prolongation of the lower jaw, and adult proportions are only attained at 50-60 mm TL (Smith 1933). A peak in juvenile (50$100 \mathrm{~mm}$ TL) numbers in the Knysna Estuary occurs during January and February (Whitfield \& Kok 1992).

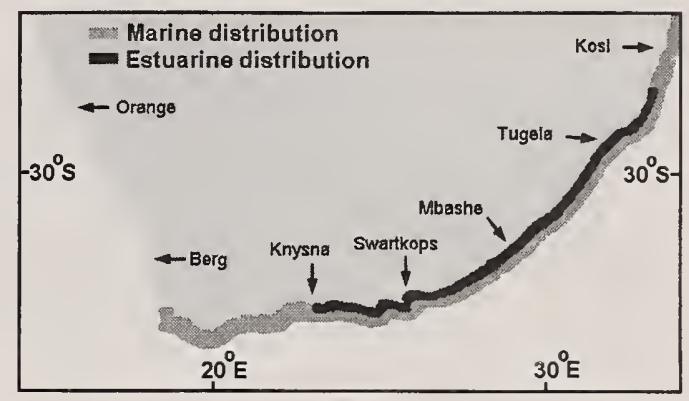

$H$. far has a recorded salinity range of $0-35 \%$, with individuals usually confined to the lower reaches of estuaries where salinities are higher. Within Knysna this species occurs throughout the estuary but is most abundant in the lower reaches (Whitfield \& Kok 1992).

The small mouth bears very fine teeth but the lower jaw extension makes the capture and consumption of large invertebrates and small fishes difficult. The diet consists primarily of aquatic plants and pelagic invertebrates, the latter being gathered by raising the short upper jaw so as to skim the water surface. Small shrimps, crab larvae, and even insects floating on the surface are eaten (van der Elst 1988).

Family: PLATYCEPHALIDAE

Species: Platycephalus indicus (Linnaeus, 1758)

Common name: Bartail flathead

Smiths' Sea Fishes number: 155.6

Illustrated specimen length: $21 \mathrm{~cm} \mathrm{SL}$

\section{Selected anatomical features}

Fin elements: Dorsal I/VII-VIII/I + 13-14;

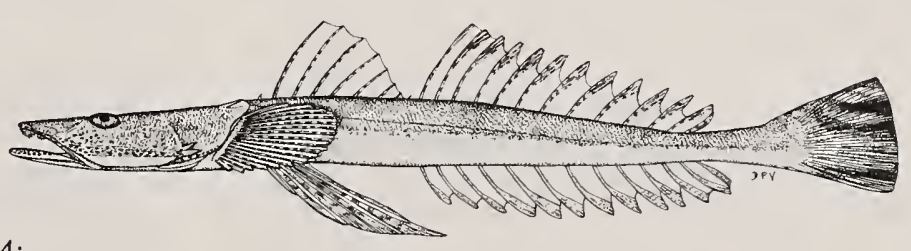
Anal 13; Pectoral 18-20.

Lateral scales: 68-82.

Maximum recorded length in southern

African waters: $\pm 86 \mathrm{~cm} \mathrm{SL}$. 


\section{Distribution}

The bartail flathead is a widespread, mainly tropical Indo-West Pacific species found in estuaries and shallow water to about $15 \mathrm{~m}$ (Knapp 1986). Within southern Africa, this species ranges from the Mossel Bay area eastwards into the subtropical waters of KwaZulu-Natal.

\section{Biology and ecology}

Sexual maturity is attained at $36 \mathrm{~cm} \mathrm{SL}$. Although a single ripe-running female was recorded in the St Lucia Estuary during November, spawning is not considered to be an estuarine function. The spawning season ranges between July and November in KwaZulu-Natal waters (Wallace 1975b). $P$. indicus less than $10 \mathrm{~cm} \mathrm{SL}$ are usually rare in estuaries, although juveniles sometimes make extensive use of mangrove areas for shelter and feeding (van der Elst 1988).

The recorded salinity range of the bartail flathead is from $1-58 \%$ (Whitfield 1996b) and also shows considerable tolerance to fluctuating turbidities (van der Elst 1988). This species is common in estuaries and open water where silt has been deposited. Its own muddy colouration blends well with these surroundings and the fish is very inconspicuous when it buries itself

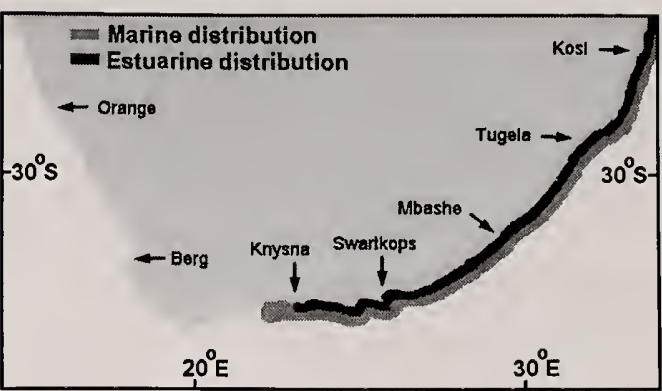

below the mud surface with only its eyes exposed (van der Elst 1988). The role of the prominent pattern on the caudal fin, which can only be seen when fully extended, is unknown but may be used for intraspecific display purposes or as a decoy for predators. In addition, the two preopercular spines may be a defence mechanism against predators.

$P$. indicus is an ambush predator (i.e. it does not actively pursue its prey), feeding on shrimps, penaeid prawns, crabs, mysids, polychaete worms, and small fishes such as Johnius dorsalis, Solea bleekeri, Thryssa vitrirostris, Gilchristella aestuaria and a wide variety of gobies (Whitfield \& Blaber 1978a, Day et al. 1981, Marais 1984). The extremely broad mouth and camouflage colouration assists in the capture of a wide variety of prey.

Family: KUHLIIDAE

Species: Kuhlia mugil (Bloch \& Schneider, 1801)

Common name: Barred flagtail

Smiths' Sea Fishes number: 164.1

Illustrated specimen length: $95 \mathrm{~mm} \mathrm{SL}$

\section{Selected anatomical features}

Fin elements: Dorsal X, 9-11;

Anal III, 9-11; Pectoral 14.

Lateral scales: 48-56.

Maximum recorded length in southern

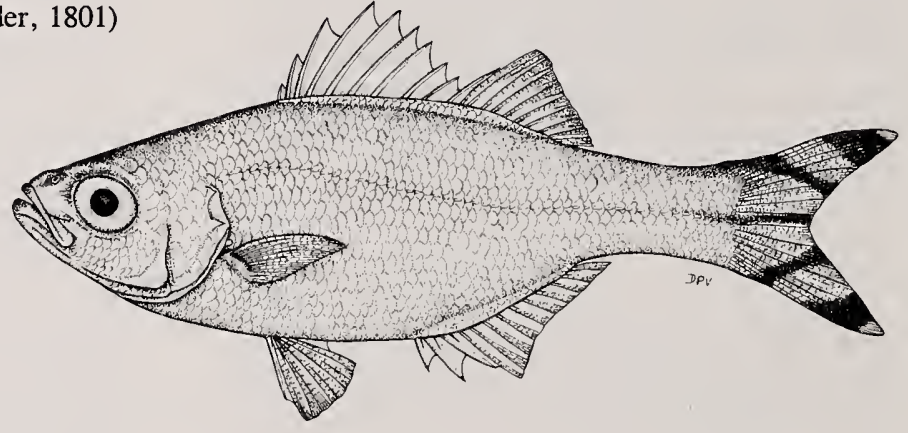

African waters: $\pm 16 \mathrm{~cm} \mathrm{SL}$.

\section{Distribution}

The barred flagtail is abundant throughout the coastal regions of the tropical Indo-Pacific, from the Galapagos to Africa, extending as far south as Cape Agulhas (Smith 1986c). The closely related rock flagtail Kuhlia rupestris also occurs in northern KwaZulu-Natal estuaries but can be distinguished from $K$. mugil by the absence of five dark stripes through the caudal fin.

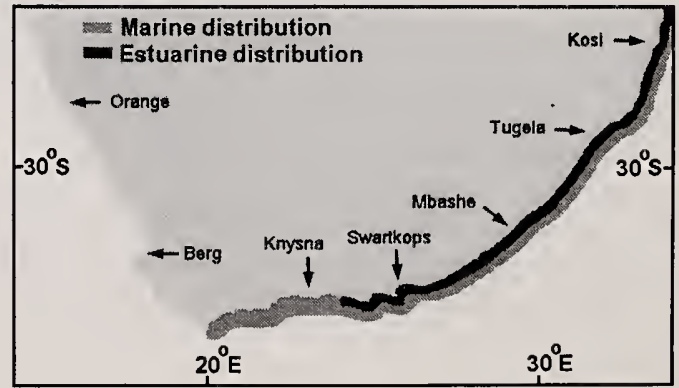


This species is often recorded from subtropical estuaries, sometimes extending into almost fresh water (Smith 1965). Spawning occurs throughout the year off the KwaZulu-Natal coast and the juveniles mainly use tidal pools as nursery areas (Smith 1986c).
The adults are common in the surf zone habit, with shoals sometimes congregating in the sheltered lee of reefs (van der Elst 1988). The diet consists mainly of zooplankton such as crab larvae and krill, but small fish are also eaten by large individuals.

Family: TERAPONIDAE

Species: Terapon jarbua (Forsskål, 1775)

Common name: Thornfish

Smiths' Sea Fishes number: 173.2

Illustrated specimen length: $11 \mathrm{~cm} \mathrm{SL}$

\section{Selected anatomical features}

Fin elements: Dorsal XI-XII, 9-11; Anal III, 7-10; Pectoral 13-14. Lateral scales: 69-93.

Maximum recorded length in southern African waters: $\pm 26 \mathrm{~cm}$ SL.

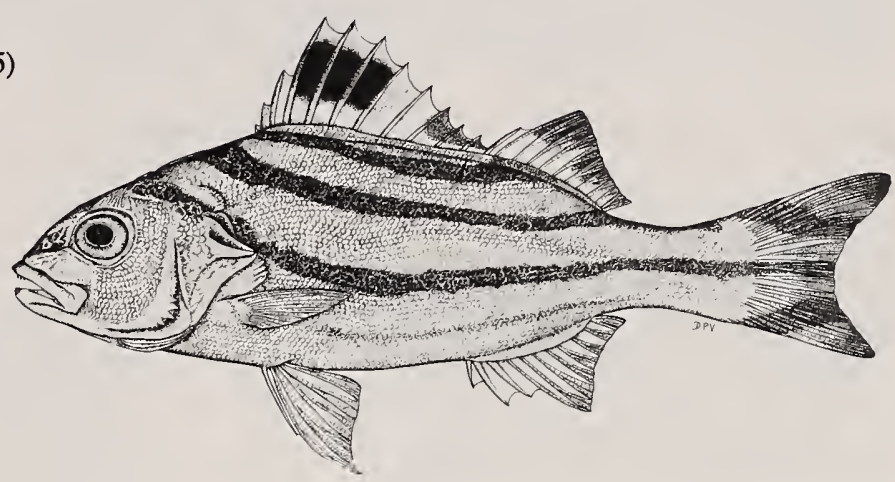

\section{Distribution}

The thornfish is widely distributed in the tropical and subtropical Indo-West Pacific region, extending into the warm-temperate waters of the southeast coast of Africa. The closely related Pelates quadrilineatus also occurs in KwaZulu-Natal estuaries but can usually be distinguished from $T$. jarbua by a higher number (4-6) of dark horizontal lines (Heemstra 1986a).

\section{Biology and ecology}

Sexual maturity is attained at $13 \mathrm{~cm} \mathrm{SL}$, with spawning occurring in KwaZulu-Natal waters during the late spring and summer (Day et al. 1981). Juveniles 10-30 mm SL enter estuaries between November and May (Wallace \& van der Elst 1975). Shoals of juveniles 10$20 \mathrm{~mm}$ SL are sometimes caught in the lower reaches of Eastern Cape estuaries during the summer but appear to leave these systems before the onset of winter. Occasional specimens are found as far west as Knysna where they are associated with a warm water power station outlet. The juveniles and adults of this species are often abundant in KwaZulu-Natal estuaries, sometimes extending into freshwater areas adjacent to these systems (Heemstra 1986a).

$T$. jarbua is a strong osmoregulator and has been recorded in salinities ranging from $0-72 \%$ (Whitfield 1996b). Although it can survive low salinities $(<1 \%$ ) under warm water conditions (Blaber \& Cyrus 1981),

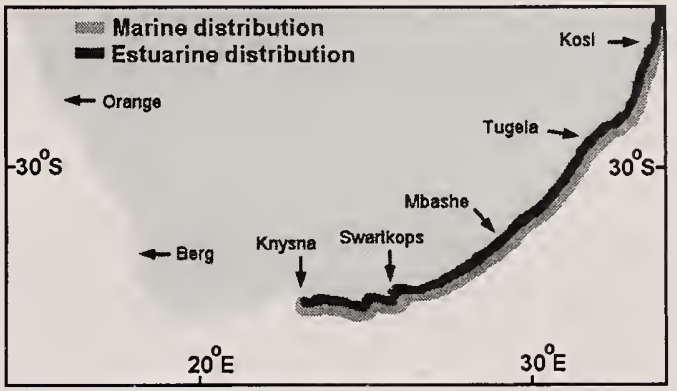

low salinities in combination with low temperatures $\left(12^{\circ} \mathrm{C}\right)$ cause mass mortalities (Blaber \& Whitfield 1976). This species is associated with water turbidities ranging from less than $10 \mathrm{NTU}$ to greater than $80 \mathrm{NTU}$ (Cyrus \& Blaber 1987c). Based on field and laboratory choice chamber experiments (Cyrus \& Blaber 1987a, 1987b) $T$. jarbua can be regarded as being indifferent to water turbidity.

New recruits ( $<30 \mathrm{~mm} \mathrm{SL}$ ) feed mainly on copepods and amphipods, but a wide variety of other organisms are also consumed (Whitfield 1985). Larger juveniles and adults have been recorded feeding mainly on fish scales removed from living fishes, as well as both terrestrial and aquatic invertebrates (Whitfield \& Blaber 1978a). T. jarbua always attacks the lateral surface of the prey species and scales are removed mainly from the posterior region of the body, particularly around the caudal peduncle. Underwater 
observations of their hunting behaviour have been described by Whitfield (1979) in estuaries and by van der Elst (1988) in the marine environment. The former observations indicate a predominantly active foraging mode by small schools of juveniles, whereas the latter describes a solitary mode of feeding.

Family: POMATOMIDAE

Species: Pomatomus saltatrix (Linnaeus, 1766)

Common name: Elf

Smiths' Sea Fishes number: 178.1

Illustrated specimen length: $24 \mathrm{~cm} \mathrm{SL}$

\section{Selected anatomical features}

Fin elements: Dorsal VII-VIII+I, 23-28;

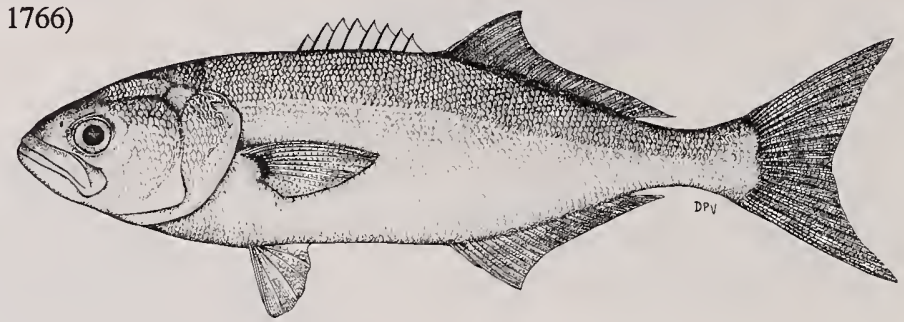

Anal II, 23-27; Pectoral 16.

Lateral scales: 90-100.

Maximum recorded length in southern

African waters: $\pm 80 \mathrm{~cm} \mathrm{SL}$.

\section{Distribution}

The elf occurs in all oceans between latitudes $50^{\circ} \mathrm{N}$ and $50^{\circ} \mathrm{S}$ (Smith \& Smith 1986a). Within southern Africa it is known to occur on the west coast but is particularly common along the south and east coasts, declining in abundance towards Mozambique (van der Elst 1976).

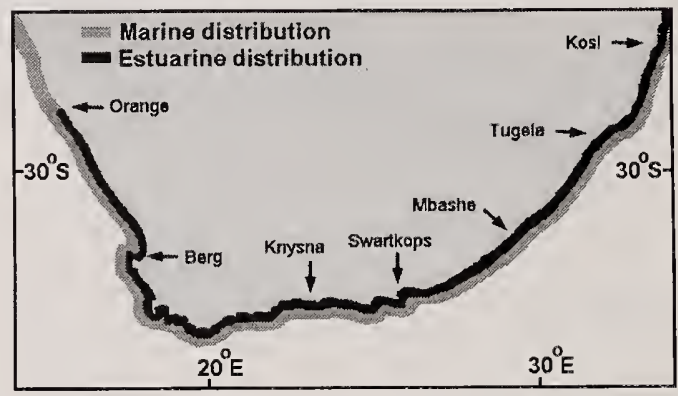

\section{Biology and ecology}

Most $P$. saltatrix become sexually active at $24 \mathrm{~cm} \mathrm{TL}$ for males and $25 \mathrm{~cm} \mathrm{TL}$ for females. The life cycle of this species involves lengthy migrations each winter from the Eastern Cape to KwaZulu-Natal. Following maturation in spring, spawning takes place between September and January, with a peak in November (van der Elst 1976). The Tugela Bank has been identified as one spawning area, with other breeding grounds also likely. The pelagic larvae drift passively in shelf waters and are transported southwards, partially assisted by the Agulhas Current (Beckley \& Connell 1996). The $0+$ juveniles spend their first year in the warmtemperate coastal waters, with some individuals utilizing estuaries in the region. Juveniles ( $<40 \mathrm{~mm}$ TL) enter the Knysna Estuary between September and December (Whitfield \& Kok 1992). Subadults and adults leave warm-temperate estuaries at the end of summer to join shoals on the annual migration to KwaZulu-Natal waters (Day et al. 1981).

The recorded salinity range of elf is $8-49 \%$ (van der Elst 1976, Whitfield 1996b), with most specimens found in the lower reaches of permanently open estuaries where salinities are similar to those in the sea.

Mortalities of $P$. saltatrix were recorded in the temporarily closed Bot Estuary when salinities declined to $3 \%$ (Bennett 1985). This species hunts by sight and is normally associated with low turbidity waters $(<10$ NTU) in estuaries.

The diet of juveniles less than $10 \mathrm{~cm}$ FL in the Knysna Estuary is dominated by small crustaceans such as shrimps, penaeid prawns and mysids (Smale \& Kok 1983). Juveniles and adults greater than $10 \mathrm{~cm} F L$ in the same system are piscivorous, with cephalopods (Loligo sp.) the only invertebrate prey item consumed. Atherina breviceps was the most important prey species in the Knysna Estuary, with both pelagic and demersal fishes recorded in the diet. Shoals of adult fish along the coast move in and out of estuary mouths with the tide, feeding on small mugilids, ambassids, clupeids and haemulids (Day et al. 1981). In certain Eastern Cape estuaries, cephalopods (Sepia sp.) were more important in the diet than fish (Marais 1984). Although $P$. saltatrix is a predator, other piscivores such as king mackerel (Scomberomorus commerson) and leervis (Lichia amia) prey extensively on this species in the marine environment (van der Elst 1976). 
Family: HAEMULIDAE

Species: Pomadasys commersonnii (Lacepède, 1801)

Common name: Spotted grunter

Smiths' Sea Fishes number: 179.10

Illustrated specimen length: $13 \mathrm{~cm} \mathrm{SL}$

\section{Selected anatomical features}

Fin elements: Dorsal XI, 14-15; Anal III, 9-10; Pectoral 17-19. Lateral scales: 52-54.

Maximum recorded length in southern African waters: $\pm 69 \mathrm{~cm}$ SL.

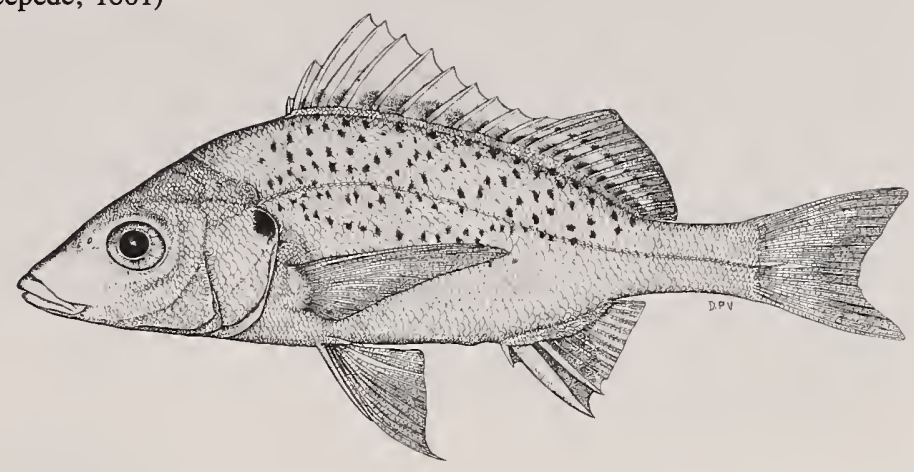

\section{Distribution}

The spotted grunter is a mainly shallow water $(<30 \mathrm{~m}$ depth) western Indian Ocean species (Smith \& McKay 1986). Within southern Africa it is common along the eastern coast, with occasional specimens recorded as far west as False Bay during summer (Day et al. 1981). The related cock grunter Pomadasys multimaculatum also occurs in KwaZulu-Natal estuaries but can be distinguished from $P$. commersonnii by the spots that extend onto the head.

\section{Biology and ecology}

Most males are mature by $30 \mathrm{~cm}$ and females by $36 \mathrm{~cm}$ SL. Spawning usually occurs at sea between August and December (Wallace 1975b) although breeding has been recorded in the marine dominated Durban Bay. Viable eggs have also been collected in the St Lucia system during August and September (Connell 1996). Partially spawned fish penetrate short distances into estuaries and on rare occasions ripe-running specimens seem to stray into this environment from adjacent spawning areas (Wallace 1975b). Most adults that enter estuaries do so in a post-spawning condition.

The egg and larval development occurs at sea with juveniles first entering estuarine nursery areas at 20-30 mm TL (Wallace \& van der Elst 1975). In certain Eastern Cape estuaries, juveniles less than $50 \mathrm{~mm} \mathrm{SL}$ are abundant in the upper reaches during the summer months, often extending their distribution into fresh water (Ter Morshuizen et al. 1996a). According to Wallace \& van der Elst (1975) the recruitment into KwaZulu-Natal estuaries is maximal during early spring and summer.

A monthly growth increment of approximately $12-$ $15 \mathrm{~mm}$ has been estimated for juveniles in their first year (Wallace 1975a), at which stage they return to the sea where maturity occurs at about three years of age. Following sexual maturity, mass increments range from

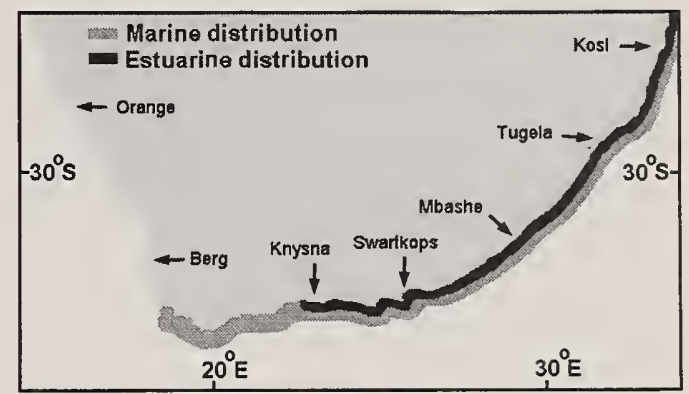

$600-700 \mathrm{~g}$ per annum. Fish which reach the maximum recorded size of $87 \mathrm{~cm} \mathrm{TL}$ are approximately 15 years of age (Wallace \& Schleyer 1979).

$P$. commersonnii has been recorded in salinities from $0-90 \%$ and can survive salinities less than $1 \%$ for prolonged periods (Blaber \& Cyrus 1981). However, mass mortalities of this species have been recorded in the Kosi and St Lucia systems when salinities declined below $4 \%$ and coincided with water temperatures below $13^{\circ} \mathrm{C}$ (Blaber \& Whitfield 1976). Similarly, the entire population was eliminated from the temporarily closed Seekoei Estuary when salinities increased above $90 \%$. The thermal preference of $0+$ juveniles was found to be between $24^{\circ} \mathrm{C}$ and $25^{\circ} \mathrm{C}$ (Deacon \& Hecht 1995). Field sampling and laboratory experiments have shown that the spotted grunter is indifferent to water turbidity (Cyrus \& Blaber 1987c, Hecht \& van der Lingen 1992).

Newly recruited juveniles prey mainly on pelagic copepods and mysids (Wooldridge \& Bailey 1982). This important angling species is primarily crepuscular and nocturnal, foraging predominantly on benthic dwelling anomurans and bivalves (Marais 1984, Hecht \& van der Lingen 1992). Mud prawns Upogebia africana are extracted from their burrows using a gill chamber pump action. 
Family: HAEMULIDAE

Species: Pomadasys kaakan (Cuvier, 1830)

Common name: Javelin grunter

Smiths' Sea Fishes number: 179.13

Illustrated specimen length: $12 \mathrm{~cm} \mathrm{SL}$

\section{Selected anatomical features}

Fin elements: Dorsal XII, 13-15;

Anal III, 7-8; Pectoral 17-18.

Lateral scales: $43-47$.

Maximum recorded length in southern

African waters: $\pm 51 \mathrm{~cm} \mathrm{SL}$.

\section{Distribution}

The javelin grunter has a mainly tropical Indo-West Pacific distribution, extending into the subtropical waters of southern Africa. The juveniles are sometimes common in the larger turbid northern KwaZulu-Natal estuaries (e.g. Richards Bay).

\section{Biology and ecology}

The length at sexual maturity is unknown since this species is mainly inactive in the estuarine environment. According to van der Elst (1988) spawning takes place during winter, often in the vicinity of estuary mouths. A small sample obtained from the Tugela Banks in June included specimens with ripe running and partially spawned gonads (Wallace 1975b). A few reproductively spent individuals have been recorded entering estuaries.

Length frequency distributions in the KwaZuluNatal estuarine environment indicate that recruitment of juveniles first occurs at lengths less than $40 \mathrm{~mm} \mathrm{TL}$, with most of the population being less than $12 \mathrm{~cm} \mathrm{TL}$ (Wallace 1975a).

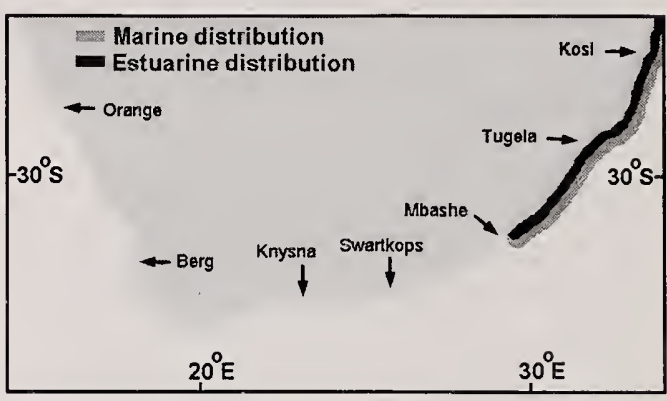

This species is tolerant of salinities between $4 \%$ and $44 \%$. Although it has been recorded in the riverine dominated Tugela Estuary it is usually absent from Lake St Lucia under oligohaline conditions. According to Cyrus (1992) P. kaakan is indifferent to turbidity.

Early juveniles feed extensively on copepods, later changing to a demersal diet of small crabs and polychaetes (van der Elst 1988). During foraging, $P$. kaakan blasts the benthos with a jet of water ejected from the mouth. The moderately developed gill rakers may assist with the filtering of food organisms during feeding, but quantities of fine sediment are also ingested (van der Elst 1988).

Family: HAEMULIDAE

Species: Pomadasys olivaceum (Day, 1875)

Common name: Piggy

Smiths' Sea Fishes number: 179.17

Illustrated specimen length: $10 \mathrm{~cm} \mathrm{SL}$

\section{Selected anatomical features}

Fin elements: Dorsal XII, 15-17; Anal III, 11-13; Pectoral 16-17.

Lateral scales: 51-54.

Maximum recorded length in southern

African waters: $\pm 21 \mathrm{~cm} \mathrm{SL}$.

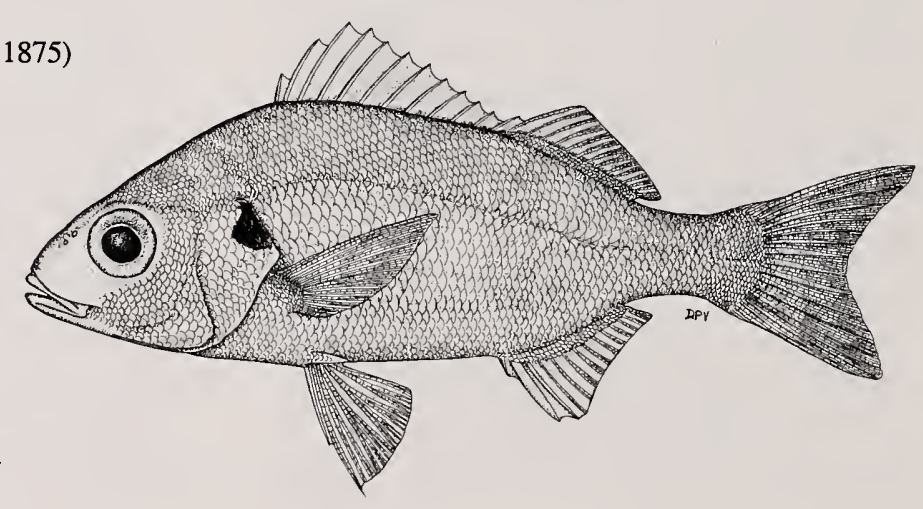




\section{Distribution}

The piggy has a mainly tropical Indo-West Pacific distribution but specimens have been collected in cooltemperate waters as far north as Swakopmund. The juveniles of this predominantly marine species occur in large shoals around shallow-water outcrops whereas the adults are generally associated with deeper offshore reefs (van der Elst 1988). Juveniles are sometimes common in warm-temperate estuaries, especially in the vicinity of submerged plant beds (Smith \& McKay 1986).

\section{Biology and ecology}

$P$. olivaceum matures at approximately $14 \mathrm{~cm} \mathrm{FL}$ (Joubert 1981). Spawning takes place in deep water (van der Elst 1988) and the breeding season is prolonged (March-December). Juveniles ( $<50 \mathrm{~mm}$ TL) occurred throughout the year in Algoa Bay (Lasiak 1983b) but only between April and January around inshore reefs along the KwaZulu-Natal coast (Joubert 1981). This size group was most abundant in the lower and middle reaches of the Knysna Estuary during December (Whitfield \& Kok 1992). Beam trawls off the Swartkops Estuary mouth revealed that piggy juveniles comprised $76 \%$ of the total catch (Beckley 1984b).

Although $P$. olivaceum is generally confined to the lower half of estuaries, stragglers have been recorded from the upper reaches of the Knysna and Swartvlei

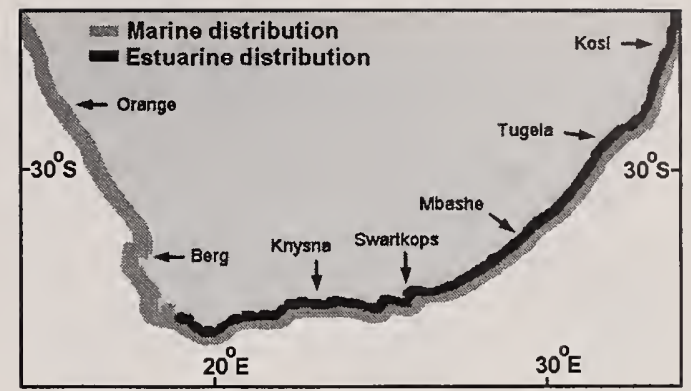

systems where salinities often decline below $10 \%$. The piggy is sensitive to rapid changes in temperature, with extensive mortalities having been recorded when cold upwelling events occur along the coast (Smith \& McKay 1986).

Juveniles in estuaries feed mainly on amphipods, with polychaetes, small crabs and prawns also being important (Day et al. 1981). Within the sea, juveniles forage on shrimps, penaeid prawns, polychaetes and mysids (Joubert \& Hanekom 1980). Adults consume mainly stomatopods, small fish, shrimps, penaeid prawns and crabs (Joubert \& Hanekom 1980). The piggy is an important forage fish and is preyed upon by piscivores such as Lichia amia in estuaries (Marais 1984) and dolphins in the sea (van der Elst 1988).

Family: LUTJANIDAE

Species: Lutjanus argentimaculatus (Forsskål, 1775)

Common name: Mangrove snapper

Smiths' Sea Fishes number: 181.5

Illustrated specimen length: $22 \mathrm{~cm} \mathrm{SL}$

\section{Selected anatomical features}

Fin elements: Dorsal X, 13-14;

Anal III, 7-8; Pectoral 16-17.

Lateral scales: $46-47$.

Maximum recorded length in southern

African waters: $\pm 85 \mathrm{~cm}$ SL.

\section{Distribution}

This species ranges from the Red Sea and tropical Indo-West Pacific region, south to Port Elizabeth (Anderson \& Allen 1986). The juveniles are sometimes common in subtropical southern African estuaries.
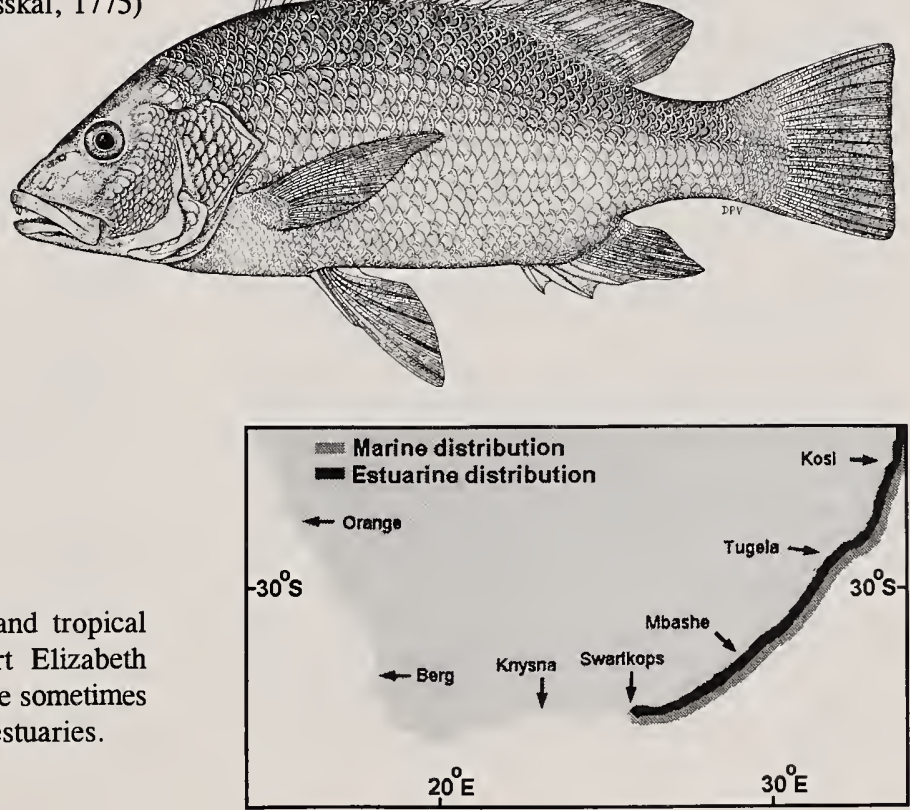
Sexual maturity is attained between $45 \mathrm{~cm}$ and $60 \mathrm{~cm}$ $\mathrm{TL}$, with spawning occurring during summer in offshore marine waters. The larvae are widely dispersed by ocean currents and when the juveniles are about $50 \mathrm{~mm}$ TL they migrate into littoral nursery areas. Within estuaries this species favours rocky areas or the prop roots of mangrove swamps (van der Elst 1988). Adults return to the sea where they occur down to $100 \mathrm{~m}$.

The recorded salinity range of juvenile mangrove snapper in estuaries is $1-35 \%$. Although this species is is frequently recorded from some of the larger subtropical estuaries, it is also capable of surviving prolonged oligohaline conditions in small temporarily closed estuaries along the KwaZulu-Natal coast, and may even enter fresh water.

The mangrove snapper is an ambush predator. In estuaries this species feeds mainly on mugilids and sparids, although crabs and prawns are also consumed. In the marine environment a variety of reef fish and crabs are eaten (van der Elst 1988).

\section{Family: LUTJANIDAE}

Species: Lutjanus fulviflamma (Forsskål, 1775)

Common name: Dory snapper

Smiths' Sea Fishes number: 181.8

Illustrated specimen length: $14 \mathrm{~cm} \mathrm{SL}$

\section{Selected anatomical features}

Fin elements: Dorsal X-XI, 12-14; Anal III, 8; Pectoral 15-17.

Lateral scales: 46-49.

Maximum recorded length in southern African waters: $\pm 28 \mathrm{~cm} \mathrm{SL}$.

\section{Distribution}

According to Anderson \& Allen (1986) L. fulviflamma ranges from the Red Sea and tropical Indo-West Pacific region, south to approximately East London. However, recent unpublished records indicate that juveniles occur in estuaries as far south as the Swartkops Estuary in the Eastern Cape.

\section{Biology and ecology}

This widespread species is especially common off rocky shores but is equally at home in estuaries over either muddy bottoms or in eelgrass beds (van der Elst 1988). Sexual maturity is attained between $16 \mathrm{~cm}$ and $17 \mathrm{~cm} \mathrm{TL}$, with spawning occurring over marine reefs from August to December. The juveniles first enter estuaries at about $20 \mathrm{~mm}$ TL (van der Elst 1988) and range upwards in size to about $16 \mathrm{~cm}$ TL (Day et al. 1981). Sexually mature individuals are absent from estuaries.

The salinity range of juveniles in southern African estuaries is $8-35 \%$ (Whitfield 1996b), although in other parts of its range juveniles have been recorded in

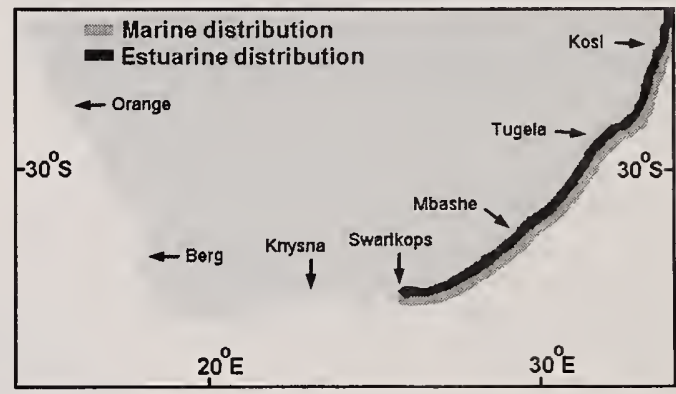

the lower reaches of freshwater streams (Allen 1985). This species is usually associated with euhaline conditions in the lower reaches of estuarine systems on the subcontinent.

Although not a typical shoaling fish species, $L$. fulviflamma does congregate in groups, and the juveniles are often associated with Rhabdosargus holubi aggregations in estuaries. The diet includes a variety of crustaceans, particularly crabs, isopods, amphipods, prawns, shrimps, mysids and polychaetes (Day et al. 1981, van der Elst 1988). Small fish, especially demersal species (e.g. gobies), are readily consumed when available. 
Family: SPARIDAE

Species: Acanthopagrus berda (Forsskål, 1775)

Common name: Estuarine bream

Smiths' Sea Fishes number: 183.1

Illustrated specimen length: $11 \mathrm{~cm} \mathrm{SL}$

\section{Selected anatomical features}

Fin elements: Dorsal XI-XII, 10-13; Anal III, 8-9; Pectoral 14.

Lateral scales: 43-47.

Maximum recorded length in southern African waters: $\pm 60 \mathrm{~cm} \mathrm{SL}$.

\section{Distribution}

The estuarine bream is abundant and widespread in the tropical Indo-West Pacific, extending into subtropical waters of the southeast coast of Africa (Smith \& Smith 1986). This species is rare in warm-temperate estuaries but occasional specimens are found as far west as Swartvlei on the Western Cape coast. It is the only sparid that has been regularly recorded in rivers and associated freshwater pans (Skelton 1993).

\section{Biology and ecology}

This important angling species is suspected of being a protandrous hermaphrodite, i.e. the fish functions first as a male, and then later changes sex into a female. Histological evidence, together with the fact that this reproductive style has been reported for other members of the genus, supports the above hypothesis (Garratt 1993).

Spawning by $A$. berda greater than $17 \mathrm{~cm} \mathrm{SL}$ occurs in the KwaZulu-Natal nearshore marine environment and estuary mouths, mainly from May to August (Wallace 1975b, Garratt 1993). In the Kosi Estuary mouth region, spawning was recorded at night and timed to coincide with the ebb tidal transport of eggs out to sea (Garratt 1993). Egg and early larval development takes place at sea, with $0+$ juveniles entering KwaZulu-Natal estuaries at approximately 10 $30 \mathrm{~mm}$ SL, mainly between July and November (Wallace \& van der Elst 1975). A monthly growth increment of 10-12 $\mathrm{mm}$ has been estimated for juveniles in their first year.

Population size estimates of $A$. berda (>22 cm TL) in the Kosi lakes were undertaken by Kyle \& Robertson (1997), who calculated that between 45000 and 56000 fish were present in the system during $1984 / 85$.

The estuarine bream is a strong osmoregulator and has been recorded in salinities ranging from $0-72 \%$ (Whitfield 1996b). This species is associated with a wide range of water turbidities, with $42 \%$ of individuals captured in estuaries occurring in water less than $50 \mathrm{NTU}$, and $58 \%$ in water greater than $50 \mathrm{NTU}$ (Cyrus \& Blaber 1987c). Based on field and laboratory choice chamber experiments (Cyrus \& Blaber 1987a, 1987b), A. berda can be regarded as a species that is indifferent to turbidity. This, together with a wide salinity tolerance, makes the estuarine bream ideally suited to utilization of estuarine environments.

Between $10 \mathrm{~mm}$ and $50 \mathrm{~mm}$ SL the juveniles feed on zooplankton, amphipods, chironomid larvae, tanaids and small crabs. From 50-100 mm SL amphipods are still consumed in large numbers but the main food is bivalve molluscs (Day et al. 1981). In Beachwood Creek (Mgeni Estuary) juvenile $(<100 \mathrm{~mm} \mathrm{SL}) A$. berda showed a positive selection for amphipods, tanaids and fish scales, with polychaetes, ostracods, gastropods and aquatic plants also being consumed (Harrison 1991). The diet of adults covers a wide spectrum and includes polychaetes, bivalves, sand dollars, crabs, prawns, shrimps and small fish (van der Elst 1988). 
Family: SPARIDAE

Species: Diplodus cervinus hottentotus (Smith, 1844)

Common name: Zebra

Smiths' Sea Fishes number: 183.16

Illustrated specimen length: $76 \mathrm{~mm} \mathrm{SL}$

\section{Selected anatomical features}

Fin elements: Dorsal XI, 12-13;

Anal III, 11; Pectoral 15.

Lateral scales: 60-67.

Maximum recorded length in southern

African waters: $\pm 46 \mathrm{~cm} \mathrm{SL}$.

\section{Distribution}

The zebra ranges from False Bay in the Western Cape Province to Sodwana Bay in KwaZulu-Natal (Smith \& Smith 1986). It is primarily a marine species, ranging from inshore shallows to depths of $60 \mathrm{~m}$ (van der Elst 1988), but is also a regular visitor to some of the larger warm-temperate estuaries.

\section{Biology and ecology}

D. cervinus hottentotus is a rudimentary hermaphrodite with no evidence of sex change (Mann \& Buxton 1993). Size at $50 \%$ sexual maturity is $285 \mathrm{~mm}$ FL which corresponds to an age of 6 years. The breeding season is mainly during spring and early summer (October - January) in the warm-temperate region (van der Elst 1988) but recruitment of juveniles less than 30 $\mathrm{mm}$ TL into the Knysna Estuary occurred as early as September and extended into December. A similar pattern of immigration was recorded in the Swartvlei Estuary (Whitfield \& Kok 1992). permanently open estuaries along the Eastern Cape coast. Its absence from temporarily closed estuaries suggests that this species is a weak osmoregulator and cannot survive prolonged reductions in salinity.

According to van der Elst (1988) 0+ juveniles are exclusively carnivorous whereas the adults have a predominantly vegetarian diet. Mann \& Buxton (1993) recorded polychaetes and amphipods as the main prey items in the diet of juvenile zebra from the Tsitsikamma National Park.

Family: SPARIDAE

Species: Diplodus sargus capensis (Smith, 1844)

Common name: Blacktail

Smiths' Sea Fishes number: 183.17

Illustrated specimen length: $10 \mathrm{~cm} \mathrm{SL}$

\section{Selected anatomical features}

Fin elements: Dorsal XII, 14-15; Anal III, 13-14; Pectoral 16-17.

Lateral scales: $62-72$.

Maximum recorded length in southern African waters: $\pm 32 \mathrm{~cm} \mathrm{SL}$.

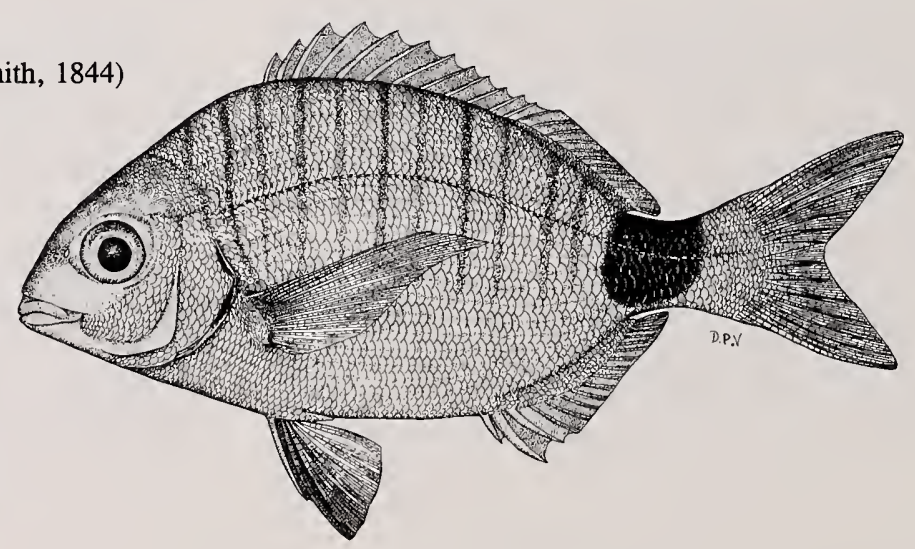




\section{Distribution}

The blacktail ranges from Angola to Mozambique and southern Madagascar (Smith \& Smith 1986). It is primarily a marine inshore species ( $<30 \mathrm{~m}$ depth), favouring turbulent seas and rocky shores. The juveniles utilize tidal pools and inshore reefs as nursery areas (Smale \& Buxton 1989) but are sometimes abundant in the lower and middle reaches of certain warm-temperate estuaries (Whitfield \& Kok 1992).

\section{Biology and ecology}

According to Mann \& Buxton (1993) this species undergoes dygynous gonadal development, with partial protandry occurring in the male population, i.e. only some males in the population appear to undergo a sex change. Size at $50 \%$ sexual maturity has been estimated at $22 \mathrm{~cm}$ FL and an age of 4 years (Mann \& Buxton 1993). The breeding season is protracted, with peak spawning activity from July to September in subtropical KwaZulu-Natal (Joubert 1981) and October-December in the warm-temperate region (Coetzee 1986).

Data from the Swartvlei Bay surf zone indicates a peak in postflexion larval abundance from October to December. Summer recruitment of juveniles into Eastern Cape intertidal pools has been documented by Beckley (1985b), and according to Smale \& Buxton (1989) blacktail less than $40 \mathrm{~mm}$ TL entered subtidal gullies in the same region mainly during February and March. Estuarine recruitment follows a similar pattern to that described for the marine inshore environment. Juveniles less than $40 \mathrm{~mm}$ TL were recorded entering the Knysna Estuary mainly during the spring and summer months, with a peak in recruitment of these size classes between October and December (Whitfield \& Kok 1992). In the Swartvlei Estuary, recruitment commenced in October and lasted until April. Beckley (1983) documented an influx of $0+$ juveniles into the

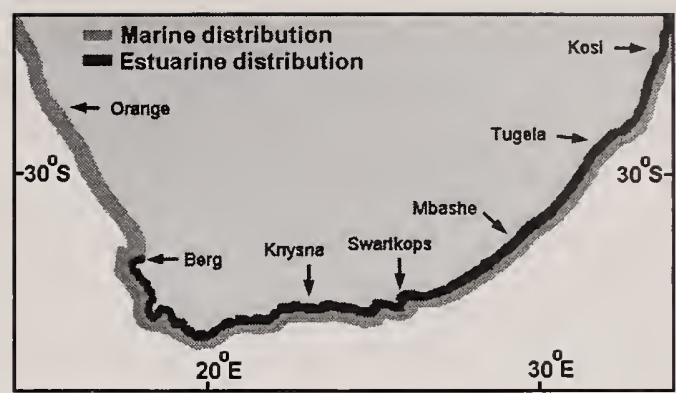

Swartkops Estuary in spring and early summer, and Bennett (1989) recorded recruitment into two Western Cape estuaries during March and May.

Although this species can survive in salinities ranging from $6 \%$ to at least $42 \%$, it is usually found in the seawater dominated lower half of open estuaries. Mortalities of blacktail were recorded in the Bot River Estuary during October 1981, when salinities in this temporarily closed system declined below 6\%o (Bennett 1985).

The less than $30 \mathrm{~mm}$ SL size class feed mainly on harpacticoid copepods, polychaetes and amphipods in Eastern Cape intertidal pools (Christensen 1978), whereas harpacticoid copepods, chironomid larvae and ostracods were important food items in the Swartvlei Estuary (Whitfield 1985). Fish above $50 \mathrm{~mm} \mathrm{SL}$ are often herbivorous and closely associated with Zostera capensis beds in warm-temperate estuaries. In the sea blacktail feed mainly on rhodophytes, chlorophytes, poriferans, pelecypods and ascidiaceans, with epiphytic diatoms being digested from the leaf surfaces of the macroalgae (Joubert \& Hanekom 1980). The change from a predominantly carnivorous to an omnivorous diet is facilitated by changes in anatomy, such as a lengthening of the intestine to cope more efficiently with the considerable amount of plant material consumed.

Family: SPARIDAE

Species: Lithognathus lithognathus (Cuvier, 1830)

Common name: White steenbras

Smiths' Sea Fishes number: 183.20

Illustrated specimen length: $12 \mathrm{~cm} \mathrm{SL}$

\section{Selected anatomical features}

Fin elements: Dorsal XI, 10;

Anal III, 8; Pectoral 16-17.

Lateral scales: 44-51.

Maximum recorded length: $\pm 89 \mathrm{~cm} \mathrm{SL}$.

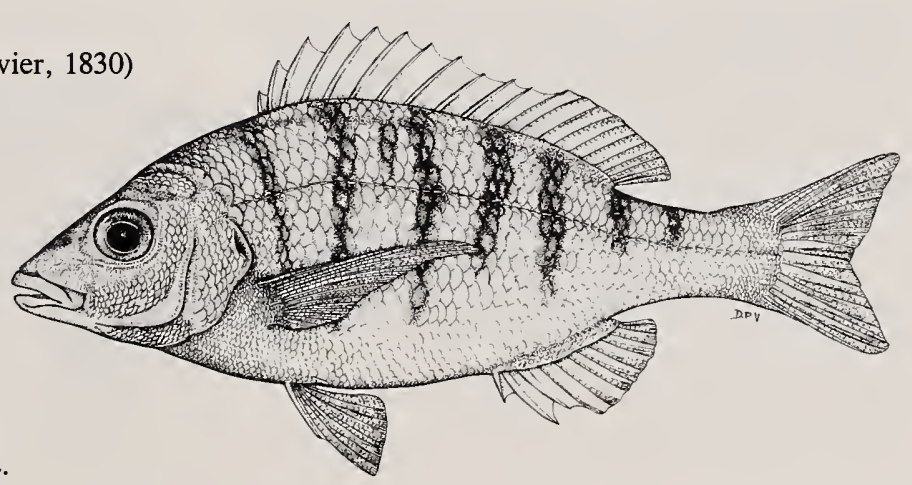




\section{Distribution}

This species ranges from the mouth of the Orange River in the west to KwaZulu-Natal in the east (Smith \& Smith 1986). Juveniles are abundant in some of the larger warm-temperate estuaries but they are rare in subtropical systems along the east coast. Post-estuarine juveniles ( $>13 \mathrm{~cm} \mathrm{SL}$ ) are semi-resident in the surf zone, with the adults extending their distribution into water up to $25 \mathrm{~m}$ deep and undertaking large-scale annual spawning migrations (Bennett 1993).

\section{Biology and ecology}

White steenbras are rudimentary hermaphrodites with genetically determined sexes and, although some mature fish have approximately equal ovarian and testicular development in the gonads, individuals function only as males or females (Mehl 1973). Out of a total of 425 mature $L$. lithognathus examined, 172 were males, 233 females and 20 hermaphrodites (Bennett 1993). Most white steenbras are mature by $54 \mathrm{~cm} \mathrm{SL}$, at which stage they commence annual spawning migrations eastwards to near the northeastern limit of their distributional range. Spawning occurs during late winter, with a return migration commencing in spring and reaching Western Cape waters during summer (Bennett 1993).

Egg and larval development occurs at sea, with $0+$ juveniles ( $<50 \mathrm{~mm} \mathrm{TL})$ entering estuaries mainly between September and November (Bennett 1993, Whitfield \& Kok 1992). A monthly growth increment of approximately $13 \mathrm{~mm}$ has been estimated for juvenile L. lithognathus (Bennett 1989, Whitfield \& Kok 1992). Fish that reach the maximum recorded size of $110 \mathrm{~cm}$ TL are approximately 20 years of age.

This species has been recorded in salinities ranging from $1-90 \%$ and is associated with both clear and turbid waters. They were recorded dying in the closed

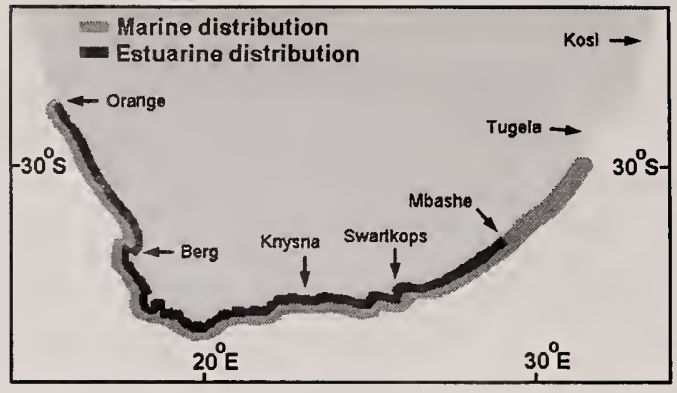

Seekoei Estuary when salinities increased above $90 \%$. Prolonged oligohaline conditions also result in mortalities of this species (Bennett 1985), as do dissolved oxygen concentrations below $1 \mathrm{mg} \mathrm{l}^{-1}$ (Russell 1994). Oxygen consumption under different temperature and feeding regimes has been investigated by Du Preez et al. (1986).

Between $10 \mathrm{~mm}$ and $30 \mathrm{~mm}$ SL the juveniles feed mainly on copepods and amphipods (Whitfield 1985, Wooldridge \& Bailey 1982). Larger individuals in estuaries have a more diverse diet, with amphipods, anomurans, brachyurans, polychaetes, isopods and insect larvae being important prey taxa (Bennett 1993, Whitfield 1988a). A study by Schlacher \& Wooldridge (1996a) has shown that male Grandidierella lignorum in the Gamtoos Estuary are consumed by $L$. lithognathus in significantly higher numbers than females due to behavioural differences between the amphipod sexes.

The white steenbras enters extremely shallow areas, where its tail can often be seen protruding out of the water as it forages. Prawns are mostly 'blown' from their burrows by a strong jet of water which is forced through the mouth of the fish by the pumping action of the powerful gill covers (van der Elst 1988).

\section{Family: SPARIDAE}

Species: Lithognathus mormyrus (Linnaeus, 1758)

Common name: Sand steenbras

Smiths' Sea Fishes number: 183.21

Illustrated specimen length: $13 \mathrm{~cm} \mathrm{SL}$

\section{Selected anatomical features}

Fin elements: Dorsal XI, 12-13;

Anal III, 10-11; Pectoral 15-17.

Lateral scales: $60-65$.

Maximum recorded length in southern

African waters: $\pm 46 \mathrm{~cm} \mathrm{SL}$.

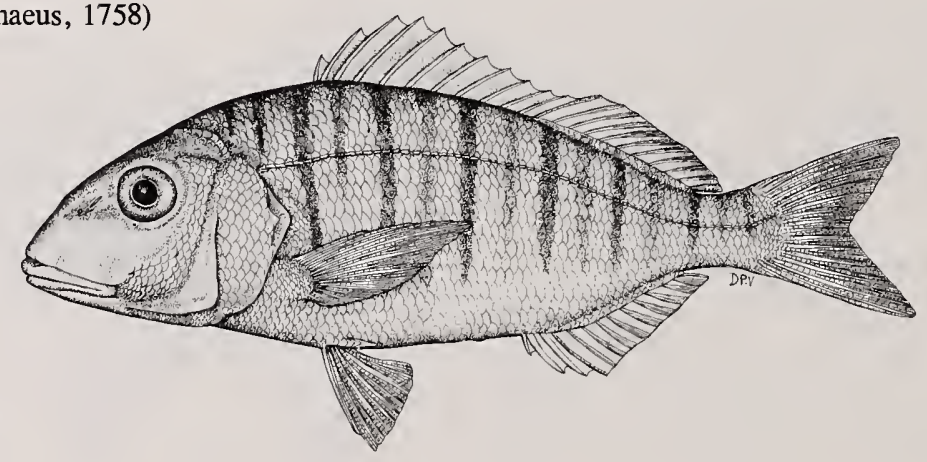




\section{Distribution}

This widespread coastal shelf species occurs from the Mediterranean region to the Cape, and round the subcontinent to Mozambique (Smith \& Smith 1986). Within southern African estuaries it is usually associated with the mouth region of these systems.

\section{Biology and ecology}

The sand steenbras makes use of permanently open estuaries in the Eastern Cape and is most frequently encountered in the sandy flood tidal deltas of these systems. The silvery coloration and darker crossbars marking its flanks provide excellent camouflage in this type of environment. Thus the sand steenbras remains inconspicuous even when present in moderate numbers (van der Elst 1988). This species has not been recorded in low salinity regions of any southern African estuary or those systems that are temporarily closed, suggesting that it is intolerant of oligohaline conditions

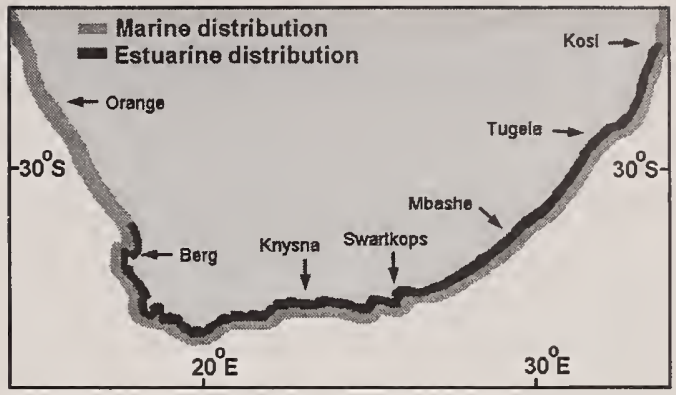

Spawning occurs in the marine environment during summer. Juveniles less than $40 \mathrm{~mm}$ TL were recorded in the Knysna Estuary between September and April, and in the Swartvlei Estuary between March and May (Whitfield \& Kok 1992). Lasiak (1983b) documented the presence of $L$. mormyrus juveniles less than $50 \mathrm{~mm}$ $\mathrm{TL}$ in Algoa Bay throughout the year.

Juveniles feed mainly on small invertebrates, with the adults consuming benthic invertebrates such as cracker shrimps, mole crabs and bivalve molluscs (van der Elst 1988)

Family: SPARIDAE

Species: Rhabdosargus globiceps (Cuvier, 1830)

Common name: White stumpnose

Smiths' Sea Fishes number: 183.35

Illustrated specimen length: $82 \mathrm{~mm} \mathrm{SL}$

\section{Selected anatomical features}

Fin elements: Dorsal XI, 11-13;

Anal III, 10-11; Pectoral 16-17.

Lateral scales: $57-61$.

Maximum recorded length: $\pm 45 \mathrm{~cm}$ SL.

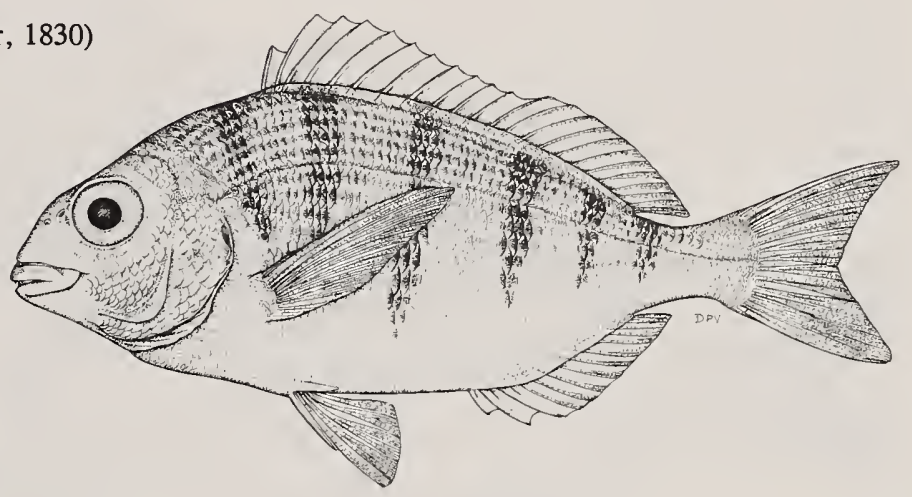

\section{Distribution}

The white stumpnose is endemic to southern African waters and has been recorded in the sea from Angola to the Eastern Cape. This temperate species is absent from subtropical KwaZulu-Natal waters and is rare in most warm-temperate estuaries of the southeastern Cape. Juveniles, up to approximately $14 \mathrm{~cm} \mathrm{SL}$, are sometimes abundant in certain of the larger estuaries along the Western Cape coast, and in sheltered areas of False Bay (Talbot 1955). Adult fishes are invariably confined to the marine environment, often occurring in large shoals down to $70 \mathrm{~m}$ depth.

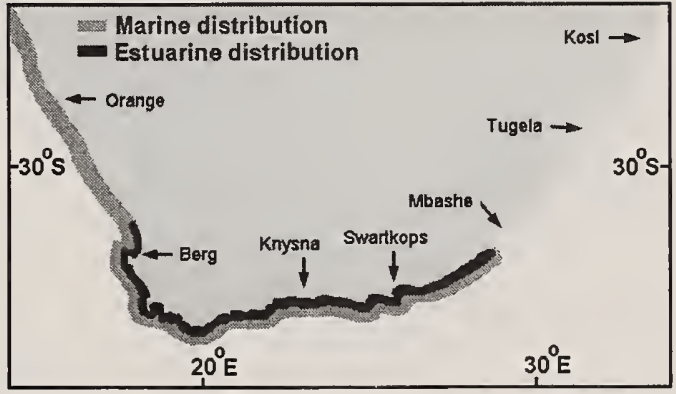


Breeding occurs at an age of approximately three years, with female $R$. globiceps showing signs of sexual maturity at $23 \mathrm{~cm} \mathrm{SL}$ and males at $27 \mathrm{~cm} \mathrm{SL}$. In the Western Cape this species breeds in inshore marine waters between August and February, with a summer spawning peak (Talbot 1955). The fertilized eggs, which are approximately $1 \mathrm{~mm}$ in diameter, are buoyant and float near the water surface (van der Elst 1988).

Recruitment of white stumpnose less than $40 \mathrm{~mm}$ SL into the Klein Estuary occurred during January/ February (Talbot 1955), and January-April in the Palmiet and Kleinmond systems (Bennett 1989). $R$. globiceps less than $20 \mathrm{~mm}$ TL were recorded in the Swartvlei Bay surf zone during September and October (Whitfield 1989b). Recruitment of less than $40 \mathrm{~mm}$ TL specimens into the Knysna and Swartvlei estuaries occurred between September and December, with a summer peak in abundance (Kok \& Whitfield 1992). Juveniles remain in estuaries for approximately two years and grow at a rate of $5 \mathrm{~mm}$ to $10 \mathrm{~mm}$ per month or 60-120 mm per annum ('Talbot 1955).
Very few $R$. globiceps are captured in the upper reaches of estuaries and none were netted during a long-term study in Swartvlei lake (Whitfield 1986a), despite the fact that salinities in this part of the system are usually above $10 \%$. The recorded salinity range of the white stumpnose is $3-35 \%$, with specimens dying in the temporarily closed Bot Estuary when salinities declined below 3\% for prolonged period (Bennett 1985).

The diet of newly recruited (20 mm SL) $R$. globiceps in estuaries is dominated by zooplankton and there appears to be a transition phase before they start feeding on amphipods, isopods and filamentous algae. At a length of approximately $40 \mathrm{~mm} \mathrm{SL}$ the juveniles start to develop molars, enabling them to consume a variety of molluscs, crabs, prawns and shrimps. They often feed in Zostera or Ruppia beds, and their stomachs are often packed with both macrophytic and filamentous algal material (Talbot 1955). The diet of adult fish in the sea is dominated by bivalves, polychaetes, amphipods, barnacles and crabs (Day et al. 1981).

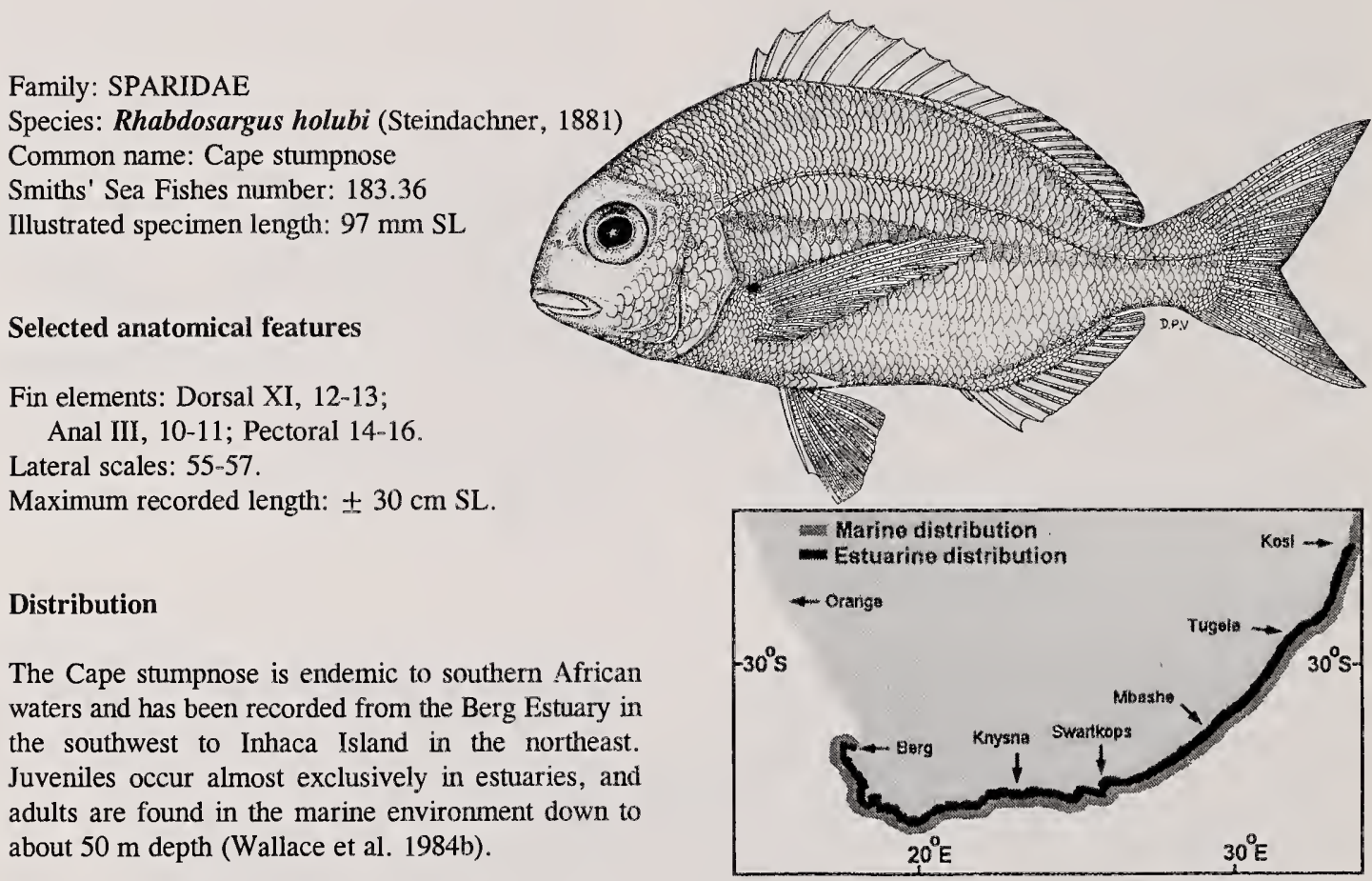

\section{Biology and ecology}

Spawning by $R$. holubi greater than $15 \mathrm{~cm} \mathrm{SL}$ occurs in the nearshore marine environment, mainly between May and August in KwaZulu-Natal (Wallace 1975b)

and between July and February in the Eastern and Western Cape. The postlarvae first enter estuaries at a length of approximately $10 \mathrm{~mm} \mathrm{SL}$ and attain a length 
of approximately $10 \mathrm{~cm}$ in their first year. The return migration to the sea appears to occur when individuals are larger than $14 \mathrm{~cm} \mathrm{SL}$ (Blaber 1974c).

This species is a strong osmoregulator, tolerant of a wide range of salinities $(0.7-70 \%)$ and temperatures $\left(10-30^{\circ} \mathrm{C}\right)$ (Blaber 1973b). When exposed to a new salinity the internal osmotic concentration does not change immediately, which is of considerable importance to a fish living in tidal estuaries subject to short-term changes in salinity (Blaber 1974a). $R$. holubi was one of the few species to survive the prolonged low salinities $(<3 \%)$ recorded in the temporarily closed Bot Estuary during 1981 (Bennett 1985). However, low salinities $(<2 \%)$ in combination with low temperatures $\left(12^{\circ} \mathrm{C}\right.$ ) are lethal to this fish (Blaber \& Whitfield 1976). In the temporarily closed Seekoei Estuary $R$. holubi was recorded dying in salinities above $90 \%$ (Whitfield 1989e), and in Rondevlei extensive mortalities were recorded when dissolved oxygen concentrations declined below $1 \mathrm{mg} \mathrm{l}^{-1}$ (Russell 1994). This species is associated with a wide range of water turbidities, with $65 \%$ of individuals occurring in water less than 10 NTU (Cyrus \& Blaber 1987c). Based on field and laboratory choice chamber experiments (Cyrus \& Blaber 1987a, 1987b) the Cape stumpnose can be regarded as a species which prefers clear water but is tolerant of high turbidities.
Copepods were the dominant component in the diet of postlarval (10-30 mm SL) $R$. holubi, whereas juveniles larger than $30 \mathrm{~mm}$ feed mainly on filamentous algae, aquatic macrophytes and epibenthic invertebrates (Whitfield 1984, 1985). The fish do not appear to assimilate the macrophytic plant material due to the absence of a cellulase or a method of breaking up the plant tissue, but do digest the epiphytic diatoms which cover the leaves (Blaber 1974b). The tricuspid teeth of juvenile $R$. holubi are specialized for grazing aquatic plants and differ from the molariform teeth of adults which consume mainly echinoderms, molluscs crustaceans and polychaetes (Buxton \& Kok 1983, Schleyer \& Wallace 1986).

Both the condition factor and food intake of the Cape stumpnose are affected by temperature. Food intake at $15^{\circ} \mathrm{C}$ was approximately half that at $22^{\circ} \mathrm{C}$, and the lipid content of summer specimens from the West Kleinemonde Estuary was $6.4 \%$ compared to $0.7 \%$ in winter (Blaber 1975). Daily summer and winter food consumption for juveniles in Swartvlei was calculated to be $6 \%$ and $3 \%$ of fish mass respectively (Whitfield 1984). Although juveniles are recorded in significantly higher numbers in association with aquatic plant beds (Hanekom \& Baird 1984), they can also survive in estuarine environments where submerged macrophytes are absent (Wallace \& van der Elst 1975).

Family: SPARIDAE

Species: Rhabdosargus sarba (Forsskål, 1775)

Common name: Tropical stumpnose

Smiths' Sea Fishes number: 183.37

Illustrated specimen length: $13 \mathrm{~cm} \mathrm{SL}$

\section{Selected anatomical features}

Fin elements: Dorsal XI, 12-13;

Anal III, 10-11; Pectoral 14-15.

Lateral scales: 56-59.

Maximum recorded length in southern African waters: $\pm 55 \mathrm{~cm}$ SL.

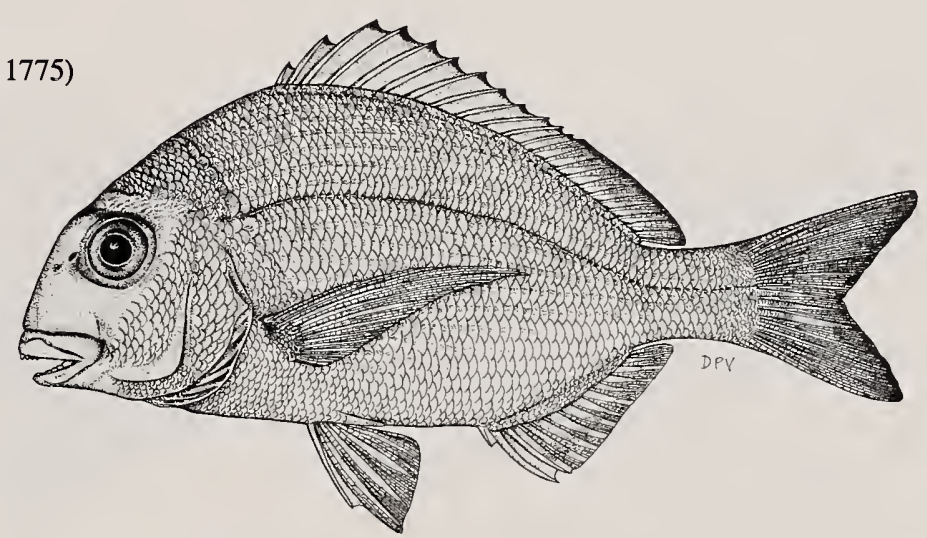

\section{Distribution}

This species has a mainly tropical Indo-West Pacific distribution, extending into the subtropical waters of the southeast coast of Africa. They are rare in warmtemperate estuaries but occasional juveniles have been found as far west as the Wilderness estuarine lakes in the Western Cape Province.

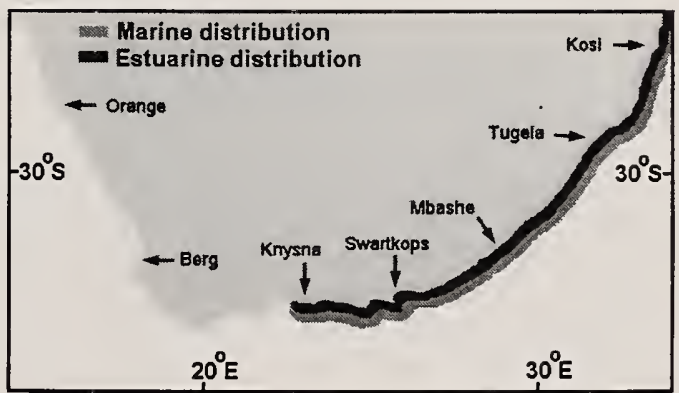


This species passes through a hermaphroditic stage with testes and ovaries present simultaneously (van der Elst 1988). $R$. sarba is regarded as protandrous (Yeung \& Chan 1987), i.e. it functions first as a male, then later changes to a female. Nocturnal serial spawning by adults greater than $20 \mathrm{~cm}$ SL occurs in the KwaZuluNatal nearshore marine environment, mainly from August to November (Wallace 1975b). A proportion of the spent individuals do return to estuaries but these are confined to fish less than $35 \mathrm{~cm} \mathrm{SL}$. According to Wallace (1975a) adults greater than $35 \mathrm{~cm}$ SL are seldom recorded in estuaries and are usually confined to sandy bays and inshore reefs shallower than $50 \mathrm{~m}$.

Larval $R$. sarba attain $10 \mathrm{~mm}$ TL within 30 days (Leu 1994) and a spring and summer monthly growth increment of $14 \mathrm{~mm}$ has been estimated for $0+$ juveniles (Wallace \& van der Elst 1975). Fry enter estuaries at approximately $15-20 \mathrm{~mm}$ SL, mainly during August to November, and sometimes as late as January when they are $20-40 \mathrm{~mm}$ in length (Wallace \& van der Elst 1975). The juveniles and subadults of this species are often common in the large KwaZulu-Natal estuaries.

The tropical stumpnose is a strong osmoregulator and has been recorded in salinities ranging from less than $1 \%$ to $80 \%$ (Whitfield 1996b). In Lake Nhlange this species was recorded in salinities less than $1 \%$ during both summer and winter, but salinities of less than $3 \%$ in combination with a drop in temperature to $12^{\circ} \mathrm{C}$ are lethal to this fish (Blaber \& Whitfield 1976). Similarly, mortalities of $R$. sarba under hypersaline conditions at Lake St Lucia were recorded after the sudden onset of cold weather (Wallace 1975a).

The tropical stumpnose is associated with water turbidities ranging from less than $10 \mathrm{NTU}$ to greater than $80 \mathrm{NTU}$, with $74 \%$ of individuals captured in estuaries occurring in water less than 50 NTU (Cyrus \& Blaber 1987c). Based on field and laboratory choice chamber experiments (Cyrus \& Blaber 1987a, 1987b) $R$. sarba can be regarded as a clear to partially turbid water species.

The diet of juveniles and subadults consists mainly of aquatic macrophytes and filamentous algae, although a considerable proportion is made up of bivalves and amphipods. The last two taxa are positively selected when little plant material is consumed (Blaber 1984). In Durban Bay, $R$. sarba feed mainly on brachyurans and surface-dwelling bivalves (Day \& Morgans 1956). The development of strong molariform teeth on the pharyngeal bones in adults results in an increased utilization of hard shelled molluscs (Day et al. 1981, Schleyer \& Wallace 1986). Foraging occurs mainly during daylight hours with a peak in activity during the early afternoon (Blaber 1984).

\section{Family: SPARIDAE}

Species: Rhabdosargus thorpei Smith, 1979

Common name: Bigeye stumpnose

Smiths' Sea Fishes number: 183.38

Illustrated specimen length: $95 \mathrm{~mm} \mathrm{SL}$

\section{Selected anatomical features}

Fin elements: Dorsal XI, 13;

Anal III, 12; Pectoral 14-15.

Lateral scales: 55-60.

Maximum recorded length: $\pm 32 \mathrm{~cm} \mathrm{SL}$.

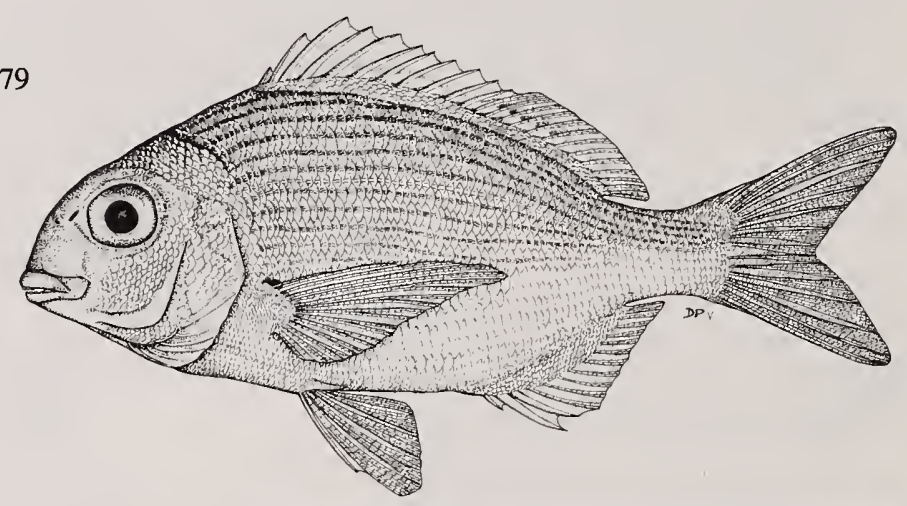

\section{Distribution}

The bigeye stumpnose is an endemic sparid that is known only from southern Mozambique to the Eastern Cape Province (Smith \& Smith 1986). Adults do not enter estuaries, but juveniles are sometimes common in certain subtropical systems (van der Elst 1988).

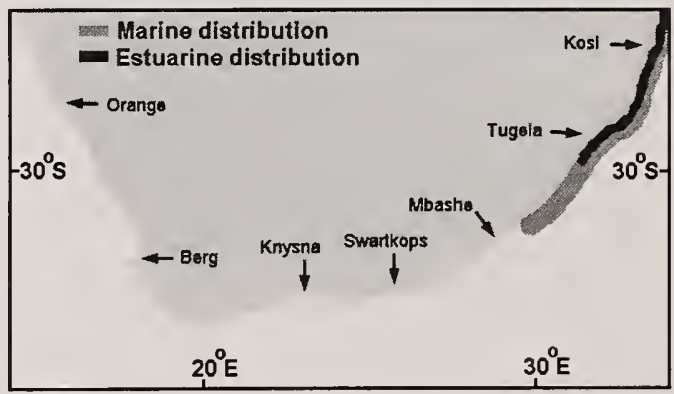


Very little is known about the life history of the bigeye stumpnose. It was previously confused with $R$. sarba but differs in having a larger eye, and the whole ventral area (including the pelvic and anal fins) is a bright yellow. The two species have a similar southern African distribution and frequently occur together in estuaries.

Newly recruited juveniles enter both turbid and clear estuaries and also occur in temporarily closed systems. They are euryhaline and have been found in salinities ranging from 8-38\% (Whitfield 1996b).
The diet of juveniles in the Kosi Estuary consists mainly of bivalves and crustaceans (Blaber 1984), with the prey being crushed and shredded by the molars and pharyngeal bones. Although small amounts of filamentous algae were found in $37 \%$ of the specimens examined from the Kosi system, this plant material was probably consumed incidentally together with the invertebrate prey (Blaber 1984). The remains of clams, mussels, barnacles, crabs and small rock lobsters have been found in the stomachs of specimens from the neritic environment (van der Elst 1988).

\section{Family: SPARIDAE}

Species: Sarpa salpa (Linnaeus, 1758)

Common name: Strepie

Smiths' Sea Fishes number: 183.39

Illustrated specimen length: $13 \mathrm{~cm} \mathrm{SL}$

\section{Selected anatomical features}

Fin elements: Dorsal XI, 14-16; Anal III, 13-15; Pectoral 16.

Lateral scales: 71-79.

Maximum recorded length in southern African waters: $\pm 26 \mathrm{~cm} \mathrm{SL}$.

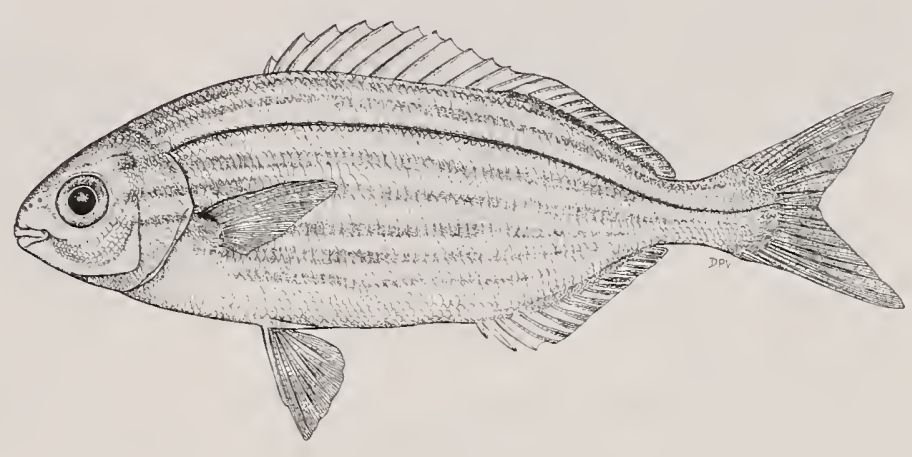

\section{Distribution}

The strepie is an inshore species, with a distribution from the Mediterranean and eastern Atlantic round South Africa to southern Mozambique (Smith \& Smith 1986). Although large shoals of juveniles are often found near eelgrass beds in warm-temperate estuaries, they are not dependent on these systems as nursery areas and are also common around subtidal reefs, in tidal pools and the sandy beach surf zone. Adult fish are usually confined to the marine environment down to a depth of $20 \mathrm{~m}$.

\section{Biology and ecology}

Males mature at $14-15 \mathrm{~cm}$ and females $16-17 \mathrm{~cm}$ FL, with indications that this species is a rudimentary hermaphrodite (Joubert 1981). Spawning occurs between April and September, with months of peak activity being June to August. Evidence suggests that $S$. salpa spawns off the KwaZulu-Natal coast and that the larvae drift southwards into warm-temperate waters, possibly assisted by nearshore components of the Agulhas Current (van der Elst 1988).

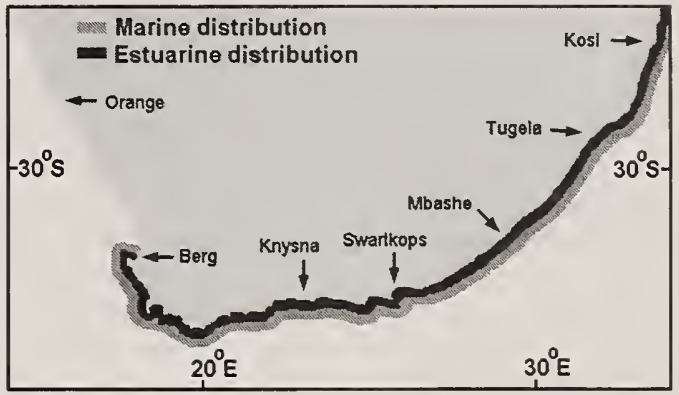

Juveniles less than $40 \mathrm{~mm}$ TL have been recorded entering Eastern and Western Cape surf zones between May and September (Lasiak 1983b, Whitfield 1989b). Recruitment of $S$. salpa less than $30 \mathrm{~mm}$ TL into Eastern Cape tide pools takes place between June and September (Christensen 1978) with peak immigration of $0+$ juveniles into Western Cape estuaŕies occurring between September and December (Whitfield \& Kok 1992). Cohort analyses from the Knysna system 
indicated a growth of approximately $14 \mathrm{~cm}$ in the first year, which was similar to the $12 \mathrm{~mm}$ per month estimated by Lasiak (1983b) for $0+$ juvenile length classes in Algoa Bay. The maximum recorded age for $S$. salpa is six years and was associated with specimens 20-27 cm FL (van der Walt \& Beckley 1997).

Although this species has been recorded in salinities ranging from $8-35 \%$ (Whitfield 1996b), it is usually found in the lower half of permanently open estuaries where salinities seldom decline below $20 \%$.

The 10-25 mm SL size classes of $S$. salpa feed mainly on harpacticoid copepods (Christensen 1978, Whitfield 1985), with fish above $50 \mathrm{~mm}$ SL in estuaries

Family: MONODACTYLIDAE

Species: Monodactylus argenteus (Linnaeus, 1758)

Common name: Round moony

Smiths' Sea Fishes number: 193.1

Illustrated specimen length: $70 \mathrm{~mm} \mathrm{SL}$

\section{Selected anatomical features}

Fin elements: Dorsal VIII, 27-30;

Anal III, 27-30; Pectoral 16-18.

Lateral scales: $52-58$.

Maximum recorded length: $\pm 19 \mathrm{~cm} \mathrm{SL}$.

\section{Distribution}

The round moony is an Indo-West Pacific fish extending into the warm-temperate waters of southern Africa. Although this is mainly a tropical species, specimens have been collected as far west as the Breë Estuary (Heemstra 1986b). Juveniles are frequently common in KwaZulu-Natal estuaries, sometimes entering freshwater areas in the vicinity of these systems.

\section{Biology and ecology}

Sexual maturity occurs at approximately $13 \mathrm{~cm} \mathrm{SL}$ and breeding takes place at sea (Day et al. 1981). Newly recruited juveniles in estuaries tend to shelter in shallow water where emergent or submerged plants are present. Juveniles have two curved dark stripes in the head region which tend to fade and eventually disappear in adults (Heemstra 1986b).

$M$. argenteus feed mainly on zooplankton, with individual selection of prey items from the water column being the dominant mode of foraging. They also consume epibenthic and epiphytic organisms such as amphipods and filamentous algae (Day et al. 1981). being mainly herbivorous on Zostera capensis and associated epiphytic algae (Whitfield 1988a). In the marine environment this sparid forages predominantly on rhodophytes (40 species) and hydrozoans (Joubert \& Hanekom 1980). The change from a carnivorous to a herbivorous diet is facilitated by changes in anatomy. The pointed and conical teeth of the $0+$ juveniles are replaced by sharp multicusped incisors, more suited to a browsing habit, and the gut lengthens considerably to cope more efficiently with the vegetarian diet (van der Elst 1988). Gerking (1984) has shown that $S$. salpa can maintain its body weight by consuming algae at a rate of approximately $6 \%$ of the body mass per day.
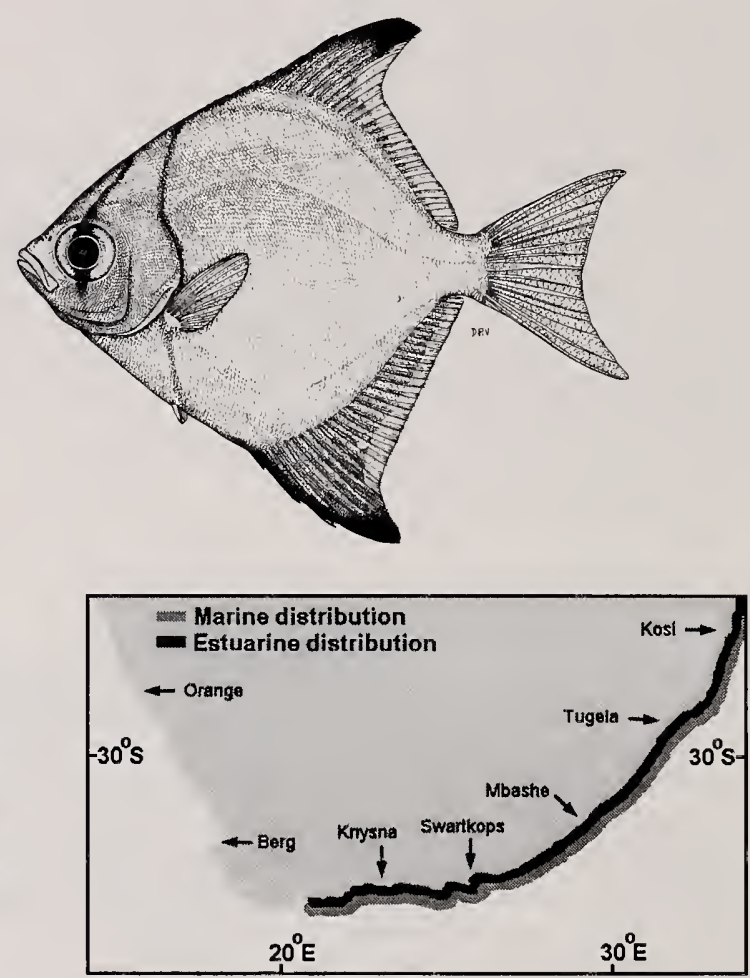

This species is strongly euryhaline and can tolerate salinities ranging from fresh water to at least $48 \%$. Although the majority of specimens captured in Lake St Lucia were associated with water turbidities less than 10 NTU (Cyrus \& Blaber 1987c), laboratory experiments have shown that the round moony prefers intermediate turbidities between 10 and 80 NTU (Cyrus \& Blaber 1987b). The possibility exists that $M$. argenteus seeks more turbid conditions when placed in an unfamiliar laboratory environment, since in estuaries it is most abundant in clear water areas (e.g. Blaber \& Cyrus 1981). 


\section{Selected anatomical features}

Fin elements: Dorsal VIII, 25-30; Anal III, 25-29; Pectoral 17-18.

Lateral scales: 51-58.

Maximum recorded length in southern African waters: $\pm 24 \mathrm{~cm} \mathrm{SL}$.

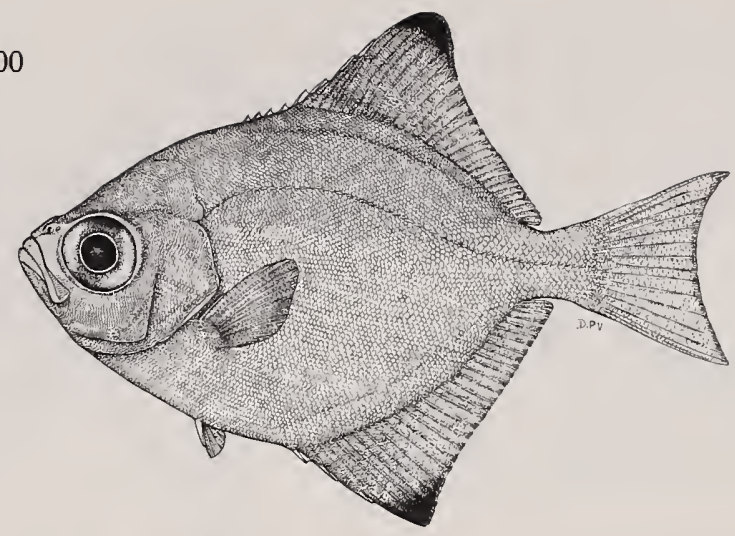

\section{Distribution}

The oval moony ranges from the Red Sea and northern Indian Ocean south to False Bay (Heemstra 1986b). Within southern African waters, the juveniles are often abundant in estuaries, but the adults are usually confined to shallow reefs in the marine environment.

\section{Biology and ecology}

Spawning by adult ( $>14 \mathrm{~cm} \mathrm{SL}) M$. falciformis occurs in the nearshore marine environment, often in the vicinity of estuary mouths (van der Elst 1988). The breeding season lasts from October to February in Western Cape waters (Whitfield \& Kok 1992) with evidence suggesting that this species is a serial spawner in Algoa Bay (Lasiak 1984a). The absence of adults from estuaries suggests that individuals do not return to these systems after spawning.

The postlarvae first enter southern African estuaries at a length of 5-10 mm SL, with most recruitment taking place between November and March (MelvilleSmith \& Baird 1980). The 0+ juveniles of $M$. falciformis have 11-12 vertical bars across the head and body, whereas those of $M$. argenteus have two curved dark bars. The bars may assist in providing camouflage since both species are often associated with submerged aquatic macrophyte beds in estuaries. Small size classes $(<15 \mathrm{~mm} \mathrm{SL}$ ) of these species also have the ability to turn almost pitch black, especially when stressed.

$M$. falciformis juveniles favour the middle and upper reaches of estuaries as nursery areas (Beckley 1984a, Hanekom \& Baird 1984, Whitfield 1984), where they sometimes form large shoals. There is a tendency to remain in the estuarine environment until a length of approximately $12 \mathrm{~cm} \mathrm{SL}$ is attained, at which stage they return to the sea.

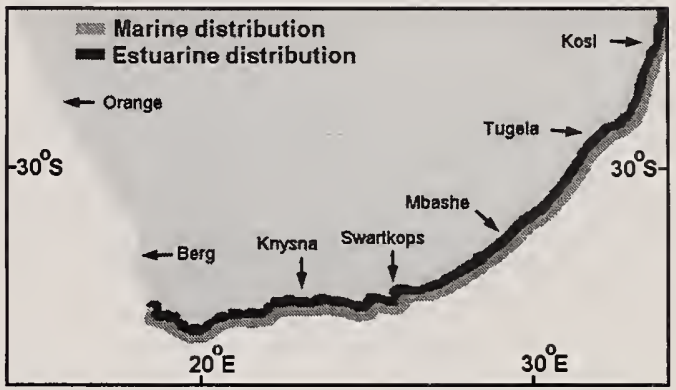

This species is a strong osmoregulator, tolerant of salinities ranging from $0-90 \%$. Juveniles less than 50 $\mathrm{mm} \mathrm{SL}$ are often recorded above the ebb and flow of estuarine systems and are tolerant of direct transfer to fresh water without ill effects (Day et al. 1981). Lower salinities do not appear to be the main reason for attracting juveniles to the upper reaches of estuaries since $M$. falciformis was still most abundant in this region under reversed salinity conditions in the Kariega Estuary (Ter Morshuizen \& Whitfield 1994). This species was recorded dying in the temporarily closed Seekoei Estuary when salinities increased above $90 \%$ (Whitfield 1989e).

Copepods were the dominant component in the diet of postlarval (19-30 mm SL) M. falciformis, whereas juveniles larger than $50 \mathrm{~mm}$ feed mainly on small crabs, isopods, amphipods and insects (Whitfield 1984, 1985). Foraging of this mainly midwater species occurs during both the day and night (van der Elst 1988), with daily summer food consumption for juveniles in Swartvlei calculated to be $2.5 \%$ of fish mass (Whitfield 1984). When invertebrate food resources are limited, small fish (e.g. Gilchristella aestuaria) are frequently consumed by subadult moonies. The shape of $M$. falciformis is such that certain small piscivorous birds (e.g. pied kingfishers) are sometimes unable to swallow the captured fish. 
Family: GERREIDAE

Species: Gerres acinaces Bleeker, 1854

Common name: Smallscale pursemouth

Smiths' Sea Fishes number: 194.1

Illustrated specimen length: $13 \mathrm{~cm} \mathrm{SL}$

\section{Selected anatomical features}

Fin elements: Dorsal IX-X, 9-11; Anal III, 7.

Lateral scales: 42-45.

Maximum recorded length in southern African waters: $\pm 23 \mathrm{~cm}$ SL.

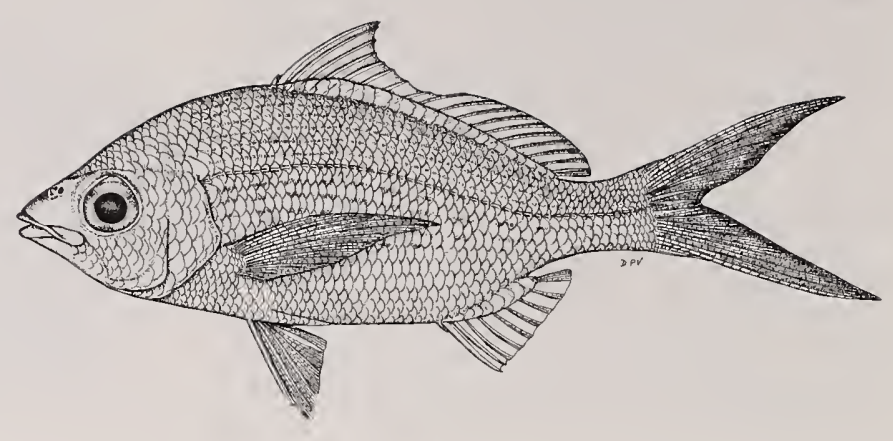

\section{Distribution}

The smallscale pursemouth has a mainly tropical IndoPacific distribution, extending into the subtropical waters of southern Africa. This species has been recorded as far south as Algoa Bay (Woodland 1986) but is seldom found in warm-temperate estuaries. Two closely related tropical species, Gerres oblongus and Gerres oyena, extend as far south as the Kosi Estuary but are rare in this system (Cyrus \& Blaber 1982a). Certain estuarine records of another related species, Gerres filamentosus, from a number of southern African systems may be incorrect due to confusion of this species with Gerres macracanthus.

\section{Biology and ecology}

Sexual maturity for both sexes is attained at approximately $11 \mathrm{~cm} \mathrm{SL}$ and mature or ripe gonads have been recorded throughout the year. The absence of riperunning individuals from KwaZulu-Natal estuaries suggests that the completion of gonadal development occurs in the sea (Cyrus \& Blaber 1984a). Spawning by $G$. acinaces in the KwaZulu-Natal nearshore marine environment probably occurs throughout the year, with newly recruited fry $( \pm 10 \mathrm{~mm}$ SL) being recorded during all four seasons in the Kosi Estuary (Cyrus \& Blaber 1982a).

It has been suggested that juveniles remain within the estuarine environment until they reach maturity, thus benefitting from reduced predation rates. Cyrus \& Blaber (1984c) have shown that predation on Gerres species by piscivorous fishes in the Kosi Estuary is very low ( $<1 \%$ of their diet), despite their abundance within this system. These authors suggest that this may be related to the 'loose association' type of shoaling by the pursemouths.

G. acinaces is abundant in salinities from $3-35 \%$ but were rare in Lake Nhlange where salinities were

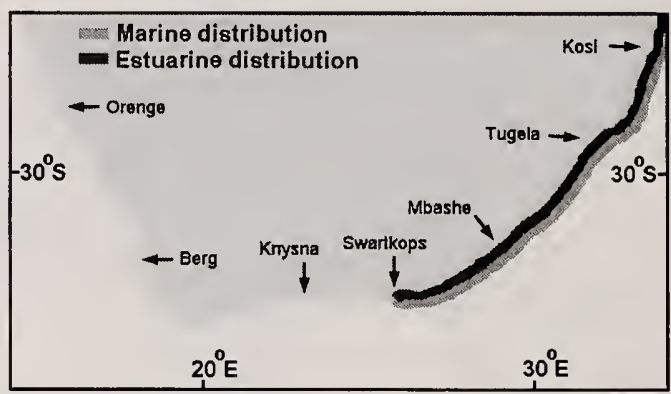

less than 1\%o (Cyrus \& Blaber 1982a). Shoals of juvenile and adult $G$. acinaces are usually more abundant in the clearer KwaZulu-Natal estuaries, with $90 \%$ of the juveniles captured occurring in water turbidities less than 10 NTU (Cyrus \& Blaber 1987).

The diet of postlarvae ( $<20 \mathrm{~mm} \mathrm{SL}$ ) in the Kosi estuarine system was dominated by marine and estuarine calanoid copepods. Larger juveniles (20-40 mm SL) consumed mainly polychaetes, bivalve siphon tips and chironomid larvae (Cyrus \& Blaber 1983a). The diet of juveniles greater than $40 \mathrm{~mm} \mathrm{SL}$ and adults consisted mainly ( $64 \%$ of energy intake) of the siphon tips belonging to the bivalve Hiatula lunulata (Cyrus \& Blaber 1983b). In Durban Bay this species feeds mainly on bivalves, polychaetes, amphipods and copepods (Day \& Morgans 1956).

Food items are usually detected visually and the protrusible jaw mechanism facilitates the capture of sedentary and motile prey (Cyrus \& Blaber 1982b). Feeding occurs mainly during the day, although some foraging has been recorded during nocturnal hours (Cyrus \& Blaber 1984b). 
Family: GERREIDAE

Species: Gerres methueni Regan, 1920

Common name: Evenfin pursemouth

Smiths' Sea Fishes number: 194.5

Illustrated specimen length: $11 \mathrm{~cm} \mathrm{SL}$

\section{Selected anatomical features}

Fin elements: Dorsal IX, 10-11; Anal III, 7.

Lateral scales: 41-49.

Maximum recorded length in southern African waters: $\pm 23 \mathrm{~cm} \mathrm{SL}$.

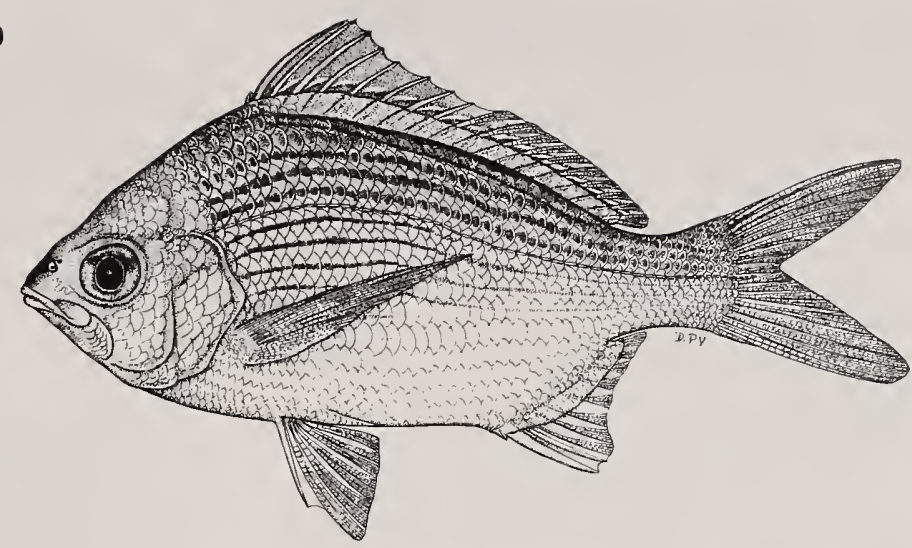

\section{Distribution}

Although Woodland (1986) describes $G$. rappi (a junior synonym of $G$. methueni) as a mainly temperate species, ranging from Algoa Bay into southern Mozambique, the available evidence (e.g. Cyrus \& Blaber 1982a) suggests a subtropical centre of distribution. The evenfin pursemouth has only been recorded in warm-temperate estuaries in small numbers, whereas it is abundant in subtropical KwaZulu-Natal estuaries (Cyrus \& Blaber 1982a). In addition, all life-history stages have been recorded in subtropical estuaries whereas only subadults and adults have been recorded in Eastern Cape systems.

\section{Biology and ecology}

Males become sexually active from $11 \mathrm{~cm} \mathrm{SL}$, while females are mature at $14 \mathrm{~cm} \mathrm{SL}$. Mature or ripe gonads have been recorded during summer, autumn and winter in the Kosi system (Cyrus \& Blaber 1984a). The above authors documented large shoals of ripe adults leaving the Kosi Estuary mouth prior to spawning. The absence of ripe-running individuals in KwaZulu-Natal estuaries, and the atresion of oocytes in mature individuals isolated in the temporarily closed Fafa Estuary, supports the view that the completion of gonad development occurs at sea (Cyrus \& Blaber 1984a). Spawning in the KwaZulu-Natal nearshore marine environment probably occurs during summer, autumn and winter, with newly recruited fry $( \pm 15 \mathrm{~mm}$ SL) being recorded during all seasons except summer in the Kosi Estuary (Cyrus \& Blaber 1982a). It has been suggested that the juveniles of this species remain within the estuarine environment until they reach maturity (Cyrus \& Blaber 1984a).

In the Kosi system G. methueni is abundant only in the low salinity $(0.5-1 \%$ o) waters of Lake Nhlange (Cyrus \& Blaber 1982a). This species is, however, able to tolerate a wide range of salinities $(0.5-40 \%)$

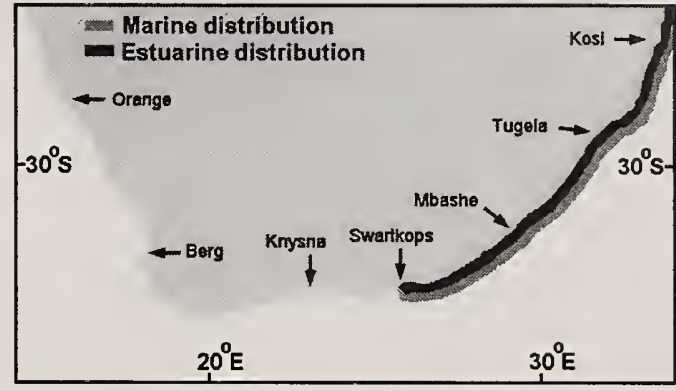

and has been recorded in a number of temporarily closed KwaZulu-Natal estuaries where salinities were less than $1 \%$. Although the evenfin pursemouth occurs mainly in clear estuarine waters, $35 \%$ of the juveniles captured in KwaZulu-Natal systems were associated with water turbidities between 10 and $50 \mathrm{NTU}$, and $5 \%$ between 50 NTU and 80 NTU (Cyrus \& Blaber 1987c).

The diet of postlarvae less than $20 \mathrm{~mm} \mathrm{SL}$ is dominated by calanoid copepods (Cyrus \& Blaber 1983a, Whitfield 1985). Larger juveniles (20-40 mm SL) consume mainly amphipods, polychaetes and copepods (Cyrus \& Blaber 1983a). The diet of juveniles greater than $40 \mathrm{~mm} \mathrm{SL}$ and adults consists mainly of bivalves ( $40 \%$ of energy intake), followed by chironomid larvae (32\%) and crabs (17\%) (Cyrus \& Blaber 1983b).

Food items are usually detected visually and the jaw protrusion and retraction time when capturing prey was calculated to be 0.2 seconds (Cyrus \& Blaber 1982b). Feeding occurs mainly during the day although some foraging has been recorded during nocturnal hours (Cyrus \& Blaber 1984b). 
Family: SILLAGINIDAE

Species: Sillago sihama (Forsskål, 1775)

Common name: Silver sillago

Smiths' Sea Fishes number: 198.3

Illustrated specimen length: $16 \mathrm{~cm} \mathrm{SL}$

\section{Selected anatomical features}

Fin elements: Dorsal XI + I, 20-23;

Anal II, 21-23; Pectoral 16-17.

Lateral scales: 62-72.

Maximum recorded length in southern African waters: $\pm 26 \mathrm{~cm}$ SL.

\section{Distribution}

The silver sillago is a widespread Indo-Pacific species reaching as far south as Knysna (McKay 1986). It is mainly a shallow water fish of sandy bays and estuaries (van der Elst 1988).

\section{Biology and ecology}

S. sihama is a predominantly shoaling species that is most common in southern African waters during summer. According to van der Elst (1988) breeding occurs mainly in tropical East African waters but Connell (1996) has recorded spawning in the subtropical St Lucia Estuary.

The silver sillago is capable of considerable colour changes, usually to blend with the colour of the substratum over which it is moving. When threatened they are known to bury themselves in the sand until danger has passed (van der Elst 1988). In addition, they sometimes skip along the water surface when disturbed.

Although this species has been recorded in salinities ranging from 3-35\%o (Whitfield 1996b), it is usually

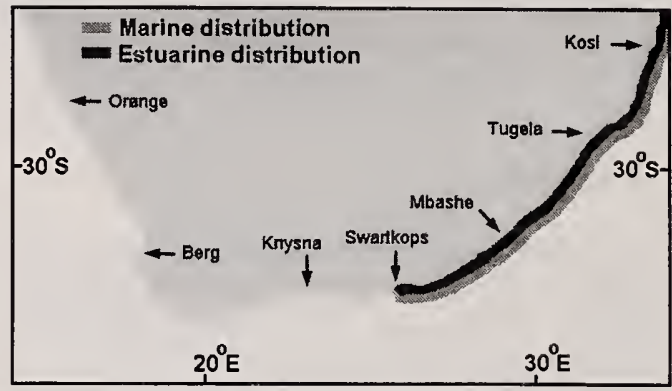

found in the lower reaches of permanently open estuaries and bays where salinities seldom decline below $20 \%$. The distribution of $S$. sihama in estuaries appears to be inversely related to turbidity, with the highest densities being recorded in clear water systems (Weerts et al. 1997).

Juveniles less than $60 \mathrm{~mm}$ SL feed predominantly on planktonic organisms, especially copepods, but with increasing size this species preys mainly on benthic crustaceans, polychaetes and bivalve siphon tips (Weerts et al. 1997). The adult diet consists mostly of marine polychaetes, shrimps, prawns and small crabs, all of which are collected from the benthos with the aid of a long, conical snout (van der Elst 1988).

Family: SCIAENIDAE

Species: Argyrosomus japonicus (Temminck \& Schlegel, 1843)

Common name: Dusky kob

Smiths' Sea Fishes number: 199.1

Illustrated specimen length: $22 \mathrm{~cm} \mathrm{SL}$

\section{Selected anatomical features}

Fin elements: Dorsal X+I, 26-29;

Anal II, 7; Pectoral 17.

Lateral scales: 48-54.

Maximum recorded length in southern African waters: $\pm 170 \mathrm{~cm} \mathrm{SL}$.

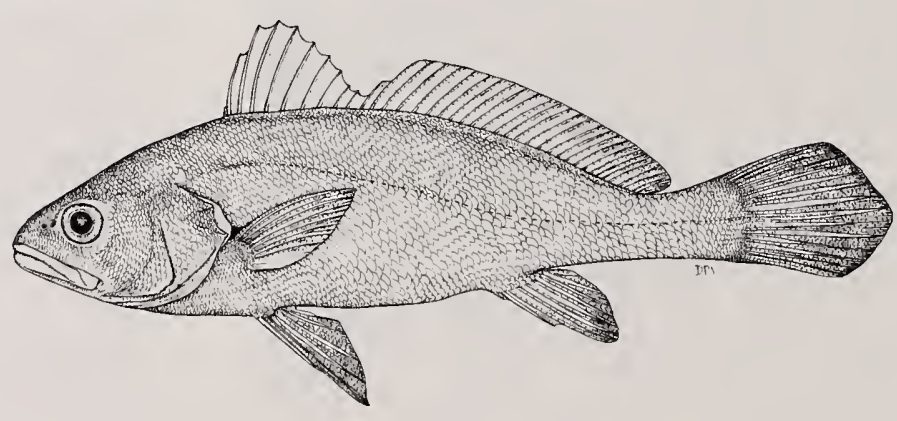




\section{Distribution}

The dusky kob, previously known as Argyrosomus hololepidotus, has an African range extending from Cape Point to southern Mozambique. It also occurs in Indo-Pacific waters to Japan and Australia in the east and Pakistan in the west (Griffiths \& Heemstra 1995). A. japonicus is a continental coastal species with a maximum recorded depth of $100 \mathrm{~m}$ (Griffiths 1996).

\section{Biology and ecology}

Dusky kob become sexually active at approximately $92 \mathrm{~cm}$ TL for males and $107 \mathrm{~cm}$ TL for females. Nocturnal spawning occurs in the marine environment from August to November in KwaZulu-Natal and from October to January in the Eastern Cape. A large proportion of the adult population migrate to KwaZuluNatal to breed, although spawning may continue once they return to the Eastern Cape (Griffiths 1996).

Newly recruited juveniles enter southern African estuaries during spring and summer, mainly between October and February (Wallace \& van der Elst 1975). The early juveniles (20-30 mm TL) appear to remain in the upper reaches of large turbid estuaries, where they find suitable food and refuge from predators (Griffiths 1996). At approximately $15 \mathrm{~cm}$ TL they move into the middle and lower reaches of estuaries, with some entering the surf zone adjacent to these systems. Juveniles do not appear to migrate great distances but remain as separate localised populations until they reach sexual maturity (Griffiths 1996).

Growth is rapid, attaining approximately $35 \mathrm{~cm}$ TL in the first year. Using the growth models of Griffiths \& Hecht (1995), all males are sexually mature by 7 years and females by 8 years. Individuals up to 42 years of age have been recorded but specimens older than 27 are rare. The maximum recorded mass is $75 \mathrm{~kg}$ and fish of $45 \mathrm{~kg}$ are common (Griffiths \& Heemstra 1995).

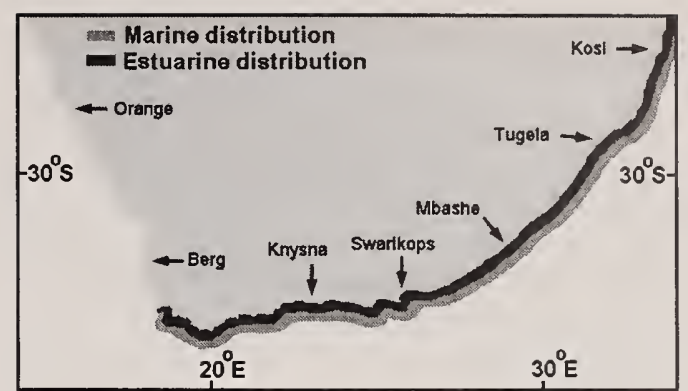

The salinity range of $A$. japonicus older than one year is usually 3-66\%o (Wallace 1975a), although some specimens have recently been captured in riverine sections above the Great Fish Estuary (Ter Morshuizen et al. 1996a). Newly recruited juveniles favour oligohaline areas $(<5 \%$ ) in certain turbid Eastern Cape systems (Griffiths 1996) but subadults were recorded dying in the Bot and St Lucia estuarine systems when exposed to prolonged low salinities $(<3 \%$ ) (Blaber \& Whitfield 1976, Bennett 1985). This species is associated with a wide range of turbidities but is particularly abundant in turbid estuaries ( $>50$ NTU).

According to van der Elst (1988) A. japonicus hunts mainly by combining olfactory and lateral line senses and is therefore well equipped to forage in turbid waters. The diet of newly recruited juveniles $(<50 \mathrm{~mm}$ TL) is dominated by calanoid copepods and mysids (Griffiths 1996). Juveniles greater than $17 \mathrm{~cm} \mathrm{SL}$ and adults in estuaries are primarily piscivorous, with fish in the diet having a frequency of occurrence ranging between $76 \%$ and $94 \%$ (Whitfield \& Blaber 1978a, Marais 1984). Smaller $A$. japonicus ( $<43 \mathrm{~cm} \mathrm{SL)} \mathrm{tend}$ to prey on small resident fish species (e.g. Gilchristella aestuaria) or the juveniles of marine taxa such as mugilids. Dusky kob larger than $43 \mathrm{~cm}$ SL consumed these fish as well as the subadults of small marine species such as Rhabdosargus holubi.

\section{Family: SCIAENIDAE}

Species: Johnius dorsalis (Peters, 1855)

Common name: Small kob

Smiths' Sea Fishes number: 199.6

Illustrated specimen length: $17 \mathrm{~cm} \mathrm{SL}$

\section{Selected anatomical features}

Fin elements: Dorsal IX-X/I, 27-30; Anal II, 7-8; Pectoral 19.

Lateral scales: 47-49.

Maximum recorded length in southern

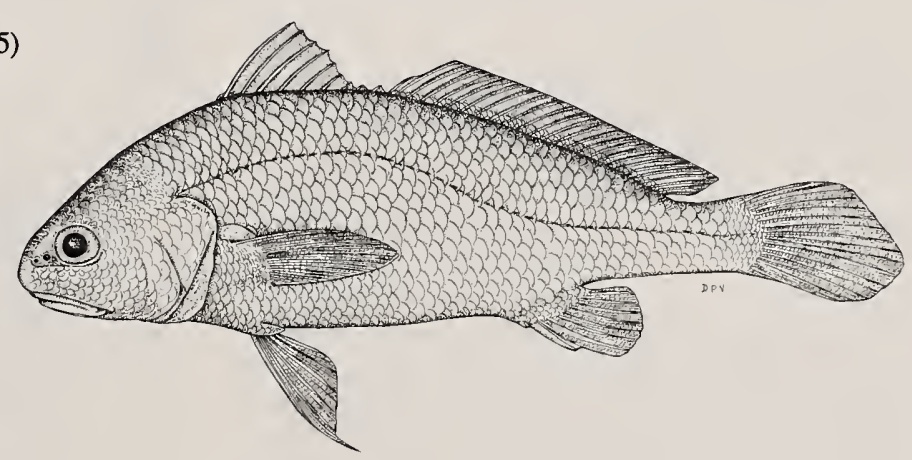
African waters: $\pm 21 \mathrm{~cm} \mathrm{SL}$. 


\section{Distribution}

This mainly tropical Indo-West Pacific species has a distribution extending from Singapore to the Eastern Cape. Although adults occur both in estuaries and the sea, they appear to be more abundant in the marine environment where they occur down to a depth of $40 \mathrm{~m}$.

\section{Biology and ecology}

The small kob is a shoaling fish, common in certain permanently open estuaries on the northern KwaZuluNatal coast but seldom recorded in temporarily closed estuaries. This species has a size range in estuaries from $2-28 \mathrm{~cm}$ TL, with the $16-26 \mathrm{~cm}$ TL size classes being most abundant (Wallace 1975a). Males become sexually active at approximately $10 \mathrm{~cm} \mathrm{SL}$ and females at $13 \mathrm{~cm}$ SL. Spawning occurs in the marine environment between September and February (Wallace $1975 \mathrm{~b}$ ), with spent adults recorded entering estuaries after breeding. The period of migration by juveniles into estuaries has not been quantified and they are only common in northern KwaZulu-Natal systems (van der Elst 1988).

The recorded salinity range of $J$. dorsalis is $1-55 \%$ (Whitfield 1996b) but large scale mortalities of this species were documented in Lake St Lucia under low salinity $(<3 \%)$ and low temperature $\left(12^{\circ} \mathrm{C}\right)$ conditions (Blaber \& Whitfield 1976). The small kob favours

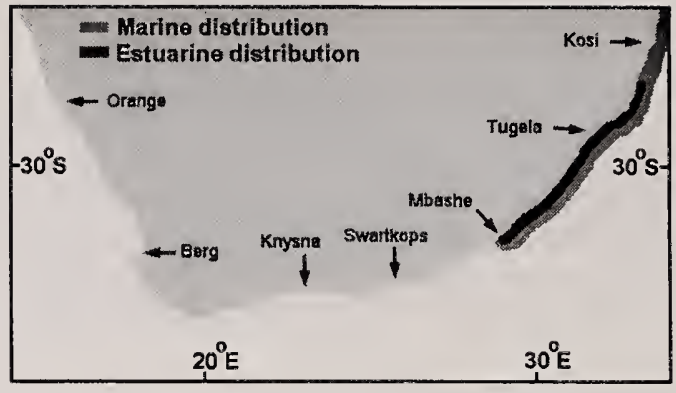

turbid water areas, with all specimens captured in Lake St Lucia by Cyrus \& Blaber (1987c) being associated with water greater than 50 NTU and almost $70 \%$ of the catch being found in turbidities greater than 80 NTU.

In estuaries $J$. dorsalis is a benthic forager over muddy substrata, preying on both invertebrates and small fishes. Invertebrate taxa in the diet include crabs, mysids, amphipods, bivalves and gastropods, with fish such as Glossogobius callidus, Gilchristella aestuaria and Thryssa vitrirostris being important prey items (Whitfield \& Blaber 1978a). Fish scales from large species were also found in the stomach contents of $5 \%$ of the individuals examined in Lake St Lucia. The subterminal mouth position of $J$. dorsalis would suggest that these scales were picked up from the substratum and not removed from living individuals as is the case for Terapon jarbua. The sluggish small kob is frequently preyed upon by larger predators such as Argyrosomus japonicus (van der Elst 1988).

\section{Family: SCIAENIDAE}

Species: Otolithes ruber (Bloch \& Schneider, 1801)

Common name: Snapper kob

Smiths' Sea Fishes number: 199.7

Illustrated specimen length: $23 \mathrm{~cm} \mathrm{SL}$

\section{Selected anatomical features}

Fin elements: Dorsal IX-X/I, 27-30; Anal II, 7-8; Pectoral 17.

Lateral scales: $48-50$.

Maximum recorded length in southern

African waters: $\pm 70 \mathrm{~cm}$ SL.

\section{Distribution}

The snapper kob is an Indo-West Pacific species (Heemstra 1986c) extending as far south as Algoa Bay in the Eastern Cape (Wallace 1975a). Although adults are frequently recorded in some of the larger northern KwaZulu-Natal estuaries, juveniles have not been found in these systems (van der Elst 1988).
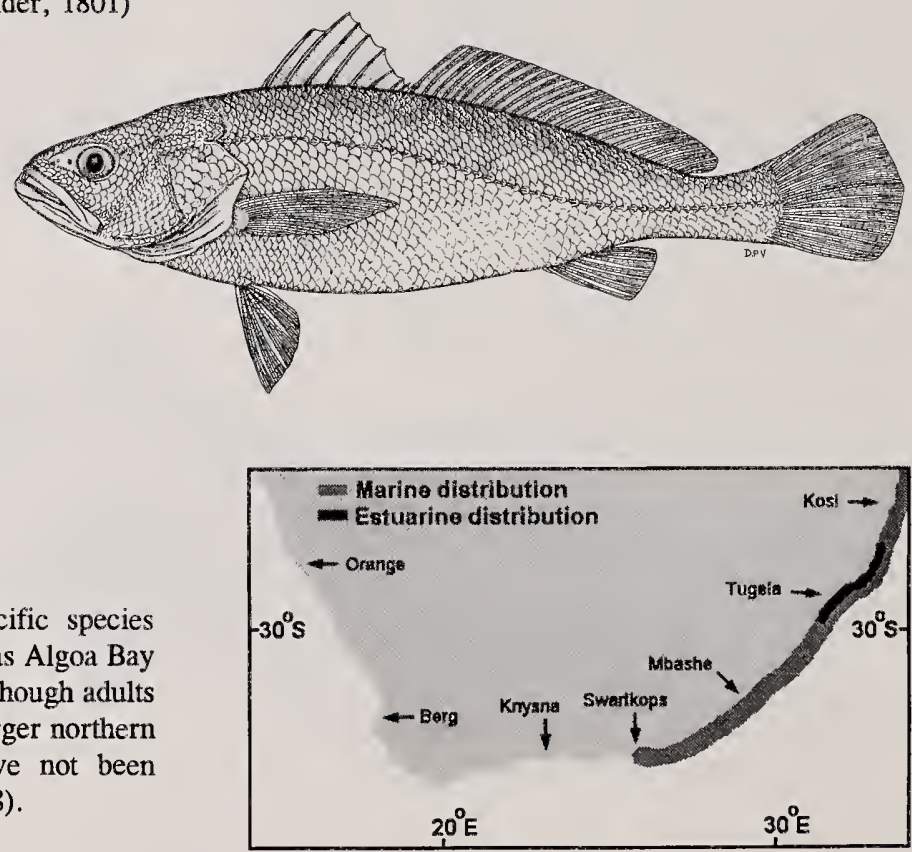


\section{Biology and ecology}

This is a shoaling fish of coastal waters, sheltered bays and large estuarine systems (van der Elst 1988). Sexual maturity is attained at about $23 \mathrm{~cm} \mathrm{SL}$, with breeding occurring in the nearshore marine environment during spring and summer (September-February) (Wallace 1975b). Both ripe and spent individuals have been recorded in estuaries, i.e. they leave estuaries before the ripe-running stage is attained and return when spawning is complete.

The larvae and $0+$ juveniles appear to use the marine environment as a nursery area because early juveniles have not been recorded in estuaries (van der Elst 1988).
The snapper kob is euryhaline and has been found in salinities ranging from 7-35\%o (Whitfield 1996b). It appears to avoid clear-water estuaries such as the Kosi system but is often associated with the high turbidity waters of Lake St Lucia.

According to van der Elst (1988) O. ruber is a rather sluggish carnivore which hunts in an opportunistic manner. Whitfield \& Blaber (1978a) found that adult snapper kob in Lake St Lucia preyed mainly on pelagic clupeids and engraulids, although penaeid prawns were also consumed. In the marine environment they feed on small fish, squid and shrimps (van der Elst 1988).
Family: LEIOGNATHIDAE

Species: Leiognathus equula (Forsskål, 1775)

Common name: Slimy

Smiths' Sea Fishes number: 201.3

Illustrated specimen length: $16 \mathrm{~cm} \mathrm{SL}$

\section{Selected anatomical features}

Fin elements: Dorsal VIII, 15-16;

Anal III, 14-15; Pectoral 18-20.

Lateral scales: 54-63.

Maximum recorded length in southern African waters: $\pm 20 \mathrm{~cm} \mathrm{SL}$.

\section{Distribution}

This mainly tropical species has an Indo-West Pacific distribution (Smith 1986c) extending as far south as the Great Fish Estuary on the Eastern Cape coast. Shoals of $L$. equula occur in estuaries and coastal waters down to a depth of $40 \mathrm{~m}$.

\section{Biology and ecology}

This species is common in permanently open estuaries on the northern KwaZulu-Natal coast but also occurs in temporarily closed systems within the subtropical region. The size range of $L$. equula in estuaries is 15$240 \mathrm{~mm}$ TL, with the $40-80 \mathrm{~mm}$ TL size classes being most abundant (Wallace 1975a).

The slimy becomes sexually mature at approximately $13 \mathrm{~cm} \mathrm{SL}$. No ripe-running individuals have been sampled in KwaZulu-Natal estuaries but the occurrence of ripe and spent fish suggests that spawning extends mainly from October to March (Wallace 1975b). The presence of partially spawned adults in the marine environment during December supports the above breeding season. Juveniles enter estuaries when less than $20 \mathrm{~mm}$ TL, with size classes between $30 \mathrm{~mm}$ and $80 \mathrm{~mm}$ TL making extensive use of KwaZulu-Natal systems as nursery areas during late summer.

The recorded salinity range of $L$. equula is from 1$37 \%$ (Whitfield 1996b), but mortalities of this species were recorded in Lake St Lucia under low salinity $\left(<3 \%\right.$ ) and low temperature $\left(12^{\circ} \mathrm{C}\right)$ conditions (Blaber \& Whitfield 1976). The slimy is an intermediate turbidity species, with $36 \%$ of the specimens captured 
in Lake St Lucia by Cyrus \& Blaber (1987c) being associated with water $10-50 \mathrm{NTU}$, and $56 \%$ between 50 NTU and 80 NTU.

Foraging is either pelagic or benthic, depending on the size of the fish. Newly recruited $0+$ juveniles feed in midwater on planktonic crustaceans such as copepods, cumacea and crab zoeae, while larger juveniles and adults prey mainly on small crabs, prawns, amphipods, polychaetes and bivalves (Whitfield 1980e, Day et al.1981, van der Elst 1988). Demersal foraging is aided by a protrusible mouth that points downwards when fully extended. Despite producing copious amounts of mucus and being able to lock the spines of both the dorsal and anal fins into an upright position, this species is preyed upon by a wide range of piscivorous fishes.
Family: LOBOTIDAE

Species: Lobotes surinamensis (Bloch, 1790)

Common name: Tripletail

Smiths' Sea Fishes number: 202.1

Illustrated specimen length: $89 \mathrm{~mm} \mathrm{SL}$

\section{Selected anatomical features}

Fin elements: Dorsal XI-XII, 15-16; Anal III, 11-12; Pectoral 17.

Lateral scales: $43-45+5$ on caudal.

Maximum recorded length in southern

African waters: $\pm 87 \mathrm{~cm} \mathrm{SL}$.

\section{Distribution}

The tripletail is found in shallow tropical and subtropical waters of all oceans, extending into the warm-temperate region of the Eastern Cape Province as far south as St Francis Bay (Heemstra 1986d). It has been recorded in the shallow waters of Lake St Lucia and, when present in river mouths or permanently open estuaries, this species is usually confined to the deeper channel areas within the lower reaches.

\section{Biology and ecology}

L. surinamensis in southern African waters appear to favour muddy estuaries and large river mouths (van der Elst 1988). Spawning occurs in summer and limited numbers of $0+$ juveniles are sometimes found in KwaZulu-Natal and Eastern Cape estuaries. Early juveniles are predominantly yellow and black while the caudal fin is translucent, giving the overall appearance of a dead mangrove leaf. Within estuaries they often mimic floating leaves by drifting slowly on their sides with the current (van der Elst 1988). In this way many manage to avoid the attentions of predators as well as approaching unsuspecting prey. Juveniles in the sea are sometimes found well offshore near floating objects (Heemstra 1986d).
The documented salinity range of $L$. surinamensis is $10-35 \%$ (Whitfield 1996b) but further sampling is likely to increase these tolerance limits. Fishermen have reported catching a wide size range of this species in the normally oligohaline Tugela Estuary. Adults have been recorded in South Lake of the St Lucia system when salinities were $10 \%$.

The tripletail is a predominantly demersal species foraging mainly on bottom-dwelling crustaceans, including crabs, penaeid prawns, mud prawns and sometimes small fish (van der Elst 1988). Three $L$. surinamensis captured by an angler in the Tugela River mouth region had been feeding on Hilsa kelee, Thryssa vitrirostris and juvenile mugilids. 
Family: CARANGIDAE

Species: Caranx ignobilis (Forsskål, 1775)

Common name: Giant kingfish

Smiths' Sea Fishes number: 210.17

Illustrated specimen length: $93 \mathrm{~mm} \mathrm{SL}$

\section{Selected anatomical features}

Fin elements: Dorsal VIII +I, 18-21; Anal II+I, 15-17.

Lateral line with $26-38$ scutes.

Maximum recorded length in southern African waters: $\pm 140 \mathrm{~cm} \mathrm{SL}$.

\section{Distribution}

C. ignobilis is a widespread tropical and subtropical Indo-Pacific species, extending into the Eastern Cape Province (Smith-Vaniz 1986). Although the adults are associated with coastal reefs, juveniles are frequently found in estuaries.
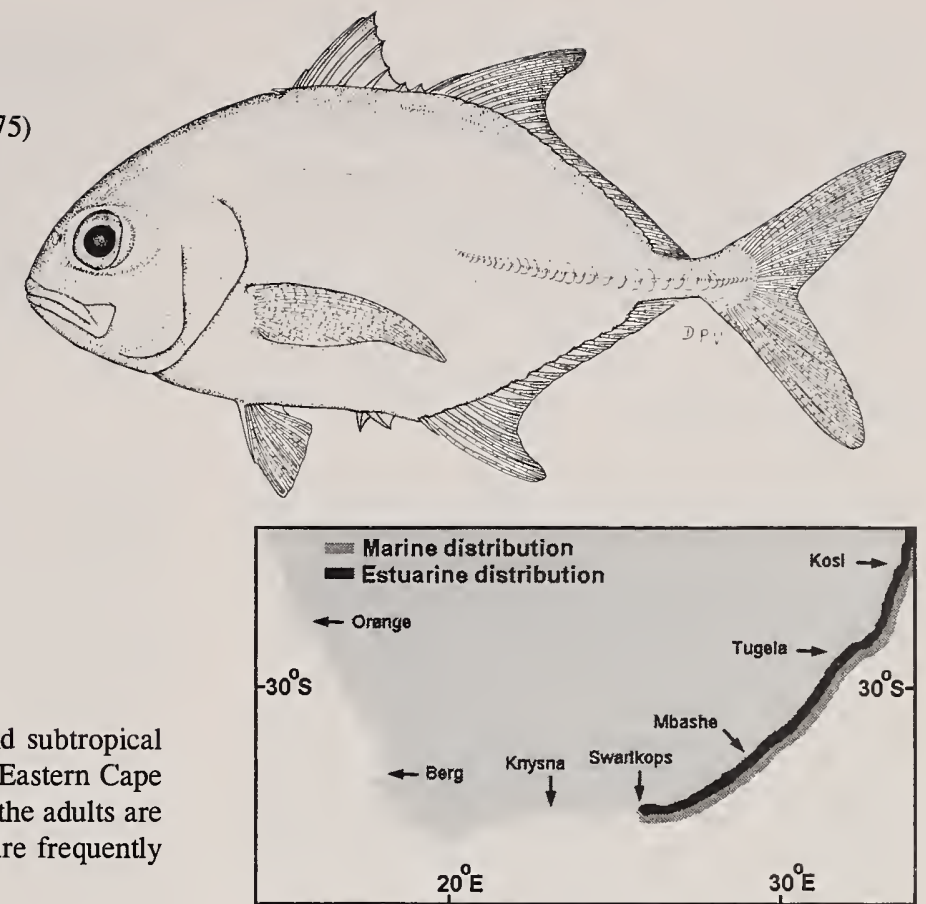

\section{Biology and ecology}

Sexual maturity is attained at $58 \mathrm{~cm} \mathrm{SL}$, with spawning in the marine environment occurring during summer (van der Elst 1988). Recruitment of 0+ juveniles into KwaZulu-Natal estuaries also occurs during summer but larger fish are present throughout the year.

Giant kingfish have been recorded in salinities from $1-38 \%$ and subadults from $1-35 \%$ (Blaber \& Cyrus $1981)$. Juveniles ( $<20 \mathrm{~cm} \mathrm{SL}$ ) occur in highly turbid waters ( $>50 \mathrm{NTU}$ ) such as St Lucia, as well as clear waters $(<5 \mathrm{NTU})$ in the Kosi Estuary. The $0+$ juveniles do not form mixed shoals with other carangids (Blaber \& Cyrus 1983) but subadults are often captured in association with Caranx papuensis.

The diet of juveniles (40-199 mm SL) in KwaZuluNatal estuaries is dominated by small fish together with large quantities of penaeid prawns (Blaber \& Cyrus 1983). Prey is primarily located by sight and this species tends to be more active during the day, especially at dusk and dawn (van der Elst 1988). Blaber \& Cyrus (1983) found that juveniles less than 20 $\mathrm{cm}$ SL feed mainly during the day with maximum stomach fullness at $18 \mathrm{~h} 00$. Subadult fish above $20 \mathrm{~cm}$ SL are almost entirely piscivorous, feeding particularly on Ambassis species (Blaber \& Cyrus 1983). In the marine environment approximately $70 \%$ of the diet of C. ignobilis comprises fish (van der Elst 1988).

Family: CARANGIDAE

Species: Caranx papuensis Alleyne \& Macleay, 1877

Common name: Brassy kingfish

Smiths' Sea Fishes number: 210.20

Illustrated specimen length: $16 \mathrm{~cm} \mathrm{SL}$

\section{Selected anatomical features}

Fin elements: Dorsal VIII +I, 21-23;

Anal II + I, 16-19.

Lateral line with 31-39 scutes.

Maximum recorded length: $\pm 66 \mathrm{~cm} \mathrm{SL}$.

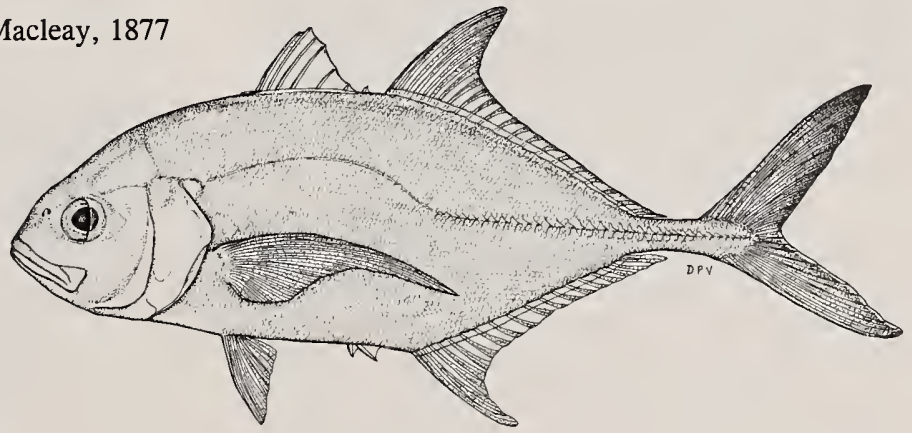




\section{Distribution}

The brassy kingfish is a widespread tropical IndoPacific species, ranging from southern Africa northward and eastward to the Marquesas Islands. According to Smith-Vaniz (1986) this is a predominantly seaward reef species but juveniles do occur in estuaries.

\section{Biology and ecology}

C. papuensis is present in KwaZulu-Natal waters throughout the year, with a peak in abundance during summer (van der Elst 1988). Juveniles occur in certain estuaries of the region, increasing in abundance from south to north (Blaber \& Cyrus 1983). Although adult fish have been captured from the Kosi and Mlalazi estuaries no reproductively active fish have been recorded. Spawning takes place in the sea but juveniles only enter estuaries above $40 \mathrm{~mm}$ SL. Juveniles 4-12 $\mathrm{cm}$ SL are found in mixed shoals with Caranx sexfasciatus and Caranx melampygus, but the subadults (18-28 cm SL) usually occur in large discrete single species shoals (Blaber \& Cyrus 1983).

Adult $C$. papuensis appear to be intolerant of turbid water and low salinity conditions (van der Elst 1988). Blaber \& Cyrus (1983) captured adults only in the lower reaches of estuaries, usually in groups of 4-6 individuals. The recorded salinity range of juveniles

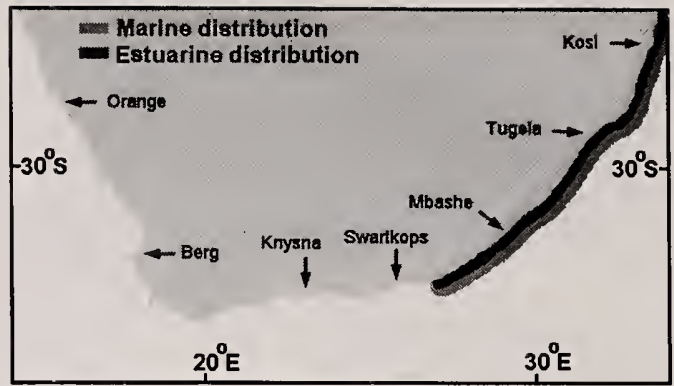

was $6-35 \%$ and of subadults $4-35 \%$. Juveniles and subadults are associated with water turbidities up to 25 NTU (Blaber \& Cyrus 1983).

The diet of juveniles (4-16 cm SL) in KwaZuluNatal estuaries consists mainly of mysids and small penaeids, with small fish also being important. The large number of mysids are probably captured by filter feeding since $C$. papuensis has long gill rakers with well developed denticles (Blaber \& Cyrus 1983). Foraging by both juveniles and subadults in KwaZuluNatal estuaries occurs mainly during the day, with peak stomach fullness occurring between $12 \mathrm{~h} 00$ and $15 \mathrm{~h} 00$ depending on fish size. Adult brassy kingfish in the marine environment hunt singly or in pairs, moving over reefs as well as sandy beaches between rocky outcrops (van der Elst 1988). They prey primarily on small fish, especially reef dwelling species, although squid, prawns and crabs are also consumed.

\section{Family: CARANGIDAE}

Species: Caranx sexfasciatus Quoy \& Gaimard, 1825

Common name: Bigeye kingfish

Smiths' Sea Fishes number: 210.22

Illustrated specimen length: $84 \mathrm{~mm}$ SL

\section{Selected anatomical features}

Fin elements: Dorsal VIII +I, 19-22; Anal II +I, 14-17.

Lateral line with 27-36 scutes.

Maximum recorded length in southern African waters: $\pm 71 \mathrm{~cm}$ SL.

\section{Distribution}

The bigeye kingfish is a widespread tropical IndoPacific species, ranging from the Eastern Cape northward and eastward to the Americas (Smith-Vaniz 1986). Although the larger juveniles and adults are usually associated with coastal reefs, $0+$ juveniles are sometimes common in certain KwaZulu-Natal estuaries.
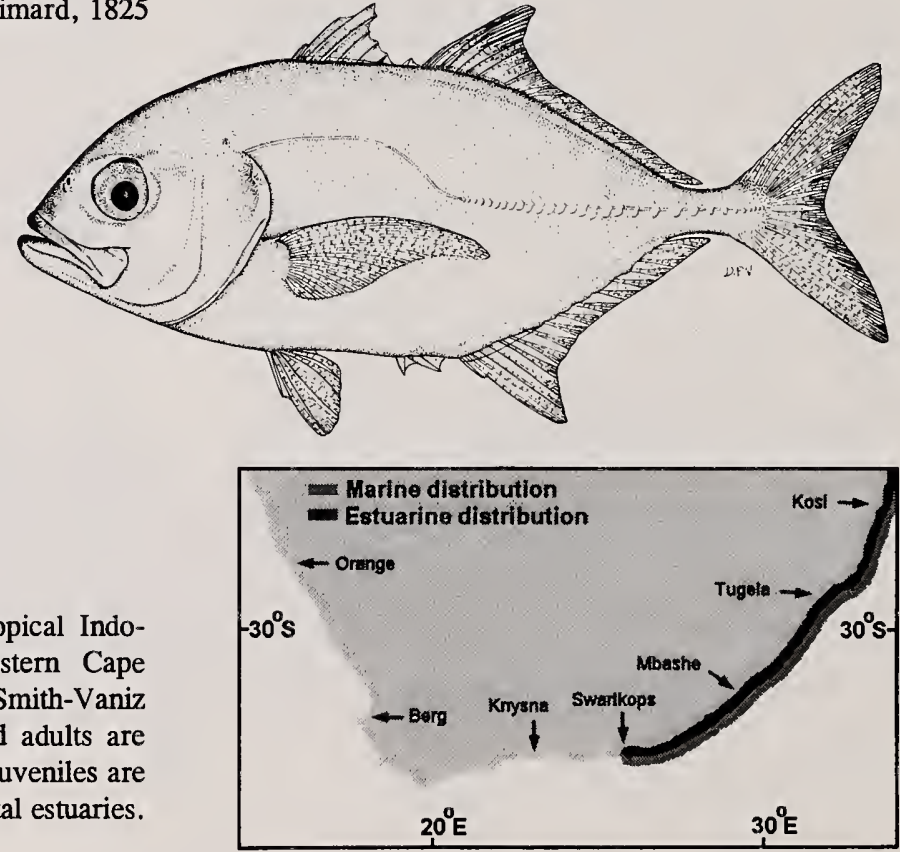


\section{Biology and ecology}

Sexual maturity is attained at approximately $42 \mathrm{~cm} \mathrm{SL}$ (van der Elst 1988). Spawning in the marine environment probably occurs during spring and summer because newly recruited juveniles $30-60 \mathrm{~mm}$ SL enter KwaZulu-Natal estuaries between October and April. Modal sizes of $C$. sexfasciatus from Kosi indicate a growth of $12 \mathrm{~cm}$ in both the first and second years, such that two year old fish measure about $25 \mathrm{~cm} \mathrm{SL}$ (Blaber \& Cyrus 1983).

Small juveniles (30-100 mm SL) usually occur in discrete shoals, but on occasion have been recorded mixed with Caranx melampygus and Caranx papuensis. All sizes of $C$. sexfasciatus in estuaries are euryhaline with a recorded salinity range from $0.5-40 \%$ (Blaber \& Cyrus 1983). Juveniles $60-70 \mathrm{~mm}$ SL have been found in fresh water above the ebb and flow of certain Eastern Cape estuaries (e.g. Keiskamma), and in Lake Nhlange they are present throughout the year in salinities of less than 1\%o (Blaber \& Cyrus 1981). The bigeye kingfish is predominantly associated with clear to partially turbid waters, with $54 \%$ of the juveniles captured in KwaZulu-Natal estuaries being associated with water turbidities less than $10 \mathrm{NTU}$, and $37 \%$ between 10 NTU and 50 NTU (Cyrus \& Blaber 1987c). Specimens larger than $12 \mathrm{~cm}$ SL were only recorded from less than 10 NTU waters (Blaber \& Cyrus 1983). It would appear that adult fish are more sensitive to changes in temperature and salinity than juveniles, with the former group showing a preference for clear marine waters (van der Elst 1988).

The diet of newly recruited juveniles ( $30 \mathrm{~mm} \mathrm{SL})$ in KwaZulu-Natal estuaries is dominated by calanoid copepods. Larger juveniles prey on the fry of a number of estuary-associated marine species, although a considerable proportion of the diet consists of penaeid prawns. Subadult $C$. sexfasciatus greater than $20 \mathrm{~cm}$ SL are almost entirely piscivorous, feeding particularly on ambassids. This size group feed mainly during the early morning and late evening, whereas the smaller juveniles showed a peak stomach fullness at $15 \mathrm{~h} 00$ (Blaber \& Cyrus 1983).

Adult fish hunt singly, moving from reef to reef in search of food which consists mainly of small fish. The diet is however supplemented with prawns, mantis shrimps, swimming crabs and other midwater organisms (van der Elst 1988).

Family: CARANGIDAE

Species: Lichia amia (Linnaeus, 1758)

Common name: Leervis or Garrick

Smiths' Sea Fishes number: 210.33

Illustrated specimen length: $16 \mathrm{~cm} \mathrm{SL}$

\section{Selected anatomical features}

Fin elements: Dorsal VII +I, 19-21; Anal II +I, 17-21.

Lateral line sinuous.

Maximum recorded length in southern

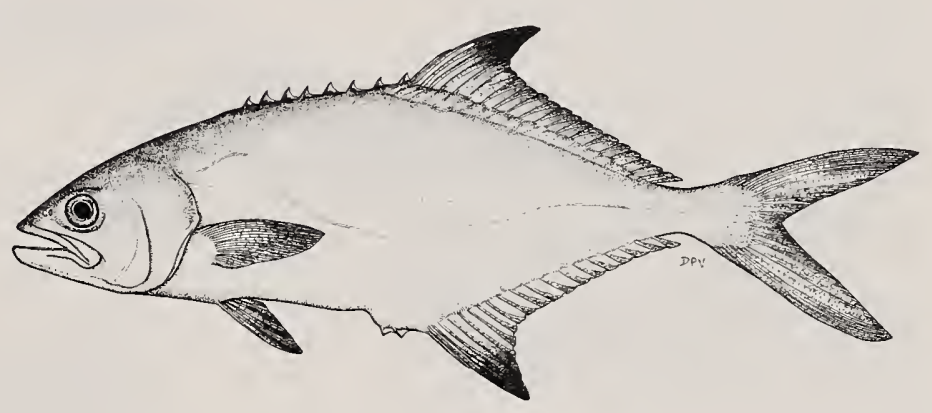
African waters: $\pm 110 \mathrm{~cm} \mathrm{SL}$.

\section{Distribution}

The leervis has a range extending from the Mediterranean Sea, southward along the entire African coast and around Cape Point to northern KwaZuluNatal (Smith-Vaniz 1986). Juveniles are mainly associated with estuaries, whereas the adults occur predominantly in the nearshore marine environment where they hunt in small shoals along the surf backline off beaches and rocky points (van der Elst 1988).

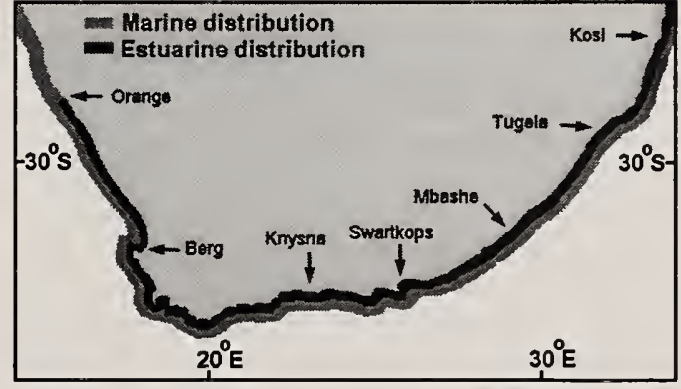


L. amia become sexually active at $58 \mathrm{~cm} \mathrm{SL}$ (van der Elst 1988). Spawning in the marine environment probably occurs during late winter and spring, with spent individuals recorded mainly between September and November in KwaZulu-Natal waters (Wallace 1975b). Small juveniles are rare in KwaZulu-Natal estuaries but become increasingly common towards the southwest where they are regularly sampled in Eastern Cape estuaries (Wallace \& van der Elst 1975). Cohorts 25-40 mm SL enter warm-temperate estuaries during summer (Beckley 1984a, Bennett 1989, Whitfield \& Kok 1992). Juveniles $40-50 \mathrm{~mm}$ SL from the Orange River Estuary indicate that breeding may also occur off the cool-temperate west coast.

The recorded salinity range is from 2-39\% (Whitfield 1996b) and the leervis was one of the few marine species not to succumb to the prolonged low salinities $(<3 \%)$ in the temporarily closed Bot Estuary (Bennett 1985). L. amia is associated with a wide range of turbidities, but it is particularly abundant in clear to partially turbid estuaries ( $<50 \mathrm{NTU})$. According to van der Elst (1988) this species undertakes seasonal migrations, moving to KwaZulu-Natal in winter (June) and back to the warm-temperate region in early summer. Winter migrations usually coincide with the annual northward movement of Sardinops sagax shoals and are associated with a period of increased gonad development by adult $L$. amia.

The diet of newly recruited leervis is dominated by mysids, shrimps and small fishes. They are voracious predators and specimens less than $80 \mathrm{~mm} \mathrm{SL}$ frequently consume prey up to $70 \%$ of their body length (Smale \& Kok 1983). Growth is extremely rapid and Blaber (1974c) recorded an $11 \mathrm{~cm}$ length increase within six months (January-July) in the West Kleinemonde Estuary. Juveniles greater than $15 \mathrm{~cm} \mathrm{SL}$ are primarily piscivorous on estuarine species such as Gilchristella aestuaria and estuary-associated taxa such as Liza richardsonii (Marais 1984). In the marine environment this species preys extensively on Pomatomus saltatrix, Pomadasys olivaceum and Sarpa salpa (van der Elst 1988).

Family: CARANGIDAE

Species: Scomberoides lysan (Forsskål, 1775)

Common name: Doublespotted queenfish

Smiths' Sea Fishes number: 210.39

Illustrated specimen length: $16 \mathrm{~cm} \mathrm{SL}$

\section{Selected anatomical features}

Fin elements: Dorsal VI-VII +I, 19-21;

Anal II+I, 17-19.

Scales on midbody lanceolate.

Maximum recorded length in southern

African waters: $\pm 65 \mathrm{~cm} \mathrm{SL}$.

\section{Distribution}

This queenfish is a widespread Indo-West Pacific species, ranging from southern Africa northward and eastward to the Hawaiian Islands (Smith-Vaniz 1986). It is found from estuaries to marine offshore areas, from surface waters to $100 \mathrm{~m}$ depth.

\section{Biology and ecology}

Within southern African estuaries $S$. lysan are commonly recorded in some of the larger KwaZuluNatal systems such as Kosi, usually in single size-class shoals numbering at least 100 individuals (Blaber \&

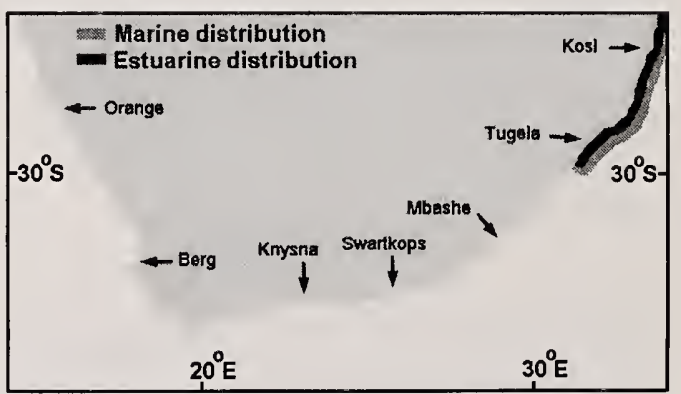

Cyrus 1983). Spawning occurs in the marine environment during spring and early summer, with the juveniles entering estuaries at a length of $20-30 \mathrm{~mm} \mathrm{SL}$ during late summer. A growth rate of $12 \mathrm{~cm}$ per 
annum has been estimated for first and second year fish, with slower growth recorded in the third year (Blaber \& Cyrus 1983). No mature fish were recorded in KwaZulu-Natal estuaries, with the largest specimen measuring $42 \mathrm{~cm}$ SL.

$S$. lysan appear to be intolerant of highly turbid water because they are absent from Lake St Lucia. According to Blaber \& Cyrus (1983) the juveniles appear to be more tolerant of turbid water than the subadults. The recorded salinity range of juveniles was approximately 6-35\% with subadults found in salinities down to $1 \%$ (Blaber \& Cyrus 1983). The closely related Scomberoides commersonnianus also enters estuaries but is generally intolerant of low salinities and turbidities (van der Elst 1988).
The diet of juveniles $20-60 \mathrm{~mm}$ SL in KwaZuluNatal estuaries comprises a variety of planktonic organisms and fish scales (Blaber \& Cyrus 1983). Major (1973) showed that young $S$. lysan in Hawaii were also lepidophagous. Juveniles $7-19 \mathrm{~cm}$ SL feed primarily on mysids and juvenile penaeid prawns, although the fry of a number of fish species are also taken. The subadults (19-42 cm SL) show a switch in diet to fish although large quantities of mysids are still consumed (Blaber \& Cyrus 1983). Filter feeding of the mysids is a distinct possibility since $S$. lysan have long gill rakers with well developed denticles. Foraging occurs mainly during the day, with peak stomach fullness occurring at $15 \mathrm{~h} 00$ for both juveniles and subadults (Blaber \& Cyrus 1983).

Family: MUGILIDAE

Species: Liza alata (Steindachner, 1892)

Common name: Diamond mullet

Smiths' Sea Fishes number: 222.2

Illustrated specimen length: $19 \mathrm{~cm} \mathrm{SL}$

\section{Selected anatomical features}

Fin elements: Dorsal IV +I, 8; Anal III, 9; Pectoral 16.

Lateral scales: 29-32.

Maximum recorded length in southern African waters: $\pm 61 \mathrm{~cm} \mathrm{SL}$.

\section{Distribution}

The diamond mullet is an Indo-West Pacific species which reaches as far as Algoa Bay in the southwest (Smith \& Smith 1986b). Juveniles and adults of $L$. alata frequent KwaZulu-Natal and Eastern Cape estuaries but are not abundant in southern Africa (Wallace 1975a, Blaber 1977).

\section{Biology and ecology}

According to Blaber (1987) spawning occurs in the inshore marine environment and the $0+$ juveniles first enter estuaries at a length of $14 \mathrm{~mm}$ SL. Recruitment into estuaries occurs between July and January but peak immigration periods are unknown.

The diamond mullet is frequently captured in low salinity and low turbidity areas of estuaries, especially the middle reaches of lagoon and lake systems (Whitfield 1980b, Blaber \& Cyrus 1981). This species has a recorded salinity range of $1-35 \%$ (Whitfield 1996b).

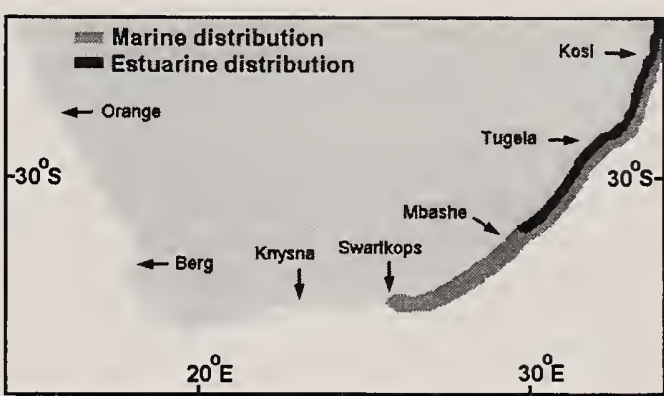

The diet of newly recruited $L$. alata in estuaries consists mainly of vertically migrating zooplankton (e.g. copepods) and meiobenthos, with the switch to microphytobenthos occurring at approximately $20 \mathrm{~mm}$ SL (Blaber \& Whitfield 1977a). Larger juveniles and adults feed mainly on filamentous algae, terrestrial plant debris, small gastropods, pennate diatoms and particulate organic matter (Blaber 1976, 1977). Relatively large sand particles with mean diameters ranging from $0.3-0.7 \mathrm{~mm}$ are also ingested. 
Family: MUGILIDAE

Species: Liza dumerilii (Steindachner, 1869)

Common name: Groovy mullet

Smiths' Sea Fishes number: 222.3

Illustrated specimen length: $11 \mathrm{~cm} \mathrm{SL}$

\section{Selected anatomical features}

Fin elements: Dorsal IV +I, 8; Anal III, 9; Pectoral 16.

Lateral scales: $36-39$.

Maximum recorded length in southern African waters: $\pm 32 \mathrm{~cm} \mathrm{SL}$.

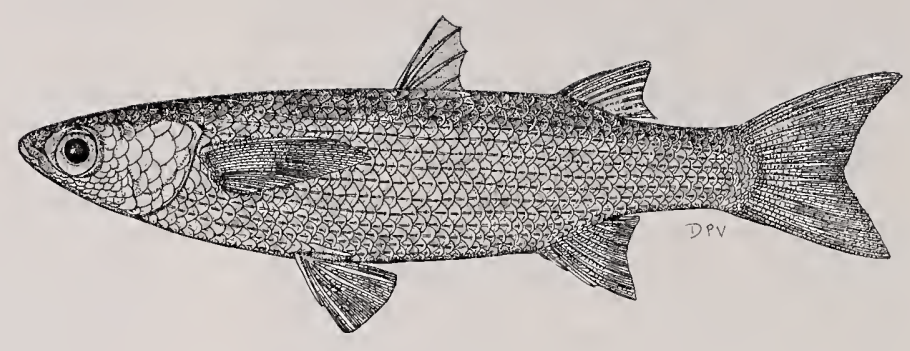

\section{Distribution}

The groovy mullet has an African distribution extending from Senegal to Namibia, and from the Western Cape to Mozambique (Smith \& Smith 1986b). In southern Africa, this species occurs as far west as False Bay (Clark et al. 1994) but is absent from the cool-temperate Western Cape coastal region. The juveniles are normally abundant in estuaries, with the adults occurring in both the estuarine and marine environment (Wallace 1975a).

\section{Biology and ecology}

Spawning by $L$. dumerilii larger than $18 \mathrm{~cm}$ SL appears to take place in the vicinity of estuaries, with some specimens in a ripe-running condition recorded within estuary mouths (van der Horst \& Erasmus 1981). In KwaZulu-Natal, breeding occurs between June and November (Wallace 1975b) but in the Eastern Cape spawning has been recorded between December and February (van der Horst \& Erasmus 1978, 1981). A large proportion of spent individuals return to the estuarine environment following spawning (Wallace 1975b).

According to Wallace \& van der Elst (1975) the recruitment of juvenile $L$. dumerilii less than $50 \mathrm{~mm}$ TL occurs mainly from August to February in KwaZulu-Natal estuaries, whereas in Eastern Cape systems peak immigration is from April to May (Beckley 1984a). On the southern Cape coast, recruitment of $L$. dumerilii less than $30 \mathrm{~mm}$ TL occurs throughout the year with a peak between November and June (Whitfield \& Kok 1992). L. dumerilii has been recorded in salinities from $1 \%$ to $90 \%$ (Whitfield 1996b) and in the temporarily closed Seekoei Estuary this species was recorded dying in salinities above $90 \%$ (Whitfield 1989e).

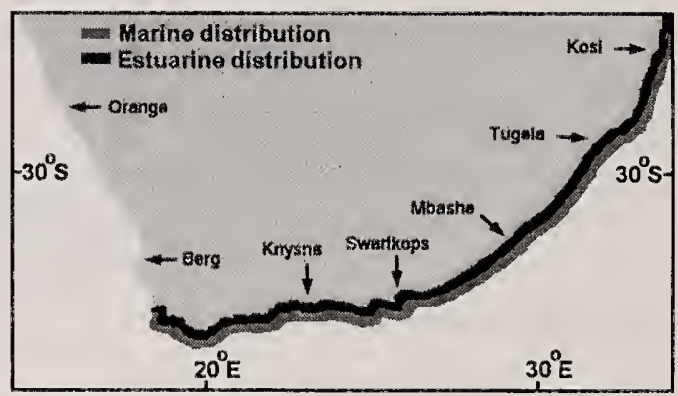

The groovy mullet is associated with water turbidities ranging from $<10-80 \mathrm{NTU}$, with more than $90 \%$ of individuals occurring in water less than 50 NTU (Cyrus \& Blaber 1987c). Based on field and laboratory choice chamber experiments $L$. dumerilii can be regarded as a clear to partially-turbid water species.

The diet of postlarval $L$. dumerilii less than $20 \mathrm{~mm}$ SL consists mainly of ostracods, insect larvae, foraminiferans and diatoms, with a switch to a typical juvenile diet occurring at a length greater than $20 \mathrm{~mm}$ (Blaber \& Whitfield 1977a). Juveniles and adults consume mainly particulate organic matter, diatoms, macrophytic plant material, foraminiferans and small gastropods. Large amounts of sand with mean particle diameters ranging from $0.2-0.5 \mathrm{~mm}$ are also ingested (Masson \& Marais 1975, Blaber 1976, 1977).

Feeding periodicity studies indicate that $\dot{L}$. dumerilii forages during the day and night, with a lower food intake during the nocturnal hours (Blaber 1976, Marais 1980). According to Marais (1978), oxygen consumption by this species displays a diel rhythm, with lowest consumption rates at midday and midnight and highest just after sunrise and sunset. 
Family: MUGILIDAE

Species: Liza macrolepis (Smith, 1846)

Common name: Largescale mullet

Smiths' Sea Fishes number: 222.5

Illustrated specimen length: $19 \mathrm{~cm} \mathrm{SL}$

\section{Selected anatomical features}

Fin elements: Dorsal IV $+\mathrm{I}, 8$; Anal III, 9; Pectoral 16.

Lateral scales: $33-35$.

Maximum recorded length in southern African waters: $\pm 29 \mathrm{~cm} \mathrm{SL}$.

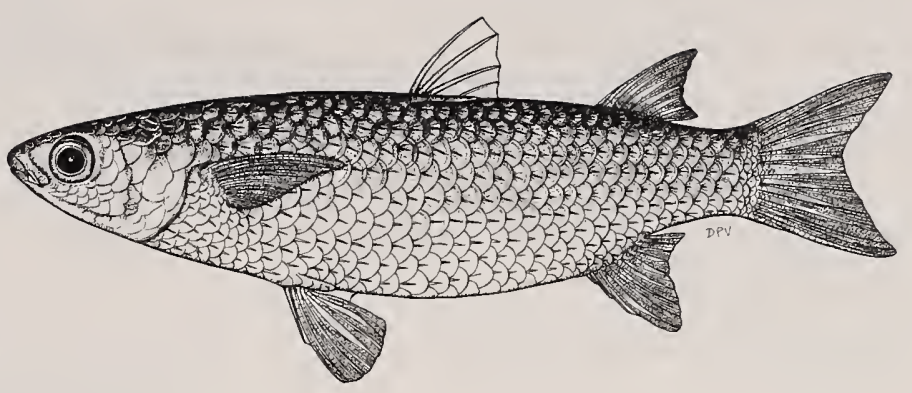

\section{Distribution}

The largescale mullet is an Indo-West Pacific species (Smith \& Smith 1986b) with stragglers extending as far as the Knysna Estuary in the Western Cape Province. Juveniles are usually abundant in KwaZulu-Natal estuaries, with the adults occurring in both the estuarine and marine environment. The relative abundance of this species in subtropical estuaries increases from south to north (Blaber 1977) with few individuals entering the warm-temperate estuaries of the Eastern Cape. The closely related Liza luciae ranges from subtropical waters in the Transkei to southern Mozambique (Smith \& Smith 1986b) but is only regularly recorded in the St Lucia system.

\section{Biology and ecology}

Spawning by largescale mullet greater than $23 \mathrm{~cm}$ SL appears to take place in the vicinity of estuaries, with the gonads of some specimens in a ripe-running condition recorded within estuary mouths (Wallace 1975b). Garratt (1993) found large quantities of $L$. macrolepis eggs leaving the Kosi Estuary on the ebb tide, i.e. spawning had taken place in the lower reaches of this system. Breeding occurs mainly during winter and spring, i.e. between May and November (Wallace 1975b, Garratt 1993). In KwaZulu-Natal estuaries, ripe and spent fish constitute the bulk of the adult population, with ripe specimens outnumbering postspawners in Lake St Lucia (Wallace 1975b).

According to Wallace \& van der Elst (1975) postlarvae 10-20 mm TL first start entering KwaZulu-Natal estuaries in winter and continue to do so until spring. Larger $0+$ juveniles (20-40 mm TL) are abundant in subtropical estuaries from September to December and may represent older recruits. Overall, the most intense recruitment period for this species is between July and December.

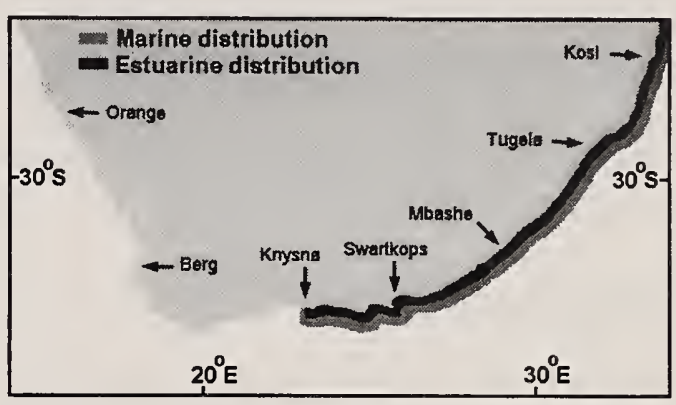

L. macrolepis occurs in salinities ranging from less than $1 \%$ to $75 \%$ (Whitfield $1996 \mathrm{~b}$, Blaber 1987) and is also associated with a wide range of water turbidities. Cyrus \& Blaber (1987c) found that $49 \%$ of individuals were captured in less than $10 \mathrm{NTU}$ and $28 \%$ in $10-50$ NTU. Data from Cyrus \& Blaber (1987a, 1987b) shows that this fish can be regarded as a clear to partially-turbid water species.

The diet of postlarvae less than $20 \mathrm{~mm}$ SL consists mainly of copepods, cladocerans, insect larvae, fish eggs and diatoms (Whitfield 1985), with a switch to a typical juvenile diet occurring at a length greater than $25 \mathrm{~mm}$ SL (Blaber \& Whitfield 1977a). Juveniles and adults consume mainly particulate organic matter, diatoms, flagellates, filamentous algae, macrophytic plant debris, foraminiferans and small gastropods. Large amounts of sand with mean particle diameters ranging from $0.1-0.3 \mathrm{~mm}$ are also ingested (Blaber 1977, Whitfield 1980b). Feeding periodicity studies indicate that $L$. macrolepis forages during the day and ceases feeding at night (Blaber 1976). 
Family: MUGILIDAE

Species: Liza richardsonii (Smith, 1846)

Common name: Southern mullet

Smiths' Sea Fishes number: 222.7

Illustrated specimen length: $16 \mathrm{~cm} \mathrm{SL}$

\section{Selected anatomical features}

Fin elements: Dorsal IV +I, 8-9;

Anal III, 9; Pectoral 16-18.

Lateral scales: 44-50.

Maximum recorded length: $\pm 32 \mathrm{~cm} \mathrm{SL}$.

\section{Distribution}

The southern mullet is an endemic species that is often abundant in temperate South African estuaries but is rarely recorded in subtropical KwaZulu-Natal systems. Although the juveniles and adults are common in Eastern and Western Cape estuaries (Bennett 1989), this species is usually more abundant in the nearshore marine environment.

\section{Biology and ecology}

L. richardsonii matures at $18 \mathrm{~cm} \mathrm{SL}$ (de Villiers 1987) and according to Lasiak (1983a) spawns in Eastern Cape waters between September and March, often close inshore (van der Horst \& Erasmus 1981). The larval development of this species, which has been described by Cambray \& Bok (1989), takes place in the nearshore marine environment.

Peak abundance of postflexion larvae in the Swartvlei Bay surf zone was between October and March, which coincided with the immigration of $L$. richardsonii less than $20 \mathrm{~mm}$ TL into the Swartvlei Estuary. It would appear, however, that juvenile recruitment into permanently open Western Cape estuaries occurs throughout the year, with peak immigration between November and May (Bennett 1989, Whitfield \& Kok 1992). Cohorts $10-40 \mathrm{~mm} \mathrm{SL}$ were recorded migrating up the Wilderness system during February (Hall et al. 1987).

Unlike most other mugilids, which rely mainly on estuarine nursery areas (Wallace et al. 1984a), the juveniles of $L$. richardsonii are common both in estuaries (Beckley 1984a) and in the marine environment (Romer \& McLachlan 1986). In the Knysna and Swartvlei estuaries $0+$ juveniles are most abundant in the lower and middle reaches (Whitfield \& Kok 1992). They do, however, penetrate the upper reaches of estuaries and were common in the littoral zone of Swartvlei lake.

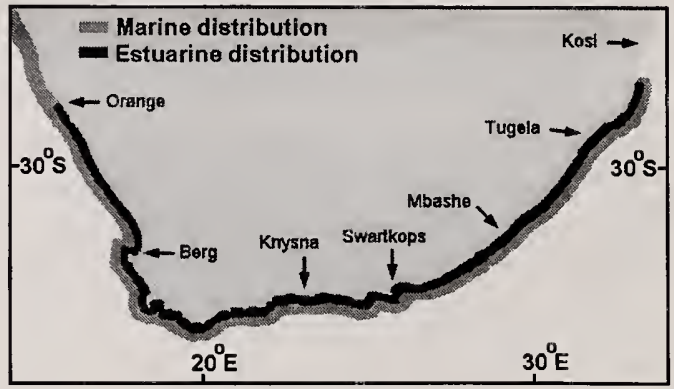

The southern mullet is euryhaline and has been recorded in salinities ranging from 2-90\%o (Branch et al. 1985, Whitfield 1996b). Limited mortalities were documented in the temporarily closed Bot Estuary when salinities remained below $3 \%$ for more than a month (Bennett 1985). It would appear that $L$. richardsonii in estuaries can maintain a better physiological condition (e.g. higher lipid levels) than marine populations due to the more favourable feeding opportunities and the retention of energy usually lost through spawning (de Decker \& Bennett 1985).

The diet of postlarval $L$. richardsonii less than 20 mm SL consists mainly of copepods and macruran larvae, with a switch to a typical juvenile diet occurring at a length greater than $20 \mathrm{~mm}$ SL (Whitfield 1985). Juveniles and adults consume mainly particulate organic matter, pennate diatoms, unicellular and filamentous algae, macrophytic plant material and foraminiferans derived from benthic substrata (Masson \& Marais 1975, Whitfield 1988a).

Large amounts of fine sand and silt are ingested by estuarine populations (Marais 1980) but planktonic feeding habits appear to be common in the marine environment (Romer \& McLachlan 1986, de Villiers 1987). Feeding periodicity studies in the Swartkops Estuary indicate that $L$. richardsonii forages mainly during the day and have a very low food intake at night (Marais 1980). 
Family: MUGILIDAE

Species: Liza tricuspidens (Smith, 1935)

Common name: Striped mullet

Smiths' Sea Fishes number: 222.8

Illustrated specimen length: $17 \mathrm{~cm} \mathrm{SL}$

\section{Selected anatomical features}

Fin elements: Dorsal IV +I, 8; Anal III, 9; Pectoral 18.

Lateral scales: 43-52.

Maximum recorded length: $\pm 60 \mathrm{~cm}$ SL.

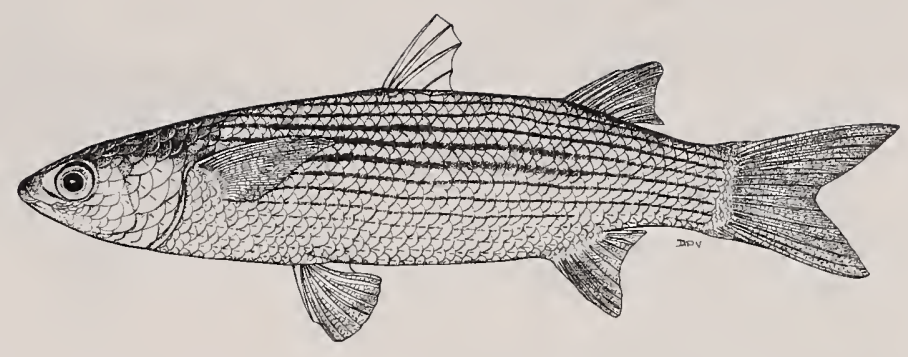

\section{Distribution}

The striped mullet is an endemic southern African species which is absent from cool-temperate estuaries of the west coast (Smith \& Smith 1986b). Juveniles and adults of this species occur both in estuaries and the nearshore marine environment. There is a decline in the abundance of $L$. tricuspidens between subtropical Eastern Cape and KwaZulu-Natal estuaries (Blaber 1977) and westwards along the Western Cape coast towards the Palmiet system (Bennett 1989).

\section{Biology and ecology}

This species matures at $38 \mathrm{~cm} \mathrm{SL}$ and spawns mainly between August and November in KwaZulu-Natal waters (Wallace 1975b). Very few juveniles have been recorded in KwaZulu-Natal estuaries (Wallace \& van der Elst 1975) but in the Eastern Cape L. tricuspidens less than $10 \mathrm{~cm}$ TL have been recorded in moderate numbers from the Sundays and Swartkops systems (Beckley 1983, 1984a) as well as from tidal pools in the area (Beckley, 1985b).

Juveniles first enter estuaries at a length of 20-30 mm TL (Wallace \& van der Elst 1975, Beckley 1983, 1984a) and according to Blaber (1987) recruitment occurs between November and January. Evidence from Whitfield \& Kok (1992) suggests an October-May influx of $0+$ juveniles into the Knysna and Swartvlei estuaries, with peak recruitment between October and December. Cohort analyses from Knysna indicate that L. tricuspidens may attain $14 \mathrm{~cm}$ TL in their first year.

In the Knysna and Swartvlei systems, this species is most abundant in the lower half of the estuaries, with relatively few individuals penetrating the upper reaches (Whitfield \& Kok 1992, Whitfield 1993). A similar situation pertains to the nearby Wilderness system, where $L$. tricuspidens was restricted to the Wilderness lagoon and did not utilize the adjoining estuarine lakes (Hall et al. 1987).

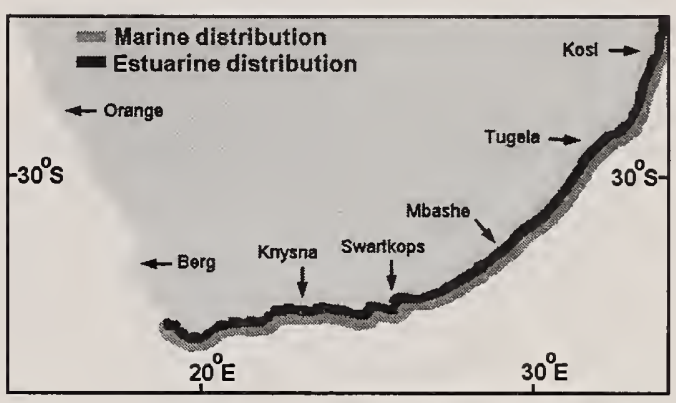

Indications are that this species has a lower salinity tolerance limit of $4 \%$ (Blaber 1987), which may account for the avoidance by $L$. tricuspidens of the upper reaches of most estuarine systems and those freshwater dominated temporarily closed estuaries where salinities often decline below $5 \%$. The striped mullet was recorded dying in the temporarily closed Seekoei Estuary when salinities increased above $90 \%$ (Whitfield 1989e).

The diet of $L$. tricupidens in estuaries consists mainly of filamentous algae, macrophytic plant material, epiphytic diatoms and foraminiferans (Masson \& Marais 1975, Blaber 1976, 1977). The tricuspid teeth of this species may aid the cropping of filamentous algae and aquatic plants such as Zostera and Ruppia (Marais 1980). The large amounts of plant material consumed by $L$. tricuspidens accounted for a higher food protein and carbohydrate content when compared to other mullet species in the Swartkops Estuary (Marais \& Erasmus 1977). Small amounts of sand with mean particle diameters ranging from 0.2$0.6 \mathrm{~mm}$ are also ingested (Blaber 1976, 1977, Marais 1980).

This species has great leaping abilities and can cover more than $10 \mathrm{~m}$ in one leap when escaping the attentions of predators (Smith 1965). 
Family: MUGILIDAE

Species: Mugil cephalus Linnaeus, 1758

Common name: Flathead mullet

Smiths' Sea Fishes number: 222.10

Illustrated specimen length: $17 \mathrm{~cm} \mathrm{SL}$

\section{Selected anatomical features}

Fin elements: Dorsal IV +I, 6-8; Anal III, 8; Pectoral 16-17.

Lateral scales: $39-42$.

Maximum recorded length in southern African waters: $\pm 54 \mathrm{~cm} \mathrm{SL}$.

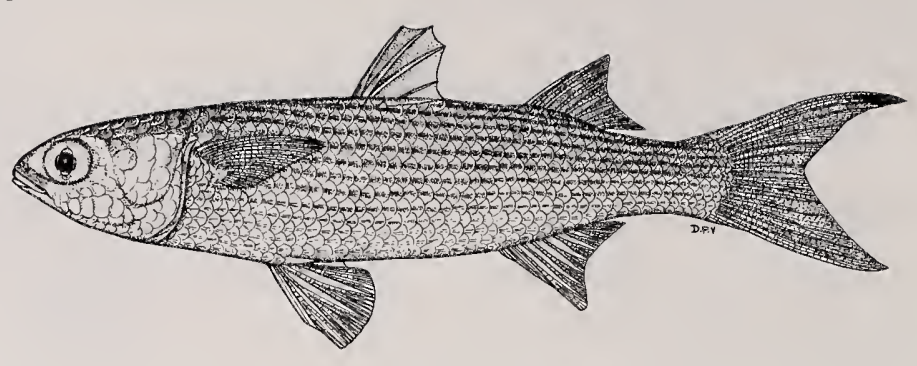

\section{Distribution}

The flathead mullet has a cosmopolitan distribution, occurring in all warm and temperate seas, estuaries and rivers (Smith \& Smith 1986b). In southern Africa, this species is abundant in subtropical and warm-temperate estuaries but also occurs in cool-temperate estuaries along the west coast. The juveniles rely on estuaries and rivers as nursery areas, with the adults occurring in both estuarine and marine environments (Wallace 1975a).

\section{Biology and ecology}

This species spawns along the coast between May and September (Wallace 1975b) with recruitment of less than $30 \mathrm{~mm}$ TL juveniles into KwaZulu-Natal estuaries occurring between June and October (Wallace \& van der Elst 1975). In Eastern Cape estuaries, the main recruitment period is June to October (Bok 1979), with a peak during August/September (Beckley 1984a). Juveniles in the Eastern Cape sometimes penetrate riverine systems up to $100 \mathrm{~km}$ from the head of the estuary (Bok 1979). Recruitment of $0+$ juveniles into the Knysna Estuary occurs from August to December, with a peak during September-November (Whitfield \& Kok 1992). Cohort analysis indicates that specimens less than $40 \mathrm{~mm} \mathrm{TL}$ recruit into the above estuary during August and may attain $16 \mathrm{~cm}$ TL by the end of March.

$M$. cephalus occurs throughout estuarine systems in a wide range of salinities $(0-84 \%)$, temperatures (10$32^{\circ} \mathrm{C}$ ) and turbidities ( $\left.<10-80 \mathrm{NTU}\right)$. Although it has been recorded dying in Lake St Lucia when low salinities $(<2 \%)$ and low temperatures occurred simultaneously (Blaber \& Whitfield 1976), the same species survived prolonged oligohaline conditions $(<3 \%)$ in the Bot and Kosi systems (Blaber \& Cyrus 1981, Bennett 1985). In the temporarily closed Seekoei Estuary $M$. cephalus was recorded dying in salinities

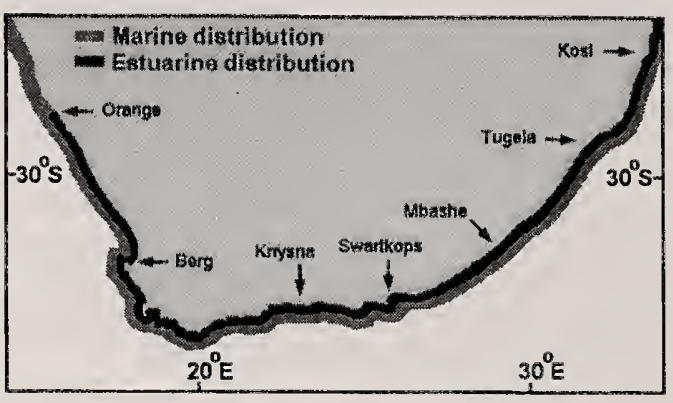

above $90 \%$ (Whitfield 1989e). In the Eastern Cape, juveniles of this species regularly migrate into freshwater areas (Bok 1979) but there is little evidence to suggest similar mass movements in either the Western Cape or KwaZulu-Natal rivers.

The seaward spawning migration of $M$. cephalus in Lake St Lucia has been well documented, with large shoals of mature fish ( +3 years of age, $+34 \mathrm{~cm} \mathrm{SL}$ ) moving down the system in April each year (Whitfield \& Blaber 1978b). Jumping by this species increases dramatically during the above migration, possibly as a result of increased predation (Whitfield \& Blaber $1979 \mathrm{c}, 1979 \mathrm{~d})$.

The diet of postlarval $M$. cephalus less than $20 \mathrm{~mm}$ SL consists mainly of copepods, ostracods, fish eggs and diatoms, with a switch to the typical juvenile diet occurring at a length greater than $20 \mathrm{~mm}$ SL (Blaber \& Whitfield 1977a). Juveniles and adults consume mainly particulate organic matter, diatoms, macroplytic plant material, foraminiferans and small gastropods (Masson \& Marais 1975, Blaber 1977). Large amounts of sand with a mean particle diameter of $0.2-0.5 \mathrm{~mm}$ are also ingested (Blaber 1976, Whitfield 1980b). Feeding periodicity studies in Lake St Lucia indicate that $M$. cephalus forages mainly during the day, with a lower food intake during nocturnal hours (Blaber 1976). 
Family: MUGILIDAE

Species: Myxus capensis (Valenciennes, 1836)

Common name: Freshwater mullet

Smiths' Sea Fishes number: 222.11

Illustrated specimen length: $23 \mathrm{~cm} \mathrm{SL}$

\section{Selected anatomical features}

Fin elements: Dorsal IV +I, 8; Anal III, 9; Pectoral 17.

Lateral scales: 43-45.

Maximum recorded length: $\pm 37 \mathrm{~cm} \mathrm{SL}$.

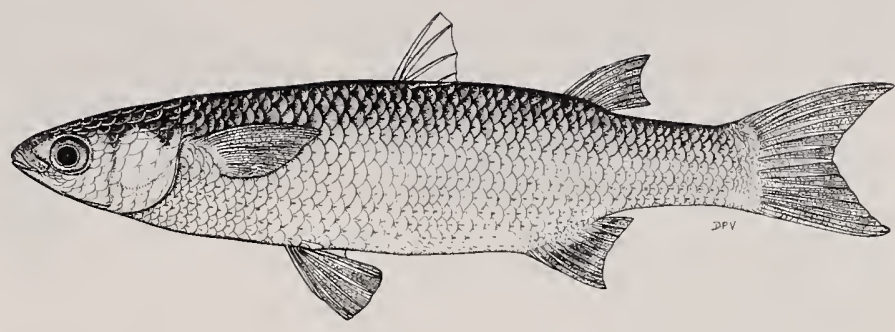

\section{Distribution}

The freshwater mullet is an endemic species which ranges from the subtropical Kosi estuarine system in the north (Blaber 1978) to the warm-temperate Palmiet Estuary in the southwest (Bennett 1989). Juveniles and adults frequently occur both in estuaries and rivers, particularly in the Eastern Cape where specimens are often captured more than $10 \mathrm{~km}$ from the head of an estuary and sometimes as far inland as $135 \mathrm{~km}$ from the mouth (Bok 1979). Although $M$. capensis also occurs in freshwater areas along the KwaZulu-Natal and Western Cape coasts, this species is usually most abundant in the estuarine reaches of systems in these regions.

\section{Biology and ecology}

The breeding season of the freshwater mullet extends from March to November, with the main recruitment period of juveniles ( $<20 \mathrm{~mm} \mathrm{SL}$ ) taking place in the late winter and early summer months in the Kowie Estuary (Bok 1979). Data from the heads of other Eastern Cape estuaries indicate a September-November peak in recruitment although $M$. capensis fry less than $30 \mathrm{~mm}$ FL were present in the upper reaches of these systems during most months (Bok 1984).

In KwaZulu-Natal estuaries, immigration of 20-50 mm TL juveniles occurs from August to December (Wallace \& van der Elst 1975), whereas recruitment of less than $30 \mathrm{~mm}$ TL $M$. capensis into Western Cape estuaries was recorded throughout the year. The main immigration period extends from July to November, with a spring peak (October/November) for the above size classes (Whitfield \& Kok 1992). Cohort analysis in the Knysna Estuary between November and January indicates an early juvenile growth rate of approximately $10 \mathrm{~mm}$ per month (Whitfield \& Kok 1992).

According to Bok (1984) M. capensis attain $10 \mathrm{~cm}$ $\mathrm{SL}$ in one year and $19 \mathrm{~cm}$ SL after two years growth.

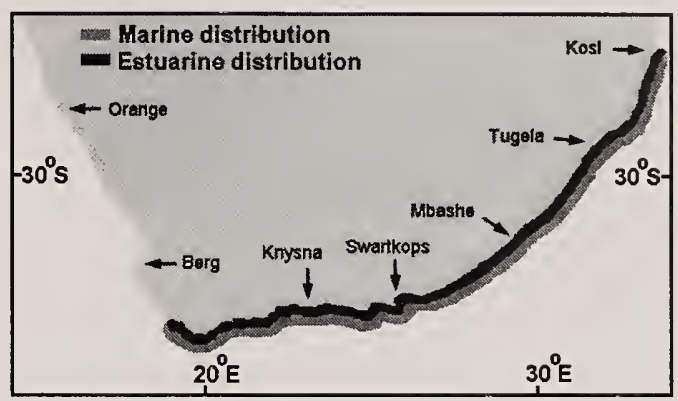

Male fish mature at approximately $19 \mathrm{~cm} \mathrm{SL}$ and females at $23 \mathrm{~cm}$ SL (Bok 1983). Bok (1979) recorded ripe-running $M$. capensis in the sea adjacent to the Great Fish Estuary in April.

The salinity range of freshwater mullet is $0-49 \%$ and it frequents both turbid ( $>100$ NTU) and clear estuaries ( $<10$ NTU) on the Eastern Cape coast. $M$. capensis is a facultative catadromous species in the Eastern Cape and survived prolonged low salinities and low temperatures in the temporarily closed Bot Estuary when other marine fish taxa were dying (Bennett 1985).

The diet of postlarval $M$. capensis less than $30 \mathrm{~mm}$ SL consists mainly of copepods, crustacean larvae and cumaceans, with a switch to a typical juvenile diet occurring at a length greater than $30 \mathrm{~mm}$ SL (Blaber \& Whitfield 1977, Whitfield 1985). Juveniles and adults consume mainly particulate organic matter, pennate diatoms, terrestrial plant debris and filamentous algae (Blaber 1976, 1977). Insects, especially flying termites, are often preyed upon in freshwater areas. Sand particles with a mean diameter of 0.2-0.3 mm are also ingested (Blaber 1977, Whitfield 1980b). 
Family: MUGILIDAE

Species: Valamugil buchanani (Bleeker, 1853)

Common name: Bluetail mullet

Smiths' Sea Fishes number: 222.12

Illustrated specimen length: $12 \mathrm{~cm} \mathrm{SL}$

\section{Selected anatomical features}

Fin elements: Dorsal IV +I, 8; Anal III, 9; Pectoral 17-18.

Lateral scales: $33-36$.

Maximum recorded length in southern African waters: $\pm 58 \mathrm{~cm}$ SL.

\section{Distribution}

The bluetail mullet is an Indo-West Pacific species with stragglers reaching as far south as the Breë Estuary. Within southern African waters the juveniles of this species are most common in subtropical estuaries.

\section{Biology and ecology}

$V$. buchanani matures at approximately $36 \mathrm{~cm} \mathrm{SL}$ and spawns in the inshore marine environment, mainly between October and December (Wallace 1975b). The peak immigration period of juveniles into subtropical KwaZulu-Natal estuaries ranges from May to July (Wallace \& van der Elst 1975) and in warm-temperate estuaries from March to June (Whitfield \& Kok 1992). Postlarvae enter estuaries from $10 \mathrm{~mm}$ SL upwards (Blaber 1987) and are usually most abundant in the lower reaches of these systems.

The bluetail mullet has been found in salinities ranging from 1-58\%o (Whitfield 1996b) but appears to avoid low salinity areas $(<10 \%)$ whenever possible. Peak abundance of juveniles occurs in permanently open estuaries, where salinities usually range between

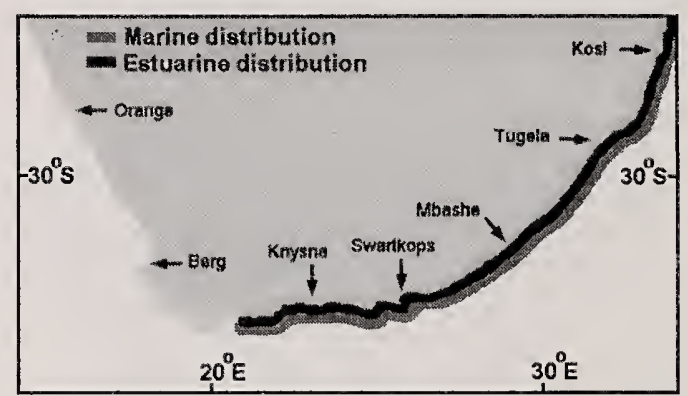

$20 \%$ and $35 \%$. Although found in a wide range of water turbidities ( $<10-80$ NTU), $90 \%$ of specimens collected in Lake St Lucia avoided waters greater than 50 NTU (Cyrus \& Blaber 1987c). Laboratory studies have confirmed the preference of $V$. buchanani for clear to partially-turbid waters (Cyrus \& Blaber 1987b).

The diet of individuals less than $20 \mathrm{~mm}$ SL consists mainly of planktonic and vertically migrating crustaceans, with a switch to a juvenile diet occurring at a length of approximately $20 \mathrm{~mm}$ SL (Blaber \& Whitfield 1977a). Juveniles and adults consume mainly diatoms, flagellates, particulate organic matter, terrestrial plant debris and foraminiferans (Blaber 1976, 1977). Large amounts of fine sand with a mean particle diameter of $0.1-0.2 \mathrm{~mm}$ are also ingested.

Family: MUGILIDAE

Species: Valamugil cunnesius (Valenciennes, 1836)

Common name: Longarm mullet

Smiths' Sea Fishes number: 222.13

Illustrated specimen length: $12 \mathrm{~cm} \mathrm{SL}$

\section{Selected anatomical features}

Fin elements: Dorsal IV +I, 8;

Anal III, 9; Pectoral 15.

Lateral scales: $33-36$.

Maximum recorded length: $\pm 27 \mathrm{~cm} \mathrm{SL}$.

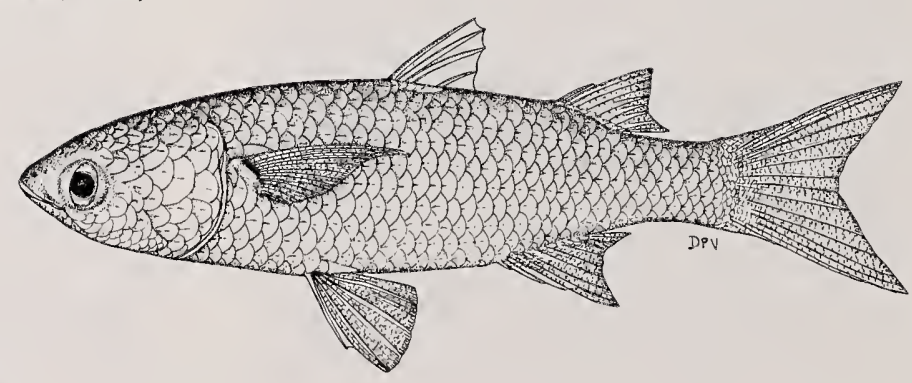




\section{Distribution}

The longarm mullet is an Indo-West Pacific species reaching as far south as the Eastern Cape Province on the African continent (Smith \& Smith 1986b). It is most common in temporarily closed subtropical estuaries along the KwaZulu-Natal coast (van der Elst 1988) and specimens have also been collected at the Save-Runde river confluence in eastern Zimbabwe.

\section{Biology and ecology}

This species matures at $17 \mathrm{~cm}$ SL and spawns inshore in the vicinity of estuary mouths between October and May (Wallace 1975b). According to Wallace \& van der Elst (1975) there is no definite recruitment season, with 20-50 mm TL juveniles entering KwaZulu-Natal estuaries over a nine month period between October and June. Whitfield (1980c) recorded 10-40 mm SL $V$. cunnesius immigrating into the temporarily open Mhlanga Estuary during summer.

The longarm mullet has been found in salinities ranging from 1-67\% (Whitfield 1996b), with the juveniles particularly abundant in the low salinity waters $(<10 \%$ ) of temporarily closed estuaries on the KwaZulu-Natal coast (Harrison \& Whitfield 1994). Although this species is associated with a wide range of

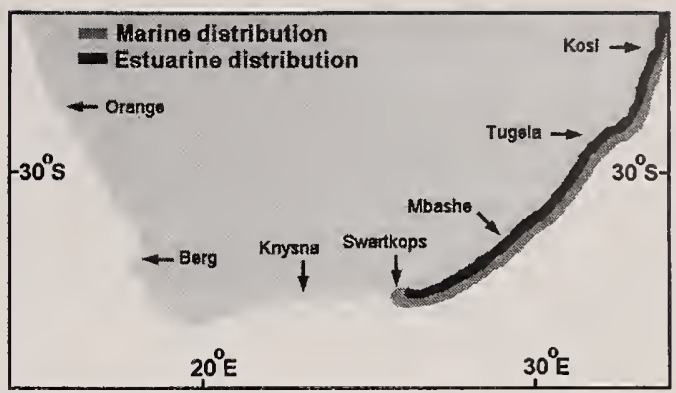

turbidities, $86 \%$ of individuals were captured in waters ranging from 50-80 NTU (Cyrus \& Blaber 1987c). Consequently $V$. cunnesius can be classified as an intermediate turbidity species (Cyrus \& Blaber 1987a).

The diet of postlarvae less than $20 \mathrm{~mm}$ SL consists mainly of copepods, cladocerans and crustacean larvae, with a switch to a typical juvenile diet occurring at a length greater than $20 \mathrm{~mm}$ SL (Whitfield 1985). Juveniles and adults consume mainly particulate organic matter, diatoms, flagellates and foraminiferans (Blaber 1976, Whitfield 1980e). Large amounts of fine sediment with a mean particle diameter of 0.1-0.2 mm are also ingested (Blaber 1976, Whitfield 1980b), indicating that this species forages on more muddy bottoms than most other mullet species.

Family: MUGILIDAE

Species: Valamugil robustus (Günther, 1861)

Common name: Robust mullet

Smiths' Sea Fishes number: 222.14

Illustrated specimen length: $12 \mathrm{~cm} \mathrm{SL}$

\section{Selected anatomical features}

Fin elements: Dorsal IV +I, 8;

Anal III, 9; Pectoral 15-16.

Lateral scales: $36-39$.

Maximum recorded length: $\pm 25 \mathrm{~cm}$ SL.

\section{Distribution}

The robust mullet is an endemic species, ranging from Mozambique and Madagascar to the Eastern Cape Province (Smith \& Smith 1986b). Although common within southern Mozambique estuaries, in South Africa this species is only abundant in the Kosi Estuary on the KwaZulu-Natal north coast (Blaber 1977).

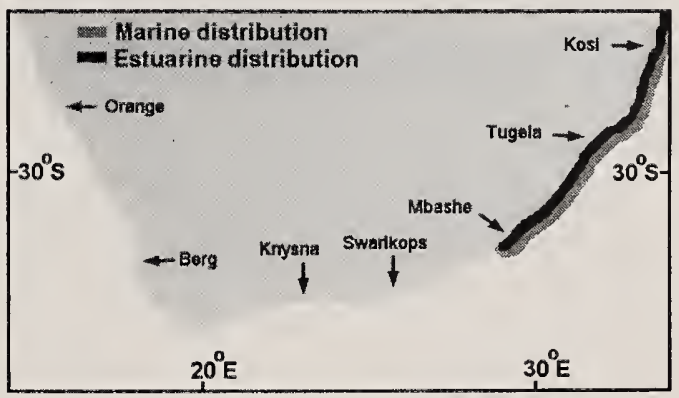




\section{Biology and ecology}

$V$. robustus attains sexual maturity within the estuarine environment but breeding occurs exclusively at sea. The immigration period of juveniles into KwaZuluNatal estuaries ranges from September to May (Blaber 1987) suggesting that spawning occurs during spring and summer. Postlarvae enter estuaries from $10 \mathrm{~mm}$ SL upwards. Within estuaries the juveniles and adults occur in salinities ranging from $1-39 \%$.
The diet of postlarval $V$. robustus less than $15 \mathrm{~mm}$ SL is dominated by vertically migratory plankton (Blaber \& Whitfield 1977a). Juveniles and adults consume mainly diatoms, blue-green algae, flagellates, filamentous algae, terrestrial plant debris and particulate organic matter (Blaber 1976, 1977). Large amounts of fine sand with a mean particle diameter of 0.1-0.2 $\mathrm{mm}$ are also ingested.

Family: SPHYRAENIDAE

Species: Sphyraena barracuda (Walbaum, 1792)

Common name: Great barracuda

Smiths' Sea Fishes number: 224.3

Illustrated specimen length: $22 \mathrm{~cm} \mathrm{SL}$

\section{Selected anatomical features}

Fin elements: Dorsal V+I, 9; Anal I, 10.

Lateral scales: $77-85$.

Maximum recorded length in southern

African waters: $\pm 140 \mathrm{~cm} \mathrm{SL}$.

\section{Distribution}

The great barracuda is a widespread species, known from KwaZulu-Natal and all tropical seas except the eastern Pacific (de Sylva \& Williams 1986). Although adults usually show a preference for reef environments, the choice of habitat is also linked to age and size, with juveniles being more common in tropical mangrove areas and estuaries (van der Elst 1988).

\section{Biology and ecology}

S. barracuda reaches a length of almost $50 \mathrm{~cm} \mathrm{SL}$ after 2 years, and sexual maturity is attained between $54 \mathrm{~cm}$ and $67 \mathrm{~cm} \mathrm{SL}$ (Blaber 1982a). Spawning occurs during summer in the tropical waters of East Africa and the Seychelles. The larvae and postlarvae are pelagic and particularly sensitive to sudden changes in water temperature (van der Elst 1988).

Immigration of postlarvae $20 \mathrm{~mm}$ SL was recorded in the Kosi estuarine system between October and April. Juveniles $20-79 \mathrm{~mm}$ SL frequented shallow $(<0.5 \mathrm{~m}$ deep) submerged plant beds within $3 \mathrm{~m}$ of the shore, specimens $8-30 \mathrm{~cm} \mathrm{SL}$ were found among mangrove root systems less than $2 \mathrm{~m}$ deep, while fish of $30-50 \mathrm{~cm}$ SL occurred in open-water areas (Blaber 1982a).

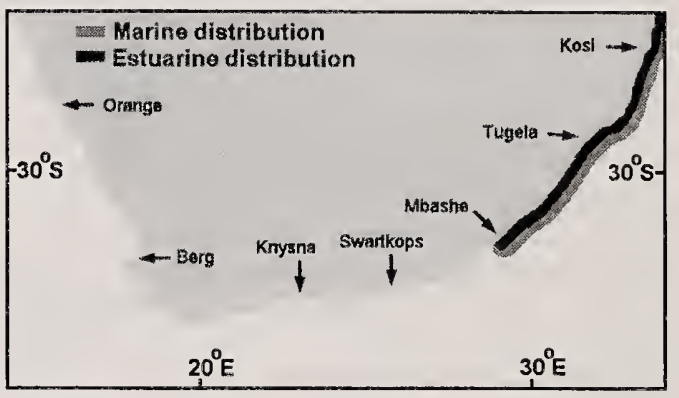

S. barracuda in Florida are seldom recorded in salinities less than 24\%o (de Sylva 1963) but within southern Africa it has been found in low salinity ( $5 \%$ ) systems (Blaber 1982a). This species is generally associated with clear waters $(<3$ NTU), the early juveniles occuring in water temperatures ranging from $20-37^{\circ} \mathrm{C}$ during summer, with larger fish being found in temperatures from $14-28^{\circ} \mathrm{C}$ (Blaber 1982a).

The diets of all three size groups found in the Kosi Estuary consisted almost entirely of fish. The first group (20-79 mm SL) consumed mainly postlarval mugilids and the cichlids which are abundant in and adjacent to littoral Potamogeton pectinatus beds. $S$. barracuda $8-30 \mathrm{~cm}$ SL preyed on a wide variety of fish 
taxa which occur in Phragmites and mangrove areas. The diet of fish larger than $30 \mathrm{~cm} \mathrm{SL}$ was dominated by Gerres and Rhabdosargus species which were captured on shallow sandy shelf areas. Foraging occurred during the day, especially during dawn and dusk (Blaber 1982a).
In the marine environment the juveniles feed on anchovies and other small shoaling teleosts, whereas the adults consume either sluggish reef fish, or faster swimming surface species such as mullet and needlefish (van der Elst 1988). This large predator is also reputed to attack humans.

Family: BOTHIDAE

Species: Pseudorhombus arsius (Hamilton, 1822)

Common name: Largetooth flounder

Smiths' Sea Fishes number: 259.17

Illustrated specimen length: $11 \mathrm{~cm} \mathrm{SL}$

\section{Selected anatomical features}

Fin elements: Dorsal 72-78;

Anal 54-60; Pectoral 11-13.

Body depth 1.7-2.0 in SL.

Maximum recorded length in southern

African waters: $\pm 38 \mathrm{~cm}$ SL.

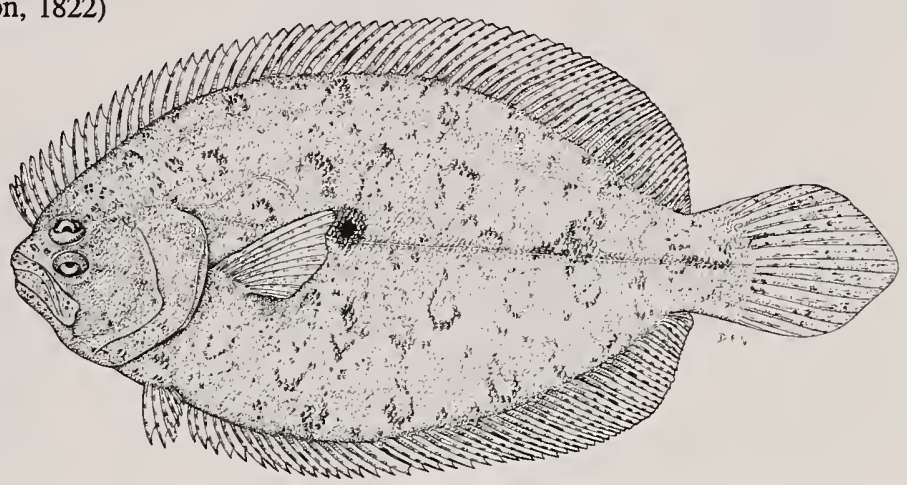

\section{Distribution}

The largetooth flounder is an Indo-West Pacific species ranging south to Algoa Bay (Hensley 1986). This species frequents sandy, muddy or gravel bottoms and has a depth distribution ranging from shallow estuaries to $100 \mathrm{~m}$ in the marine environment. The related leopard flounder Bothus pantherinus also occurs in southern African estuaries, from the Bushmans Estuary in the south to the Kosi system in the north (Cyrus \& Martin 1991).

\section{Biology and ecology}

Reproductive maturity is attained at about $20 \mathrm{~cm} \mathrm{SL}$ (Cyrus \& Martin 1991). Records from the northern Indian Ocean show that this species spawns at sea during late spring (Bawazeer 1987). The larvae look very similar to other teleost larvae after hatching but with the onset of the juvenile phase they begin to swim with the left side facing upwards and the right eye begins to migrate towards the left side of the head (van der Elst 1988).

Recruitment into southern African estuaries occurs at a standard iength greater than $50 \mathrm{~mm}$. Indications are that $P$. arsius is not dependent on estuaries as nursery

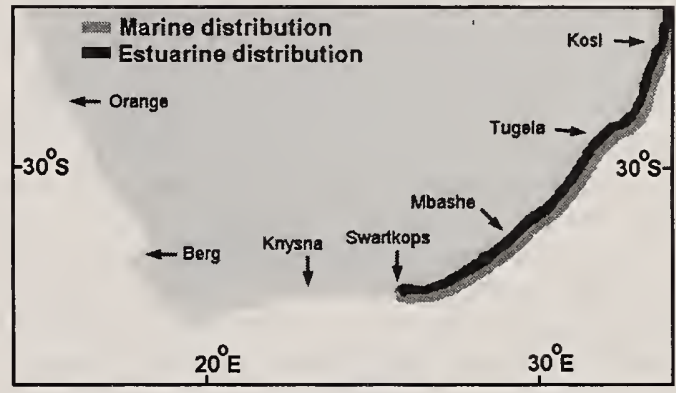

areas but are present in the larger KwaZulu-Natal systems in low numbers throughout the year. Juveniles attain between $8 \mathrm{~cm}$ and $16 \mathrm{~cm}$ in their first year of growth (Bawazeer 1987).

Juveniles in KwaZulu-Natal estuaries feed mainly on benthic crustaceans whereas adults in the sea prey mainly on fish, prawns, crabs and polychaetes (Cyrus \& Martin 1991). According to van der Elst (1988) this species uses its excellent camouflage when lying on the seabed and then pounces on unsuspecting prey. It can also move surprisingly quickly by undulating the dorsal and anal fins, while using the pectorals for steering. 
Family: SOLEIDAE

Species: Heteromycteris capensis Kaup, 1858

Common name: Cape sole

Smiths' Sea Fishes number: 262.5

Illustrated specimen length: $80 \mathrm{~mm} \mathrm{SL}$

Selected anatomical features

Fin elements: Dorsal 95-102;

Anal 64-75.

Body depth 2.5-2.8 in SL.

Maximum recorded length: $\pm 17 \mathrm{~cm}$ SL.

\section{Distribution}

The Cape sole is a southern African endemic species, confined to shallow, sandy habitats between Walvis Bay in the west and the Kei Estuary in the east. This sole frequents water 1-25 $\mathrm{m}$ in depth (Heemstra \& Gon 1986) and is most common in the lower reaches of permanently open estuaries.

\section{Biology and ecology}

$H$. capensis attains sexual maturity at approximately 80 mm SL (Cyrus \& Martin 1991). Spawning occurs in the nearshore marine environment throughout the year, with a peak between October and February (Brownell 1979).

Larvae have been recorded in False Bay and Algoa Bay throughout the year (Beckley 1986), with postflexion larvae present in the Swartvlei Bay surf zone from September to March (Whitfield 1989b). Recruitment of larvae and postlarvae into warm-temperate estuaries occurs mainly between October and March at a length of 5-15 mm BL (Whitfield \& Kok 1992).

This species has a recorded salinity range of $5-35 \%$ (Whitfield 1996b) but is usually confined to the lower

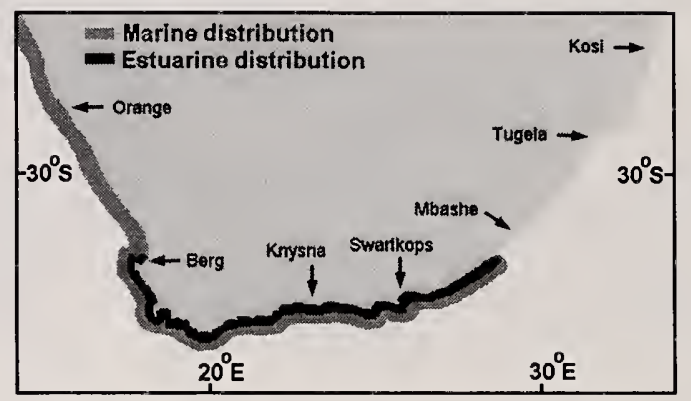

reaches of permanently open estuaries where salinities seldom decline below $30 \%$. However, sediment characteristics and not salinity appear to be the main factor influencing longitudinal distribution within an estuary. In the Kariega system $H$. capensis was common in the sandy lower reaches but did not extend its distribution into the muddy middle and upper reaches, despite the absence a salinity gradient within this estuary at the time of sampling.

The diet of Cape sole in estuaries consists mainly of small benthic invertebrates. The habits and cryptic colouration of both juveniles and adults on a sandy background provide excellent protection from pelagic predatory fishes and wading piscivorous birds.

Family: SOLEIDAE

Species: Solea bleekeri Boulenger, 1898

Common name: Blackhand sole

Smiths' Sea Fishes number: 262.12

Illustrated specimen length: $77 \mathrm{~mm} \mathrm{SL}$

\section{Selected anatomical features}

Fin elements: Dorsal 61-74;

Anal 46-59; Pectoral 7-8.

Body depth 1.9-2.7 in SL.

Maximum recorded length: $\pm 13 \mathrm{~cm} \mathrm{SL}$.

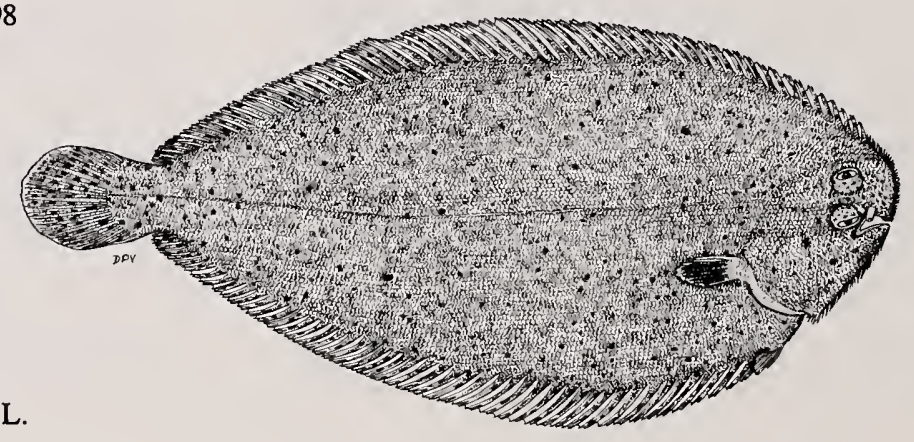




\section{Distribution}

The blackhand sole is a southern African endemic species, ranging from the Olifants Estuary on the South African west coast to the Morrumbene Estuary in Mozambique (Heemstra \& Gon 1986). The localised distribution of this sole is governed primarily by a preference for muddy rather than sandy substrata.

\section{Biology and ecology}

S. bleekeri attains sexual maturity at about $60 \mathrm{~mm} \mathrm{SL}$ (Cyrus 1991a). Breeding takes place both in the sea and in certain large estuarine systems when conditions are suitable (Cyrus 1991b). Spawning occurs between June and December in KwaZulu-Natal waters, with a peak in reproductive activity during early summer (Cyrus 1991a). The abundance of larvae $(<5 \mathrm{~mm} \mathrm{BL})$ in nearshore marine waters between November and March (Beckley 1986, Whitfield 1989b) suggests that spawning in the warm-temperate region is also a mainly summer phenomenon. Migration of larvae and juveniles into Cape estuaries occurs primarily between November and March (Melville-Smith \& Baird 1980).

S. bleekeri has a recorded salinity range of $1-42 \%$ (Whitfield 1996b) and occurs in the lower, middle and upper reaches of estuaries (Whitfield \& Kok 1992).

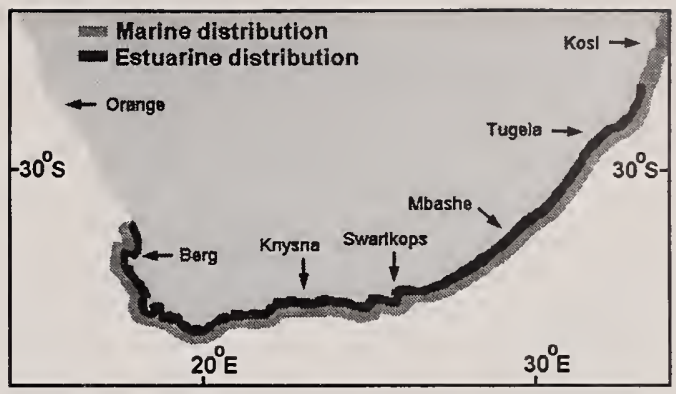

Cyrus \& Blaber (1987c) categorized the blackhand sole as a turbid water species because it occurred in greatest numbers in areas where turbidities exceeded 80 NTU. The absence of this species from the clear Kosi Estuary (Blaber \& Cyrus 1981) supports the view that this fish prefers turbid water habitats.

The diet of both juvenile and adult $S$. bleekeri in estuaries consists mainly of benthic crustaceans (Cyrus \& Martin 1991), with bivalve siphons being consumed in large quantities by adult fish (Cyrus 1988b).

According to van der Elst (1988) this is a sluggish species which only moves from its position if disturbed or to snatch prey. Despite its cryptic colouration and occupation of turbid water areas, the blackhand sole is preyed upon by the reed cormorant Phalacrocorax africanus (Whitfield \& Blaber 1979c).

Family: TETRAODONTIDAE

Species: Amblyrhynchotes honckenii (Bloch, 1795)

Common name: Evileye blaasop

Smiths' Sea Fishes number: 268.1

Illustrated specimen length: $78 \mathrm{~mm} \mathrm{SL}$

\section{Selected anatomical features}

Fin elements: Dorsal 9-10;

Anal 8; Pectoral 14-16.

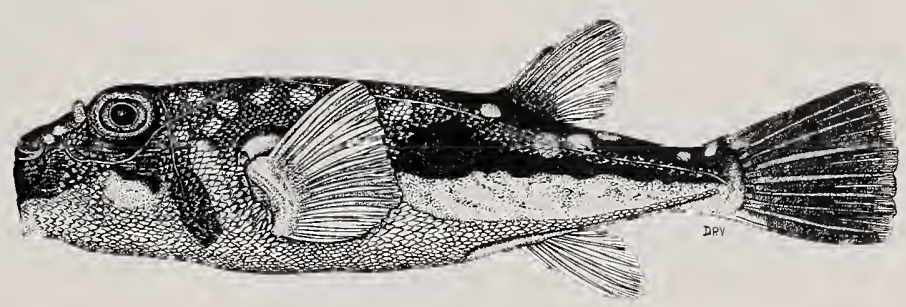

About 42 spinules across belly

between pectoral bases.

Maximum recorded length: $\pm 25 \mathrm{~cm} \mathrm{SL}$.

\section{Distribution}

The evileye blaasop has an extensive distribution, ranging from South Africa to China. This mainly tropical Indo-West Pacific species is found in tide pools, estuaries and in the sea down to depths of $400 \mathrm{~m}$ (Smith \& Heemstra 1986b). Within southern African estuaries it is frequently associated with eelgrass beds in the lower reaches.

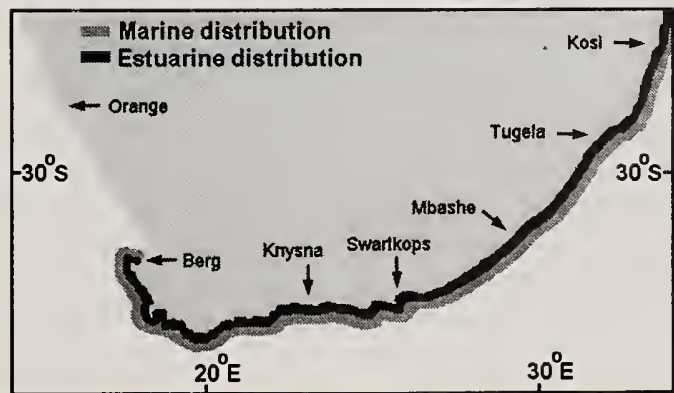


A. honckenii attains sexual maturity at approximately $80 \mathrm{~mm} \mathrm{SL}$ and is ready to spawn towards the end of winter (Day et al. 1981). Details of the early lifehistory are unknown, but van der Elst (1988) has suggested that the juveniles are dispersed by sheltering beneath floating objects borne along by ocean currents. Although the juveniles do not appear to be closely associated with estuaries, adults are sometimes common in the lower reaches of permanently open systems. This species is usually recorded in salinities above $30 \%$ but has also been found at $14 \%$.
The evileye blaasop is both a scavenger and a predator, feeding on small crustacea (mainly isopods) and bivalves, with eelgrass also being incidentally consumed (Day et al. 1981). According to van der Elst (1988) it is a predominantly demersal species and often buries itself beneath the sand with only its eyes protruding. From such a position it may dart out to snatch unsuspecting prey, including small crabs, slowswimming fishes and various benthic invertebrates. $A$. honckenii is poisonous and if threatened can inflate its body to act as a deterrent to predators.

Family: TETRAODONTIDAE

Species: Arothron immaculatus (Bloch \& Schneider, 1801)

Common name: Blackedged blaasop

Smiths' Sea Fishes number: 268.3

Illustrated specimen length: $10 \mathrm{~cm}$ SL

\section{Selected anatomical features}

Fin elements: Dorsal 9-10;

Anal 9-10; Pectoral 16-17.

Maximum recorded length in southern

African waters: $\pm 25 \mathrm{~cm} \mathrm{SL}$.

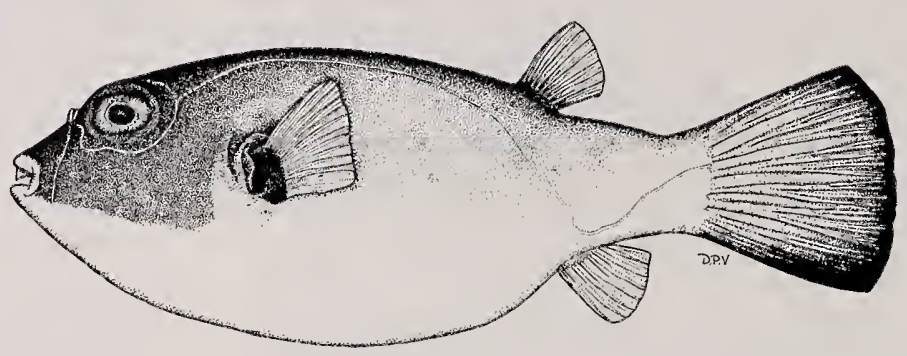

\section{Distribution}

The blackedged blaasop is a tropical Indo-West Pacific pufferfish, ranging as far south as the Bushmans Estuary in southern African waters (Smith \& Heemstra 1986b). This blaasop is sometimes common in submerged plant beds of subtropical estuaries in KwaZulu-Natal and the Eastern Cape. The related whitespotted blaasop Arothron hispidus has a distribution which overlaps with that of $A$. immaculatus in the subtropical region.

\section{Biology and ecology}

A. immaculatus attains sexual maturity at approximately $12 \mathrm{~cm}$ TL and females with ripening ovaries have been found in estuaries during spring (Day et al. 1981). Breeding probably takes place in the sea during early summer, with the larvae utilizing the marine environment for the early developmental stages. Juveniles first enter estuaries at a length of approximately $20 \mathrm{~mm}$ TL and individuals up to $16 \mathrm{~cm}$ TL are often associated with aquatic plant beds in these systems.

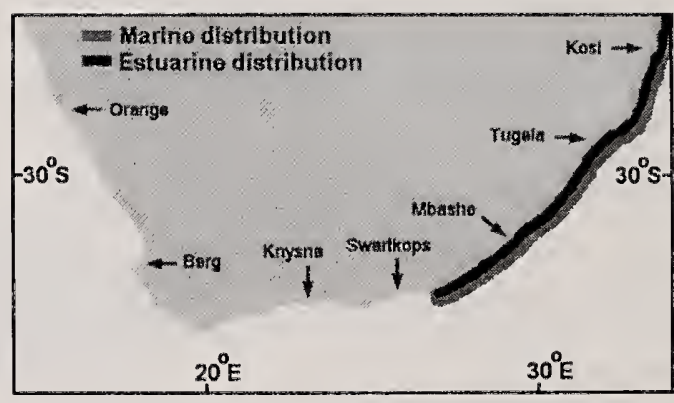

Listed by Wallace (1975a) as a euryhaline species, it has been recorded in estuaries where salinities have ranged between $8 \%$ and $38 \%$. A. immaculatus is usually found in the lower reaches of permanently open estuaries where salinities are usually above $30 \%$.

Newly recruited blackedged blaasops feed mainly on copepods when first entering an estuary, but larger juveniles and adults prey on bivalves, gastropods and crabs (Day et al. 1981). Zostera capensis is also incidentally consumed when feeding in eelgrass beds. 


\subsection{ESTUARINE GROUP}

Family: CLUPEIDAE

Species: Gilchristella aestuaria (Gilchrist, 1914)

Common name: Estuarine roundherring

Smiths' Sea Fishes number: 54.3

Illustrated specimen length: $59 \mathrm{~mm} \mathrm{SL}$

\section{Selected anatomical features}

Fin elements: Dorsal 14-15;

Anal 20; Pectoral 11-12.

Lateral scales: $39-42$.

Maximum recorded length: $\pm 90 \mathrm{~mm}$ SL.

\section{Distribution}

G. aestuaria is a southern African endemic species, ranging from the Kosi system in the northeast to the Orange River Estuary in the southwest. This shoaling fish is usually abundant in all types of estuaries and is also common in certain freshwater coastal lakes.

\section{Biology and ecology}

The estuarine roundherring matures within 7 months at approximately $28 \mathrm{~mm} \mathrm{SL}$ (Talbot 1982). Although this species has been reported breeding throughout the year, spawning peaks usually occur during spring and summer, with very little activity during winter (Blaber 1979, Cyrus et al. 1993). The eggs are approximately $1 \mathrm{~mm}$ in diameter (Connell 1996) and are usually found within the water column of the upper and middle reaches of permanently open estuaries (Wooldridge \& Bailey 1982).

G. aestuaria larvae are most abundant between September and April (Whitfield 1989c, Harris 1996), sometimes reaching densities in excess of 800 fish per $10 \mathrm{~m}^{3}$ (Harrison \& Whitfield 1990). In the Sundays Estuary, the larvae avoid ebb-tide surface currents in order to maintain their position in the middle and upper reaches (Melville-Smith et al. 1981). A similar horizontal larval distribution pattern was recorded in the Swartkops Estuary (Melville-Smith \& Baird 1980).

The estuarine roundherring has been recorded in coastal water bodies where salinities range from fresh water to $53 \%$. This species was recorded dying in the hypersaline Seekoei Estuary at concentrations above 90\% (Whitfield 1989). The salinity tolerance of the egg and larval stages ranges from $0-48 \%$ (Day et al. 1981). The estuarine roundherring is common in both clear and turbid water systems.

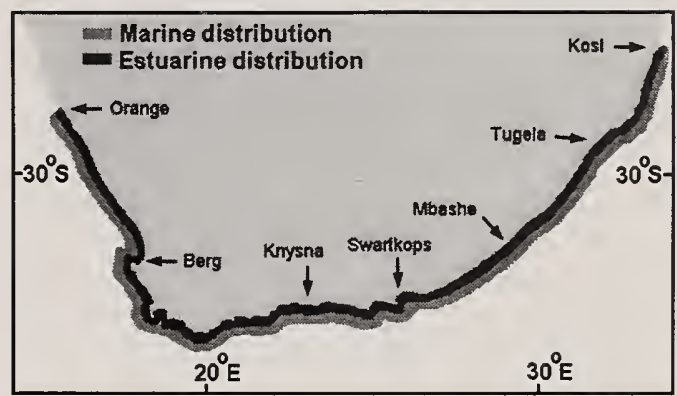

The diet of $G$. aestuaria has been studied in a wide variety of estuarine and freshwater systems, with copepods, ostracods, mysids, macruran larvae, amphipods, chironomid larvae and diatoms all recorded as important food items (Coetzee 1982, White \& Bruton 1983, Talbot \& Baird 1985a, Whitfield 1988a, Cyrus et al. 1993). In turbid Lake St Lucia this species was a non-selective zooplankton filter feeder (Blaber 1979), whereas a predominantly visual mode of foraging is used in relatively clear estuarine systems with poor zooplankton food resources (Blaber et al. 1981). It forages mainly during daylight hours (Blaber 1979, Bennett \& Branch 1990) with approximately $37 \mathrm{~kg}$ dry mass per day being consumed in the Sundays Estuary during summer and only $1 \mathrm{~kg}$ per day during winter (Whitfield \& Harrison 1996).

This small clupeid is preyed upon by a wide range of piscivorous birds (Whitfield 1986b) and fishes (Marais 1984), especially the ladyfish Elops machnata, dusky kob Argyrosomus japonicus and leervis Lichia amia. The numbers of $E$. machnata captured in different parts of Lake St Lucia were closely related to the abundance of G. aestuaria in these areas (Whitfield \& Blaber 1978a). In the Swartkops Estuary $99 \%$ of the estuarine roundherring population were less than 2 years old (Talbot 1982), thus indicating that less than $1 \%$ of the population attains 3 years of age. 
Family: ATHERINIDAE

Species: Atherina breviceps Valenciennes, 1835

Common name: Cape silverside

Smiths' Sea Fishes number: 111.1

Illustrated specimen length: $64 \mathrm{~mm} \mathrm{SL}$

\section{Selected anatomical features}

Fin elements: Dorsal V-VIII +I, 11-15; Anal I, 15-18; Pectoral 13-16.

Lateral scales: 44-50.

Maximum recorded length: $\pm 11 \mathrm{~cm} \mathrm{SL}$.

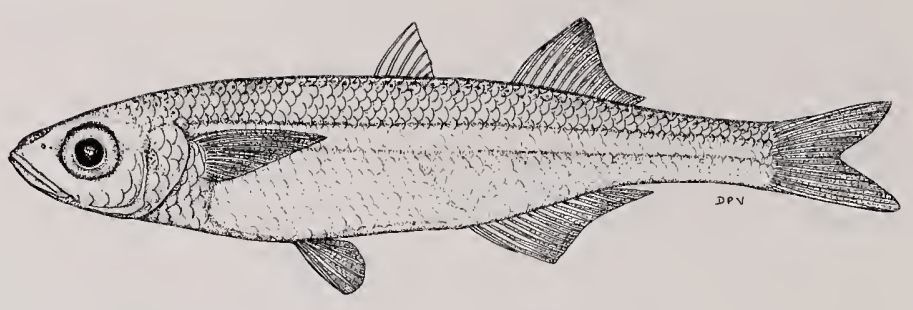

\section{Distribution}

The Cape silverside is a southern African endemic species from northern KwaZulu-Natal to southern Namibia (Ivantsoff 1991). This shoaling fish is often associated with submerged aquatic macrophytes in estuaries. It is also common in certain freshwater and brackish coastal lakes that are isolated from the sea. Large populations occur in the nearshore marine environment, particularly the relatively sheltered bays of the Eastern Cape Province (Lasiak 1984b).

\section{Biology and ecology}

This species reaches sexual maturity within 8 months, at a standard length of $40 \mathrm{~mm}$ SL (Ratte 1989). It breeds mainly during spring and summer, with a September-January peak. The eggs are approximately $1.5 \mathrm{~mm}$ in diameter, and are usually attached to submerged plants and other objects by $6-12$ chorionic filaments (see below). A. breviceps larvae $(5-8 \mathrm{~mm}$ BL) are most abundant in surface waters between September and March (Melville-Smith \& Baird 1980, Whitfield 1989c).

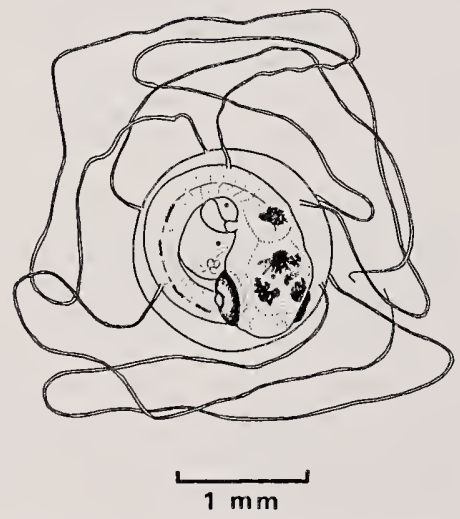

Late stage egg of $A$. breviceps (after Neira et al. 1988).

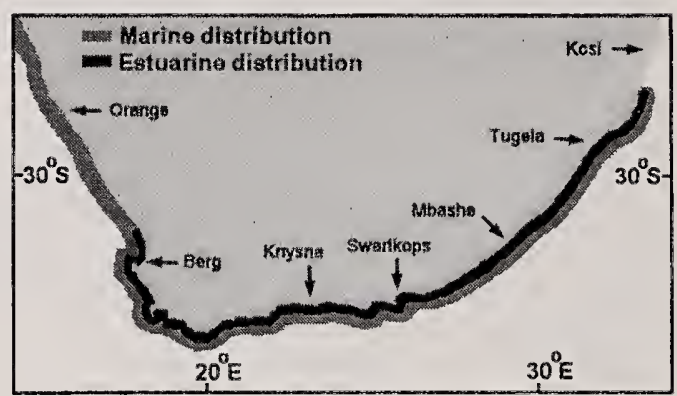

The Cape silverside has been recorded in coastal water bodies where salinities range from $0-42 \%$ (Whitfield 1996b). Although this species is found in both clear and turbid estuaries, it is more abundant in the former type of system, possibly due to increased feeding efficiency associated with clearer waters. According to Hecht \& van der Lingen (1992) the reactive distance of foraging $A$. breviceps is substantially reduced by increased turbidity levels.

The diet has been studied in a wide variety of estuarine systerns (e.g. Blaber 1979, Coetzee 1982b, Bennett \& Branch 1990, Hecht \& van der Lingen 1992) and includes copepods, amphipods, isopods, gastropods, ostracods, decapods and insect larvae. Juveniles in the Swartvlei and Groenvlei systems feed mainly on small organisms such as rotifers, copepod nauplii, molluscan veligers and phytoplankton, whereas adults prey on larger ostracods, copepods, isopods, amphipods, insects and molluscs (Coetzee 1982b, Whitfield 1988a). Most feeding takes place during twilight and noctumal hours (Bennett \& Branch 1990).

A. breviceps represents an important link in the food web, as it is extensively preyed upon by a wide variety of gamefish and piscivorous birds (van der Elst 1988). In the Swartvlei estuarine system, less than $1 \%$ of the Cape silversides reach $2+$ years of age (Ratte 1989), probably due to high predation rates (Whitfield 1986b). 
Family: HEMIRAMPHIDAE

Species: Hyporhamphus capensis (Thominot, 1886)

Common name: Cape halfbeak

Smiths' Sea Fishes number: 115.4

Illustrated specimen length: $11 \mathrm{~cm} \mathrm{SL}$

\section{Selected anatomical features}

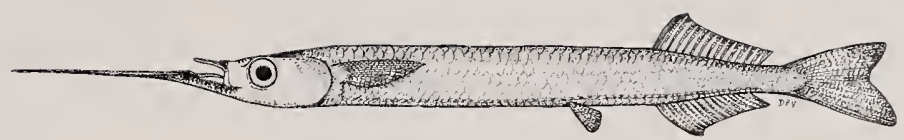

Fin elements: Dorsal 14-17;

Anal 15-16; Pectoral 10-12.

Predorsal scales: $31-38$.

Maximum recorded length: $\pm 20 \mathrm{~cm} \mathrm{SL}$.

\section{Distribution}

The Cape halfbeak is a southern African endemic confined to estuarine and coastal waters from False Bay to Lake Piti in southern Mozambique (Collette 1986b). Although this littoral species is often abundant in estuarine lakes, some of which have tenuous links to the sea, it is absent from coastal lakes that have been isolated from the marine environment (Bruton \& Kok 1980). This fish is usually found just below the surface, especially at night.

\section{Biology and ecology}

H. capensis mature between $80 \mathrm{~mm}$ and $100 \mathrm{~mm}$ TL. The breeding season covers the period October to March, with ripe-running and partially spawned specimens recorded in KwaZulu-Natal estuaries during October, December and March (Wallace 1975b). The eggs of this species are $1.6 \mathrm{~mm}$ in diameter and densely covered with glutinous hair-like filaments which are considerably longer than the diameter of the egg (Smith 1933). H. capensis larvae less than $10 \mathrm{~mm}$ BL have been recorded in Swartvlei during summer (Whitfield 1989c) and are most abundant in other Western Cape estuaries during November and December.

The Cape halfbeak occupies those estuaries or parts of systems where salinities range from $1-42 \%$ (Whitfield 1996b), especially in the vicinity of submerged aquatic macrophytes. According to Smith (1933), this species is present in tidal estuaries throughout the year, occasionally extending into fresh water. The absence of $H$. capensis from isolated freshwater coastal lakes may be linked to long-term salinity requirements of adult fish, or freshwater tolerance limitations of egg and larval stages.

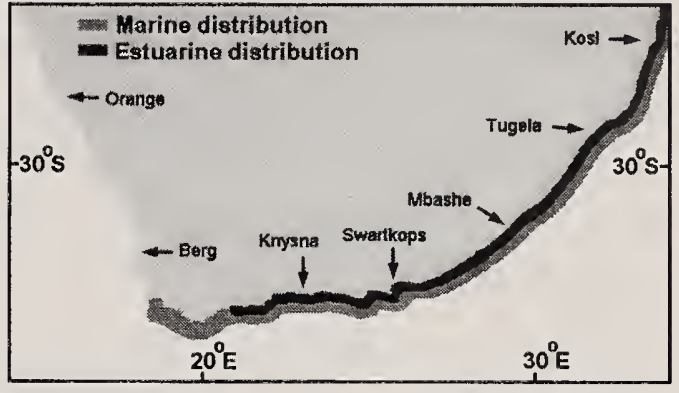

The diet of $H$. capensis in Rondevlei lake has been studied by Coetzee (1981b), who found that the gut contents of juveniles $50-90 \mathrm{~mm}$ TL were dominated by amphipods, isopods, ostracods and insects. Between 90 $\mathrm{mm}$ and $190 \mathrm{~mm}$ TL they consumed submerged aquatic macrophytes and small bivalves which were attached to the plants.

Coetzee (1981b) determined that the annual cycle in the occurrence of Ruppia cirrhosa and Potamogeton pectinatus directly influenced the feeding of the Cape halfbeak, with considerably more plant material being consumed in summer than in winter. The diet of this species and dorsal position of the mouth suggests that it feeds mainly amongst submerged plant canopies. The role of the extended lower jaw (beak) in foraging is unknown but may be related to invertebrate prey detection in surface waters (Smith 1933).

$H$. capensis are preyed upon by a wide range of piscivorous fishes, especially the yellowfin needlefish Strongylura leiura in Lake St Lucia (Whitfield \& Blaber 1978a). One of the methods of escape is to leap along the water surface in an attempt to evade predatory fish (Day et al. 1981). 


\section{Family: SYNGNATHIDAE}

Species: Hippichthys heptagonus Bleeker, 1849

Common name: Belly pipefish

Smiths' Sea Fishes number: 145.14

Illustrated specimen length: $12 \mathrm{~cm} \mathrm{SL}$

\section{Selected anatomical features}

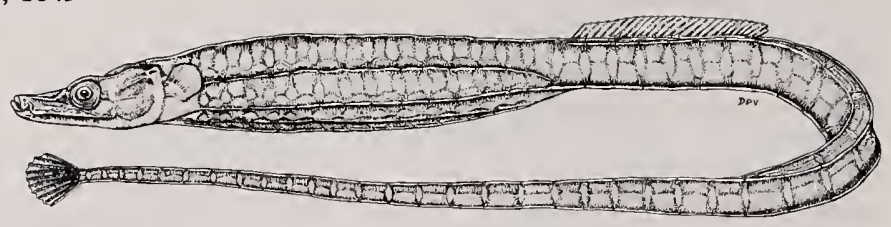

Fin elements: Dorsal 23-30;

Pectoral 13-16.

Ring count: Trunk 14-15; Tail 36-42.

Maximum recorded length in southern African waters: $\pm 15 \mathrm{~cm} \mathrm{SL}$.

\section{Distribution}

The belly pipefish is a tropical species ranging from the Solomon Islands in the western Pacific to KwaZuluNatal (Dawson 1986).

\section{Biology and ecology}

$H$. heptagonus is the most common pipefish in subtropical southern African estuaries. This species usually shelters in Zostera capensis and Halodule uninervis beds (Day et al. 1981) but the mainly brownish colouration and general lack of distinctive markings also provides excellent camouflage in the turbid waters of KwaZulu-Natal estuaries. The recorded salinity range of $H$. heptagonus is $1-38 \%$.

\section{Family: SYNGNATHIDAE}

Species: Hippocampus capensis Boulenger, 1900

Common name: Knysna seahorse

Smiths' Sea Fishes number: 145.17

Illustrated specimen length: $70 \mathrm{~mm}$ TL

\section{Selected anatomical features}

Fin elements: Dorsal 16-18;

Anal 3; Pectoral 15-17

Ring count: Trunk 10-11; Tail 32-34

Maximum recorded length: $\pm 12 \mathrm{~cm} \mathrm{SL}$

\section{Distribution}

The Knysna seahorse has only been recorded from estuaries along the eastern portion of the Western Cape coast between the Klein Brak and Keurbooms systems.

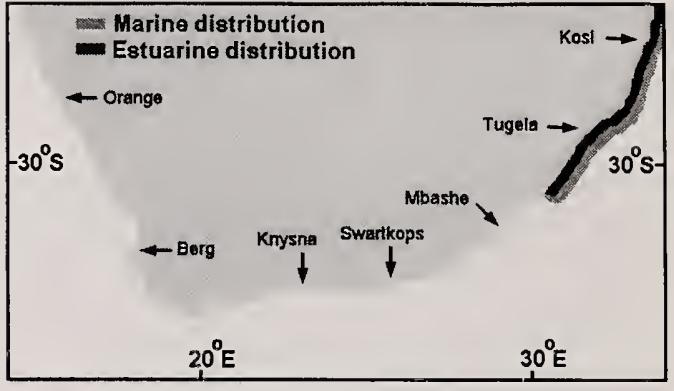

The length at sexual maturity for males is $75-80 \mathrm{~mm}$ SL (Dawson 1985). Breeding occurs in estuaries with the male retaining the developing embryos in a brood pouch. Relatively high densities of juveniles with a mean length of $23 \mathrm{~mm} \mathrm{SL}$ were recorded in the St Lucia Estuary plankton by Harris \& Cyrus (1995). The diet of $H$. heptagonus is dominated by zooplankton, particularly copepods and amphipods (Day et al. 1981).

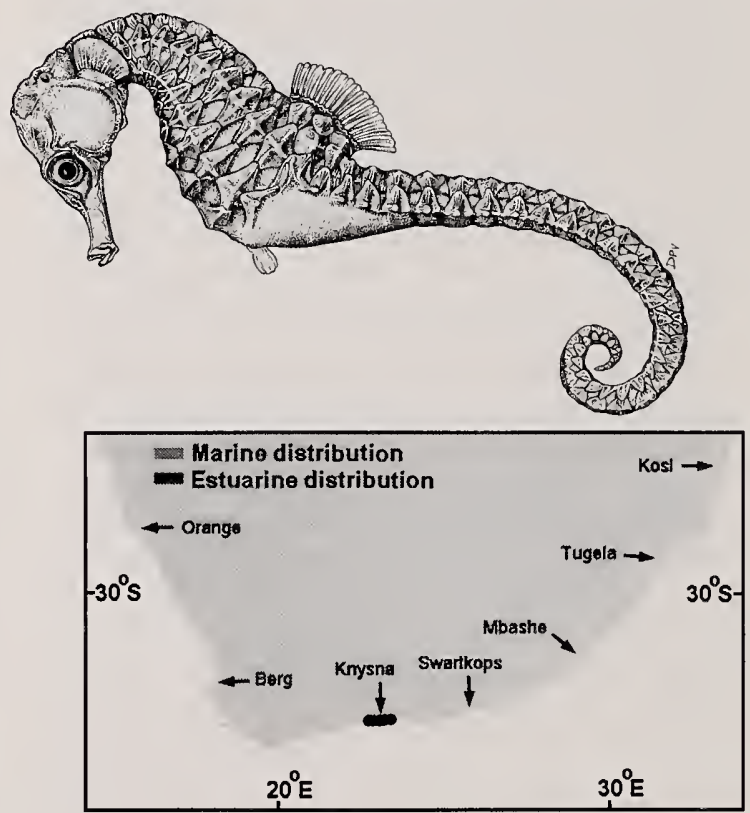


The Knysna seahorse is a vulnerable fish species (Baillie \& Groombridge 1996) which is usually associated with submerged eelgrass beds or macroalgae (Whitfield 1995c). The sometimes slightly mottled greenish or brownish colouration of this species provides excellent camouflage in Zostera capensis beds and it has the ability to coil its tail around submerged objects to prevent it from being washed away by tidal currents. Although not a strong swimmer this species can move in the vertical position, using both the dorsal and pectoral fins. The eyes can move independently of one another (Smith 1981, Genade \& Hirst 1986).

Sexual maturity is attained within one year at a length of approximately $65 \mathrm{~mm}$ TL. Breeding occurs in summer when water temperatures reach about $20^{\circ} \mathrm{C}$. The lower abdomen of the male becomes silvery and an orange fringe develops along the dorsal fin. The male indicates his intention to mate by grasping the female with his prehensile tail and attempting to move into the 'face to face' position. The female is courted until she is ready to deposit her eggs into his inflated brood pouch, a process that sometimes lasts several hours (Grange \& Cretchley 1995). Fertilisation occurs within the pouch which swells as the embryos develop. After an approximately two to four week development period (depending upon temperature) the juveniles (9$10 \mathrm{~mm}$ TL), which may number between 30 and 120 , emerge singly from the pouch while the male experiences contractions to help expel them. The newly released young tend to swim in the horizontal position and some are carried by ebb tidal currents into the sea where their chances of survival are unknown. Up until a length of $20 \mathrm{~mm}$ is attained, juveniles have an almost uniform black colouration. Thereafter the colour of individuals can change according to the immediate environment, from greyish white to green, brown, black or speckled (Smith 1981, Genade \& Hirst 1986).

Evidence suggests that this species has the ability to survive salinities ranging from $1-59 \%$, including direct transfer from $32 \%$ to $1 \%$ and $32 \%$ to $59 \%$. The salinity extremes were tolerated for at least 7 days. The Knysna seahorse cannot survive in fresh water or at salinities greater than 59\% (Riley 1986). A mass mortality of this species was recorded in the Swartvlei Estuary when water temperatures approached $32^{\circ} \mathrm{C}$ (Russell 1994).

The diet of juvenile $H$. capensis consists exclusively of zooplanktonic organisms up to $0.75 \mathrm{~mm}$ in size whereas adults feed predominantly on small crustaceans and fish larvae that are sucked from submerged leaf surfaces or from the water column. Adults can swallow individual prey items up to $12 \mathrm{~mm}$ in length, provided the width is not greater than $2 \mathrm{~mm}$ (Genade \& Hirst 1986). The Knysna seahorse is preyed upon by herons and egrets (Smith 1981).

Family: SYNGNATHIDAE

Species: Syngnathus acus Linnaeus, 1758

Common name: Longsnout pipefish

Smiths' Sea Fishes number: 145.29

Illustrated specimen length: $19 \mathrm{~cm} \mathrm{SL}$

\section{Selected anatomical features}

Fin elements: Dorsal 33-42;

$$
\text { Anal 3; Pectoral 10-14. }
$$

Ring count: Trunk 18-21; Tail 36-43.

Maximum recorded length in southern

African waters: $\pm 30 \mathrm{~cm}$ SL.

\section{Distribution}

S. acus occurs in both the Mediterrean and eastern Atlantic regions. Locally it is most abundant in the warm-temperate estuaries of southern Africa but extends into both the subtropical east coast and cooltemperate west coast waters. This species also occurs offshore to depths of at least $110 \mathrm{~m}$ (Dawson 1986).

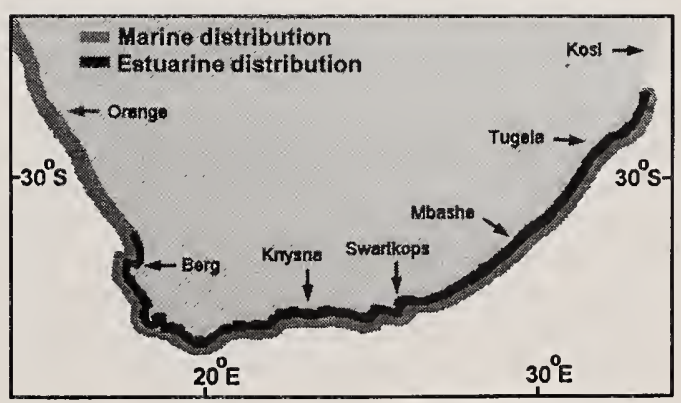




\section{Biology and ecology}

The longsnout pipefish is the most common pipefish in southern African estuaries (Dawson 1986) and is often associated with submerged aquatic vegetation such as Zostera capensis. The body shape and light greenish to dark brown colouration of this species provides excellent camouflage in estuarine eelgrass beds. According to Smith (1965) the colour is variable according to that of the sheltering aquatic plants.

Sexual maturity is attained at approximately $12 \mathrm{~cm}$ SL (Bennett 1989). Breeding occurs both in estuaries and the sea between November and March, with the male retaining the developing embryos in a brood pouch (Day et al. 1981). Males accept eggs from more than one female (Vincent et al. 1995). Densities of these pipefish are usually low, with 0.008 individuals per square metre being recorded in the Bot Estuary (Bennett \& Branch 1990). This species has been recorded in salinities ranging from $3-42 \%$ (Whitfield $1996 \mathrm{~b}$ ) and a mass mortality was recorded in the Swartvlei Estuary when water temperatures approached $32^{\circ} \mathrm{C}$ (Russell 1994).

$S$. acus is an active predator that feeds on zooplankton, particularly copepods, which are sucked in individually. It also captures amphipods from the surfaces of submerged aquatic plants (Day et al. 1981). In the Bot Estuary $57 \%$ of the diet (dry mass) consisted of copepods, $24 \%$ amphipods, $15 \%$ isopods and $3 \%$ aquatic insect larvae. Feeding in the above system occurred mainly during the day between 10 h00 and 18 h00 (Bennett \& Branch 1990).

Family: SYNGNATHIDAE

Species: Syngnathus watermeyeri Smith, 1963

Common name: Estuarine pipefish

Smiths' Sea Fishes number: 145.30

Illustrated specimen length: $12 \mathrm{~cm} \mathrm{SL}$

\section{Selected anatomical features}

Fin elements: Dorsal 28-32;

Anal 3; Pectoral 6-8.

Ring count: Trunk 16-18; Tail 37-40.

Maximum recorded length: $\pm 13 \mathrm{~cm} \mathrm{SL}$.

\section{Distribution}

S. watermeyeri was known only from the Bushmans, Kariega and Kasuka estuaries on the Eastern Cape coast (Dawson 1986). Indications are that it has disappeared from the Kariega system, with a small population surviving in the lower reaches of the Bushmans Estuary. Since 1963 only one known specimen has been captured in any of the above three estuaries. In 1996 a healthy population of $S$. watermeyeri was discovered in the East Kleinemonde Estuary.

\section{Biology and ecology}

This critically endangered pipefish (Baillie \& Groombridge 1996) is usually found in association with submerged plants, especially Zostera capensis which forms extensive beds in both the Bushmans and Kariega estuaries. The longsnout pipefish Syngnathus acus occurred sympatrically with estuarine pipefish in the eelgrass beds, with the former species still common

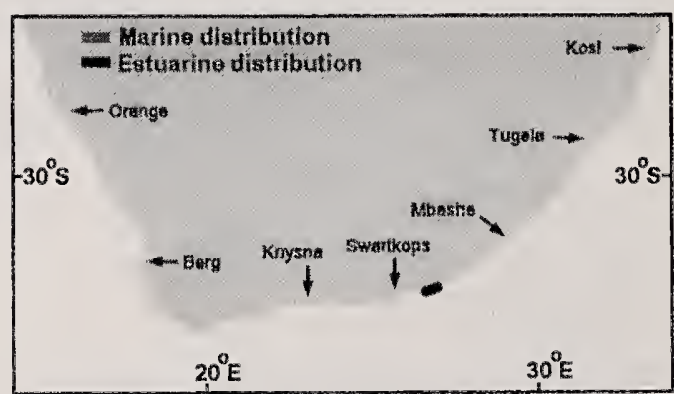

in these areas (Whitfield \& Ter Morshuizen 1992). Within the East Kleinemonde Estuary this species is found in association with submerged Ruppia cirrhosa beds and has also been found in similar habitats within the West Kleinemonde system.

Sexual maturity is attained at approximately $10 \mathrm{~cm}$ $\mathrm{SL}$, with breeding occurring within the estuarine 
environment. Reproductively active specimens were collected in the Kariega Estuary during September 1963 , with males of $10.11 \mathrm{~cm} \mathrm{SL}$ retaining up to 44 developing embryos in the brood pouch (Whitfield 1995b).

The disappearance of the estuarine pipefish from the Kariega system and its small population size in the Bushmans Estuary, suggests that this species is vulnerable to human perturbations of the aquatic environment. Catchment mismanagement within the Bushmans and Kariega systems, particularly the absence of environmental freshwater allocations from major impoundments, has resulted in the estuaries becoming deprived of essential freshwater pulses (Whitfield \& Wooldridge 1994). These pulses provide mutrients that facilitate phytoplankton development within estuaries and, together with particulate organic material brought down by the rivers, support the zooplankton community on which pipefish depend for food. The prolonged absence of river inflow, together with frequently recorded hypersaline conditions $(>40 \%)$ in all three estuaries during recent decades (Ter Morshuizen \& Whitfield 1994), may be directly or indirectly responsible for the rarity of this species.

Family: AMBASSIDAE

Species: Ambassis gymnocephalus (Lacepède, 1801)

Common name: Bald glassy

Smiths' Sea Fishes number: 163.1

Illustrated specimen length: $46 \mathrm{~mm} \mathrm{SL}$

\section{Selected anatomical features}

Fin elements: Dorsal VI-VII/I, 8-10; Anal III, 8-10; Pectoral 14-15.

Lateral scales: $27-29$ interrupted.

Predorsal scales: 13-16.

Maximum recorded length in southern African waters: $\pm 70 \mathrm{~mm}$ SL.

\section{Distribution}

The bald glassy occurs mainly in the tropical and subtropical waters of the Indian Ocean, Indonesia and Philippines (Heemstra \& Martin 1986). It extends south into the warm-temperate region of southern Africa and is most abundant in the mouth region of KwaZuluNatal estuaries (Martin 1989).

\section{Biology and ecology}

Little is known about the length at sexual maturity or breeding behaviour of $A$. gymnocephalus. It has been suggested that this species may spawn under estuarine conditions (Wallace 1975b) with confirmed eggs and larvae having been collected from Durban Bay (Connell 1996). Ambassid eggs, tentatively identified as $A$. gymnocephalus, have also been found in the $\mathrm{St}$ Lucia Estuary. The scarcity of ambassid larvae in most local estuaries and their abundance in the sea (Harris \& Cyrus 1996) points to a marine larval phase.

Although laboratory tests have shown that $A$. gymnocephalus can survive extended periods (21 days) in fresh water (Martin 1988), the large change ( $42 \%$ )

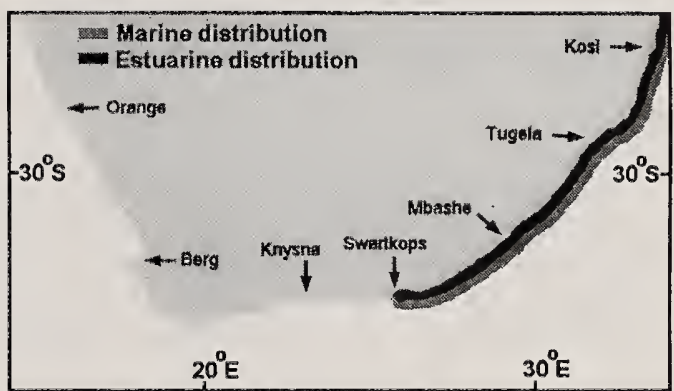

in blood osmolality after transfer from sea water into fresh water suggests that it is the least euryhaline of the ambassids in the region (Martin 1990).

All three Ambassis species from southern Africa have well developed dentition and pharyngeal teeth, which together with a low relative gut length, suggest a carnivorous habit (Martin \& Blaber 1984). The diet of A. gymnocephalus in KwaZulu-Natal estuaries is dominated by zooplanktonic crustaceans, with fish eggs and fish larvae of secondary and tertiary importance respectively (Martin \& Blaber 1983). This species feeds during both the day and night, with peak stomach fullness recorded at night. 
Family: AMBASSIDAE

Species: Ambassis natalensis Gilchrist \& Thompson, 1908

Common name: Slender glassy

Smiths' Sea Fishes number: 163.2

Illustrated specimen length: $54 \mathrm{~mm} \mathrm{SL}$

\section{Selected anatomical features}

Fin elements: Dorsal VII/I, 9-11; Anal III, 9-11; Pectoral 14-15.

Lateral scales: 27-29.

Predorsal scales: 9-11.

Maximum recorded length in southern African waters: $\pm 10 \mathrm{~cm} \mathrm{SL}$.

\section{Distribution}

The slender glassy occurs from Inhaca Island southwards to Algoa Bay, with unconfirmed records from East Africa (Martin \& Heemstra 1988).

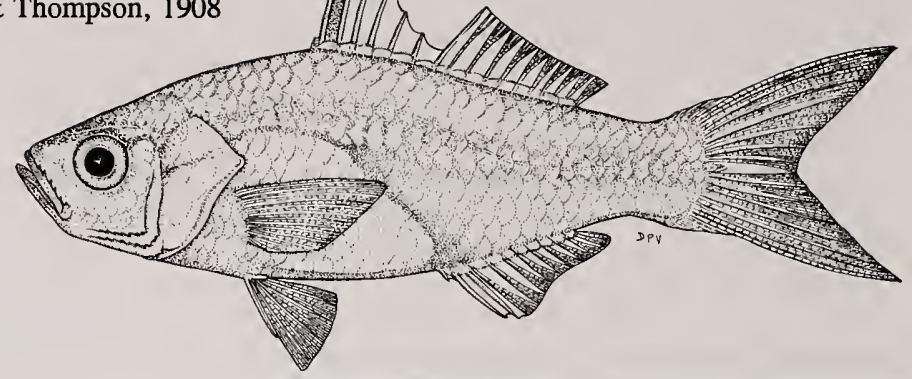

\section{Biology and ecology}

Sexual maturity is attained at a length of approximately $35 \mathrm{~mm}$ SL with spawning recorded in estuaries between August and November (Wallace 1975b). Large numbers of ambassid larvae (probably $A$. natalensis) $3-8 \mathrm{~mm}$ in length have been documented from St Lucia lake and estuary (Wallace 1975b). High densities of postflexion larvae (probably $A$. natalensis) have also been recorded in the Kosi Estuary (Harris et al. 1995).

The slender glassy is euryhaline but is incapable of maintaining a constant blood osmolality in salinities above 52\%o (Martin 1990) and below 7\%o (Martin 1989). Direct transfer from sea water to fresh water results in an internal osmotic concentration change of only 20\% (Martin 1990). Both juveniles and adults were present in Lake Nhlange at salinities below $1 \%$ (Blaber \& Cyrus 1981). The euryhalinity of $A$. natalensis has facilitated its colonisation of all types of estuaries, but the greatest numbers occur in the middle reaches of subtropical systems where the salinity range is $8-28 \%$ (Martin 1989).

The slender glassy has a diverse diet, feeding mainly during the morning and evening on zooplanktonic crustaceans and insects at the water surface. In addition, smaller quantities of fish larvae, polychaete larvae, bivalve spat and filamentous algae are also consumed (Martin \& Blaber 1983).

Family: AMBASSIDAE

Species: Ambassis productus Guichenot, 1866

Common name: Longspine glassy

Smiths' Sea Fishes number: 163.3

Illustrated specimen length: $66 \mathrm{~mm} \mathrm{SL}$

\section{Selected anatomical features}

Fin elements: Dorsal VII/I, 9-10;

Anal III, 9-11; Pectoral 14-15.

Lateral scales: 28-29.

Predorsal scales: $14-18$.

Maximum recorded length in southern

African waters: $\pm 14 \mathrm{~cm} \mathrm{SL}$.

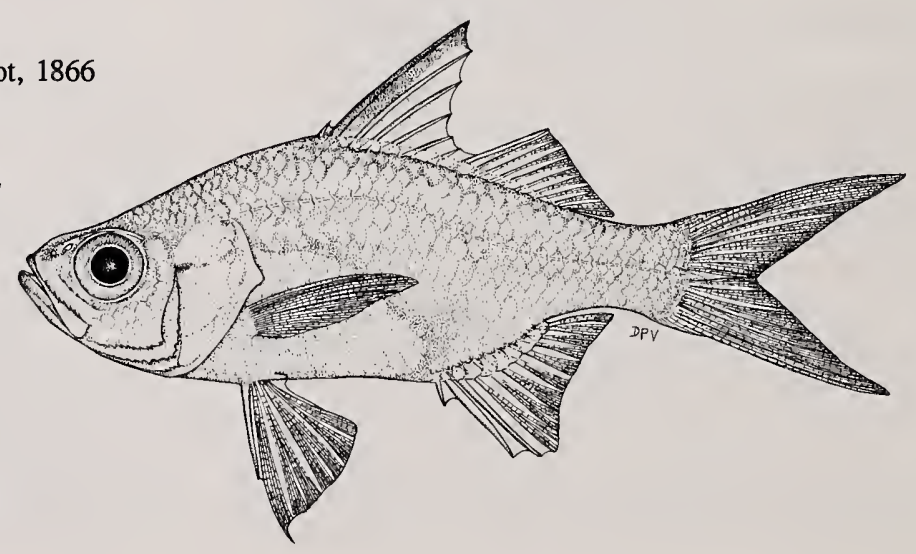




\section{Distribution}

A. productus has been reported from East Africa southwards to the Mtata Estuary (Martin \& Heemstra 1988). This species is most abundant in temporarily closed estuaries along the KwaZulu-Natal coast.

\section{Biology and ecology}

Sexual maturity is attained at a length of approximately $50 \mathrm{~mm}$ SL. Little is known about the breeding biology of $A$. productus but spawning reputedly occurs within estuarine systems (van der Elst 1988). Larval development probably occurs at sea, with the juveniles returning to the estuarine environment for the remainder of their life cycle.

The longspine glassy is an efficient osmoregulator in salinities below $35 \%$ but is unable to maintain its internal body fluid concentration as efficiently as the other two Ambassis species in salinities above sea water (Martin 1990). The inability to osmoregulate efficiently in salinities above $35 \%$ may be one of the factors restricting $A$. productus mainly to low salinity areas $(<10 \%$ ) within the estuaries of KwaZulu-Natal (Martin

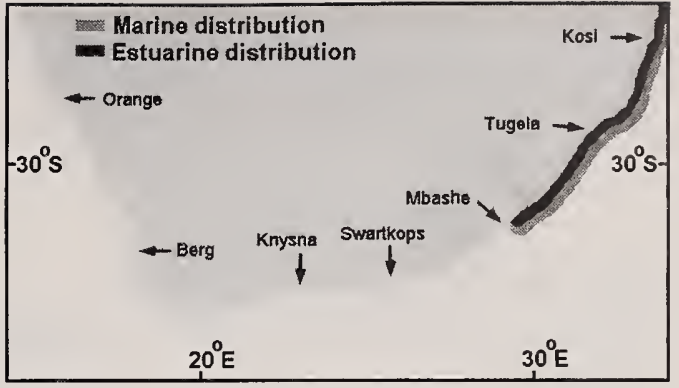

1988). This species was present throughout the year in Lake Nhlange in salinities less than $1 \%$ o (Blaber ix Cyrus 1981). In Lake St Lucia, where salinities usually exceed $15 \%$, A. productus numbers are exceptionally low when compared to the other two ambassid species (Martin 1983).

The longspine glassy has a diet comprising mainly zooplanktonic and benthic crustaceans. In addition large quantities of fish larvae and juveniles, together with insects, are also consumed. The relatively large size of $A$. productus compared to other ambassids may account for the fact that this species derived almost as much energy from fish as it did from crustaceans in its diet (Martin \& Blaber 1983). Feeding occurs mainly during the night and early morning (Martin 1989).

Family: BLENNIIDAE

Species: Omobranchus woodi (Gilchrist \& Thompson, 1908)

Common name: Kappie blenny

Smiths' Sea Fishes number: 235.30

Illustrated specimen length: $72 \mathrm{~mm} \mathrm{SL}$

\section{Selected anatomical features}

Fin elements: Dorsal XI-XIII, 19-21;

Anal II, 20-22; Pectoral 13.

Lateral line tubes on body: 2-6.

Maximum recorded length: $\pm 80 \mathrm{~mm}$ SL.

\section{Distribution}

This endemic species has been recorded in estuaries from Mlalazi in KwaZulu-Natal to Swartvlei in the Western Cape.

\section{Biology and ecology}

Very little is known about the kappie blenny, probably because it is a shy species, often living in burrows under stones in the mouth region of estuaries. It has well developed teeth and exceptionally large canines
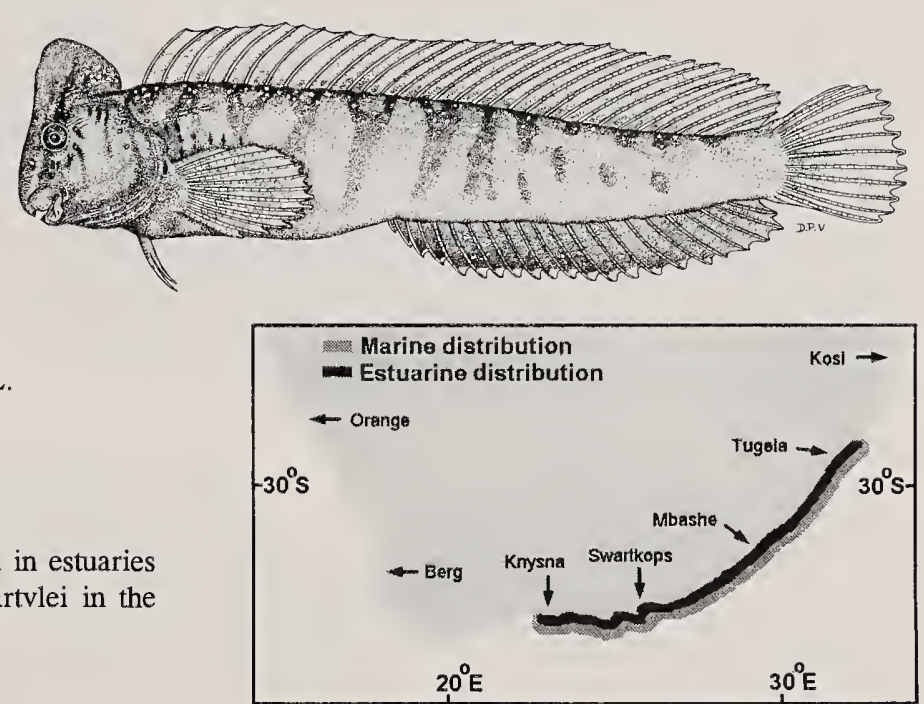

with which it will bite any intruder. The nuchal crest on top of the head of large males (above $40 \mathrm{~mm} \mathrm{SL}$ ) probably has some territorial or reproductive display function. 
O. woodi is most common in the lower reaches of certain permanently open warm-temperate estuaries, especially where submerged rocky areas are present. Breeding occurs during summer and the nest in which the eggs are laid is guarded by the male. Newly hatched larvae (2-4 mm BL) are carried out to sea on the ebb tide, only to return several weeks later when the postlarval stage has been attained (Whitfield 1989a).

\section{Family: CLINIDAE}

Species: Clinus spatulatus Bennett, 1983

Common name: Estuary klipfish

Smiths' Sea Fishes number: 237.21

Illustrated specimen length: $73 \mathrm{~mm} \mathrm{SL}$

\section{Selected anatomical features}

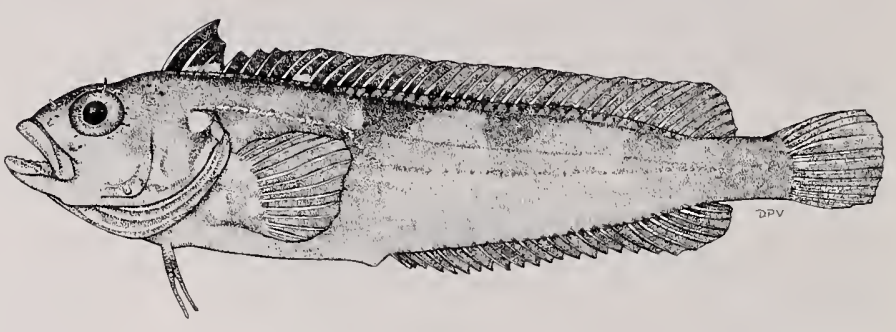

Fin elements: Dorsal XXXII-XXXV, 6-8;

Anal II, 23-25; Pectoral 13-15.

Supraorbital tentacle usually with a spatulate tip.

Maximum recorded length: $\pm 15 \mathrm{~cm}$ SL.

\section{Distribution}

The estuary klipfish has only been reported from Port Nolloth (E. Anderson, pers. comm.) and the adjacent Bot and Kleinmond estuaries (Whitfield 1996c).

\section{Biology and ecology}

Females of this viviparous species mature in their first year at a length of 75-80 mm TL (Bennett 1983). The sex ratio appears skewed, with seine net catches revealing one male to approximately 15 females. Embryos in an advanced stage of development $(>15$ $\mathrm{mm} \mathrm{BL}$ ) were present in the Bot Estuary between March and September and grew from $25 \mathrm{~mm}$ to $90 \mathrm{~mm}$ TL in one year (Bennett 1983). Few fish appear to survive for more than 18 months.

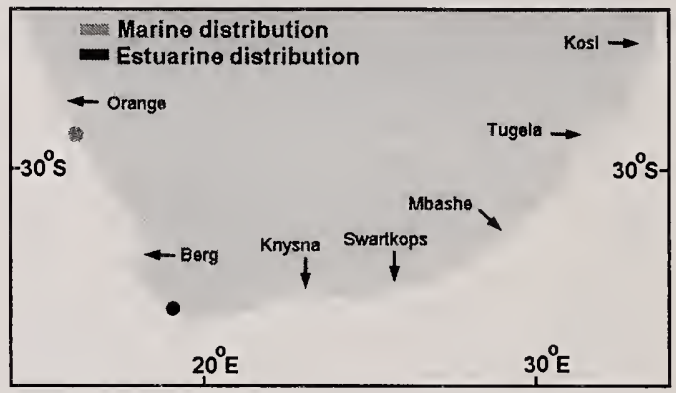

This species has been recorded in salinity and temperature ranges of $2-15 \%$ and $14-25^{\circ} \mathrm{C}$ respectively (Bennett 1983). In the Bot Estuary C. spatulatus had a density of 0.03 fish $\mathrm{m}^{-2}$ (Bennett \& Branch 1990).

In the Bot Estuary this fish feeds mainly on gastropods, isopods, amphipods, insect larvae and small fish (Bennett \& Branch 1990). The dominant prey items were the gastropod Tomichia sp., isopod Exosphaeroma sp. and amphipod Melita zeylanica.

\section{Family: CLINIDAE}

Species: Clinus superciliosus (Linnaeus, 1758)

Common name: Super klipfish

Smiths' Sea Fishes number: 237.22

Illustrated specimen length: $78 \mathrm{~mm} \mathrm{SL}$

\section{Selected anatomical features}

Fin elements: Dorsal XXXI-XLII, 5-10; Anal II, 21-30; Pectoral 15-18.

Supraorbital tentacle mostly with a branching tip.

Maximum recorded length in southern

$$
\text { African waters: } \pm 27 \mathrm{~cm} \text { SL. }
$$




\section{Distribution}

C. superciliosus occurs in coastal waters from approximately $19^{\circ} \mathrm{S}$ on the west coast to the Kei Estuary on the east coast (Smith 1986d). This species is most common among stones and submerged aquatic plants in the lower reaches of selected Cape estuaries, as well as tidepools on the open coast.

\section{Biology and ecology}

The viviparous super klipfish matures at a length of approximately $55 \mathrm{~mm}$ TL (Prochazka 1994) with breeding occurring both in estuaries and the sea (Day et al. 1981). Gestation is intrafollicular, with autoradiographic studies indicating that the embryos absorb nutrients through the epidermis, fins and gut. These structures have become extensively modified in order to act as absorbtive tissues (Veith 1978).

Breeding appears to occur mainly during winter and early summer but gravid females can be captured in all seasons (Veith 1979). The reduction in embryo numbers normally associated with viviparity is therefore partially overcome by $C$. superciliosus in that it breeds throughout the year, thus increasing the number of fish spawned per annum. In addition, through superembryonation the embryos are not all spawned at the same time, and this possibly decreases the chance of detection by predators (Veith 1979).

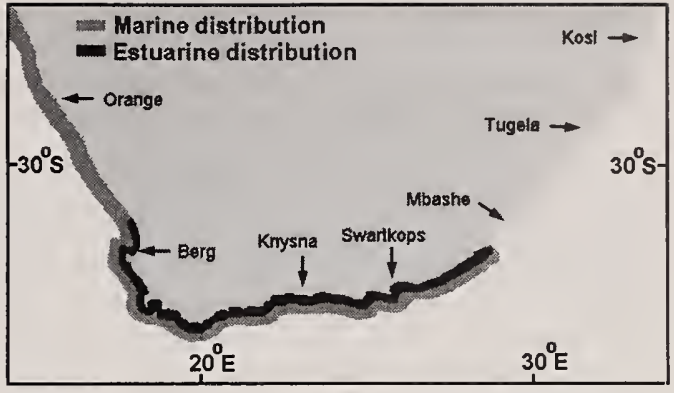

The super klipfish has been recorded in a salinity range of 8-42\% (Ter Morshuizen \& Whitfield 1994, Whitfield 1996b) but can probably survive lower salinities when river floods pass through estuarine systems. This species occurs in a wide temperature range, from less than $10^{\circ} \mathrm{C}$ to greater than $25^{\circ} \mathrm{C}$, and the body colouration varies according to its surroundings (Smith 1965).

In estuaries $C$. superciliosus feeds mainly on amphipods, brachyurans, isopods, gastropods and insect larvae (Day et al. 1981, Whitfield 1988a). Large adults also prey on gobies and hermit crabs. In the marine intertidal zone this species consumes mainly amphipods, decapods, molluscs, polychaetes and isopods (Bennett et al. 1983). Indications are that the super klipfish consumes between $2.5 \%$ and $9.1 \%$ of its body mass per day, with smaller individuals eating proportionately more than larger ones (Bennett 1984).

Family: GOBIIDAE

Species: Caffrogobius gilchristi (Boulenger, 1900)

(formerly Caffrogobius multifasciatus Smith, 1959)

Common name: Prison goby

Smiths' Sea Fishes number: 240.21

Illustrated specimen length: $59 \mathrm{~mm} \mathrm{SL}$

\section{Selected anatomical features}

Fin elements: Dorsal VI+I, 11-12;

Anal I, 9-10; Pectoral 17-19.

Lateral scales: 43-53.

Maximum recorded length: $\pm 13 \mathrm{~cm} \mathrm{SL}$.

\section{Distribution}

C. gilchristi is endemic to southern African waters, with an estuarine distribution from the Olifants system to Durban Bay. This fish is also common in tidepools and is particularly abundant in the middle and upper reaches of certain warm-temperate estuaries, especially those that are permanently open to the sea.
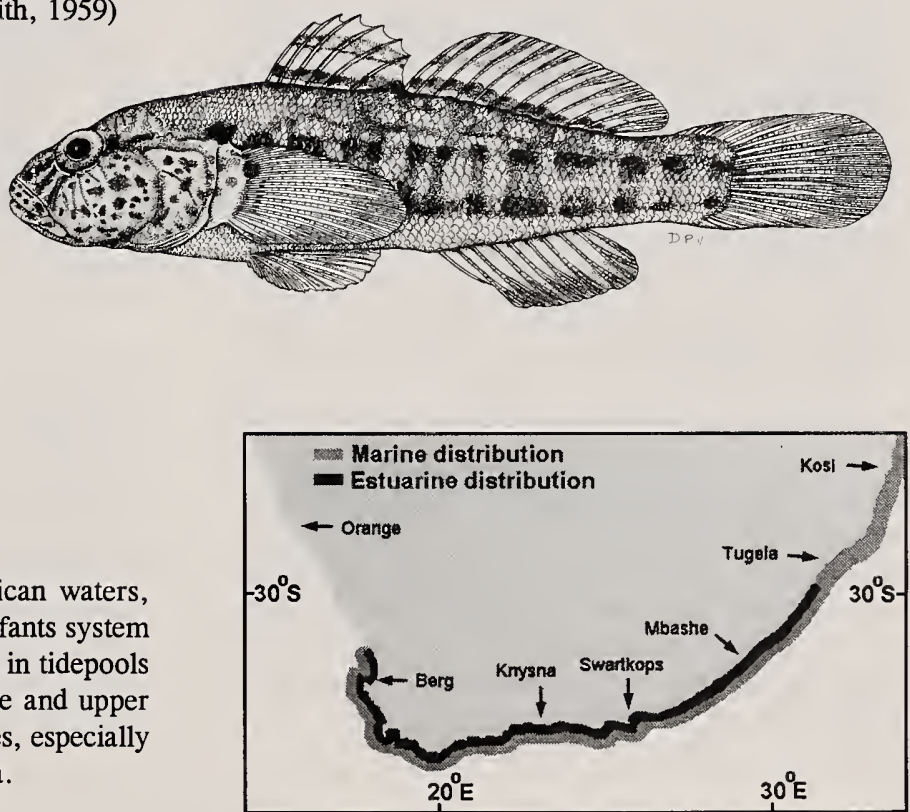
The prison goby matures at a length of approximately $50 \mathrm{~mm}$ SL (Bennett 1989), with breeding occurring mainly during the spring and early summer (September-January). Clusters of eggs are attached to shells, stones and other submerged objects. The mass hatching of larvae usually coincides with the nocturnal high tide. The larvae, which are mostly 3-4 mm BL, are then carried passively out of the estuary by the ebb tide (Whitfield 1989a). Following completion of larval development in the marine environment, the postlarvae enter adjacent estuaries as permanent residents.

C. gilchristi has been recorded in a salinity range of $0-42 \%$, thus enabling it to survive the low estuarine salinities which prevail during river flooding. This goby is also sometimes abundant in temporarily closed systems where salinities often decline below $5 \%$ for prolonged periods. In the Swartvlei lake littoral zone this species had a mean biomass of $0.4 \mathrm{~g} \mathrm{~m}^{-2}$ (Whitfield 1993) and in the Bot system the value was $0.01 \mathrm{~g} \mathrm{~m}^{-2}$ (Bennett \& Branch 1990).

The diet of $C$. gilchristi in the Swartvlei and Bot estuaries has been studied by Whitfield (1988a) and Bennett \& Branch (1990) respectively. They found that this goby feeds primarily on amphipods, isopods, brachyurans, insect larvae, anomurans, macrurans, polychaetes and small fishes. It forages mainly at dawn and dusk, with an estimated daily food consumption of $3.5 \%$ of body mass (Bennett \& Branch 1990).

\section{Family: GOBIIDAE}

Species: Caffrogobius nudiceps (Valenciennes, 1827)

Common name: Barehead goby

Smiths' Sea Fishes number: 240.23

Illustrated specimen length: $68 \mathrm{~mm}$ SL

\section{Selected anatomical features}

Fin elements: Dorsal VI+I, 11-12;

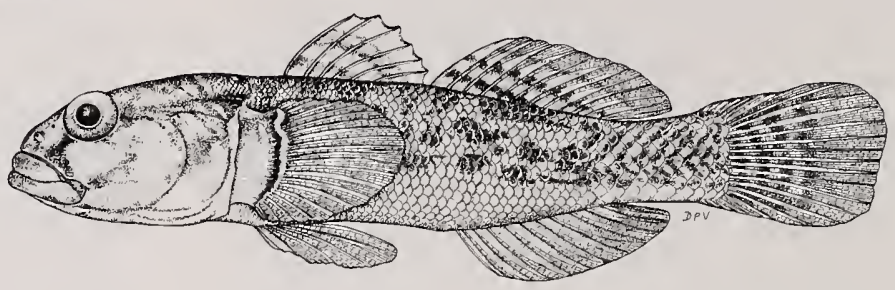

Anal I, 10-11; Pectoral 19-23.

Lateral scales: $33-50$.

Maximum recorded length: $\pm 12 \mathrm{~cm} \mathrm{SL}$.

\section{Distribution}

The barehead goby is endemic to southern African waters, ranging from East London in the warmtemperate region to Walvis Bay on the cool-temperate west coast (Hoese 1986a). Within Eastern Cape estuaries it is most abundant in the lower reaches, although specimens are also regularly captured in the middle reaches of certain systems.

\section{Biology and ecology}

C. nudiceps matures at a length of approximately 45 $\mathrm{mm}$ SL. Although little is known about the breeding biology of this goby, it is likely to follow a similar lifehistory style to that of the closely related Caffrogobius gilchristi, i.e. estuarine spawning followed by a marine larval phase and postlarvae entering nearby estuaries. C. nudiceps is not as dependent on estuaries as $C$. gilchristi, with the former species often recorded in the littoral marine zone.

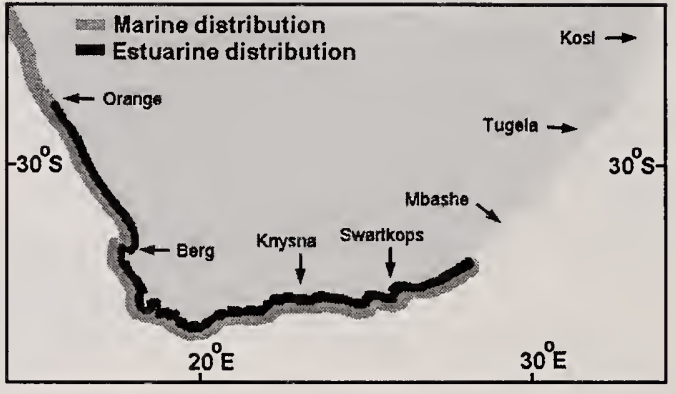

The barehead goby has been recorded in a salinity range of $1-42 \%$, and is usually associated with submerged Zostera capensis beds in the lower half of permanently open estuaries (Ter Morshuizen \& Whitfield 1994). In the warm-temperate region, the closely related Caffrogobius natalensis also occurs mainly in the lower reaches of estuaries but, in contrast to $C$. nudiceps, most specimens are located in the channel rather than littoral plant beds. 
Family: GOBIIDAE

Species: Croilia mossambica Smith, 1955

Common name: Naked goby

Smiths' Sea Fishes number: 240.29

Illustrated specimen length: $33 \mathrm{~mm} \mathrm{SL}$

\section{Selected anatomical features}

Fin elements: Dorsal VI, 11-12;

Anal 12; Pectoral 13-15.

Sides of body with 6-10 vertical lines.

Maximum recorded length: $\pm 55 \mathrm{~mm} \mathrm{SL}$.

\section{Distribution}

The naked goby is a southern African endemic, ranging from southern Mozambique to KwaZulu-Natal (Hoese 1986a) and occurring in water 1-27 m deep (Blaber \& Whitfield 1977b). This species is particularly abundant in sandy areas of certain estuarine and freshwater coastal lakes (e.g. Poelela and Sibaya), as well as small temporarily open/closed systems (e.g. Mhlanga and Mpenjati) as far south as Sandlundlu.

\section{Biology and ecology}

C. mossambica mature at a length of approximately $30 \mathrm{~mm} \mathrm{SL}$, at which stage the fish constructs burrows up to $9 \mathrm{~cm}$ deep and $1 \mathrm{~cm}$ in diameter in fine to medium grained sand. When disturbed the fish always enter the burrow head first and despite its relatively narrow width, turn round within it, and position the head at the entrance to the burrow. Respiratory currents within the burrow are maintained by lateral undulations of the body together with expansion and contraction of the buccal cavity.

The naked goby is a summer breeder with a protracted spawning season. Male gonads begin ripening in July whereas large numbers of ripe females are only present from October onwards. Males are territorial, and about 50 bright yellow adhesive eggs, 0.7-0.8 mm diameter, are laid.

Large numbers of planktonic postflexion larvae (9$13 \mathrm{~mm} \mathrm{BL}$ ) were recorded in the Kosi Estuary during January (Harris et al. 1995). Little is known about the early juvenile stages but evidence from Lake Sibaya suggests that they inhabit littoral plant beds (Blaber \& Whitfield 1977). In Lake Sibaya the population density of adults varied from one individual per $10 \mathrm{~m}^{2}$ to one fish per $70 \mathrm{~m}^{2}$ (Blaber \& Whitfield 1977b).

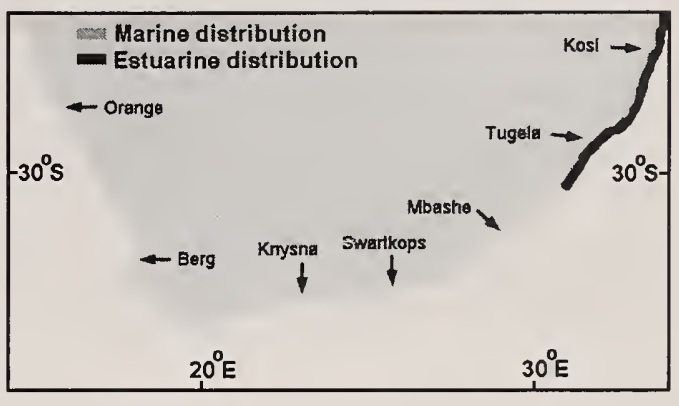

C. mossambica has been recorded in a salinity range of 0-35\% (Whitfield 1996b), and experimental evidence has shown that this species can tolerate major salinity fluctuations (Blaber \& Whitfield 1977b). This is particularly important in the lower reaches of some of the temporarily open KwaZulu-Natal estuaries where salinities often range between fresh water and $35 \%$ within a single tidal cycle. The abundance of the naked goby in Lake Sibaya suggests that it is also well adapted to permanent freshwater conditions. The upper temperature tolerance lies between $32^{\circ} \mathrm{C}$ and $35^{\circ} \mathrm{C}$.

The diet of $C$. mossambica consists of slow moving benthic invertebrates such as chironomid larvae, gastropods, bivalves, ostracods and amphipods. The relative importance of each depends upon its abundance within the environment (Blaber \& Whitfield 1977b). All feeding apparently takes place outside the burrow and prey is removed from the surface of the substratum. Sight is the primary sense used in locating food and all foraging occurs during the day.

The naked goby is preyed upon by piscivorous fishes and birds which forage over benthic habitats (e.g. sharptooth catfish Clarias gariepinus and the whitebreasted cormorant Phalacrocorax carbo). 
Family: GOBIIDAE

Species: Favonigobius reichei (Bleeker, 1853)

Common name: Spotted sandgoby

Smiths' Sea Fishes number: 240.38

Illustrated specimen length: $43 \mathrm{~mm} \mathrm{SL}$

\section{Selected anatomical features}

Fin elements: Dorsal VI+I, 8; Anal I, 7-8; Pectoral 16-17.

Lateral scales: $25-26$.

Maximum recorded length in southern African waters: $\pm 65 \mathrm{~mm}$ SL.

\section{Distribution}

The spotted sandgoby is a tropical Indo-West Pacific species reaching as far south as KwaZulu-Natal (Hoese 1986a). Both this species and the closely related blackthroat goby Favonigobius melanobranchus have been recorded in the Mgeni Estuary (Begg 1984a).

\section{Biology and ecology}

Little is known about the life-history of $F$. reichei in southern African waters, possibly due to its rarity, small size and excellent camouflage. This species is at the southern extremity of its distribution and is known from only four estuaries in KwaZulu-Natal.

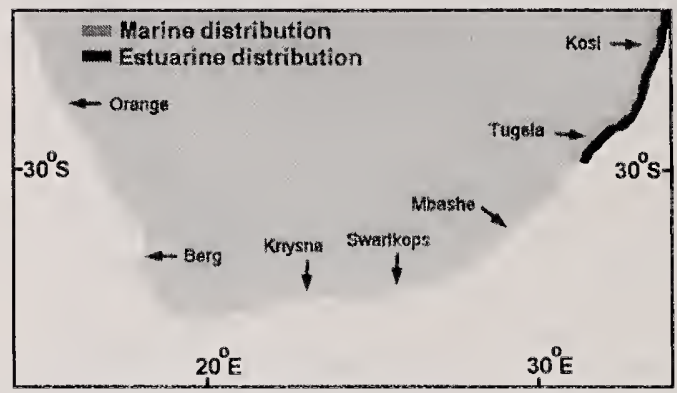

The recorded salinity range of this goby is $3-28 \%$ but biogeographic data suggests that it should be able to survive in full sea water. Specimens captured in KwaZulu-Natal estuaries occur over substrata ranging from silt to muddy sand.

Family: GOBIIDAE

Species: Glossogobius callidus (Smith, 1937)

Common name: River goby

Smiths' Sea Fishes number: 240.43

Illustrated specimen length: $56 \mathrm{~mm}$ SL

\section{Selected anatomical features}

Fin elements: Dorsal VI+I, 8-10;

Anal I, 7-9; Pectoral 14-19.

Lateral scales: 28-32.

Maximum recorded length: $\pm 85 \mathrm{~mm}$ SL.

\section{Distribution}

The endemic $G$. callidus is abundant in coastal plain rivers and estuaries of southern Africa, ranging from Mozambique to the Swartvlei region of the Western Cape. Specimens have also been recorded from the northwestern lowveld region (Greenwood 1994).

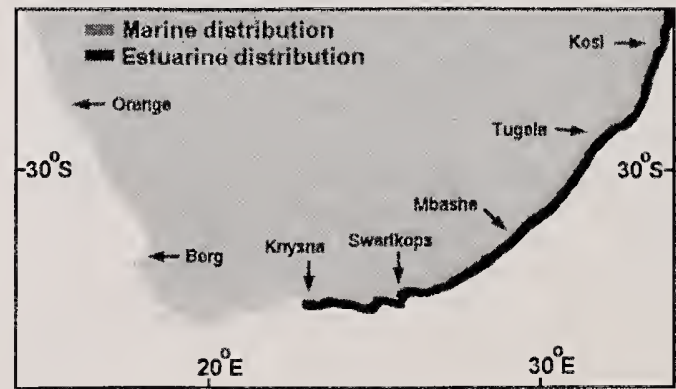




\section{Biology and ecology}

The river goby is abundant in both freshwater and estuarine systems of southern Africa, and appears tolerant of both flowing and still water conditions. The colouration of this species provides excellent benthic camouflage. Individual fish usually remain motionless on the bottom unless feeding or fleeing (Boulle 1989).

Sexual maturity is attained at approximately $35 \mathrm{~mm}$ SL, with breeding occurring mainly during spring (October-November) in the Eastern Cape. Depending on size, females release up to 350 oval eggs, each with a diameter of approximately $0.8 \mathrm{~mm}$ (Boullé 1989). In the St Lucia Estuary, the densities of G. callidus larvae are greatest during November ( $>800$ individuals per $100 \mathrm{~m}^{3}$ ), declining gradually over the summer (Harris 1995). Although the larvae are dominant in the lower St Lucia Estuary (Harris \& Cyrus 1995), the juveniles have been collected mainly from the middle and upper reaches of southern African estuaries.
The river goby has been found in a salinity range of $0-42 \%$, the upper value being recorded during a reversed salinity gradient situation in the Kariega Estuary (Ter Morshuizen \& Whitfield 1994). The highest densities were documented in the upper reaches of this estuary, despite the fact that salinities were lower towards the mouth. It would appear, therefore, that salinity is not the major factor governing the distribution of this species in estuaries.

The diet of $G$. callidus in the freshwater pans of the Phongolo floodplain is dominated by insect larvae, although copepods, ostracods and branchiopods are also consumed (P. la Hausse de Lalouvière, unpublished document). In Eastern Cape Province rivers this species feeds mainly on chironomid, trichopteran and ephemeropteran larvae, and in the estuaries of this region amphipods and chironomid larvae are the dominant food items.

\section{Family: GOBIIDAE}

Species: Oligolepis acutipennis (Valenciennes, 1837)

Common name: Sharptail goby

Smiths' Sea Fishes number: 240.65

Illustrated specimen length: $48 \mathrm{~mm} \mathrm{SL}$

\section{Selected anatomical features}

Fin elements: Dorsal VI +I, 10;

Anal I, 11; Pectoral 20-21.

Lateral scales: 25-27.

Maximum recorded length in southern

African waters: $\pm 95 \mathrm{~mm}$ SL.

\section{Distribution}

O. acutipennis is a tropical Indo-West Pacific species reaching as far south as the Great Fish Estuary (Hoese 1986a). This goby is, however, rare in warm-temperate estuaries of the Eastern Cape but is frequently encountered in the subtropical estuaries of KwaZuluNatal.

\section{Biology and ecology}

As is the case with other species belonging to this genus little is known about the life-history of $O$. acutipennis. According to Day et al. (1981) this species is confined to estuaries on the subcontinent, remaining in these systems even during river flooding. The recorded salinity range of the sharptail goby is $0-35 \%$.

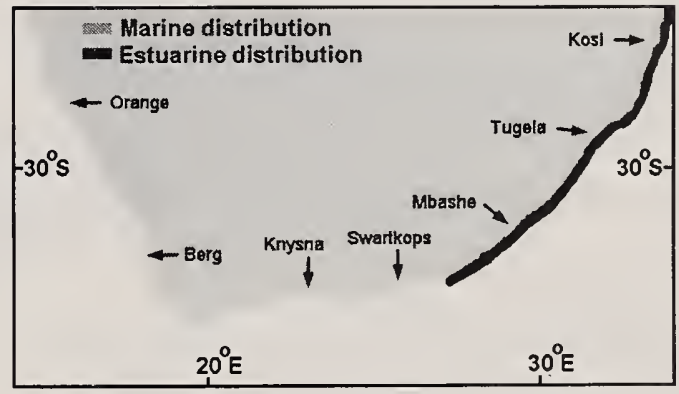

Breeding occurs within estuaries and the eggs are guarded (Day et al. 1981). Larvae and postlarvae between $9 \mathrm{~mm}$ and $21 \mathrm{~mm}$ BL have been recorded in the St Lucia Estuary (Harris \& Cyrus 1995). Juveniles and adults are most abundant in shallow water where they feed on small crustaceans and detritus. 
Family: GOBIIDAE

Species: Oligolepis keiensis (Smith, 1938)

Common name: Speartail goby

Smiths' Sea Fishes number: 240.66

Illustrated specimen length: $43 \mathrm{~mm}$ SL

\section{Selected anatomical features}

Fin elements: Dorsal VI+I, 11-12;

Anal I, 12; Pectoral 20-22.

Lateral scales: 26-28.

Maximum recorded length in southern

African waters: $\pm 50 \mathrm{~mm} \mathrm{SL}$.

\section{Distribution}

The speartail goby is a western Indian Ocean species ranging from eastern Africa, including Seychelles and Madagascar, southwards to the Sundays Estuary in the Eastern Cape.

\section{Biology and ecology}

Very little is known about the life-history of $O$. keiensis. Within the subtropical and warm-temperate regions of southern Africa this species appears to be exclusively estuarine, since it is not found in either the marine or freshwater environments. Within estuaries it is usually confined to the upper reaches.

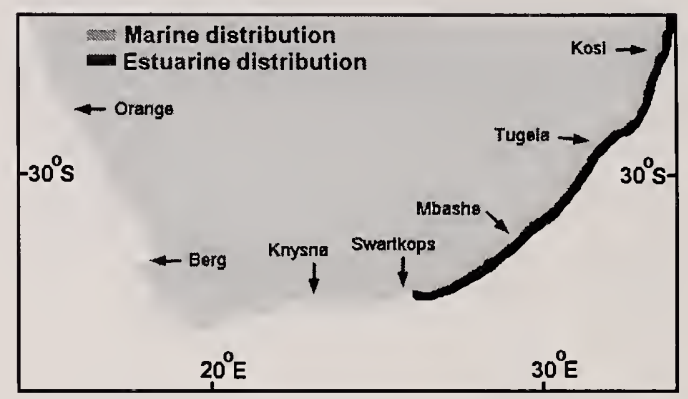

Breeding probably takes place within estuaries and no information is available on the length at sexual maturity, fecundity or the areas occupied by the larvae and postlarvae. The recorded salinity range of the speartail goby is $0-35 \%$ and the diet is dominated by small crustaceans and polychaetes.

Family: GOBIIDAE

Species: Periophthalmus argentilineatus (Valenciennes, 1837)

Common name: Bigfin mudskipper

Smiths' Sea Fishes number: 240.79

Illustrated specimen length: $81 \mathrm{~mm} \mathrm{SL}$

\section{Selected anatomical features}

Fin elements: Dorsal XIV-XVII+I, 10;

Anal I, 9-10; Pectoral 12-13.

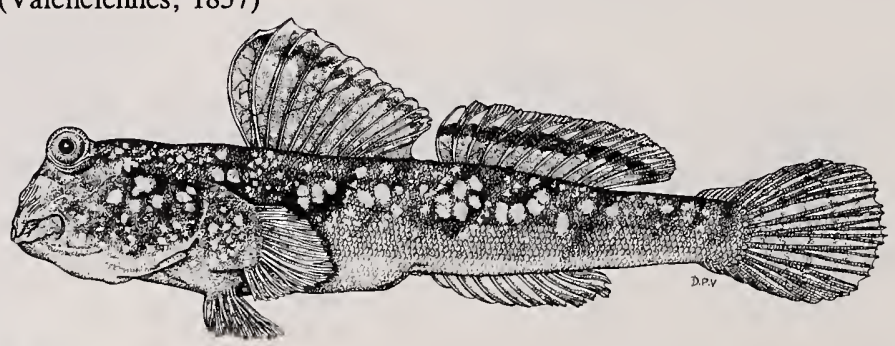

Dorsals with white margin and black stripe below.

Maximum recorded length in southern

African waters: $\pm 90 \mathrm{~mm} \mathrm{SL}$.

\section{Distribution}

$P$. argentilineatus has a range extending from the IndoWest Pacific to the subtropical region of southern Africa, with a single specimen recorded in the warmtemperate Kariega Estuary (Whitfield 1994e).

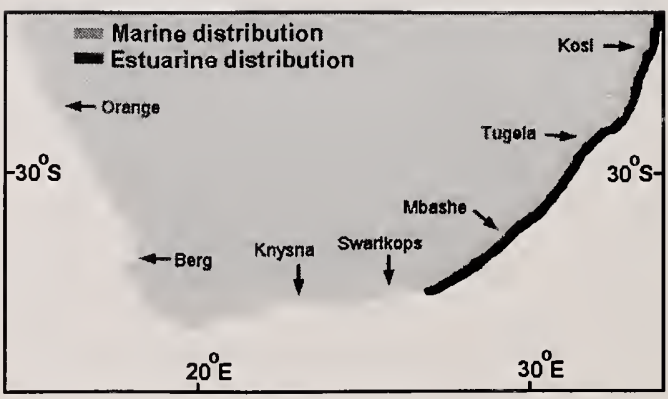


Bigfin mudskippers spend much time out of water, and are commonest along the banks of mangrove creeks from just below the lowest trees to almost the high tide mark (Macnae 1968). The muscular pectoral fins are used for crawling over the muddy substratum, dragging the tail behind. A hopping action is employed when rapid movement is required (e.g. to escape predators) and is performed by a push from the pectorals and rapid straightening of the posterior part of the body using the caudal region as a launching pad (van Dijk 1959). Once the fish has landed after a skip, which can be over a metre in length and up to $30 \mathrm{~cm}$ in height, the body is immediately flexed in preparation for another possible hop. When swimming this species has a sinuous motion with the top of the head usually kept above the water surface (Macnae \& Kalk 1958).

$P$. argentilineatus is territorial, especially during the breeding season, and the males raise their striped dorsal fins when proclaiming their domains (Brillet 1975). Sexual maturity occurs at approximately $60 \mathrm{~mm}$ TL (Stebbins \& Kalk 1961). This species breeds in estuaries, the male digging a hole in the mud with its mouth and constructing underground chambers (Macnae 1958). These chambers are interconnected by tunnels with external turrets that are $3-8 \mathrm{~cm}$ high and 8-10 cm apart (Stebbins \& Kalk 1961). The male then attracts a female to his chambers by a courtship display. The eggs are attached to the walls of the burrow and guarded (Day et al. 1981). After hatching the young escape from the nest at high tide and spend some time confined to the water before adopting an amphibious existence (Macnae \& Kalk 1958).

The bigfin mudskipper tolerates a wide range of salinities and can survive in a freshwater environment for several weeks (Day et al. 1981). Its ability to withstand prolonged periods out of water is made possible by virtue of its capacity to retain oxygenated water in the gill chamber, and because of the superficial blood vessels that are able to absorb oxygen directly from the surrounding air (van der Elst 1988). According to Teal \& Carey (1967) $P$. argentilineatus obtain as much as $60 \%$ of their oxygen requirements through the skin, which is maintained in a moist condition for diffusion by frequent body wetting.

The bulbous eyes on the top of the head are able to be retracted into their sockets. As the eye is depressed it moves so that the eyelid sweeps over the eyeball, cleaning and moistening the eye at the same time (Stebbins \& Kalk 1961).

The diet of $P$. argentilineatus is usually dominated by insects, polychaetes, amphipods, nematodes, copepods, tanaids, small crabs, prawns, shrimps and fish (Stebbins \& Kalk 1961, Day et al. 1981, van der Elst 1988). When watching for prey the head is held high and the fish adopts an attentive, immobile attitude before leaping at the prey. The act of feeding is accompanied by expulsion of the air and water from the branchial chambers (Stebbins \& Kalk 1961).

\section{Family: GOBIIDAE}

Species: Psammogobius knysnaensis Smith, 1936

Common name: Speckled sandgoby

Smiths' Sea Fishes number: 240.87

Illustrated specimen length: $46 \mathrm{~mm}$ SL

\section{Selected anatomical features}

Fin elements: Dorsal VI+I, 9-10;

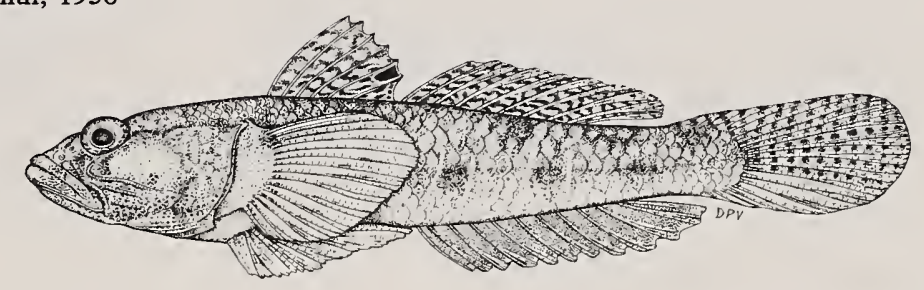

Anal I, 9-11; Pectoral 17-18.

Lateral scales: 27-30.

Maximum recorded length: $\pm 60 \mathrm{~mm}$ SL.

\section{Distribution}

P. knysnaensis is a southern African endemic, ranging from Port Nolloth to KwaZulu-Natal. This species is particularly abundant in the lower reaches of permanently open Western and Eastern Cape estuaries, occupying the sandy shallows less than one metre in depth.

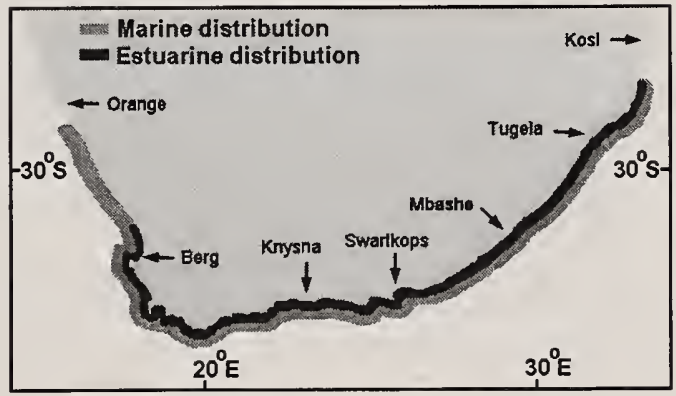


The speckled sandgoby matures at a length of approximately $30 \mathrm{~mm}$ SL (Bennett 1989), with the dominant lengths in estuaries ranging between $15 \mathrm{~mm}$ and $30 \mathrm{~mm} \mathrm{SL}$. Breeding occurs predominantly during spring and summer (October-March), with clusters of elongated eggs being laid on the substratum. The mass hatching of larvae usually coincides with the nocturnal high tide. The larvae, which are $2-3 \mathrm{~mm} \mathrm{BL}$, are then carried passively out of the estuary by the ebb tide, only to return as postlarvae (Whitfield 1989a).

The speckled sandgoby has been recorded in a salinity range of 2-35\%o (Whitfield 1996b, Bennett 1985), thus enabling it to survive the low salinities that prevail in the lower reaches during river flooding. This species can also survive in temporarily closed systems where salinities often decline below $5 \%$ for prolonged periods.

The diet of $P$. knysnaensis in the Swartvlei and Bot estuaries has been studied by Whitfield (1988a) and Bennett \& Branch (1990) respectively. They found that it feeds mainly at night on amphipods, isopods, polychaetes, insect larvae, cumaceans, decapods, copepods and ostracods. During the day this species is particularly vulnerable to predation by wading birds, and uses crab and prawn holes as temporary refuges or relies on its mottled sandy colouration for camouflage. When disturbed it moves by short zigzag dashes, finally burying itself in the sand (Hoese 1986a).

\section{Family: GOBIIDAE}

Species: Redigobius dewaalii (Weber, 1897)

Common name: Checked goby

Smiths' Sea Fishes number: 240.93

Illustrated specimen length: $27 \mathrm{~mm} \mathrm{SL}$

\section{Selected anatomical features}

Fin elements: Dorsal VI+I, 7-8;

Anal I, 5-7; Pectoral 16-18.

Lateral scales: 25-29.

Maximum recorded length: $\pm 40 \mathrm{~mm}$ SL.

\section{Distribution}

The endemic $R$. dewaalii ranges from southern Mozambique to Knysna (Hoese 1986a). According to Skelton (1993) this small species occurs in clear, vegetated littoral habitats in floodplain pans, lakes and estuaries.

\section{Biology and ecology}

The checked goby matures within one year at a length of approximately $24 \mathrm{~mm} \mathrm{SL}$, with breeding occurring mainly during spring and summer. Spawning in the freshwater pans of the Phongolo floodplain coincides with the summer flooding of these water bodies. Depending on size, females usually release between 700 and 1200 spherical eggs $0.5-0.6 \mathrm{~mm}$ in diameter (P. la Hausse de Lalouvière, unpublished document).

Settlement of juveniles $10 \mathrm{~mm}$ SL occurs within a few weeks of spawning. More than $99 \%$ of individuals in freshwater and estuarine areas are less than $30 \mathrm{~mm}$ SL and it has been hypothesized that this species lives

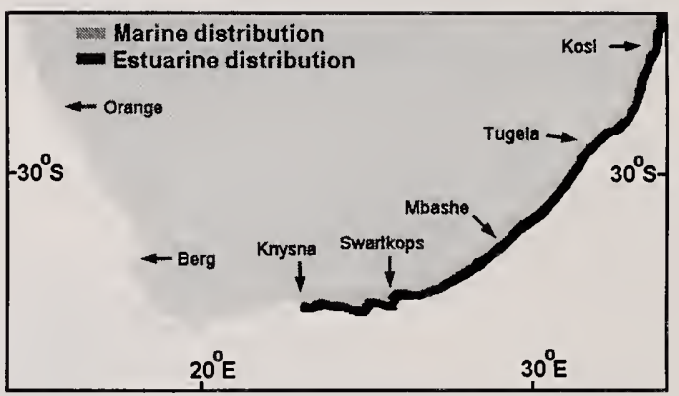

for less than two years (P. la Hausse de Lalouvière, unpublished document). High predation rates of this sluggish fish may be the reason why so few specimens reach the maximum recorded length of $42 \mathrm{~mm} \mathrm{SL}$ (Skelton 1993).

$R$. dewaalii has been recorded in salinities ranging from $0-42 \%$, the maximum value being recorded during a reversed salinity gradient situation in the Kariega Estuary (Ter Morshuizen \& Whitfield 1994). Despite the lower salinities in the middle and lower reaches of the Kariega Estuary, this species was confined to the upper part of the system. 
The diet of the checked goby in freshwater pans of the Phongolo floodplain is dominated by dipteran larvae, copepods, ostracods and branchiopods (P. la Hausse de Lalouvière, unpublished document). In estuaries this fish species feeds mainly on small crustaceans such as amphipods and copepods, as well as chironomid larvae. Males have considerably larger mouths than females of an equivalent size (Kok \& Blaber 1977) thus facilitating the consumption of larger prey items by the former sex.

\section{Family: GOBIIDAE}

Species: Silhouettea sibayi Farquharson, 1970

Common name: Barebreast goby

Smiths' Sea Fishes number: 240.95

Illustrated specimen length: $25 \mathrm{~mm}$ SL.

\section{Selected anatomical features}

Fin elements: Dorsal VI +I, 11; Anal I, 13; Pectoral 14-15.

Lateral scales: 24-25.

Maximum recorded length: $\pm 40 \mathrm{~mm}$ SL.

\section{Distribution}

S. sibayi is a southern African endemic, known only from the estuaries and coastal lakes of northern KwaZulu-Natal (Hoese 1986a, Harris \& Cyrus 1995).

\section{Biology and ecology}

The barebreast goby is a small, cryptic species which occurs over sand, mainly in shallow littoral areas but also down to about $20 \mathrm{~m}$ depth (Skelton 1993). It has been recorded from both open habitats and areas with aquatic macrophytes (Skelton 1987). This goby often buries itself in the sand leaving only the eyes uncovered. The long dorsal fin is erected above the sand either for intraspecific communication or as a lure to attract prey (Bruton 1979a).
$S$. sibayi has been recorded in a salinity range of 0 $35 \%$ and breeds both in freshwater and estuarine environments. Juveniles have been observed in the littoral plant beds of Lake Sibaya (Bruton 1979a) and Harris \& Cyrus (1995) recorded planktonic specimens $11-19 \mathrm{~mm}$ SL in the St Lucia Estuary. There is no information on the diet of this species but the available evidence suggests that it feeds mainly on benthic invertebrates.

\section{Family: GOBIIDAE}

Species: Taenioides jacksoni Smith, 1943

Common name: Bearded eelgoby

Smiths' Sea Fishes number: 240.99

Illustrated specimen length: $11 \mathrm{~cm} \mathrm{SL}$

\section{Selected anatomical features}

Fin elements: Dorsal VI, 27-28;

Anal 30; Pectoral 17.

Jaws with 20 conical teeth in outer row.

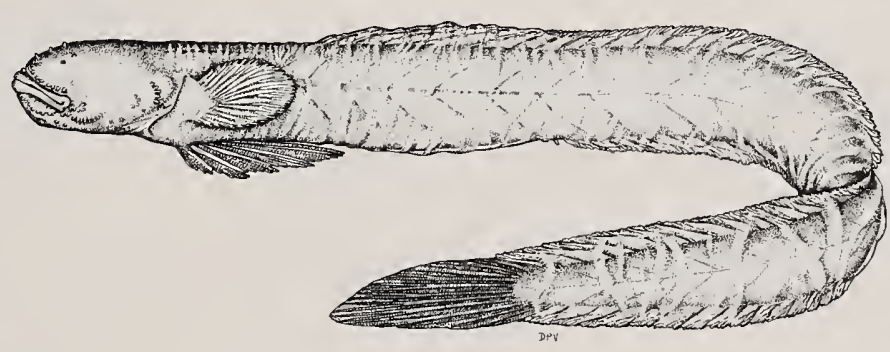

Maximum recorded length: $\pm 14 \mathrm{~cm} \mathrm{SL}$. 


\section{Distribution}

T. jacksoni is endemic to the subtropical region of southern Africa but may be more widespread (Hoese 1986a). This species is usually found in the lower reaches of estuaries where it burrows into the soft sediments associated with subtidal mudflats and mangroves.

\section{Biology and ecology}

Very little is known about the bearded eelgoby (Bruton 1996a) or the bulldog eelgoby Taenioides esquivel, both of which occur in permanently open KwaZuluNatal estuaries. This lack of information is probably because of their small size and burrowing habits. The flesh of $T$. jacksoni is semi-transparent, with lack of pigmentation and rudimentary eyes indicating that the adults live and probably breed within their mud burrows.

Dispersion is achieved by the larvae and juveniles which are pelagic. $T$. jacksoni and $T$. esquivel larvae were particularly abundant in the open waters of the St

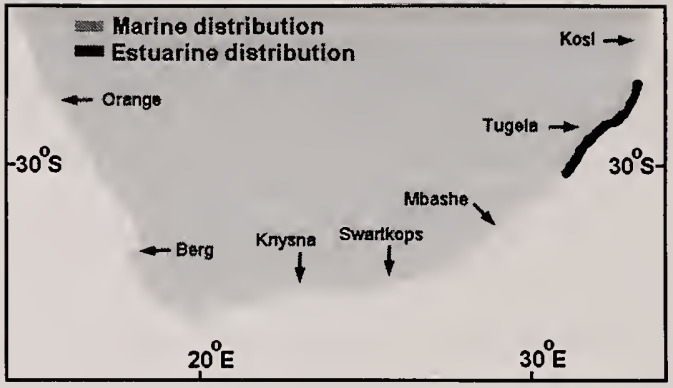

Lucia Estuary, attaining mean densities of 2.2 and 3.9 individuals per $100 \mathrm{~m}^{3}$ respectively (Harris \& Cyrus 1995).

The bearded eelgoby is euryhaline and has been recorded in estuaries and river mouths where salinities range from 0-35\% (Begg 1984a). In contrast, $T$. esquivel appears to be confined to the mouth region of permanently open muddy estuaries where salinities seldom decline below 35\%o (Millard \& Broekhuysen 1970). The teeth of $T$. jacksoni are well developed for a fish this size and indicate a carnivorous diet, probably feeding on benthic invertebrates.

\section{Family: ELEOTRIDAE}

Species: Eleotris fusca (Bloch \& Schneider, 1801)

Common name: Dusky sleeper

Smiths' Sea Fishes number: 241.4

Illustrated specimen length: $75 \mathrm{~mm} \mathrm{SL}$

\section{Selected anatomical features}

Fin elements: Dorsal VI $+\mathrm{I}, 8$;

Anal I, 8; Pectoral 17-19.

Lateral scales: $57-65$.

Maximum recorded length in southern

African waters: $\pm 22 \mathrm{~cm}$ SL.

\section{Distribution}

E. fusca is a tropical Indo-West Pacific species (Hoese 1986b) extending into the subtropical region of southern Africa. Individuals have been recorded in several warm-temperate estuaries as far south as the Sundays system. The related widehead sleeper Eleotris mauritianus and broadhead sleeper Eleotris melanosoma also occur in southern African estuaries but are rarely encountered.

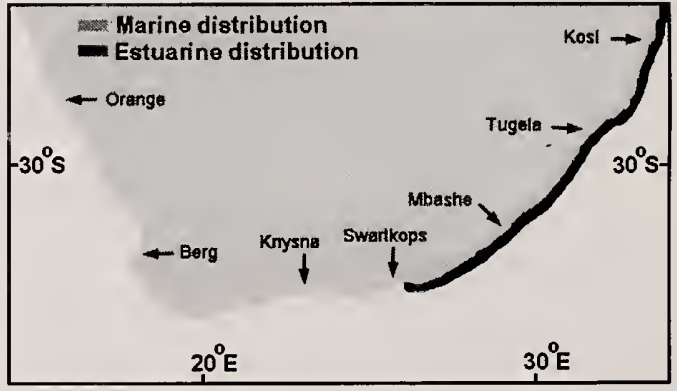




\section{Biology and ecology}

Virtually no life-history information is available on the dusky sleeper, probably because it is uncommon in most systems and is secretive by nature. This inactive fish is found under logs, stones and rootstocks in the muddy reaches of estuaries and mangrove swamps (Skelton 1993). E. fusca also occurs in freshwater streams leading into coastal lagoons, as well as submerged and emergent macrophyte beds surrounding these systems. Indications from tagging experiments are that the adults of this species are territorial.

Adult males have a well developed genital papilla, the function of which is unknown. According to Day et al. (1981) this species breeds in estuaries and nektonic E. fusca larvae and postlarvae $11-22 \mathrm{~mm} \mathrm{BL}$ have been recorded in the St Lucia Estuary (Harris \& Cyrus 1995). Breeding may also take place in fresh water, since juveniles have been found in semi-isolated coastal systems such as Lake Zilonde, which is occasionally linked to the Kosi Estuary. The absence of $E$. fusca from
Lake Sibaya suggests intermittent connections with the estuarine environment are necessary for the long-term survival of this species in freshwater areas.

The largest $E$. fusca in southern Africa (16-22 cm $\mathrm{SL}$ ) have been collected from brackish and freshwater coastal lakes on the northern KwaZulu-Natal coast, e.g. Nhlange, Mgobezeleni and Nhlabane. Juveniles are frequently captured in the ebb and flow region of permanently open estuaries, often in fresh water. Studies conducted in the headwaters of the Keiskamma Estuary suggest that an upstream migration of $0+$ juveniles into the river takes place.

Based on the available information, $E$. fusca occurs in a salinity range of $0-35 \%$, with most specimens collected in water less than 5\%o. According to Crass (1964) the food consists of "any small aquatic creatures which come within reach of this rather sluggish little predator". The relatively wide mouth enables this fish to consume fairly large food items for its size. 


\subsection{FRESHWATER GROUP}

Family: ANGUILLIDAE

Species: Anguilla mossambica (Peters, 1852)

Common name: Longfin eel

Smiths' Sea Fishes number: 39.4

Illustrated specimen length: $46 \mathrm{~cm}$ TL

\section{Selected anatomical features}

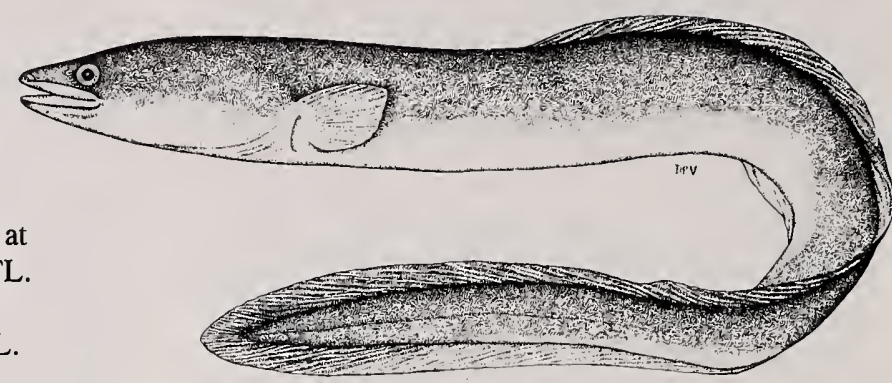

\section{Distribution}

The longfin eel is well known from most of the larger freshwater systems of the warm-temperate region northwards into East Africa, including islands such as Madagascar and Mauritius (Castle 1986b). Although migrating glass eels and adults pass through estuaries, records from southern African systems are sporadic and suggest a limited residence period within these brackish water habitats. The longfin eel is the most common of the anguillid eel species in local systems (Jubb 1967).

\section{Biology and ecology}

Larvae of $A$. mossambica are carried southwards from the Western Indian Ocean spawning grounds by the warm Agulhas Current. Metamorphosis of the leptocephali larvae into glass eels occurs once they approach continental shelf waters where estuarine and other land based cues are often present. Entry into estuaries occurs at a body length of $50-60 \mathrm{~mm}$, mainly during spring and summer (Harris \& Cyrus 1995), with most glass eels migrating up the adjoining rivers between November and January. Strong summer river flow into an estuary, especially during the spring tidal cycle, appears to attract large numbers of glass eels for the nocturnal upstream migration (Bruton et al. 1987).

In fresh water the glass eels change into elvers and continue to migrate upstream, ascending natural and artificial barriers. Once an eel has attained 25-30 $\mathrm{cm}$ TL it ceases to move upstream and remains in a particular pool or river stretch until fully mature (Skelton 1993). Juvenile eels up to $20 \mathrm{~cm}$ TL prey

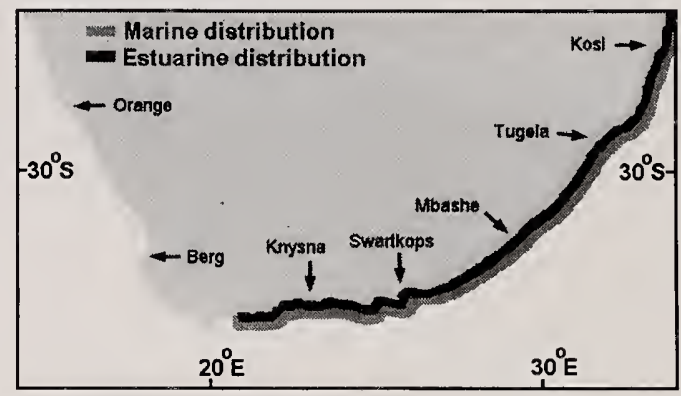

entirely on aquatic insects and the aquatic larvae and nymphs of terrestrial insects. Between 20-50 cm TL, the proportion of these food items declines, and crustacea and fish increase in importance. Above 50 $\mathrm{cm}$ TL the diet consists of fish, crabs and frogs (Bruton et al. 1987). Most foraging takes place at night.

Males are usually smaller than females and remain in fresh water for 8-10 years, females for 1520 years (Jubb 1970). A. mossambica has the slowest growth rate of several anguillids studied, reaching only $50 \mathrm{~cm}$ TL after 10 years and $65 \mathrm{~cm}$ TL after 15 years in fresh water (McEwan \& Hecht 1984). On maturity the eyes enlarge, the snout becomes more pointed and body fats increase in preparation for the seaward migration. The gonads only ripen when the eels are in the marine environment. The return migration by the adults through the estuary takes place in summer, usually in association with strong river flows after heavy rains (Skelton 1993). 
Family: CICHLIDAE

Species: Oreochromis mossambicus (Peters, 1852)

Common name: Mozambique tilapia

Smiths' Sea Fishes number: 218.1

Illustrated specimen length: $11 \mathrm{~cm} \mathrm{SL}$

\section{Selected anatomical features}

Fin elements: Dorsal XV-XVII, 10-13; Anal III, 7-10; Pectoral 13-14.

Lateral scales: $30-32$.

Maximum recorded length: $\pm 40 \mathrm{~cm} \mathrm{SL}$.

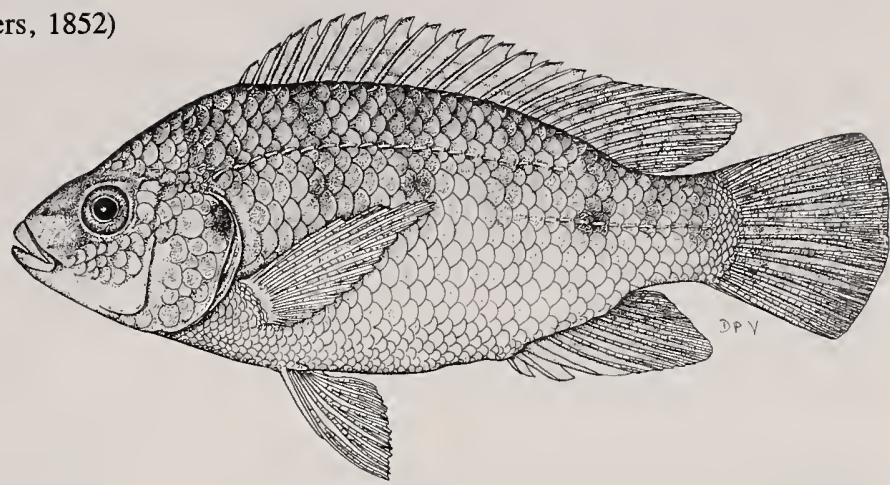

\section{Distribution}

The Mozambique tilapia is endemic to southern African rivers, lagoons and lakes, from the lower Zambezi system in the north to the Bushmans River in the south (Skelton 1993). This species is sometimes abundant in coastal lakes and temporarily closed estuaries, but is usually absent from the lower and middle reaches of permanently open estuaries (Whitfield \& Blaber 1979a). O. mossambicus has been introduced to farm dams in the Eastern and Western Cape, from which it has colonised both river and estuarine systems in these regions.

\section{Biology and ecology}

Sexual maturity is usually attained within one year (Bruton \& Allanson 1974) at a length of $80-120 \mathrm{~mm} \mathrm{SL}$ (Bruton \& Kok 1980). Breeding commences in spring when nests, $30-100 \mathrm{~cm}$ diameter, are excavated by males in the littoral zone of lagoons, lakes, vleis, pans and estuaries (Cooper \& Harrison 1992, James \& Bruton 1992). After a brief courtship the female leaves the nest and mouthbroods the eggs and larvae for 14-22 days (Bruton \& Boltt 1975). The fry (9-10 mm SL) are then released into the shallows where they form large shoals. A single female may produce several broods in a season, which usually lasts from September to February (Bruton \& Boltt 1975).

The Mozambique tilapia is strongly euryhaline and eurythermal, and has been recorded in salinities ranging from $0-100 \%$. Although at home in fresh water or sea water, this species is rarely found in the marine environment. It is associated with water turbidities ranging from less than 10 NTU to greater than 80 NTU. Mass mortalities occurred in freshwater Lake Bangazi at temperatures of between $10^{\circ} \mathrm{C}$ and $13^{\circ} \mathrm{C}$ (Bruton \& Taylor 1979) whereas equally low water temperatures were tolerated by populations in the nearby estuarine Lake St Lucia (Blaber \& Whitfield 1976). Allanson et al. (1971) have shown that brackish

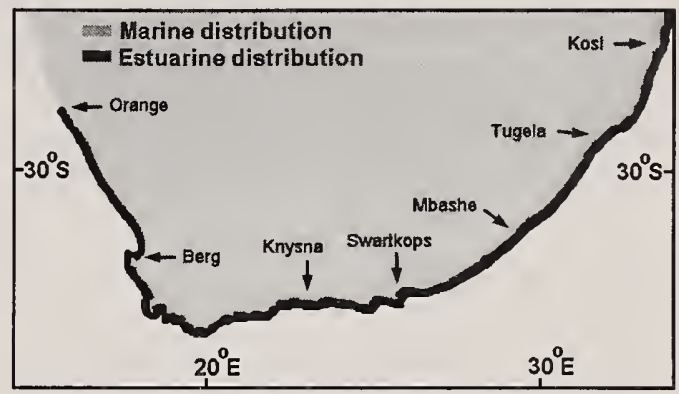

water increases the tolerance of $O$. mossambicus to low water temperatures. Adults appear to be more susceptible to low temperatures than juveniles (Jubb 1979). The optimum temperature range for this species is from $20-35^{\circ} \mathrm{C}$, depending on size and previous thermal history (Bruton \& Taylor 1979). Kyle (1984) recorded shoals of $10-18 \mathrm{~mm}$ juveniles in eulittoral pools where the water temperature reached $42^{\circ} \mathrm{C}$.

Juvenile $O$. mossambicus feed predominantly on zooplankton and benthic microfauna, whereas adults are mainly detritivorous but may also take advantage of planktonic organisms (Trewavas 1983, Whitfield \& Blaber 1978b). The detritus on which they feed is mainly a mixture of diatoms, bacteria and benthic floc (Bowen 1976, 1978). This cichlid is an opportunistic forager and may also feed on filamentous algae, aquatic macrophytes, insects, foramaniferans, gastropods, bivalves and planktonic crustacea (Bruton \& Boltt 1975, Whitfield \& Blaber 1978b). It sometimes consumes other fish and has also been recorded feeding on its own young. The Mozambique tilapia is preyed upon by a wide range of piscivores, including fishes, egrets, herons, cormorants, pelicans, kingfishers, fish eagles and crocodiles (Bruton 1979a, Whitfield \& Blaber 1979b, 1979c). 
Family: CICHLIDAE

Species: Pseudocrenilabrus philander (Weber, 1897)

Common name: Southern mouthbrooder

Illustrated specimen length: $58 \mathrm{~mm} \mathrm{SL}$

\section{Selected anatomical features}

Fin elements: Dorsal XIII-XVI, 9-11; Anal III, 7-9; Pectoral 13-14.

Lateral scales: 27-30.

Maximum recorded length: $\pm 10 \mathrm{~cm} \mathrm{SL}$.

\section{Distribution}

$P$. philander is a southern African species, extending from the Orange River and southern KwaZulu-Natal northwards to the southern Zaire tributaries and Lake Malawi (Skelton 1993). Within estuarine systems it has been recorded from the Mzumbe to the Kosi system in KwaZulu-Natal (Begg 1984a, Bruton \& Kok 1980).

\section{Biology and ecology}

The southern mouthbrooder reaches sexual maturity at approximately $25 \mathrm{~mm}$ SL (Ribbink 1975). In Lake Sibaya this species occurs to a depth of at least $30 \mathrm{~m}$ and breeds to a depth of $24 \mathrm{~m}$ (Bruton \& Kok 1980).

Breeding occurs in fresh water during spring and summer, with several broods sometimes being raised in a single season. The males establish and defend a territory, construct a simple cleared nest and attract ripe females by means of an elaborate courtship display (Ribbink 1971). Eggs are laid in the nest, fertilised by the male and collected by the female. She then withdraws to a quiet nursery area and broods the eggs (14 days), larvae and juveniles until they are able to fend for themselves (Skelton 1993). This species has not been recorded breeding in estuarine systems.

$P$. philander occurs in a wide variety of habitats from flowing streams to estuarine lakes, usually favouring vegetated zones (Skelton 1993). In the St Lucia system this species was most abundant in shallow littoral areas, particularly where eulittoral pools were present following flooding. The salinity tolerance of the southern mouthbrooder is unknown, but it has been recorded in estuarine waters where salinities were as high as 21\%o (Millard \& Broekhuysen 1970).

$P$. philander in freshwater areas is a predator on small crustaceans and insects as well as on small fishes, and in turn falls prey to predatory fishes and birds (Bruton \& Kok 1980). In Lake St Lucia it has been recorded feeding on invertebrates associated with aquatic plant beds (Millard \& Broekhuysen 1970).

Family: CICHLIDAE

Species: Tilapia rendalli (Boulenger, 1896)

Common name: Redbreast tilapia

Illustrated specimen length: $73 \mathrm{~mm} \mathrm{SL}$

\section{Selected anatomical features}

Fin elements: Dorsal XIV-XVI, 12-13; Anal III, 9-10; Pectoral 12-14.

Lateral scales: $28-32$.

Maximum recorded length in southern African waters: $\pm 33 \mathrm{~cm} \mathrm{SL}$.

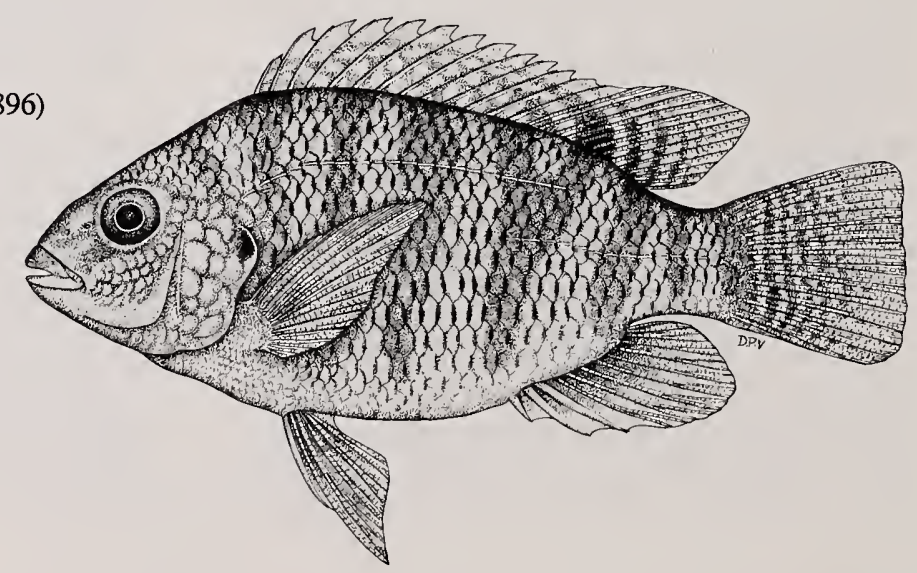




\section{Distribution}

$T$. rendalli is a mainly tropical African freshwater cichlid, occurring naturally in eastern coastal rivers as far south as the Phongolo system (Skelton 1993). This species has been recorded in estuarine systems on the Mozambique coast (Hill et al. 1975) and has recently colonised several KwaZulu-Natal estuaries (Begg 1984a).

\section{Biology and ecology}

The redbreast tilapia reaches sexual maturity at 11-13 $\mathrm{cm}$ SL. Breeding pairs clear the littoral vegetation to form a nest about $50-120 \mathrm{~cm}$ across and excavate several tunnel-like brood chambers in which the eggs and larvae are protected (Skelton 1993). Juveniles up to about $15 \mathrm{~mm}$ SL are confined to the protective holes, and parental care occurs up to a length of approximately $40 \mathrm{~mm} \mathrm{SL}$ (Ribbink et al. 1981). Breeding takes place between October and March (Bruton \& Kok 1980), and several broods may be raised each summer.

$T$. rendalli has been recorded in estuaries where salinities ranged from 1-8\% (Hill et al. 1975) but this species does have the ability to tolerate salinities up to 19\% (Whitfield \& Blaber 1976). The maximum salinity tolerance is at temperatures between $20^{\circ} \mathrm{C}$ and $28^{\circ} \mathrm{C}$ but the normal temperature preferendum of adults and subadults is $35-37^{\circ} \mathrm{C}$, with fry found in water up to

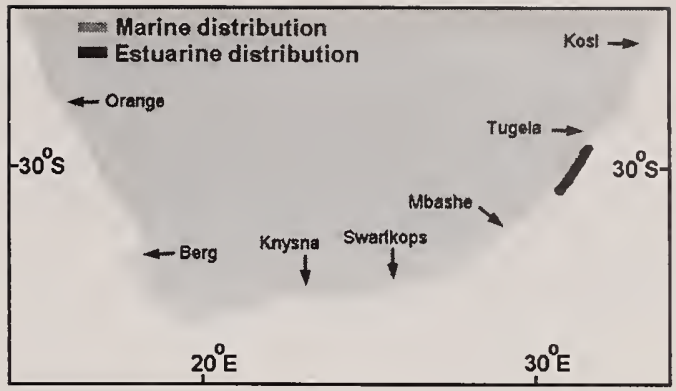

$41^{\circ} \mathrm{C}$ (Caulton 1975). Diel movements of juvenile $T$. rendalli between warm $\left(>30^{\circ} \mathrm{C}\right)$ shallow water during the day and cooler $\left(<20^{\circ} \mathrm{C}\right)$, deeper water at night have been shown to enhance growth in this species (Caulton 1978).

The redbreast tilapia feeds mainly on water plants and filamentous algae, but also takes aquatic invertebrates and even small fish (Skelton 1993). The release of nutrients from consumed aquatic macrophytes is largely due to an efficient shredding and partial trituration of the ingested plants by well adapted pharyngeal teeth (Caulton 1976).

This tilapia appears to be particularly vulnerable to bird predation. Density dependent mortality which could be attributed to piscivorous birds, especially the reed cormorant Phalacrocorax africanus and whitebreasted cormorant $P$. carbo, was documented by Batchelor (1978).

\section{Family: CLARIIDAE}

Species: Clarias gariepinus (Burchell, 1822)

Common name: Sharptooth catfish

Illustrated specimen length: $19 \mathrm{~cm} \mathrm{SL}$

\section{Selected anatomical features}

Fin elements: Dorsal 61-75;

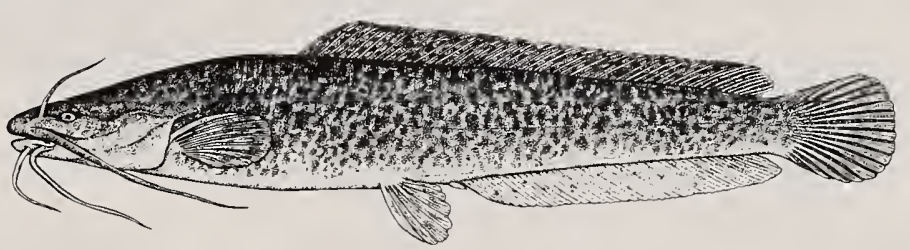
Anal 45-60; Pectoral I, 10-11.

Four pairs of long filamentous barbels.

Maximum recorded length in southern

African waters: $\pm 140 \mathrm{~cm} \mathrm{SL}$.

\section{Distribution}

The natural distribution of $C$. gariepinus in Africa ranges from the Nile system in the north to the Orange system in the south (Skelton 1993). Along the southern coast of Africa this species originally occurred as far south as the Mtamvuna River but has been translocated to several systems in the Eastern and Western Cape.

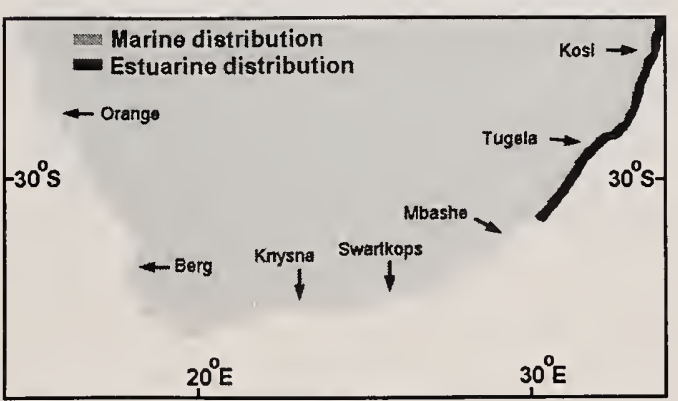


The sharptooth catfish occurs in almost any aquatic habitat but favours floodplains, large sluggish rivers and lakes. Although this species is seldom found in estuaries, it has been recorded in systems ranging from the Mvoti to Kosi (Begg 1984a). In Lake St Lucia this fish becomes an important predator during low salinity periods (Whitfield \& Blaber 1978a).

Breeding takes place during summer (September April) after rains, when large numbers of mature fishes migrate to flooded shallow grassy verges of rivers and lakes. The eggs, which are adhesive, are laid on submerged vegetation and hatch within about 25-40 hours (Bruton 1979b). Larvae are free-swimming and feed within two or three days, remaining inshore within vegetation cover. Growth is rapid, but greatly dependent on local conditions, individuals reaching about $20 \mathrm{~cm} \mathrm{SL}$ within one year. Individuals may mature after a year but most take two or more years (Skelton 1993).

Although this species can endure harsh conditions such as high turbidity or desiccation, it is uncommon in salinities above 9\%o (Whitfield et al. 1981). In Lake St Lucia this fish retreats up inflowing rivers when salinities in the lake approach $10 \%$, and it is usually absent from the system when salinities reach $12 \%$. A mass mortality of $C$. gariepinus in the mouth region of the Mkuze River was attributed to hypersaline water from Lake St Lucia entering this system during a wind induced seiche (Blaber 1981b).

C. gariepinus is a versatile predator and scavenger, feeding on crustaceans, molluscs, insects and small fishes (Bruton \& Kok 1980). Most foraging takes place at night on active benthic organisms, but they may also feed during the day and at the water surface (Bruton 1979c). Individual bottom foraging is the normal mode of feeding, although social hunting in groups at the water surface has been recorded in a wide variety of habitats, including Lake St Lucia. The diet of the sharptooth catfish (33-65 cm TL) in Lake St Lucia was dominated by small demersal fish species (e.g. gobies) but also included molluscs and crustaceans (Whitfield \& Blaber 1978a).

C. gariepinus is a favoured prey item of the fish eagle Haliaeetus vocifer in both freshwater and estuarine systems (Brown 1970, Whitfield \& Blaber 1978 c), probably because it enters shallow areas to feed and rises to the surface at frequent intervals when air breathing.

Family: GOBIIDAE

Species: Awaous aeneofuscus (Peters, 1852)

Common name: Freshwater goby

Smiths' Sea Fishes number: 240.9

Illustrated specimen length: $16 \mathrm{~cm} \mathrm{SL}$

\section{Selected anatomical features}

Fin elements: Dorsal VI+I, 9-11;

Anal I, 10-11; Pectoral 15-17.

Lateral scales: 50-62.

Maximum recorded length in southern

African waters: $\pm 22 \mathrm{~cm} \mathrm{SL}$.

\section{Distribution}

The freshwater goby occurs mainly in coastal plain streams and rivers, from Tanzania southwards to the Eastern Cape Province where it is rare (Skelton 1993). This species has also been recorded from a number of estuaries within this geographical range and may breed within these systems (Crass 1964).
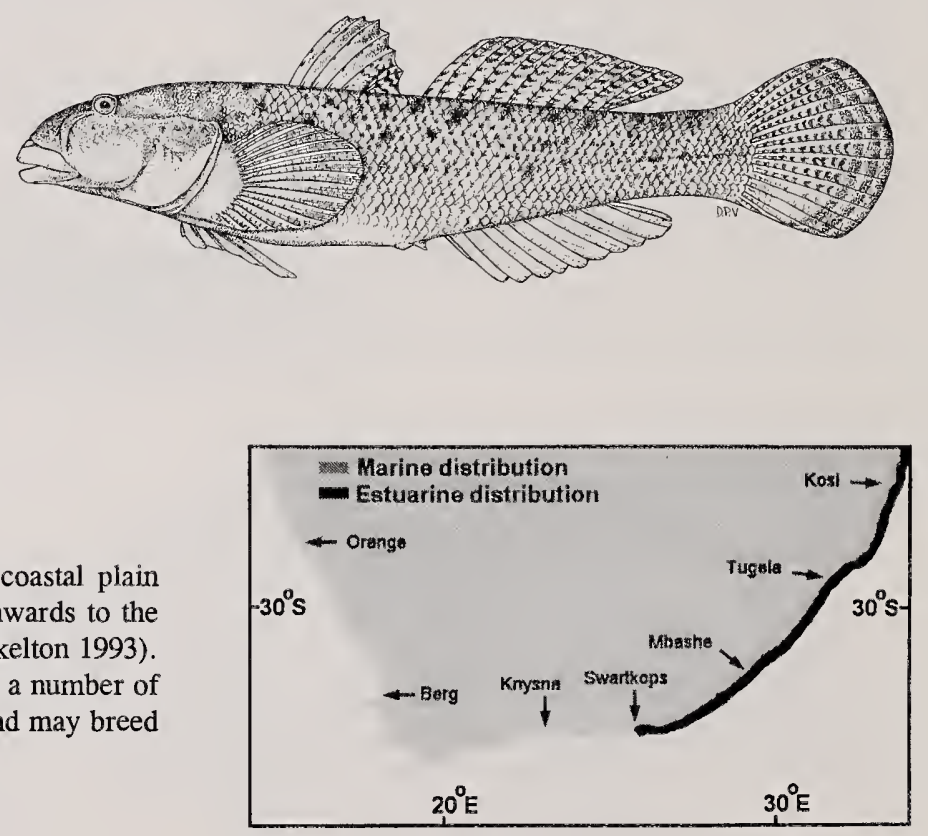


\section{Biology and ecology}

Very little is known about the life-history of $A$. aeneofuscus, possibly due to its excellent camouflage and secretive habits. It is found in both still and flowing water, usually over sandy bottoms into which it may bury itself with only the head and eyes exposed (Skelton 1993).
The recorded salinity range of the freshwater goby is $0-35 \%$ with greater abundance of this species in subtropical than warm-temperate waters. The diet is dominated by benthic invertebrates. The subterminal mouth is larger in males than in females (Hoese 1986a) which may influence prey selection.

\section{Family: GOBIIDAE}

Species: Glossogobius giuris (Hamilton, 1822)

Common name: Tank goby

Smiths' Sea Fishes number: 240.44

Illustrated specimen length: $25 \mathrm{~cm} \mathrm{SL}$

\section{Selected anatomical features}

Fin elements: Dorsal VI +I, 9;

Anal 1, 8; Pectoral 19-20.

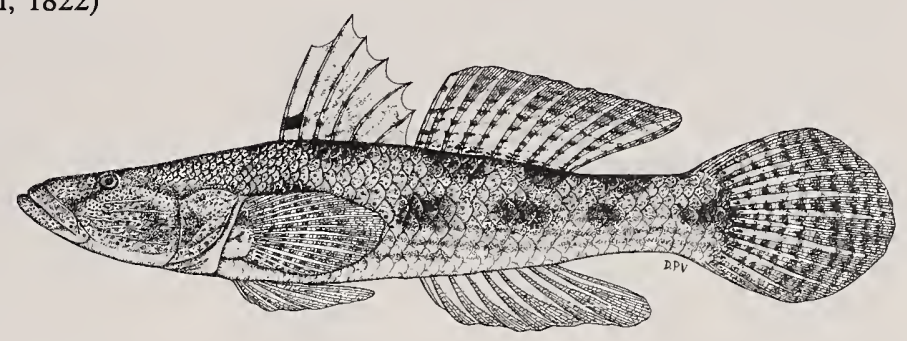

Lateral scales: 29-33.

Maximum recorded length in southern

African waters: $\pm 33 \mathrm{~cm}$ SL.

\section{Distribution}

G. giuris is a tropical Indo-West Pacific species extending south to Port St Johns (Hoese 1986a). According to van der Elst (1988) this goby is widely distributed in warm marine, estuarine and freshwater systems. Within southern Africa it is primarily a freshwater species, occupying quiet backwater habitats and floodplain pans but sometimes extending hundreds of kilometres inland in the larger rivers (Skelton 1993).

\section{Biology and ecology}

Earlier confusion with two closely related taxa, Glossogobius callidus and Glossogobius biocellatus, has called into question previously published information on the tank goby. Although $G$. giuris appears to be a mainly freshwater species, the largest specimens in southern Africa have been found in estuarine lagoons and lakes.

The tank goby normally occurs singly or in pairs, and is usually confined to shallow water where its drab colouration and sedentary habits make it cryptic and inconspicuous (van der Elst 1988).

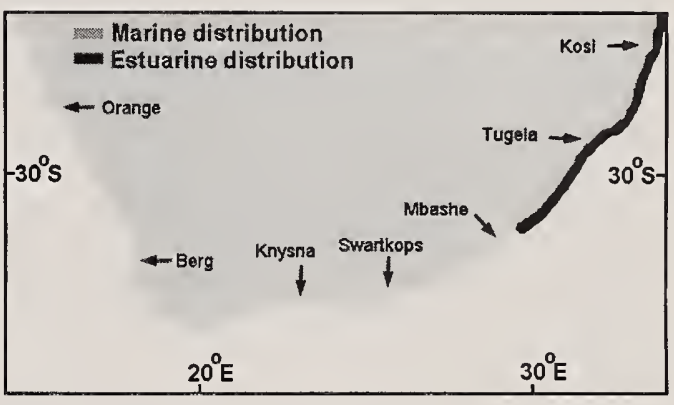

Sexual maturity is attained at approximately 55 mm SL, with breeding occurring during summer (Skelton 1993). According to van der Elst (1988) the elongated eggs adhere to submerged objects and are probably guarded by the male until they hatch.

Juveniles in freshwater habitats feed on benthic invertebrates whereas larger individuals also prey on fish and tadpoles (Skelton 1993). In estuaries they feed on amphipods, decapods, tanaids, chironomid larvae and small fishes (Day et al. 1981, van der Elst 1988). 


\section{Family: ELEOTRIDAE}

Species: Hypseleotris dayi Smith, 1950

Common name: Golden sleeper

Smiths' Sea Fishes number: 241.7

Illustrated specimen length: $41 \mathrm{~mm}$ SL

\section{Selected anatomical features}

Fin elements: Dorsal VI $+\mathrm{I}, 8$;

Anal I, 9; Pectoral 12-14.

Lateral scales: 24-25.

Maximum recorded length: $\pm 60 \mathrm{~mm}$ SL.

\section{Distribution}

H. dayi is a southern African endemic, ranging from the Mtamvuna system in southern KwaZulu-Natal to at least the Kosi system in the north (Bruton 1996b).

\section{Biology and ecology}

This rare species is known only from a few coastal streams and estuaries in KwaZulu-Natal, some of which are being threatened by human activities. Indeed, there are indications that it may have disappeared from some localities where it was previously recorded, e.g. Lake St Lucia (Bruton 1996b). In the 1996 IUCN Red List of Threatened Animals, $H$. dayi is listed as 'near threatened' (Baillie \& Groombridge 1996).

According to Skelton (1993) the golden sleeper favours shallow vegetated margins of freshwater streams entering estuaries but has also been recorded in Lake St Lucia where salinities were greater than $35 \%$. Within the upper reaches of the Kosi system it is reasonably widespread, occurring in the reed margins of the lakes and channels. According to Bruton (1996b) breeding takes place in the shallow margins of estuarine lakes and lagoons following flooding. This

statement is supported by observations which suggest that $H$. dayi is more abundant during wet periods when shallow vegetated marginal habitats are more extensive than in dry years (Skelton 1987). In addition, Kyle (1989) reports that after heavy rain $H$. dayi appears to migrate upstream into newly flooded areas to spawn. Support for the above hypothesis on spawning requirements also comes from the fact that although individuals have been kept in aquaria for up to 15 years, there have been no reports of breeding in captivity.

No specific biological or ecological studies have been conducted on $H$. dayi. According to Crass (1968) the golden sleeper may remain resting on the bottom for long periods, but will dart to and fro if disturbed or when searching for food. Dietary information from the natural environment is lacking, but in captivity they feed readily on small insect larvae (Skelton 1987). 


\section{Estuarine ecosystems and their ichthyofauna}

\subsection{INTRODUCTION}

Africa south of latitude $26^{\circ} \mathrm{S}$ has a $3400 \mathrm{~km}$ coastline with a total estuarine area of approximately $600 \mathrm{~km}^{2}$, about $70 \%$ of which is located in the subtropical areas of KwaZulu-Natal, Eastern Cape and Mozambique. However, more than $80 \%$ of KwaZulu-Natal's approximately $400 \mathrm{~km}^{2}$ estuarine area consists of the St Lucia and Kosi lake systems. The dominance of coastal lakes in terms of estuarine surface area is overwhelming but the geographic spread of this type of system is limited. Numerically these lakes comprise only about $3 \%$ of estuaries found on the subcontinent. This chapter assesses the relative importance of different types of systems to the estuary-associated fish groups, and highlights broader ecological processes operating within the region's estuaries.

It has been postulated by several authors (e.g. Blaber 1981a) that southern African estuaries are ecologically important because they provide the only significant sheltered areas for the juveniles of some marine fish species. Potter et al. (1990) suggested that in contrast to the high energy coastline associated with south-eastern Africa, the south-western Australian inshore waters are used as an alternative nursery habitat by many estuary-associated marine species because of the physical protection afforded by fringing reefs and rocky headlands. Cooper et al. (1995) focused on the wave-dominated and current-swept KwaZulu-Natal region, and concluded that even small, seasonally open estuaries are important for juvenile marine fishes. They also suggested that collectively, fish from these estuarine nursery areas make a considerable contribution to the adjacent Indian Ocean coastal ecosystem.

A variety of factors influence the use of estuaries by fishes and it is highly unlikely that all these factors will be the same for any two systems. Since no two estuaries are identical in terms of either biotic or abiotic characteristics, it could be postulated that the ichthyofaunas of each estuary will also differ. However, if the resident and marine migrant fishes are responding to the environment in a consistent manner, then the communities occupying similar types of estuaries in a particular region would be expected to reflect this similarity. In the following sections the fish assemblages of different estuary types in the different biogeographic regions are reviewed and compared.

\subsection{TEMPORARILY OPEN/CLOSED ESTUARIES}

The majority (72\%) of estuaries along the southern African coast are relatively small systems which close off to the sea for varying periods and are particularly vulnerable to degradation and human impact (Begg 1978). It is imperative therefore that the ecological significance of these estuaries and their importance to fishes be understood prior to making recommendations about management, conservation or exploitation. Although limited ichthyological information is available on most subtropical systems (Begg 1984a, 1984b), five temporarily open/closed estuaries (Tongati, Mdloti, Mhlanga, Damba and Zotsha) on the KwaZulu-Natal coast have been well studied (Blaber et al. 1984, Harrison \& Whitfield 1995). Similarly, among small warm-temperate estuaries on the subcontinent, only the
West Kleinemonde, van Stadens, Kabeljous, Seekoei and Kleinmond systems have received detailed ichthyological study (Blaber 1973a, Bennett 1989, Dundas 1994). In the cool-temperate region, the only temporarily open/closed estuary which has had its fish fauna surveyed is the Diep (Millard \& Scott 1954).

In temporarily closed KwaZulu-Natal estuaries Oreochromis mossambicus is the dominant freshwater species, with another cichlid Tilapia rendalli sometimes found in association with submerged aquatic plants. Gilchristella aestuaria is usually the most abundant estuarine species, with Ambassis productus, Oligolepis acutipennis and Glossogobius callidus also reaching high densities in certain systems (Begg 1984a, Harrison \& Whitfield 1995). The dominant estuary-associated 
marine fishes include Valamugil cunnesius, Myxus capensis, Mugil cephalus and Rhabdosargus holubi, with Liza alata, Liza dumerilii, Liza macrolepis, Valamugil robustus, Terapon jarbua, Monodactylus falciformis, Pomadasys commersonnii and Gerres methueni sometimes common in these systems. Most of the above species are mugilids. The dominance of this family, both in terms of species and fish numbers, in small subtropical estuaries has also been noted in other studies (Whitfield 1980e, Blaber et al. 1984).

A similar community structure to that described above exists in warm-temperate systems along the southeast and southwest coasts (Bennett 1989, Dundas 1994). The introduced Oreochromis mossambicus represents the only freshwater component in most temporarily closed estuaries, with an ideal breeding habitat often present in the lower reaches of these systems. The most abundant estuarine species in this biogeographic region are Gilchristella aestuaria, Atherina breviceps and Psammogobius knysnaensis. Although mugilids, especially Liza richardsonii, Mugil cephalus and Liza dumerilii still comprise a large component of the estuary-associated marine fishes, the sparids (Rhabdosargus holubi and Lithognathus lithognathus) are of increasing importance, with $R$. holubi usually the dominant species in south-eastern and southern Cape estuaries (Blaber 1973a).

In cool-temperate estuaries the diversity declines even further, with no indigenous freshwater fishes present. Although the major estuarine residents are similar to those in warm-temperate estuaries (e.g. Gilchristella aestuaria, Caffrogobius nudiceps and Atherina breviceps), some of the common warmtemperate marine fishes (e.g. Rhabdosargus holubi, Liza dumerilii and Myxus capensis) are either rare or absent. The marine group in small west coast systems is usually dominated by Liza richardsonii, Mugil cephalus, Lithognathus lithognathus and Rhabdosargus globiceps (Millard \& Scott 1954).

Intermittent estuaries are those temporarily closed systems which lose their estuarine characteristics, usually by evaporation of all surface water, for considerable periods each year. A range of intermittent estuaries are found in the arid Northern Cape and these systems, when they contain water, may act as temporary refuges for small populations of mugilids (Bickerton 1981, Harrison 1998).

Marine stragglers (mainly stenohaline taxa) are not dependent on estuaries and these fishes do not contribute significantly to the ichthyofauna of small systems on the subcontinent. Probable reasons include the minimal tidal exchange with the sea, frequent mouth closure and relatively low salinities, thus reducing the potential for the above group of fishes to utilise this estuary type. Harrison \& Whitfield (1995) found that marine stragglers comprised $0.2-0.3 \%$ of the fish fauna in the Mhlanga and Zotsha systems, and were absent from the Damba Estuary. A similar situation pertains to temporarily open/closed estuaries in the Eastern Cape where marine stragglers were absent from this type of system (Dundas 1994).

Temporarily open/closed estuaries in KwaZuluNatal are dominated at different periods by different assemblages of fishes. This changing pattern is linked to the spawning and migration patterns of the various species as well as the hydrological regime of each estuary. During the winter these systems are normally closed off from the sea (Figure 24a), with relatively deep waters and high food resource and habitat availability (Whitfield 1980e). Freshwater and estuarine species mainly inhabit the upper reaches of the systems, while marine species (which dominate the community) occur predominantly in the middle and lower reaches. When these estuaries open following the spring/summer rains, adult and subadult estuaryassociated marine species emigrate to the sea and $0+$ marine juveniles begin recruiting into the systems. Spring is also the peak breeding period of resident estuarine and freshwater species, resulting in an increase in the contribution of these fishes to the overall ichthyofauna. When temporarily closed estuaries open in spring or early summer (Figure 24b), the water level falls, concentrating fishes in the lower reaches of the system where moderate water depths are present, thus increasing the proportion of freshwater and estuarine species in this region. The prolonged spawning and recruitment of $0+$ juveniles of estuaryassociated marine species increases the proportion of these fishes present in the estuaries during summer. In autumn the systems usually close again, water levels rise and the available food resources and habitat increase. This allows the redistribution of freshwater and estuarine species upstream, leaving estuarinedependent marine species to again dominate the lower and middle reaches (Harrison \& Whitfield 1995).

Mouth condition appears to be a major determinant of species diversity (as measured using the ShannonWiener, Pielou and Margalef indices) in small estuaries. As expected, higher numbers and biomasses of marine fish taxa were captured in estuaries with more frequent mouth openings (Harrison \& Whitfield 1995). On average, the Damba Estuary remained closed the longest and it had the lowest number of marine fish species when compared to the Mhlanga and Zotsha estuaries. The Zotsha Estuary remained open the longest and, of the three systems, had the highest marine fish diversity. Although estuarine and freshwater taxa were well represented in all three estuaries, only the Zotsha and Mhianga estuaries had diverse marine fish assemblages. The species composition of these latter two systems also exhibited the greatest similarity (as measured using the Jaccard and Sørensen similarity indices) when compared to pairings with the Damba Estuary. 


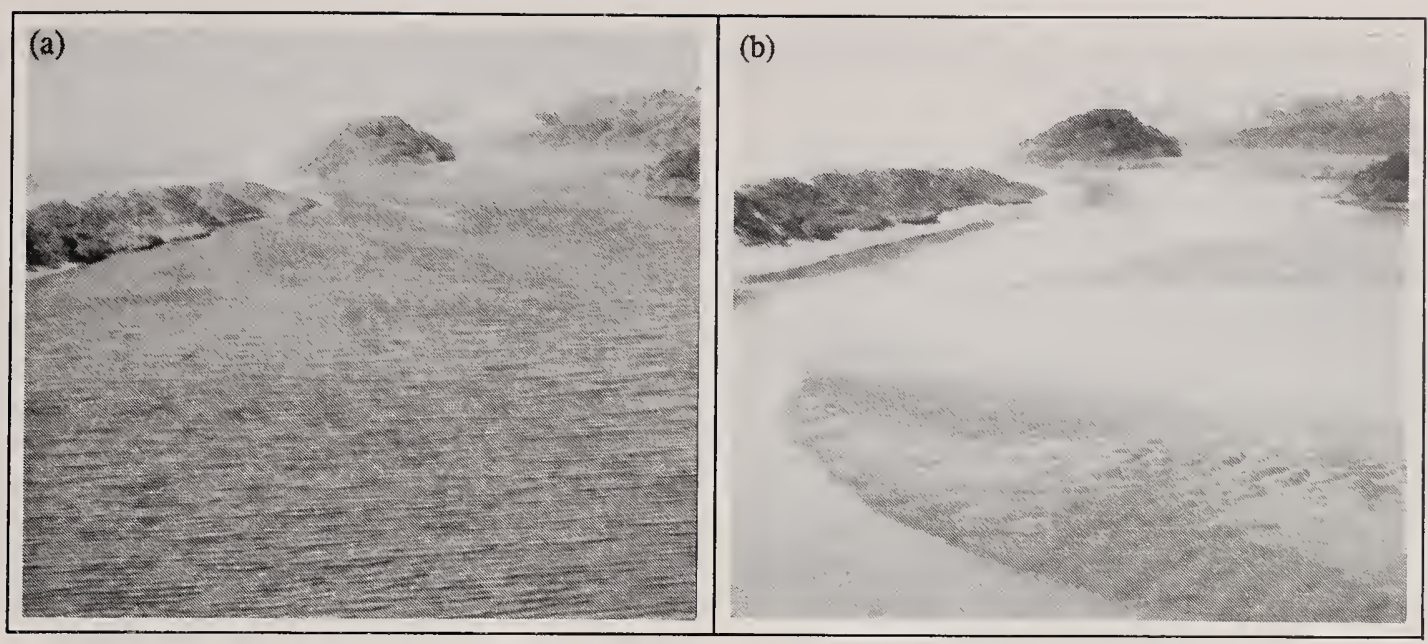

Figure 24. The Mhlanga Estuary during temporarily closed (a) and open (b) mouth phases.

The similarity between two fish communities is not only a function of the number of common and unique taxa, but also of the amount of each species present. A quantitative similarity measure (Ellenberg's index), which can use either fish numbers or biomass, revealed that the ichthyofaunal assemblages of the Mhlanga and Zotsha systems had a similarity greater than $95 \%$ (Harrison \& Whitfield 1995). Comparative pairings between the fish communities of the Mhlanga/Damba and Zotsha/Damba gave values above $80 \%$ for both numerical and biomass analyses. This indicates that temporarily open/closed estuaries on the KwaZuluNatal coast, despite the changes in fish composition brought about by different magnitudes and periods of marine connection, have similarly structured fish assemblages. In the warm-temperate region, results from gill and seine net catches in the Seekoei and Kabeljous estuaries revealed that the top 10 fish taxa were similar for both systems (Dundas 1994). The above analyses suggest that only a relatively short open mouth phase during the peak marine fish recruitment period is necessary to 'saturate' an estuary with a wide variety of juvenile fish.

In contrast to permanently open estuaries where marine larvae and postlarvae are usually well represented in ichthyoplankton catches (Melville-Smith \& Baird 1980, Harrison \& Whitfield 1990), temporarily closed systems have very low numbers of this faunal component. The ichthyoplankton of three temporarily closed Eastern Cape estuaries was overwhelmingly dominated by estuarine spawners (Dundas 1994), especially the clupeid Gilchristella aestuaria. In the subtropical Mhlanga Estuary, $G$. aestuaria larvae also dominated the ichthyoplankton during the closed phase (Whitfield 1980e).
Although recent information tends to support Begg (1984a) in his assessment of the importance of estuarine mouth state in structuring fish communities, his conclusions regarding the marine nursery value of temporarily open/closed estuaries do not appear to be correct. Begg's data showed that permanently open estuaries were dominated by migrant marine species but that temporarily closed systems were dominated by resident estuarine and freshwater taxa. These findings led him to conclude that temporarily closed estuaries on the KwaZulu-Natal coast did not serve a major nursery function for estuary-associated marine fishes. However, sampling in his study was confined to a $1 \mathrm{~m}$ beam trawl which tended to undersample mugilids and other marine species. Harrison \& Whitfield (1995), using four types of sampling gear, have shown that a $1 \mathrm{~m}$ beam trawl gives the poorest representation of fish assemblages in these temporarily open/closed estuaries.

The distribution of the majority of fishes in the Mhlanga Estuary was closely associated with that of their dominant food, except for the Mugilidae where sediment particle sizes influenced fish composition in an area (Whitfield 1980b). Zoobenthos feeders such as Pomadasys commersonnii, Leiognathus equula and Gerres methueni were most common in the lower reaches of the estuary where invertebrate stocks were highest. The detritivorous Oreochromis mossambicus was found to be most abundant in the upper reaches where benthic floc was most readily available. The mugilid Liza alata was concentrated in the lower reaches, Valamugil cunnesius in the middle reaches and Myxus capensis in the upper reaches. Zooplanktivorous species such as Gilchristella aestuaria showed no zonation pattern, thus reflecting the relatively even distribution of zooplankton throughout the estuary. 
The trophic structure of the Mhlanga fish community was similar to that of the available food resources (Figure 25, Whitfield 1980e). These resources were most abundant during the closed phase of the estuary (Figure 24a), possibly due to the relative stability of the physical environment and increased habitat availability, e.g. zooplankton stocks were an order of magnitude higher during the winter closed phase when compared to the summer open phase. A similar peak in zooplankton and zoobenthos was recorded during winter in the Mdloti Estuary when the mouth was closed (Blaber et al. 1984). The relatively high numerical contribution of estuarine species in the Mhlanga system during the spring of 1990 and 1991 was attributed (Harrison \& Whitfield 1995) to the successful reproduction of Gilchristella aestuaria and Glossogobius callidus during the winter closed phase. When temporarily closed estuaries are breached (Figure 24b), the available habitat and food resources are drastically reduced due to the loss of plankton, prolonged exposure of the benthos, and the effect of floodwater scouring on accumulated benthic floc (Whitfield 1980e, Blaber et al. 1984). Competition among fishes in the shallow estuary channel, both for suitable habitat and food, increases during this phase (Harrison \& Whitfield 1995).

The ichthyofauna of temporarily closed estuaries is less diverse than permanently open estuaries, but the importance of the former systems in supplementing estuarine-dependent marine fish stocks should not be underestimated. Seine and gill net catch per unit effort data quoted by Dundas (1994) suggests that temporarily closed and permanently open estuaries possess similar standing stocks of fishes. By providing a continuous sequence of sheltered environments over a long stretch of coast, millions of marine fishes are able to make use of these vital nursery areas and, when they return to the sea, supplement the coastal breeding populations.

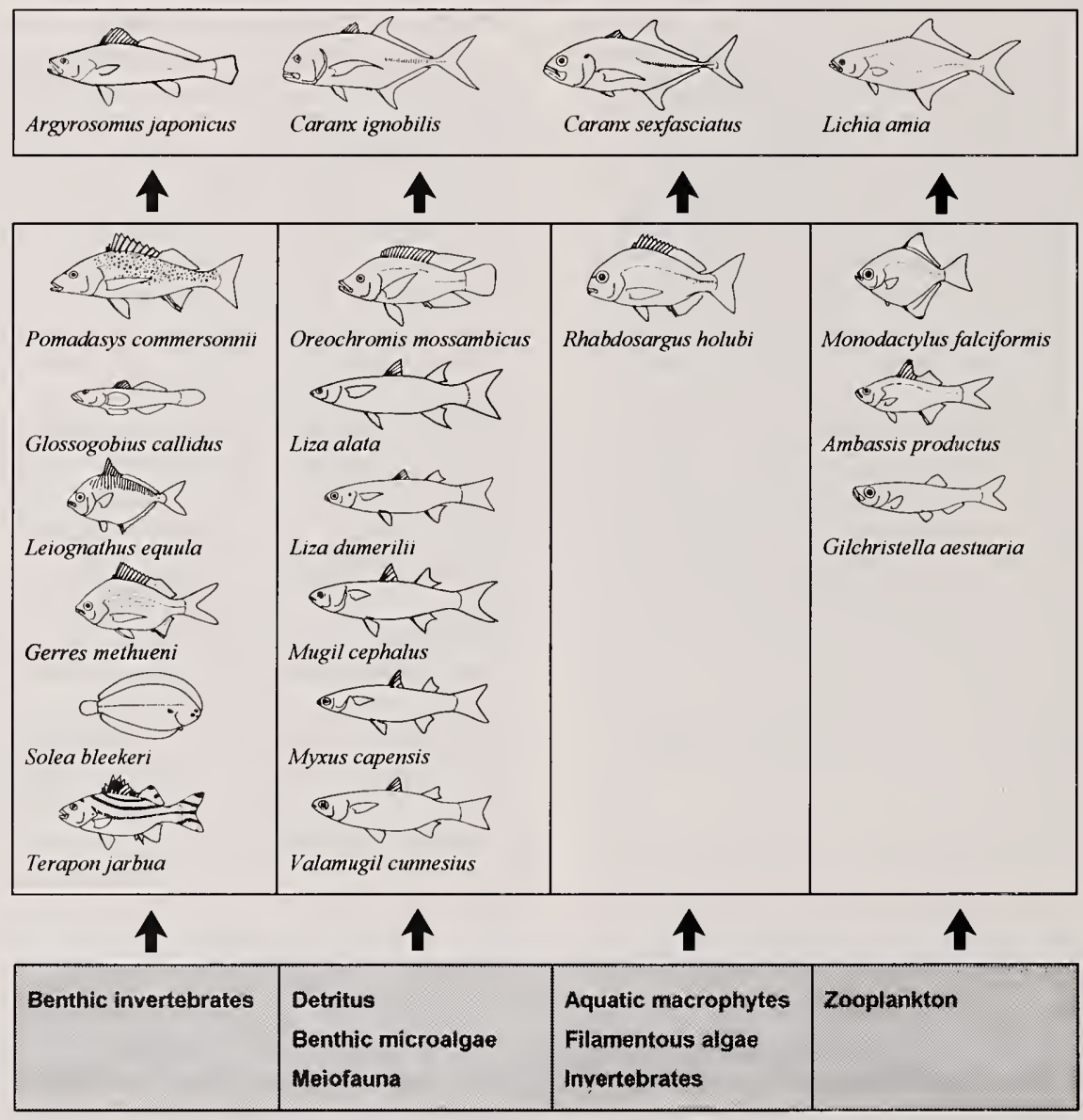

Figure 25. Simplified trophic structure of the dominant fish species in the Mhlanga Estuary (information from Whitfield 1980e, Harrison \& Whitfield 1995). 


\subsection{PERMANENTLY OPEN ESTUARIES AND RIVER MOUTHS}

Estuaries with permanently open mouths constitute approximately $23 \%$ of all systems on the subcontinent. However, about $5 \%$ of these systems may be classified as river mouths which offer a relatively hostile environment to both marine and estuarine fish species for much of the year. The remainder $(18 \%)$ are extremely important nursery areas which are readily accessible to a wide variety of fish taxa during all seasons, except during episodic flood events.

Limited ichthyofaunal information is available from permanently open systems in the KwaZulu-Natal portion of the subtropical coastline (Hill 1966). In contrast, several detailed studies have been undertaken in both the subtropical and warm-temperate regions of the Eastern Cape (e.g. Beckley 1984a, Marais 1981, Plumstead et al. 1985, 1989a, 1989b, 1991), as well as from warm and cool-temperate regions of the Western Cape (e.g. Ratte 1982, Branch \& Day 1984, Bennett 1994).

In permanently open subtropical estuaries, Oreochromis mossambicus is the only freshwater species which is regularly found in these systems. Gilchristella aestuaria is usually the most abundant estuarine species, with Ambassis gymnocephalus, Ambassis natalensis and Glossogobius callidus also attaining high densities in certain estuaries. The dominant marine fishes include Acanthopagrus berda, Argyrosomus japonicus, Caranx sexfasciatus, Hilsa kelee, Johnius dorsalis, Leiognathus equula, Liza alata, Liza dumerilii, Liza macrolepis, Monodactylus falciformis, Mugil cephalus, Myxus capensis, Pomadasys commersonnii, Rhabdosargus holubi, Rhabdosargus sarba, Solea bleekeri, Terapon jarbua, Thryssa vitrirostris, Valamugil buchanani, Valamugil cunnesius and Valamugil robustus.

A similar community structure exists in warmtemperate systems along both the southeast and southwest coasts, with Oreochromis mossambicus still representing the freshwater component. The most abundant estuarine species in this biogeographic region are Atherina breviceps, Gilchristella aestuaria, Caffrogobius gilchristi and Psammogobius knysnaensis. In those systems where eelgrass beds are present, estuarine spawners such as Clinus superciliosus, Hyporhamphus capensis and Syngnathus acus are frequently captured. Although mugilids, especially Liza dumerilii, Liza richardsonii and Mugil cephalus, tend to dominate the marine fish component, species such as Argyrosomus japonicus, Diplodus sargus capensis, Galeichthys feliceps, Heteromycteris capensis, Lichia amia, Lithognathus lithognathus, Liza tricuspidens, Monodactylus falciformis, Myxus capensis, Pomadasys commersonnii, Rhabdosargus holubi, Sarpa salpa and Solea bleekeri are also common.
In cool-temperate west coast estuaries the biodiversity declines even further, with indigenous freshwater fish species seldom present. Although the majority of estuarine residents (viz. Atherina breviceps, Gilchristella aestuaria, Caffrogobius nudiceps and Psammogobius knysnaensis) are similar to those found in warm-temperate estuaries, some of the common warm-temperate estuarine-dependent marine fishes (e.g. Liza dumerilii, Myxus capensis and Rhabdosargus holubi) are either rare or absent from west coast systems. The marine group in permanently open west coast estuaries is overwhelmingly dominated by Liza richardsonii, with Lichia amia, Mugil cephalus Lithognathus lithognathus, Pomatomus saltatrix, Solea bleekeri and Rhabdosargus globiceps occurring in smaller numbers.

Marine stragglers are often recorded in permanently open estuaries along the southern African coast, particularly in the lower reaches of these systems. In subtropical estuaries these are usually warm water species, whereas in warm-temperate systems more cosmopolitan taxa are often represented. The endemic elasmobranch Rhinobatos annulatus is known to enter both warm-temperate and cool-temperate estuaries, especially when upwelling occurs along the coast.

Seine net catches in permanently open St Francis Bay estuaries (Eastern Cape) indicate that the number of species in these systems are considerably higher than those recorded for temporarily open/closed estuaries in the region (Dundas 1994). However, these differences are primarily due to the presence of small numbers of marine stragglers in the permanently open systems. The dominant species in both types of estuaries are similar, and include both estuarine residents and marine migrants.

Permanently open estuaries tend to be dominated at different periods by changing assemblages of fishes. This is linked to the spawning and migration patterns of the various species as well as the hydrological regime of each estuary. During spring and summer large numbers of $0+$ marine juveniles enter these systems which, by virtue of the permanently open mouth, allows estuarine access to the full range of potential species from a particular coastal region. However, the well developed mouth also permits the entry of a wide variety and size range of piscivorous fishes, including large Elops machnata, Argyrosomus japonicus and Lichia amia. Although the diet of these predators includes a wide range of marine fish species (Marais 1984), the dominant prey item is often the clupeid Gilchristella aestuaria.

Whitfield (1994a) has shown that the magnitude of juvenile fish recruitment into permanently open Eastern Cape estuaries is related to the longitudinal salinity 
gradient and therefore the amount of river water entering these systems. Those estuaries with a poorly developed longitudinal salinity gradient have a relatively low fish abundance when compared to systems with a well developed gradient. However, it is probable that riverine and estuarine based olfactory cues entering the marine environment, and not salinity gradients or reduced salinities, stimulate immigration of these euryhaline fishes into estuaries. Although fish abun-dance is usually higher in those systems with a perennial water supply, permanently open systems with little or no freshwater input often have a higher species diversity because of the sheltered marine conditions prevailing in the lower reaches (Whitfield et al. 1994).

The food and feeding ecology of fishes in permanently open Eastern Cape estuaries has been studied by several authors (e.g. Masson \& Marais 1975, Marais 1984). Systems that are deprived of an adequate river flow have a food web which is centred around autochthonous detrital sources, usually derived from intertidal salt marshes and submerged aquatic macrophytes (Heymans \& Baird 1995, Paterson \& Whitfield 1997). In contrast, those estuaries which receive regular pulses of fresh water usually have a phytoplankton dominated trophic structure (Wooldridge \& Bailey 1982, Allanson \& Read 1995) that supports large zooplanktivorous fish populations. Intermediate estuaries such as the Swartkops have considerable energy flows along the macrophytic, benthic microalgal and phytoplanktonic pathways (Baird 1988), and the fish faunas of these systems reflect this range of energy sources with a wide spectrum of well represented feeding guilds (Figure 26). According to Baird et al. (1991) the Swartkops Estuary is very productive, retaining a large proportion of material within the system. Retention takes place over short circuits with few trophic links, thus indicating a relatively simplistic cycling structure for the estuary.

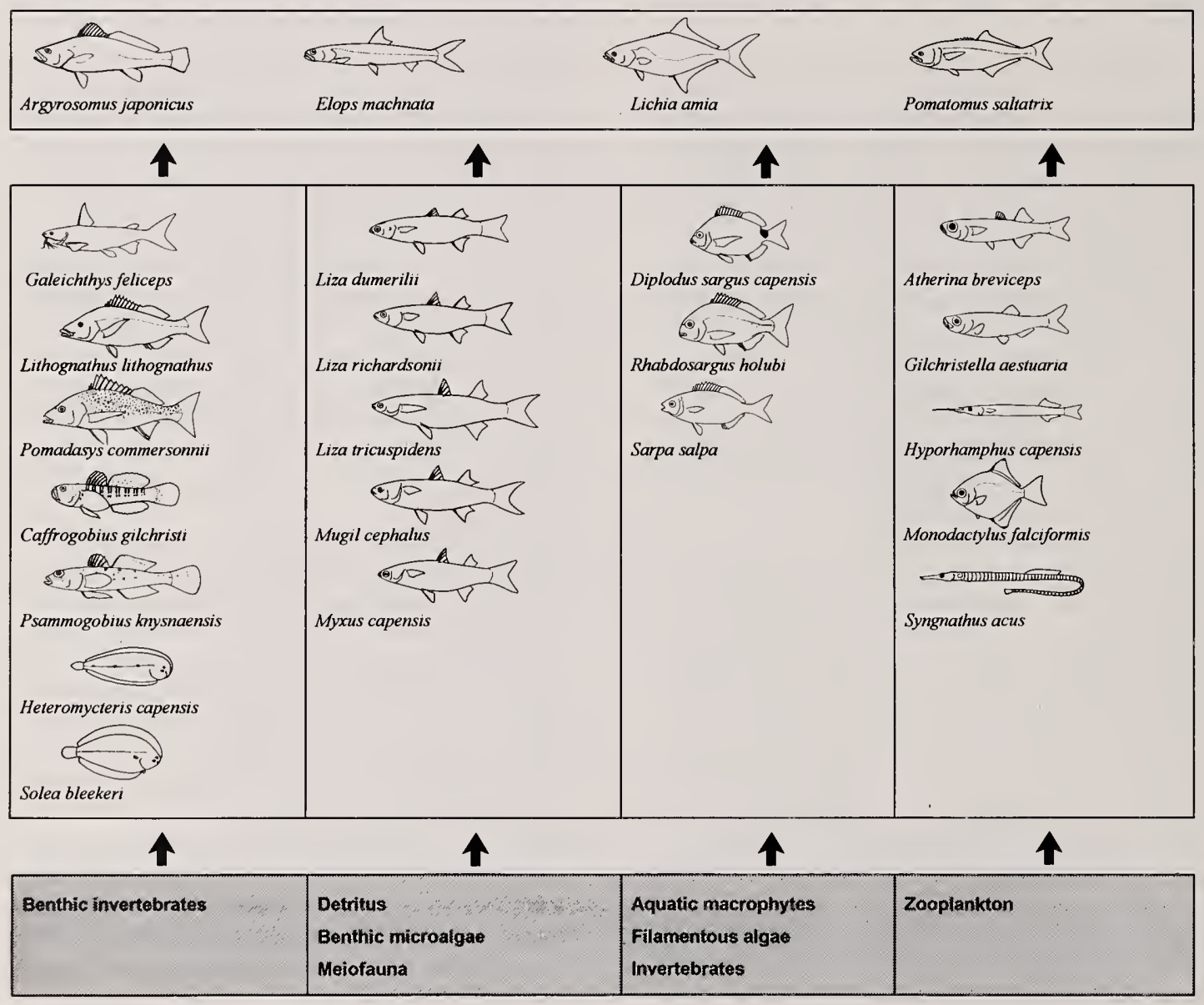

Figure 26. Simplified trophic structure of the dominant fish species in the Swartkops Estuary (information from Masson \& Marais 1975, Marais \& Baird 1980a, Beckley 1983, Marais 1984, Baird 1988, Baird et al. 1991). 
Although a moderate supply of fresh water appears to be essential for the maintenance of high primary and secondary productivity within permanently open estuaries, recent research in the Great Fish Estuary (Ter Morshuizen et al. 1996b) has indicated that large riverine inputs into these systems can temporarily depress fish abundance. These influences can take the form of large-scale fish mortalities caused by excessive silt loads carried by flood waters (Whitfield \& Paterson 1995) or longer-term effects arising from reduced conductivity levels associated with the inflowing river water. Ter Morshuizen et al. (1996b) have shown that reduced conductivity of the Great Fish River following floods was associated with a significant decline in the abundance of euryhaline marine fish species in the lower river. Marais (1982) also identified the key role of river flooding on the food resources of fishes in permanently open estuaries. These resources may be either temporarily enhanced or depleted, depending on the magnitude of the flood and configuration of the estuary.

A river mouth differs from a permanently open estuary in that processes within the former system are riverine dominated. Indeed river volumes are sometimes so great that freshwater species may even be found outside the mouth of this type of system (Day 1981c). Since the rivers of southern Africa support relatively few species (Skelton 1993), and most marine taxa are incapable of surviving prolonged periods in fresh water, this invariably leads to river mouths which are depleted both in terms of fish biodiversity and abundance. In the cool-temperate Orange River mouth region, nine fish species have been recorded, with freshwater taxa predominating during high river flow and marine species during low flow conditions (Day 1981c, Morant \& O'Callaghan 1990). Along the warmtemperate Tsitsikamma coast a number of river mouths have been sampled by Harrison et al. (1996), with no single system having more than nine fish species. Although the subtropical ichthyofauna of the Tugela River mouth is more diverse, there are considerably less species than in the nearby permanently open Mlalazi Estuary where at least 58 fish taxa have been documented (Hill 1966).

Indications are that estuarine phytoplankton and invertebrate food resources in river mouths are severely limited by the widely fluctuating salinities and frequent freshwater flooding (Brown 1958). In addition, residence time of water within these systems is generally too short for phytoplankton stocks to develop, and benthic invertebrates have to cope with major sediment movements associated with river flow characteristics. The scarcity of large piscivorous fishes from southern African river mouths is perhaps indicative of an unpredictable food supply in the form of either migrant or resident fish species.

From the above it is apparent that these estuaries represent extremely demanding environments that are not conducive to permanent colonization by large numbers of marine, estuarine or even freshwater fish species. River mouths are, however, used opportunistically by estuary-associated fishes when suitable salinity regimes and other conditions (e.g. food resources) prevail.

\subsection{ESTUARINE LAKES AND BAYS}

There are very few estuarine lakes (3\% of southern African systems) or estuarine bays (1\% of systems) along the coast. Although neither type of estuary is present in the cool-temperate region, Verlorenvlei and Langebaan Lagoon come close to qualifying as an estuarine lake and bay respectively. Despite the fact these ecosystems are poorly represented on the subcontinent, in terms of surface area they are very important, with Lake St Lucia alone comprising more than $50 \%$ of available estuarine habitat in the region.

Two major estuarine lake systems occur in the subtropical zone, viz. St Lucia and Kosi. Lake St Lucia is a well studied estuarine system, with much of this research being generated by the need to understand the influence of large-scale salinity fluctuations on the flora and fauna of the lake (Day et al. 1954). Although more than 100 fish species have been recorded from both the St Lucia and Kosi systems (Whitfield 1980d), fewer than 30 species are abundant within the large lake compartments of these estuaries. In Lake St Lucia the dominant taxa vary according to both salinity and season, with Argyrosomus japonicus, Elops machnata, Gilchristella aestuaria, Glossogobius callidus, Hilsa kelee, Hyporhamphus capensis, Johnius dorsalis, Leiognathus equula, Liza dumerilii, Liza macrolepis, Mugil cephalus, Oreochromis mossambicus, Platycephalus indicus, Pomadasys commersonnii, Rhabdosargus holubi, Rhabdosargus sarba, Solea bleekeri, Terapon jarbua and Thryssa vitrirostris being numerically dominant. More than $80 \%$ of the recorded taxa in both Lake St Lucia and the Kosi lakes are marine species (Blaber 1978, Mann 1993).

A number of relatively small estuarine lakes occur in the warm-temperate region, the most important of which are the Swartvlei, Wilderness, Botriviervlei and Klein systems. All these lakes are dominated by marine fish taxa but estuarine spawners are also well represented (Scott et al. 1952, Bennett et al. 1985, Hall 
et al. 1987). Species diversity is lower than that recorded in the subtropical systems, with fewer than 40 species recorded in each of the warm-temperate lakes and less than 20 species resident in these systems at any one time. The dominant species are usually Atherina breviceps, Caffrogobius gilchristi, Galeichthys feliceps, Gilchristella aestuaria, Hyporhamphus capensis, Lichia amia, Lithognathus lithognathus, Liza dumerilii, Liza richardsonii, Mugil cephalus, Myxus capensis, Monodactylus falciformis, Oreochromis mossambicus, Psammogobius knysnaensis and Rhabdosargus holubi.

Studies by Scott et al. (1952), Bennett et al. (1985), Kok \& Whitfield (1986), Hall et al. (1987) and Whitfield \& Kok (1992) have all emphasized the importance of an open mouth phase to the structuring of fish communities within estuarine lakes. Recent work by Russell (1996) indicates that opening of the estuary mouths for relatively short intervals during peak recruitment periods will ensure the maintenance of healthy fish assemblages within these water bodies.

Estuarine waters in the Kosi system, even during flood conditions, are relatively clear when compared to Lake St Lucia. Consequently, turbid water species such as Hilsa kelee, Johnius dorsalis and Thryssa vitrirostris are absent from the Kosi system and clear water taxa such as Gerres acinaces, Monodactylus argenteus and Rhabdosargus sarba are common. Piscivorous fish taxa that are predominantly visual hunters (e.g. carangids and sphyraenids) are considerably more diverse and abundant in the Kosi system when compared to Lake St Lucia (Blaber 1982a, Blaber \& Cyrus 1983). Conversely the piscivorous Argyrosomus japonicus, which is more dependent on its olfactory and other senses when foraging, is abundant in turbid Lake St Lucia but rarely captured in the Kosi system.

The estuarine waters of Swartvlei have low suspensoid levels but are stained by humic substances carried into the lake by inflowing rivers (Allanson \& Howard-Williams 1984). Fish species which are indifferent to water turbidity, as well as those associated with clear or turbid waters, are found within the Swartvlei system. Typical turbid water species such as Argyrosomus japonicus and Galeichthys feliceps avoid the clear littoral zone of the lake during daylight hours but are frequently captured in these areas at night (Whitfield 1993). In contrast, predominantly clear water taxa such as Monodactylus falciformis and Liza dumerilii are common in shelf waters during the day and night.

Both the subtropical Lake Mpungwini (Kosi system) and warm-temperate Swartvlei have been shown to be meromictic (Begg 1980, Allanson \& Howard-Williams 1984). This condition results in the hypolimnion in both lakes being unavailable to fishes because of depleted oxygen levels and presence of hydrogen sulphide. In addition, zoobenthic and zooplanktonic prey organisms are confined to the littoral zone and epilimnion for as long as these conditions persist. Erosion of the hypolimnion in Swartvlei does occur under certain conditions (Allanson \& Howard-Williams 1984) and colonization of the lake basin by both invertebrates and fishes is rapid during such interludes. In contrast to Lake Mpungwini and Swartvlei most estuarine lakes in southern Africa are considerably shallower than $12 \mathrm{~m}$, with both fish and invertebrates occurring throughout the water column.

A feature that is shared by both the subtropical Kosi and the warm-temperate Wilderness lakes system is segmentation, a wave generated process that has transformed previously larger water bodies into a series of smaller lakes, each separated by low beach barriers (Orme 1973). This process of segmentation results in each compartment having different physico-chemical characteristics, particularly in terms of salinity regime. Thus in the Kosi system, Lake Amanzimnyana is fresh, Lake Nhlange oligohaline, Lake Mpungwini normally mesohaline and Lake Makhawulani usually polyhaline. These differential salinity regimes have a major influence on the fish species composition in the various lake compartments (Blaber 1978).

In addition to salinity changes, the degree of constriction between lake compartments influences the ability of juvenile marine fish to recruit into particular sections, thus determining the ichthyological structure of the community. Hall et al. (1987) have shown that the depth of interconnecting channels in the Wilderness system had a major influence on fish community structure within the component lakes. They found a marked decline in marine fish species diversity between Eilandvlei and Langvlei due to the tenuous connection between these two lakes. A similar situation probably pertains to Lagoa Poelela in southern Mozambique, an estuarine lake that is connected to the sea via a $75 \mathrm{~km}$ long chain of narrow lakes and interconnecting channels. The salinity of Lagoa Poelela in 1973 was $8 \%$ but only two marine fish species were recorded in the system (Hill et al. 1975). In contrast, Blaber (1978) has shown that marine species dominate the Kosi system by virtue of the excellent connections between the lake compartments.

The Mgobezeleni lake system is an example of an estuary in transition. The lake itself has an elevated chloride level ( $\left.>100 \mathrm{mg} \mathrm{l}^{-1}\right)$ and feeds a small stream that flows parallel to coastal sand dunes for $2 \mathrm{~km}$ before entering the sea (Bruton \& Appleton 1975). This lake appears to be in the final stages of losing its marine link. The only marine fish species still found in the lake are the catadromous Myxus capensis and Megalops cyprinoides, both of which will eventually disappear from the system once the tenuous marine connection is finally broken. Although a wide variety of estuary-associated marine species are present in the mouth region (Bruton 1980b), these taxa do not appear to extend their distribution into the upper lake. 
A considerable amount of work has been conducted on the feeding ecology of fishes in southern African estuarine lakes, particularly the large St Lucia system. Aquatic plants, including phytoplankton, benthic microalgae, filamentous algae and macrophytes, provide the primary sources of food at Lake St Lucia (Whitfield 1980a). Live biomass estimates of 400 tonnes for phytoplankton and 40 tonnes for zooplankton have been calculated for the lake (Grindley 1976). Although there are no phytoplanktivorous fish species in the system, Gilchristella aestuaria, Thryssa vitrirostris and Hilsa kelee (Figure 27) are abundant and all feed extensively on zooplankton (Blaber 1979). G. aestuaria and $T$. vitrirostris are in turn preyed upon in large numbers by the dominant piscivorous fishes Argyrosomus japonicus and Elops machnata (Whitfield \& Blaber 1978a). Indeed, it was found that the numbers of these pelagic piscivores in an area was related to the densities of the above zooplanktivorous fishes. Zooplankton is also a major food item of Hyporhamphus capensis in the lake and this species was, in turn, intensively preyed upon by Strongylura leiura (Whitfield \& Blaber 1978a).

Despite the extensive beds of Zostera capensis, Ruppia spiralis and Potamogeton pectinatus in Lake St Lucia, aquatic macrophytes are not directly utilized by fishes. Although the mainly herbivorous Rhabdosargus holubi consumes the above plants (Figure 27), it digests only the epiphytic growth from the leaf blades (Blaber 1974b). The omnivorous Rhabdosargus sarba also feeds extensively on aquatic plants in the lake, especially

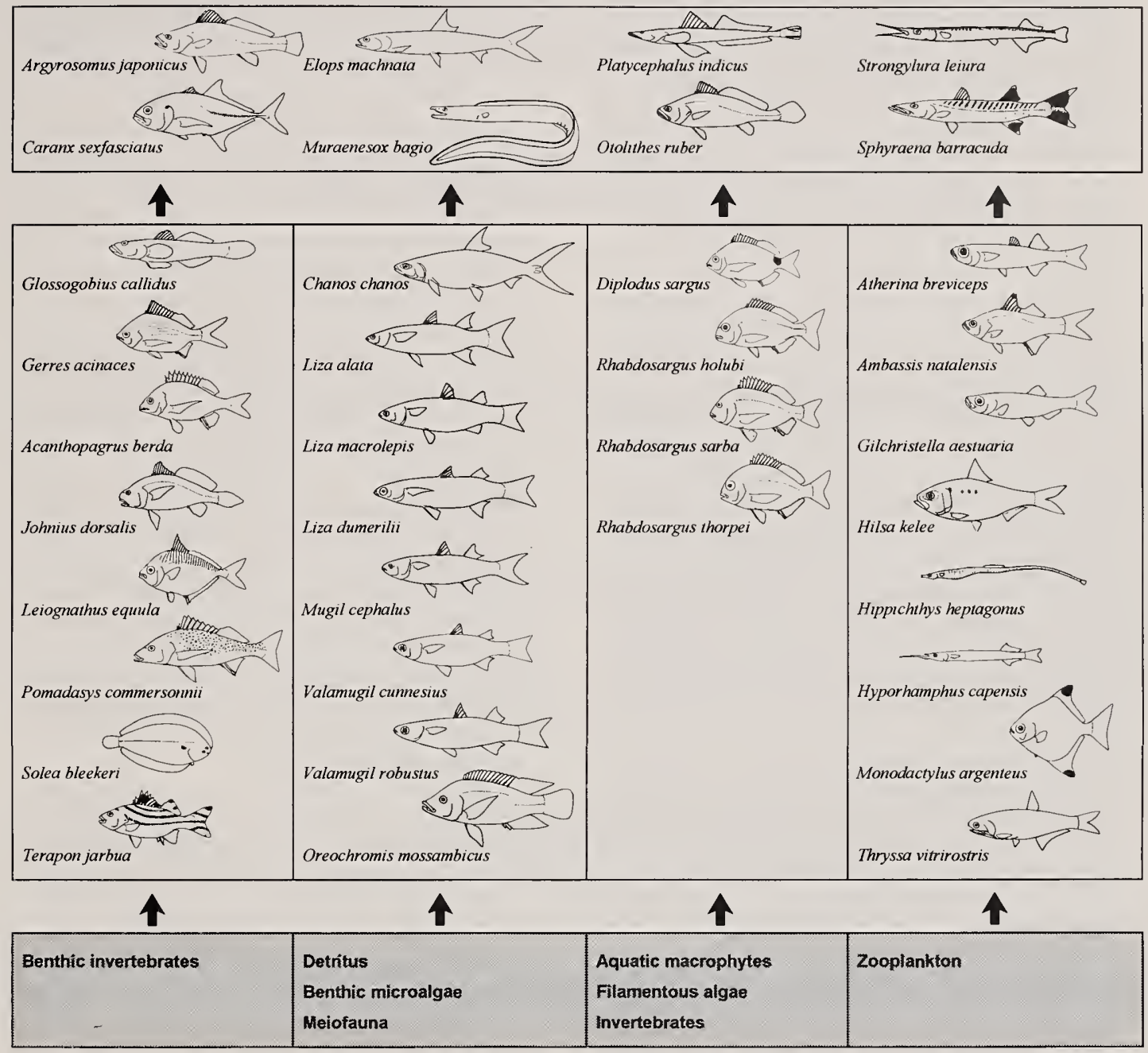

Figure 27. Trophic grouping of some of the dominant fish species in Lake St Lucia during 1975 (modified from Whitfield 1980a, Blaber 1982b). 
filamentous algae (Blaber 1984). The absence of an exclusively herbivorous fish species from Lake St Lucia may be due to the cyclical disappearance of aquatic macrophytes during hypersaline conditions (Wallace 1975a). However, the organic debris from decomposing plants in the form of detritus is permanently available to the aquatic fauna. Indeed, it has been suggested that the cyclical destruction of aquatic macrophytes in the lake during high salinity regimes may increase the amount of detritus available, and is therefore beneficial to the fauna (Hutchison 1977). Although the detritus pool may be temporarily increased by the decomposition of plant beds, the longterm effects are probably negative because growing macrophytes are absent during high salinity conditions.

Detritivorous fishes (Figure 27) are abundant in Lake St Lucia, with the family Mugilidae represented by eleven species. In addition, the detritivorous cichlid Oreochromis mossambicus maintains high standing stocks, especially during oligohaline salinity conditions. Although the diets of the above species overlap in terms of detrital consumption, competition for microflora is reduced through different habitat preferences and feeding mechanisms (Whitfield \& Blaber 1978b). Differential sand particle size selection by mugilids (Blaber 1976), which also influences the distribution of individual species within the lake (Whitfield and Blaber 1978d), has been postulated as a mechanism to assist in the partial segregation of abundant microalgal and meiofaunal food resources. Resource segregation also occurs in terms of fish size, with juvenile mugilids $10-50 \mathrm{~mm}$ SL occurring in water $<5 \mathrm{~cm}$ deep and those $50-100 \mathrm{~mm}$ SL frequenting areas $<100 \mathrm{~cm}$ deep (Whitfield 1980a). However, by frequenting the margins of the lake these juvenile fishes then become vulnerable to avifauna foraging in this zone (Whitfield \& Blaber 1978c, 1979b, 1979c). The piscivorous birds appear to concentrate fishing activities in those parts of the lake where small fish are most abundant because the number of birds in an area was found to be positively correlated to the number of fish captured during seine net operations (Whitfield 1978).

The feeding habits of predatory fishes and birds at St Lucia vary both seasonally and according to location in different parts of the lake. Argyrosomus japonicus prey extensively on penaeid prawns in summer but not in winter (Whitfield \& Blaber 1978a). The white pelican Pelecanus onocrotalus change their feeding pattern according to the availability of fish in different parts of the lake and time of the year. Between April and June the pelicans prey intensively on Mugil cephalus shoals migrating through the estuary towards the sea; between June and October they feed on freshwater fishes from the drying Phongolo pans; and from October onwards they revert to preying on fishes in Lake St Lucia (Whitfield \& Blaber 1979c).
Sudden fish kills due to exceptionally low salinity conditions (Blaber \& Whitfield 1976) also result in temporary changes in the energy flow pattern at $\mathrm{St}$ Lucia. During June 1976 a wide variety of piscivorous birds were recorded feeding on dead or dying fish at the lake, some of which were not part of the individual bird species' normal diet. An extensive fish kill during a cold snap in June 1987, and subsequent shortage of food, was given as the reason for the failure of the Caspian tern breeding attempt that year (Cyrus \& McLean 1994).

During high salinity conditions, the decline in fish stocks has a major impact on both the numbers and breeding success of piscivorous birds. Hypersaline conditions in 1968 and associated low fish populations (van der Elst et al. 1976) resulted in depleted bird populations and an absence of breeding activity by most piscivorous bird species (Forrest 1969). Of the approximately 1000 white pelican chicks hatched in 1968 , only four reached maturity.

A wide variety of zocbenthic feeding fishes also occur in Lake St Lucia, with some of the more common species shown in Figure 27. Although there is considerable overlap in the diets of benthic foraging fishes, there is also a degree of resource partitioning. During 1981 and 1982 approximately $80 \%$ of the diet of Solea bleekeri comprised siphon tips of the bivalve Solen cylindraceus, with limited amounts of the amphipod Grandidierella lignorum and tanaid Apseudes digitalis also being consumed (Cyrus 1988b). In contrast the haemulid Pomadasys commersonnii preyed intensively on $A$. digitalis with few $G$. lignorum in its diet. The sparid Rhabdosargus sarba was almost the complete opposite of $P$. commersonnii, showing a definite selection for $G$. lignorum and with a minimal contribution by $A$. digitalis (Blaber 1984). Another invertebrate species which features in the diet of many zoobenthic predators from Lake St Lucia is the crab Hymenosoma orbiculare. Approximately $50 \%$ of the diet of Johnius dorsalis and $19 \%$ of items consumed by Terapon jarbua comprised $H$. orbiculare (Whitfield \& Blaber 1978a). However, the dominant food in the case of $T$. jarbua was fish scales removed from living fishes (Whitfield \& Blaber 1978e).

Epibenthic invertebrates such as penaeid prawns are an important component of the diet of several fish predators in Lake St Lucia. Certain piscivorous species such as Argyrosomus japonicus and Elops machnata feed extensively on these prawns during the summer months when this prey component is particularly abundant (Joubert \& Davies 1966). However, the highly significant correlation $(r=0.68, P<0.001)$ between the composition of prey fish species in the lake and prey fish species in the diet of the piscivores (Whitfield \& Blaber 1978a) suggests that these predators are primarily fish consumers, with prawns acting as a supplementary food source. 

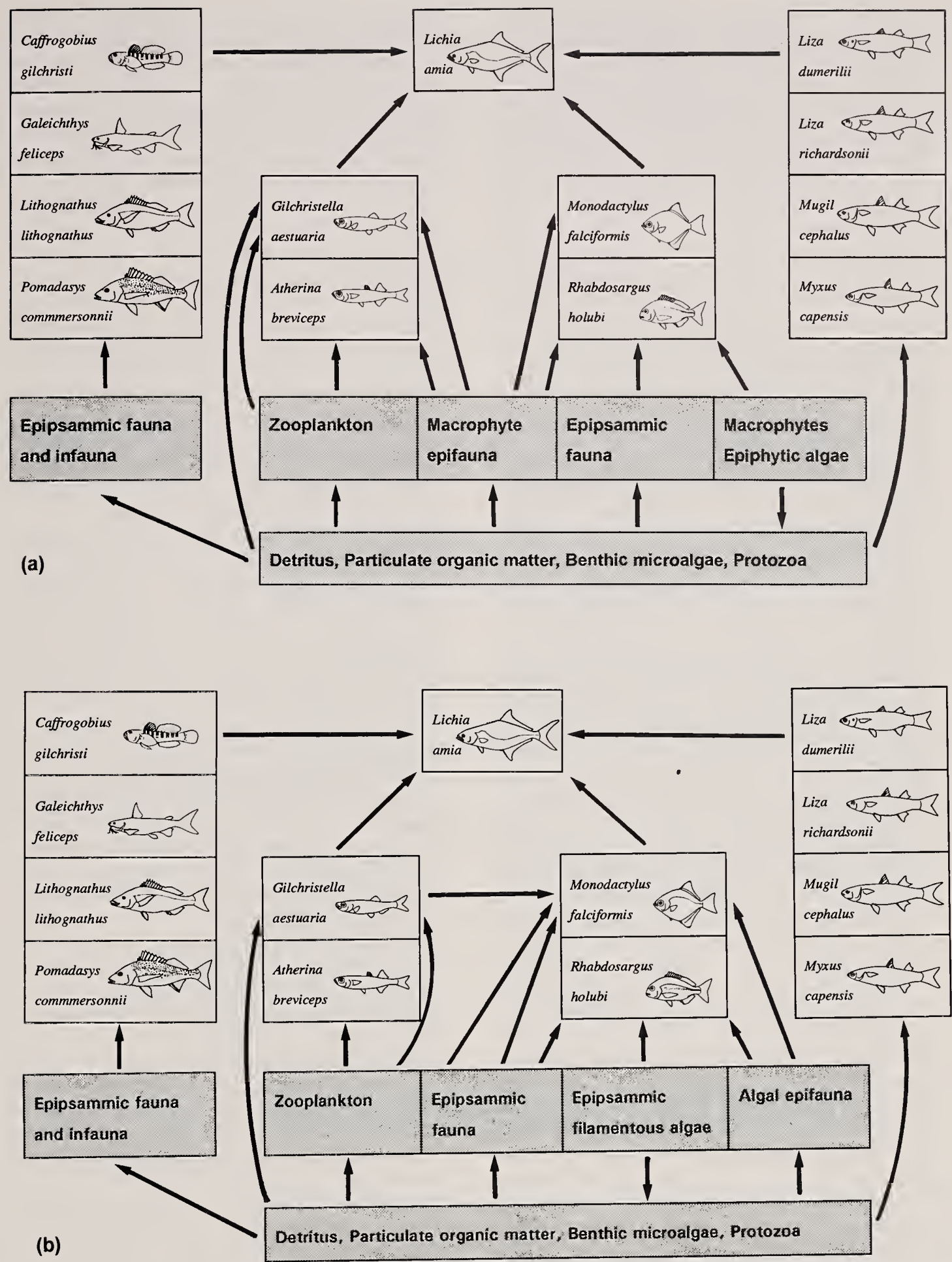

Figure 28. Simplified food web in Swartvlei during (a) the macrophyte phase, and (b) the macrophyte senescent phase (modified from Whitfield 1982). 
Turbidity can affect food availability to individual fish species, with both factors sometimes interacting to influence fish distribution within Lake St Lucia. Although the juveniles of some marine fish species have been shown to have a distribution which corresponds with both turbidity preferences and food availability, others were distributed according to turbidity and not their preferred foods (Cyrus \& Blaber 1987a).

Episodic flood events cause widespread scouring and deposition of new sediments. In the St Lucia system these disturbances have short-term negative consequences for small benthic fish taxa such as Croilia mossambica (Martin et al. 1992). These authors also suggested that the elevated turbidity gradients in the sea off the St Lucia Estuary mouth may have resulted in the increased recruitment densities recorded for most marine migrant species in the months following a cyclone flood event. In addition, this cyclone provided increased amounts of nutrients for phytoplankton development, which in turn had beneficial effects on the stocks of both zooplankton and filter feeding fishes such as Gilchristella aestuaria (Martin et al. 1992).

Studies on the ichthyofauna of Swartvlei indicate a similar trophic composition to that recorded at Lake St Lucia (Figure 28). Prior to 1979 Swartvlei was characterized by extensive submerged Potamogeton pectinatus and charophyte beds (Howard-Williams \& Liptrot 1980). These plants, together with associated epiphytic algae and periphyton, accounted for $74 \%$ of the total primary production in the lake (HowardWilliams \& Allanson 1981). In the spring of 1979 this community underwent a senescence that was to last more than a decade, and resulted in a $60 \%$ decline in primary production (Taylor 1983), a $74 \%$ slump in littoral invertebrate biomass (Davies 1982) and a 54\% decline in the abundance of macrophyte associated fish species (Whitfield 1984). These changes did not lead to the disappearance of fish species but did result in alterations to the energy flow pathways (Figure 28) and a restructuring of the Swartvlei fish community (Whitfield 1986a). In particular there was an increase in the abundance and biomass of all the mugilid species and a decline in the dominant vegetation associated taxa such as Monodactylus falciformis and Rhabdosargus holubi. Invertebrate consumption by the latter two fish species declined from $33 \mathrm{mg} \mathrm{m}^{-2} \mathrm{~d}^{-1}$ during the Potamogeton canopy phase to $8 \mathrm{mg} \mathrm{m}^{-2} \mathrm{~d}^{-1}$ during the senescent phase (Whitfield 1984).

A detailed study on food consumption by six resident estuarine species in Botriviervlei revealed that this group of fishes had an annual invertebrate intake of approximately $6 \mathrm{~g} \mathrm{~m}^{-2}$ or an average of $16 \mathrm{mg} \mathrm{m}^{-2} \mathrm{~d}^{-1}$ (Bennett \& Branch 1990). These species consumed $17 \%$ of invertebrate secondary production during the closed mouth phase, indicating that under these conditions food was not in short supply. However, when the estuary mouth opened and extensive areas of the littoral zone were exposed, a major decline in invertebrate biomass occurred (de Decker 1987) and these fish then consumed almost $90 \%$ of secondary production. If one considers that some of the migrant fish species in the Bot Estuary also prey extensively on aquatic invertebrates, it is likely that competition for food will be intense during the open mouth phase.

Estuarine bays are also large systems but differ from estuarine lakes in that the connection with the marine environment is very well developed. Ichthyological studies in bays have, until recently, been confined to surveys and some preliminary information on the diet of selected fish species. Although Durban Bay is essentially a marine dominated tidal system, it supports a biota similar to that of other KwaZulu-Natal estuaries. Day \& Morgans (1956) recorded 181 fish species from the system but many of those taxa were only represented by a few marine stragglers. Wallace (1975a) also noted that the stenohaline marine component in Durban Bay was well represented when compared to other estuaries in the region, but the system as a whole was dominated by euryhaline marine and estuarine species.

In a recent study by Beckley et al. (1995), 53 fish species were recorded from a graving dock in the upper reaches of Durban Bay. Although typical estuary-associated fish species dominated catches in the graving dock, marine stragglers were also recorded. A similar situation pertains to the warm-temperate Knysna system where estuary-associated marine species predominated but typical marine taxa were also recorded (Whitfield \& Kok 1992). During the summer months, species such as Diplodus cervinus, Lithognathus mormyrus, Pomadasys olivaceum and Spondyliosoma emarginatum were relatively common in the lower reaches of this estuary. The presence of marine stragglers in the Knysna, Durban and Richards Bay systems ensures that a greater variety of fish species occupy estuarine bays than any other type of estuary in a particular region. This view is reinforced by Whitfield et al. (1989) who found that the fish species richness index $(R)$ within estuarine bay eelgrass beds was always higher than index values from the same habitat in other estuaries.

The stable salinity conditions that prevail for much of the year in estuarine bays results in several marine fish species, which usually breed at sea, spawning within these environments. Although the eggs of these fish are probably carried into the marine environment by the strong ebb tidal currents, the larvae are likely to be retained in coastal waters in the vicinity of the bays and therefore recruit into these systems at the postlarval stage of development.

Both subtropical and warm-temperate estuarine bays are dominated by $0+$ juvenile marine fishes which utilize these systems as nursery areas (Whitfield \& Kok 
1992). The sheltered waters and rich food resources within these embayments (Day et al. 1952) are not the only attraction. Richards Bay and Durban Bay also provide the only large estuarine intertidal mud and sand flats along the KwaZulu-Natal coast (Cyrus \& Forbes 1996) and Knysna has extensive intertidal areas in the lower reaches (Day et al. 1952). Whereas salt marshes and eelgrass beds are important nursery areas for fishes in the Knysna littoral, mangroves provide the equivalent habitat in the Durban and Richards Bay systems. Indeed, Cyrus \& Forbes (1996) have suggested that the estuarine nursery function is directly coupled with the mangrove component of the latter bays. Unfortunately, extensive mangrove areas in both Durban and Richards Bay, and salt marshes at Knysna, have already been destroyed or are under threat.

\subsection{ESTUARINE TYPE AND ICHTHYOFAUNAL STRUCTURE}

Southern African microtidal estuaries differ considerably from the macrotidal systems that are prevalent in other parts of the world (e.g. Europe and North America). Although these microtidal estuaries are similar to those found in certain parts of Australia, the wave climate along the east and west coasts of the two continents is very different. Thus, the southern African coastline is subject to heavy wave action when compared to extensive areas in Western Australia or Queensland which are protected by offshore reefs. As a consequence, the only sheltered areas available to fishes along the southern African littoral are estuaries, whereas relatively calm areas are often readily available in the marine environment in other parts of the world. It is therefore not surprising to find that the juveniles of most marine fish species found in temperate Western Australian estuaries are also abundant in the sea, whereas in temperate southern African waters there are a number of species whose juveniles are generally confined to estuaries (Potter et al. 1990).

Based upon the information reviewed in this chapter it becomes apparent that biogeography and estuary mouth condition are the two major factors influencing southern African ichthyofaunal structure. Even in those tidal inlets that are permanently open (e.g. estuarine bays and river mouths) there are considerable differences in mouth depth, width, substratum, tidal prism etc., all of which can influence fish movements into and out of an estuary. At the other end of the spectrum are temporarily closed estuaries where fish migrations may be severely constrained for extended periods, thus having a considerable influence on ichthyofaunal structure. Indeed, Schlacher \& Wooldridge (1996b) have shown that calculated indices of southern African fish biodiversity are markedly higher in estuaries having a permanent connection to the sea than those which have a temporarily closed phase. This trend of declining biodiversity with increasing isolation from the marine environment is reflected in the low number of fish species present in coastal lakes (e.g. Sibaya and Groenvlei) that have lost their estuarine links with the sea.
As has been mentioned the geographical position of an estuary on the coastline has a major influence on ichthyofaunal composition. Although factors such as salinity have been shown to influence the fish in a particular system, the availability of juvenile recruits from the sea is primarily dependant on the distributional range of that species in the marine environment. For example, a permanently open estuary on the subtropical east coast will have a considerably greater ichthyofaunal diversity than a similar estuary on the cool-temperate west coast.

Within a particular biogeographic region, the type of estuary will have a major influence on the detailed ichthyofaunal structure that develops. A conceptual diagram of how estuary type can influence the fish assemblage in a particular system is given in Figure 29. What this illustration shows is a gradual decline in biodiversity from left to right along the figure axis as the number of marine migrants decreases. The proportions of the different fish groups within the overall community also changes between the different types of systems, with an increasing preponderance of marine species being recorded when moving from a freshwater dominated towards a seawater dominated system. The paucity of freshwater fish taxa used in Figure 29 is indicative of the exceptionally low species diversity of this component. Even in river mouths, where freshwater conditions often extend almost to the sea, only a few riverine species are usually recorded.

Despite the influence of biogeography and estuary type on the composition of fishes in an estuary, the basic trophic structure within these systems is usually very similar. Although the numbers of species in a particular type of estuary decline between the subtropical and cool-temperate region, the proportional representation between the trophic groups appears to be maintained. For example, there is an approximate $50 \%$ decline in the number of piscivorous fish species between the subtropical estuarine lakes of northern KwaZulu-Natal and the warm-temperate lakes of the Western Cape, and this is matched by similar declines in detritivorous, zooplanktivorous and zoobenthivorous fish taxa. 


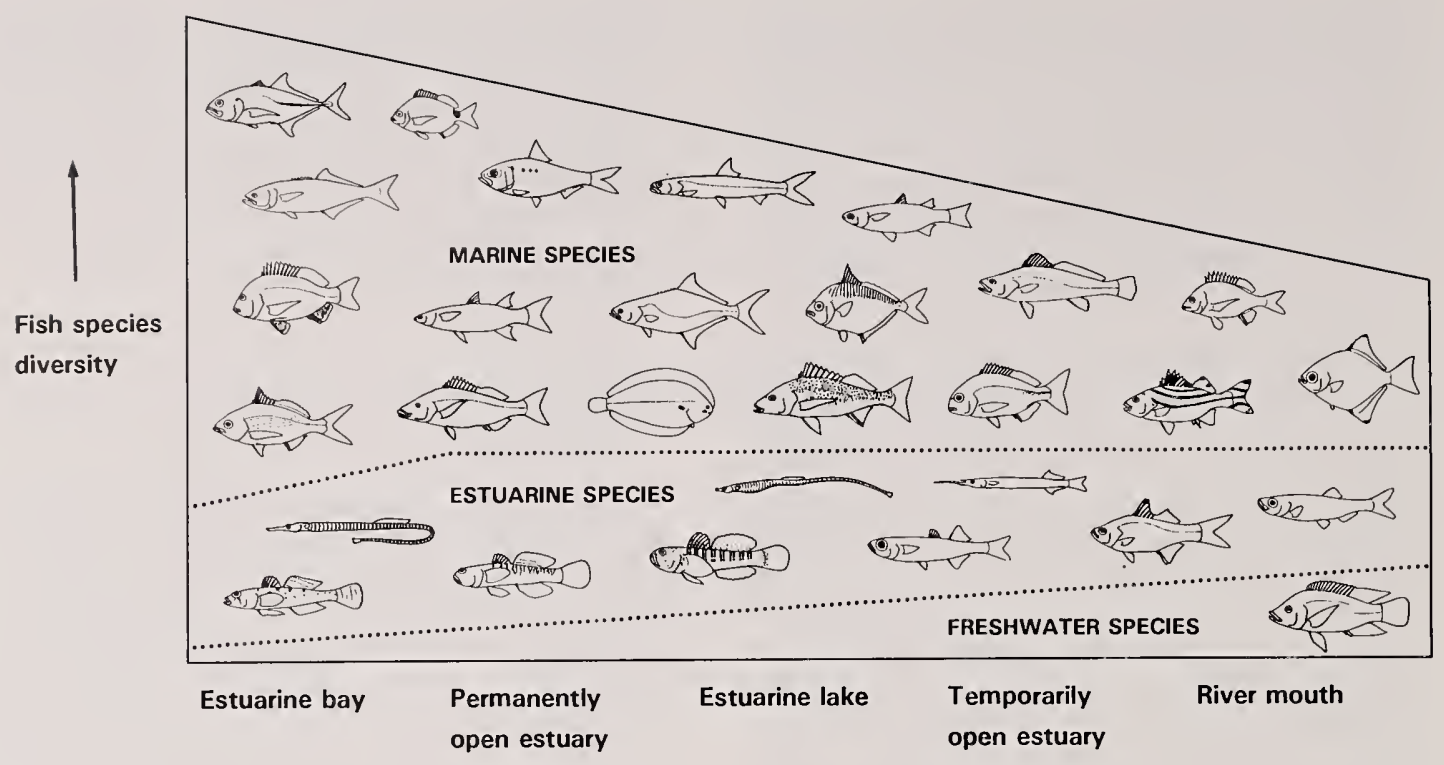

Figure 29. Diagrammatic representation of trends in fish group composition between one estuarine type and another.

Phytoplankton production in all types of estuaries is usually much lower than that of macrophytes and benthic microalgae, with detritivory greatly exceeding herbivory (Baird \& Ulanowicz 1993). Most detritivory occurs in association with the benthos, with macroinvertebrates being particularly active in the process. Estuaries, in contrast to certain other types of coastal ecosystems (e.g. upwelling regions), show a strong coupling between the benthic and pelagic components. This coupling is, to a large extent, facilitated by the ichthyofauna which converts benthic carbon sources into a highly mobile fish resource. Organic carbon transfer occurs both vertically and laterally depending on fish movements. Lateral carbon transfer by fish out of an estuary has been documented in all types of systems but is likely to be more frequent in highly fluctuating environments such as river mouths.

The high productivity of estuaries has often been identified as a primary reason why fish are attracted to these areas in such large numbers. Food, especially detritus and benthic invertebrates, is abundant in most sytems. However, the availability of a particular food type is likely to show marked fluctuations over time and space, especially in response to environmental changes which characterize all types of systems on the subcontinent, e.g. the temporary loss of aquatic macrophytes in the Swartkops and Swartvlei estuaries, or the collapse of zooplankton stocks associated with a lack of riverine pulses in the Kromme and Kariega estuaries.
As a consequence of the above fluctuating energy pathways, most estuary-associated fishes are not highly specialized feeders and show considerable flexibility in their diet. An example of this flexibility was documented in the Swartvlei estuarine system (Whitfield 1984) where the senescence of submerged Potamogeton beds resulted in the collapse of invertebrate stocks that were important prey items of the predatory fish Monodactylus falciformis. With the loss of its principal food source, $M$. falciformis became piscivorous and preyed extensively on the small shoaling clupeid Gilchristella aestuaria (see Figure 28). The dietary flexibility revealed by $M$. falciformis is not unique but a characteristic of most fishes on the subcontinent, thus conferring stability to the estuarine food web.

In conclusion, the fish assemblages of southern African estuaries adjust constantly in response to changing seasons, mouth condition, water turbidities, temperatures, salinities etc. Despite persistent fluctuations in both the biotic and abiotic environment, the basic ichthyofaunal structure appears to have an underlying stability and is, to some extent, predictable in terms of the response of individual species to specific conditions. The inherent fish community stability is governed by factors such as the dominance of eurytopic taxa within estuarine assemblages and the robust nature of food webs within these systems. The predictability arises from factors such as the seasonality associated with estuarine spawning cycles and juvenile fish recruitment patterns. 


\title{
Environmental and anthropogenic impacts
}

\author{
5.1 INTRODUCTION
}

The estuarine environment is attractive not only to fishes but also to people. Although the functioning of the natural biota and the recreational activities of humans are usually compatible to the overall wellbeing of an estuarine ecosystem, there are often anthropogenic impacts which do have major deleterious consequences for the fish community. Since estuaries are already highly stressed ecosystems, the additional

\begin{abstract}
pressures resulting from poor catchment and estuarine management all contribute to a degraded environment which is unable to fulfill its natural functions (Table 9, Day \& Grindley 1981). In a southern African context the excessive abstraction of fresh water from river systems has been identified as a major threat to the long-term survival of certain estuarine fish species and is therefore dealt with in some detail below.
\end{abstract}

\subsection{FRESHWATER DEPRIVATION: A MAJOR THREAT?}

Much of southern Africa has a semi-arid climate with a highly seasonal and variable rainfall pattern. The subtropical northern-eastern section of the subcontinent receives most rain in summer whereas the more temperate south-western region has a Mediterranean climate. The average precipitation in South Africa is only $497 \mathrm{~mm}$ compared with a world average of $860 \mathrm{~mm}$ (Department of Water Affairs 1986). In addition, years of above-average rainfall frequently alternate with dry cycles, the latter often punctuated by heavy rains of varying magnitude and extent. These natural extremes provide the perturbations which contribute to the range and temporal variability of estuarine systems, especially with respect to physico-chemical states which in turn affect biotic processes (Forbes \& Cyrus 1993).

Growing demand for fresh water in southern Africa has led to widespread impoundment and extraction of surface and underground water resources, usually without adequate consideration of the impacts on aquatic ecosystems (Jezewski \& Roberts 1986). In addition, invasive alien trees are having a considerable negative influence on the water yields from catchment areas (Dye \& Poulter 1995). When river flow patterns are altered and the intensity and frequency of flood events are modified, these disturbances change natural fluctuations within the riverine and estuarine ecosystems. Smaller floods are commonly removed from the river discharge spectrum altogether and large flood events may be attenuated according to the available dam storage capacity at the time of the flood (Davies \& Day 1986, Adams \& Talbot 1992). Imposition of these anthropogenic disturbances often results in estuarine processes deviating from natural successionary patterns, the implications of which need to be understood before effective management strategies can be devised to maintain or restore the diversity of estuarine ecosystems along the coast.

\section{Freshwater supplies}

The combined average annual runoff of South Africa's rivers is estimated to be $53500 \times 10^{6} \mathrm{~m}^{3}$. In some areas the highly variable river flow can have periods of up to 10 consecutive years of less than average flow. Because of this variability and the high evaporation losses from storage, it is estimated that only about $62 \%$ of the mean annual runoff (MAR) can be exploited economically.

The largest users of fresh water in South Africa are farmers, who account for approximately half of all the water used. The demand for water is increasing due to growing human populations, together with a rapid urbanisation process and increased access to urban water reticulation schemes. Based on projected demand, it has been estimated that all surface water resources will be fully utilized by the year 2020 (Davies \& Day 1986). 


\section{Freshwater requirements of estuaries}

Fresh water is an essential component of estuaries (Schroeder 1978). Although the natural environment in South Africa has been recognised as a legitimate user of fresh water, less than $3000 \times 10^{6} \mathrm{~m}^{3}$ of water per annum was allocated to this category in 1986 . The Department of Water Affairs also suggested that all estuaries were not equally important and that certain systems may be found to "have little ecological value and enjoy low priority when water is scarce, whilst others would be regarded as being so important that they would be allocated water in almost any circumstances". More recently there has been a change in attitude by the Department of Water Affairs \& Forestry, with the Water Law Principles of 1996 stating that "the quantity, quality and reliability of water required to maintain the ecological functions on which humans depend should be reserved so that the human use does not individually or cumulatively compromise the long term sustainability of aquatic and associated ecosystems".

Jezewski \& Roberts (1986) estimated the total South African estuarine freshwater requirement as $2160 \times 10^{6}$ $\mathrm{m}^{3}$ per annum. The percentage of virgin MAR that was allocated to each estuary was based on two basic requirements: (a) Evaporative requirement - the volume of fresh water necessary to counter the loss due to evaporation and thus prevent the occurrence of undesirable hypersaline conditions in the estuary; (b) Flooding requirement - the volume of water necessary to open temporarily closed estuaries, flush out accumulated sediment and flood the wetlands on the fringes of the estuary. Although the freshwater requirements calculated by Jezewski \& Roberts (1986) were not intended to represent allocations of water resources for estuaries, their estimates were an important aid to water resource planning at that time.

Table 9. Some likely consequences of anthropogenic disturbances on the southern African estuarine environment.

\begin{tabular}{|c|c|c|c|}
\hline \multirow[t]{2}{*}{ FEATURE } & \multirow{2}{*}{$\begin{array}{l}\text { EXPECTED } \\
\text { ENVIRONMENTAL } \\
\text { EFFECT }\end{array}$} & \multicolumn{2}{|c|}{ PROBABLE IMPACTS ON ESTUUARINE BIOTA } \\
\hline & & ADVERSE & BENEFICIAL \\
\hline $\begin{array}{l}\text { Excessive soil } \\
\text { erosion in } \\
\text { catchment }\end{array}$ & $\begin{array}{l}\text { Sediment reduces estuarine } \\
\text { water volume; increased } \\
\text { turbidity }\end{array}$ & $\begin{array}{l}\text { Smothering of benthic flora and } \\
\text { fauna; decrease in aquatic } \\
\text { habitat for biota }\end{array}$ & $\begin{array}{l}\text { Expansion of reed beds and } \\
\text { mangroves into previously open- } \\
\text { water areas of the estuary }\end{array}$ \\
\hline Dredging of estuary & $\begin{array}{l}\text { Increased tidal exchange; } \\
\text { substratum disruption; } \\
\text { increased turbidity }\end{array}$ & $\begin{array}{l}\text { Decreased primary and } \\
\text { secondary production; loss of } \\
\text { certain zoobenthic species }\end{array}$ & $\begin{array}{l}\text { Deepened areas offer refuge to } \\
\text { certain large fishes }\end{array}$ \\
\hline $\begin{array}{l}\text { Destruction of } \\
\text { marginal vegetation }\end{array}$ & $\begin{array}{l}\text { Bank erosion and } \\
\text { shallowing of estuary profile }\end{array}$ & $\begin{array}{l}\text { As above; reduction in nursery } \\
\text { habitats }\end{array}$ & None \\
\hline $\begin{array}{l}\text { Disruption of } \\
\text { wetland functions }\end{array}$ & $\begin{array}{l}\text { Reduced dry season flow; } \\
\text { increased sedimentation }\end{array}$ & $\begin{array}{l}\text { As above; loss of certain } \\
\text { upstream detrital sources }\end{array}$ & None \\
\hline Estuary canalization & $\begin{array}{l}\text { Reduction in range and } \\
\text { amount of estuarine habitat }\end{array}$ & $\begin{array}{l}\text { Major decline in productivity and } \\
\text { biodiversity }\end{array}$ & None \\
\hline Dam construction & $\begin{array}{l}\text { Modification of river flow } \\
\text { giving rise to mouth closure }\end{array}$ & $\begin{array}{l}\text { Impeded migration of both } \\
\text { fishes and invertebrates }\end{array}$ & None \\
\hline $\begin{array}{l}\text { Bridges and } \\
\text { associated } \\
\text { embankments }\end{array}$ & $\begin{array}{l}\text { Fixing of channel position } \\
\text { and modification of flood } \\
\text { scouring processes }\end{array}$ & $\begin{array}{l}\text { Reduction in tidal exchange, } \\
\text { altered nutrient balance and } \\
\text { primary production }\end{array}$ & None \\
\hline Weir construction & $\begin{array}{l}\text { Altered water levels, salinity } \\
\text { regime and circulation }\end{array}$ & $\begin{array}{l}\text { Barriers to fish and invertebrate } \\
\text { movements }\end{array}$ & None \\
\hline Mouth manipulation & $\begin{array}{l}\text { As above; reduced scouring } \\
\text { of sediments arising from } \\
\text { premature mouth breaching }\end{array}$ & $\begin{array}{l}\text { Premature mouth closure } \\
\text { reduces potential marine fish } \\
\text { and invertebrate recruitment }\end{array}$ & None \\
\hline Nutrient pollution & Eutrophication & $\begin{array}{l}\text { Low dissolved oxygen levels } \\
\text { when algal blooms senesce }\end{array}$ & $\begin{array}{l}\text { Certain organisms may benefit } \\
\text { from phytoplankton blooms }\end{array}$ \\
\hline Industrial pollution & $\begin{array}{l}\text { Deterioration in water } \\
\text { quality; presence of toxic } \\
\text { compounds }\end{array}$ & $\begin{array}{l}\text { Modification of species } \\
\text { composition and abundance; } \\
\text { mass mortalities }\end{array}$ & None \\
\hline
\end{tabular}


Jezewski \& Roberts (1986) did not, however, address the biotic/abiotic interactions within southern African estuarine systems and how these are influenced by a reduction in riverine input into estuaries. Whitfield \& Bruton (1989), using a variety of sources, synthesized some of the principal effects of freshwater deprivation on the physical and biotic components of small and large estuaries in the Eastern Cape Province. These authors emphasized that one of the main effects of impoundments is to reduce the incidence and amplitude of minor floods in rivers and estuaries. Floods are a critical determinant of the physical structure (van Heerden 1986), functioning (Cooper 1989) and evolution (Reddering \& Rust 1990) of estuaries, and a change in the pattern and magnitude of floods can lead to an alteration in sedimentary processes, depth profiles, mouth configuration, duration of the open phase and tidal prism within an estuary. Since both river floods and the physical variables described above have a direct and indirect effect on the estuarine biota (e.g. McLachlan \& Grindley 1974, Marais 1982, Talbot et al. 1990, Whitfield \& Paterson 1995), future research in this field should be directed at elucidating these complex short and longer term interactions. In addition, the relative importance of minor and major floods to scouring processes within estuaries, and the degree to which existing impoundments reduce their impact, is also in need of further research and quantification.

Rivers and estuaries are increasingly being regarded as renewable natural resources, which can only be exploited within sustainable limits. This change in attitude has resulted in further attempts to develop methods of assessing instream flow needs (Davies et al. 1993, Slinger \& Breen 1995). The Department of Water Affairs and Forestry now requires that for any river affected by a water resource development scheme, an assessment should be made of the amount of fresh water that should flow downstream to maintain the river and estuary in some predetermined condition. This required amount of water for the environment is determined by scientists and engineers in co-operation with interested and affected parties, and is called the Instream Flow Requirement (IFR) in the case of a river and Estuarine Freshwater Requirement (EFR) in the case of an estuary.

\section{Effects of impoundments on estuaries}

The effects of freshwater deprivation will vary according to estuary type and locality. Estuaries in regions of low rainfall and high evaporation rates are more likely to be adversely affected by excessive freshwater abstraction than similar systems in higher rainfall areas. This is reflected in the virtual absence of hypersaline conditions in KwaZulu-Natal estuaries when compared with the frequent occurrence of such conditions in some of the drier Eastern and Western Cape estuaries (Day 1981c).
Estuaries on the subcontinent seem to have innumerable small-scale spatial and temporal successions that are superimposed on the weak overall ecological succession, and thus constantly move back and forth along a continuum of successionary states (Whitfield \& Bruton 1989). These trends can also be reversed or changed by episodic events, e.g. the September 1987 floods in KwaZulu-Natal (Perry 1989). In addition, the frequency and intensity of episodic events within a single estuary vary, thus producing a range of possible successionary trajectories. The effects of certain human perturbations (e.g. impoundments) are to hasten the succession along trajectories which often result in the temporary or permanent disruption of certain estuarine functions. For example, most of the estuarine fishes and invertebrates were lost from the Seekoei Estuary in the Eastern Cape as a result of the hypersaline conditions of $1988 / 89$. In instances where freshwater pulses are prevented from reaching estuaries, the natural sequence of estuarine biota responses is altered, and small scale successions (e.g. zooplankton community changes) become less frequent (Wooldridge \& Melville-Smith 1979).

Long-term freshwater deprivation can lead to a complete restructuring of energy flow within the affected estuary. In general, a high proportion of primary production in those southern African estuaries which receive adequate riverine input is contributed by phytoplankton. Conversely, when riverine discharge into an estuary has been drastically curtailed, food webs usually centre around benthic primary production (Allanson \& Read 1995). How differing riverine inputs may be reflected in estuarine system properties can be illustrated by a comparison of the Swartkops and Kromme estuaries (Table 10). Both have similar physical dimensions, lie in the same climatic region, but differ in the amount of riverine input by an order of magnitude, a reduction solely due to impoundments in the catchment (Schlacher \& Wooldridge 1996b). The resulting shifts in ecosystem properties (Table 10) suggest that river flow is vital to both pelagic productivity and the maintenance of a range of food chains within estuaries.

The continued functioning of most, if not all, estuarine processes clearly relies on the natural dynamism and the range of oscillations imposed on these systems by riverine and marine influences (Benson 1981). The increasing abstraction of fresh water from both large and small river catchments has had the effect of forcing some southern African estuaries into extreme states (Whitfield \& Bruton 1989). This has had deleterious consequences for certain processes within these systems and retarded a return towards the conditions prevailing in the preimpoundment estuary.

With the above serving as background information, what are the likely impacts of freshwater deprivation on each of the five estuarine types described in Chapter 1? Some of the potential impacts on these estuaries are discussed below. 
Table 10. Comparison of some ecosystem properties between the Swartkops Estuary which receives moderate freshwater inflow and the Kromme Estuary where major dams in the catchment have severely reduced riverine inflow (data from Baird \& Ulanowicz 1993).

\begin{tabular}{|c|c|c|c|c|c|}
\hline Estuary & Swartkops & Kromme & & Swartkops & Kromme \\
\hline Area $\left(\mathrm{km}^{2}\right)$ & 4 & 3 & Net primary production & & \\
\hline Temperature range $\left({ }^{\circ} \mathrm{C}\right)$ & $13-26$ & $13-28$ & Pelagic (mg C m ${ }^{-2}$ day $^{-1}$ ) & 319 & 28 \\
\hline Freshwater inflow $\left(\mathrm{m}^{3} \mathrm{~s}^{-1}\right)$ & 0.6 & 0.06 & Benthic ( $\mathrm{mg} \mathrm{C} \mathrm{m}^{-2} \mathrm{day}^{-1}$ ) & 1504 & 2284 \\
\hline Salinity range $(\%)$ & $10-35$ & $33-35$ & Pelagic: Benthic & $1: 5$ & $1: 81$ \\
\hline \multicolumn{3}{|l|}{ Primary consumers biomass } & Secondary consumers biomass & & \\
\hline Suspension feeders ( $\mathrm{mg} \mathrm{C} \mathrm{m}^{-2}$ ) & 45721 & 21814 & Suspension feeders ( $\left.\mathrm{mg} \mathrm{C} \mathrm{m}^{-2}\right)$ & 5900 & 3 \\
\hline Deposit feeders ( $\mathrm{mg} \mathrm{C} \mathrm{m}^{-2}$ ) & 8050 & 21556 & Deposit feeders ( $\mathrm{mg} \mathrm{C} \mathrm{m}^{-2}$ ) & 15500 & 6579 \\
\hline Suspension: Deposit & $1: 0.28$ & $1: 0.99$ & Pelagic: Benthic & $1: 3$ & $1: 2193$ \\
\hline
\end{tabular}

\section{Permanently open estuaries}

A total of only 37 South African estuaries maintain permanent tidal inlets with the sea (Reddering \& Rust 1990) and it is these systems that are most threatened by reduced freshwater inputs. The extent to which river water is impounded varies, but in some catchments the combined capacity of existing impoundments already exceeds the mean annual runoff of the river system. The Lake Mentz impoundment, for example, is capable of holding seven times the MAR of the Sundays River catchment. In the Kromme system the MAR is $105 \times 10^{6} \mathrm{~m}^{3}$, with the combined capacity of the Churchill and Mpofu dams being $133 \times 10^{6} \mathrm{~m}^{3}$ (Bickerton \& Pierce 1988). Large episodic floods $\left(>80 \times 10^{6} \mathrm{~m}^{3}\right)$ will probably flow over the walls of these impoundments, depending on water volumes held at the time of the flood. However, smaller floods do not appear to reach the Kromme Estuary, with a resultant loss of nutrient input and scouring action within the system (Emmerson \& Erasmus 1987).

The prevailing water column mixing process in permanently open estuaries is tidally and riverine driven (balance depends mainly on catchment run-off regime), and salinities usually fluctuate between $15 \%$ and $35 \%$. However, where major impoundments prevent significant river flow into these systems, tidal mixing processes become dominant and temporarily change the estuary into an 'arm of the sea' (Whitfield \& Bruton 1989). Hypersaline conditions (>40\%o), particularly during summer, have been recorded in the upper reaches of certain permanently open estuaries deprived of freshwater inflow e.g. Kromme, Bushmans and Kariega systems. These conditions are most prevalent during extended droughts due to high evaporation rates and an absence of river inflow. In recent decades the Kariega and Bushmans rivers, for example, have had no fresh water flowing towards these estuaries for periods in excess of a year.

Oligohaline conditions $(<5 \%)$ in the upper reaches of permanently open estuaries can extend into the middle reaches for brief periods during major river floods, and may even cause extensive mortalities of the biota in these regions (McLachlan \& Grindley 1974). However, these extreme low salinity events will probably become less common as more dams are built in the catchments and an increasing proportion of river floods are captured by these impoundments.

Further results of reduced flood events in permanently open estuaries, particularly those along the Eastern Cape coast, could take the form of an increase in the size of sand shoals situated in the lower reaches and a greater degree of mud compaction in the middle and upper reaches (Reddering 1988a). These modifications have two main effects. Firstly, disproportionately large flood-tidal deltas tend to constrict the channel of the lower estuary. This reduces tidal exchange between the sea and the estuary, and consequently the tidal prism, coupled with a reduced freshwater scouring action, cannot maintain an open tidal inlet as before. Secondly, when a river flood does occur, the amount of accumulated sediment in the delta would be larger than normal and would require a flood of greater magnitude to remove the increased amount of sediment. In the case of muddy estuaries, or sections of an estuary where mud is the dominant sediment, these substrata would attain a higher degree of erosion resistance. As an overall result, smaller estuary channel dimensions are established under prolonged conditions of reduced freshwater inflow (Reddering 1988a). 
The biota of permanently open estuaries in the Eastern Cape undergoes several important changes following significant long-term reductions in riverine input (Table 10, Figure 30). Primary food resources in the water column (e.g. phytoplankton) declinc (Allanson \& Read 1995, Grange \& Allanson 1995) while macrophyte production increases due to the spread of marine plants such as Zostera capensis (Adams et al. 1992, Schlacher \& Wooldridge 1996b).
Zooplankton abundance declines in association with reduced sestonic food availability (Grange \& Allanson 1995, Baird \& Heymans 1996) and the estuary is left with a predominantly zoobenthic driven food web. This conclusion is reinforced by the stable carbon isotope information documented by Paterson \& Whitfield (1997) in the freshwater deprived Kariega Estuary, which showed that phytoplankton is relatively unimportant in the bionomics of this system.
NATURAL REGIME

(Pristine river catchment with unimpeded flow into estuary)

\section{ARTIFICIAL REGIME}

(Excessive damming and extraction of fresh water from the catchment)

\section{Freshwater supply}

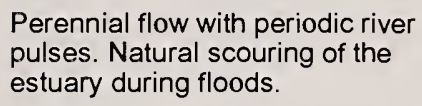

Perennial flow with periodic river pulses. Natural scouring of the estuary during floods.

Intermittent flow with loss of minor river pulses. Reduced scouring efficiency during flood events.

\section{$\checkmark \quad$ Physical state}

Estuary mouth usually open.

Salinity in the upper reaches often less than $15 \%$ with a normal axial salinity gradient present.
Increased frequency and duration of estuary mouth closure. Average salinity frequently greater than $35 \%$ in the upper reaches.

\section{Botanical state}

Primary production mainly in the water column with a rapid turnover of phytoplankton. Emergent and submergent plants present. High species diversity.
Benthic plant production may exceed phytoplankton production. Oligohaline plant species absent and overall reduction in plant diversity.

\section{$\checkmark$ Zoological state}

Peak production of zooplankton. Complex foodweb has strong links with the water column. Freshwater, estuarine and marine species well represented.
Low production of zooplankton Foodweb mainly benthic associated. Oligohaline group generally absent. Major species reduction at salinities above $50 \%$.

\section{Estuarine ecosystem state}

Natural succession between physico-chemical events and estuarine states. High degree of variability and diversity.
Characterized by low variability and loss of certain estuarine functions. System remains in this state for protracted periods.

Figure 30. Flow chart summarizing broad hypotheses arising from different freshwater supply regimes and estuarine response in a typical tidal Eastern Cape estuarine system (modified from Whitfield \& Wooldridge 1994). 
The positive effect of freshwater inflow on phytoplankton biomass usually involves two processes; firstly, the development of vertical stratification creates hydrodynamically more stable conditions which retain phytoplankton inside the estuary and favour the formation of blooms. Secondly, the bulk of inorganic nutrients in estuaries is allochthonous, and increases in river flow result in an increase in nutrient availability to estuarine primary producers (Mallin et al. 1993). The increased phytoplankton productivity is usually reflected in a higher zooplankton biomass which, in turn, is able to support a higher fish biomass when compared to those estuaries where pelagic productivity is low (Figure 31).
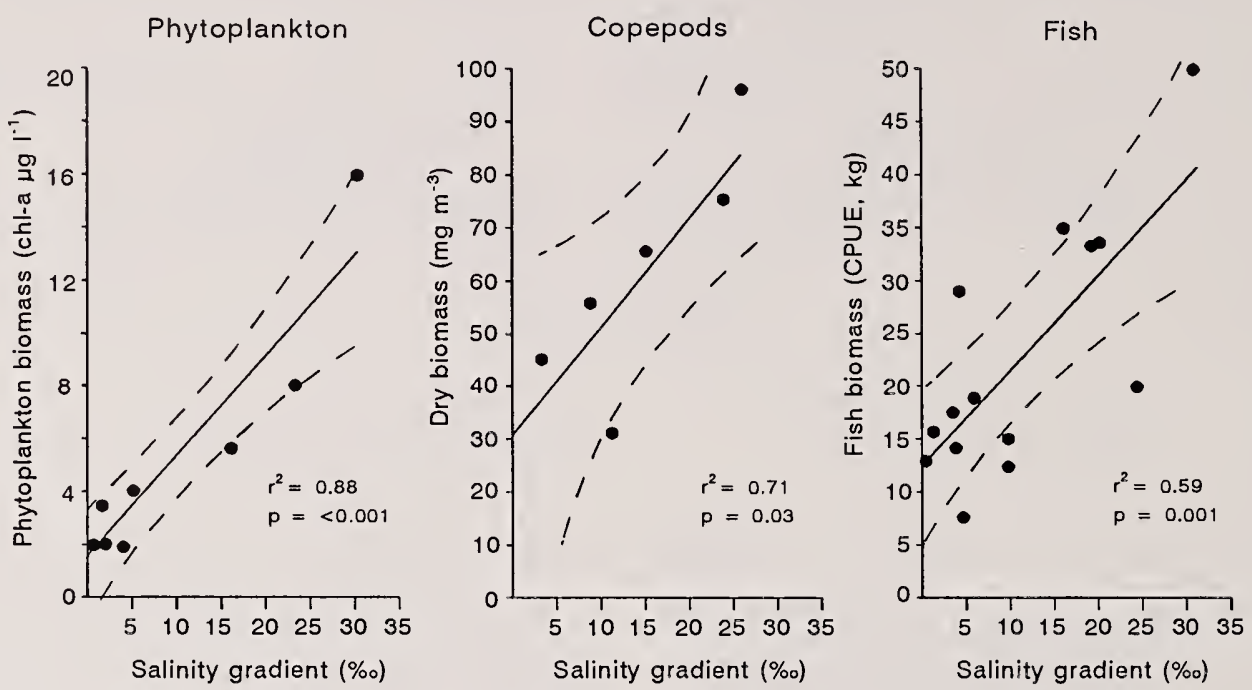

Figure 31. Relationship between biomass of different biota and the magnitude of freshwater inflow over a range of permanently open estuaries along the Eastern Cape coast. The measure of riverine inflow is reflected in the longitudinal salinity gradient which is the difference in mean salinity between the tidal head and mouth of an estuary. Each data point represents mean values for an estuary and the $95 \%$ confidence limits are shown by a dotted band on either side of each regression line (after Schlacher \& Wooldridge 1996b).

\section{Temporarily open/closed estuaries}

Most of these systems have small river catchments $\left(<500 \mathrm{~km}^{2}\right)$ and extended periods when the river flow is minimal or even ceases altogether (Whitfield 1992). The magnitude of river flow into some of these estuaries has declined considerably in recent years as a result of the growing number of farm dams that retain increasing proportions of freshwater flow from the catchments. The effect of farm dams is most noticeable during and after prolonged periods of drought and at the beginning of the rainy season.

Large amounts of sediment, which accumulate during the lagoonal phase (Cooper 1989), are removed from temporarily open estuaries during river flooding (Reddering \& Esterhuysen 1987). Since mouth opening and closing of the above systems is directly linked to the amount of runoff feeding the inflowing rivers, impoundments within the catchment can have a major influence on the duration of the open and closed phases. Reduced river inflow will lead to prolonged mouth closure and a shorter open phase, thus inhibiting invertebrate and fish migrations between the estuary and the sea (Forbes \& Benfield 1986, Kok \& Whitfield 1986, Wooldridge 1991).

In addition to its influencing mouth phase, freshwater deprivation during droughts can also lead to hypersaline conditions $(>60 \%$ ) developing within closed systems, which can in turn result in the loss of major components of the food web. Whitfield (1989e) documented an extensive fish kill in the Seekoei estuarine lagoon (salinity 98\%o), whereas no fish kill was recorded in the adjacent Kabeljous system (salinity $55 \%$ ). The Seekoei catchment, which is similar in size to that of the Kabeljous catchment, has more farm dams than the latter system. The inference here is that abstraction of fresh water in the Seekoei catchment during the 1988/89 drought was sufficient to elevate hypersaline conditions in this estuary, thereby resulting in the loss of a high proportion of the aquatic biota. 


\section{Estuarine lakes}

Most estuarine lakes in southern Africa evolved from drowned river valleys (Hill 1975) that were filled in by sediments to varying degrees and are now separated from the sea by vegetated sand dune systems. In some instances (e.g. Lake Sibaya) the dune barrier has completely isolated the lake, which then loses its estuarine character and is referred to simply as a coastal lake (Whitfield 1992). The transformation of estuarine lakes into coastal lakes could be accelerated if reductions in freshwater supplies to these systems were of sufficient magitude and duration.

Salinities in estuarine lakes are highly variable and depend on a variety of factors, the most important of which is the balance between freshwater input, evaporation, and water exchange across the mouth. Salinity variations in the St Lucia system can range from less than 5\%o to more than 100\% (Day 1981c). Although salinity extremes have always been a natural feature of Lake St Lucia, the magnitude of the salinity peaks in recent decades has increased following the construction of impoundments in the catchment basin (Branch \& Branch 1981). Unless freshwater supply can be assured, the amplitude and temporal scale of the salinity fluctuations within this estuarine system are likely to increase in the future, i.e. hypersaline conditions will be higher and last longer than under natural conditions. The adverse impact of salinities above $50 \%$ on the fauna and flora of Lake St Lucia has been well documented (Boltt 1975, Wallace 1975a, Whitfield 1977) and management strategies aimed at reducing the magnitude of future hypersaline conditions are being investigated.

Freshwater deprivation in Western Cape systems such as Swartvlei and Botriviervlei are unlikely to cause hypersaline conditions, but would result in prolonged mouth closure. These conditions favour estuarine animal species which can complete their life cycle in brackish waters, but would result in a decline in marine dependent invertebrate and fish populations due to natural mortality and a breakdown in recruitment processes (Bennett et al. 1985, Wooldridge 1991). Long term freshwater deprivation would also lead to a reduced nutrient input, with concomitant declines in primary production within nutrient poor Western Cape lakes (Howard-Williams 1977).

\section{Estuarine bays}

Increased freshwater abstraction from inflowing rivers would result in an increase in salinities in the upper reaches of these systems, but little change would be recorded in the lower reaches and middle due to strong tidal exchange patterns. Water temperatures in the lower and middle reaches are strongly influenced by marine conditions and these would extend further up the estuary if river flow ceased.
The fauna and flora of estuarine bays are dominated by marine species (Day \& Morgans 1956) which are unlikely to be adversely affected by a reduction in freshwater input. However, loss of river flow into an estuarine bay would have a negative impact on oligohaline and migratory species (e.g. freshwater prawns Macrobrachium spp. and the freshwater mullet Myxus capensis) which use the riverine portions of these systems (Bok 1979, Reavell \& Cyrus 1989).

\section{River mouths}

Freshwater deprivation in these systems would lead to marine conditions extending higher up the estuary, provided the mouth remained open. If the estuary mouth closed, oligohaline conditions are likely to prevail behind the sand bar during the lagoonal phase, depending on overtopping events during mouth closure.

A task group was set up in 1989 to assess the water requirements of the Orange River Estuary. This task group found that more than $20 \times 10^{6} \mathrm{~m}^{3}$ of fresh water per month would be required to maintain a permanently open estuary mouth and that less than $4 \times 10^{6} \mathrm{~m}^{3}$ per month would result in closure of the mouth (Prins 1990). A similar conclusion was reached for the Tugela Estuary where flows above $25 \times 10^{6} \mathrm{~m}^{3}$ per month would ensure a permanently open mouth condition, with regular closure occurring at flows below $13 \times 10^{6} \mathrm{~m}^{3}$ per month (Huizinga \& van Niekerk 1997).

Freshwater and estuarine biota tend to dominate river mouths (Day 1981c). Marine and estuarine organisms are usually confined to the lower reaches (Brown 1958), extending upstream during periods of reduced freshwater input. In general, river mouths have a relatively depauperate aquatic biota both in terms of biodiversity and biomass. Under high river flow conditions the estuarine zone may even be pushed out to sea, thus limiting the usefulness of this type of estuary to estuarine or marine organisms.

A reduction in river flow into this type of system would probably be beneficial to both estuarine and marine fish species. This would apply particularly if the mouth remained open during low flow conditions and salinities within the estuary increased. In the Tugela system there was an inverse relationship between the CPUE of fishes within the estuary and river flow, i.e. highest fish densities were recorded when river flow was lowest and vice versa (Whitfield \& Harrison, unpublished information)

Closure of river mouth type systems would result in an increased surface area and volume of water present in the estuary. These conditions would be beneficial to those fishes which had already migrated into the system prior to mouth closure. The increased residence time of waters within the estuary would probably also give rise to increased levels of phytoplankton production which would benefit the zooplanktonic component in particular. 


\subsection{FISHES AS ENVIRONMENTAL INDICATORS}

The use of fishes as indicators of environmental health or biological integrity is based on the tenet that fish species or fish communities are sensitive indicators of the relative health of an aquatic ecosystem (Karr 1981). Biological monitoring is preferred to chemical monitoring because the latter misses many of the anthropogenic-induced perturbations of aquatic systems, e.g. habitat degradation. This view is reinforced by Karr \& Dudley (1981) who emphasized that physical and chemical attributes of water are unsuccessful as surrogates for measuring biotic integrity.

According to Hocutt (1981) structurally and functionally diverse fish communities provide evidence of water quality in that they incorporate all the local environmental perturbations into the stability of the communities themselves. He concluded that fish communities present a viable option for assessing manrelated impacts on freshwater ecosystems. More recently Elliott et al. (1988) have shown that the setting of estuarine environmental standards in Britain can be facilitated by the assessment of the health of fish populations, using studies of the ecology, pathology, biochemistry and contaminant bioaccumulation of fish in relation to anthropogenic influences.
What is the current status of our knowledge concerning the use of fish as indicators of estuarine health in southern African aquatic ecosystems and how is this information being used? This chapter reviews the evidence, and examines how scientists and managers can incorporate biological and ecological data into decision support systems on the subcontinent.

\section{Why use fishes as biological indicators?}

Fishes utilize a wide variety of habitats in both the marine and estuarine environments. These habitats, and consequently the fish assemblages associated with them, are potentially affected by a number of anthropogenic influences (Sauriau et al. 1994), some of which are depicted in Figure 32. In addition, some of these potential impacts can have a direct influence on the food resources, distribution, abundance, growth, survival and behaviour of fishes in aquatic environments. Therefore both the direct and indirect coupling between ichthyofaunal communities and human impacts on estuaries suggests that this taxonomic group is an obvious choice for use as a biological indicator.

\section{ECOSYSTEMS LIFE-HISTORIES HABITATS POTENTIAL IMPACTS}

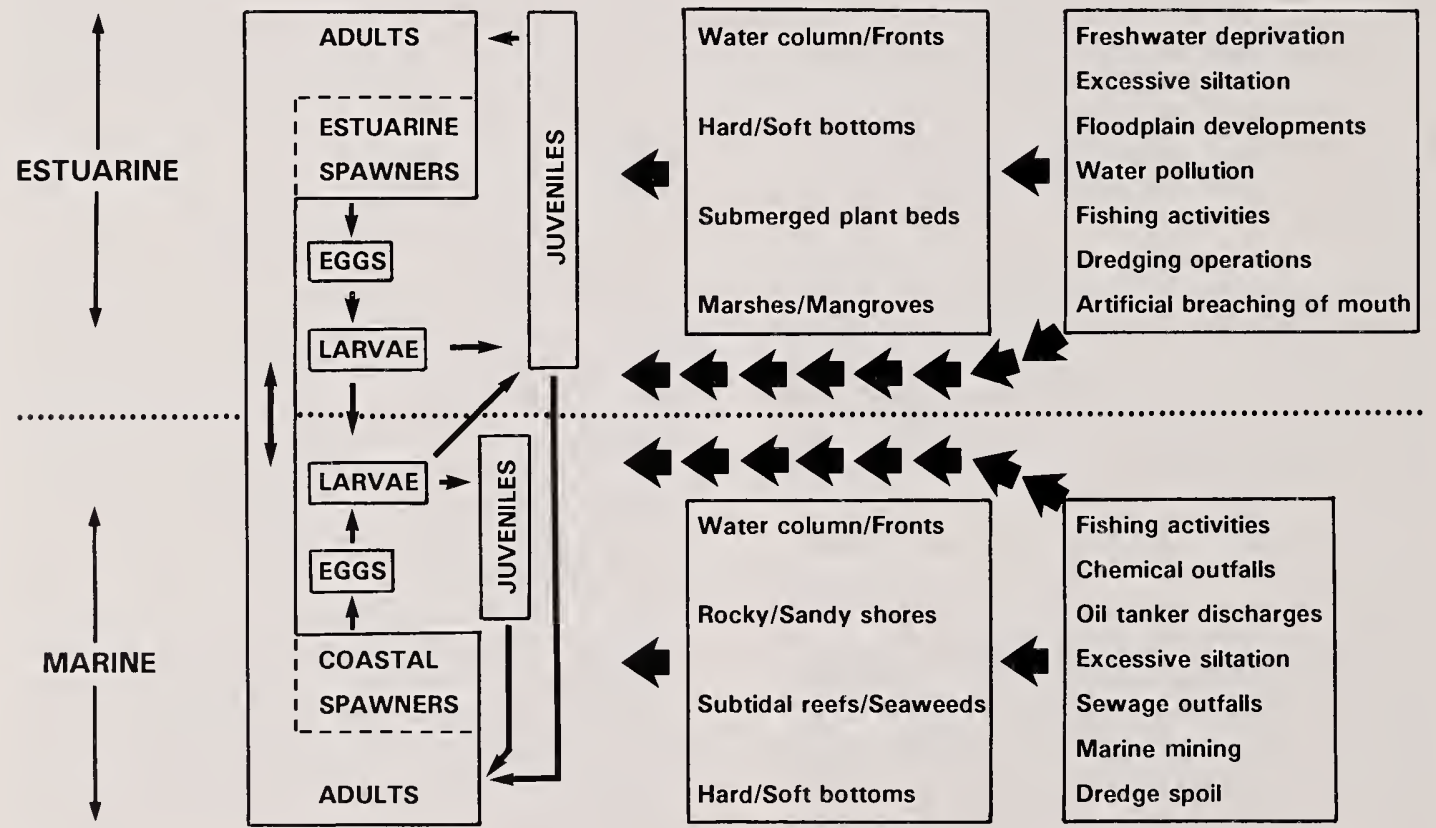

Figure 32. Diagram showing potential environmental modifications to fish habitats and life-history stages, as applied to southern African coastal regions (after Whitfield 1996d). 
Within southern Africa, many groups of organisms have been proposed as indicators of ecosystem health and, although no single group is favoured by all biologists, it appears that fish and macroinvertebrates have received the most attention (Roux et al. 1993, Harrison et al. 1994). Fish have numerous advantages as indicator organisms for biological monitoring programmes, including:

- Fish are typically present in all aquatic systems, with the exception of highly polluted waters.

- There is extensive life-history information available for most species.

- When compared to invertebrates, fish are relatively easy to identify and most samples can be processed in the field, with the fish being returned to the water.

- Fish communities usually include a range of species that represent a variety of trophic levels and include foods of both aquatic and terrestrial origin. They are therefore able to reflect the adverse effects of stresses on a variety of ecosystem components.

- Fish are comparatively long-lived and therefore provide a long-term record of environmental stress.

- Acute toxicity and stress effects can be evaluated in the laboratory using selected species, some of which may be missing from the study system.

- The general public are more likely to relate to information about the condition of the fish community than data on invertebrates.

- Societal costs of environmental degradation are more readily evaluated because of the economic and aesthetic values attached to fishes.

However, the use of fishes as indicators of biological integrity does have difficulties and problems, including the following:

- The selective nature of sampling gear for certain sizes and species of fishes.

- Sometimes substances physically or chemically harmful to other life forms do not have a detrimental effect on fishes.

- The mobility of fishes on seasonal and diel time scales can lead to sampling bias.

- Diverse fish communities may exist in environments significantly altered by humans (Hocutt 1981). Brown (1978) has suggested that the absence of fishes in a particular environment can be of far greater importance than their presence when assessing biological integrity.

- The number of technicians needed for ichthyofaunal field sampling is usually greater than that required for physical or chemical monitoring of the aquatic environment.

Many of the disadvantages described above are outweighed by the widespread advantages. In addition, it should be emphasized that a number of the negative aspects would also apply to other taxonomic groups (e.g. invertebrates) which may be used in biological monitoring of the aquatic environment.

\section{Fish health studies in southern African estuaries}

Fish health studies deal primarily with the causes, processes and effects of disease (Roux et al. 1993). Pathological studies may include procedures such as necropsies, histological examinations, liver enzyme assays and parasitological examinations (Albert \& Washuta 1992). Fish health is also influenced by the accumulation of heavy metals and other toxins (e.g. pesticide residues) from polluted environments. The determination of detoxification mechanisms in fish after field or experimental exposure to contaminants is showing promise as a technique for identifying pollution (Davies et al. 1984).

Several studies have been conducted on the effect of various pollutants on southern African estuarine fishes (e.g. Hemens et al. 1975, de Kock \& Lord 1988) but considerably more field and laboratory work is required. An example of how fishes can be used as indicators of estuarine environmental abuse can be found in the study by Blaber et al. (1984). They determined that juvenile Mugilidae from the Mdloti Estuary had average dieldrin levels of $49 \mathrm{mg} \mathrm{kg}^{-1}$ (maximum value $187 \mathrm{mg} \mathrm{kg}^{-1}$ ) at a time when dieldrin was a banned substance in South Africa (van Dyk et al. 1982). Chlorinated hydrocarbon pesticides such as dieldrin are fat soluble and thus accumulate in fat tissue (Grobler 1994). Mugilidae are ideal fish for monitoring such compounds as they have a relatively high fat content and feed on detritus and microorganisms which are at the base of the estuarine food web.

The use of DDT for agricultural purposes ceased in 1976, but according to Davies \& Randall (1989) approximately 121 tonnes were still being used annually for malaria control in 1985. Fish samples collected from the Kosi estuarine system in 1976 all had DDT in both the muscle and liver, with the mugilid Mugil cephalus having DDT concentrations of $400 \mathrm{mg} \mathrm{kg}^{-1}$ (wet mass) in the muscle and $860 \mathrm{mg} \mathrm{kg}^{-1}$ (wet mass) in the liver (Butler et al. 1983). The regional health authority which was responsible for the anti-malarial spraying operations in the area subsequently instituted stricter control of the procedures used, and samples of the same fish species collected in 1981 revealed DDT values $<0.05 \mathrm{mg} \mathrm{kg}^{-1}$ (wet mass) in every case.

Based on the above evidence it is perhaps surprising that fish health studies have generally not been incorporated as part of routine water quality monitoring programmes in South Africa (Roux et al. 1993). However, the high costs and expertise required to undertake biochemical and bioaccumulation assays are a mitigating factor against their routine use. Nevertheless, it would appear that such studies, when performed as an adjunct to other water quality measurements, can provide a more complete picture of the overall environmental condition (Albert \& Washuta 1992). 
Fish parasite studies in southern African estuaries

The health (condition) of estuary-associated fishes in relation to internal and external parasite loads, as well as the direct effect of pollution events on ectoparasites, is poorly known. However, a number of preliminary studies in southern African estuaries have shown that some fish carry high parasite loads which may affect not only the fitness but also the survival of the host, e.g. $63 \%$ of the needlefish Strongylura leiura examined in Lake St Lucia were found to have intestinal infestations of adult Ptychobothrium belones, some with as many as six cestodes in a single fish (Whitfield \& Heeg 1977). The second intermediate host of this parasite is probably the halfbeak Hyporhamphus capensis which feeds on copepods, among which the first intermediate host is likely to be found.

A similar life cycle is found in the cestode Grillotia perelica, the plerocercoids of which infect at least eight mullet species in southern Africa, with Mugil cephalus achieving a $40 \%$ infestation rate in the Mntafufu Estuary (Schramm 1991). The large size of $G$. perelica plerocercoids makes it likely that small infected mugilids would die before becoming available to the final host. Consequently, the pattern of infestation of the mullet is such that there is increasing prevalence and intensity of infection with increasing fish size.

The final hosts of $G$. perelica have been identified by Schramm (1991) as the bull shark Carcharinus leucas and sandbar shark Carcharinus plumbeus, both of which feed on mugilids. One $C$. leucas caught in the mouth of the Mbashe Estuary contained six $G$. perelica in its intestine. C. leucas, along with the blacktip shark Carcharinus limbatus, is also the final host of the cestode Poecilancistrium caryophyllum which has the dusky kob Argyrosomus japonicus as its second intermediate host (Schramm 1989). Both $C$. leucas and $A$. japonicus are associated with turbid waters in large subtropical estuaries. The leervis Lichia amia, which is also a piscivore, has been found to harbour Callitetrarhynchus gracilis plerocercoids (Schramm 1991) but the final host of this parasite has yet to be identified.

Parasitic nematodes belonging to the genus Contracaecum occur in the mesenteries of a number of fish species in Lake St Lucia. Percentage infestation of estuary-associated marine species ranged from $3 \%$ for Elops machnata to $19 \%$ for Platycephalus indicus (Whitfield \& Heeg 1977). The final hosts of this genus are piscivorous birds, and adult Contracaecum spiculigerum and $C$. microcephalum were identified from the regurgitated stomach contents of the whitebreasted cormorant Phalacrocorax carbo and white pelican Pelecanus onocrotalis respectively. The cichlid Oreochromis mossambicus, which had a Contracaecum infestation rate of $15 \%$, is a likely intermediate host for one or both of the above species because it is common to the diets of all piscivorous birds at Lake St Lucia (Whitfield \& Heeg 1977). Strongylura leiura, which was the only piscivorous fish species in the St Lucia system parasitised by adult cestodes, was also the only piscivore in the lake not to be found infested by parasitic nematodes.

Known ectoparasites on fishes in southern African estuaries include Isopoda, Copepoda, Hirudinea and Branchiura. The site of attachment varies according to the type of parasite and its method of feeding on the host.

Ectoparasitic isopods (e.g. Anilocra capensis) infest fishes such as Pomadasys commersonnii, $P$. olivaceum, Rhabdosargus holubi and $R$. sarba, usually attaching themselves to the side of the head immediately above and behind the eye (Figure 33). Several isopods may parasitize a single fish, each parasite opening up a small wound from which the blood and body juices are drawn.

Rhabdosargus sarba is also vulnerable to the parasitic copepod Lernanthropus sarbae. This copepod seems to parasitize mainly sparids because it has also been found attached to the gills of Rhabdosargus holubi in Lake St Lucia (Olivier \& van Niekerk 1995).

In contrast to the location of isopods and copepods, parasitic leeches in subtropical Lake St Lucia have been found attached to the inside of the mouth of fishes such as Elops machnata, Rhabdosargus sarba and Terapon jarbua, as well as externally on species such as the Acanthopagrus berda, Liza dumerilii and Pomadasys commersonnii. The same fish species in the more temperate regions of the subcontinent do not appear to be parasitized by leeches.

Branchiurans belonging to the genus Argulus are also found on fish in estuaries, with the most recently discovered species Argulus kosus being found on Sarpa salpa in the Kosi system (Avenant-Oldewage 1994).

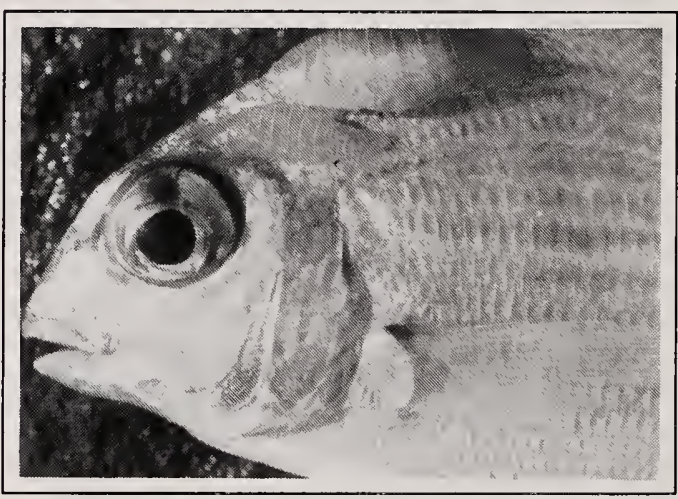

Figure 33. A photograph showing the typical position of parasitic isopods Anilocra capensis on the head of the Cape stumpnose Rhabdosargus holubi. 


\section{Estuarine fish communities as biological indicators}

Both fish abundance and species diversity can provide managers with a good indication of the "health' of a particular system. Guastella (1994) found that the catch rate of anglers in Durban Bay declined between 1976 and 1991, and attributed this decrease to factors such as loss of habitat, poor water quality, disturbance by harbour traffic and possible over exploitation of fish stocks. He concluded that careful management and efficient policing of the harbour are essential prerequisites to ensure a healthy aquatic environment and sustainable catches in the future.

Fish species diversity in an estuary can also assist in the evaluation of the condition of a system. Results of ichthyofaunal surveys are generally presented as lists of species and their relative abundances, which require specialist interpretation and are usually beyond the comprehension of most coastal managers and planners (Cooper et al. 1994). A method of condensing this data into a more functional format is essential if this information is to be used in any planning or management process. A standard method of condensing biological community information is through the use of an index. A Community Degradation Index (CDI) developed by Ramm (1988) is based on a comparison of the biological community present within an aquatic system, to the community that would exist in the absence of, or prior to, degradation. The index assumes that differences between the potential community and the present assemblage are due to habitat degradation.
The Community Degradation Index has been applied to numerous KwaZulu-Natal estuaries (Ramm 1990b). A total of 62 systems were first classified into six groupings based upon eight physical/hydrological parameters. This classification procedure involved the use of detrended correspondence analysis, two-way classification techniques and principle components analysis. Since the entire biological community could not be sampled, the fish assemblage of each estuary was selected (for reasons outlined on page 159) to represent the overall community in the analysis. Reference ichthyofaunal lists were then developed for each of the physical groupings, and CDI values were calculated for each system by comparing the reference faunal list with a species list from biological surveys on that particular estuary (Ramm 1990b). Computed CDI values for KwaZulu-Natal estuaries ranged from 0.2 (undegraded) to 8.2 (severely degraded).

The Sezela Estuary was described by Begg (1978) as the most severely polluted estuary in KwaZulu-Natal. It was essentially devoid of fish life and consequently had a CDI of 9-10 (Ramm 1990b). As a result of concerted efforts to correct the problems in the Sezela Estuary between 1982-1984, recovery of the aquatic community was able to commence. By 1984, surveys indicated a CDI of approximately 8 , and by early 1986 the CDI had improved to about 6. In 1987 the CDI had improved to approximately 5 (Ramm 1990b) and clearly demonstrates the advantage of using this method to monitor the recovery of an estuary. On the same basis, the CDI could be used to document the faunistic
By comparing the community within an estuary...

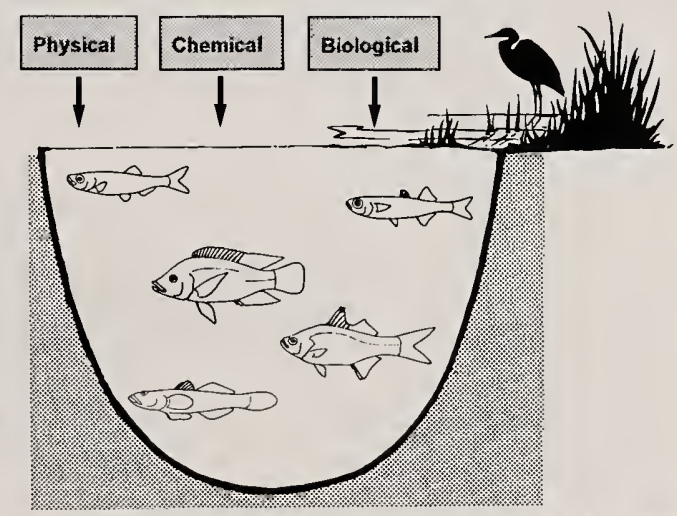

.with what ought to be in that estuary...

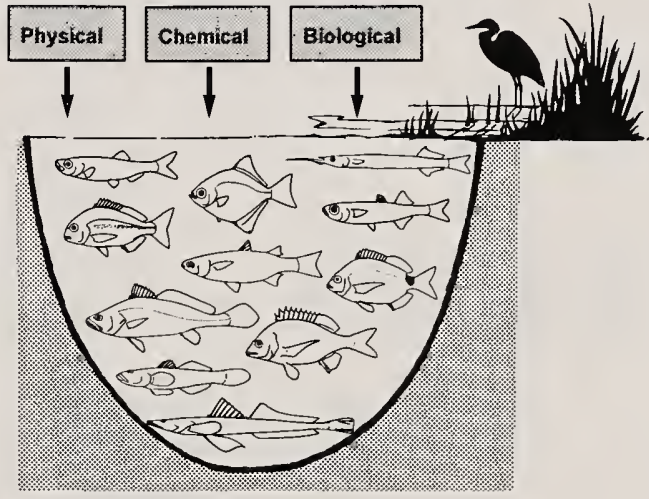

one can measure the relative health of that estuary

Figure 34. Conceptual diagram showing how the fish community in an estuary is dependent upon the physical, chemical and biological environment and can therefore be used to determine a Community Degradation Index (CDI) and/or Biological Health Index (BHI) for the system. 
degradation of an estuary over time and assist in the identification of types of estuaries where the fish communities are most threatened.

Using species diversity, or any other traditional index method, one could conclude that in 1987 the Sezela Estuary (19 species) was as degraded as the Mvoti Estuary (17 species). This would clearly have been inappropriate, as the comparison involves two systems which are physically very different. The Mvoti Estuary is a river mouth type system which has a naturally low diversity of fish species. The CDI, however, accommodates this incongruity and reflects an improvement in the Sezela Estuary during the period 1982-1987 from severely degraded to moderately degraded status (Ramm 1990b).

The CDI measures the degree of dissimilarity between the potential community and the actual community (Ramm 1988). More recently, a Biological Health Index (BHI) has been developed by Cooper et al. (1994) that modifies the CDI to incorporate a measure of the degree of similarity between the potential community and the actual community (Figure 34). The formula for calculating the Biological Health Index is BHI $=10(\mathrm{~J})\left[\mathrm{Ln}(\mathrm{P}) / \mathrm{Ln}\left(\mathrm{P}_{\max }\right)\right]$, where $\mathbf{J}$ is the number of species in the system divided by the number of species in the reference community, $P$ is the potential species diversity (number of species) of each reference community and $\mathrm{P}_{\max }$ is the maximum potential species diversity from all the reference communities. The index ranges from 0 (poor) to 10 (good).
Reference communities are usually determined by establishing the normal range of fish community components such as presence/absence of taxa in the most unimpaired waters representative of the area or region under consideration. In a study by Harrison et al. (1994), estuaries on the west coast of South Africa were classified into groups of similar systems based upon a variety of physical-geological factors, and the resulting groupings were then treated as regions of ecological similarity. Reference ichthyofaunal lists, based primarily on biological surveys, were then drawn up for each physical group of estuaries under consideration. Freshwater fish species, stenohaline marine taxa and exotic fishes were excluded from the ichthyofaunal lists. On comparing the relative biological health of the 21 estuaries/river mouths on the Western Cape coast, eight $(38 \%)$ systems were considered to be in a relatively poor condition, ten systems (48\%) were considered to be in an acceptable or average condition, and three systems (14\%) were in a relatively good condition.

The BHI can also be used to monitor the state of a particular system over time. The Damba Estuary was sampled over a two year period and the biological (fish community) health of the system calculated after each sampling event. Despite the dynamic nature of estuaries, the results were fairly consistent, with the same biological index value (2.58) being obtained on five of the eight sampling occasions (Cooper et al. 1994). This reproducibility further highlights the usefulness of the index as a monitoring tool.

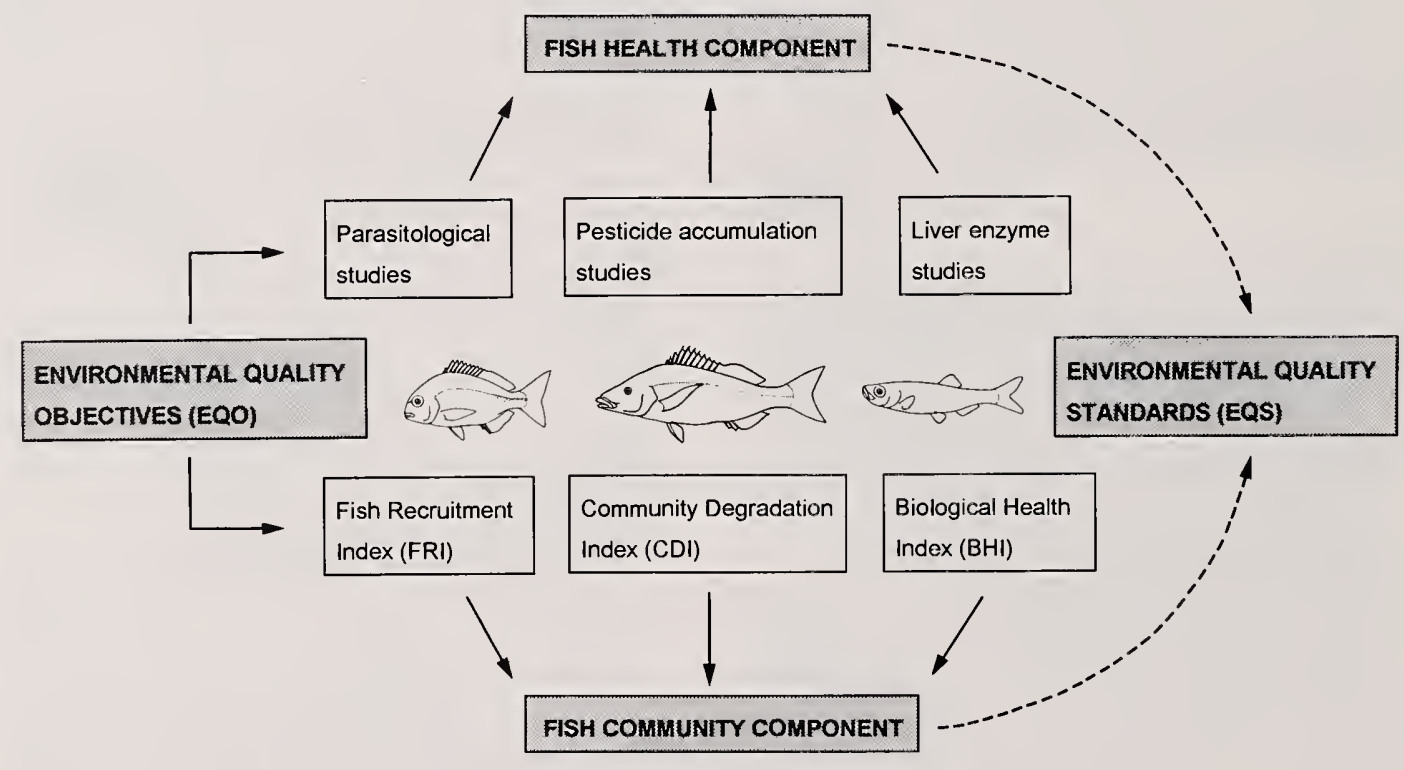

Figure 35. Summary diagram showing how estuarine fish studies can contribute to the maintenance of a healthy aquatic environment. 


\section{Fish Recruitment Index}

As the competition for scarce water resources increases, it is essential that the freshwater requirements of estuaries are well articulated and that suitable methodologies are available to assist in determining the optimal scheduling of freshwater allocations. The development of a fish recruitment index which will adequately reflect the suitability of freshwater release policies for fish populations utilizing estuaries was perceived to be a major need by both managers and scientists. This need was addressed with the recent development by Quinn et al. (1998a) of a Fish Recruitment Index (FRI). A major requirement of the FRI was that this index should be biologically meaningful and be readily understandable by biologists and water resource managers alike. A secondary objective was to make the best use of previous research and existing understanding, and in so doing to provide guidelines for future research.

The FRI is a biologically meaningful management index which is based on the integration of three key information sets. The first set is the current understanding relating to the importance or significance (dependency score) of marine fish species in the estuarine environment and whether it is endemic to southern African waters or not. The second is the preferred timing of the immigration period for a particular species (optimal recruitment score). The third information set incorporates known environmental requirements for the recruitment by juvenile marine fish into southern African estuaries. Details of the formula and practical application of the above index in a temporarily open/closed (Great Brak) and permanently open (Kromme) estuary are given in Quinn et al. (1998a, 1998b). In both these systems, a variety of river flow scenarios were examined and the predicted changes in the magnitude of marine fish recruitment into these estuaries assessed.

\section{Some preliminary conclusions}

The basis for using biological monitoring of fishes to assess environmental condition is that the relative health of a fish community is a sensitive indicator of direct and indirect stresses on the entire aquatic ecosystem (Fausch et al. 1990). Ideally, studies should determine stress at the community, population, individual, physiological and subcellular level (Figure 35), using techniques such as production ecology, biochemistry, bioaccumulation studies, pathology, genetics, behaviour and physiology. The sound recommendation by Elliott et al. (1988) that fish studies should be one component in a holistic approach, using chemical, hydrographical and other biological data to interpret the fish results, is fully endorsed.
Within southern African estuaries a number of approaches have been adopted by scientists, depending on the information required by planners and managers. The type of assessments range from the Biological Health Index (BHI) to the Fish Recruitment Index (FRI). In addition, monitoring of fish pathology, trends in anglers catches, relative abundance of juvenile marine fishes in estuaries, sudden fish mortalities etc. can all provide insights into the health of these systems. A combination of these techniques would assist in the identification of potential threats to the estuarine biota, especially the fishes.

The importance of estuaries for fish has resulted in environmental quality objectives (EQO) being adopted to protect estuarine usage by fish and fish population health (Elliot et al. 1988). These fish orientated EQO include: (a) the water quality always allows the passage of migratory fish; (b) the estuary's residential fish community is consistent with the hydrophysical conditions; (c) the benthos and sediments are of sufficient quality to support the fish populations; (d) the levels of persistent toxic and tainting substances in the biota should be insignificant and should not affect predatory fish (Elliot et al. 1988). More recent developments in the EQO field are directed not only towards the maintenance of healthy estuarine fish populations, but also incorporate the health of people. The adoption of a set of EQO for southern African estuaries, together with a system of appropriate environmental quality standards (EQS), is strongly recommended. Information from existing fish studies could be used in the preliminary formulation of both EQO and EQS for estuaries on the subcontinent. Further studies should then be initiated on those topics where current information is either inadequate or lacking altogether.

Fausch et al. (1990) suggested that future research in biological monitoring by means of fish communities should focus on: (a) standardization of methods of sampling and data analysis; (b) documentation of natural variation in fish communities, against which changes due to degradation can be compared; and (c) experimental manipulation to test assumptions underpinning indices. Within southern Africa, the necessary infrastructures to conduct biological monitoring of fish populations need to be established in each of the biogeographic regions. Aspects to be addressed by these regional institutions would include fish recruitment indices, biological health indices, bioassessment protocols, acute and chronic bioassays, pathology and tissue residues assessment. The information generated from a broad spectrum of biomonitoring options in both estuaries and their associated catchments will facilitate an increase in ecologically focused management of estuaries, thus benefitting both fishes and people who utilize these waters (Whitfield 1996d). 


\subsection{MASS MORTALITIES OF FISHES IN ESTUARIES}

Fishes of southern African estuaries are adapted to highly variable conditions, and individual species can usually tolerate wider ranges of salinity, temperature and other factors than are normally found in these systems. Indeed, Bennett (1985) expressed a view that, if changes of equivalent magnitude to those recorded in estuaries were to occur at sea, massive mortalities of marine life would be the end result.

Mass mortalities of fishes in estuaries are usually triggered by extreme and infrequent external changes such as floods, droughts, cold snaps and pollution events impinging on the aquatic environment. A review of the documented causes of southern African fish kills may assist in the prediction of future mortalities in estuaries, and highlight research areas which need to be explored if we are to understand the physiological basis for the species responses observed.

\section{Salinity}

Detailed information on the salinity tolerance of fishes on the subcontinent is limited to a few species, e.g. see Blaber's (1973b) laboratory study on Rhabdosargus holubi. Field records on the occurrence of fishes in different salinities are extensive (Whitfield 1996b) and indicate that not all species found in estuaries are adapted to the same extent. This would account for the fact that certain fish species are recorded in fish kills on certain occasions but absent at others.

Most mass mortalities of fish in southern African estuaries are associated with a combination of low salinities $(<3 \%)$ and low water temperatures $\left(<14^{\circ} \mathrm{C}\right)$. More than 100000 fish belonging to at least 11 species were recorded dying in subtropical Lake St Lucia during June 1976 when the salinity declined below $3 \%$ and the temperature dropped to $12^{\circ} \mathrm{C}$ (Blaber \& Whitfield 1976). Examination of dead and dying fish during the winter of 1976 revealed skin lesions and haemorrhaging over large areas of the body, although most commonly encountered around the caudal peduncle, fin bases, opercula and mouth. The large mortality was probably due to either a lethal combination of low salinities and sudden low temperature leading to osmoregulatory failure, or to fungal infection of the skin lesions which usually follow severe osmoregulatory stress. The disorientation shown by dying fish in the lake was symptomatic of osmoregulatory failure (Blaber 1974a). Although Lake St Lucia (surface area $\pm 325 \mathrm{~km}^{2}$ ) is linked to the sea by a $20 \mathrm{~km}$ long winding channel (The Narrows), the relatively uniform salinity conditions prevailing over the entire system may have prevented the marine fish species from returning to sea before critical conditions developed.
A similar mass mortality was recorded in the warm-temperate Botriviervlei during October 1981. Salinity concentrations in the lake declined to $2-3 \%$ o and the temperature was less than $18^{\circ} \mathrm{C}$ when at least 7000 fish belonging to nine species died in the system (Bennett 1985). Indications that all the species killed were avoiding the lowest salinities is provided by the fact that most dead fish were found in the southern areas of the estuary where salinity readings were highest $(3 \%)$ ). It should be emphasized that the marine fish killed in October 1981 had survived salinities less than $8 \%$ for four months, and $3 \%$ for at least two weeks prior to the mortality. If the duration of exposure had been shorter or the water temperature higher, these species might not have succumbed. Another factor which may have played a role was the age of the fish. All the fish that died in the Bot system were estimated to be older than three years, indicating that juveniles may be more tolerant of low salinities than subadult and adult fish (Bennett 1985).

Mass mortalities under hypersaline conditions appear to be less frequent than under oligohaline conditions, and such kills usually occur when fish are trapped in an estuary that lacks freshwater inflow for prolonged periods. During April 1989, the temporarily closed Seekoei Estuary on the Eastern Cape coast experienced salinities above $90 \%$ as a result of a protracted drought and excessive freshwater abstraction by farmers in the catchment. More than 6000 juvenile and adult fish, belonging to at least 11 species (comprising both marine and estuarine taxa), were recorded dying in the estuary (Whitfield 1989e). In contrast to the above mass mortalities, Wallace (1975a) documented the fish fauna in the St Lucia system under salinities ranging from $60 \%$ o to $110 \%$. He recorded very few dead fish at these salinities and suggested that the lower species diversity in the most hypersaline regions was indicative of a movement towards lower salinity areas in the south of the system.

Freshwater fish species such as Clarias gariepinus often undergo mass mortalities in Lake St Lucia when exposed to high salinity arising from wind-induced seiches up inflowing rivers or being washed into high salinity waters by sudden flooding of rivers into the lake (Blaber 1981b).

\section{Water temperature}

As discussed above, water temperature often plays an important role in determining the salinity extremes tolerated by both marine and freshwater fish species. Under normal circumstances fish can escape temperature extremes by either moving from the littoral zone into deeper offshore waters or vice versa. 
In very shallow systems such as Lake St Lucia, with high surface to volume ratios, this is often not possible. A fish kill involving an estimated 250000 estuarine, marine and freshwater teleosts was noted during the winter of 1987 at Lake St Lucia (Forbes \& Cyrus 1993). A sudden cold snap during mid-June 1987 was listed as the primary cause of the above mortality, with salinities at the time (29-33\%o) being euhaline (Cyrus \& McLean 1996). The majority of the 21 species recorded dying during the above event were small species, with taxa of tropical origin being most affected.

Low water temperatures in estuaries have been directly linked to the mass mortality of adult Oreochromis mossambicus (300-350 $\mathrm{mm}$ TL) in the Kasuka Estuary during July 1979 (Jubb 1979). Winter mortalities of $O$. mossambicus have also been recorded in both the St Lucia and Wilderness lakes systems when temperatures declined below $14{ }^{\circ} \mathrm{C}$.

Upwelling events along the southern Cape coast can cause mass mortalities of marine fishes, some of which are often washed into estuaries on the flood tide. Dead specimens of 14 marine fish species were recorded in the mouth region of the Storms River Estuary following an upwelling event which resulted in sudden water temperature declines from $21^{\circ} \mathrm{C}$ to $11^{\circ} \mathrm{C}$ (Hanekom et al. 1989). Large shoals (200-3000 individuals) of marine fish frequently take refuge in estuaries along the Tsitsikamma coast when upwelling occurs. Those that are unable to find warmer waters often succumb to the sudden drop in sea temperature.

High littoral water temperatures of up to $32^{\circ} \mathrm{C}$ resulted in the death of at least 3000 Hippocampus capensis and several hundred Syngnathus acus in the marginal areas of the Swartvlei Estuary (Russell 1994). These fish were presumably trapped in overheated macrophyte beds by receding water levels after the estuary mouth had opened in February 1991. More mobile species, which are also associated with aquatic plants in estuaries (e.g. Rhabdosargus holubi), presumably escaped the warmer littoral areas. $R$. holubi is abundant in the Swartvlei Estuary (Whitfield 1988a) and cannot survive in water temperatures above $30^{\circ} \mathrm{C}$ (Blaber 1973b).

\section{Dissolved oxygen}

The first record of a mass fish mortality attributed to low concentrations of dissolved oxygen was that at Rondevlei, an estuarine lake which is part of the Wilderness system. In March 1993, hundreds of dead Rhabdosargus holubi (324-410 mm FL) and Lithognathus lithognathus (713-778 mm FL) were observed in shallow water along the western side of the lake (Russell 1994). Measurements undertaken in Rondevlei when the mortality was first noted revealed that temperature, salinity and concentrations of suspended solids were within ranges previously recorded. However, dissolved oxygen levels in the water column were $0.1-0.7 \mathrm{mg} \mathrm{l}^{-1}$, far below the normal range of 4-14 $\mathrm{mg} \mathrm{l}^{-1}$. Concentrations of less than $1 \mathrm{mg} \mathrm{l}^{-1}$ persisted for at least five days and may have resulted from the senescence of a dinoflagellate/algal bloom (Russell 1994). Despite these low dissolved oxygen levels, pelagic schools of Atherina breviceps and Gilchristella aestuaria were observed in the lake.

Fish mortalities, probably caused by low concentrations of dissolved oxygen arising from treated sewage effluent inputs and other types of pollution, have also been recorded in the subtropical Tongati Estuary in November 1981 (Blaber et al. 1984). Surface water had oxygen saturation levels of less than $25 \%$ in November 1981, and no fish were recorded in the system between July and October 1981 when bottom waters also had oxygen concentrations less than $25 \%$ saturation. Fish kills in the Sezela Estuary on the KwaZulu-Natal south coast in April 1977 were probably also linked to near-zero dissolved oxygen values (Begg 1978). According to Ramm et al. (1987) the deposition of untreated sugar mill waste into the Sezela system resulted in extensive anoxic sludge deposits on the floor of the estuary, which then used up the available oxygen in the water column.

Toxic sulphide-rich waters are often associated with anoxic conditions in certain meromictic southern African estuarine lakes such as Swartvlei (Allanson \& Howard-Williams 1984) and Lake Mpungwini (Ramm 1992). Mixing of high concentrations of these free sulphides into Mpungwini surface waters during periods of turbulence or upwelling always had the potential to cause mass mortalities of fish and other biota. During the spring equinox tides of September 1989 , thousands of fish, representing all the major species in the central Kosi system, died as a result of toxic concentrations of suphides $\left(>10 \mathrm{mg} \mathrm{l}^{-1}\right)$ being upwelled into surface waters of Lake Mpungwini (Ramm 1990a).

\section{Suspended sediment}

High riverine silt loads have previously been associated with fish kills in southern African freshwater systems, but it was only in January 1995 that a large-scale mortality of fish in the Sundays and Great Fish estuaries was attributed to this particular source (Whitfield \& Paterson 1995). A total of 16 fish species, belonging to marine, estuarine and freshwater taxa, was recorded dying in the Sundays Estuary. Both juvenile and adult fish appeared to be affected by the high levels of silt and clay carried by the floodwaters. Although available evidence suggests that clogging of the fish gill filaments by suspended sediments was primarily responsible for the mass mortalities, osmoregulatory and other stress factors may also have contributed to the fish kill. 


\section{Factors influencing fish mortalities}

From the above discussion it is apparent that major changes to the physico-chemical environment often cause mass mortalities of fishes in estuaries. These changes may be natural (e.g. a river flood) or induced by some anthropogenic activity such as a pollution event (Moldan et al. 1979). Although both natural and human induced mortalities have been recorded in southern African estuaries, the increasing frequency of occurrence of the latter is cause for concern.

A striking feature of most fish kills in estuaries is the range of species affected in the same manner, despite their differing physiological tolerances to particular conditions. In many cases, mass mortalities of fish have been linked to a single dominant factor. However, in reality, the relatively minor perturbations associated with supplementary factors can often trigger a fish kill, e.g. species may survive salinity extremes provided the water temperatures remain above a certain minimum. If water temperatures were to decline due to the passage of a cool weather frontal system, this may lead to osmoregulatory failure in a number of fish species, thus precipitating a mass mortality event.

The most frequently interacting factors in a southern African context appear to be salinity and water temperature, dissolved oxygen and water temperature, and suspensoids and dissolved oxygen (Figure 36). In some cases, three or even four factors may be in operation simultaneously (e.g. water temperature, dissolved oxygen, suspensoids and salinity) thus creating an environment unsuitable for the survival of the ichthyofauna.

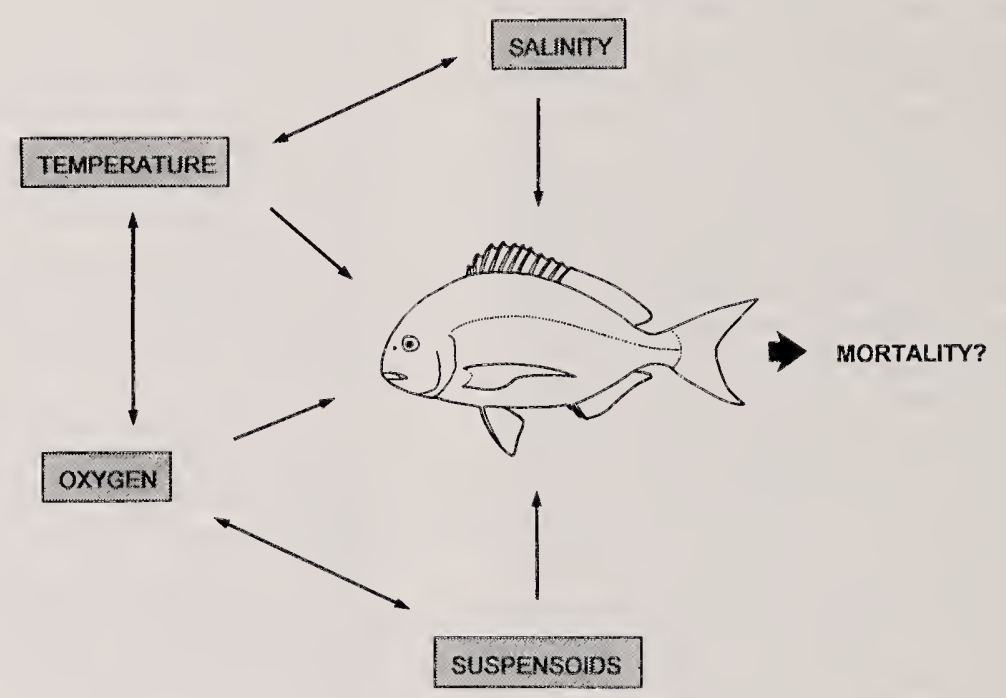

Figure 36. Diagrammatic representation of environmental factors and the major interactions influencing fish mortalities in southern African estuaries. Small-scale interactions between salinity and suspensoids, dissolved oxygen and salinity, and suspensoids and water temperature are possible, but unlikely to influence mortality. 


\section{Chapter 6}

\section{Conservation of fishes in southern African estuaries}

\subsection{INTRODUCTION}

Aquatic conservation, and the conservation of fish in particular, is an issue which should be important to all people. This view is highlighted by Bruton (1995) who states "The vital role of fishes in aquatic ecosystems, and of aquatic ecosystems in the physiology of the planet, make it essential that more attention is given for fish conservation, even if it is for the selfish motive of human survival". Similar views are expressed by Greenwood (1992) who suggests that "because fishes are less obvious than terrestrial life they are often overlooked, as is their role in global ecology. There is an urgent need to change that situation and to ensure that we have the information to effect their conservation". It is important to note that both the above authors use the word 'conservation' rather than 'protection', although elements of protection are implied in the former word.

The conservation of biodiversity has become a major national and international concern, and gained further momentum with the signing of the United Nations Convention on Biological Diversity. A major obligation of the signatories to the above convention is the development of national, regional and local strategies for the conservation and sustainable use of biodiversity. Planning where priority conservation sites should be located and evaluating estuarine use options are essential components of such a strategy. Since fish are a dominant biotic component in most estuaries, and are also used by people for food and recreation, it would be wise to highlight the importance of this taxon in the above exercise.

Estuaries, like many other types of wetland worldwide, are under long-term threat of damage and destruction. As will be seen in the following section, a number of southern African fish species are dependent on estuaries for the maintenance of healthy populations. The viability of estuaries as nurseries and feeding grounds is directly related to the large amount of suitable food in these areas. Mismanagement of either the catchments or the estuaries leads to impoverished systems which are of little value to fish or people.

\subsection{HOW DEPENDENT ARE FISHES ON ESTUARIES?}

The reliance of juveniles of migrant marine species on estuarine nursery grounds varies considerably, and ranges from marine stragglers which are seldom found in estuaries, to those species that are dependent on estuaries during the juvenile phase of their life cycle (Wallace et al. 1984a). Some species such as Liza richardsonii and Pomatomus saltatrix appear to use favourable estuarine conditions opportunistically, with the juveniles also being very abundant in the sea. Other taxa such as Rhabdosargus holubi and Monodactylus falciformis are considered to be dependent on estuaries, and Bennett et al. (1985) have gone so far as to suggest that certain species might even become extinct if denied access to these nursery areas.

Adult marine fish also show considerable variability in their association with estuaries, with some species making extensive use of this environment and others never returning to their natal habitat. For example, large post-spawning shoals of Pomadasys commersonnii regularly enter estuaries during early spring, whereas Rhabdosargus holubi adults are seldom recorded in these systems, despite the overwhelming dependence of their juveniles on this environment.

In addition, a number of species breed in southern African estuaries, some of which are totally dependent upon these habitats for their survival (e.g. Syngnathus watermeyeri). A few fishes (e.g. Anguilla mossambica) use estuaries as transit routes in their migrations between rivers and sea, and others make only sporadic use of these productive systems. From the above observations it becomes apparent that the degree of estuarine dependence varies from one species to another. There is clearly a need to develop a rational estuary-association classification for fishes according to the importance these systems represent in the life cycles of individual species. 


\section{Categorization of fishes in estuaries}

Estuary-dependent fish species are defined as those taxa whose southern African populations would be adversely affected by the loss of estuarine habitats on the subcontinent. Wallace et al. (1984a) divided South Africa's estuary-associated ichthyofauna into six categories according to their use of these systems and identified 81 species which were wholly or partially dependent on these systems. More recent research has provided additional information on many fish species, and identified life-history styles of taxa previously excluded from the 1984 analysis.

A new estuarine association classification system for southern African fishes, based on a version developed by Whitfield (1994c), is described in Table 11. It comprises five major categories with two divisions in Category I, three divisions in Category II and two divisions in Category $\mathrm{V}$. Of the five major categories only divisions Ia and IIa are totally dependent on estuaries. Categories $\mathrm{Ib}, \mathrm{IIb}, \mathrm{IIc}$ and $\mathrm{Vb}$ represent species which are at least partially dependent on estuarine systems, a large proportion of which could be regarded as marine/estuarine opportunists. Category III comprises mainly stenohaline marine species which occur in low numbers in estuaries and have been sampled in at least three systems in a particular region. Category IV consists of a few euryhaline freshwater fish species, for which the degree of penetration into estuaries is determined primarily by salinity tolerance. Finally, Category V includes obligate catadromous species which use estuaries as transit routes between marine and freshwater environments, and facultative catadromous species which also utilize estuaries as nursery areas. Myxus capensis is placed in Category Vb but may be regarded as estuary dependent since it seldom occurs in Western Cape rivers but is abundant in the estuaries of this region.

The list of indigenous fish species associated with southem African estuaries is given in Table 13. Out of a total of 155 species, only about $50 \%$ may be regarded as having a strong association (Categories Ia, $\mathrm{Ib}, \mathrm{IIa}, \mathrm{IIb}, \mathrm{Vb}$ ) with estuaries on the subcontinent. If both completely and partially estuarine-dependent species are included in the analysis, then more than 100 fish species may be linked to estuaries on the subcontinent. A total of 38 species are endemic to the region, with endemic taxa being defined as those species which have only been recorded on the African continent and/or adjacent waters south of $20^{\circ} \mathrm{S}$ (Brown \& Jarman 1978).

Table 11. The five major categories of fishes which utilize southern African estuaries.

\section{Categories Description of categories}

Estuarine species which breed in southern African estuaries. Further subdivided into:

Ia. Resident species which have not been recorded spawning in marine or freshwater environments. Ib. Resident species which also have marine or freshwater breeding populations.

II

Euryhaline marine species which usually breed at sea with the juveniles showing varying degrees of dependence on southern African estuaries. Further subdivided into:

IIa. Juveniles dependant on estuaries as nursery areas.

IIb. Juveniles occur mainly in estuaries, but are also found at sea.

IIc. Juveniles occur in estuaries but are usually more abundant at sea.

III

IV

V

Marine species which occur in estuaries in small numbers but are not dependent on these systems.

Freshwater species, whose penetration into estuaries is determined primarily by salinity tolerance. This category includes some species which may breed in both freshwater and estuarine systems.

Catadromous species which use estuaries as transit routes between the marine and freshwater environments but may also occupy estuaries in certain regions. Further subdivided into:

Va. Obligate catadromous species which require a freshwater phase in their development.

Vb. Facultative catadromous species which do not require a freshwater phase in their development. 


\section{Biogeographical considerations}

Wallace et al. (1984a) and Cyrus (1991c) examined southern African estuaries and their associated fish fauna as a single entity. However, very few specics occur in all systems, with some taxa confined to a particular biogeographical region, or even to a few estuaries within that region. The following three sections provide an insight into the ichthyofaunal changes that occur between subtropical estuaries in the northeast and cool-temperate systems in the southwest. Tropical estuaries (i.e. north of $26^{\circ} \mathrm{S}$ on the east coast) are not dealt with in this review because of a paucity of information from Mozambique.

\section{Cool-temperate estuaries}

Cool-temperate estuaries of the Northern and Western Cape Province have a relatively low ichthyofaunal diversity and are dominated by only a few species (Millard \& Scott 1954). Several authors (e.g. Wallace \& van der Elst 1975, Day et al. 1981, Whitfield et al. 1989) have highlighted the southward decline in estuarine fish diversity from KwaZulu-Natal around the Cape to the Atlantic west coast. The reason for the decline is linked to the subtraction of tropical and subtropical species (Blaber 1981a), which together comprise the bulk of the estuarine ichthyofauna. Only seven of the 24 species associated with cool-temperate estuaries have distributions which extend into tropical waters, the remainder being confined to areas south of $26^{\circ} \mathrm{S}$. As many as $16(67 \%)$ of the 24 taxa are endemic to southern Africa and this group includes all the dominant species found in these systems. The overwhelming dominance of Liza richardsonii and relative scarcity of most other species from west coast estuaries is noteworthy.

Marine water temperatures probably play a major role in the low fish species representation described above. There is a marked decline in the average summer and winter sea temperatures from Durban $\left(24-19^{\circ} \mathrm{C}\right)$ southwards to Port Elizabeth $\left(22-16^{\circ} \mathrm{C}\right)$ and Table Bay $\left(18-13^{\circ} \mathrm{C}\right)$. As expected, lower temperatures are also found in estuaries as one moves in a southwesterly direction along the coast (Day 1981b). The minimum winter water temperatures of $10-12^{\circ} \mathrm{C}$ recorded in cool-temperate estuaries would probably be lethal for many of the warm water species found in subtropical and warm-temperate systems. In addition, low winter temperatures in combination with low salinities can result in severe physiological stress, even to estuarine fish species (Whitfield et al. 1981). Since low temperatures and salinities are frequently recorded in cool-temperate estuaries, this combination probably limits the colonization of these systems by certain species; e.g. Rhabdosargus holubi, which is abundant in both warm-temperate and subtropical estuaries, is represented by a few 'stragglers' in cool-temperate systems. Indeed, winter temperature and salinity combinations in these estuaries are at the edge of the tolerance limits for this species (Blaber 1973a).

\section{Warm-temperate estuaries}

The warm-temperate region represents a transition zone between subtropical estuaries to the north-east and cool-temperate systems to the west. Most warmtemperate estuaries contain species which are representative of all three biogeographic regions discussed in this chapter, as well as the tropical region. Of the 78 estuary-associated species occurring in warm-temperate systems, $31(40 \%)$ are endemic to southern African waters, with the remainder mainly having a distribution which extends into tropical areas north of $26^{\circ} \mathrm{S}$ on the African east coast. A total of 39 fish species (50\%) may be regarded as having a strong association with estuaries in the region.

Many of the tropical and subtropical species found in warm-temperate estuaries are more common in the northern part of the Eastern Cape during the summer months, and are usually rare or absent from estuaries west of Algoa Bay (e.g. Acanthopagrus berda). In addition, a number of endemic fish species which are particularly abundant in some Western Cape estuaries reach the north-eastern limits of their distribution in the Eastern Cape area (e.g. Rhabdosargus globiceps). The northeastern portion of the warm-temperate region therefore represents an important subtraction zone in the distribution of both tropical and temperate fish species.

Anguilla mossambica is the only anguillid eel which occurs in large numbers in the riverine and estuarine systems of the warm-temperate region. However, numerous specimens of Anguilla marmorata and $A$. bicolor bicolor have also been recorded in the rivers of the region (Bruton et al. 1987).

During or shortly after strong easterly winds have been blowing along the Eastern and Western Cape coast in summer, some unusual marine fish species may make an appearance in estuaries, e.g. large shoals of Sparodon durbanensis, Cheimerius nufar, Coracinus capensis and Pachymetopon grande have been recorded sheltering in the Storms River Estuary during upwelling events on the Tsitsikamma coast (Hanekom et al. 1989). These easterly winds set up water movements which result in the upwelling of cool $\left(10-15^{\circ} \mathrm{C}\right)$ waters into the nearshore area (Schumann et al. 1988) and are therefore indirectly responsible for essentially marine fishes sometimes seeking refuge in the warmer waters of adjacent estuaries. Such species are not regarded as being part of the typical estuarine ichthyofauna and are not included in this analysis. 


\section{Subtropical estuaries}

The highest ichthyofaunal diversity on the subcontinent occurs in the subtropical region. Altogether, 142 species are associated with these systems, of which $26(18 \%)$ are endemic to southern Africa. A total of 72 species $(50 \%)$ may be regarded as having a strong association with estuaries in the subtropical region. More than 100 of the species have a distribution which extends into the tropics, thus illustrating the dominance of subtropical estuaries by species with tropical zoogeographical affinities (Blaber 1981a).

Maximum summer temperatures in the estuaries of southern Africa do not differ greatly and usually range from $24-28^{\circ} \mathrm{C}$. This suggests that high temperatures are not an important factor in limiting fish distribution, since temperate, subtropical and tropical species all live in estuaries which attain these levels. For example, the maximum recorded channel temperatures in the Berg Estuary (Western Cape) is $27^{\circ} \mathrm{C}$ and that in the Morrumbene Estuary (Mozambique) is $28^{\circ} \mathrm{C}$ (Day 1981b). Minimum winter water temperatures in KwaZulu-Natal estuaries are usually above $14^{\circ} \mathrm{C}$ (Begg 1978) and are an important factor, together with the general absence of cool upwelled marine waters along the coast, in accounting for the relatively high fish species diversity in subtropical estuaries.

\section{Estuary-association analysis}

An analysis of the degree of estuarine dependence by the various categories of indigenous fishes in southern African estuaries is given in Table 12. Species that are totally dependent on these systems comprise $32(21 \%)$ of the 155 estuary-associated fish taxa. Estuarine species that breed in these systems comprise $27 \%$ (42 species) of the total ichthyofaunal diversity, with the dominant component being derived from marine taxa that use estuarine systems as nurseries and/or foraging areas ( 61 species $=39 \%$ of total). The above taxa (103 species $=66 \%$ of total) are either completely or partially dependent on estuaries for their existence.

Altogether 53 families of fishes are associated with southern African estuaries (Table 13), of which 50 have a primarily marine origin, two are derived from freshwater environments, and one is represented by obligate catadromous species. In terms of species number, the Gobiidae (23 species), Mugilidae (13 species) and Sparidae (13 species) are the most diverse. Within the above families, $43 \%$ (10 species) of the Gobiidae, $62 \%$ ( 8 species) of the Sparidae and $23 \%$ ( 3 species) of the Mugilidae associated with estuaries are endemic to the region. Altogether 38 species $(25 \%$ of all estuary-associated taxa) are endemic to southern African waters.

Table 12. Categories of fishes (for details see Table 11) which utilize southern African estuaries to varying degrees. The total number of estuary-associated species $=155$. Full circles $(\bullet)$ show strong dependence on a particular habitat, open circles (O) indicate that species use particular habitats facultatively, and squares (ש) indicate that estuaries represent transit corridors for obligate catadromous species.

Abbreviations: fre. $=$ freshwater; est. = estuary; mar. = marine; spec. $=$ species; abs. = absolute; cum. $=$ cumulative .

Spawning sites Juvenile habitat Species analysis

1. Estuarine residents:

a. Breeding only in estuaries

b. Breeding mainly in estuaries

2. Marine migrants whose juveniles are:

a. Wholly estuary dependent

b. Mainly estuary dependent

c. Weakly estuary dependent

3. Marine stragglers

4. Freshwater migrants

5. Catadromous migrants:

a. Obligate freshwater phase

b. Facultative freshwater phase

\begin{tabular}{|c|c|c|c|c|c|c|c|c|}
\hline \multirow[b]{2}{*}{0} & \multirow{2}{*}{$\bullet$} & & \multirow[b]{2}{*}{0} & \multicolumn{2}{|l|}{ - } & \multirow{2}{*}{$\begin{array}{l}18 \\
24\end{array}$} & \multirow[t]{2}{*}{$\begin{array}{l}12 \\
15\end{array}$} & 12 \\
\hline & & 0 & & $\bullet$ & 0 & & & 27 \\
\hline & & $\bullet$ & & • & & 13 & 8 & 35 \\
\hline & & - & & - & 0 & 20 & 13 & 48 \\
\hline & & $\bullet$ & & 0 & - & 28 & 18 & 96 \\
\hline & & $\bullet$ & & & - & 39 & 25 & 91 \\
\hline • & 0 & & - & 0 & & 7 & 5 & 96 \\
\hline & & - & $\bullet$ & E & & 4 & 3 & \\
\hline & & $\bullet$ & 0 & • & & 2 & 1 & 100 \\
\hline
\end{tabular}


Table 13. Ichthyofauna associated with southern African estuaries, indicating their geographical range, geographical occurrence in estuaries on the subcontinent, and the estuarine dependence category for each species. Family and species names primarily after Smith \& Heemstra (1986a) and Skelton (1993). For common names see Appendix 2 (page 220).

\begin{tabular}{|c|c|c|c|c|}
\hline Family & Scientific name & $\begin{array}{l}\text { Geographical } \\
\text { range }^{1}\end{array}$ & $\begin{array}{l}\text { Southern } \\
\text { African } \\
\text { estuaries }^{2}\end{array}$ & $\begin{array}{l}\text { Estuarine } \\
\text { dependence } \text { category }\end{array}$ \\
\hline \multirow{3}{*}{ Ambassidae } & Ambassis gymnocephalus & $\mathrm{T}-\mathrm{W}$ & $\mathrm{S} / \mathrm{W}$ & $\mathrm{Ib} ?$ \\
\hline & Ambassis natalensis & $\mathrm{T}-\mathrm{S}$ & $\mathrm{S}$ & $\mathrm{Ib} ?$ \\
\hline & Ambassis productus & T-S & $\mathrm{S}$ & Ia? \\
\hline \multirow[t]{4}{*}{ Anguillidae } & Anguilla bengalensis labiata & $\mathrm{T}-\mathrm{S}$ & $\mathrm{S}$ & $\mathrm{Va}$ \\
\hline & Anguilla bicolor bicolor & T-W & $\mathrm{S}$ & Va \\
\hline & Anguilla marmorata & $\mathrm{T}-\mathrm{W}$ & $\mathrm{S}$ & $\mathrm{Va}$ \\
\hline & Anguilla mossambica & T-W & $\mathrm{S} / \mathrm{W}$ & $\mathrm{Va}$ \\
\hline Ariidae & Galeichthys feliceps * & S-C & $\mathrm{S} / \mathrm{W} / \mathrm{C}$ & $\mathrm{IIb}$ \\
\hline \multirow[t]{2}{*}{ Atherinidae } & Atherina breviceps * & S-C & $\mathrm{S} / \mathrm{W} / \mathrm{C}$ & $\mathrm{Ib}$ \\
\hline & Atherinomorus lacunosus & T-S & $\mathrm{S}$ & $\mathrm{Ib}$ \\
\hline Belonidae & Strongylura leiura & $\mathrm{T}-\mathrm{S}$ & $\mathrm{S}$ & IIc \\
\hline Blenniidae & Omobranchus woodi ${ }^{*}$ & W-S & $\mathrm{W}$ & Ia \\
\hline Bothidae & Bothus pantherinus & $\mathrm{T}-\mathrm{W}$ & $\mathrm{S} / \mathrm{W}$ & III \\
\hline \multirow[t]{10}{*}{ Carangidae } & Caranx heberi & T-S & $S$ & III \\
\hline & Caranx ignobilis & $\mathrm{T}-\mathrm{W}$ & $\mathrm{S}$ & $\mathrm{IIb} ?$ \\
\hline & Caranx melampygus & T-S & $\mathrm{S}$ & IIc? \\
\hline & Caranx papuensis & $\mathrm{T}-\mathrm{W}$ & $\mathrm{S} / \mathrm{W}$ & IIc? \\
\hline & Caranx sexfasciatus & $\mathrm{T}-\mathrm{W}$ & $\mathrm{S} / \mathrm{W}$ & IIb \\
\hline & Lichia amia & $\mathrm{T}-\mathrm{C}$ & $\mathrm{S} / \mathrm{W} / \mathrm{C}$ & IIa \\
\hline & Scomberoides commersonnianus & $\mathrm{T}-\mathrm{W}$ & $\mathrm{S}$ & III \\
\hline & Scomberoides lysan & $\mathrm{T}-\mathrm{S}$ & $\mathrm{S}$ & IIb? \\
\hline & Scomberoides tol & T-S & $\mathrm{S}$ & III \\
\hline & Trachinotus africanus & $\mathrm{T}-\mathrm{S}$ & $\mathrm{S}$ & III \\
\hline Carcharhinidae & Carcharhinus leucas & $\mathrm{T}-\mathrm{W}$ & $\mathrm{S}$ & IIc \\
\hline Chanidae & Chanos chanos & $\mathrm{T}-\mathrm{W}$ & $\mathrm{S} / \mathrm{W}$ & IIc \\
\hline \multirow[t]{3}{*}{ Cichlidae } & Oreochromis mossambicus & $\mathrm{T}-\mathrm{W}$ & $\mathrm{S} / \mathrm{W} / \mathrm{C}$ & IV \\
\hline & Pseudocrenilabrus philander & T-S & $\mathrm{S}$ & IV \\
\hline & Tilapia rendalli & $\mathrm{T}-\mathrm{S}$ & $\mathrm{S}$ & IV \\
\hline Clariidae & Clarias gariepinus & $\mathrm{T}-\mathrm{W}$ & $\mathrm{S}$ & IV \\
\hline \multirow{2}{*}{ Clinidae } & Clinus spatulatus* & W-C & W & $\mathrm{Ib}$ \\
\hline & Clinus superciliosus * & W-C & $\mathrm{W} / \mathrm{C}$ & $\mathrm{Ib}$ \\
\hline \multirow[t]{4}{*}{ Clupeidae } & Etrumeus whiteheadi $*$ & $\mathrm{~S}-\mathrm{C}$ & $\mathrm{W}$ & III \\
\hline & Gilchristella aestuaria* & $\mathrm{S}-\mathrm{C}$ & $\mathrm{S} / \mathrm{W} / \mathrm{C}$ & Ia \\
\hline & Herklotsichthys quadrimaculatus & T-S & $\mathrm{S}$ & III \\
\hline & Hilsa kelee & T-S & $\mathrm{S}$ & IIc \\
\hline \multirow[t]{3}{*}{ Dasyatidae } & Dasyatis chrysonota & $\mathrm{T}-\mathrm{C}$ & $\mathrm{W}$ & III \\
\hline & Gymnura natalensis * & S-W & $\mathrm{W}$ & III \\
\hline & Himantura uarnak & T-W & $\mathrm{S}$ & III \\
\hline Drepanidae & Drepane longimanus & $\mathrm{T}-\mathrm{W}$ & $\mathrm{S}$ & III \\
\hline Eleotridae & Butis butis & $\mathrm{T}-\mathrm{S}$ & $\mathrm{S}$ & Ia? \\
\hline
\end{tabular}

${ }^{1}$ Range: $\mathrm{T}=$ Tropical; $\mathrm{S}=$ Subtropical; $\mathrm{W}=$ Warm-temperate; $\mathrm{C}=$ Cool-temperate; $*=$ Endemic to southern Africa.

${ }^{2}$ Geographical distribution in estuaries: $\mathrm{S}=$ Subtropical; $\mathrm{W}=$ Warm-temperate; $\mathrm{C}=$ Cool-temperate.

${ }^{3}$ Estuarine dependence categories: For a description of the codes used, see Table 11. 
Table 13. Continued.

\begin{tabular}{|c|c|c|c|c|}
\hline Family & Scientific name & $\begin{array}{l}\text { Geographical } \\
\text { range }^{1}\end{array}$ & $\begin{array}{l}\text { Southern } \\
\text { African } \\
\text { estuaries }^{2}\end{array}$ & $\begin{array}{l}\text { Estuarine } \\
\text { dependence } \\
\text { category }^{3}\end{array}$ \\
\hline \multirow[t]{4}{*}{ Eleotridae } & Eleotris fusca & T-S & $S$ & Ia? \\
\hline & Eleotris mauritianus & T-S & $\mathrm{S}$ & Ia? \\
\hline & Eleotris melanosoma & T-S & $\mathrm{S}$ & Ia? \\
\hline & Hypseleotris dayi* & $\mathrm{S}$ & $\mathrm{S}$ & IV \\
\hline Elopidae & Elops machnata & $\mathrm{T}-\mathrm{W}$ & $\mathrm{S} / \mathrm{W}$ & IIa \\
\hline \multirow[t]{4}{*}{ Engraulidae } & Engraulis japonicus * & W-C & $\mathrm{W}$ & III \\
\hline & Stolephorus holodon & $\mathrm{T}-\mathrm{W}$ & $\mathrm{S} / \mathrm{W}$ & IIc \\
\hline & Thryssa setirostris & $\mathrm{T}-\mathrm{S}$ & $\mathrm{S}$ & III \\
\hline & Thryssa vitrirostris & $\mathrm{T}-\mathrm{W}$ & S & IIb \\
\hline Fistulariidae & Fistularia commersonii & $\mathrm{T}-\mathrm{W}$ & $\mathrm{S} / \mathrm{W}$ & III \\
\hline \multirow[t]{5}{*}{ Gerreidae } & Gerres acinaces & $\mathrm{T}-\mathrm{W}$ & $\mathrm{S} / \mathrm{W}$ & IIlb \\
\hline & Gerres filamentosus & T-S & $\mathrm{S}$ & $\mathrm{IIb}$ \\
\hline & Gerres methuen $i^{*}$ & $\mathrm{~T}-\mathrm{W}$ & $S$ & $\mathrm{IIb}$ \\
\hline & Gerres oblongus & $\mathrm{T}-\mathrm{S}$ & $S$ & III \\
\hline & Gerres oyena & T-S & $\mathrm{S}$ & IIc \\
\hline \multirow[t]{23}{*}{ Gobiidae } & Awaous aeneofuscus & $\mathrm{T}-\mathrm{W}$ & $S$ & IV \\
\hline & Caffrogobius gilchristi $*$ & $\mathrm{~S}-\mathrm{C}$ & $\mathrm{S} / \mathrm{W} / \mathrm{C}$ & $\mathrm{Ib}$ \\
\hline & Caffrogobius natalensis* & S-W & $\mathrm{S} / \mathrm{W}$ & $\mathrm{Ib}$ \\
\hline & Caffrogobius nudiceps * & W-C & $\mathrm{W} / \mathrm{C}$ & $\mathrm{Ib}$ \\
\hline & Croilia mossambica ${ }^{*}$ & T-S & $\mathrm{S}$ & $\mathrm{Ib}$ \\
\hline & Favonigobius melanobranchus & T-S & $\mathrm{S}$ & $\mathrm{Ib}$ ? \\
\hline & Favonigobius reichei & $\mathrm{T}-\mathrm{S}$ & $S$ & $\mathrm{lb} ?$ \\
\hline & Glossogobius biocellatus & T-S & $\mathrm{S}$ & Ia? \\
\hline & Glossogobius callidus * & $\mathrm{T}-\mathrm{W}$ & $\mathrm{S} / \mathrm{W}$ & $\mathrm{Ib}$ \\
\hline & Glossogobius giuris & T-S & $\mathrm{S}$ & IV \\
\hline & Oligolepis acutipennis & $\mathrm{T}-\mathrm{W}$ & S & Ia? \\
\hline & Oligolepis keiensis & $\mathrm{T}-\mathrm{W}$ & $\mathrm{S} / \mathrm{W}$ & Ia? \\
\hline & Pandaka silvana & $\mathrm{T}-\mathrm{W}$ & $\mathrm{S} / \mathrm{W}$ & Ia? \\
\hline & Periophthalmus koelreuteri africanus & T-S & $\mathrm{S}$ & Ia \\
\hline & Periophthalmus argentilineatus & T-S & $\mathrm{S}$ & Ia \\
\hline & Psammogobius knysnaensis * & $\mathrm{S}-\mathrm{C}$ & $\mathrm{S} / \mathrm{W} / \mathrm{C}$ & $\mathrm{Ib} ?$ \\
\hline & Redigobius bikolanus & $\mathrm{T}-\mathrm{S}$ & S & Ia? \\
\hline & Redigobius dewaalii * & S-W & $\mathrm{S} / \mathrm{W}$ & $\mathrm{Ib}$ \\
\hline & Silhouettea sibayi * & S & $\mathrm{S}$ & $\mathrm{Ib}$ \\
\hline & Taenioides esquivel * & $\mathrm{T}-\mathrm{S}$ & $\mathrm{S}$ & $\mathrm{Ib} ?$ \\
\hline & Taenioides jacksoni $*$ & T-S & $\mathrm{S}$ & Ia? \\
\hline & Trypauchen microcephalus & T-S & $\mathrm{S}$ & $\mathrm{Ib}$ ? \\
\hline & Yongeichthys nebulosus & $\mathrm{T}-\mathrm{S}$ & $\mathrm{S}$ & $\mathrm{Ib} ?$ \\
\hline \multirow[t]{4}{*}{ Haemulidae } & Pomadasys commersonnii & $\mathrm{T}-\mathrm{W}$ & $\mathrm{S} / \mathrm{W}$ & IIa \\
\hline & Pomadasys kaakan & $\mathrm{T}-\mathrm{S}$ & S & IIc \\
\hline & Pomadasys multimaculatum & $\mathrm{T}-\mathrm{W}$ & $\mathrm{S}$ & III \\
\hline & Pomadasys olivaceum & $\mathrm{T}-\mathrm{W}$ & $\mathrm{S} / \mathrm{W}$ & III \\
\hline \multirow[t]{2}{*}{ Hemiramphidae } & Hemiramphus far & S-W & $\mathrm{S} / \mathrm{W}$ & IIc \\
\hline & Hyporhamphus capensis * & S-W & $\mathrm{S} / \mathrm{W}$ & Ia \\
\hline \multirow{2}{*}{ Kuhliidae } & Kuhlia mugil & $\mathrm{T}-\mathrm{W}$ & $\mathrm{S} / \mathrm{W}$ & III \\
\hline & Kuhlia rupestris & $\mathrm{T}-\mathrm{S}$ & $\mathrm{S}$ & III \\
\hline Leiognathidae & Leiognathus equula & $\mathrm{T}-\mathrm{S}$ & $\mathrm{S}$ & $\mathrm{IIb}$ \\
\hline Lobotidae & Lobotes surinamensis & $\mathrm{T}-\mathrm{W}$ & $\mathrm{S}$ & III \\
\hline
\end{tabular}


Table 13. Continued.

\begin{tabular}{|c|c|c|c|c|}
\hline Family & Scientific name & $\begin{array}{l}\text { Geographical } \\
\text { range }^{1}\end{array}$ & $\begin{array}{l}\text { Southern } \\
\text { African } \\
\text { estuaries }^{2}\end{array}$ & $\begin{array}{l}\text { Estuarine } \\
\text { dependence } \\
\text { category }^{3}\end{array}$ \\
\hline \multirow[t]{2}{*}{ Lutjanidae } & Lutjanus argentimaculatus & T-W & $\mathrm{S} / \mathrm{W}$ & IIc \\
\hline & Lutjanus fulviflamma & $\mathrm{T}-\mathrm{W}$ & $\mathrm{S} / \mathrm{W}$ & IIc \\
\hline Megalopidae & Megalops cyprinoides & $\mathrm{T}-\mathrm{W}$ & $\mathrm{S}$ & $\mathrm{Vb}$ \\
\hline Monacanthidae & Stephanolepis auratus & $\mathrm{T}-\mathrm{W}$ & $\mathrm{S} / \mathrm{W}$ & III \\
\hline \multirow[t]{2}{*}{ Monodactylidae } & Monodactylus argenteus & $\mathrm{T}-\mathrm{W}$ & $\mathrm{S} / \mathrm{W}$ & $\mathrm{IIb}$ \\
\hline & Monodactylus falciformis & $\mathrm{T}-\mathrm{W}$ & $\mathrm{S} / \mathrm{W}$ & IIa \\
\hline \multirow[t]{13}{*}{ Mugilidae } & Crenimugil crenilabis & T-W & $\mathrm{S} / \mathrm{W}$ & IIb \\
\hline & Liza alata & T-S & $\mathrm{S}$ & IIb \\
\hline & Liza dumerilii & S-W & $\mathrm{S} / \mathrm{W}$ & $\mathrm{Ilb}$ \\
\hline & Liza luciae & $\mathrm{T}-\mathrm{S}$ & $\mathrm{S}$ & IIb \\
\hline & Liza macrolepis & T-S & $\mathrm{S}$ & IIa \\
\hline & Liza richardsonii $*$ & $\mathrm{~S}-\mathrm{C}$ & $\mathrm{S} / \mathrm{W} / \mathrm{C}$ & IIc \\
\hline & Liza tricuspidens * & S-W & $\mathrm{S} / \mathrm{W}$ & IIb \\
\hline & Mugil cephalus & $\mathrm{T}-\mathrm{C}$ & $\mathrm{S} / \mathrm{W} / \mathrm{C}$ & IIa \\
\hline & Myxus capensis * & S-W & $\mathrm{S} / \mathrm{W}$ & $\mathrm{Vb}$ \\
\hline & Valamugil buchanani & $\mathrm{T}-\mathrm{W}$ & $\mathrm{S} / \mathrm{W}$ & IIc \\
\hline & Valamugil cunnesius & T-S & $\mathrm{S}$ & IIa \\
\hline & Valamugil robustus & $\mathrm{T}-\mathrm{S}$ & $\mathrm{S}$ & IIa \\
\hline & Valamugil seheli & $\mathrm{T}-\mathrm{S}$ & $\mathrm{S}$ & IIc \\
\hline Muraenesocidae & Muraenesox bagio & $\mathrm{T}-\mathrm{W}$ & $\mathrm{S}$ & III \\
\hline Muraenidae & Strophidon sathete & $\mathrm{T}-\mathrm{S}$ & $\mathrm{S}$ & III \\
\hline Myliobatidae & Myliobatis aquila & $\mathrm{S}-\mathrm{C}$ & $\mathrm{S} / \mathrm{W}$ & III \\
\hline Ophichthidae & Ophisurus serpens & $\mathrm{T}-\mathrm{W}$ & $\mathrm{S} / \mathrm{W} / \mathrm{C}$ & IIc \\
\hline Paralichthyidae & Pseudorhombus arsius & T-W & $\mathrm{S} / \mathrm{W}$ & III \\
\hline Platycephalidae & Platycephalus indicus & $\mathrm{T}-\mathrm{W}$ & $\mathrm{S} / \mathrm{W}$ & IIc \\
\hline Polynemidae & Polydactylus sextarius & $\mathrm{T}-\mathrm{W}$ & $\mathrm{S}$ & III \\
\hline Pomatomidae & Pomatomus saltatrix & $\mathrm{T}-\mathrm{C}$ & $\mathrm{S} / \mathrm{W} / \mathrm{C}$ & IIc \\
\hline Pristidae & Pristis zijsron & $\mathrm{T}-\mathrm{S}$ & $\mathrm{S}$ & IIc \\
\hline Rhinobatidae & Rhinobatos annulatus* & $\mathrm{S}-\mathrm{C}$ & $\mathrm{S} / \mathrm{W} / \mathrm{C}$ & III \\
\hline \multirow[t]{3}{*}{ Sciaenidae } & Argyrosomus japonicus & T-W & $\mathrm{S} / \mathrm{W}$ & IIa \\
\hline & Johnius dorsalis & $\mathrm{T}-\mathrm{W}$ & $\mathrm{S}$ & IIc \\
\hline & Otolithes ruber & T-S & $\mathrm{S}$ & III \\
\hline \multirow[t]{2}{*}{ Serranidae } & Epinephelus andersoni & $\mathrm{T}-\mathrm{W}$ & $\mathrm{S} / \mathrm{W}$ & III \\
\hline & Epinephelus malabaricus & T-S & $\mathrm{S}$ & III \\
\hline Siganidae & Siganus sutor & $\mathrm{T}-\mathrm{W}$ & $\mathrm{S} / \mathrm{W}$ & III \\
\hline Sillaginidae & Sillago sihama & $\mathrm{T}-\mathrm{W}$ & $\mathrm{S}$ & IIc \\
\hline \multirow[t]{2}{*}{ Soleidae } & Heteromycteris capensis $*$ & $\mathrm{~S}-\mathrm{C}$ & $\mathrm{S} / \mathrm{W} / \mathrm{C}$ & $\mathrm{Ilb}$ \\
\hline & Solea bleekeri * & $\mathrm{S}-\mathrm{C}$ & $\mathrm{S} / \mathrm{W} / \mathrm{C}$ & $\mathrm{IIb}$ \\
\hline \multirow[t]{3}{*}{ Sparidae } & Acanthopagrus berda & $\mathrm{T}-\mathrm{W}$ & S/W & IIa \\
\hline & Crenidens crenidens & $\mathrm{T}-\mathrm{S}$ & $\mathrm{S}$ & III \\
\hline & Diplodus cervinus hottentotus * & S-W & $\mathrm{S} / \mathrm{W}$ & III \\
\hline \multirow[t]{7}{*}{ Sparidae } & Diplodus sargus capensis* & $\mathrm{T}-\mathrm{C}$ & $\mathrm{S} / \mathrm{W} / \mathrm{C}$ & IIc \\
\hline & Lithognathus lithognathus* & S-C & $\mathrm{S} / \mathrm{W} / \mathrm{C}$ & IIa \\
\hline & Lithognathus mormyrus & S-C & $\mathrm{S} / \mathrm{W}$ & III \\
\hline & Rhabdosargus globiceps* & W-C & $\mathrm{W} / \mathrm{C}$ & IIc \\
\hline & Rhabdosargus holubi* & S-C & $\mathrm{S} / \mathrm{W} / \mathrm{C}$ & IIa \\
\hline & Rhabdosargus sarba & $\mathrm{T}-\mathrm{W}$ & $\mathrm{S} / \mathrm{W}$ & Ilb \\
\hline & Rhabdosargus thorpei* & $\mathrm{S}$ & $\mathrm{S}$ & $\mathrm{IIb}$ \\
\hline
\end{tabular}




\begin{tabular}{|c|c|c|c|c|}
\hline Family & Scientific name & $\begin{array}{l}\text { Geographical } \\
\text { range }^{1}\end{array}$ & $\begin{array}{l}\text { Southern } \\
\text { African } \\
\text { estuaries }^{2}\end{array}$ & $\begin{array}{l}\text { Estuarine } \\
\text { dependence } \\
\text { category }^{3}\end{array}$ \\
\hline \multirow[t]{3}{*}{ Sparidae } & Sarpa salpa & S.C & $\mathrm{S} / \mathrm{W} / \mathrm{C}$ & IIc \\
\hline & Sparodon durbanensis* & S-C & W & III \\
\hline & Spondyliosoma emarginatum * & $\mathrm{S}-\mathrm{C}$ & $\mathrm{W} / \mathrm{C}$ & III \\
\hline \multirow[t]{2}{*}{ Sphyraenidae } & Sphyraena barracuda & T-S & $\mathrm{S}$ & IIb? \\
\hline & Sphyraena jello & $\mathrm{T}-\mathrm{W}$ & $\mathrm{s}$ & IIc? \\
\hline \multirow[t]{7}{*}{ Syngnathidae } & Hippichthys heptagonus & $\mathrm{T}-\mathrm{S}$ & S & $\mathrm{Ib} ?$ \\
\hline & Hippichthys spicifer & $\mathrm{T}-\mathrm{W}$ & $\mathrm{S}$ & $\mathrm{Ib} ?$ \\
\hline & Hippocampus capensis* & W & W & Ia \\
\hline & Microphis fluviatilis & T-S & $\mathrm{S}$ & $\mathrm{Ib}$ ? \\
\hline & Microphis brachyurus & T-S & $\mathrm{S}$ & $\mathrm{Ib}$ ? \\
\hline & Syngnathus acus & $\mathrm{S}-\mathrm{C}$ & $\mathrm{S} / \mathrm{W} / \mathrm{C}$ & $\mathrm{Ib}$ \\
\hline & Syngnathus watermeyeri $*$ & $\mathrm{~W}$ & $\mathrm{~W}$ & Ia \\
\hline \multirow[t]{2}{*}{ Teraponidae } & Pelates quadrilineatus & T-S & $\mathrm{S}$ & IIc \\
\hline & Terapon jarbua & T-W & $\mathrm{S} / \mathrm{W}$ & IIa \\
\hline \multirow[t]{3}{*}{ Tetraodontidae } & Amblyrhynchotes honckenii & $\mathrm{T}-\mathrm{C}$ & $\mathrm{S} / \mathrm{W} / \mathrm{C}$ & III \\
\hline & Arothron hispidus & $\mathrm{T}-\mathrm{W}$ & $\mathrm{S} / \mathrm{W}$ & III \\
\hline & Arothron immaculatus & T-W & $\mathrm{S} / \mathrm{W}$ & III \\
\hline \multirow[t]{2}{*}{ Torpedinidae } & Torpedo fuscomaculata & T-W & $\mathrm{S} / \mathrm{W}$ & IIc? \\
\hline & Torpedo sinuspersici & $T-W$ & $\mathrm{~S} / \mathrm{W}$ & IIc? \\
\hline
\end{tabular}

Estuaries appear to provide a nursery area for a different set of fish species to those found in other coastal habitats (Lasiak 1981). Table 14 shows the 10 most abundant fish species in four different coastal environments in the Algoa Bay region. Only two species in the estuarine list feature in any of the other three habitats. The sparid Rhabdosargus holubi, which is ranked number two in the estuarine category, is ranked number nine in tidal pools. The mugilid Liza richardsonii, ranked number nine under estuaries, is number seven in the surf zone and number ten in tidal pools. None of the other eight estuary-associated species were recorded in the top ten species found in tidal pools, subtidal gullies or surf zone habitats (Table 14). This result implies a degree of habitat specialisation by these species.

A Bray-Curtis similarity analysis of the Table 14 data indicated that the estuarine fish assemblage had only a $10 \%$ similarity with the ichthyofauna in the other three habitats. This result points to a distinctive fish community which is highly dependent on estuaries as nursery areas. For a habitat to serve as a nursery area for juvenile fish it must be physiologically suitable in terms of chemical and physical features, it must provide abundant and suitable food, and it must afford a degree of protection from predators (Beckley 1985b). Based upon the large proportion of juvenile fish present in each of the coastal habitats listed in Table 14, it would appear that collectively these environments provide major nursery areas for at least 30 species.

Indications from the above are that the juveniles of many fish taxa tend to select different coastal environments, which implies true dependence on these habitats as opposed to opportunistic utilization. However, a few taxa were abundant in more than one habitat, e.g. Chirodactylus brachydactylus was abundant in both tidal pools and subtidal gulleys. Diplodus sargus is perhaps the most widespread species and was ranked number six or above in tidal pools, subtidal gullies and the surf zone (Table 14). Although $D$. sargus was not ranked in the top ten species found in the Sundays Estuary (Beckley 1984a), juveniles are very abundant in submerged eelgrass beds of the nearby Swartkops Estuary (Beckley 1983). It would appear therefore that $D$. sargus, together with $L$. richardsonii, are two species which are least dependent on particular coastal environments and are able to utilise a wide variety of habitats. 
Table 14. Fishes associated with four Algoa Bay coastal environments; estuaries (Beckley 1984a), tidal pools (Beckley 1985b), subtidal gullies (Smale \& Buxton 1989) and surf zone (Lasiak 1984b). The 10 most dominant species in each habitat, all of which are represented mainly by juveniles, are ranked according to their recorded abundance.

\section{HABITAT}

Estuarine littoral

Tidal pool

1. Gilchristella aestuaria

2. Rhabdosargus holubi

3. Liza dumerilii

4. Monodactylus falciformis

5. Psammogobius knysnaensis

6. Mugil cephalus

7. Solea bleekeri

8. Heteromycteris capensis

9. Liza richardsonii

10. Caffrogobius gilchristi
1. Clinus superciliosus

2. Chirodactylus brachydactylus

3. Diplodus sargus capensis

4. Caffrogobius caffer

5. Caffrogobius saldanha

6. Atherina breviceps

7. Clinus cottoides

8. Sparodon durbanensis

9. Rhabdosargus holubi

10. Liza richardsonii

\section{HABITAT}

Subtidal gully

1. Chirodactylus brachydactylus

2. Sarpa salpa

3. Caffrogobius saldanha

4. Cheilodactylus fasciatus

5. Galeichthys ater

6. Diplodus sargus capensis

7. Clinus cottoides

8. Halidesmus scapularis

9. Chorisochismus dentex

10. Pavoclinus gramminus
Surf zone

1. Atherina breviceps

2. Pomadasys olivaceum

3. Sarpa salpa

4. Lithognathus mormyrus

5. Trachurus capensis

6. Diplodus sargus capensis

7. Liza richardsonii

8. Rhabdosargus globiceps

9. Argyrosomus japonicus

10. Rhinobatos annulatus 


\subsection{PRESENT AND FUTURE CONSERVATION TRENDS}

Only about $3 \%$ of the Earth's area is protected within refuges (Western 1989) and most of these reserves are designed to cater for terrestrial rather than aquatic conservation. Even if the total area under protection were to be doubled or tripled, the Earth's biodiversity would still be threatened (Moyle \& Leidy 1992). This applies particularly to fishes in estuaries which are highly mobile and cannot be confined to the boundaries of a particular reserve. In addition, the linear nature of most estuaries, and their high degree of linkage with freshwater and marine ecosystems, makes estuarine habitats highly vulnerable to external perturbations.

Many issues and developments, such as the siting of industries and recreational facilities, are subject to government control, consent or guidance. Ichthyologists are committed to supporting the appropriate and sustainable use of estuaries without prejudicing the fish resources. A 'sustainable development' approach is particularly relevant to estuaries, since it presupposes that risks of damage to the environment will be anticipated and avoided. Research projects within southern Africa are contributing to the establishment of minimum standards for environmental assets, and environmental accounting of the state of those assets. With the signing of the Convention on Biological Diversity by the South African Government, there is a national and international obligation to maintain the resource of estuarine habitats, their fishes and their value for all citizens of the country (Whitfield 1997).

\section{Threats to fishes}

Factors that have caused fishes to become threatened are varied and often differ from one biogeographic area to another (Bruton 1995). These factors can include habitat degradation, disruption of essential ecological processes, hydrological manipulations, environmental pollution, over exploitation due to fishing activities, global effects, genetic contamination, and impacts of introduced aquatic animals. In southern African estuaries, habitat degradation through land use changes, and hydrological manipulations through excessive freshwater abstraction are important factors. Less important at present, but showing increasing signs towards becoming a major problem is environmental pollution, especially organic and inorganic wastes from industrial, agricultural and domestic sources.

Although certain alien freshwater fish species have been recorded in selected oligohaline systems, these taxa are restricted both in estuarine distribution and abundance. Genetic contamination of indigenous fish stocks through hybridisation has not been documented for any estuaries on the subcontinent.
Cyrus (1991c) lists 20 'problems' arising from anthropogenic activities "which could lead to the periodic or permanent elimination of estuarinedependent fish species from individual systems". These include increased siltation, loss of certain habitat types, hypersaline conditions, fish mortalities due to pollution and prolonged mouth closure. According to Cyrus (op. cit.) virtually every 'pressure' that estuaries face can be considered under the heading habitat destruction, which can be divided into three subcategories, viz. physical, chemical or biological in origin. He goes on to suggest that the mounting pressures facing southern African estuaries and the consequent problems that arise, indicate that the fish fauna is under threat. In this context $17 \%$ of the estuaries in the subtropical province, $11 \%$ in the warm-temperate province, and $50 \%$ in the cooltemperate province were recently classified as being in poor condition (Table 15).

Although major threats to fishes are usually linked to environmental degradation, there is also evidence to suggest that certain fish species are declining in abundance primarily as a result of overfishing. According to Gilchrist (1918) the sparid Lithognathus lithognathus formed an important component of anglers catches in the Swartkops Estuary during the early part of this century. However, monitoring of angling in the Swartkops Estuary during the 1970s (Marais \& Baird 1980b) suggested a dramatic decline in the abundance of this species and its replacement by Pomadasys commersonnii as the prime angling species. More recent sampling information shows a complete absence of $L$. lithognathus from gill net catches in the Swartkops Estuary (Baird et al. 1996), with angling pressures in estuaries and along the coast being identified as a primary cause of the depleted stocks.

\section{Maintaining estuarine productivity}

Most fish species in southern African estuaries are adapted to normal tidal salinity fluctuations, and can even tolerate prolonged oligohaline or hypersaline conditions, provided these changes occur gradually over an extended period. Although salinity extremes are a natural feature of Lake St Lucia, the levels attained by the salinity peaks have increased following the construction of impoundments in the catchment basin (Branch and Branch 1981). Unless alternative sources of fresh water can be found, salinity peaks within this estuarine system are likely to increase in the future. Hypersaline conditions result in the direct loss of species which cannot tolerate particular salinities and also result in a decline in food resources for the remaining fish (Boltt 1975, Wallace 1975a). 
Table 15. A composite analysis of the condition of South African estuaries in each biogeographical region (data from Whitfield 1995a).

\begin{tabular}{|c|c|c|c|c|c|c|c|c|}
\hline \multirow{3}{*}{$\begin{array}{l}\text { ESTUARINE } \\
\text { CONDITION }\end{array}$} & \multicolumn{6}{|c|}{ REGION } & & \\
\hline & \multicolumn{2}{|c|}{ Cool-temperate } & \multicolumn{2}{|c|}{ Warm-temperate } & \multicolumn{2}{|c|}{ Subtropical } & \multicolumn{2}{|c|}{ South Africa } \\
\hline & No. & $\%$ & No. & $\%$ & No. & $\%$ & No. & $\%$ \\
\hline Poor & 5 & 50 & 13 & 11 & 20 & 17 & 38 & 15 \\
\hline Fair & 2 & 20 & 21 & 17 & 36 & 31 & 59 & 24 \\
\hline Good & 2 & 20 & 54 & 44 & 22 & 19 & 78 & 31 \\
\hline Excellent & 1 & 10 & 35 & 28 & 39 & 33 & 75 & 30 \\
\hline TOTAL & 10 & 100 & 123 & 100 & 117 & 100 & 250 & 100 \\
\hline
\end{tabular}

The majority of southern African estuarine systems are naturally closed off from the sea for varying periods, and in the past this has led to actions by poorly informed land owners and local authorities attempting to maintain open mouth conditions (Begg 1984a). Legislation and information dissemination (e.g. Heydorn \& Tinley 1980) has drastically curtailed the ad hoc breaching of estuarine sand bars, but existing housing and agricultural developments on adjacent floodplains have necessitated the continued premature opening of a large number of temporarily closed estuary mouths. This has a negative influence on effective sediment scour by the released lagoonal waters and hence the duration of the open phase.

Estuaries are usually more productive than adjacent seas or inflowing rivers. Unfortunately the high primary and secondary productivity of estuaries on the subcontinent is seldom taken into account when assessing the value of these systems. The viability of estuaries as nurseries and feeding grounds for fishes is directly related to the accessibility and productivity of these systems (Paterson \& Whitfield 1996).

A holistic approach to ecosystem productivity and management is urgently required. Mismanagement of either the river catchments or their adjacent estuaries leads to impoverished systems which are of little value to aquatic organisms or people. In this context almost 100 of the 250 estuaries along the South African coast have been assessed as being in a poor or fair condition (Table 15). Not only should we ensure that this number does not increase, but an effort needs to made to restore those estuaries that have been damaged into viable ecosystems.

\section{Reducing estuary mouth manipulation}

The species composition, abundance and size distribution of marine fishes within southern African estuaries undergo seasonal variations that are directly related to migration patterns. Recruitment of most species into Eastern and Western Cape estuaries reaches a peak during early summer, which coincides with maximum food resource availability and corresponds to the time when systems along this section of the coast are normally open to the sea (Whitfield \& Kok 1992). The prolonged recruitment periods of most fish species into estuaries provide a buffer against the variability in mouth opening and other short-term extremes in the aquatic environment, e.g. nearshore upwelling (Schumann et al. 1982). However, artificial winter opening of southern Cape estuary mouths has occurred in the past and has generally led to the premature closure of these systems, to the detriment of juvenile marine fish recruitment (Whitfield \& Kok 1992). In addition, the larvae of several summer recruiting species are absent from the nearshore marine environment during winter (Whitfield 1989b). Loss of the 'head' of water accumulated during the winter rains effectively reduces the chances of a summer opening, thereby denying certain fish species access to estuarine nursery areas.

Dredging, on both a small and large scale, has been undertaken in several southern African estuaries. The primary aim of these operations varies according to management needs, i.e. to maintain open mouth conditions, increase water depth for recreational purposes, maintenance of marina hydrodynamics etc. 
The St Lucia Estuary was initially dredged to remove accumulated sediment deposited in the Narrows and mouth region. For more than three decades dredging was directed at the maintenance of a permanently open system, a management decision that was only recently reversed to allow the mouth to close naturally. No detailed impact studies were undertaken in the system prior to the commencement of the large-scale dredging operations. A study by Hay (1985) showed that channel areas dredged between 1973 and 1976 had zoobenthos concentrations of less than 200 animals $\mathrm{m}^{-2}$ (1 species), whereas adjacent undredged areas had densities of more than 3000 animals $\mathrm{m}^{-2}$ (7-10 species). Since many estuary-associated fish species feed on zoobenthos, it could be expected that dredging operations lower the available food resources for these teleosts. In addition, the abnormally high suspensoid levels during dredging operations in the St Lucia Estuary may also have a direct negative influence on the fish fauna (Cyrus \& Blaber 1988), especially those species which are sensitive to high turbidities.

\section{Catchment conservation}

The management and conservation of rivers should take into account the vital role fresh water plays in the functioning of estuaries. The 1956 South African Water Act did not legally recognise the freshwater require-ments of natural ecosystems. However, new legislation governing water resource utilization within the country promotes the concept that aquatic systems, including estuaries, are the resource and not simply users of fresh water.

The transformation of estuaries into less suitable habitats for fishes has accelerated rapidly within the last 100 years. Begg (1984b) quotes numerous examples of systems on the KwaZulu-Natal coast to illustrate this deterioration, e.g. he describes the Mzumbe Estuary as having been reduced to "a shallow sheet of freshwater gravitating towards the sea over a bed of sand". This transformation has been caused by extensive catchment deterioration, floodplain cultivation and canalization, all of which have increased the sediment load transported downstream. Catchment mismangement is probably the single most important factor accounting for the loss of estuarine habitat within southern African systems and will reduce the feeding grounds available to estuaryassociated fish species. Ultimately the negative impact of this degradation will be felt more widely since, for several estuarine dependent species, there is a close relationship between the availability of estuarine nursery areas and adult abundance in the marine environment.

Additional evidence of catchment mismanagement affecting estuarine fish stocks comes from the poorly managed Mbashe system. Plumstead (1990) found that a barrage constructed on the Mbashe River in 1984 was associated with a decline in both the abundance and diversity of fish species in the Mbashe Estuary. One possible reason for these declines was the trapping of suspensoids by the barrage, which had an initial basin capacity of $9 \times 10^{6} \mathrm{~m}^{3}$, but by 1988 was reduced to $10 \%$ of capacity as a result of accumulated inorganic sediments and organic material (Plumstead 1990).

The catadromous anguillid eels are also highly vulnerable to human manipulations of inland waters due to their obligate migrations. The construction of impoundments and abstraction of fresh water has reduced habitat availability in rivers, and introduced barriers to migration. Glass eel migrations through estuaries and into fresh water occur mainly during summer but differ in magnitude between years (Bruton et al. 1987). The occurrence of river pulses into an estuary are a major trigger in facilitating the upstream migratory behaviour of glass eels. Maximum eel recruitment into Eastern Cape river systems occurs during above-average river flow following a flood, especially if the flooding event coincides with the spring tidal cycle (Bruton et al. 1987). Clearly, the capture of freshwater pulses by large impoundments will reduce olfactory cues and other migratory stimuli entering estuaries and the sea, with a concomitant decline in the number of glass eels entering suitable river catchments.

\section{Fish conservation}

Bruton (1995) has suggested that fish conservation needs to be approached from a different perspective to the conservation of mammals, mainly because of the high mobility of fishes and the continuous nature of many aquatic habitats. With few exceptions, fish species associated with southern African estuaries are highly mobile and have wide distributions, often encompassing both the marine and estuarine environment. Fish cannot be confined to specific protected estuaries by the erection of barriers, but this does not mean that estuarine reserves would be of little or no value. On the contrary, well conserved estuaries would facilitate the rapid recolonisation of adjacent systems if the latter areas were depleted of fish stocks through pollution or catchment mismanagement (Whitfield 1997).

Some innovative means of fish conservation include the controlled release of water from impoundments to facilitate fish migrations, spawning and recruitment, the zoning of river catchments and estuaries for different uses, the determination of the ecological freshwater requirements of rivers and estuaries, the recognition that the maintenance of ecological processes are vital to aquatic ecosystem health, and the introduction of measures to reduce river reset distances below impoundments (Bruton 1995). During the past decade, the Department of 
Water Affairs and Forestry has recognised that the health of both rivers and estuaries necessitates that adequate freshwater allocations be implemented. Consequently the policy of the Department has been to conduct both Instream Flow Requirement (IFR) and Estuarine Freshwater Requirement (EFR) studies on individual systems prior to the allocation of water resources from proposed dams. An important feature of these studies and follow-up worksessions has been an assessment of the river flow requirements of the ichthyofauna in affected estuaries.

Apart from the designation of protected areas, the main direct means of conserving fish species and stocks include habitat conservation, controls over fishing methods, effort, efficiency and seasonality, other forms of legislation, construction of fish passes, pollution control, benign translocations and captive breeding (Bruton 1995). Of these, the conservation of fish habitats is by far the most important, since healthy aquatic environments invariably support healthy fish populations. A local example of the importance of the above statement can be seen in the rapid recovery of the Sezela Estuary fish community following habitat restoration (Ramm et al. 1987). Another example of how habitat conservation in conjunction with wise fisheries management has led to sustainable human exploitation of fish stocks, can be seen in the Kosi estuarine system (Kyle 1993). Both traditional and modern methods of fishing by local residents have been examined, and destructive methods such as jigging have been discouraged.

The basis for any effective fish conservation programme must also include appropriate legislation, such as the Endangered Species Act in the United States of America (Angermeier \& Williams 1994). Many countries, including South Africa, have only lists of threatened and extinct fishes, which have no legal standing. Conservation legislation or lists are useless if enforcement and restoration programmes are not effectively carried out (Bruton 1995). Conservation actions need to be based on a sound knowledge of the biology and ecology of threatened species, their communities and their habitats. This view is reinforced by Skelton (1987) who stated "Research is an essential component of any conservation exercise. Conservation authorities need to know what species are threatened, why they are threatened and what the priority requirements are for the effective conservation of those species".

Cyrus (1991) proposed that an assessment of the relative importance of all South African estuaries to the survival of fishes dependent on them should be conducted. The most important fish species should be singled out and a policy adopted which will, in the long-term, ensure the survival of these taxa. Similar sentiments have been expressed by Skelton (1983) who suggested that apart from establishing data bases for fishes, the nature conservation authorities need to formulate and publish conservation policies with regard to both the ichthyofauna and the aquatic environment.
The concepts of 'indicator', 'keystone', 'umbrella' and 'flagship' species are useful in setting priorities for conservation action (Bruton 1995). Indicator species are those taxa that are sensitive to environmental changes and whose incidence and abundance can be used to assess environmental quality. For example, the sparid Acanthopagrus berda would be a useful indicator species in subtropical southern African estuaries. Keystone species are those whose continued well-being is vital as a functional need of a whole community. For example, the zoobenthic predator Lithognathus lithognathus, detritivorous Liza dumerilii, planktivorous Gilchristella aestuaria and piscivorous Argyrosomus japonicus would provide a useful suite of keystone species for southern African estuaries. An umbrella species is important as its protection serves to conserve a multitude of lesser known co-existing taxa in the same habitat, both vertebrate and invertebrate. For example, the widespread and omnivorous Rhabdosargus holubi would be a useful umbrella species in estuaries on the subcontinent. Flagship species have particular public appeal and other features that render them suitable for communicating conservation concern. For example, the piscivorous Lichia amia or zoobenthic predator Pomadasys commersonnii, both of which are popular angling species, could act as flagship species in southern African estuaries.

\section{Aquatic reserves}

The concept of marine reserves or marine protected areas (MPAs) is well established in South Africa and elsewhere (Bennett \& Attwood 1993). Marine reserves are usually designed as a viable alternative to classical marine fisheries management techniques, or at least as an additional tool in the management of fishes (Buxton 1993). Reasons for this include (a) protection of the spawner stock, (b) providing a recruitment source for surrounding areas, (c) restocking of adjacent areas through adult emigration, (d) maintenance of natural population age structure, (e) conservation of biodiversity, undisturbed habitat and natural life support processes, ( $f$ ) insurance against failure of other management techniques and $(\mathrm{g})$ simplified law enforcement. Most, if not all, of the above advantages apply equally to estuarine reserves.

In recent years the benefits of marine reserves in replenishing depleted fish stocks and 'seeding' adjacent unprotected areas has become apparent (Bennett \& Attwood 1991, Buxton 1993). For several decades estuaries have been recognised as nursery areas for a number of recreationally important fish species, yet these systems have not been targeted for protection or formed an integral component in the selection of marine reserves. Surely the dependence of many marine fishes on estuarine habitats as nursery areas necessitates the inclusion of these ecosystems in any marine reserve planning exercise? 
Major marine protected areas along the southern African coast include only a limited number of minor estuaries within their borders. The Tsitsikamma and St Lucia Marine Reserves are each approximately $80 \mathrm{~km}$ in length, with the former reserve incorporating only six short river mouths and the latter one small estuary. Indeed, from an estuarine perspective it would be difficult to select two worse $80 \mathrm{~km}$ sections of coastline as multi-purpose aquatic reserves. Fortunately the creation of the St Lucia Game Reserve, Kosi Bay Nature Reserve and Wilderness National Park have provided protection for some of southern Africa's largest and more important estuarine systems. All three systems are recognised under the Ramsar Convention as being wetlands of international importance, not because of their role as vital fish habitats, but rather their importance to birds (Cowan 1995). In addition to these large systems, there are also several smaller estuaries along the coast which are protected to varying degrees by national, provincial or municipal legislation (Robinson \& de Graaff 1994, Figure 37). Little or no planning has been undertaken in the above selection process.
The optimum shape and size of terrestrial nature reserves has been the subject of considerable speculation. Most of the principles that have been developed in recent times have been applied to terrestrial reserves but Moyle \& Sato (1991) have proposed useful guidelines for the design of aquatic reserves. The conservation of aquatic biotas requires the protection not only of aquatic habitats but of the surrounding land habitats as well. Aquatic reserves therefore need to include wide buffer zones to protect these systems from changes occurring in surrounding environments. Estuarine reserves also need the protection of upstream areas if their full potential as conservation areas is to be realised.

Attwood et al. (1997) have pointed out that estuaries suffer from the unique problem of falling on the boundary of the jurisdiction of management authorities. These habitats are neither land nor sea and, being tidal with mostly marine species, they are usually excluded from river management initiatives. In practise the management of all these zones affect the estuary, and unless the estuary is specifically considered in management plans, its requirements are ignored.

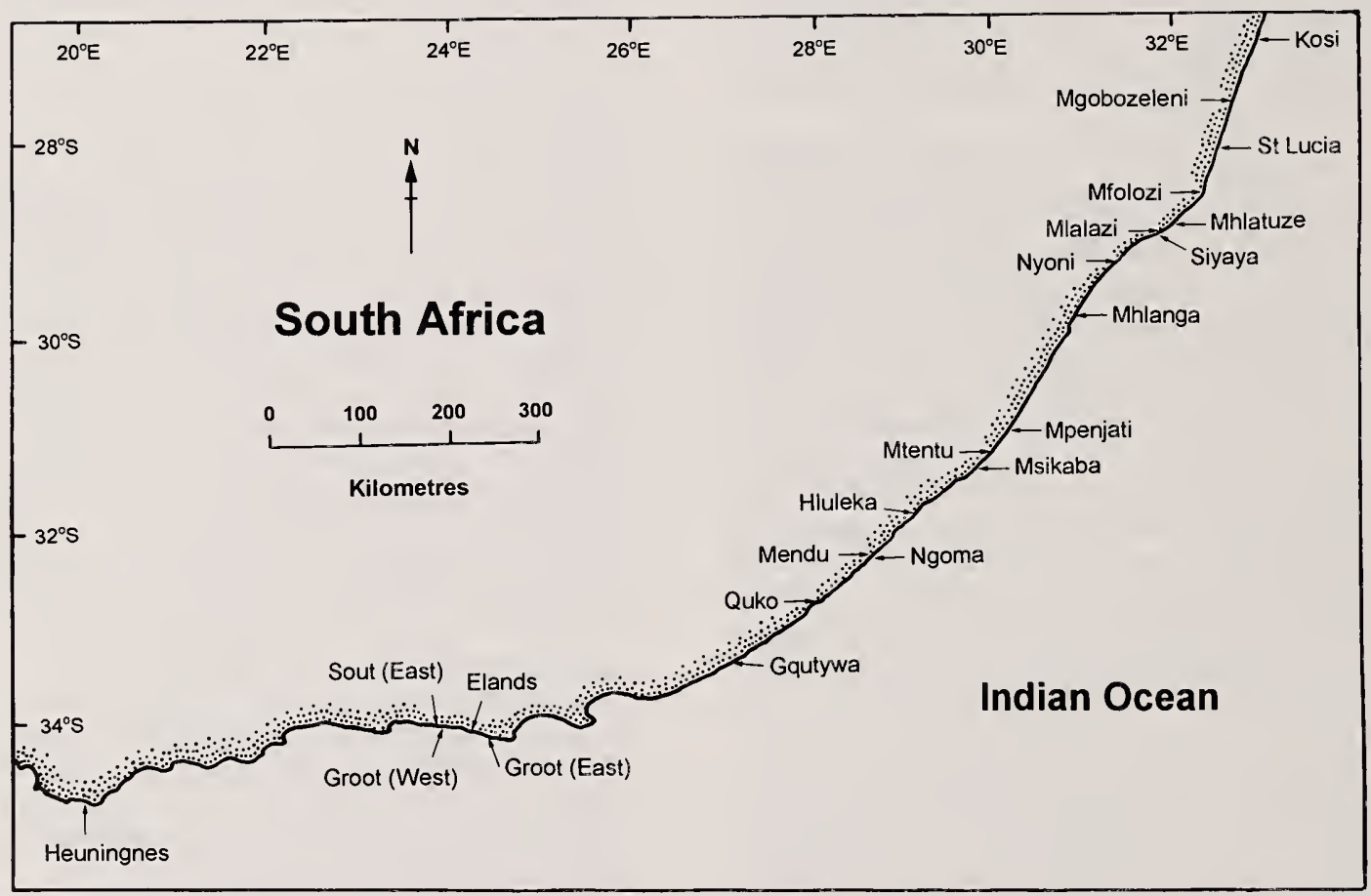

Figure 37. Map of South Africa showing functional estuaries which have a formally recognized conservation or protected status. In almost all the above systems the fish are not protected, i.e. angling and in some cases netting is permitted. Those estuaries which have only a portion of the water area conserved are not shown above and include the Orange, Diep, Wilderness, Swartvlei, Goukamma, Knysna, Keurbooms, Seekoei, Gamtoos, Mbizana and Mgeni systems. 
Perhaps the answer for southern African estuarine protection lies with a modified version of the United States of America system, one of the most developed in the world. The U.S.A. National Estuarine Research Reserve System (NERRS) is distinct from the National Marine Sanctuary Program, and is a system which recognises that estuaries are important and have special management requirements. The NERRS was authorised under the Coastal Management Act, in response to concerns about threats to estuaries. Estuaries require integrated management of the entire river catchment, the coastal zone and the adjacent ocean. The NERRS provides this, not by imposing restrictive legislation in estuaries, but rather by facilitating federal, state and local partnerships which serve to promote informed estuarine management. Public stewardship, education and scientific monitoring are important initiatives of the NERRS. Potential estuarine sites are designated by NERRS for NERR-status, which elevates the estuary to a higher level of management, with access to financial, adminstrative and technical support.

Estuarine sanctuaries in Australia are not treated separately but are included in the general category, Marine and Estuarine Protected Area (MEPA), of which 228 have been established (Rigney 1990). MEPAs are based on a sustainable use principle and most activities are allowed in certain zones or under reasonable control. Less than $2 \%$ of Australian MEPAs are closed to all forms of fishing (Attwood et al. 1997).

Within South Africa there are 33 functional estuaries or portions of these systems that are conserved (Figure 37), few of which protect fish species from exploitation. This is surprising when it is considered that estuaries are important nursery areas for several important angling species on the subcontinent. What is needed is an expansion of the existing Estuarine Protected Area (EPA) network, as well as the upgrading of selected 'estuarine reserves' where fishing is permitted, into 'estuarine sanctuaries' where no exploitation of biological resources is allowed.

\section{Conserving endemic species}

Endemic fishes are those species which are confined to a particular region and are found nowhere else in the world. In southern Africa approximately $13 \%$ of the 2200 marine species are endemic to the subcontinent (Smith \& Heemstra 1986a), compared to a freshwater ichthyofaunal endemicity of approximately $61 \%$ (Skelton 1993). Estuaries lie between these two extremes, with 38 fish species $(2.5 \%$ of all estuaryassociated taxa) being endemic to southern African waters (Table 13). However, the percentage endemicity in the region increases from $18 \%$ ( 25 species) in subtropical estuaries to $67 \%$ (16 species) in cooltemperate estuaries.
The South African Red Data Book on fishes (Skelton 1987) lists eight threatened endemic estuarine fish species, three of which are classified as vulnerable and five rare. However these statistics do not tell the complete story. The degradation of southern African estuaries during the past century has contributed to the depletion of previously abundant species such as the sparid Acanthopagrus berda, hence its usefulness as an 'indicator' species. According to van der Elst (1978) the catch of $A$. berda in the St Lucia Estuary fluctuated between two and 48 per 100 angling hours between 1956 and 1962, but declined to less than two per 100 angling hours between 1963 and 1977. The average individual mass of $A$. berda landed by anglers over the same period declined from $900 \mathrm{~g}$ to approximately $700 \mathrm{~g}$. Although this species is not listed as threatened, the message that these catch statistics are conveying indicates that previously abundant estuary-associated species are showing considerable declines in abundance.

The mugilid Myxus capensis has also been adversely affected by anthropogenic influences. Obstructions across rivers in the form of weirs and dams prevent the upstream migration of this catadromous species. According to Bok (1984) $M$. capensis penetrate between $100 \mathrm{~km}$ and $200 \mathrm{~km}$ above the estuarine zones of some of the larger Eastern Cape systems, but the widespread construction of low weirs and dams on coastal rivers has reduced both the range and abundance of this species. Excessive freshwater abstraction from rivers has reduced the size and number of large, deep pools in coastal rivers. Since these pools are a prime habitat for freshwater mullet (especially in the Eastern Cape) for up to 3 years in the case of males and 5 years in females (Bruton et al. 1987), one can only conclude that the decline in the numbers of freshwater mullet is also associated with this negative influence.

The recent history of the pipefish Syngnathus watermeyeri is even more disconcerting than that described for the above two species. S. watermeyeri was previously restricted to three estuaries in the Eastern Cape Province but now appears to have disappeared from two of these systems, viz. the Kariega and Kasuka. Can we identify any cause(s) which may have pushed the estuarine pipefish onto the verge of extinction? Although speculative, it would appear that changes in freshwater supplies to the above estuaries may have been responsible for this disturbing event. Catchment mismanagement within the Kariega system, particularly the absence of environmental freshwater allocations from dams and other impoundments, has resulted in this estuary becoming deprived of essential freshwater pulses (Whitfield \& Wooldridge 1994). These pulses provide nutrients which facilitate phytoplankton development within the estuaries and, together with particulate organic material brought down by the rivers, support the zooplankton community on which pipefish depend 
for food (Whitfield 1995b). Marked reductions in zooplankton stocks, arising from depleted pelagic food resources, would have placed additional survival pressures on a species which was already rare and had a limited distribution.

The responses of the above three endemic fish species can all be regarded as indicators of environmental deterioration. The signals that these taxa are sending out needs a positive reaction on our part. In the case of the estuarine pipefish there is a need for urgent remedial action to save the species. Such moves would benefit not only $S$. watermeyeri but also other estuarine inhabitants. This action could take the form of an environmental freshwater allocation from impoundments on the Kariega and Bushmans rivers, something that has until recently not been considered. The implementation of an upstream freshwater release policy would also benefit $M$. capensis, particularly if such a move coincided with the erection of fish ladders on dams and weirs where feasible. The case of $A$. berda is more difficult to solve, since it involves catchment restoration and a reduction in angling pressure, both of which can be improved by appropriate legislation but in practise are difficult to enforce.

\section{Concluding comment}

Although it is generally recognized that the path to effective species conservation is through sound ecosystem conservation, threatened species sometimes demand urgent individual attention if they are to survive at all. In other words, each threatened species has its own set of circumstances which calls for different solutions (Whitfield 1997). Even if there is little or no room for a strategy aimed at the species level in southem Africa, the species themselves can be most useful indicators as to what are threatened ecosystems. A comparison of the proportion of threatened fish taxa in freshwater environments (Skelton 1987) to those found in estuaries on the subcontinent, suggests that the latter habitats are generally in better condition than their inflowing rivers. This coincides with the views of Moyle \& Leidy (1992) who conservatively estimated that at least $20 \%$ of the freshwater fish species of the world are already extinct or in serious decline.

According to Bruton (1995), groupings of scientists and resource managers may result in more efficient cooperation and a reduction in the duplication of conservation effort. According to him there is no greater force in conservation than the commitment of a group of people united in their protective feelings towards a given fauna or taxon, and backed by legislation that is imaginatively formulated and strictly enforced. The Consortium for Estuarine Research and Management (CERM) is a multidisciplinary group of South African scientists and managers who concentrate their efforts on research which will lead to the wise management and conservation of estuaries on the subcontinent. Within CERM are individuals and groups who are totally focused on research which will lead to the development of long-term strategies for the conservation of fishes in estuaries.

There are approximately 250 functional estuaries along southern Africa's coastline, and each system requires careful management and protection if it is to be maintained as a vital national resource. A wide range of government authorities and interest groups form opinions and make decisions which have major impacts on estuaries. Only with access to the best possible scientific information can these decisions result in the wise management of estuarine resources, now and into the next century. The future health of estuaries on the subcontinent depends on imaginative resource management and on the improved implementation of conservation measures in partnership with decision-makers, managers, scientists and estuarine users. The goal proposed by Begg (1984a) of "implementing a comprehensive nation-wide policy to conserve estuaries and lagoons throughout the country no matter how large or small" needs to be pursued with vigour. In this regard, the cooperation of the public is essential if implementation is to be successful, and will require an extensive education programme highilighting the value of the resource.

Humans have shared the African subcontinent with other animals, including fishes, for millennia. Indeed, the fish species currently threatened with extinction by human activities were residents in the area long before Homo sapiens arrived on the scene. Unfortunately this fact has not helped the case for harmonious coexistence in the past or present situation. Until we change our attitudes towards manipulation of the natural environment and over-exploitation of fishes, endemic species in particular will continue to decline in status from vulnerable to endangered to critically endangered. As inhabitants of this region we have a responsibility for the maintenance of aquatic biodiversity and the survival of indigenous fishes in particular. Greater emphasis on catchment conservation, aquatic reserves and wise utilization of fish resources is urgently required. Actions today will ensure an improvement in the quality of life tomorrow - not only for people, but for all organisms inhabiting and depending on southem African waters for their existence.

\author{
In the beginning there were no estuaries \\ In the end there will be no estuaries \\ In between we are brief custodians of one of \\ the most fascinating environments on earth
}




\section{References}

Adams, J.B. \& Talbot, M.M. 1992. The influence of river impoundment on the estuarine seagrass Zostera capensis Setchell. Botanica Marina 35, 6975.

Adams, J.B., Knoop, W.T. \& Bate, G.C. 1992. The distribution of estuarine macrophytes in relation to freshwater. Botanica Marina 35, 215-226.

Albaret, J.J. \& Diouf, P.S. 1994. Diversité des poissons des lagunes et des estuaires OuestAfricains. In: Biological Diversity of African Fresh- and Brackish Water Fishes (ed. G.G. Teugels, J.F. Guégan \& J.J. Albaret). Annales du Musée Royal de l'Afrique Centrale 275, 149-163.

Albert, R.C. \& Washuta, E.J. 1992. Fish health study - a first for the Delaware estuary. Water Environment and Technology 4, 18-22.

Allanson, B.R. 1979. The phytoplankton and primary productivity of the lake. Monographiae Biologicae 36, 75-87.

Allanson, B.R. 1981. The coastal lakes of southern Africa. In: Estuarine Ecology with Particular Reference to Southern Africa (ed. J.H. Day), pp. 331-344. Balkema, Cape Town.

Allanson. B.R., Bok, A.H. \& van Wyk, N.I. 1971. The influence of exposure to low temperature on Tilapia mossambica Peters (Cichlidae). Journal of Fish Biology 3, 181-185.

Allanson, B.R., Hill, B.J., Boltt, R.E. \& Schultz, V. 1966. An estuarine fauna in a freshwater lake in South Africa. Nature 209, 532-533.

Allanson, B.R. \& Howard-Williams, C. 1984. A contribution to the physico-chemical limnology of Swartvlei. Archiv für Hydrobiologie 99, 133-159.

Allanson, B.R. \& Read, G.H.L. 1995. Further comment on the response of Eastern Cape Province estuaries to variable freshwater flows. Southern African Journal of Aquatic Sciences 21, 56-70.

Allanson, B.R. \& van Wyk, J.D. 1969. An introduction to the physics and chemistry of some lakes in northern Zululand. Transactions of the Royal Society of South Africa 38, 217-240.

Allen, G.R. 1985. FAO species catalogue. Volume 6. Snappers of the world. An annotated and illustrated catalogue of lutjanid species known to date. FAO Fisheries Synopsis No. 125, 1-208.

Anderson. M.E. 1995. Fossil fishes at Grahamstown. The Naturalist 39(1), 26-27.

Anderson, M.E., Hiller, N. \& Gess, R.W. 1994. The first Bothriolepis-associated Devonian fish fauna from Africa. South African Journal of Science 90, $397-403$.
Anderson, W.D. \& Allen, G.R. 1986. Family No. 181: Lutjanidae. In: Smiths' Sea Fishes (ed. M.M. Smith \& P.C. Heemstra), pp. 572-579. Macmillan South Africa, Johannesburg.

Angermeier, P.L. \& Williams, J.E. 1994. Conservation of imperilled species and reauthorisation of the Endangered Species Act of 1973. Fisheries 19, 2629.

Attwood, C.G., Harris, J. \& Williams, A. 1997. International experience of marine protected areas with relevance for South Africa. South African Network for Coastal and Oceanic Research, Occasional Report No. 2, 13-52.

Avenant-Oldewage, A. 1994. A new species of Argulus from Kosi Bay, South Africa and distribution records of the genus. Koedoe 37(2), 89-95.

Badenhorst, P., Cooper, J.A., Crowther, J., Gonsalves, J., Grobler, N.A., Illenberger, W.K., Laubscher, W.I., Mason, T.R., Moller, J.P., Perry, J.E., Reddering, J.S. \& van der Merwe, L. 1989. Survey of the September 1987 Natal floods. South African National Scientific Programmes Report No. 164, 1-134.

Bagarinao, T. 1994. Systematics, distribution, genetics and life history of milkfish, Chanos chanos. Environmental Biology of Fishes 39, 23-41.

Baillie, J. \& Groombridge, B. 1996. 1996 IUCN Red List of Threatened Animals. IUCN, Gland, Switzerland, $368 \mathrm{pp}$.

Baird, D. 1988. Synthesis of ecological research in the Swartkops estuary. In: The Swartkops Estuary (ed. D. Baird, J.F.K. Marais \& A.P. Martin), pp. 4156. South African National Scientific Programmes Report No. 156.

Baird, D. \& Heymans, J.J. 1996. Assessment of ecosystem changes in response to freshwater inflow of the Kromme River Estuary, St Francis Bay, South Africa: a network analysis approach. Water SA 22, 307-318.

Baird, D., Marais, J. \& Daniel, C. 1996. Exploitation and conservation of angling fish species in selected South African estuaries. Aquatic Conservation: Marine and Freshwater Ecosystems 6, 319-330.

Baird, D., McGlade, J.M. \& Ulanowicz, R.E. 1991. The comparative ecology of six marine ecosystems. Philosophical Transactions of the Royal Society of London, Series B 333, 15-29.

Baird, D. \& Ulanowicz, R.E. 1993. Comparative study on the trophic structure, cycling and ecosystem properties of four tidal estuaries. Marine Ecology Progress Series 99, 221-237. 
Bally, R. \& McQuaid, C.D. 1985. Physical and chemical characteristics of the waters of the Bot River estuary, South Africa. Transactions of the Royal Society of South Africa 45, 291-304.

Balon, E.K. 1981. Saltatory processes and altricial to precocial forms in the ontogeny of fishes. American Zoologist 21, 573-596.

Bass, A.J., D'Aubrey, J.D. \& Kistnasamy, N. 1973. Sharks of the east coast of southern Africa. 1. The genus Carcharhinus (Carcharhinidae). Investigational Report of the Oceanographic Research Institute 33, 1-168.

Bass, A.J., Heemstra, P.C. \& Compagno, L.J.V. 1986. Family No. 9: Carcharhinidae. In: Smiths' Sea Fishes (ed. M.M. Smith \& P.C. Heemstra), pp. 67-87. Macmillan South Africa, Johannesburg.

Batchelor, G.R. 1978. Population structure and apparent predation on the red-breasted kurper, Tilapia rendalli, in a northern Transvaal impoundment. South African Journal of Wildlife Research 8, 39-41.

Bawazeer, A.S. 1987. Stock assessment of the largetooth flounder (Khoffah, Pseudorhombus arsius) in Kuwait waters. Kuwait Bulletin of Marine Science 9, 207-214.

Beckley, L.E. 1983. The ichthyofauna associated with Zostera capensis Setchell in the Swartkops estuary, South Africa. South African Journal of Zoology 18, 15-24.

Beckley, L.E. 1984a. The ichthyofauna of the Sundays estuary, South Africa, with particular reference to the juvenile marine component. Estuaries 7, 248- 250.

Beckley, L.E. 1984b. Shallow water trawling off Swartkops estuary, Algoa Bay. South African Journal of Zoology 19, 248-258.

Beckley, L.E. 1985a. Tidal exchange of ichthyoplankton in the Swartkops estuary mouth, South Africa. South African Journal of Zoology 20,15-20.

Beckley, L.E. 1985b. The fish community of east Cape tidal pools and an assessment of the nursery function of this habitat. South African Journal of Zoology 20, 21-27.

Beckley, L.E. 1986. The ichthyoplankton assemblage of the Algoa Bay nearshore region in relation to coastal zone utilization by juvenile fish. South African Journal of Zoology 21, 244-252.

Beckley, L.E. \& Connell, A.D. 1996. Early life history of Pomatomus saltatrix off the east coast of South Africa. Marine and Freshwater Research 47, 319-322.

Beckley, L.E., van der Elst, R.P., Chater, S.A. \& Birnie, S.L. 1995. Fish trapping during the operation of the Durban Harbour graving dock, South Africa. Southern African Journal of Aquatic Sciences 21, 78-87.
Beckley, L.E. \& van Ballegooyen, R.C. 1992. Oceanographic conditions during three ichthyoplankton surveys of the Agulhas Current in 1990/91. In: Benguela Trophic Functioning (ed. A.I.L. Payne, K.H. Brink, K.H. Mann \& R. Hilborn). South African Journal of Marine Science 12, 83-93.

Begg, G.W. 1978. The estuaries of Natal. Natal Town and Regional Planning Report 41, 1-657.

Begg, G.W. 1980. The Kosi system: aspects of its biology, management and research. In: Studies on the Ecology of Maputaland (ed. M.N. Bruton \& K.H. Cooper), pp. 358-373. Rhodes University, Grahamstown \& Wildlife Society, Durban.

Begg, G.W. 1984a. The comparative ecology of Natal's smaller estuaries. Natal Town and Regional Planning Report 62, 1-182.

Begg, G.W. 1984b. The Estuaries of Natal (Part 2). Natal Town and Regional Planning Report 55, 1631.

Bennett, B.A. 1983. Clinus spatulatus, a new species of clinid fish (Perciformes: Blennioidei) from South Africa, with a modified definition of the genus Clinus. Special Publication of the J.L.B. Smith Institute of Ichthyology 29, 1-9.

Bennett, B.A. 1984. A population energy budget for Clinus superciliosus L., with an assessment of the role of resident fish as predators in the intertidal zone. Marine Biology Letters 5, 323-334.

Bennett, B.A. 1985. A mass mortality of fish associated with low salinity conditions in the Bot River estuary. Transactions of the Royal Society of South Africa 45, 437-448.

Bennett, B.A. 1989. A comparison of the fish communities in nearby permanently open, seasonally open and normally closed estuaries in the south-western Cape, South Africa. South African Journal of Marine Science 8, 43-55.

Bennett, B.A. 1993. Aspects of the biology and life history of white steenbras Lithognathus lithognathus in southern Africa. South African Journal of Marine Science 13, 83-96.

Bennett, B.A. 1994. The fish community of the Berg River estuary and an assessment of the likely effects of reduced freshwater inflows. South African Journal of Zoology 29, 118-125.

Bennett, B.A. \& Attwood, C.G. 1991. Evidence for recovery of a surf-zone fish assemblage following the establishment of a marine reserve on the southern coast of South Africa. Marine Ecology Progress Series 75, 173-181.

Bennett, B.A. \& Attwood, C.G. 1993. In defence of the De Hoop Marine Reserve. In: Fish, Fishers and Fisheries (ed. L.E. Beckley \& R.P. van der Elst). Oceanographic Research Institute Special Publication No. 2, 175-176. 
Bennett, B.A. \& Branch, G.M. 1990. Relationships between production and consumption of prey species by resident fish in the Bot, a cool temperate South African estuary. Estuarine, Coastal and Shelf Science 31, 139-155.

Bennett, B.A., Griffiths, C.L. \& Penrith, M-L. 1983. The diets of littoral fish from the Cape Peninsular. South African Journal of Zoology 18, 343-352.

Bennett, B.A., Hamman, K.C.D., Branch, G.M. \& Thorne, S.C. 1985. Changes in the fish fauna of the Bot River estuary in relation to opening and closure of the estuary mouth. Transactions of the Royal Society of South Africa 45, 449-464.

Benson, N.G. 1981. The freshwater-inflow-toestuaries issue. Fisheries 6, 8-10.

Bickerton, I.B. 1981. Report No. 3: Groen (CW7). In: Estuaries of the Cape. Part II: Synopses of Available Information on Individual Systems (ed. A.E.F. Heydorn \& J.R. Grindley). CSIR Research Report No. 402, 1-40.

Bickerton, I.B. \& Pierce, S.M. 1988. Report No. 33: Krom (CMS 45), Seekoei (CMS 46) and Kabeljous (CMS 47). In: Estuaries of the Cape. Part II: Synopses of Available Information on Individual Systems (ed. A.E.F. Heydorn \& J.R. Grindley). CSIR Research Report No. 432, 1-109.

Bird, E.C.F. 1984. Coasts. An Introduction to Coastal Morphology. Australian National University, Canberra, $320 \mathrm{pp}$.

Blaber, S.J.M. 1973a. Population size and mortality of juveniles of the marine teleost Rhabdosargus holubi (Pisces: Sparidae) in a closed estuary. Marine Biology 21, 219-225.

Blaber, S.J.M. 1973b. Temperature and salinity tolerance of juvenile Rhabdosargus holubi (Steindachner) (Teleostei: Sparidae). Journal of Fish Biology 5, 593-598.

Blaber, S.J.M. 1974a. Osmoregulation in juvenile Rhabdosargus holubi (Steindachner) (Teleostei: Sparidae). Journal of Fish Biology 6, 797-800.

Blaber, S.J.M. 1974b. Field studies of the diet of Rhabdosargus holubi (Pisces: Teleostei: Sparidae). Journal of Zoology, London 173, 407-417.

Blaber, S.J.M. 1974c. The population structure and growth of juvenile Rhabdosargus holubi (Steindachner) (Teleostei: Sparidae) in a closed estuary. Journal of Fish Biology 6, 455-460.

Blaber, S.J.M. 1975. Lipid content and condition in an estuarine teleost. Zoologica Africana 10, 63-73.

Blaber, S.J.M. 1976. The food and feeding ecology of Mugilidae in the St Lucia lake system. Biological Journal of the Linnean Society 8, 267-277.

Blaber, S.J.M. 1977. The feeding ecology and relative abundance of mullet (Mugilidae) in Natal and Pondoland estuaries. Biological Journal of the Linnean Society 9, 259-275.
Blaber, S.J.M. 1978. Fishes of the Kosi system. Lammergeyer No. 24, 28-41.

Blaber, S.J.M. 1979. The biology of filter feeding teleosts in Lake St Lucia, Zululand. Journal of Fish Biology 15, 37-59.

Blaber, S.J.M. 1981a. The zoogeographical affinities of estuarine fishes in south-east Africa. South African Journal of Science 77, 305-307.

Blaber, S.J.M. 1981b. An unusual mass mortality of Clarias gariepinus in the Mkuze River at Lake St Lucia. Lammergeyer 31, 43.

Blaber, S.J.M. 1982a. The ecology of Sphyraena barracuda (Osteichthyes: Perciformes) in the Kosi system with notes on the Sphyraenidae of other Natal estuaries. South African Journal of Zoology 17, 171-176.

Blaber, S.J.M. 1982b. Fish research at St Lucia. In: St Lucia Research Review (ed. R.H. Taylor), pp. 125-137. Natal Parks Board, Pietermaritzburg.

Blaber, S.J.M. 1984. The diet, food selectivity and niche of Rhabdosargus sarba (Teleostei: Sparidae) in Natal estuaries. South African Journal of Zoology 19, 241-246.

Blaber, S.J.M. 1985. The ecology of fishes of estuaries and lagoons of the Indo-Pacific with particular reference to southeast Africa. In: Fish Community Ecology in Estuaries and Coastal Lagoons (ed. A. Yanez-Aráñcibia), pp. 247-266. Universidad Nacional Autónoma de México, México.

Blaber, S.J.M. 1987. Factors affecting recruitment and survival of mugilids in estuaries and coastal waters of southeastern Africa. American Fisheries Society Symposium 1, 507-518.

Blaber, S.J.M. 1991. Deep sea, estuarine and freshwater fishes: life history strategies and ecological boundaries. Southern African Journal of Aquatic Sciences 17, 2-11.

Blaber, S.J.M. \& Blaber, T.G. 1980. Factors affecting the distribution of juvenile estuarine and inshore fish. Journal of Fish Biology 17, 143-162.

Blaber, S.J.M. \& Cyrus, D.P. 1981. A revised checklist and further notes on the fishes of the Kosi system. Lammergeyer 31, 5-14.

Blaber, S.J.M. \& Cyrus, D.P. 1983. The biology of Carangidae (Teleostei) in Natal estuaries. Journal of Fish Biology 22, 173-188.

Blaber, S.J.M., Cyrus, D.P. \& Whitfield, A.K. 1981. The influence of zooplankton food resources on the morphology of the estuarine clupeid Gilchristella aestuarius (Gilchrist, 1914). Environmental Biology of Fishes 6, 351-355.

Blaber, S.J.M., Hay, D.G., Cyrus, D.P. \& Martin, T.J.1984. The ecology of two degraded estuaries on the north coast of Natal, South Africa. South African Journal of Zoology 19, 224-240. 
Blaber, S.J.M., Hill, B.J. \& Forbes, A.T. 1974. Infratidal zonation in a deep South African estuary. Marine Biology 28, 333-337.

Blaber, S.J.M. \& Whitfield, A.K. 1976. Large scale mortality of fish at St Lucia. South African Journal of Science 72, 218.

Blaber, S.J.M. \& Whitfield, A.K. 1977a. The feeding of juvenile mullet (Mugilidae) in southeast African estuaries. Biological Journal of the Linnean Society 9, 277-284.

Blaber, S.J.M. \& Whitfield, A.K. 1977b. The biology of the burrowing goby Croilia mossambica Smith (Teleostei, Gobiidae). Environmental Biology of Fishes 1, 197-204.

Boehlert, G.W. \& Mundy, B.C. 1988. Roles of behavioral and physical factors in larval and juvenile fish recruitment to estuarine nursery areas. American Fisheries Society Symposium 3, 51-67.

Bok, A.H. 1979. The distribution and ecology of two mullet species in some freshwater rivers in the eastern Cape, South Africa. Journal of the Limnological Society of Southern Africa 5, 97-102.

Bok, A.H. 1983. The demography, breeding biology and management of two mullet species (Pisces: Mugilidae) in the eastern Cape, South Africa. $\mathrm{PhD}$ thesis, Rhodes University, Grahamstown, $268 \mathrm{pp}$.

Bok, A.H. 1984. Freshwater mullet in the eastern Cape - a strong case for fish ladders. The Naturalist 28(3), 31-35.

Boltt, R.E. 1975. The benthos of some southern African lakes. Part 5. The recovery of the benthic fauna of St Lucia following a period of excessively high salinity. Transactions of the Royal Society of South Africa 41, 295-323.

Boullé, D.P. 1989. Aspects of the biology and ecology of a small stream fish community. BSc (Hons) Project, Rhodes University, Grahamstown, $45 \mathrm{pp}$.

Bowen, S.H. 1976. Mechanisms for digestion of detrital bacteria by the cichlid fish Sarotherodon mossambicus (Peters). Nature 260, 137-138.

Bowen, S.H. 1978. Benthic diatoms and grazing by juvenile Sarotherodon mossambicus (Peters) in Lake Sibaya, South Africa. Freshwater Biology 8, 449453.

Bowen, S.H. \& Allanson, B.R. 1982. Behavioral and trophic plasticity of juvenile Tilapia mossambica in utilization of the unstable littoral habitat. Environmental Biology of Fishes 7, 357-362.

Branch, G. \& Branch, M. 1981. The Living Shores of Southern Africa. Struik, Cape Town, 272 pp.

Branch, G.M., Bally, R., Bennett, B.A., De Decker, H.P., Fromme, G.A.W., Heÿl, C.W. \& Willis, J.P. 1985. Synopsis of the impact of artificially opening the mouth of the Bot River estuary: implications for management. Transactions of the Royal Society of South Africa 45, 465-483.
Branch, G.M. \& Day, J.A. 1984. Ecology of southern African estuaries: Part XIII. The Palmiet river estuary in the south-western Cape. South African Journal of Zoology 19, 63-77.

Branch, G.M., Griffiths, C.L., Branch, M.L. \& Beckley, L.E. 1994. Two Oceans. A Guide to the Marine Life of Southern Africa. David Philip, Cape Town, $360 \mathrm{pp}$.

Branch, G.M. \& Grindley, J.R. 1979. Ecology of southern African estuaries. Part XI. Mngazana: a mangrove estuary in Transkei. South African Journal of Zoology 14, 149-170.

Branstetter, S. \& Stiles, R. 1987. Age and growth estimates of the bull shark, Carcharhinus leucas, from the northern Gulf of Mexico. Environmental Biology of Fishes 20, 169-181.

Brillet, C. 1975. Relations entre territoire et comportement agressif chez Periophthalmus sobrinus Eggert (Pisces, Periophthalmidae) au laboratoire et en milieu naturel. Zeitschrift fuer Tierpsychologie 39, 283-331.

Broekhuysen, G.J. \& Taylor, H. 1959. The ecology of South African estuaries. Part 8. Kosi Bay estuary system. Annals of the South African Museum 44, 279-296.

Brown, A.C. 1958. The ecology of South African estuaries. Part 9: Notes on the estuary of the Orange River. Transactions of the Royal Society of South Africa 35, 463-473.

Brown, A.C. \& Jarman, N. 1978. Coastal marine habitats. In: Biogeography and Ecology of Southern Africa (ed. M.J. Werger \& A.C. van Bruggen), pp. 1239-1277. Dr W. Junk, The Hague.

Brown, V.M. 1978. Fish as indicators of water quality. In: Elaboration on the Scientific Basis for Monitoring the Quality of Surface Water by Hydrobiological Indicators (ed. J.W.G. Lund \& G.G. Vinberg), pp. 92-108. Proceedings: First Joint Anglo-Soviet Committee on Cooperation in the Field of Environmental Protection, Valdai.

Brownell, C.L. 1979. Stages in the early development of 40 marine fish species with pelagic eggs from the Cape of Good Hope. Ichthyological Bulletin of the J.L.B. Smith Institute of Ichthyology 40, 1-84.

Bruton, M.N. 1979a. The fishes of Lake Sibaya. Monographiae Biologicae 36, 286-312.

Bruton, M.N. 1979b. The breeding biology and early development of Clarias gariepinus (Pisces: Clariidae) in Lake Sibaya, South Africa, with a review of breeding in species of the subgenus Clarias (Clarias). Transactions of the Zoological Society, London 35, 1-45.

Bruton, M.N. 1979c. The food and feeding behaviour of Clarias gariepinus (Pisces: Clariidae) in Lake Sibaya, South Africa, with emphasis on its role as a predator of cichlids. Transactions of the Zoological Society, London 35, 47-114. 
Bruton, M.N. 1980a. An outline of the ecology of Lake Sibaya, with emphasis on the vertebrate communities. In: Studies on the Ecology of Maputaland (ed. M.N. Bruton \& K.H. Cooper) pp. 382-407. Rhodes University, Grahamstown \& Wildlife Society, Durban.

Bruton, M.N. 1980b. An outline of the ecology of the Mgobezeleni lake system at Sodwana, with emphasis on the mangrove community. In: Studies on the Ecology of Maputaland (ed. M.N. Bruton \& K.H. Cooper), pp. 408-426. Rhodes University, Grahamstown \& Wildlife Society, Durban.

Bruton, M.N. 1989. The ecological significance of alternative life-history styles. In: Alternative LifeHistory Styles of Animals (ed. M.N. Bruton), pp. 503-553. Kluwer Academic Publishers, Dordrecht.

Bruton, M.N. 1995. Have fishes had their chips? The dilemma of threatened fishes. Environmental Biology of Fishes 43, 1-27.

Bruton, M.N. 1996a. Threatened fishes of the world: Taenioides jacksoni Smith, 1943 (Gobiidae). Environmental Biology of Fishes 47, 327.

Bruton, M.N. 1996b. Threatened fishes of the world: Hypseleotris dayi Smith, 1950 (Eleotridae). Environmental Biology of Fishes 46, 184.

Bruton, M.N. \& Allanson, B.R. 1974. The growth of Tilapia mossambica in Lake Sibaya, South Africa. Journal of Fish Biology 6, 701-715.

Bruton, M.N. \& Appleton, C.C. 1975. Survey of Mgobezeleni lake-system in Zululand, with a note on the effect of a bridge on the mangrove swamp. Transactions of the Royal Society of South Africa 41, 283-294.

Bruton, M.N., Bok, A.H. \& Davies, M.T.T. 1987. Life history styles of diadromous fishes in inland waters of southern Africa. American Fisheries Society Symposium 1, 104-121.

Bruton, M.N. \& Boltt, R.E. 1975. Aspects of the biology of Tilapia mossambica Peters (Pisces: Cichlidae) in a natural freshwater lake (Lake Sibaya, South Africa). Journal of Fish Biology 7 , 423-445.

Bruton, M.N. \& Kok, H.M. 1980. The freshwater fishes of Maputaland. In: Studies on the Ecology of Maputaland (ed. M.N. Bruton \& K.H. Cooper), pp. 210-244. Rhodes University, Grahamstown \& Wildlife Society, Durban.

Bruton, M.N. \& Merron, G.S. 1990. The proportion of different eco-ethological sections of reproductive guilds of fishes in some African inland waters. Environmental Biology of Fishes 28, 179-187.

Bruton, M.N. \& Taylor, R.H. 1979. Cichlid fish mortality in a freshwater lake in Natal. Lammergeyer 27, 1-4.
Butler, A.C., Sibbald R.R. \& Gardner, B.D. 1983. Gas chromatographic analysis indicates decrease in chlorinated hydrocarbon levels in northern Zululand. South African Journal of Science 79, 162-163.

Buxton, C.D. 1993. Marine reserves - the way ahead. In: Fish, Fishers and Fisheries (ed. L.E. Beckley \& R.P. van der Elst). Oceanographic Research Institute Special Publication No. 2, 170-174.

Buxton, C.D. \& Kok, H.M. 1983. Notes on the diet of Rhabdosargus holubi (Steindachner) and Rhabdosargus globiceps (Cuvier) in the marine environment. South African Journal of Zoology $18,406-408$.

Cambray, J.A. \& Bok, A.H. 1989. Early development of artificially spawned southern mullet, Liza richardsonii (Smith, 1846). South African Journal of Zoology 24, 193-198.

Campbell, E.E., Knoop, W.T. \& Bate, G.C. 1991. A comparison of phytoplankton biomass and primary production in three eastern Cape estuaries, South Africa. South African Journal of Science 87, 259-264.

Campbell, G.D. \& Allanson, B.R. 1952. The fishes of the 1947, 1948 and 1949 scientific investigations of the Kosi area, organised by the Natal Society for the Preservation of Wild Life and Natural Resorts. Natal Society for the Preservation of Wild Life and Natural Resorts 1(4), 13-20.

Carter, R.A. 1978. The distribution of calanoid copepoda in the Agulhas Current system off Natal, South Africa. CSIR Research Report 363, 1-165.

Castle, P.H.J. 1986a. Family No. 45: Muraenesocidae: Smiths' Sea Fishes (ed. M.M. Smith \& P.C. Heemstra), pp. 188. Macmillan South Africa, Johannesburg.

Castle, P.H.J. 1986b. Family No. 39: Anguillidae. In: Smiths' Sea Fishes (ed. M.M. Smith \& P.C. Heemstra), pp. 160-161. Macmillan South Africa, Johannesburg.

Castle, P.H.J. \& McCosker, J.E. 1986. Family No. 41: Muraenidae. In: Smiths' Sea Fishes (ed. M.M. Smith \& P.C. Heemstra), pp. 165-176, Macmillan South Africa, Johannesburg.

Caulton, M.S. 1975. Diurnal movement and temperature selection by juvenile and sub-adult Tilapia rendalli Boulenger (Cichlidae). Transactions of the Rhodesian Scientific Association 56, 51-56.

Caulton, M.S. 1976. The importance of pre-digestive food preparation to Tilapia rendalli Boulenger when feeding on aquatic macrophytes. Transactions of the Rhodesian Scientific Association 57, 22-28.

Caulton, M.S. 1978. The importance of habitat temperatures for growth in the tropical cichlid Tilapia rendalli Boulenger. Journal of Fish Biology 13, 99-112. 
Christensen, M.S. 1978. Trophic relationships in juveniles of three species of sparid fishes in the southern African marine littoral. Fishery Bulletin 76, 389-401.

Christensen, M.S. 1980. Sea-surface temperature charts for southern Africa, south of $26^{\circ} \mathrm{S}$. South African Journal of Science 76, 541-546.

Clark, B.M., Bennett, B.A. \& Lamberth, S.J. 1994. A comparison of the ichthyofaunas of two estuaries and their adjacent surf zones, with an assessment of the effects of beach-seining on the nursery function of estuaries for fish. South African Journal of Marine Science 14, 121-131.

Coetzee, D.J. 1981a. Zooplankton distribution in relation to environmental conditions in the Swartvlei system, southern Cape. Journal of the Limnological Society of Southern Africa 7, 5-12.

Coetzee, D.J. 1981b. Analysis of the gut contents of the needlefish, Hyporhamphus knysnaensis (Smith), from Rondevlei, southern Cape. South African Journal of Zoology 16, 14-20.

Coetzee, D.J. 1982a. Stomach content analysis of the leervis, Lichia amia (L.), from the Swartvlei system, southern Cape. South African Journal of Zoology 17, 177-181.

Coetzee, D.J. 1982b. Stomach content analyses of Gilchristella aestuarius and Hepsetia breviceps from the Swartvlei system and Groenvlei, southern Cape. South African Journal of Zoology $17,59-66$.

Coetzee, P.S. 1986. Diet composition and breeding cycle of blacktail, Diplodus sargus capensis (Pisces: Sparidae), caught off St Croix Island, Algoa Bay, South Africa. South African Journal of Zoology 21, 237-243.

Collette, B.B. 1986a. Family No. 113: Belonidae. In: Smiths' Sea Fishes (ed. M.M. Smith \& P.C. Heemstra), pp. 385-388. Macmillan South Africa, Johannesburg.

Collette, B.B. 1986b. Family No. 115: Hemiramphidae. In: Smiths' Sea Fishes (ed. M.M. Smith \& P.C. Heemstra), pp. 388-391. Macmillan South Africa, Johannesburg.

Compagno, L.J.V. 1986a. Family No. 22: Pristidae. In: Smiths' Sea Fishes (ed. M.M. Smith \& P.C. Heemstra), pp. 110-111. Macmillan South Africa, Johannesburg.

Compagno, L.J.V. 1986b. Family No. 23: Torpedinidae. In: Smiths' Sea Fishes (ed. M.M. Smith \& P.C. Heemstra), pp. 112-114. Macmillan South Africa, Johannesburg.

Compagno, L.J.V. 1986c. Family No. 28: Myliobatidae. In: Smiths' Sea Fishes (ed. M.M. Smith \& P.C. Heemstra), pp. 132-135. Macmillan South Africa, Johannesburg.
Compagno, L.J.V. 1986d. Family No. 30: Dasyatidae. In: Smiths' Sea Fishes (ed. M.M. Smith \& P.C. Heemstra), pp. 135-142. Macmillan South Africa, Johannesburg.

Compagno, L.J.V., Ebert, D.A. \& Smale, M.J. 1989. Guide to the Sharks and Rays of Southern Africa. Struik, Cape Town, 160 pp.

Connell, A.D. 1996. Sea fishes spawning pelagic eggs in the St Lucia estuary. South African Journal of Zoology 31, 37-41.

Cooper, J.A.G. 1989. Fairweather versus flood sedimentation in Mhlanga lagoon, Natal: implications for environmental management. South African Journal of Geology 92, 279-294.

Cooper, J.A.G. 1993. Sedimentation in the cliff-bound, microtidal Mtamvuna Estuary, South Africa. Marine Geology 112, 237-256.

Cooper, J.A.G. \& Harrison, T.D. 1992. Effects of nesting activities of Oreochromis mossambicus (Pisces: Cichlidae) on bank stability in small lagoons. South African Journal of Science 88, 398-400.

Cooper, J.A.G., Harrison, T.D. \& Ramm, A.E.L. 1995. The role of estuaries in large marine ecosystems: examples from the Natal coast, South Africa. In: Status and Future of Large Marine Ecosystems of the Indian Ocean (ed. E. Okemwa, M.J. Ntiba \& K. Sherman), pp. 92-100. IUCN, Gland.

Cooper, J.A.G., Ramm, A.E.L. \& Harrison, T.D. 1994. The Estuarine Health Index: a new approach to scientific information transfer. Ocean \& Coastal Management 25, 103-141.

Correll, D.L. 1978. Estuarine productivity. Bioscience $28,646-650$.

Cowan, G.I. 1995. South Africa and the Ramsar Convention. In: Wetlands of South Africa (ed. G.I. Cowan), pp. 1-20. Department of Environmental Affairs and Tourism, Pretoria.

Crass, R.S. 1964. Freshwater fishes of Natal. Shuter \& Shooter, Pietermaritzburg, $167 \mathrm{pp}$.

Crass, R.S. 1968. A rare freshwater fish from Natal. African Aquarist 1, 7-8.

Cyrus, D.P. 1988a. Turbidity and other physical factors in Natal estuarine systems. Journal of the Limnological Society of Southern Africa 14, 60-71.

Cyrus, D.P. 1988b. Episodic events and estuaries: effects of cyclonic flushing on the benthic fauna and diet of Solea bleekeri (Teleostei) in Lake St Lucia on the south-eastern coast of Africa. Journal of Fish Biology 33 (Supplement A), 1-7.

Cyrus, D.P. 1991a. The reproductive biology of Solea bleekeri (Teleostei) in Lake St Lucia on the south-east coast of Africa. South African Journal of Marine Science 10, 45-51. 
Cyrus, D.P. 1991b. The biology of Solea bleekeri (Teleostei) in Lake St Lucia on the southeast coast of Africa. Netherlands Journal of Sea Research 27, 209-216.

Cyrus, D.P. 1991c. Fish conservation in South African estuaries: pressures, problems and prospects. Southern African Journal of Aquatic Sciences 17, 19-27.

Cyrus, D.P. 1992. Turbidity gradients in two IndoPacific estuaries and their influence on fish distribution. Southern African Journal of Aquatic Sciences 18: 51-63.

Cyrus, D.P. \& Blaber, S.J.M. 1982a. Species identification, distribution and abundance of Gerreidae (Teleostei) Bleeker, 1859 in the estuaries of Natal. South African Journal of Zoology 17, 105-116.

Cyrus, D.P. \& Blaber, S.J.M. 1982b. Mouthpart structure and function and the feeding mechanisms of Gerres. South African Journal of Zoology 17, 117-121.

Cyrus, D.P. \& Blaber, S.J.M. 1983a. Diet of Gerres fry in the Kosi system. South African Journal of Zoology 18, 403-406.

Cyrus, D.P. \& Blaber, S.J.M. 1983b. The food and feeding ecology of Gerreidae, Bleeker 1859, in the estuaries of Natal. Journal of Fish Biology 22, 373393.

Cyrus, D.P. \& Blaber, S.J.M. 1984a. The reproductive biology of Gerres in Natal estuaries. Journal of Fish Biology 24, 491-504.

Cyrus, D.P. \& Blaber, S.J.M. 1984b. The feeding ecology of Gerreidae (Teleostei) in the Kosi system, with special reference to their seasonal diet. Lammergeyer 32, 35-49.

Cyrus, D.P. \& Blaber, S.J.M. 1984c. Predation and sources of mortality of Gerreidae Bleeker, 1859 (Teleostei), in Natal estuaries with special reference to the Kosi system. Lammergeyer 32, 14-20.

Cyrus, D.P. \& Blaber S.J.M. 1987a. The influence of turbidity on juvenile marine fishes in estuaries. Part 1. Field studies at Lake St Lucia on the southeastern coast of Africa. Journal of Experimental Marine Biology and Ecology 109, 53-70.

Cyrus, D.P. \& Blaber S.J.M. 1987b. The influence of turbidity on juvenile marine fishes in estuaries. Part 2. Laboratory studies, comparisons with field data and conclusions. Journal of Experimental Marine Biology and Ecology 109, 71-91.

Cyrus, D.P. \& Blaber, S.J.M. 1987c. The influence of turbidity on juvenile marine fish in the estuaries of Natal, South Africa. Continental Shelf Research 7, 1411-1416.

Cyrus, D.P. \& Blaber, S.J.M. 1988. The potential effects of dredging activities and increased silt load on the St Lucia system, with special reference to turbidity and the estuarine fauna. Water SA 14, 43-47.
Cyrus, D.P. \& Forbes, A.T. 1996. Preliminary results on the role of KwaZulu-Natal harbours as nursery grounds for juveniles of selected marine organisms which utilize estuaries. South African Journal of Wildlife Research 26(1), 26-33.

Cyrus, D.P. \& Martin, T.J. 1991. The importance of estuaries in life histories of flatfish species on the southern coast of Africa. Netherlands Journal of Sea Research 27, 255-260.

Cyrus, D.P. \& McLean, S. 1994. Water temperature and the reproductive success of Caspian terns Sterna caspia at Lake St Lucia, southeastern coast of Africa. Marine Ornithology 22, 193-203.

Cyrus, D.P. \& McLean, S. 1996. Water temperature and the 1987 fish kill at Lake St Lucia on the south eastern coast of Africa. Southern African Journal of Aquatic Sciences 22, 105-110.

Cyrus, D.P., Wellmann, E.C. \& Martin, T.J. 1993. Diet and reproductive activity of the estuarine roundherring Gilchristella aestuaria in Cubhu, a freshwater coastal lake in northern Natal, South Africa. Southern African Journal of Aquatic Sciences 19, 3-13.

Dando, P.R. 1984. Reproduction in estuarine fish. In: Fish Reproduction: Strategies and Tactics (ed. G.W. Potts \& R.J. Wootton), pp. 155-170. Academic Press, London.

D'Aubrey, J.D. 1971. The taxonomy of two shark species of the genus Carcharhinus. MSc thesis, University of Natal, Durban.

Davies, B.R. 1982. Studies on the zoobenthos of some southern Cape coastal lakes. Spatial and temporal changes in the benthos of Swartvlei, South Africa, in relation to changes in the submerged littoral macrophyte community. Journal of the Limnological Society of Southern Africa 8, 33-45.

Davies, B.R. \& Day, J.A. 1986. The Biology and Conservation of South Africa's Vanishing Waters. University of Cape Town, Rondebosch, $186 \mathrm{pp}$.

Davies, B.R., O'Keeffe, J.H. \& Snadden, C.D. 1993. A synthesis of ecological functioning, conservation and management of South African river ecosystems. Water Research Commission Report No. TT62/93.

Davies, J.M., Bell, J.S. \& Houghton, C. 1984. A comparison of the levels of hepatic aryl hydrocarbon hydroxylase in fish caught close to and distant from North Sea oil fields. Marine Environmental Research 18, 267-275.

Davies, R.A.G. \& Randall, R.M. 1989. Historical and geographical patterns in eggshell thickness of African fish eagles Haliaeetus vocifer, in relation to pesticide use within southern Africa. In: Raptors in the Modern World (ed. B.U. Meyburg \& R.D. Chancellor). WWGBP, Berlin.

Dawson, C.E. 1985. Indo-Pacific Pipefishes. Gulf Coast Research Laboratory, Mississippi. 
Dawson, C.E. 1986. Family No. 145: Syngnathidae. In: Smiths' Sea Fishes (ed. M.M. Smith \& P.C. Heemstra), pp. 445-458. Macmillan South Africa, Johannesburg.

Day, J.H. 1967. The biology of Knysna estuary, South Africa. In: Estuaries (ed. G.H. Lauff), American Association for the Advancement of Science Publication No. 83, 397-407.

Day, J.H. 1977. Marine biology in South Africa. In: A History of Scientific Endeavour in South Africa (ed. A.C. Brown), pp. 86-108. Royal Society of South Africa, Cape Town.

Day, J.H. 1980. What is an estuary? South African Journal of Science 76, 198.

Day, J.H. 1981a. The nature, origin and classification of estuaries. In: Estuarine Ecology with Particular Reference to Southern Africa (ed. J.H. Day), pp. 1-6. Balkema, Cape Town.

Day, J.H. 1981b. Estuarine currents, salinities and temperatures. In: Estuarine Ecology with Particular Reference to Southern Africa (ed. J.H. Day), pp. 27-44. Balkema, Cape Town.

Day, J.H. 1981c. Summaries of current knowledge of 43 estuaries in southern Africa. In: Estuarine Ecology with Particular Reference to Southern Africa (ed. J.H. Day), pp. 251-330. Balkema, Cape Town.

Day, J.H. 1981d. The estuarine flora. In: Estuarine Ecology with Particular Reference to Southern Africa (ed. J.H. Day), pp. 77-99. Balkema, Cape Town.

Day, J.H., Blaber, S.J.M. \& Wallace, J.H. 1981. Estuarine fishes. In: Estuarine Ecology with Particular Reference to Southern Africa (ed. J.H. Day), pp. 197-221. Balkema, Cape Town.

Day, J.H. \& Grindley: J.R. 1981. The estuarine ecosystem and environmental constraints. In: Estuarine Ecology with Particular Reference to Southern Africa (ed. J.H. Day), pp. 345-372. Balkema, Cape Town.

Day, J.H., Millard, N.A.H. \& Broekhuysen, G.J. 1954. The ecology of South African estuaries. Part 4: The St Lucia system. Transactions of the Royal Society of South Africa 34, 129-156.

Day, J.H., Millard, N.A.H. \& Harrison, A.D. 1952. The ecology of South African estuaries. Part 3. Knysna: A clear open estuary. Transactions of the Royal Society of South Africa 33, 367-413.

Day, J.H. \& Morgans, J.F. 1956. The ecology of South African estuaries. Part 7: The biology of Durban Bay. Annals of the Natal Museum 13, 259. 312.

Deacon, N. \& Hecht, T. 1995. Observations on the thermoregulatory behaviour of juvenile spotted grunter, Pomadasys commersonnii (Haemulidae: Pisces). Journal of Applied Ichthyology 11, 100110. de Decker, H.P. 1987. Breaching the mouth of the Bot River estuary, South Africa: impact on its benthic macrofaunal communities. Transactions of the Royal Society of South Africa 46, 231-250.

de Decker, H.P. \& Bennett, B.A. 1985. A comparison of the physiological condition of the southern mullet Liza richardsonii (Smith), in a closed estuary and the sea. Transactions of the Royal Society of South Africa 45, 427-436.

de Kock, A.C. \& Lord, D. 1988. Kinetics of the uptake and elimination of polychlorinated biphenols by an estuarine fish species Rhabdosargus holubi after aqueous exposure. Chemosphere 17, 2381-90.

de Sylva, D.P. 1963. Systematics and life history of the great barracuda, Sphyraena barracuda (Walbaum). Studies in Tropical Oceanography 1, 1-179.

de Sylva, D.P. \& Williams, F. 1986. Family No. 224: Sphyraenidae. In: Smiths' Sea Fishes (ed. M.M. Smith \& P.C. Heemstra), pp. 721-726. Macmillan South Africa, Johannesburg.

de Villiers, G. 1987. Harvesting harders Liza richardsoni in the Benguela upwelling region. South African Journal of Marine Science 5, 851-862.

Department of Water Affairs 1986. Management of the Water Resources of the Republic of South Africa. Government Printer, Pretoria, 488 pp.

Dundas, A. 1994. A comparative analysis of fish abundance and diversity in three semi-enclosed estuaries in the eastern Cape. MSc thesis, University of Port Elizabeth, Port Elizabeth.

Du Preez, H.H., Strydom, W. \& Winter, P.E.D. 1986. Oxygen consumption of two marine teleosts, Lithognathus mormyrus (Linnaeus, 1758) and Lithognathus lithognathus (Cuvier, 1830) (Teleostei: Sparidae). Comparative Biochemistry and Physiology 85a, 313-331.

Dye, P. \& Poulter, A. 1995. Clearing invasive trees in riparian zones increases streamflow. Environmental Planning and Management 6(3), 13-15.

Eldredge, N. 1979. Alternative approaches to evolutionary theory. Bulletin of the Carnegie Museum of Natural History 13, 7-19.

Elliott, M., Griffiths, A.H. \& Taylor, C.J.L. 1988. The role of fish studies in estuarine pollution assessment. Journal of Fish Biology 33, 51-61.

Emmerson, W.D. 1989. The nutrient status of the Sundays River estuary South Africa. Water Research 23, 1059-1067.

Emmerson, W.D. \& Erasmus, T. 1987. The nutrient status of the Kromme River estuary, eastern Cape. Hydrobiologia 148, 87-96.

Fausch, K.D., Lyons, J., Karr, J.R. \& Angermeier, P.L. 1990. Fish communities as indicators of environmental degradation. American Fisheries Society Symposium 8, 123-144. 
Forbes, A.T. \& Benfield, M.C. 1986. Tidal behaviour of post-larval penaeid prawns (Crustacea: Decapoda: Penaeidae) in a southeast African estuary. Journal of Experimental Marine Biology and Ecology 102, 23-34.

Forbes, A.T. \& Cyrus, D.P. 1993. Biological effects of salinity gradient reversals in a southeast African estuarine lake. Netherlands Journal of Aquatic Ecology 27, 483-488.

Forrest, G.W. 1969. Some bird notes from Lake St Lucia. Lammergeyer 10, 89-91.

Fortier, L. \& Leggett, W. 1982. Fickian transport and the dispersal of fish larvae in estuaries. Canadian Journal of Fisheries and Aquatic Science 39, 11501163.

Fromme, G.A.W. 1985. The hydrology of the Bot River Estuary. Transactions of the Royal Society of South Africa 45, 305-315.

Garratt, P.A. 1993. Spawning of riverbream, Acanthopagrus berda, in Kosi estuary. South African Journal of Zoology 28, 26-31.

Genade, A.B. \& Hirst, A.L. 1986. 'n Perdjie van 'n ander kleur. Custos 15, 34-36.

Gerking, S.D. 1984. Assimilation and maintenance ration of an herbivorous fish, Sarpa salpa, feeding on a green alga. Transactions of the American Fisheries Society 113, 378-387.

Gess, R. 1995. Unlocking Grahamstown's past - an upper Devonian estuary. Naturalist 39(1), 20-25.

Gess, R.W. \& Hiller, N. 1995. A preliminary catalogue of fossil algal, plant, arthropod, and fish remains from a Late Devonian black shale near Grahamstown, South Africa. Annals of the Cape Provincial Museums (Natural History) 19, 225304.

Gilchrist, J.D.F. 1918. Report on nettings in the Zwartkops River. Marine Biological Report of the Union of South Africa 4, 56-72.

Grange, N. \& Allanson, B.R. 1995. The influence of freshwater inflow on the nature, amount and distribution of seston in estuaries of the Eastern Cape, South Africa. Estuarine, Coastal and Shelf Science 40, 403-420.

Grange, N. \& Cretchley, R. 1995. A preliminary investigation of the reproductive behaviour of the Knysna seahorse, Hippocampus capensis Boulenger, 1900. Southern African Journal of Aquatic Sciences 21, 103-104.

Greenwood, P.H. 1992. Are the major fish faunas well-known? Netherlands Journal of Zoology 42, 131-138.

Greenwood, P.H. 1994. Gobiid fishes of the genus Glossogobius in the Limpopo system: a first record and a range extension of $G$. callidus (Smith, 1937). Southern African Journal of Aquatic Sciences 20, 88-92.
Griffiths, M.H. 1996. On the taxonomy and life history of Argyrosomus japonicus and A. inodorus, two important sciaenids off the South African coast. $\mathrm{PhD}$ thesis, Rhodes University, Grahamstown.

Griffiths, M.H. \& Hecht, T. 1995. Age and growth of South African dusky kob Argyrosomus japonicus (Sciaenidae) based on otoliths. South African Journal of Marine Science 16, 119-128.

Griffiths, M.H. \& Heemstra, P.C. 1995. A contribution to the taxonomy of the marine fish genus Argyrosomus (Perciformes: Sciaenidae), with descriptions of two new species from southern Africa. Ichthyological Bulletin of the J.L.B. Smith Institute of Ichthyology 65, 1-40.

Grindley, J.R. 1976. Zooplankton of St Lucia. In: St Lucia Scientific Advisory Council Workshop Meeting - Charters Creek (ed. A.E.F. Heydorn), Paper 12. Natal Parks, Game and Fish Preservation Board, Pietermaritzburg.

Grindley, J.R. 1981. Estuarine plankton. In: Estuarine Ecology with Particular Reference to Southern Africa (ed. J.H. Day), pp. 117-146. Balkema, Cape Town.

Grindley, J.R. 1985. Report No. 30: Knysna (CMS 13). In: Estuaries of the Cape. Part II: Synopses of Available Information on Individual Systems (ed. A.E.F. Heydorn \& J.R. Grindley). CSIR Research Report No. 429, 1-82.

Grobler, D.F. 1994. A note on PCBs and chlorinated hydrocarbon pesticide residues in water, fish and sediment from the Olifants River, Eastern Transvaal, South Africa. Water SA 20, 187-194.

Groombridge, B. (ed.) 1993. 1994 IUCN red list of threatened animals. IUCN, Gland, $286 \mathrm{pp}$.

Guastella, L.A.M. 1994. A quantitative assessment of recreational angling in Durban harbour, South Africa. South African Journal of Marine Science 14, 187-203.

Haigh, E.H. \& Whitfield, A.K. 1993. Larval development of Gilchristella aestuaria (Gilchrist, 1914) (Pisces: Clupeidae) from southern Africa. South African Journal of Zoology 28, 168-172.

Hall, C.M., Whitfield, A.K. \& Allanson, B.R. 1987. Recruitment, diversity and the influence of constrictions on the distribution of fishes in the Wilderness Lakes system, South Africa. South African Journal of Zoology 22, 163-169.

Hanekom, N. \& Baird, D. 1984. Fish community structures in Zostera and non-Zostera regions of the Kromme estuary, St Francis Bay. South African Journal of Zoology 19, 295-301.

Hanekom, N., Hutchings, L., Joubert, P.A. \& van der Byl, P.C.N. 1989. Sea temperature variations in the Tsitsikamma Coastal National Park, South Africa, with notes on the effect of cold conditions on some fish populations. South African Journal of Marine Science 8, 145-153. 
Harris, S.A. 1996. Larval fish assemblages of selected estuarine and coastal systems in KwaZulu-Natal, South Africa. PhD thesis, University of Zululand, KwaDlangezwa.

Harris, S.A. \& Cyrus, D.P. 1995. Occurrence of fish larvae in the St Lucia Estuary, KwaZuluNatal, South Africa. South African Journal of Marine Science 16, 333-350.

Harris, S.A. \& Cyrus, D.P. 1996. Larval and juvenile fishes in the surf zone adjacent to the St Lucia Estuary mouth, KwaZulu-Natal, South Africa. Marine and Freshwater Science 47, 465-482.

Harris, S.A., Cyrus, D.P. \& Forbes, A.T. 1995. The larval fish assemblage at the mouth of the Kosi Estuary, KwaZulu-Natal, South Africa. South African Journal of Marine Science 16, 351-364.

Harris, T.F.W. 1978. Review of coastal currents in southern African waters. South African National Scientific Programmes Report 30, 1-103.

Harrison, T.D. 1991. A note on the diet and feeding selectivity of juvenile riverbream, Acanthopagrus berda (Forskal, 1775), in a subtropical mangrove creek. South African Journal of Zoology 26, 3642.

Harrison, T.D. 1998. A preliminary survey of coastal river systems on the South African west coast, Orange River - Groot Berg, with particular emphasis on the fish fauna. Transactions of the Royal Society of South Africa 52(2), in press.

Harrison, T.D. \& Cooper, J.A.G. 1991. Active migration of juvenile mullet (Teleostei: Mugilidae) into a small lagoonal system on the Natal coast. South African Journal of Science 87, 395-396.

Harrison, T.D., Cooper, J.A.G., Ramm, A.E.L. \& Singh, R.A. 1994. Health of South African estuaries, Orange River - Buffels (Oos). CSIR Technical Report, Durban.

Harrison, T.D., Cooper, J.A.G., Ramm, A.E.L. \& Singh, R.A. 1996. Health of South African estuaries, Groot (Wes) - Great Fish. CSIR Technical Report, Durban.

Harrison, T.D. \& Whitfield, A.K. 1990. Composition, distribution and abundance of ichthyoplankton in the Sundays River estuary. South African Journal of Zoology 25, 161-168.

Harrison, T.D. \& Whitfield, A.K. 1995. Fish community structure in three temporarily open/ closed estuaries on the Natal coast. Ichthyological Bulletin of the J.L.B. Smith Institute of Ichthyology 64, 1-80.

Hay, D.G. 1985. The macrobenthos of the St Lucia Narrows. MSc thesis, University of Natal, Pietermaritzburg.

Hecht, T. \& van der Lingen, C.D. 1992. Turbidityinduced changes in feeding strategies of fish in estuaries. South African Journal of Zoology 27, 95-107.
Heemstra, P.C. 1986a. Family No. 173: Teraponidae. In: Smiths' Sea Fishes (ed. M.M. Smith \& P.C. Heemstra), pp. 543-544. Macmillan South Africa, Johannesburg.

Heemstra, P.C. 1986b. Family No. 193: Monodactylidae. In: Smiths' Sea Fishes (ed. M.M. Smith \& P.C. Heemstra), pp. 607. Macmillan South Africa, Johannesburg.

Heemstra, P.C. 1986c. Family No. 199: Sciaenidae. In: Smiths' Sea Fishes (ed. M.M. Smith \& P.C. Heemstra), pp. 616-619. Macmillan South Africa, Johannesburg.

Heemstra, P.C. 1986d. Family No. 202: Lobotidae. In: Smiths' Sea Fishes (ed. M.M. Smith \& P.C. Heemstra), pp. 621-622. Macmillan South Africa, Johannesburg.

Heemstra, P.C. \& Gon, O. 1986. Family No. 262: Soleidae. In: Smiths' Sea Fishes (ed. M.M. Smith \& P.C. Heemstra), pp. 868-874. Macmillan South Africa, Johannesburg.

Heemstra, P.C. \& Martin, T.J. 1986. Farnily No. 163: Ambassidae. In: Smiths' Sea Fishes (ed. M.M. Smith \& P.C. Heemstra), pp. 507-508. Macmillan South Africa, Johannesburg.

Hemens, J., Warwick, R.J. \& Oliff, W.D. 1975. Effect of extended exposure to low fluoride concentration on estuarine fish and crustacea. Progress in Water Technology 7, 579-585.

Hensley, D.A. 1986. Family No. 259: Bothidae. In: Smiths' Sea Fishes (ed. M.M. Smith \& P.C. Heemstra), pp. 854-863. Macmillan South Africa, Johannesburg.

Heydorn, A.E.F. 1989. The conservation status of southern African estuaries. In: Biotic Diversity in Southern Africa: Concepts and Conservation (ed. B.J. Huntley). Oxford University Press, Oxford.

Heydorn, A.E.F., Bang, N.D., Pearce, A.F., Flemming, B.W., Carter, R.A., Schleyer, M.H., Berry, P.F., Hughes, G.R., Bass, A.J., Wallace, J.H., van der Elst, R.P., Crawford, R.J.M. \& Shelton, P.A. 1978. Ecology of the Agulhas Current region: an assessment of biological responses to environmental parameters in the southwest Indian Ocean. Transactions of the Royal Society of South Africa 43, 151-190.

Heydorn, A.E.F. \& Flemming, B.W. 1985. South Africa. In: The World's Coastline (ed. E.C.F. Bird \& M.L. Schwartz), pp. 653-667. Van Nostrand Reinhold, New York.

Heydorn, A.E.F. \& Tinley, K.L. 1980. Estuaries of the Cape. Part 1. Synopsis of the Cape coast natural features, dynamics and utilization. CSIR Research Report No. 380, 1-97.

Heymans, J.J. \& Baird, D. 1995. Energy flow in the Kromme estuarine ecosystem, St Francis Bay, South Africa. Estuarine, Coastal and Shelf Science 41, 39-59. 
Hill, B.J. 1966. A contribution to the ecology of the Umlalazi estuary. Zoologica Africana 2, 1-24.

Hill, B.J. 1975. The origin of southern African coastal lakes. Transactions of the Royal Society of South Africa 41, 225-239.

Hill, B.J., Blaber, S.J.M. \& Boltt, R.E. 1975. The limnology of Lagoa Poelela. Transactions of the Royal Society of South Africa 41, 263-271.

Hilmer, T. \& Bate, G.C. 1991. Vertical migration of a flagellate-dominated bloom in a shallow South African estuary. Botanica Marina 34, 113-121.

Hobday, D.K. 1979. Geological evolution and geomorphology of the Zululand coastal plain. In: Lake Sibaya (ed. B.R. Allanson), pp. 1-20. Dr W. Junk Publishers, The Hague.

Hocutt, C.H. 1981. Fish as indicators of biological integrity. Fisheries 6, 28-31.

Hoese, D.F. 1986a. Family No. 240: Gobiidae. In: Smiths' Sea Fishes (ed. M.M. Smith \& P.C. Heemstra), pp. 774-807. Macmillan South Africa, Johannnesburg.

Hoese, D.F. 1986b. Family No. 241: Eleotridae. In: Smiths' Sea Fishes (ed. M.M. Smith \& P.C. Heemstra), pp. 807-811. Macmillan South Africa, Johannnesburg.

Houde, E.D. 1987. Fish early life dynamics and recruitment variability. American Fisheries Society Symposium 2, 17-29.

Howard-Williams, C. 1977. The distribution of nutrients in Swartvlei, a southern Cape coastal lake. Water SA 3, 213-217.

Howard-Williams, C. \& Allanson, B.R. 1981. An integrated study on littoral and pelagic primary production in a southern African coastal lake. Archiv für Hydrobiologie 92, 507-534.

Howard-Williams, C. \& Liptrot, M.R. 1980. Submerged macrophyte communities in a brackish South African estuarine-lake system. Aquatic Botany 9, 101-116.

Hughes, P. \& Brundrit, G.B. 1992. An index to assess South Africa's vulnerability to sea-level rise. South African Journal of Science 88, 308-313.

Huizinga, P. \& van Niekerk, L. 1997. The hydrodynamics of the Thukela estuary. Unpublished Report, CSIR, Stellenbosch.

Hutchison, I.P.G. 1977. Lake St Lucia - the computer points the way. African Wildlife 31(2), 25-27.

Hutchison, I.P.G. \& Midgley, D.C. 1978. Modelling the water and salt balance in a shallow lake. Ecological Modelling 4, 211-235.

Ivantsoff, W. 1986. Family No. 111: Atherinidae. In: Smiths' Sea Fishes (ed. M.M. Smith \& P.C. Heemstra), pp. 381-383. Macmillan South Africa, Johannesburg.

James, N.P.E. \& Bruton, M.N. 1992. Alternative lifehistory traits associated with reproduction in
Oreochromis mossambicus (Pisces: Cichlidae) in small water bodies of the eastern Cape, South Africa. Environmental Biology of Fishes 34, 379392.

Jezewski, W.A. \& Roberts, C.P.R. 1986. Estuarine and lake freshwater requirements. Department of Water Affairs Technical Report No. 129, 1-39.

Joubert, C.S.W. 1981. Aspects of the biology of five species of inshore reef fishes on the Natal coast, South Africa. Investigational Report of the Oceanographic Research Institute 51, 1-16.

Joubert, C.S.W. \& Hanekom, P.B. 1980. A study of feeding in some inshore reef fish of the Natal coast, South Africa. South African Journal of Zoology 15, 262-274.

Joubert, L.S. \& Davies, D.H. 1966. The penaeid prawns of the St Lucia lake system. Investigational Report of the Oceanographic Research Institute $13,1-40$.

Jubb, R.A. 1967. Freshwater Fishes of Southern Africa. Balkema, Cape Town.

Jubb, R.A. 1970. Freshwater eels: Anguilla species. Eastern Cape Naturalist 39, 10-15.

Jubb, R.A. 1979. Cichlid fish mortality: Kasouga River estuary. Lammergeyer 27, 51.

Kapoor, B.G., Smit, H. \& Verighnia, I.A. 1975. The alimentary canal and digestion in teleosts. Advances in Marine Biology 13, 109-239.

Karr, J.R. 1981. Assessment of biotic integrity using fish communities. Fisheries 6, 21-27.

Karr, J.R. \& Dudley, D.R. 1981. Ecological perspective on water quality goals. Environmental Management 5, 55-68.

Kennedy, V.S. 1990. Anticipated effects of climate change on estuarine and coastal fisheries. Fisheries 15, 16-24.

Kennish, M.J. 1986. Ecology of Estuaries. Volume 1. Physical and Chemical Aspects. CRC Press, Boca Raton.

Kennish, M.J. 1990. Ecology of Estuaries. Volume 2. Biological Aspects. CRC Press, Boca Raton.

Knapp, L.W. 1986. Family No. 155: Platycephalidae. In: Smiths' Sea Fishes (ed. M.M. Smith \& P.C. Heemstra), pp. 482-486. Macmillan South Africa, Johannesburg.

Kok, H.M. \& Blaber, S.J.M. 1977. A new freshwater goby (Teleostei: Gobiidae) from the Pongolo floodplain, Zululand, South Africa. Zoologica Africana 12, 163-168.

Kok, H.M. \& Whitfield, A.K. 1986. The influence of open and closed mouth phases on the marine fish fauna of the Swartvlei estuary. South African Journal of Zoology 21, 309-315.

Kyle, R. 1984. Tolerance of high temperatures by the cichlid Oreochromis mossambicus in the Kosi system. Lammergeyer 32, 50. 
Kyle, R. 1989. Two interesting fish records from Maputaland. Lammergeyer 40, 40-41.

Kyle, R. 1993. Towards the wise use of the fishes of the Kosi Bay Nature Reserve. In: Fish, Fishers and Fisheries (ed. L.E. Beckley \& R.P. van der Elst), pp. 107-122. Oceanographic Research Institute Special Publication No. 2, Durban.

Kyle, R. \& Robertson, W.D. 1997. Preliminary estimates of population size and capture rates of mature Acanthopagus berda in the Kosi lakes system, South Africa, using mark-recapture methods. South African Journal of Zoology 32, 124-128.

Largier, J.L. \& Slinger, J.H. 1991. Circulation in highly stratified southern African estuaries. Southern African Journal of Aquatic Sciences 17, 103-115.

Lasiak, T.A. 1981. Nursery grounds of juvenile teleosts: evidence from the surf zone of King's Beach, Port Elizabeth. South African Journal of Science 77, 388-390.

Lasiak, T.A. 1983a. Aspects of the reproductive biology of the southern mullet, Liza richardsoni, from Algoa Bay, South Africa. South African Journal of Zoology 18, 89-95.

Lasiak, T.A. 1983b. Recruitment and growth patterns of juvenile teleosts caught at Kings Beach, Algoa Bay, South Africa. South African Journal of Zoology 18, 25-30.

Lasiak, T.A. 1984a. The reproductive biology of the moony, Monodactylus falciformis, in Algoa Bay. South African Journal of Zoology 19, 250-252.

Lasiak, T.A. 1984b. Structural aspects of the surfzone fish assemblage at King's beach, Algoa Bay, South Africa: long-term fluctuations. Estuarine, Coastal and Shelf Science 18, 459-483.

Last, P.R. \& Stevens, J.D. 1994. Sharks and Rays of Australia. CSIRO, Australia, 513 pp. +84 plates.

Lenanton, R.C.J. \& Hodgkin, E.P. 1985. Life history strategies of fish in some temperate Australian estuaries. In: Fish Community Ecology in Estuaries and Coastal Lagoons: Towards an Ecosystem Integration (ed. A. Yanez-Aráñcibia), pp. 267-284. Universidad Nacional Autónoma de México, México.

Leu, M.Y. 1994. Natural spawning and larval rearing of silver bream, Rhabdosargus sarba (Forsskål), in captivity. Aquaculture 120, 115-122.

Levinton, J.S. 1980. Genetic divergence in estuaries. In: Estuarine Perspectives (ed. V.S. Kennedy), pp. 509-520. Academic Press, New York.

Long, J.A., Anderson, M.E., Gess, R. \& Hiller, N. 1997. New placoderm fishes from the Late Devonian of South Africa. Journal of Vertebrate Palaeontology 17, 253-268.

Macfarlane, J.M. 1923. The Evolution and Distribution of Fishes. Macmillan, New York, 564 pp.
MacKay, H.M. \& Schumann, E.H. 1990. Mixing and circulation in the Sundays River estuary. Estuarine, Coastal and Shelf Science 31, 203-216.

Macnae, W. 1968. Mudskippers. African Wildlife 22, 241-248.

Macnae, W. \& Kalk, M. (ed.) 1958. A Natural History of Inhaca Island, Mocambique. Witwatersrand University Press, Johannesburg, $163 \mathrm{pp}$.

Major, P.F. 1973. Scale feeding behavior of the leather-jacket, Scomberoides lysan and two species of the genus Oligoplites (Pisces: Carangidae). Copeia 1973, 151-154.

Mallin, M.A., Paerl, H.W., Rudek, J. \& Bates, P.W. 1993. Regulation of estuarine primary production by watershed rainfall and river flow. Marine Ecology Progress Series 93, 199-203.

Mann, B.Q. 1993. The importance of fish and fishing at Lake St Lucia. In: Proceedings of the Workshop on Water Requirements for Lake St Lucia (ed. R.H. Taylor), pp. 58-61. Department of Environment Affairs, Pretoria.

Mann, B.Q. \& Buxton, C.D. 1993. The biology and management of blacktail (Diplodus sargus capensis) and zebra ( $D$. cervinus hottentotus) off the southeastern Cape coast. In: Fish, Fishers and Fisheries (ed. L.E. Beckley \& R.P. van der Elst), pp. 26-27. Oceanographic Research Institute Special Publication No. 2, Durban.

Marais, J.F.K. 1978. Routine oxygen consumption of Mugil cephalus, Liza dumerili and L. richardsoni at different temperatures and salinities. Marine Biology 50, 9-16.

Marais, J.F.K. 1980. Aspects of food intake, food selection, and alimentary canal morphology of Mugil cephalus (Linnaeus, 1758), Liza tricuspidens (Smith, 1935), L. richardsoni (Smith, 1846), and $L$. dumerili (Steindachner, 1869). Journal of Experimental Marine Biology and Ecology 44, 193-209.

Marais, J.F.K. 1981. Seasonal abundance, distribution and catch per unit effort using gill-nets, of fishes in the Sundays estuary. South African Journal of Zoology 16, 144-150.

Marais, J.F.K. 1982. The effects of river flooding on the fish populations of two eastern Cape estuaries. South African Journal of Zoology 17, 96-104.

Marais, J.F.K. 1983a. Seasonal abundance, distribution and catch per unit effort of fishes in the Krom estuary, South Africa. South African Journal of Zoology 18, 96-102.

Marais, J.F.K. 1983b. Fish abundance and distribution in the Gamtoos estuary with notes on the effect of floods. South African Journal of Zoology $18,103-109$.

Marais, J.F.K. 1984. Feeding ecology of major carnivorous fish from four eastern Cape estuaries. South African Journal of Zoology 19, 210-223. 
Marais, J.F.K. 1988. Some factors that influence fish abundance in South African estuaries. South African Journal of Marine Science 6, 67-77.

Marais, J.F.K. \& Baird, D. 1980a. Seasonal abundance, distribution, and catch per unit effort of fishes in the Swartkops estuary. South Africain Journal of Zoology 15, 66-71.

Marais, J.F.K. \& Baird, D. 1980b. Analysis of angler's catch data from the Swartkops estuary. South African Journal of Zoology 15, 61-65.

Marais, J.F.K. \& Erasmus, T. 1977. Chemical composition of alimentary canal contents of mullet (Teleostei: Mugilidae) caught in the Swartkops estuary near Port Elizabeth, South Africa. Aquaculture 10, 263-273.

Marais, J.F.K. \& Venter, D.J.L. 1991. Changes in body composition associated with growth and reproduction in Galeichthys feliceps (Teleostei: Ariidae). South African Journal of Marine Science 10, 149-157.

Margalef, R. 1968. Perspectives in Ecological Theory. University of Chicago Press, Chicago.

Margalef, R. 1969. Diversity and stability: a practical proposal and a model of interdependence. Brookhaven Symposia in Biology 22, 25-37.

Marker, M.E. \& Miller, D.E. 1993. A MidHolocene high stand of the sea at Knysna. South African Journal of Science 89, 100-101.

Martin, T.J. 1988. Interaction of salinity and temperature as a mechanism for spatial separation of three co-existing species of Ambassidae (Cuvier) (Teleostei) in estuaries on the south-east coast of Africa. Journal of Fish Biology 33 (Supplement A), 9-15.

Martin, T.J. 1989. Niche separation in Ambassis (Pisces: Perciformes) species co-existing in estuaries of south-east Africa. Journal of Fish Biology 35 (Supplement A), 321-328.

Martin, T.J. 1990. Osmoregulation in three species of Ambassidae (Osteichthyes: Perciformes) from estuaries in Natal. South African Journal of Zoology 25, 229-234.

Martin, T.J. \& Blaber, S.J.M. 1983. The feeding ecology of Ambassidae (Osteichthyes: Perciformes) in Natal estuaries. South African Journal of Zoology 18, 353-362.

Martin, T.J. \& Blaber, S.J.M. 1984. Morphology and histology of the alimentary tracts of Ambassidae (Cuvier) (Teleostei) in relation to feeding. Journal of Morphology 182, 295-305.

Martin, T.J., Cyrus, D.P. \& Forbes, A.T. 1992. Episodic events: the effects of cyclonic flushing on the ichthyoplankton of St Lucia estuary on the southeast coast of Africa. Netherlands Journal of Sea Research 30, 273-278.
Martin, T.J. \& Heemstra, P.C. 1988. Identification of Ambassis species (Pisces: Perciformes, Ambassidae) from South Africa. South African Journal of Zoology 23, 7-12.

Masson, H. \& Marais, J.F.K. 1975. Stomach content analyses of mullet from the Swartkops estuary. Zoologica Africana 10, 193-207.

May, R.C. 1974. Larval mortality in marine fishes and the critical period concept. In: The Early Life History of Fish (ed. J.H.S. Blaxter), pp. 3-19. Springer-Verlag, Berlin.

McEwan, A. \& Hecht, T. 1984. Age and growth of the longfin eel, Anguilla mossambica Peters, 1852 (Pisces: Anguillidae) in Transkei rivers. South African Journal of Zoology 19, 280-285.

McKay, R.J. 1986. Family No. 198: Sillaginidae. In: Smiths' Sea Fishes (ed. M.M. Smith \& P.C. Heemstra), pp. 615-616. Macmillan South Africa, Johannesburg.

McLachlan, A. \& Grindley, J.R. 1974. Distribution of macrobenthic fauna of soft substrata in Swartkops estuary, with observations on the effects of floods. Zoologica Africana 9, 211-233.

Mehl, J.A.P. 1973. Ecology, osmoregulation and reproductive biology of the white steenbras Lithognathus lithognathus (Teleostei: Sparidae). Zoologica Africana 8, 157-230.

Melville-Smith, R. \& Baird, D. 1980. Abundance, distribution and species composition of fish larvae in the Swartkops estuary. South African Journal of Zoology 15, 72-78.

Melville-Smith, R., Baird, D. \& Wooldridge, T. 1981. The utilization of tidal currents by the larvae of estuarine fish. South African Journal of Zoology 16, 10-13.

Millard, N.A.H. \& Broekhuysen, G.J. 1970. The ecology of South African estuaries. Part X. St Lucia: a second report. Zoologica Africana 5, 277-307.

Millard, N.A.H. \& Harrison, A.D. 1954. The ecology of South African estuaries. Part 5. Richards Bay. Transactions of the Royal Society of South Africa 34, 157-179.

Millard, N.A.H. \& Scott, K.M.F. 1954. The ecology of South African estuaries. Part 6. Milnerton estuary and the Diep River, Cape. Transactions of the Royal Society of South Africa 34, 279-324.

Miller, D.E. 1990. A southern African Late Quarternary sea-level curve. South African Journal of Science 86, 456-458.

Miller, J.M., Crowder, L.B. \& Moser, M.L. 1985. Migration and utilization of estuarine nurseries by juvenile fishes: an evolutionary perspective. Contributions in Marine Science 27 (Supplement), 338-352. 
Miller, J.M., Reed, J.P. \& Pietrafesa, L.J. 1984. Patterns, mechanisms and approaches to the study of migrations of estuarine-dependent fish larvae and juveniles. In: Mechanisms of Migration in Fishes (ed. J.D. McCleave), pp. 209-225. Plenum, New York.

Mires, D., Shak, Y. \& Shilo, S. 1974. Further observations on the effect of salinity and temperature changes on Mugil capito and Mugil cephalus fry. Bamidgeh 26, 104-109.

Moldan, A., Chapman, P. \& Fourie, H.O. 1979. Some ecological effects of the Venpet-Venoil collision. Marine Pollution Bulletin 10, 60-63.

Morant, P.D. \& O'Callaghan, M. 1990. Some observations on the impact of the March 1988 flood on the biota of the Orange River mouth. Transactions of the Royal Society of South Africa 47, 295-305.

Moyle, P.B. \& Cech, J.J. 1982. Fishes: An Introduction to Ichthyology. Prentice-Hall, Englewood Cliffs, 593 pp.

Moyle, P.B. \& Leidy, R.A. 1992. Loss of biodiversity in aquatic ecosystems: evidence from fish faunas. In: Conservation Biology: The Theory and Practice of Nature Conservation, Preservation and Management (ed. P.L. Fielder \& S.K. Jain), pp. 129-169. Chapman \& Hall, New York.

Moyle, P.B. \& Sato, G.M. 1991. On the design of preserves to protect native fishes. In: Battle against Extinction: Native Fish Management in the American West (ed. W. Minckley \& J. Deacon), pp. 155-173. University of Arizona Press, Tucson.

Neira, F.J., Beckley, L.E. \& Whitfield, A.K. 1988. Larval development of the Cape silverside, Atherina breviceps Cuv. \& Val., 1835 (Teleostei, Atherinidae) from southern Africa. South African Journal of Zoology 23, 176-183.

Neira, F.J. \& Potter, I.C. 1994. The larval fish assemblage of the Nornalup-Walpole estuary, a permanently open estuary on the southern coast of Western Australia. Australian Journal of Marine and Freshwater Research 45, 1193-1207.

Noble, R.G. \& Hemens, J. 1978. Inland water ecosystems in South Africa - a review of research needs. South African National Scientific Programmes Report No. 34, 1-148.

Norcross, B.L. \& Shaw, R.F. 1984. Oceanic and estuarine transport of fish eggs and larvae: a review. Transactions of the American Fisheries Society $113,153-165$.

Odum, W.E. 1971. Fundamentals of Ecology. W.B. Saunders, Philadelphia, 574 pp.

Olivier, P.A.S. \& van Niekerk, J.P. 1995. New morphological information on the parasitic copepod Lernanthropus sarbae Kensley \& Grindley, 1973 (Copepoda: Lernanthropidae) from Lake St Lucia, South Africa, using scanning electron microscopy. Koedoe 38(2), 99-104.
Orme, A.R. 1973. Barrier and lagoon systems along the Zululand coast, South Africa. In: Coastal Geomorphology (ed. R.D. Coates), pp. 181-217. State University of New York, Binghampton.

Panikkar, N.K. 1960. Physiological aspects of adaptation to estuarine conditions. Australian Fisheries Council Proceedings 32, 168-175.

Paterson, A.W. 1995. Preliminary observations on the ecology of the blackspotted electric ray. The Naturalist 39(1), 32-34.

Paterson, A.W. \& Whitfield, A.K. 1996. Fish associated with a salt marsh creek in the Kariega Estuary, South Africa. Transactions of the Royal Society of South Africa 51, 195-218.

Paterson, A.W. \& Whitfield, A.K. 1997. A stable carbon isotope study of the food-web in a freshwater-deprived South African estuary, with particular emphasis on the ichthyofauna. Estuarine, Coastal and Shelf Science 45, 705-715.

Perry, J.E. 1989. The impact of the September 1987 floods on the estuaries of Natal/Kwazulu; a hydrophotographic perspective. CSIR Research Report No. 640, 1-29.

Plumstead, E.E. 1990. Changes in ichthyofaunal diversity and abundance within the Mbashe estuary, Transkei, following construction of a river barrage. South African Journal of Marine Science 9, 399-407.

Plumstead, E.E., Prinsloo, J.F. \& Schoonbee, H.J. 1985. A survey of the fish fauna of Transkei estuaries. Part 1. Kei River estuary. South African Journal of Zoology 20, 213-220.

Plumstead, E.E., Prinsloo, J.F. \& Schoonbee, H.J. 1989a. A survey of the fish fauna of Transkei estuaries. Part 2. The Mbashe estuary. South African Journal of Zoology 24, 273-281.

Plumstead, E.E., Prinsloo, J.F. \& Schoonbee, H.J. 1989b. A survey of the fish fauna of Transkei estuaries. Part 3: The Mtata River estuary. South African Journal of Zoology 24, 282-289.

Plumstead, E.E., Prinsloo, J.F. \& Schoonbee, H.J. 1991. A survey of the fish fauna of Transkei estuaries. Part 4: The Mntafufu and Mzamba River estuaries. South African Journal of Zoology 26, 153-163.

Pooley, A.C. 1975. New fish records for Ndumu Game Reserve. Lammergeyer 22, 50-51.

Potter, I.C., Beckley, L.E., Whitfield, A.K. \& Lenanton, R.C.J. 1990. Comparisons between the roles played by estuaries in the life cycles of fishes in temperate Western Australia and southern Africa. Environmental Biology of Fishes 28, 143 178.

Prins, J.G. 1990. Assessment of environmental water requirements for the Orange River mouth. Department of Water Affairs, Pretoria, $69 \mathrm{pp}$. 
Pritchard, D.W. 1967. What is an estuary: physical viewpoint. In: Estuaries (ed. G.H. Lauff), pp. 35. American Association for the Advancement of Science, Washington D.C.

Prochazka, K. 1994. The reproductive biology of intertidal klipfish (Perciformes: Clinidae) in South Africa. South African Journal of Zoology 29, 244251.

Quinn, N.W., Whitfield, A.K., Breen, C.M. \& Hearne, J.W. 1998a. An index for the management of South African estuaries for juvenile fish recruitment from the marine environment. Fisheries Management and Ecology, in press.

Quinn, N.W., Breen, C.M., Hearne, J.W. \& Whitfield, A.K. 1998b. Decision support systems for environmental management: a case study on estuary management. Orion, in press.

Ramm, A.E.L. 1988. The community degradation index: a new method for assessing the deterioration of aquatic habitats. Water Research 22, 293-301.

Ramm, A.E.L. 1990a. Oxygen-sulphide dynamics in Lake Mpungwini: implications for the Kosi Lakes Reserve. 7th National Oceanographic Conference, San Lameer, South Africa, 4 pp.

Ramm, A.E.L. 1990b. Application of the community degradation index to South African estuaries. Water Research 24, 383-389.

Ramm, A.E.L. 1992. Aspects of the biogeochemistry of sulphur in Lake Mpungwini, southern Africa. Estuarine, Coastal and Shelf Science 34, 253-261.

Ramm, A.E.L., Cerff, E.C. \& Harrison, T.D. 1987. Documenting the recovery of a severely degraded coastal lagoon. Journal of Shoreline Management 3, 159-167.

Ratte, T.W. 1982. 'n Opname van die visbevolkings van die Breëriviermond. Bontebok 2, 13-18.

Ratte, T.W. 1989. Population structure, production, growth, reproduction and the ecology of Atherina breviceps Valenciennes, 1935 (Pisces, Atherinidae) and Gilchristella aestuaria (Gilchrist, 1914) (Pisces, Clupeidae), from two southern Cape coastal lakes. $\mathrm{PhD}$ thesis, University of Port Elizabeth, Port Elizabeth, 319 pp.

Ratte, T.W. \& Ritchie, G. 1984. Southern Cape lake created by glaciers. Custos 13, 8-9.

Read, G.H.L. 1983. The effect of a dry and a wet summer on the thermal and salinity structure of the middle and upper reaches of the Keiskamma estuary, Ciskei. Transactions of the Royal Society of South Africa 45, 45-62.

Reavell, P.E. \& Cyrus, D.P. 1989. Preliminary observations on the macrocrustacea of coastal lakes in the vicinity of Richards Bay, Zululand, South Africa. Southern African Journal of Aquatic Sciences 15, 103-128.
Reddering, J.S.V. 1988a. Prediction of the effects of reduced river discharge on the estuaries of the south-eastern Cape Province, South Africa. South African Journal of Science 84, 726-730.

Reddering, J.S.V. 1988b. Coastal and catchment basin controls on estuary morphology of the south-eastern Cape coast. South African Journal of Science 84, 154-157.

Reddering, J.S.V. \& Esterhuysen, K. 1984. Research on sedimentation in estuaries. Sedimentation in the Kromme estuary. Geology Department, University of Port Elizabeth, Rosie Report No. 6, 1-92.

Reddering, J.S.V. \& Esterhuysen, K. 1987. The effects of river floods on sediment dispersal in small estuaries: a case study from East London. South African Journal of Geology 90, 458-470.

Reddering, J.S.V. \& Rust, I.C. 1990. Historical changes and sedimentary characteristics of southern African estuaries. South African Journal of Science 86, 425-428.

Rensch, B. 1959. Evolution above the Species Level. Methuen, London, $419 \mathrm{pp}$.

Ribbink, A.J. 1971. The behaviour of Hemihaplochromis philander, a South African cichlid fish. Zoologica Africana 6, 263-288.

Ribbink, A.J. 1975. A contribution to the understanding of the ethology of the cichlids of southern Africa. PhD thesis, Rhodes University, Grahams-town, $211 \mathrm{pp}$.

Ribbink, A.J. 1994. Biodiversity and speciation of freshwater fishes. In: Aquatic Ecology: Scale, Pattern and Process (ed. P.S. Giller, A.G. Hildrew \& D.G. Raffaelli), pp. 261-288. Blackwell Scientific Publications, Oxford.

Ribbink, A.J., Marsh, A.C. \& Marsh, B.A. 1981. Nest-building and communal care of young by Tilapia rendalli Dumeril (Pisces, Cichlidae) in Lake Malawi. Environmental Biology of Fishes 6, 219-222.

Rigney, H. 1990. Marine reserves - blueprint for protection. Australian Fisheries, 18-22

Riley, A.K. 1986. Aspekte van die soutgehalte toleransie van die Knysna seeperdjie, Hippocampus capensis (Boulenger, 1900) in die Knysna estuarium. Unpublished Report, Cape Technikon, Cape Town, 17 pp.

Robinson, G.A. \& de Graaff, G. 1994. Marine protected areas of the Republic of South Africa. Council for the Environment, Pretoria, 203 pp.

Rogers, J. 1985. Geomorphology, offshore bathymetry and quaternary lithostratigraphy around the Bot River estuary. Transactions of the Royal Society of South Africa 45, 211-237.

Romer, G.S. \& McLachlan, A. 1986. Mullet grazing on surf zone diatom accumulations. Journal of Fish Biology 28, 93-104. 
Roper, D.S. 1986. Occurrence and recruitment of fish larvae in a northern New Zealand estuary. Estuarine, Coastal and Shelf Science 22, 705-717.

Rossouw, J., Perry, J.E., Bickerton, I.B. \& Morant, P.D.1991. Flood impacts on estuaries, river mouths, bays and coastal wetlands. Unpublished CSIR Report, Stellenbosch, 19 pp.

Roux, D.J., van Vliet, H.R. \& van Veelen, M. 1993. Towards integrated water quality monitoring: assessment of ecosystem health. Water SA 19, 275-280.

Russell, I.A. 1994. Mass mortality of marine and estuarine fish in the Swartvlei and Wilderness lake systems, southern Cape. Southern African Journal of Aquatic Sciences 20, 93-96.

Russell, I.A. 1996. Fish abundance in the Wilderness and Swartvlei lake systems: changes relative to environmental factors. South African Journal of Zoology 31, 1-9.

Sauriau, P.G., Robin, J.P. \& Marchand, J. 1994. Effects of excessive organic enrichment of the Loire estuary on the downstream migratory patterns of the amphihaline grey mullet Liza ramada (Pisces: Mugilidae). In: Changes in Fluxes in Estuaries: Implications from Science to Management (ed. K.R. Dyer \& R.J. Orth), pp. 349-356. Olsen \& Olsen, Fredensborg.

Schlacher, T.A. \& Wooldridge, T.H. 1996a. Patterns of selective predation by juvenile, benthivorous fish on estuarine macrofauna. Marine Biology 125, 241-247.

Schlacher, T.A. \& Wooldridge, T.H. $1996 \mathrm{~b}$. Ecological responses to reductions in freshwater supply and quality in South Africa's estuaries: lessons for management and conservation. Journal of Coastal Conservation 2, 115-130.

Schleyer, M.H. \& Wallace, J.H. 1986. Stomach contents of some shore-caught teleosts of Natal, South Africa. South African Journal of Zoology 21, 272-274.

Schramm, M. 1989. Some trypanorhynch tapeworms found in marine fish. The Naturalist 33(1), 22-26.

Schramm, M. 1991. Grillotia perelica (Cestoda: Trypanorhyncha) plerocercoids in mullet (Pisces: Mugilidae) from estuaries in Transkei, southern Africa. South African Journal of Marine Science 11, 169-178.

Schroeder, W.W. 1978. Riverine influence on estuaries: a case study. In: Estuarine Interactions (ed. M.L. Wiley), pp. 347-364. Academic Press, New York.

Schubel, J.R. \& Hirschberg, D.J. 1978. Estuarine graveyards, climatic change, and the importance of the estuarine environment. In: Estuarine Interactions (ed. M.L. Wiley), pp. 285-303. Academic Press, New York.
Schumann, E.H., Perrins, L.A. \& Hunter, I.T. 1982. Upwelling along the south coast of the Cape Province, South Africa. South African Journal of Science 78, 238-242.

Schumann, E.H., Ross, G.J.B. \& Goschen, W.S. 1988. Cold water events in Algoa Bay and along the Cape south coast, South Africa, in March/April 1987. South African Journal of Science 84, 579-584.

Scott, K.M.F., Harrison, A.D. \& Macnae, W. 1952. The ecology of South African estuaries. Part 2: The Klein River estuary, Hermanus, Cape. Transactions of the Royal Society of South Africa 33, 282-331.

Shannon, L.V. \& Chapman, P. 1983. Suggested mechanism for the chronic pollution by oil of beaches east of Cape Agulhas, South Africa. South African Journal of Marine Science 1, 231144.

Shaw, R.F., Rogers, B.D., Cowan, J.H. \& Herke, W.H. 1988. Ocean-estuary coupling of ichthyoplankton and nekton in the northern Gulf of Mexico. American Fisheries Society Symposium 3, 77-89.

Skelton, P.H. 1983. Perspectives on the conservation of threatened fishes in southern Africa. The Naturalist 27(1), 3-12.

Skelton, P.H. 1986. Distribution patterns and biogeography of non-tropical southern African freshwater fishes. In: Paleoecology of Africa and the Surrounding Islands, (ed. E. van Zinderen Bakker, J.A. Coetzee \& L. Scott), Volume 17, pp. 211-230. Balkema, Rotterdam.

Skelton, P.H. 1987. South African Red Data Book Fishes. South African National Scientific Programmes Report No. 137, 1-197.

Skelton, P.H. 1993. A Complete Guide to the Freshwater Fishes of Southern Africa. Macmillan South Africa, Halfway House, 388 pp.

Skelton, P.H., Whitfield, A.K. \& James, N.P.E. 1989. Distribution and diversity of Mkuze swamp fishes during a summer flood. Southern African Journal of Aquatic Sciences 15, 50-66.

Slinger, J.H. \& Breen, C.M. 1995. Integrated research into estuarine management. Water Science and Technology 32, 79-86.

Smale, M.J. \& Buxton, C.D. 1989. The subtidal gully fish community of the eastern Cape and the role of this habitat as a nursery area. South African Journal of Zoology 24, 58-67.

Smale, M.J. \& Kok, H.M. 1983. The occurrence and feeding of Pomatomus saltatrix (elf) and Lichia amia (leervis) juveniles in two Cape south coast estuaries. South African Journal of Zoology 18, 337-342. 
Smith, J.L.B. 1933. The South African species of the genus Hemirhamphus Cuv. Transactions of the Royal Society of South Africa 21, 129-150.

Smith, J.L.B. 1965. The Sea Fishes of Southern Africa. Central News Agency, South Africa, 580 pp.

Smith, J.L.B. \& Smith, M.M. 1986. Family No. 183: Sparidae. In: Smiths' Sea Fishes (ed. M.M. Smith \& P.C. Heemstra), pp. 580-594. Macmillan South Africa, Johannesburg.

Smith, M.M. 1980. Marine fishes of Maputaland. In: Studies on the Ecology of Maputaland (ed. M.N. Bruton \& K.H. Cooper), pp. 164-187. Rhodes University, Grahamstown \& Wildlife Society, Durban.

Smith, M.M. 1981. The seahorse of the Knysna lagoon. African Wildlife 35 (6), 5-7.

Smith, M.M. 1986a. Family No. 36: Elopidae. In: Smiths' Sea Fishes (ed. M.M. Smith \& P.C. Heemstra), pp. 155-156. Macmillan South Africa, Johannesburg.

Smith, M.M. 1986b. Family No. 37: Megalopidae. In: Smiths' Sea Fishes (ed. M.M. Smith \& P.C. Heemstra), pp. 156. Macmillan South Africa, Johannesburg.

Smith, M.M. 1986c. Family No. 164: Kuhliidae. In: Smiths' Sea Fishes (ed. M.M. Smith \& P.C. Heemstra), pp. 508-509. Macmillan South Africa, Johannesburg.

Smith, M.M. 1986d. Family No. 201: Leiognathidae. In: Smiths' Sea Fishes (ed. M.M. Smith \& P.C. Heemstra), pp. 620-621. Macmillan South Africa, Johannesburg.

Smith, M.M. 1986e. Family No. 237: Clinidae. In: Smiths' Sea Fishes (ed. M.M. Smith \& P.C. Heemstra), pp. 758-769. Macmillan South Africa, Johannesburg.

Smith, M.M. \& Heemstra, P.C. (ed.) 1986a. Smiths' Sea Fishes. Macmillan South Africa, Johannesburg, 1047 pp.

Smith, M.M. \& Heemstra, P.C. 1986b. Family No. 268: Tetraodontidae. In: Smiths' Sea Fishes (ed. M.M. Smith \& P.C. Heemstra), pp. 894-903. Macmillan South Africa, Johannesburg.

Smith, M.M. \& McKay, R.J 1986. Family No. 179: Haemulidae. In: Smiths' Sea Fishes (ed. M.M. Smith \& P.C. Heemstra), pp. 564-571. Macmillan South Africa, Johannesburg.

Smith, M.M. \& Smith, J.L.B. 1986a. Family No. 178: Pomatomidae. In: Smiths' Sea Fishes (ed. M.M. Smith \& P.C. Heemstra), pp. 564. Macmillan South Africa, Johannesburg.

Smith, M.M. \& Smith, J.L.B. 1986b. Family No. 222: Mugilidae. In: Smiths' Sea Fishes (ed. M.M. Smith \& P.C. Heemstra), pp. 714-720. Macmillan South Africa, Johannesburg.
Smith-Vaniz, W.F. 1986. Family No. 210: Carangidae. In: Smiths' Sea Fishes (ed. M.M. Smith \& P.C. Heemstra), pp. 638-661. Macmillan South Africa, Johannesburg.

Stabell, O.B. 1992. Olfactory control of homing behaviour in salmonids. In: Fish Chemoreception (ed. T.J. Hara). Chapman \& Hall, London.

Stebbins, R.C. \& Kalk, M. 1961. Observations on the natural history of the mud-skipper, Periophthalmus sobrinus. Copeia 1961, 18-27.

Stone, J.H., Day, J.W., Bahr, L.M. \& Muller, R.A. 1978. The impact of possible climatic changes on estuarine ecosystems. In: Estuarine Interactions (ed. M. Wiley), pp. 305-322. Academic Press, New York.

Swart, D.H., Morant, P.D., Möller, J.P., Crowley, J.B. \& de Wet, A. 1988. A record of events at the Orange River mouth during the March 1988 flood. South African Journal of Science 84, 881-924.

Sylvester, J.R., Nash, C.E. \& Emberson, C.R. 1975. Salinity and oxygen tolerances of eggs and larvae of Hawaiian striped mullet, Mugil cephalus L. Journal of Fish Biology 7, 621-629.

Talbot, F.H. 1955. Notes on the biology of the white stumpnose, Rhabdosargus globiceps (Cuvier), and on the fish fauna of the Klein River estuary. Transactions of the Royal Society of South Africa 34, 387-407.

Talbot, M.M.B. \& Bate, G.C. 1987. The distribution and biomass of the seagrass Zostera capensis in a warm-temperate estuary. Botanica Marina 30, 9199.

Talbot, M.M.B., Knoop, W.T. \& Bate, G.C. 1990. The dynamics of estuarine macrophytes in relation to flood/siltation cycles. Botanica Marina 33, 159164.

Talbot, M.M.J. 1982. Aspects of the ecology and biology of Gilchristella aestuarius ( $\mathrm{G} \& \mathrm{~T}$ ) (Pisces: Clupeidae) in the Swartkops estuary, Port Elizabeth. MSc thesis, University of Port Elizabeth, Port Elizabeth, 128 pp.

Talbot, M.M.J. \& Baird, D. 1985a. Feeding of the estuarine round herring Gilchristella aestuarius (G \& T) (Stolephoridae). Journal of Experimental Marine Biology and Ecology 87, 199-214.

Talbot, M.M.J. \& Baird, D. 1985b. Oxygen consumption of the estuarine round herring Gilchristella aestuarius ( $\mathrm{G} \& \mathrm{~T}$ ). South African Journal of Zoology 20, 1-4.

Taylor, D.I. 1983. The effects of a major macrophyte regression upon primary production in the littoral of Swartvlei. Archiv für Hydrobiologie 96, 345-353.

Taylor, R.H. 1982. St Lucia estuary: the aquatic environment. In: St Lucia Research Review (ed. R.H. Taylor), pp. 42-56. Natal Parks, Game and Fish Preservation Board, Pietermaritzburg. 
Teal, J.M. \& Carey, F.G. 1967. Skin respiration and oxygen debt in the mudskipper Periophthalmus sobrinus. Copeia 1967, 677-679.

Ter Morshuizen, L.D. \& Whitfield, A.K. 1994. The distribution of littoral fish associated with eelgrass Zostera capensis beds in the Kariega estuary, a southern African system with a reversed salinity gradient. South African Journal of Marine Science 14, 95-105.

Ter Morshuizen, L.D., Whitfield, A.K. \& Paterson, A.W. 1996a. Distribution patterns of fishes in an Eastern Cape estuary and river with particular emphasis on the ebb and flow region. Transactions of the Royal Society of South Africa 51, 257-280.

Ter Morshuizen, L.D., Whitfield, A.K. \& Paterson, A.W. 1996b. Influence of freshwater flow regime on fish assemblages in the Great Fish River and estuary. Southern African Journal of Aquatic Sciences 22, 52-61.

Tilney, R.L. \& Hecht, T. 1990. The food and feeding habits of two co-occurring marine catfish Galeichthys feliceps and $G$. ater (Osteichthyes: Ariidae) along the south-east coast of South Africa. Journal of Zoology, London 221, 171-193.

Tilney, R.L. \& Hecht, T. 1993. Early ontogeny of Galeichthys feliceps from the south east coast of South Africa. Journal of Fish Biology 43, 171-193.

Trewavas, E. 1983. Tilapiine fishes of the genera Sarotherodon, Oreochromis and Danakilia. British Museum (Natural History), London, 583 pp.

van der Elst, R.P. 1976. Game fish of the east coast of southern Africa. I. The biology of the elf, Pomatomus saltatrix (Linnaeus), in the coastal waters of Natal. Investigational Report of the Oceanographic Research Institute 44, 1-59.

van der Elst, R.P. 1978. The St Lucia sport fishery A 21 year catch analysis. Oceanographic Research Institute Unpublished Report, 16 pp.

van der Elst, R.P. 1988. A Guide to the Common Sea Fishes of Southern Africa. Struik, Cape Town.

van der Elst, R.P., Blaber, S.J.M., Wallace, J.H. \& Whitfield, A.K. 1976. The fish fauna of Lake St Lucia under different salinity regimes. In: St Lucia Scientific Advisory Council Workshop Meeting (ed. A.E.F. Heydorn), Appendix F. Natal Parks, Game and Fish Preservation Board, Pietermaritzburg.

van der Horst, G. \& Erasmus, T. 1978. The breeding cycle of male Liza dumerili (Teleostei: Mugilidae) in the mouth of the Swartkops estuary. Zoologica Africana 13, 259-273.

van der Horst, G. \& Erasmus, T. 1981. Spawning time and spawning grounds of mullet with special reference to Liza dumerili (Steindachner, 1869). South African Journal of Science 77, 73-78.

van der Horst, G. \& Lasiak, T. 1989. Characteristics of mature oocytes from four species of marine teleosts. South African Journal of Zoology 24, 74 75.

van der Walt, B.A. \& Beckley, L.E. 1997. Age and growth of Sarpa salpa (Pisces: Sparidae) off the east coast of South Africa. Fisheries Research 31, 241-248.

van Dijk, D.E. 1959. A fish that walks, jumps, climbs and burrows. Nucleon 1, 36-38.

van Dyk, L.P., Wiese, I.H. \& Mullen, J.E.C. 1982. Management and determination of pesticides residues in South Africa. Residue Reviews 82, 38-124.

van Heerden, I.L. 1985. Barrier/estuarine processes; Bot River estuary - an interpretation of aerial photographs. Transactions of the Royal Society of South Africa 45, 239-251.

van Heerden, I.L. 1986. Fluvial sedimentation in the ebb-dominated Orange estuary. South African Journal of Science 82, 141-147.

Veith, W.J. 1978. Autoradiographic and electron microscopic study of embryonic nutrition in the teleost, Clinus superciliosus. PhD thesis, University of Cape Town, Rondebosch.

Veith, W.J. 1979. Reproduction in the live-bearing teleost Clinus superciliosus. South African Journal of Zoology 14, 208-211.

Vernberg, W.B. \& Vernberg, F.J. 1972. Environmental Physiology of Marine Animals. SpringerVerlag, Berlin.

Vieira, J.P. \& Musick, J.A. 1993. Latitudinal patterns in diversity of fishes in warm-temperate and tropical estuarine waters of the Western Atlantic. Atlantica (Rio Grande) 15, 115-133.

Villaluz, A.C. \& Unggui, A.S. 1983. Effects of temperature on behavior, growth, development and survival of young milkfish, Chanos chanos (Forsskål). Aquaculture 35, 321-330.

Vincent, A.C.J., Berglund, A. \& Ahnesjö, I. 1995. Reproductive ecology of five pipefish species in one eelgrass meadow. Environmental Biology of Fishes 44, 347-361.

Vrba, E.S. 1980. Evolution, species and fossils: how does life evolve. South African Journal of Science $76,61-84$.

Wallace, J.H. 1967a. The batoid fishes of the east coast of southern Africa. Part I: sawfishes and guitarfishes. Investigational Report of the Oceanographic Research Institute 15, 1-32.

Wallace, J.H. $1967 \mathrm{~b}$. The batoid fishes of the east coast of southern Africa. Part III: skates and electric rays. Investigational Report of the Oceanographic Research Institute 17, 1-62.

Wallace, J.H. 1967c. The batoid fishes of the east coast of southern Africa. Part II: manta, eagle, duckbill, cownose, butterfly and sting rays. Investigational Report of the Oceanographic Research Institute 16, 1-56. 
Wallace, J.H. 1975a. The estuarine fishes of the east coast of South Africa. Part I. Species composition and length distribution in the estuarine and marine environments. Part II. Seasonal abundance and migrations. Investigational Report of the Oceanographic Research Institute 40, 1-72.

Wallace, J.H. 1975b. The estuarine fishes of the east coast of South Africa. Part III. Reproduction. Investigational Report of the Oceanographic Research Institute 41, 1-48.

Wallace, J.H., Kok, H.M., Beckley, L.E., Bennett, B., Blaber, S.J.M. \& Whitfield, A.K. 1984a. South African estuaries and their importance to fishes. South African Journal of Science 80, 203-207.

Wallace, J.H., Kok, H.M. \& Beckley, L.E. 1984 b. Inshore small-mesh trawling survey of the Cape south coast. Part 2. Occurrence of estuarineassociated fishes. South African Journal of Zoology 19, 165-169.

Wallace, J.H. \& Schleyer, M.H. 1979. Age determination in two important species of South African angling fishes, the kob (Argyrosomus hololepidotus Lacep.) and the spotted grunter (Pomadasys commersonnii Lacep.). Transactions of the Royal Society of South Africa 44, 15-26.

Wallace, J.H. \& van der Elst, R.P. 1975. The estuarine fishes of the east coast of South Africa. Part IV. Occurrence of juveniles in estuaries. Part V. Ecology, estuarine dependence and status. Investigational Report of the Oceanographic Research Institute 42, 1-63.

Walsh, W.A., Swanson, C. \& Lee, C.S. 1991. Combined effects of temperature and salinity on embryonic development and hatching of striped mullet, Mugil cephalus. Aquaculture 97, 281-289.

Weerts, S.P., Cyrus, D.P. \& Forbes, A.T. 1997. The diet of juvenile Sillago sihama (Forsskal, 1775) from three estuarine systems in KwaZulu-Natal. Water SA 23, 95-100.

Weinstein, M.P., Weiss, S.L., Hodson, R.G. \& Gerry, L.R. 1980. Retention of three taxa of postlarval fishes in an intensively flushed tidal estuary, Cape Fear River, North Carolina. Fishery Bulletin U.S. 78, 419-436.

Western, D. 1989. Conservation without parks: wildlife in a rural landscape. In: Conservation for the Twenty-First Century (ed. D. Western \& M. Pearl), pp. 158-165. Oxford University Press, New York.

White, P.N. \& Bruton, M.N. 1983. Food and feeding mechanisms of Gilchristella aestuarius (Pisces: Clupeidae). South African Journal of Zoology 18, 31-36.

Whitehead, P.J.P. \& Wongratana, T. 1986a. Family No. 54: Clupeidae. In: Smiths' Sea Fishes (ed. M.M. Smith \& P.C. Heemstra), pp. 199-204. Macmilian South Africa, Johannesburg.
Whitehead, P.J.P. \& Wongratana, T. 1986b. Family No. 55: Engraulidae. In: Smiths' Sea Fishes (ed. M.M. Smith \& P.C. Heemstra), pp. 204-207. Macmillan South Africa, Johannesburg.

Whitfield, A.K. 1977. The future of aquatic birds at Lake St Lucia. Bokmakierie 29, 100-101.

Whitfield, A.K. 1978. Relationship between fish and piscivorous bird densities at Lake St Lucia. South African Journal of Science 74, 478.

Whitfield, A.K. 1979. Field observations of the lepidophagous teleost Terapon jarbua (Forskål). Environmental Biology of Fishes 4, 171-172.

Whitfield, A.K. 1980a. Food chains in Lake St Lucia. In: Studies on the Ecology of Maputaland (ed. M.N. Bruton \& K.H. Cooper), pp. 427-431. Rhodes University, Grahamstown \& Wildlife Society, Durban.

Whitfield, A.K. 1980b. Distribution of fishes in the Mhlanga estuary in relation to food sources. South African Journal of Zoology 15, 159-165.

Whitfield, A.K. 1980c. Factors influencing the recruitment of juvenile fishes into the Mhlanga estuary. South African Journal of Zoology 15, 166169.

Whitfield, A.K. 1980d. A checklist of fish species recorded from Maputaland estuarine systems. In: Studies on the Ecology of Maputaland (ed. M.N. Bruton \& K.H. Cooper), pp. 204-209. Rhodes University, Grahamstown \& Wildlife Society, Durban.

Whitfield, A.K. 1980e. A quantitative study of the trophic relationships within the fish community of the Mhlanga estuary. Estuarine, Coastal and Marine Science $10,417-435$.

Whitfield, A.K. 1982. Trophic relationships and resource utilization within the fish communities of the Mhlanga and Swartvlei estuarine systems. PhD thesis, University of Natal, Pietermaritzburg, 157 pp.

Whitfield, A.K. 1983. Factors influencing the utilization of southern African estuaries by fishes. South African Journal of Science 79, 362-365.

Whitfield, A.K. 1984. The effects of prolonged aquatic macrophyte senescence on the biology of the dominant fish species in a southern African coastal lake. Estuarine, Coastal and Shelf Science 18, 315-329.

Whitfield, A.K. 1985. The role of zooplankton in the feeding ecology of fish fry from some southern African estuaries. South African Journal of Zoology 20, 166-171.

Whitfield, A.K. 1986a. Fish community structure response to major habitat changes within the littoral zone of an estuarine coastal lake. Environmental Biology of Fishes 17, 41-51.

Whitfield, A.K. 1986b. Predation by whitebreasted cormorants on fishes in a southern Cape estuarine system. Ostrich 57, 248-249. 
Whitfield, A.K. 1988a. The fish community of the Swartvlei estuary and the influence of food availability on resource utilization. Estuaries 11, 160-170.

Whitfield, A.K. 1988b. The role of tides in redistributing macrodetrital aggregates within the Swartvlei estuary. Estuaries 11, 152-159.

Whitfield, A.K. 1989a. Ichthyoplankton interchange in the mouth region of a southern African estuary. Marine Ecology Progress Series 54, 2533.

Whitfield, A.K. 1989b. Ichthyoplankton in a southern African surf zone: nursery area for the postlarvae of estuarine associated fish species? Estuarine, Coastal and Shelf Science 29, 533-547.

Whitfield, A.K. 1989c. Fish larval composition, abundance and seasonality in a southern African estuarine lake. South African Journal of Zoology 24, 217-224.

Whitfield, A.K. 1989d. The benthic invertebrate community of a southern Cape estuary: structure and possible food sources. Transactions of the Royal Society of South Africa 47, 159-179.

Whitfield, A.K. 1989e. Paradise lagoon or paradise lost? Ichthos No. 22, 2-3.

Whitfield, A.K. 1990. Life-history styles of fishes in South African estuaries. Environmental Biology of Fishes 28, 295-308.

Whitfield, A.K. 1992a. A characterization of southern African estuarine systems. Southern African Journal of Aquatic Sciences 18, 89-103.

Whitfield, A.K. 1992b. Juvenile fish recruitment over an estuarine sand bar. Ichthos 36, 23.

Whitfield, A.K. 1993. Fish biomass estimates from the littoral zone of an estuarine coastal lake. Estuaries 16, 280-289.

Whitfield, A.K. 1994a. Abundance of larval and 0+ juvenile marine fishes in the lower reaches of three southern African estuaries with differing freshwater inputs. Marine Ecology Progress Series 105, 257-267.

Whitfield, A.K. 1994b. Fish species diversity in southern African estuarine systems: an evolutionary perspective. Environmental Biology of Fishes 40, 37-48.

Whitfield, A.K. 1994c. An estuary-association classification for the fishes of southern Africa. South African Journal of Science 90, 411-417.

Whitfield, A.K. 1994d. A review of ichthyofaunal biodiversity in southern African estuarine systems. In: Biological Diversity of African Fresh- and Brackish Water Fishes (ed. G.G. Teugels, J.F. Guégan \& J.J. Albaret), pp. 149-163. Annales du Musée Royal de l'Afrique Centrale 275, Tervuren.

Whitfield, A.K. 1994e. Bigfin mudskipper found in the Kariega estuary. Ichthos No. 43, 14-15.
Whitfield, A.K. 1995a. Available scientific information on individual South African estuarine systems. WRC Report No. 577/1/95, 1-204.

Whitfield, A.K. 1995b. Threatened fishes of the world: Syngnathus watermeyeri Smith, 1963 (Syngna-thidae). Environmental Biology of Fishes 43, 152.

Whitfield, A.K. 1995c. Threatened fishes of the world: Hippocampus capensis Boulenger, 1900 (Syngnathidae). Environmental Biology of Fishes 44,362 .

Whitfield, A.K. 1995d. Mass mortalities of fish in South African estuaries. Southern African Journal of Aquatic Sciences 21, 29-34.

Whitfield, A.K. 1996a. A review of estuarine ichthyology in South Africa over the past 50 years. Transactions of the Royal Society of South Africa 51, 79-89.

Whitfield, A.K. 1996b. A review of factors influencing fish utilization of South African estuaries. Transactions of the Royal Society of South Africa 51, 115-137.

Whitfield, A.K. 1996c. Threatened fishes of the world: Clinus spatulatus Bennett, 1983 (Clinidae). Environmental Biology of Fishes 46, 26.

Whitfield, A.K. 1996d. Fishes and the environmental status of South African estuaries. Fisheries Management and Ecology 3, 45-57.

Whitfield, A.K. 1997. Fish conservation in South African estuaries. Aquatic Conservation: Marine and Freshwater Ecosystems 7, 1-11.

Whitfield, A.K., Allanson, B.R. \& Heinecken, T.J.E. 1983. Swartvlei (CMS 11). In: Estuaries of the Cape. Part II: Synopses of Available Information on Individual Systems (ed. A.E.F. Heydorn \& J.R. Grindley). CSIR Research Report No. 421, 1-62.

Whitfield, A.K., Beckley, L.E., Bennett, B.A., Branch, G.M., Kok, H.M., Potter, I.C. \& van der Elst, R.P. 1989. Composition, species richness and similarity of ichthyofaunas in eelgrass Zostera capensis beds of southern Africa. South African Journal of Marine Science 8, 251-259.

Whitfield, A.K. \& Blaber, S.J.M. 1976. The effects of temperature and salinity on Tilapia rendalli Boulenger 1896. Journal of Fish Biology 9, 99104.

Whitfield, A.K. \& Blaber, S.J.M. 1978a. Food and feeding ecology of piscivorous fishes at Lake St Lucia, Zululand. Journal of Fish Biology 13, 675691.

Whitfield, A.K. \& Blaber, S.J.M. 1978b. Resource segregation among iliophagous fish in Lake St Lucia, Zululand. Environmental Biology of Fishes 3, 293-296. 
Whitfield, A.K. \& Blaber, S.J.M. 1978c. Feeding ecology of piscivorous birds at Lake St Lucia, Part 1: diving birds. Ostrich 49, 185-198.

Whitfield, A.K. \& Blaber, S.J.M. 1978d. Distribution. movements and fecundity of Mugilidae at Lake St Lucia. Lammergeyer 26, 53-63.

Whitfield, A.K. \& Blaber, S.J.M. 1978e. Scaleeating habits of the marine teleost Terapon jarbua (Forskål). Journal of Fish Biology 12, 61-70.

Whitfield, A.K. \& Blaber, S.J.M. 1979a. The distribution of the freshwater cichlid Sarotherodon mossambicus in estuarine systems. Environmental Biology of Fishes 4, 77-81.

Whitfield, A.K. \& Blaber, S.J.M. 1979b. Feeding ecology of piscivorous birds at Lake St Lucia. Part 2: Wading birds. Ostrich 50, 1-9.

Whitfield, A.K. \& Blaber, S.J.M. 1979c. Feeding ecology of piscivorous birds at Lake St Lucia. Part 3: Swimming birds. Ostrich 50, 10-20.

Whitfield, A.K. \& Blaber, S.J.M. 1979d. Predation on striped mullet (Mugil cephalus) by Crocodylus niloticus at St Lucia, South Africa. Copeia 1979, 266-269.

Whitfield, A.K., Blaber, S.J.M. \& Cyrus, D.P. 1981. Salinity ranges of some southern African fish species occurring in estuaries. South African Journal of Zoology 16, 151-155.

Whitfield, A.K. \& Bruton, M.N. 1989. Some biological implications of reduced fresh water inflow into eastern Cape estuaries: a preliminary assessment. South African Journal of Science 85, 691-694.

Whitfield, A.K. \& Harrison, T.D. 1996. Gilchristella aestuaria (Pisces: Clupeidae) biomass and consumption of zooplankton in the Sundays Estuary. South African Journal of Marine Science $17,49-53$.

Whitfield, A.K. \& Heeg, J. 1977. On the life cycles of the cestode Ptychobothrium belones and nematodes of the genus Contracaecum from Lake St Lucia, Zululand. South African Journal of Science 73, 121-122.

Whitfield, A.K. \& Kok, H.M. 1992. Recruitment of juvenile marine fishes into permanently open and seasonally open estuarine systems on the southern coast of South Africa. Ichthyological Bulletin of the J.L.B. Smith Institute of Ichthyology 57, 1-39.

Whitfield, A.K. \& Paterson, A.W. 1995. Floodassociated mass mortality of fishes in the Sundays estuary. Water SA 21, 385-389.
Whitfield, A.K., Paterson, A.W., Bok, A.H. \& Kok, H.M. 1994. A comparison of the ichthyofaunas in two permanently open eastern Cape estuaries. South African Journal of Zoology 29, 175-185.

Whitfield, A.K. \& Ter Morshuizen, L.D. 1992. Is the river pipefish extinct? Conserva 7, 21.

Whitfield, A.K. \& Wooldridge, T.H. 1994. Changes in freshwater supplies to southern African estuaries: some theoretical and practical considerations. In: Changes in Fluxes in Estuaries: Implications from Science to Management (ed. K.R. Dyer \& R.J. Orth), pp. 41-50. Olsen \& Olsen, Fredensborg.

Woodland, D.J. 1986. Family No. 194: Gerreidae. In: Smiths' Sea Fishes (ed. M.M. Smith \& P.C. Heemstra), pp. 608-609. Macmillan, Johannesburg.

Wooldridge, T. 1991. Exchange of two species of decapod larvae across an estuarine mouth inlet and implications of anthropogenic changes in the frequency and duration of mouth closure. South African Journal of Science 87, 519-525.

Wooldridge, T. \& Bailey, C. 1982. Euryhaline zooplankton of the Sundays estuary and notes on trophic relations. South African Journal of Zoology 17, 151-163.

Wooldridge, T. \& Mellville-Smith, R. 1979. Copepod succession in two South African estuaries. Journal of Plankton Research 1, 329. 341.

Yanez-Aráñcibia, A. (ed.) 1985. Fish community ecology in estuaries and coastal lagoons: towards an ecosystem integration. Universidad Nacional Autónoma de México, México, 653 pp.

Yeung, W.S.B. \& Chang, S.T.H. 1987. The gonadal pattern of the protandrous sex-reversing fish, Rhabdosargus sarba (Teleostei: Sparidae). Journal of Zoology, London 212, 521-532.

Yoklavich, M.M., Cailliet, G.M., Barry, J.P., Ambrose, D.A. \& Antrim, B.S. 1991. Temporal and spatial patterns in abundance and diversity of fish assemblages in Elkhorn Slough, California. Estuaries 14, 465-480.

Zimmerman, R.J., Minello, T.J., Klima, E.F. \& Nance, J.M. 1991. Effects of accelerated sealevel rise on coastal secondary production. In: Coastal Wetlands Conference, pp. 110-124. Long Beach, California. 


\section{Glossary}

Abdomen: the underside of the body between the pectoral and pelvic fins.

Abiotic: non-living (characteristics).

Adaptation: a genetically determined characteristic that enhances the ability of an organism to cope with its environment.

Aggregation: a group of fish not necessarily all swimming in a co-ordinated, i.e. as opposed to a shoal.

Alien species: a species not naturally occurring in a defined area but introduced into that area from elsewhere.

Allochthonous: materials or organisms originating in another biotope.

Amphipods: bilaterally compressed crustaceans of the order Amphipoda.

Anadromous: descriptive of fish which migrate from the sea to spawn in freshwater.

Anal fin: ventral median fin behind the anus.

Anomura: decapod crustaceans that include burrowing prawns.

Anoxic: devoid of oxygen.

Anthropogenic: caused by humans.

Anus: the termination of the alimentary canal, through which faeces are excreted.

Anterior: front or head region.

Assemblage: group of organisms sharing a particular environment by chance.

Assimilation: the transformation of absorbed nutrient substances into body substances.

Autecology: ecology of individual organisms and populations.

Authochthonous: materials or organisms arising in the biotope under consideration.

Autotroph: organism that uses carbon dioxide as its main or sole source of carbon.

Avifauna: bird life.

Barbel: a slender projection on the jaws or head, used mainly as an organ of taste and touch.

Barrier overwash: marine overtopping of the sand bar in the mouth region of estuaries.

Bathymetry: depth profile or bottom contours of a water body obtained by measurements from the surface.

Benthic: living on the bottom.

Biodiversity: the variety of plant and animal species in an area.

Biogenic: arising as a result of life processes of organisms.

Biogeographical: biological subdivision of the Earth's surface.

Biomass: the mass of living matter present.
Biotic: living (characteristics).

Bivalves: common name for a large class of molluscs that have a soft body enclosed in a calcareous twopart shell.

Body length (BL): the notochord length of fish larvae.

Bony fishes: or teleosts, i.e. fishes with a true bone skeleton.

Brachyura: true crabs

Branchial: pertaining to the gills.

Canine: a sharp-pointed conical tooth.

Carnivorous: flesh eating.

Catadromous: descriptive of fish which migrate from freshwater to the sea in order to breed.

Caudal fin: the unpaired fin at the tail of most fishes.

Caudal peduncle: the narrow region that attaches the caudal fin to the body.

Cellulase: enzyme that catalyses the hydrolosis of cellulose into glucose.

Cephalopods: a class of molluses, the members of which have distinct heads, e.g. squid and octopus.

Cestodes: endoparasitic flatworms which lack an alimentary canal.

Cohort: group of individuals of the same age.

Common name: an informal vernacular name for an organism.

Community: populations of different organisms living together in a particular environment.

Competition: use or defense of a resource by one individual that reduces the availability of that resource to other individuals.

Conspecific: applied to individuals that belong to the same species.

Cool-temperate region: the area north of Cape Point on the West Coast.

Copepods: a subclass of minute crustaceans which usually form part of the zooplankton.

Crepuscular: active around dusk and dawn.

CPUE: Catch per unit of fishing effort.

Crustaceans: a large group of mostly aquatic invertebrate animals such as shrimps and crabs.

Cryptic: protective coloration and/or behaviour that maximizes an organism's ability to conceal itself.

Demersal: living near the bottom.

Denticles: small tooth-like processes (e.g. scales of certain elasmobranchs) composed of dentine.

Dentition: the characteristic arrangement of teeth.

Detritivorous: feeding primarily on detritus.

Detritus: particles of decaying plant and animal material, and associated micro-organisms.

Devonian: a period that began 410 million years ago and lasted approximately 65 million years. 
Diadromous: descriptive of fish which evidence structured life-history migration through differing salinities.

Diatoms: unicellular algae with walls impregnated with silica.

Diel: during a 24 hour period.

Digestion: chemical breakdown of food into a form that can be assimilated by the organism.

Disc: the fused head and fin region of some depressed fishes, e.g. skates and rays.

Disc width: the width or 'wingspan' of rays.

Dispersal: movement of organisms away from the place of birth or from centres of population density.

Diurnal: pertaining to the daylight hours.

Diversity index: an index used to characterize the diversity of species in a community or area.

Dorsal: pertaining to the uppermost surface.

Dorsal fin: a fin located on the back between the head and caudal fin.

Dygynous: fish species that have females maturing directly from juveniles and also from previously mature males in the population.

East Coast: the coastline between East London in the south and Mozambique in the north.

Ecosystem: a natural system of interacting organisms and their environment.

Elasmobranchs: cartilaginous fishes, including all modern sharks and rays.

Embryo: the developing organism either within the egg envelope or hatched, and which is dependent on egg yolk for nourishment.

Endemic: organisms that are limited to a particular geographic region.

Environment: surroundings of an organism, including the plants and animals with which it interacts.

Epifauna: animals found on the surface of any substratum.

Epilimnion: the surface layer of a lake.

Epiphyte: non-parasitic plants which live on the surface of other plants.

Episodic floods: large river floods which occur irregularly.

Equinox: time or date at which the sun crosses the equator and day and night are equal.

Estuarine fish species: fishes which breed in estuaries and spend most or all of their life-cycle within the estuarine environment.

Estuary: that part of a river system closest to the sea where salinities fluctuate considerably.

Euhaline: salinities between $30 \%$ and $39.9 \%$.

Euryhaline: the ability of an organism to tolerate wide-ranging salinities.

Eurytopic: an organism that has a wide range of tolerance.

Eustatic: applied to worldwide changes in sea-level caused by tectonic movements or by the growth or decay of glaciers.
Eutrophic: waters with an excellent supply of nutrients and hence high organic production.

Eutrophication: enrichment of water bodies, primarily caused by sewage and runoff from fertilized agricultural land.

Extant: applied to a taxon, some of whose members are living at the present time.

Extinct: applied to a taxon, no member of which is living at the present time.

Fecundity: reproductive potential.

Filamentous: thin and thread-like.

Food chain: a continuum of organisms in which each is the food of one or more subsequent members of the chain.

Food web: a system of inter-relating food chains.

Foraminifera: microscopic animals with calcareous exoskeletons.

Fork length (FL): the length of a fish measured from the tip of the snout to the tip of the mid-caudal rays.

Freshwater fish species: fishes which breed in inland waters and spend most or all of their life-cycle in freshwater environments.

Fry: a lay term for early juvenile fish.

Gastropods: molluscs with a ventral muscular disc adapted for creeping.

Genital papilla: a projection behind the anus that carries the external opening of the reproductive system.

Geomorphology: study of the physical features of the earth's surface and their relation to its geological structures.

Gestation period: length of time from conception to birth in a viviparous animal.

Gill arch: the bony arch to which the gill membranes and rakers are attached.

Gill chamber: the space behind the gill arches for the gills.

Gill net: a vertically hung net left in the water, usually overnight, into which fish swim and become enmeshed.

Gill rakers: projections along the edge of each gill arch that filter food from water passing through the gill chamber.

Gills: the breathing organs of fishes consisting of vascularised filaments attached to the gill arches.

Glass eel: transparent larval stage of anguillid eels.

Gonads: reproductive organs.

Gravid: female with eggs or pregnant uterus.

Gregarious: descriptive of behaviour that, in fish, leads to the formation of aggregations or shoals.

Habitat: the specific environment of an organism.

Halocline: a layer of water exhibiting a steep salinity gradient.

Herbivorous: feeding on plants.

Hermaphrodite: an organism possessing both male and female reproductive organs.

Heterotroph: organism that uses organic compounds as its main or sole source of carbon. 
Holocene: period that covers the last 10000 years.

Hydrography: scientific study of water bodies.

Hypersaline: water that has a salt concentration greater than the normal seawater average of $35 \%$.

Hypertonic: fluid with a higher concentration of dissolved salt than another fluid.

Hypolimnion: the deep layer of a lake removed from surface influences.

Hypotonic: fluid with a lower concentration of dissolved salt than another fluid.

Ichthyofauna: the assemblage of fishes in a particular area.

Ichthyology: the scientific study of fishes.

Ichthyonekton: fish larvae and juveniles which are motile.

Ichthyoplankton: larval fishes that are part of the plankton.

Indo-Pacific: embracing the Indian and, usually, the eastern Pacific oceans.

Incisors: front, cutting teeth.

Intermittent estuary: an estuary which is functional for only a brief period each year.

Interspecific: referring to interactions between individuals of different species.

Intertidal: between the high-tide and low-tide levels on the shore.

Intraspecific: referring to interactions between individuals of the same species.

Invertebrates: any animal which lacks a vertebral column or backbone.

Isopods: dorsoventrally flattened crustaceans.

Isotopes: elements that occupy the same place in the periodic table but have a different atomic weight.

Juvenile: young organism essentially similar to the adult form.

Larva: a developing organism after hatching from the egg, which has begun to feed itself and is not solely dependent on egg yolk for nourishment.

Lateral line: a series of sensory tubercles forming a raised line along either side of the body of some fishes.

Lepidophagous: feeding on fish scales.

Leptocephalus: the transparent, leaf-like larva of eels and tarpons.

Littoral: at or near the shore of a water body.

Longitudinal salinity gradient: the difference in mean salinity between the tidal head and mouth region of an estuary.

Lower reaches: the lower longitudinal third of an estuary.

Macrophytes: large plants.

Macrotidal: applied to coastal areas or estuaries in which the tidal range is in excess of $4 \mathrm{~m}$.

Macrurans: decapod crustaceans such as swimming prawns and shrimps.

Marine fish species: fishes which breed at sea and spend most or all of their life-cycle in the marine environment.
Marine stragglers: marine fish species which rarely enter estuaries.

Meiofauna: microscopic or semi-microscopic animals that inhabit sediments (often interstitial).

Melanophore: cell containing black pigment.

Meromixis: water bodies (usually lakes) that undergo only partial circulation down to a depth determined by a density stratification.

Mesentery: a fold of the peritoneum that connects the intestine with the abdominal wall.

Mesohaline: salinities between 5\%o and $17.9 \%$.

Mesotrophic: waters with a moderate supply of nutrients and hence a moderate organic production.

Microalgae: unicellular plants.

Microphytobenthos: benthic microalgae.

Microtidal: applied to coastal areas or estuaries in which the tidal range is less than $2 \mathrm{~m}$.

Middle reaches: the middle longitudinal third of an estuary.

Migration: coordinated movement of animals from one place to another.

Molar: tooth with a smooth, flattened or rounded surface for grinding.

Molluscs: invertebrates mostly distinguished by the presence of a hard, calcareous external shell.

Morphology: the study of shape or form.

Morphometry: physical dimensions such as shape, depth, width, length, etc.

Mucus: a viscous or slimy fluid secreted by the skin of many fishes.

Mutualism: interaction of species populations that benefit both populations.

Mysids: small, shrimp-like crustaceans.

Neap tide: smallest tidal range experienced due to the sun's gravitational forces acting against those of the moon.

Nekton: animals that are highly mobile within the water column.

Nematode: small cylindrical worm with tapered ends.

Neritic: inhabiting the sea above the continental shelf.

Niche: the place or position that an organism occupies in its environment.

Nocturnal: pertaining to the night hours.

Nuchal: body region behind the head.

Nutrient: any substance required by organisms for normal growth and maintenance.

Olfactory: concerned with the sense of smell.

Oligohaline: salinities between $0.5 \%$ and $4.9 \%$.

Oligotrophic: waters with a limited supply of nutrients and hence a reduced organic production.

Omnivorous: feeding on a wide variety of fonds including plants and animals.

Operculum: the principal bone in the gill cover of a fish.

Opportunistic species: a species that takes advantage of temporary or local conditions.

Organic matter: carbon compounds derived from plants and animals. 
Osmoregulation: the control of osmotic processes (water/salt balance) within an organism.

Osteichthyes: class of bony fish.

Ostracods: minute crustaceans, often living in a paired shell.

Otolith: a calcium carbonate structure in the inner ear of bony fishes.

Oviparous: producing eggs that are fertilised, develop and hatch after being laid.

Ovoviviparous: reproduction in which the eggs are fertilised internally and the embryos develop within maternal body and are expelled at hatching.

Palaeozoic: an era which began 570 million years ago and lasted 345 million years.

Parasite: an organism living on or in another and being nourished by it.

Parturition: act of bringing forth young.

Pectoral fin: paired fins located closely behind the head.

Pelagic: organisms living in open water, especially near the surface.

Pelvic fin: a paired fin located on the ventral side of the body, below and behind the pectoral fin, and in front of the anal fin.

Periphyton: Biotic material found on, or attached to, the submerged parts of aquatic plants.

Pharynx: the throat or hind region of the mouth, surrounded by the gill arches.

Phytoplankton: microscopic plants drifting in the plankton.

Piscivorous: feeding primarily on fish.

Placenta: an organ in the uterus through which nutriment is passed to the embryo.

Planktivorous: feeding primarily on plankton.

Plankton: mainly microscopic floating organisms that drift more or less passively within the water column.

Polychaete: a segmented marine worm with bristles.

Polyhaline: salinities between $18 \%$ and $29.9 \%$.

Postflexion larva: developmental stage from formation of the caudal fin to attainment of full external meristic complements (fin rays and scales).

Predator: an animal that feeds on other animals.

Preflexion larva: developmental stage beginning at hatching and ending with commencement of upward flexion of the notochord.

Prey: animals that are the food of predators.

Primary production: the production of organic matter from inorganic materials by autotrophic organisms.

Protandrous: an individual that is initially male, then becomes female.

Protogynous: an individual that is initially female and later becomes male.

Protrusible: capable of being extended and retracted.

Ray: a cartilaginous and jointed fin support.

Relative abundance: proportional representation of a species in a sample or a community.
Resource: a substance or object required by an organism for normal maintenance, growth and reproduction.

Ripe running: term used to describe fish about to spawn.

Rostrum: the forward projection or extension of the snout of a fish.

Scutes: enlarged dermal plates or scales.

Sea level: level continuous with that of the sea, halfway between high and low tide.

Seine net: a net, hanging from floats and having a central bag and equal-sized wings, that can be pulled through the water and onto the shore.

Semi-diurnal tides: tides with two high and two low waters during a tidal day (24 hours and 50 minutes).

Sensory: capable of perceiving external stimuli.

Serrate: notched or saw-like.

Seston: particulate matter in the water column.

Shoal: a group of fish, with most members swimming in the same direction.

Snout: the front end of the head, the head section before the eyes.

South Coast: the coastline of South Africa between East London in the east and False Bay in the west.

Species: a particular kind of organism; the fundamental taxonomic unit.

Species diversity: the variety (usually number of taxa) of species in a community or area (see also Diversity index).

Species richness (R): a diversity index which relates the number of species present in a community or area to the total number of individuals sampled.

Spent: describes reproductive condition after spawning has been completed.

Spine: pointed bony fin support.

Spiracle: a small respiratory opening behind the eye and first gill slit of most sharks and rays.

Spring tide: maximum tidal amplitude during the new and full moon periods.

Standard length (SL): the length of a fish from the tip of the snout to the base of the tail.

Standing stock: the biomass present in a body of water at a particular time.

Stenohaline: species which cannot tolerate a wide range of salinities during their life histories.

Stenotopic: an organism with a narrow tolerance range.

Stratification: a word used to describe a layered water body.

Substratum: a bottom surface of a habitat.

Subterminal mouth: a mouth located on the underside of the head, behind the snout.

Subtidal: below the lowest level on the shore reached by the tides.

Subtropical region: the area between the Mbashe Estuary and Maputo Bay.

Supratidal: above the level on the shore reached by the tides. 
Surf zone: the area of beach where the waves break.

Suspensoids: fine particles of an insoluble substance uniformly dispersed throughout the water column.

Swim bladder: a gas-filled sac situated below the backbone of many bony fishes.

Sympatry: the occurrence of species together in the same area.

Synecology: the study of whole plant and animal communities.

Synonym: one of two or more different names applied to the same taxon.

Tactile: pertaining to the sense of touch.

Taxon: any taxonomic unit (e.g. family, genus, species).

Teleosts: see bony fishes.

Thermocline: a relatively narrow layer of water with a steep temperature gradient across it.

Tidal delta: delta formed in the estuary mouth region due to deposition of riverine and marine sediments.

Tidal prism: the difference between the volume of water (in an estuary) at high tide and that at low tide.

Total length (TL): the overall length of a fish measured in a straight line from the tip of the snout to the tip of the tail.
Trawl net: a net which is pulled by a boat.

Tricuspid: teeth with three points.

Trophic group: a group of consumers that feed at a similar trophic level.

Turbid: descriptive of water which is muddy or murky due to the presence of suspended particles.

Upper reaches: the upper longitudinal third of an estuary.

Upwelling: a process whereby deeper, cold waters, rise to the surface as a result of the combined effects of wind, ocean currents and the Earth's rotation.

Ventral: on or near the lower surface of the body.

Viviparous: bearing live young after the development of an embryo within the maternal organism.

Warm-temperate region: the area between the Mbashe Estuary and Cape Point.

Water column: the body of water between the bottom and surface.

West Coast: the Atlantic coastline from Cape Point northwards into Namibia.

Zoea: pelagic larval stage of certain crustaceans.

Zoobenthos: bottom-dwelling animals.

Zooplankton: minute animals drifting in the water column. 


\section{Index}

Anthropogenic disturbances 152

Aquatic conservation 167, 176

Aquatic reserves 179-181

Catchment conservation 178

Estuary/Estuaries

bays 12

characteristics 6,7

consumer biomass 154

definition 3

descriptions 4

Devonian 45

dredging 177,178

environment 1,44

environmental quality objectives 163

environmental quality standards 163

fish assemblages 137, 149, 150

freshwater deprivation 153-157

freshwater requirements 152

freshwater supplies 151-157

health 177

impacts 152

lakes 11

management 158, 159,161,162,181, 182

map 2

mouth dynamics 3

mouth manipulation 177

permanently open 7

production 154

productivity 176,177

protected areas 181

reserves 180

river flow 4

river mouths 10

sanctuaries 181

temporarily open/closed 9

tidal range 6

types 6

water exchange 3

water temperatures 5

Estuarine utilization

catchment size 39

dissolved oxygen 37,38

estuary size 39

habitat variability 38

mouth phase 36,37

productivity 40

river flow 34

salinity 29-33

seasonality 39

turbidity 34-36

water depths 40

zoogeography 38,39
Estuary photographs

Cebe 218

Durban 13

Gqunqe 218

Gqutywa 215

Great Fish 24

Haga Haga 37

Kariega 216, 222

Kasuka 9

Keiskamma 8

Klein Palmiet 215

Knysna 12

Mdloti 219

Mhlanga 139

Siyaya 221

St Lucia 221

Swartkops 14

Swartvlei 11, 220

Tugela 10, 217

West Kleinemonde 219

Fish/Fishes

biogeography $46,169-174$

biological health index 162

biological indicators $158,159,161,162$

catadromous behaviour 19

catadromous species 18

community degradation index 161

community traits 46

competition 43

conservation $167,176,178-182$

endemic species 181,182

energy pathways 42

estuarine association 168,170

estuarine bays 148

estuarine cues 25

estuarine dependence $167,168,171-174$

estuarine ecosystems 137

estuarine groups 18

estuarine lakes $143-148$

estuarine recruitment 23,24

estuarine spawning 21

estuarine type 149,150

estuarine utilization 29-43

eurytopes 47-50

fish recruitment index 163

freshwater species 19

health studies 159

ichthyoplankton 28

life-history patterns 158

life-history styles 18

marine group 18

marine spawning 21,22 
mass mortalities $156,164-166$

mouth phase 149

nursery areas 174,175

parasite studies 160

permanently open estuaries 141,142

recruitment patterns $25-27$

reproductive modes 47

reproductive specializations 20

resource utilization 40,150

river mouths 143

salinity 30-33

sexual maturity 19,20

speciation 44,49

species profiles 51

stenotopes 47-50

successionary trends 49

temporarily open/closed estuaries 137-140

threats 176

trophic grouping 140, 142, 145, 147

trophic groupings 41

zoogeography 149

zooplankton resources 27,28

Fish family

Atherinidae 110

Gobiidae 124, 127

Ambassidae 115, 116

Anguillidae 130

Ariidae 63

Belonidae 64

Blenniidae 117

Bothidae 105

Carangidae 91-93

Carcharhinidae 52

Chanidae 62

Cichlidae 131, 132

Claridae 133

Clinidae 118

Clupeidae 59, 109

Dasyatidae 55

Eleotridae 128, 136

Elopidae 56

Engraulidae 60, 61

Gerreidae 84, 85

Gobiidae 119-127, 134, 135

Haemulidae 69, 70

Hemiramphidae 65, 111

Kuhliidae 66

Leiognathidae 89

Lobotidae 90

Lutjanidae 71, 72

Megalopidae 57

Monodactylidae 83

Mugilidae 95-1 04

Muraenesocidae 59

Muraenidae 58

Myliobatidae 55

Platycephalidae 65

Pomatomidae 68

Pristidae 53
Sciaenidae $86-88$

Sillaginidae 86

Soleidae 106

Sparidae 72, 74-81

Sphyraenidae 104

Syngnathidae 112-114

Teraponidae 67

Tetraodontidae 107, 108

Torpedinidae 54

Fish species

Acanthopagrus berda 73

Ambassis gymnocephalus 115

Ambassis natalensis 116

Ambassis productus 116

Amblyrhynchotes honckenii 107

Anguilla mossambica 130

Argyrosomus japonicus 86

Arothron immaculatus 108

Atherina breviceps 110

Awaous aeneofuscus 134

Caffrogobius gilchristi 119

Caffrogobius nudiceps 120

Caranx ignobilis 91

Caranx papuensis 91

Caranx sexfasciatus 92

Carcharhinus leucas 52

Chanos chanos 62

Clarias gariepinus 133

Clinus spatulatus 118

Clinus superciliosus 118

Croilia mossambica 121

Diplodus cervinus hottentotus 74

Diplodus sargus capensis 74

Eleotris fusca 128

Elops machnata 56

Favonigobius reichei 122

Galeichthys feliceps 63

Gerres acinaces 84

Gerres methueni 85

Gilchristella aestuaria 109

Glossogobius callidus 122

Glossogobius giuris 135

Hemiramphus far 65

Heteromycteris capensis 106

Hilsa kelee 59

Himantura uarnak 55

Hippichthys heptagonus 112

Hippocampus capensis 112

Hyporhamphus capensis 111

Hypseleotris dayi 136

Johnius dorsalis 87

Kuhlia mugil 66

Leiognathus equula 89

Lichia amia 93

Lithognathus lithognathus 75

Lithognathus mormyrus 76

Liza alata 95

Liza dumerilii 96

Liza macrolepis 97 
Liza richardsonii 98

Liza tricuspidens 99

Lobotes surinamensis 90

Lutjanus argentimaculatus 71

Lutjanus fulviflamma 72

Megalops cyprinoides 57

Monodactylus falciformis 83

Mugil cephalus 100

Muraenesox bagio 59

Myliobatus aquila 55

Myxus capensis 101

Oligolepis acutipennis 123

Oligolepis keiensis 124

Omobranchus woodi 117

Oreochromis mossambicus 131

Otolithes ruber 88

Periophthalmus argentilineatus 124

Platycephalus indicus 65

Pomadasys commersonnii 69

Pomadasys kaakan 70

Pomadasys olivaceum 70

Pomatomus saltatrix 68

Pristis zijsron 53

Psammogobius knysnaensis 125

Pseudocrenilabrus philander 132

Pseudorhombus arsius 105

Redigobius dewaalii 126

Rhabdosargus globiceps 77

Rhabdosargus holubi 78

Rhabdosargus sarba 79

Rhabdosargus thorpei 80

Sarpa salpa 81

Scomberoides lysan 94

Silhouettea sibayi 127

Sillago sihama 86
Solea bleekeri 106

Sphyraena barracuda 104

Stolephorus holodon 60

Strongylura leiura 64

Strophidon sathete 58

Syngnathus acus 113

Syngnathus watermeyeri 114

Taenioides jacksoni 127

Terapon jarbua 67

Thryssa vitrirostris 61

Tilapia rendalli 132

Torpedo fuscomaculata 54

Valamugil buchanani 102

Valamugil cunnesius 102

Valamugil robustus 103

Freshwater demand 152

Ichthyology

future 17

history 14-16

Impoundments 153

Marine protected areas 179, 180

Parasites

branchiurans 160

cestodes 160

copepods 160

isopods 160

leeches 160

nematodes 160

Rainfall pattern 151

River flow 151

Water Law 152

Salinity

Venice system 1

extremes 4

stratification 6,8 


\section{Appendix 1}

Photographs of selected estuarine systems and associated ichthyofaunal habitats along the southern African coast.

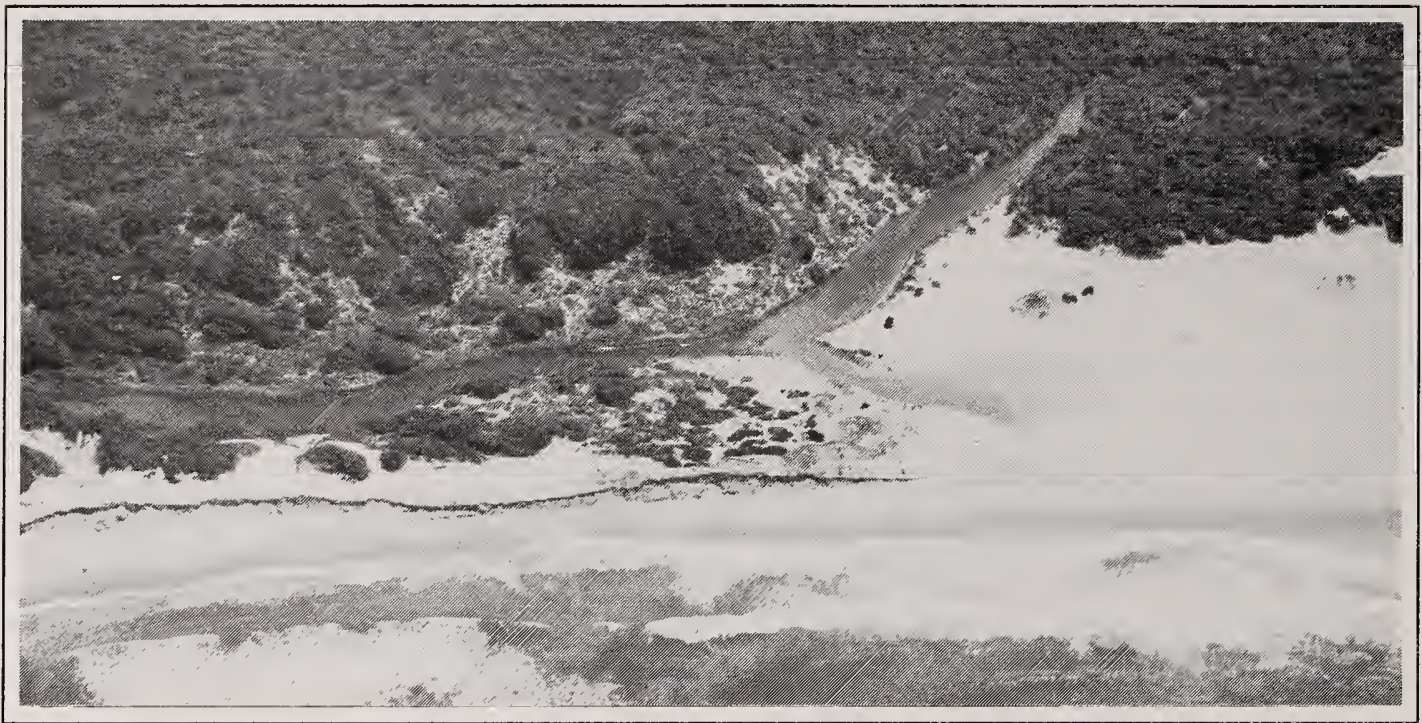

Plate 1. Klein Palmiet - a very small temporarily closed estuary in the Eastern Cape (photograph by A. Whitfield).

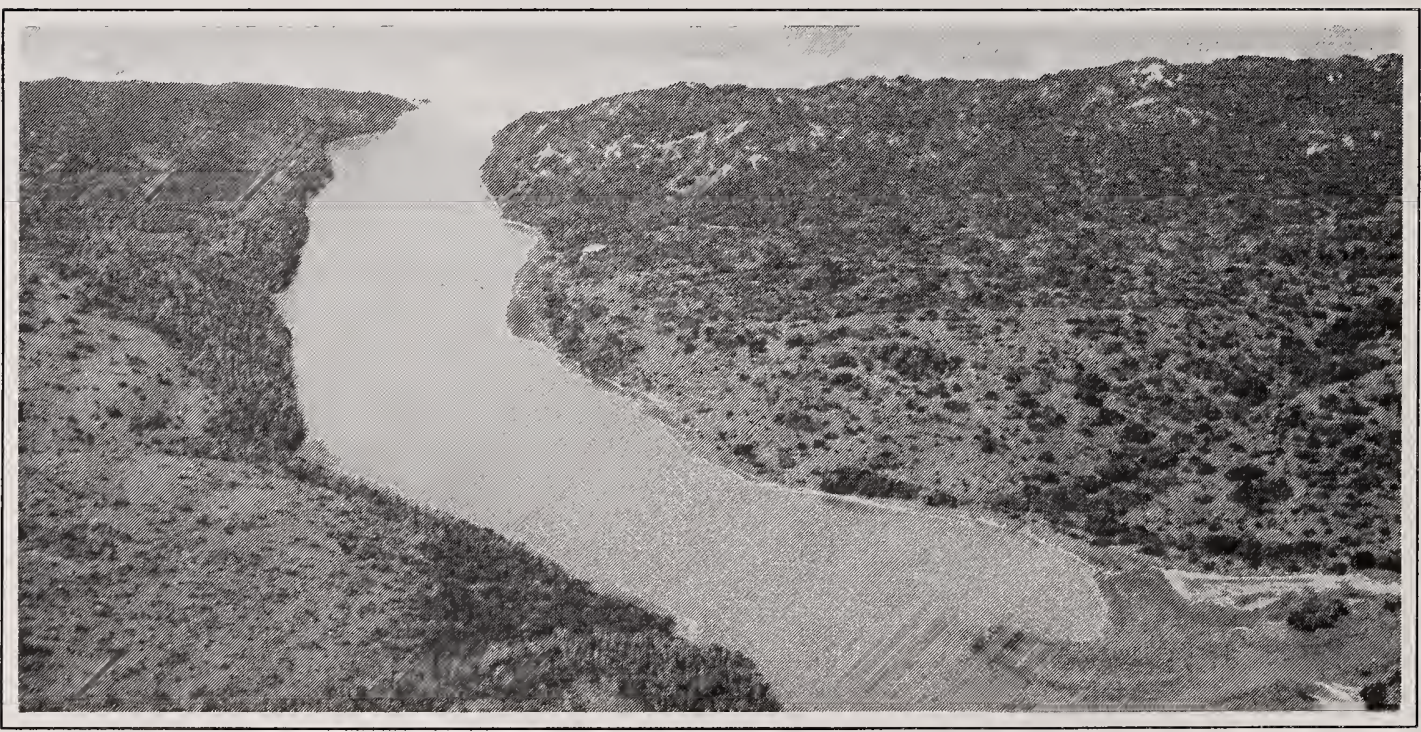

Plate 2. Gqutywa - a small temporarily closed estuary in the Eastern Cape (photograph by A. Whitfield). 


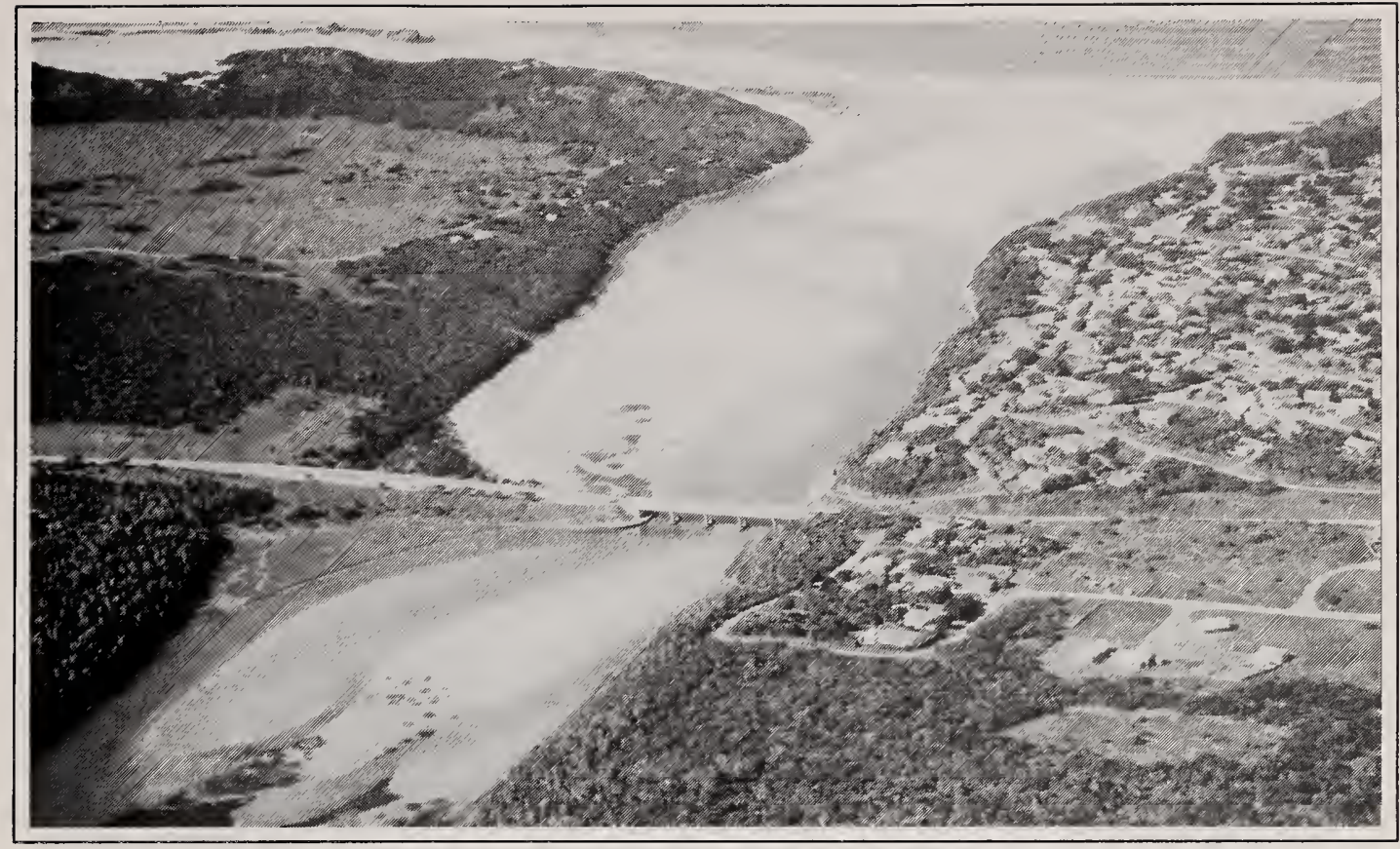

Plate 3. Kariega - a permanently open estuary in the Eastern Cape. Note the flood tidal delta, comprising mainly marine sediments, extending upstream beyond the road bridge (photograph by A. Whitfield).

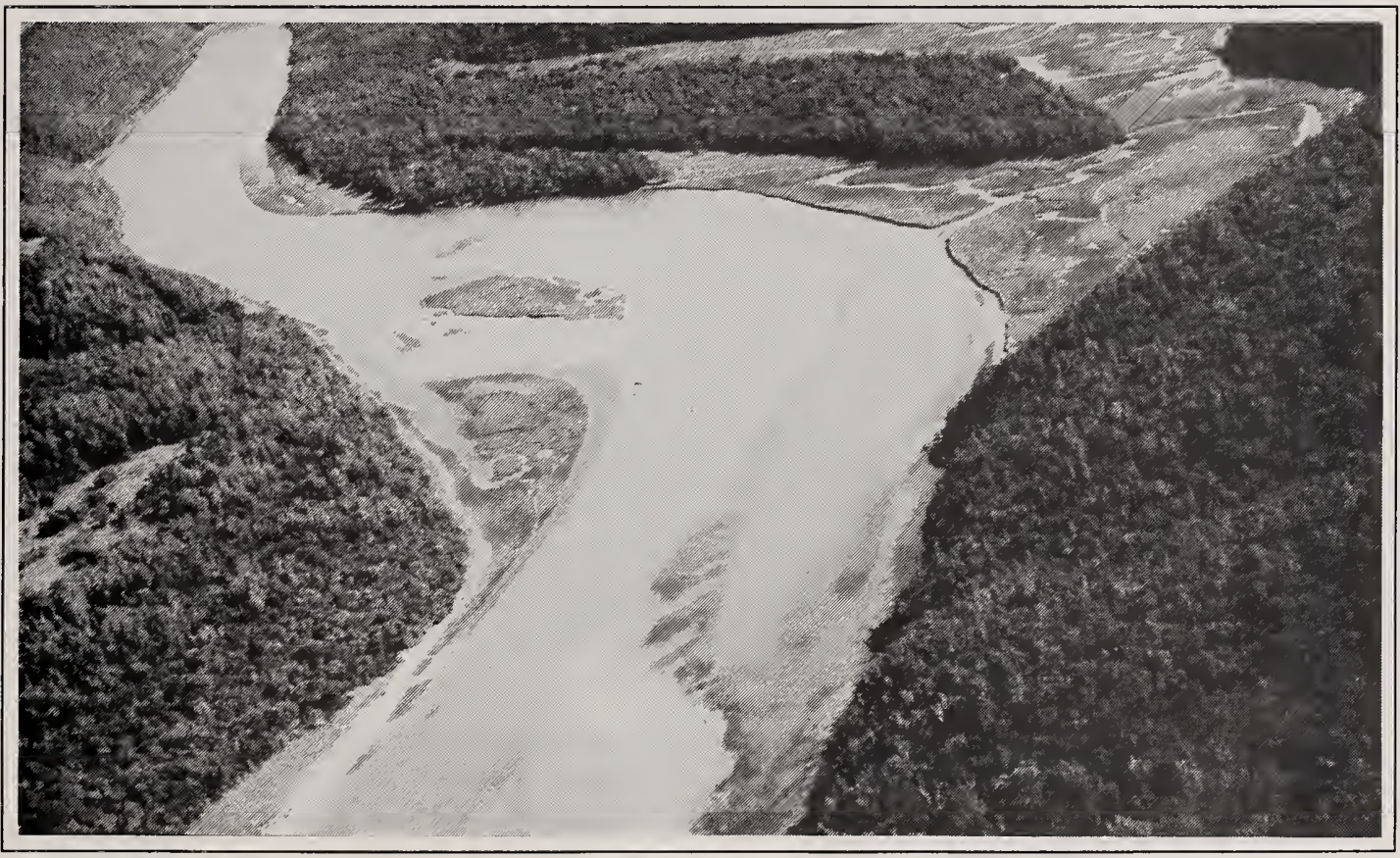

Plate 4. Kariega - lower reaches of the estuary showing submerged eelgrass beds adjacent to the main channel and salt marshes in the intertidal region (photograph by A. Whitfield). 


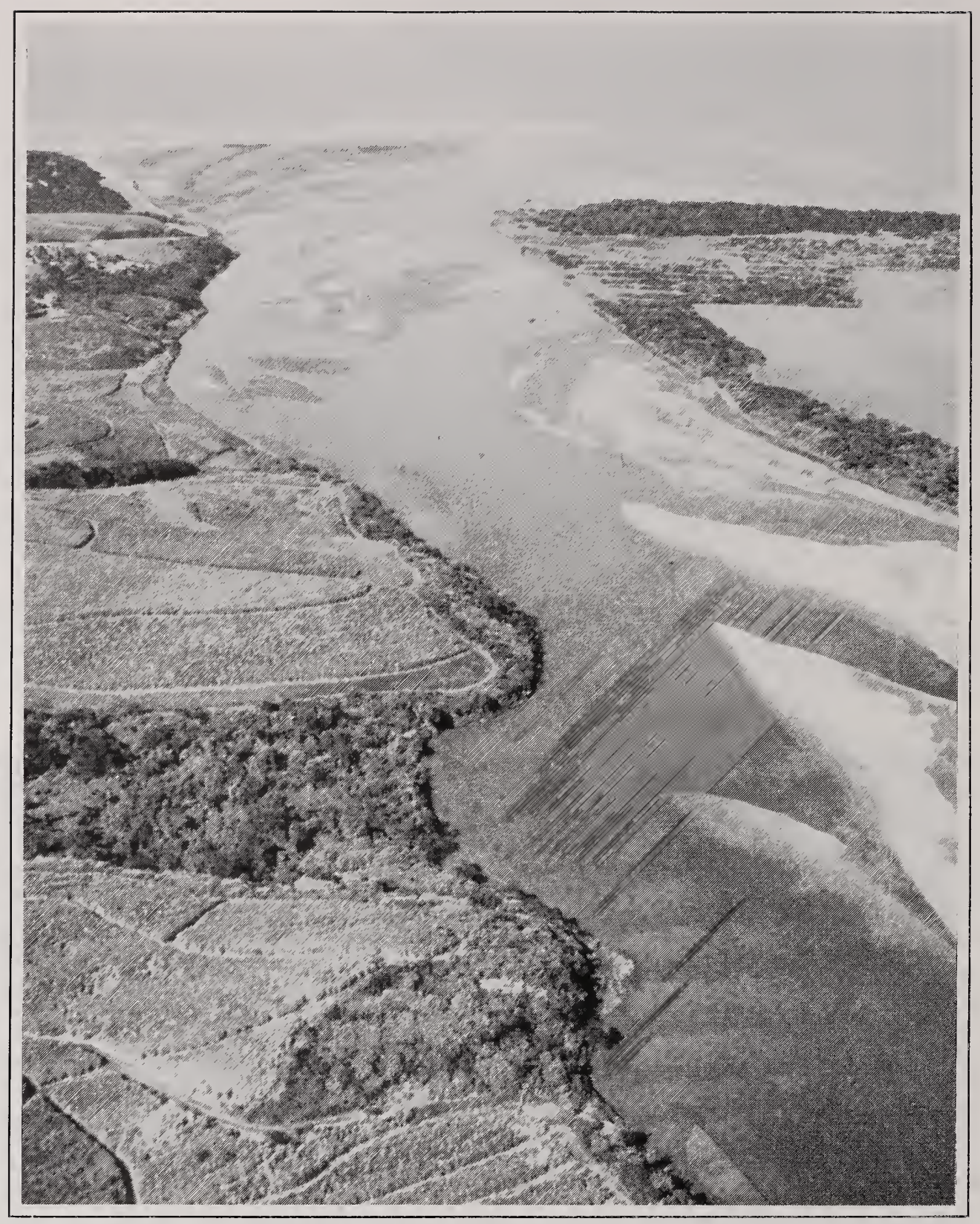

Plate 5. Tugela - a river mouth type estuary in the subtropical region of KwaZulu-Natal. Note the ebb tidal delta and extensive sand shoals throughout the estuary (photograph by T. Wooldridge). 


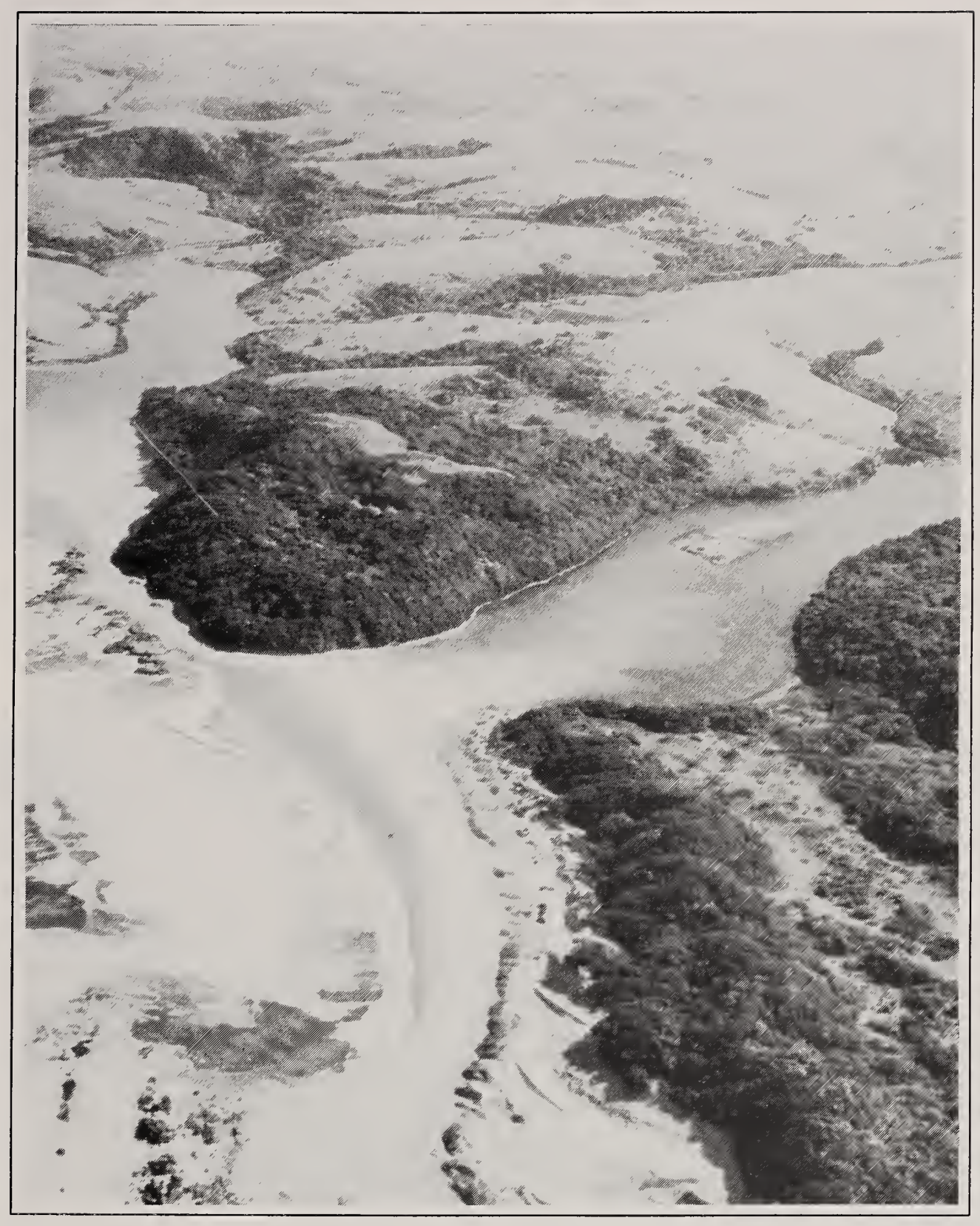

Plate 6. Cebe (left) and Gqunqe (right) - two temporarily closed estuaries in the warm-temperate region of the Transkei (photograph by $\mathrm{T}$. Wooldridge). 


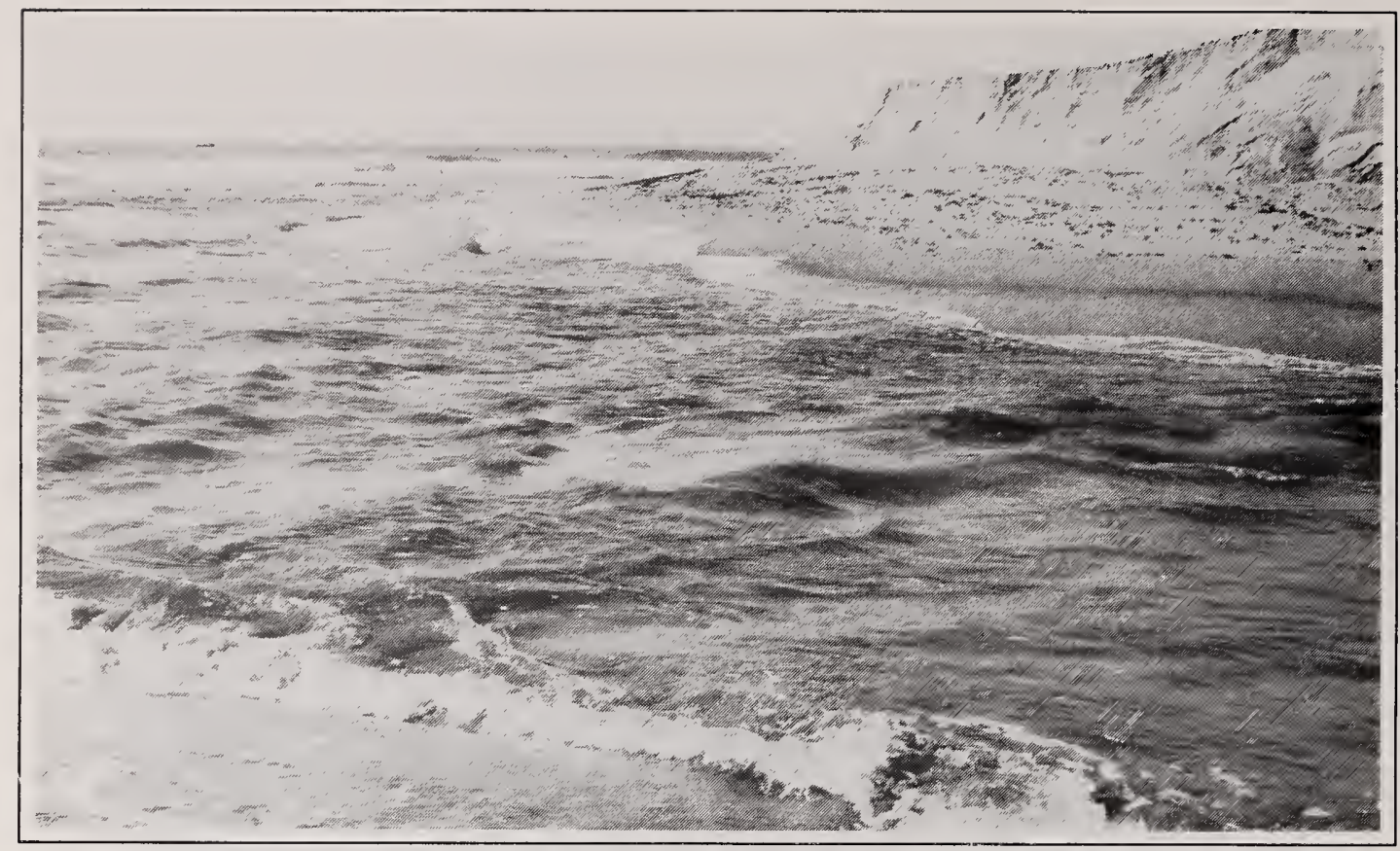

Plate 7. Mdloti - a temporarily open estuary in the subtropical region of KwaZulu-Natal. Note the absence of any rocky areas associated with the mouth region (photograph by $\mathrm{A}$. Whitfield).

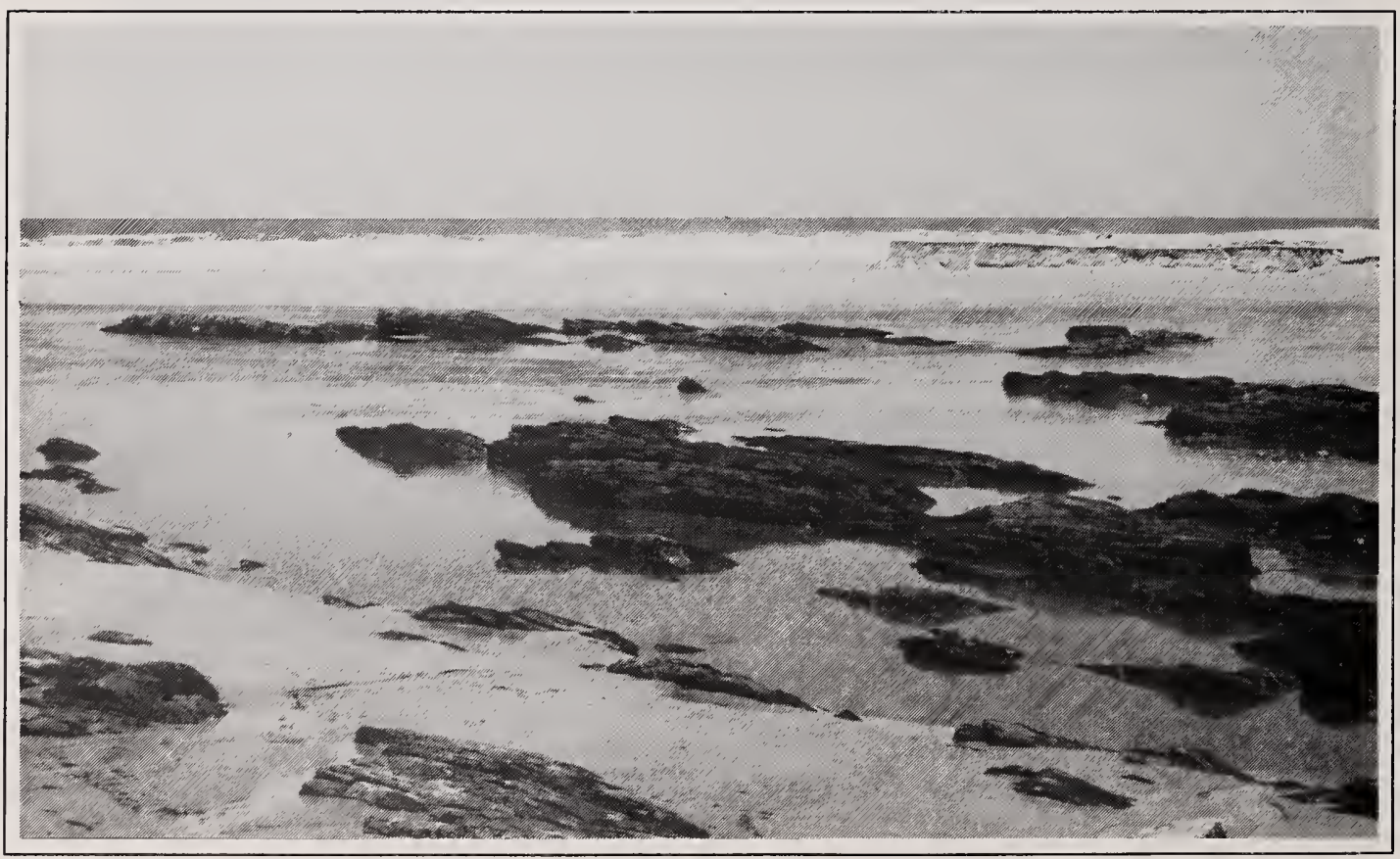

Plate 8. West Kleinemonde - a temporarily open estuary in the warm-temperate region of the Eastern Cape. Note the extensive rocky areas associated with the mouth region (photograph by A. Whitfield). 


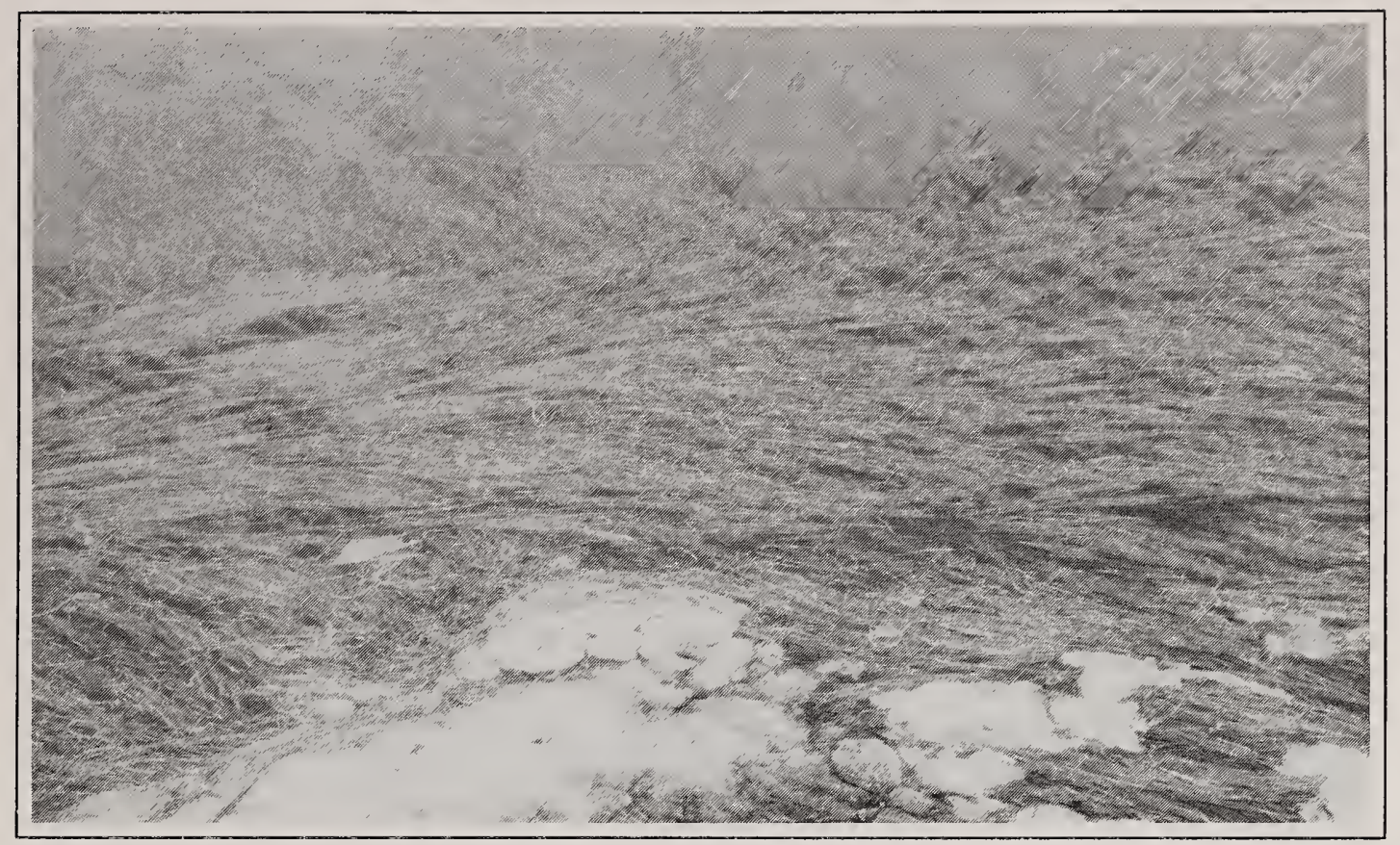

Plate 9. Swartvlei Estuary eelgrass bed. Note the mat of filamentous algae (Enteromorpha spp.) smothering the Zostera capensis in the foreground (photograph by A. Whitfield).

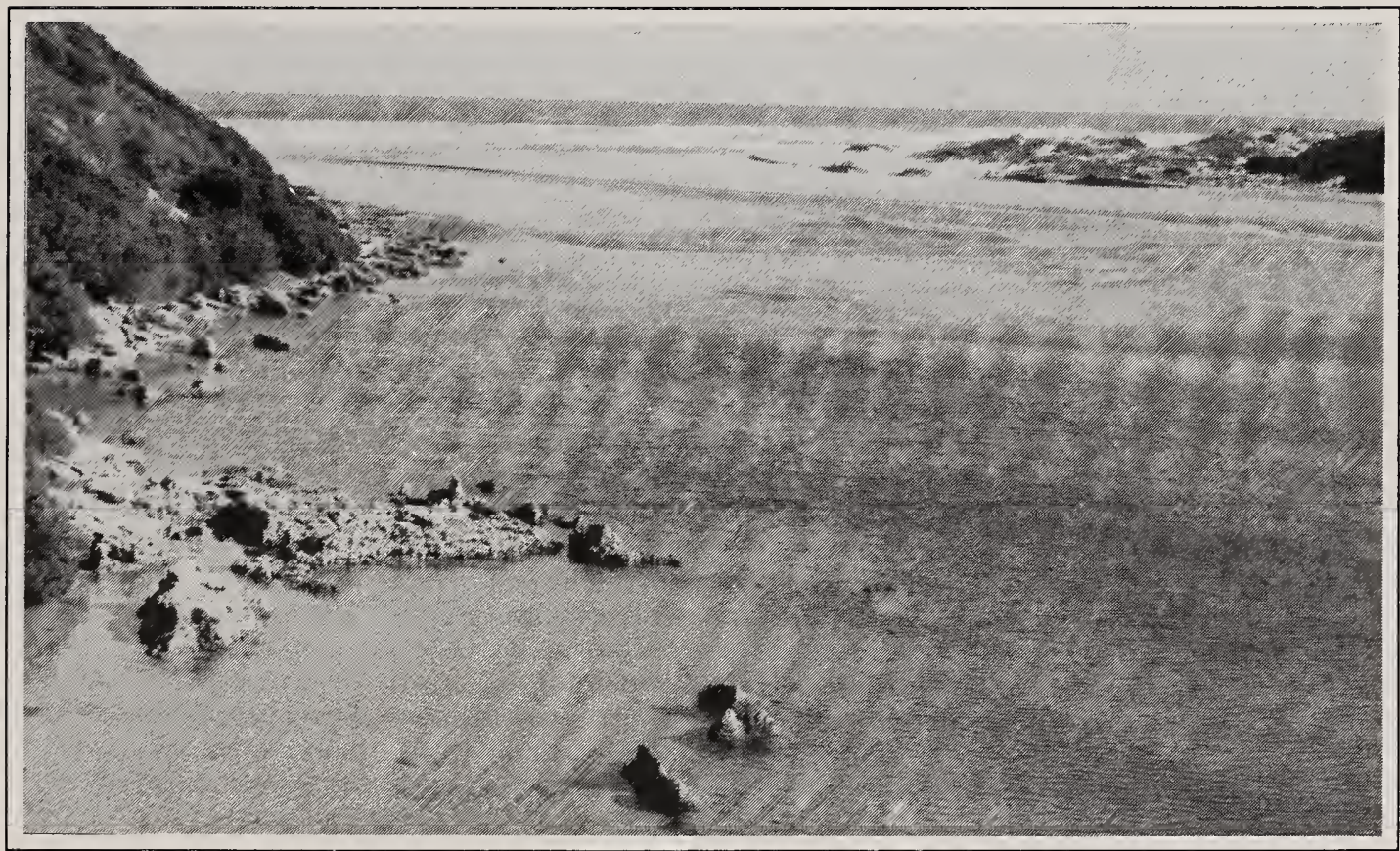

Plate 10. Swartvlei Estuary mouth region. Note the extensive rocky and sandy areas which provide contrasting ichthyofaunal habitats (photograph by A. Whitfield). 


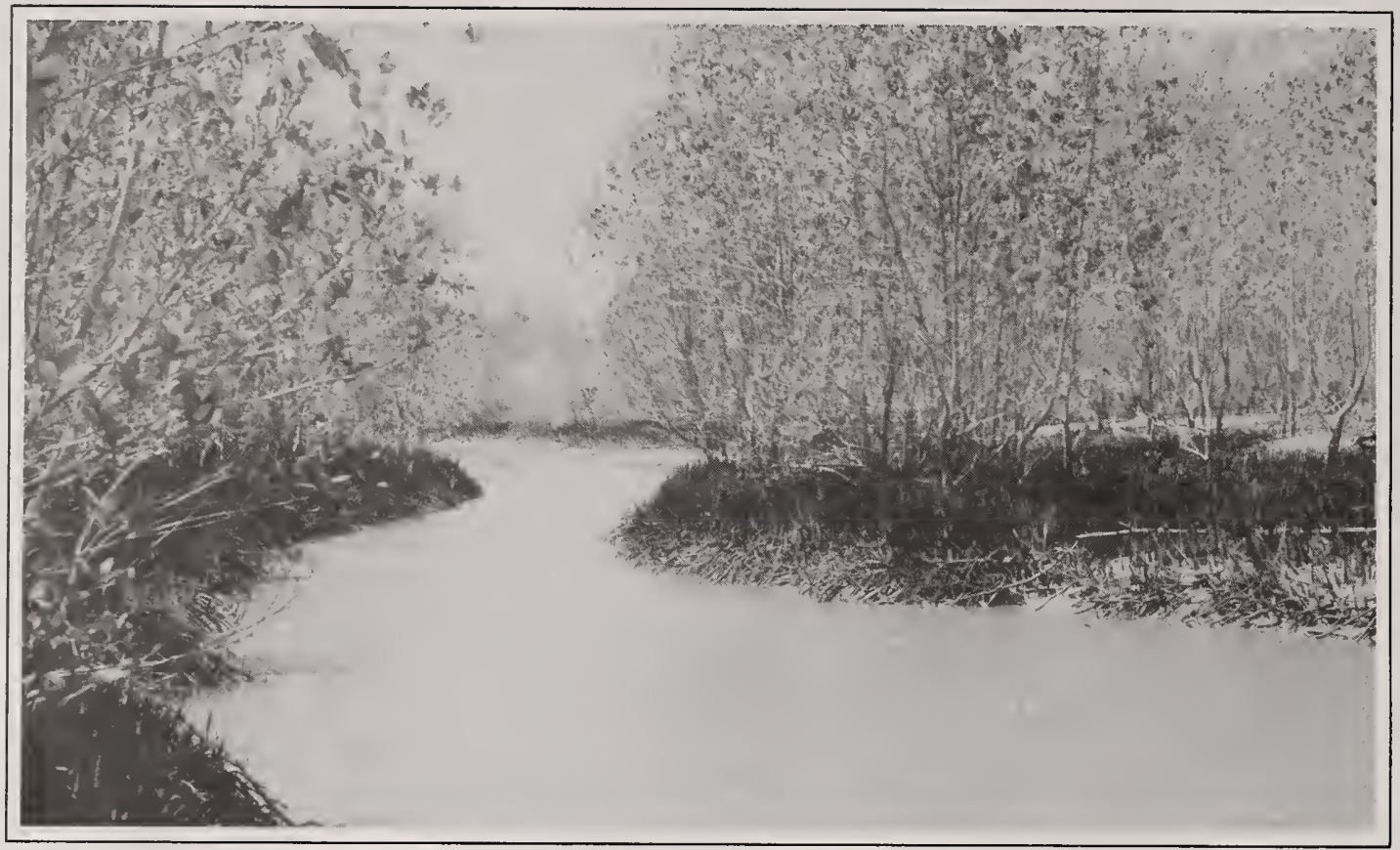

Plate 11. St Lucia Estuary mangrove creek. Note the shelter afforded to small fishes by the aerial roots of Avicennia marina (photograph by A. Whitfield).

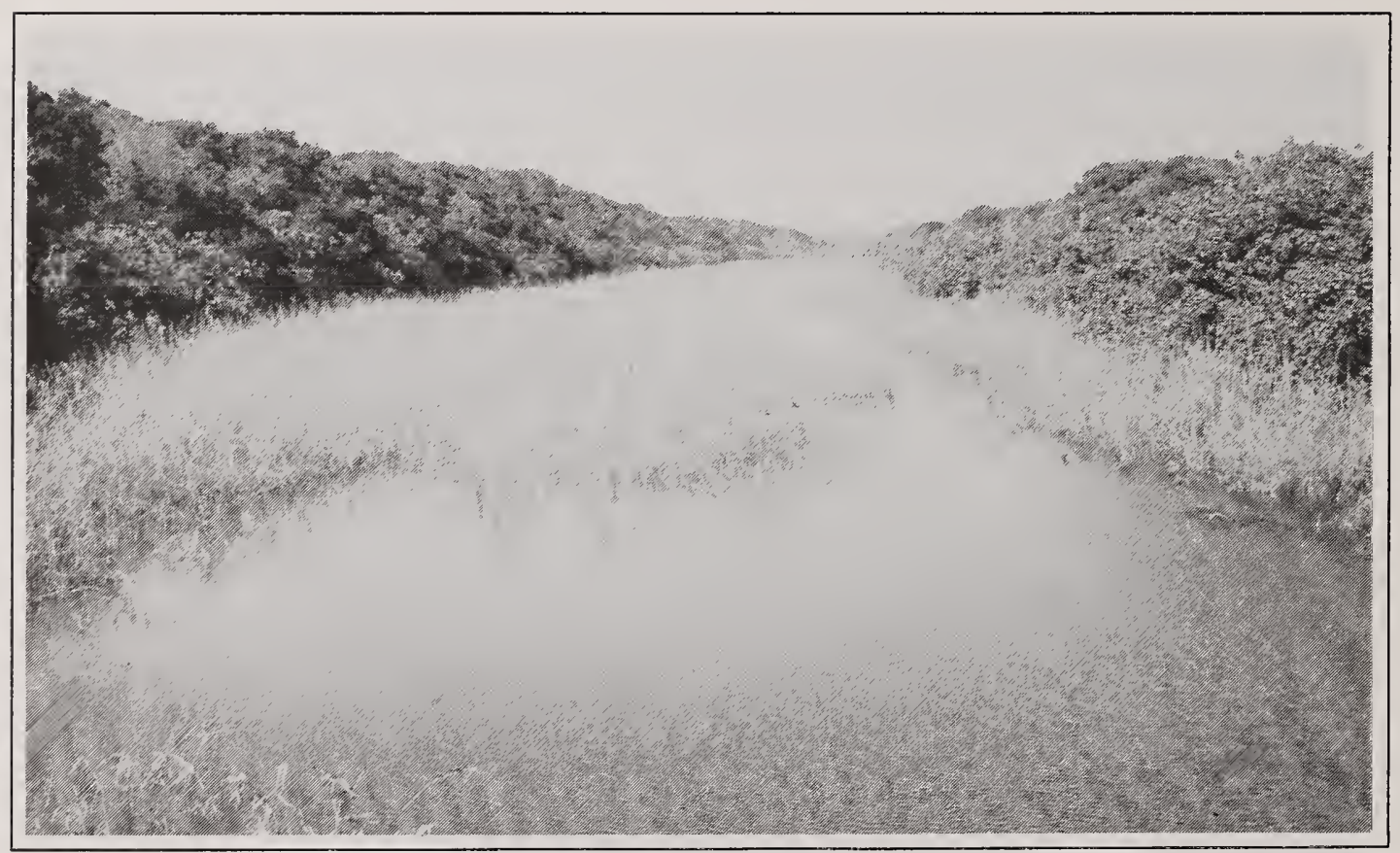

Plate 12. Siyaya Estuary during the closed phase. Note the extensive reed beds (Phragmites australis) which are encroaching into the lagoon and freshwater mangroves Hibiscus tiliaceus on the right bank (photograph by A. Whitfield). 


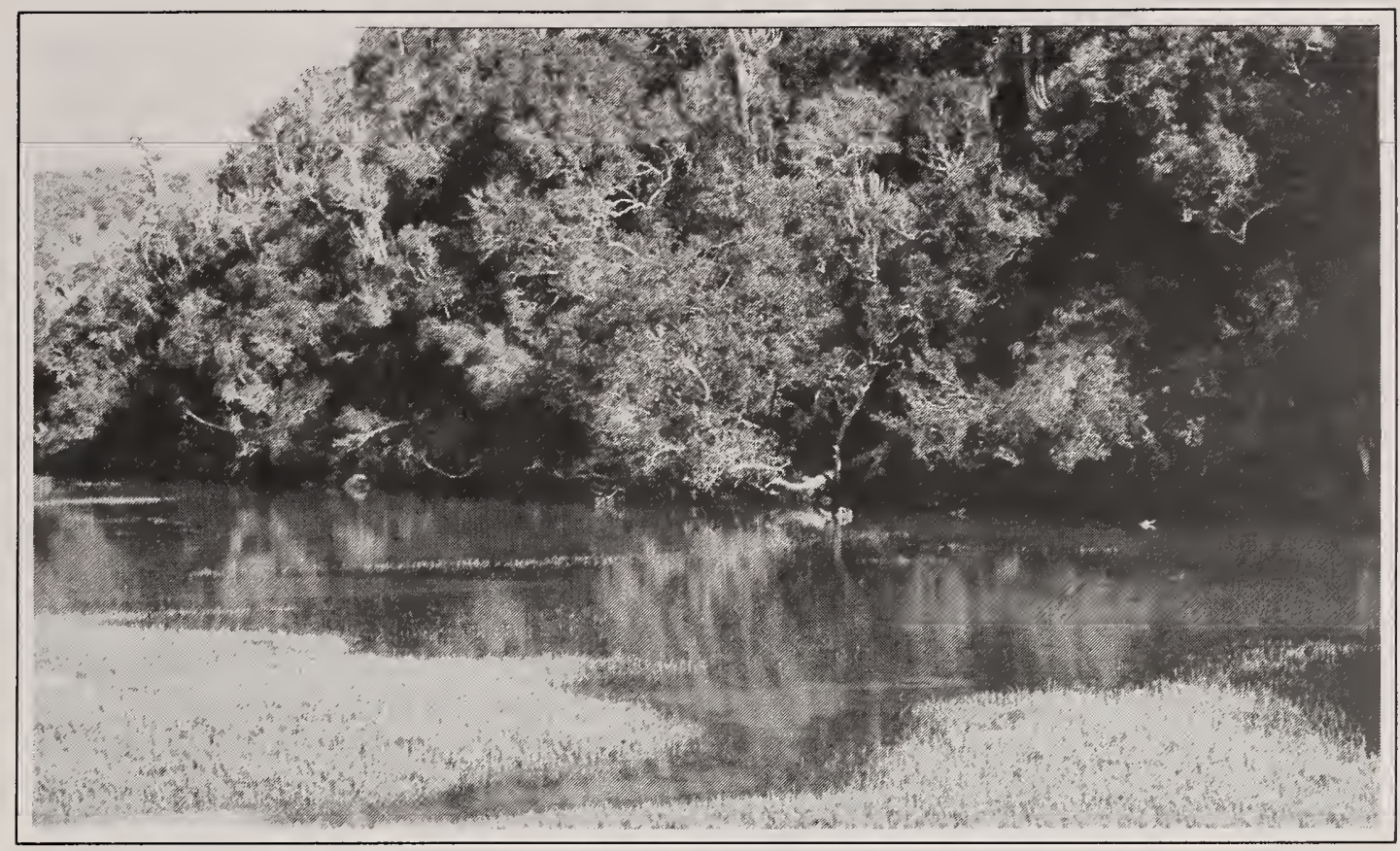

Plate 13. Grant's saltmarsh creek (Kariega Estuary). Note the Sarcocornia perennis and Chenolia diffusa dominated salt marsh vegetation in the foreground and the input of terrestrial plant material by overhanging vegetation in the background (photograph by $\mathrm{A}$. Whitfield).

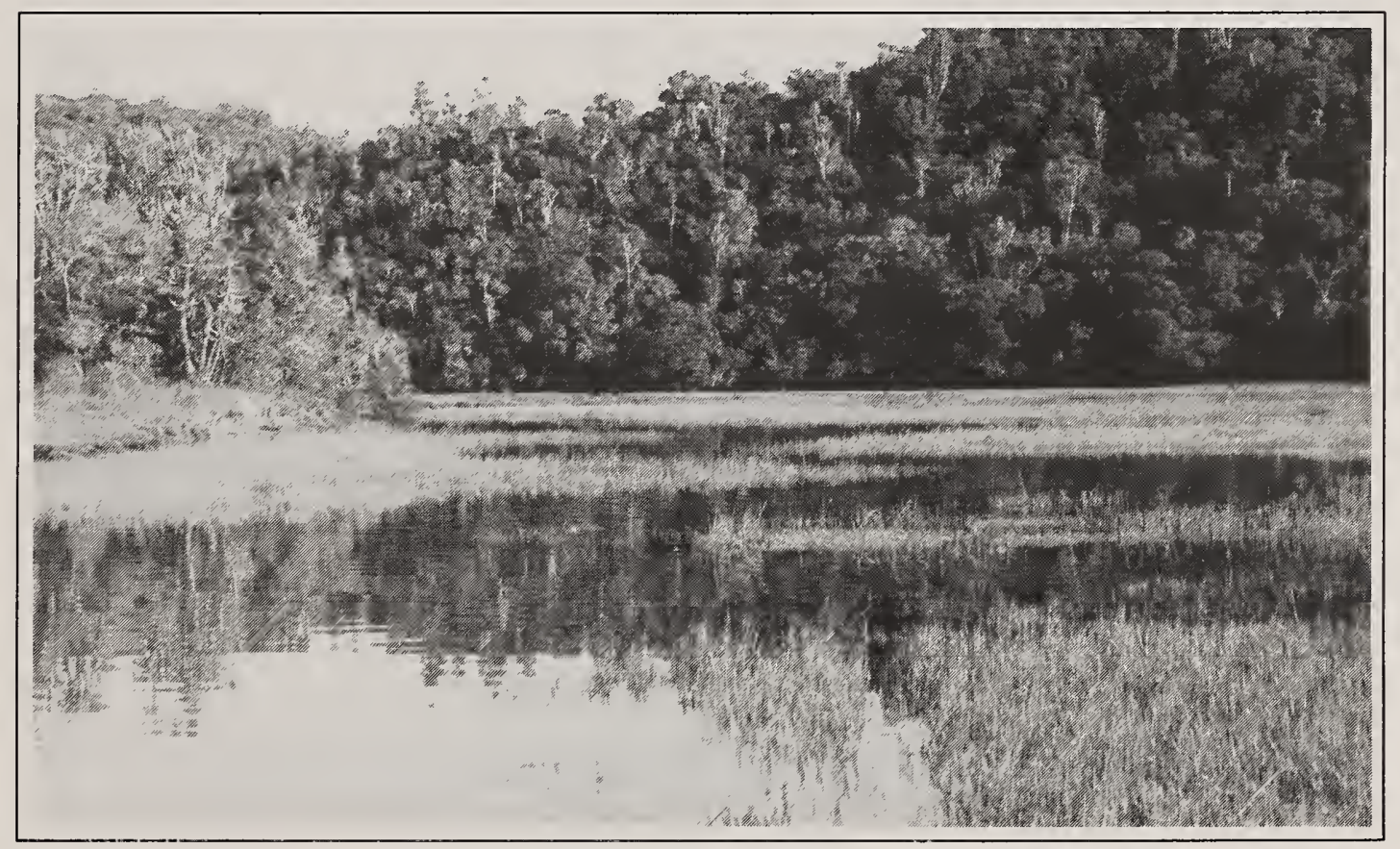

Plate 14. Grant's saltmarsh creek (Kariega Estuary). Note the Spartina maritima dominated salt marsh vegetation in the foreground (photograph by A. Whitfield). 


\section{Appendix 2}

A list of scientific and South African common names for the estuary-associated fishes quoted in this book.

Family

Scientific name and author(s)

Common name

Ambassidae

Ambassidae

Ambassidae

Anguillidae

Anguillidae

Anguillidae

Anguillidae

Ariidae

Atherinidae

Atherinidae

Belonidae

Blenniidae

Bothidae

Carangidae

Carangidae

Carangidae

Carangidae

Carangidae

Carangidae

Carangidae

Carangidae

Carangidae

Carangidae

Carcharhinidae

Chanidae

Cichlidae

Cichlidae

Cichlidae

Clariidae

Clinidae

Clinidae

Clupeidae

Clupeidae

Clupeidae

Dasyatidae

Dasyatidae

Dasyatidae

Drepanidae

Eleotridae

Eleotridae

Eleotridae
Ambassis gymnocephalus (Lacepède, 1801)

Ambassis natalensis Gilchrist \& Thompson, 1908

Ambassis productus Guichenot, 1866

Anguilla bengalensis labiata (Peters, 1852)

Anguilla bicolor bicolor McClelland, 1844

Anguilla marmorata Quoy \& Gaimard, 1824

Anguilla mossambica (Peters, 1852)

Galeichthys feliceps Valenciennes, 1840

Atherina breviceps Valenciennes, 1835

Atherinomorus lacunosus (Foster, 1801)

Strongylura leiura (Bleeker, 1851)

Omobranchus woodi (Gilchrist \& Thompson, 1908)

Bothus pantherinus (Rüppel, 1830)

Caranx heberi (Bennett, 1830)

Caranx ignobilis (Forsskål, 1775)

Caranx melampygus Cuvier, 1833

Caranx papuensis Alleyne \& Macleay, 1877

Caranx sexfasciatus Quoy \& Gaimard, 1825

Lichia amia (Linnaeus, 1758)

Scomberoides commersonnianus Lacepède, 1801

Scomberoides lysan (Forsskål, 1775)

Scomberoides tol (Cuvier, 1832)

Trachinotus africanus Smith, 1967

Carcharhinus leucas (Valenciennes, 1839)

Chanos chanos (Forsskål, 1775)

Oreochromis mossambicus (Peters, 1852)

Pseudocrenilabrus philander (Weber, 1897)

Tilapia rendalli (Boulenger, 1896)

Clarias gariepinus (Burchell, 1822)

Clinus spatulatus Bennett, 1983

Clinus superciliosus (Linnaeus, 1758)

Gilchristella aestuaria (Gilchrist, 1914)

Herklotsichthys quadrimaculatus (Rüppel, 1837)

Hilsa kelee (Cuvier, 1829)

Dasyatis chrysonota (Linnaeus, 1758)

Gymnura natalensis (Gilchrist \& Thompson, 1911)

Himantura uarnak (Forsskål, 1775)

Drepane longimanus (Bloch \& Schneider, 1801)

Butis butis (Hamilton, 1822)

Eleotris fusca (Bloch \& Schneider, 1801)

Eleotris mauritianus Bennett, 1831
Bald glassy

Slender glassy

Longspine glassy

African mottled eel

Shortfin eel

Giant mottled eel

Longfin eel

White seacatfish

Cape silverside

Hardyhead silverside

Yellowfin needlefish

Kappie blenny

Leopard flounder

Blacktip kingfish

Giant kingfish

Bluefin kingfish

Brassy kingfish

Bigeye kingfish

Garrick/Leervis

Talang queenfish

Doublespotted queenfish

Needlescaled queenfish

Southern pompano

Bullshark

Milkfish

Mozambique tilapia

Southern mouthbrooder

Redbreast tilapia

Sharptooth catfish

Estuary klipfish

Super klipfish

Estuarine roundherring

Blueline herring

Kelee shad

Blue stingray

Backwater butterflyray

Honeycomb stingray

Concertina fish

Duckbill sleeper

Dusky sleeper

Widehead sleeper 
Eleotridae

Eleotridae

Elopidae

Engraulidae

Engraulidae

Engraulidae

Engraulidae

Fistulariidae

Gerreidae

Gerreidae

Gerreidae

Gerreidae

Gerreidae

Gobiidae

Gobiidae

Gobiidae

Gobiidae

Gobiidae

Gobiidae

Gobiidae

Gobiidae

Gobiidae

Gobiidae

Gobiidae

Gobiidae

Gobiidae

Gobiidae

Gobiidae

Gobiidae

Gobiidae

Gobiidae

Gobiidae

Gobiidae

Gobiidae

Gobiidae

Gobiidae

Haemulidae

Haemulidae

Haemulidae

Haemulidae

Hemiramphidae

Hemiramphidae

Kuhliidae

Kuhliidae

Leiognathidae

Lobotidae

Lutjanidae

Lutjanidae

Megalopidae

Monacanthidae
Eleotris melanosoma Bleeker, 1852

Hypseleotris dayi Smith, 1950

Elops machnata (Forsskål, 1775)

Engraulis japonicus Schlegel, 1846

Stolephorus holodon (Boulenger, 1900)

Thryssa setirostris (Broussonet, 1782)

Thryssa vitrirostris (Gilchrist \& Thompson, 1908 )

Fistularia commersonii Rüppel, 1838

Gerres acinaces Bleeker, 1854

Gerres filamentosus Cuvier, 1830

Gerres methueni Regan, 1920

Gerres oblongus Cuvier, 1830

Gerres oyena (Forsskål, 1775)

Awaous aeneofuscus (Peters, 1852)

Caffrogobius gilchristi (Boulenger, 1900)

Caffrogobius natalensis (Günther, 1874)

Caffrogobius nudiceps (Valenciennes, 1827)

Croilia mossambica Smith, 1955

Favonigobius melanobranchus (Fowler, 1934)

Favonigobius reichei (Bleeker, 1853)

Glossogobius biocellatus (Valenciennes, 1837)

Glossogobius callidus (Smith, 1937)

Glossogobius giuris (Hamilton, 1822)

Oligolepis acutipennis (Valenciennes, 1837)

Oligolepis keiensis (Smith, 1938)

Pandaka silvana (Barnard, 1943)

Periophthalmus koelreuteri africanus Eggert, 1935

Periophthalmus argentilineatus (Valenciennes, 1837)

Psammogobius knysnaensis Smith, 1936

Redigobius bikolanus (Herre, 1927)

Redigobius dewaalii (Weber, 1897)

Silhouettea sibayi Farquharson, 1970

Taenioides esquivel Smith, 1946

Taenioides jacksoni Smith, 1943

Trypauchen microcephalus Bleeker, 1860

Yongeichthys nebulosus (Forsskål, 1775)

Pomadasys commersonnii (Lacepède, 1801)

Pomadasys kaakan (Cuvier, 1830)

Pomadasys multimaculatum (Playfair, 1866)

Pomadasys olivaceum (Day, 1875)

Hemiramphus far (Forsskål, 1775)

Hyporhamphus capensis (Thominot, 1886)

Kuhlia mugil (Bloch \& Schneider, 1801)

Kuhlia rupestris (Lacepède, 1802)

Leiognathus equula (Forsskål, 1775)

Lobotes surinamensis (Bloch, 1790)

Lutjanus argentimaculatus (Forsskål, 1775)

Lutjanus fulviflamma (Forsskål, 1775)

Megalops cyprinoides (Broussonet, 1782)

Stephanolepis auratus (Castelnau, 1861)
Broadhead sleeper

Golden sleeper

Ladyfish

Cape anchovy

Thorny anchovy

Longjaw glassnose

Orangemouth glassnose

Smooth flutemouth

Smallscale pursemouth

Longspine pursemouth

Evenfin pursemouth

Oblong pursemouth

Slenderspinepursemouth

Freshwater goby

Prison goby

Baldy

Barehead goby

Naked goby

Blackthroat goby

Spotted sandgoby

Sleepy goby

River goby

Tank goby

Sharptail goby

Speartail goby

Dwarf goby

African mudskipper

Bigfin mudskipper

Speckled sandgoby

Bigmouth goby

Checked goby

Barebreast goby

Bulldog eelgoby

Bearded eelgoby

Comb goby

Shadow goby

Spotted grunter

Javelin grunter

Cock grunter

Piggy

Spotted halfbeak

Cape halfbeak

Barred flagtail

Rock flagtail

Slimy

Tripletail

Mangrove snapper

Dory snapper

Oxeye tarpon

Porky 
Monodactylidae

Monodactylidae

Mugilidae

Mugilidae

Mugilidae

Mugilidae

Mugilidae

Mugilidae

Mugilidae

Mugilidae

Mugilidae

Mugilidae

Mugilidae

Mugilidae

Mugilidae

Muraenesocidae

Muraenidae

Myliobatidae

Ophichthidae

Paralichthyidae

Platycephalidae

Polynemidae

Pomatomidae

Pristidae

Rhinobatidae

Sciaenidae

Sciaenidae

Sciaenidae

Serranidae

Serranidae

Siganidae

Sillaginidae

Soleidae

Soleidae

Sparidae

Sparidae

Sparidae

Sparidae

Sparidae

Sparidae

Sparidae

Sparidae

Sparidae

Sparidae

Sparidae

Sparidae

Sparidae

Sphyraenidae

Sphyraenidae

Syngnathidae
Monodactylus argenteus (Linnaeus, 1758)

Monodactylus falciformis Lacepède, 1800

Crenimugil crenilabis (Forsskål, 1775)

Liza alata (Steindachner, 1892)

Liza dumerilii (Steindachner, 1869)

Liza luciae (Penrith \& Penrith, 1967)

Liza macrolepis (Smith, 1846)

Liza richardsonii (Smith, 1846)

Liza tricuspidens (Smith, 1935)

Mugil cephalus Linnaeus, 1758

Myxus capensis (Valenciennes, 1836)

Valamugil buchanani (Bleeker, 1853)

Valamugil cunnesius (Valenciennes, 1836)

Valamugil robustus (Günther, 1861)

Valamugil seheli (Forsskål, 1775)

Muraenesox bagio (Hamilton, 1822)

Strophidon sathete (Hamilton, 1822)

Myliobatis aquila (Linnaeus, 1758)

Ophisurus serpens (Linnaeus, 1766)

Pseudorhombus arsius (Hamilton, 1822)

Platycephalus indicus (Linnaeus, 1758)

Polydactylus sextarius (Bloch \& Schneider, 1801)

Pomatomus saltatrix (Linnaeus, 1766)

Pristis zijsron Bleeker, 1851

Rhinobatos annulatus Smith, 1841

Argyrosomus japonicus (Temminck \& Schlegel, 1843)

Johnius dorsalis (Peters, 1855)

Otolithes ruber (Bloch \& Schneider, 1801)

Epinephelus andersoni Boulenger, 1903

Epinephelus malabaricus (Schneider, 1801)

Siganus sutor (Valenciennes, 1836)

Sillago sihama (Forsskål, 1775)

Heteromycteris capensis Kaup, 1858

Solea bleekeri Boulenger, 1898

Acanthopagrus berda (Forsskảl, 1775)

Crenidens crenidens (Forsskål, 1775)

Diplodus cervinus hottentotus (Smith, 1844)

Diplodus sargus capensis (Smith, 1844)

Lithognathus lithognathus (Cuvier, 1830)

Lithognathus mormyrus (Linnaeus, 1758)

Rhabdosargus globiceps (Cuvier, 1830)

Rhabdosargus holubi (Steindachner, 1881)

Rhabdosargus sarba (Forsskål, 1775)

Rhabdosargus thorpei Smith, 1979

Sarpa salpa (Linnaeus, 1758)

Sparodon durbanensis (Castelnau, 1861)

Spondyliosoma emarginatum (Cuvier, 1830)

Sphyraena barracuda (Walbaum, 1792)

Sphyraena jello Cuvier, 1829

Hippichthys heptagonus Bleeker, 1849
Round moony

Oval moony

Fringelip mullet

Diamond mullet

Groovy mullet

St Lucia mullet

Largescale mullet

Southern mullet

Striped mullet

Flathead mullet

Freshwater mullet

Bluetail mullet

Longarm mullet

Robust mullet

Bluespot mullet

Pike conger

Slender giant moray

Eagleray

Sand snake-eel

Largetooth flounder

Bartail flathead

Sixfinger threadfin

Elf

Green sawfish

Lesser guitarfish

Dusky kob

Smail kob

Snapper kob

Catface rockcod

Malabar rockcod

Whitespotted rabbitfish

Silver sillago

Cape sole

Blackhand sole

Estuarine bream

Karanteen

Zebra

Blacktail

White steenbras

Sand steenbras

White stumpnose

Cape stumpnose

Tropical stumpnose

Bigeye stumpnose

Strepie

White musselcracker

Steentjie

Great barracuda

Pickhandle barracuda

Belly pipefish 
Syngnathidae

Syngnathidae

Syngnathidae

Syngnathidae

Syngnathidae

Syngnathidae

Teraponidae

Teraponidae

Tetraodontidae

Tetraodontidae

Tetraodontidae

Torpedinidae

Torpedinidae
Hippichthys spicifer (Rüppel, 1838)

Hippocampus capensis Boulenger, 1900

Microphis fluviatilis (Peters, 1852)

Microphis brachyurus (Bleeker, 1853)

Syngnathus acus Linnaeus, 1758

Syngnathus watermeyeri Smith, 1963

Pelates quadrilineatus (Bloch, 1790)

Terapon jarbua (Forsskål, 1775)

Amblyrhynchotes honckenii (Bloch, 1795)

Arothron hispidus Linnaeus, 1758

Arothron immaculatus (Bloch \& Schneider, 1801)

Torpedo fuscomaculata Peters, 1855

Torpedo sinuspersici Olfers, 1831
Bellybarred pipefish

Knysna seahorse

Freshwater pipefish

Short-tail pipefish

Longsnout pipefish

Estuarine pipefish

Trumpeter

Thornfish

Evileye blaasop

Whitespotted blaasop

Blackedged blaasop

Blackspotted electric ray

Marbled electric ray

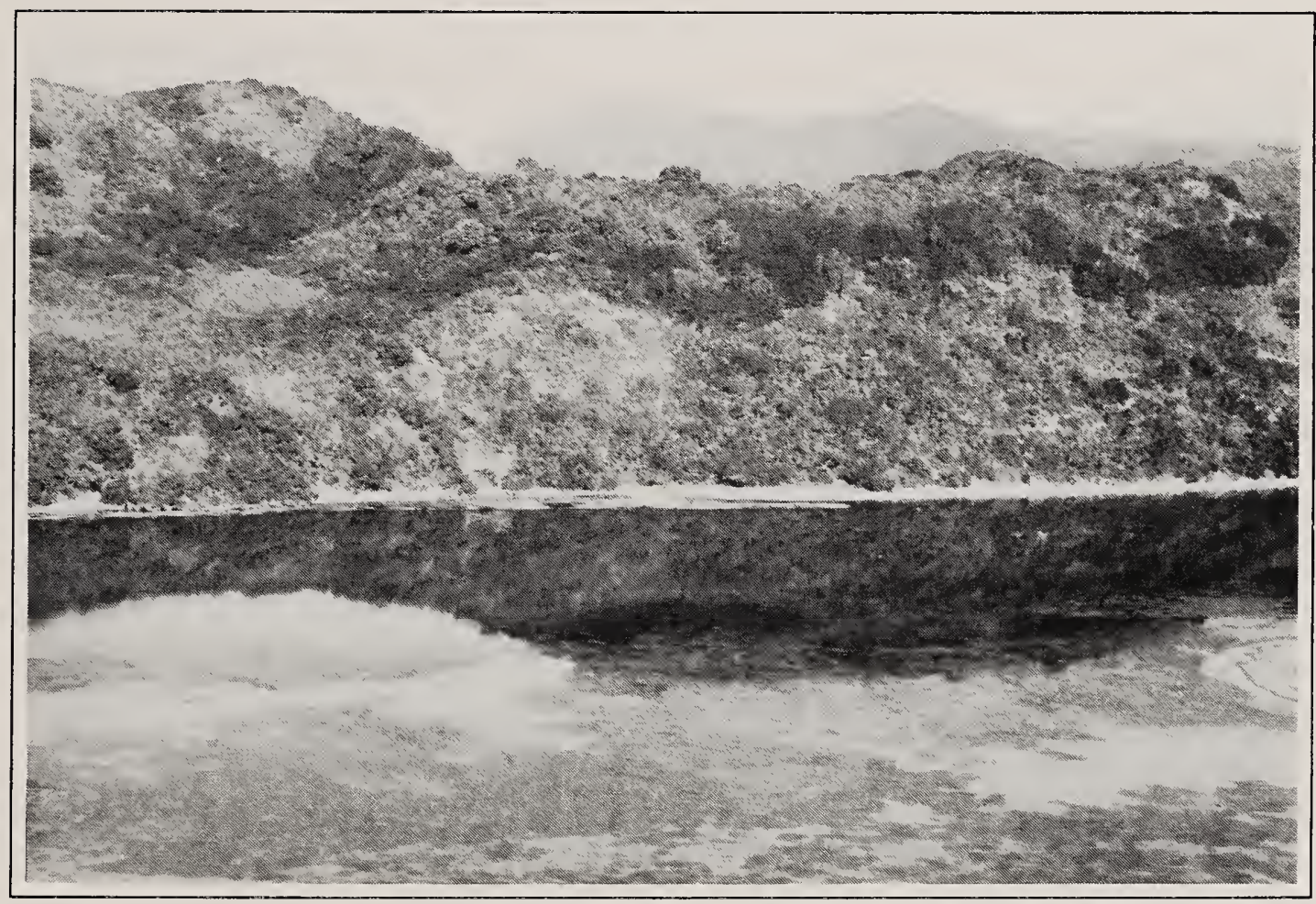

Drifting over an undulating meadow of green

Ears filled by a myriad sounds from far and near

Parachutes of bubbles rising to meet the summer sky

and shards of light dancing over the rippled sand

This is the home of silver shoals folding and unfolding secrets

for all who want to share their world 


The conservation and wise utilization of estuaries is deppendent on a sound scientific understanding of the biology and ecology of resident and migrant fishes. This book brings together a wealth of information on the teleosts of southern African estuaries, highlighting the importance of these ecosystems to both the aquatic biota and people of the region. It is an important reference work for all those individuals whose work or hobby revolves around fishes, as well as those who have a wider interest in estuaries.

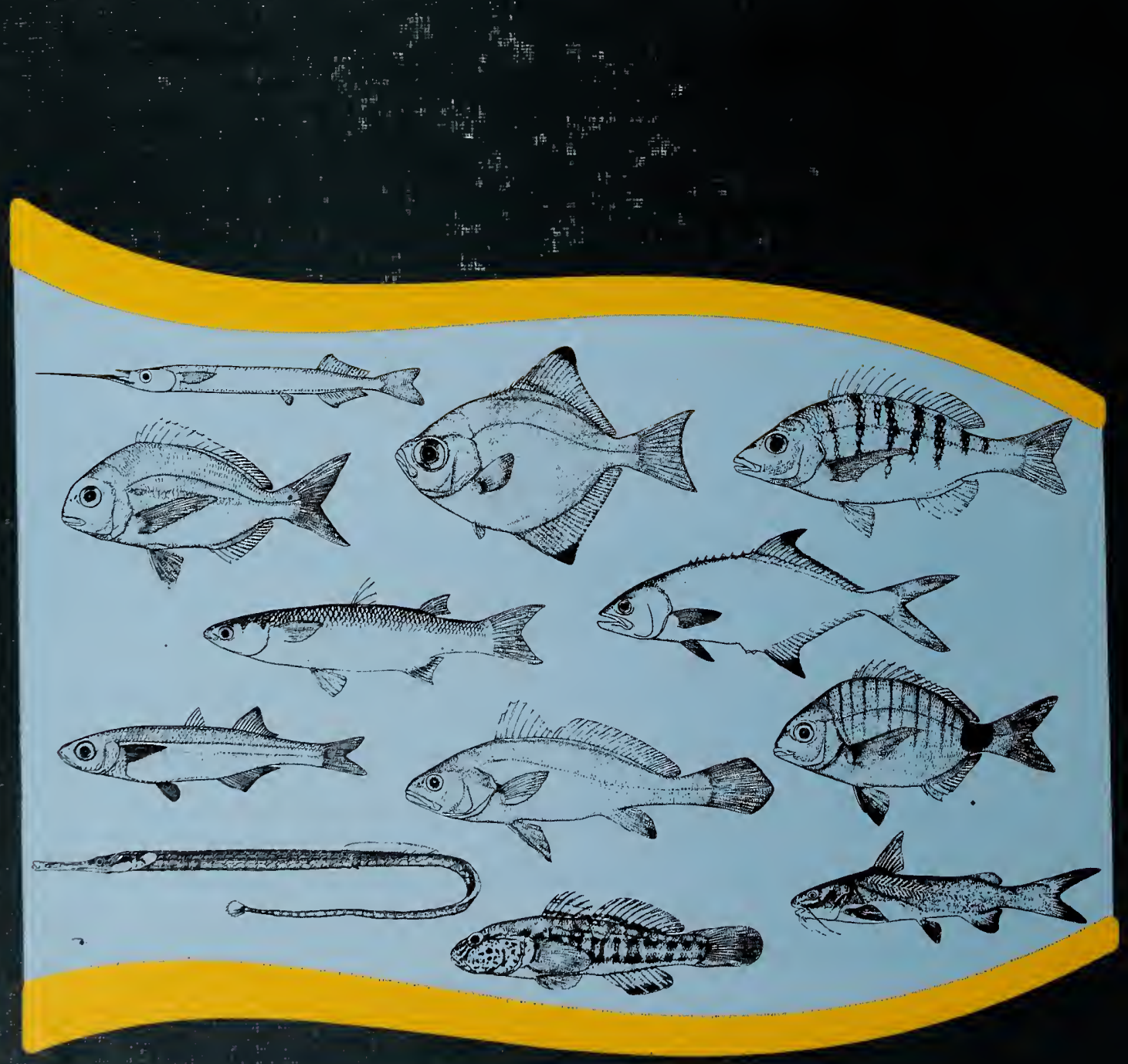

